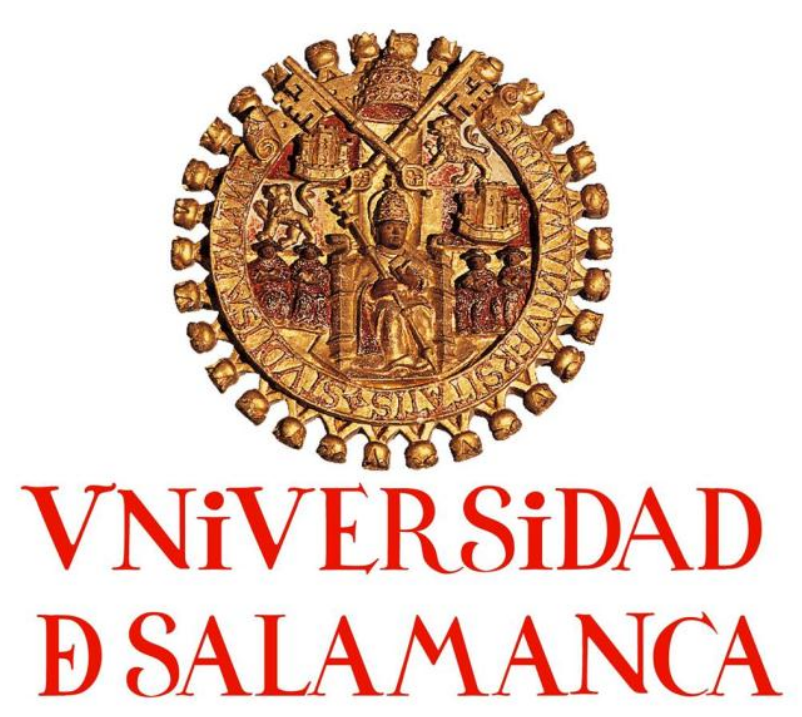

FACULTAD de GEOGRAFía E Historia

TESIS DOCTORAL

\title{
EL ACERVO INTEGRACIONISTA EN EUROPA Y AMÉRICA: UNA HISTORIA COMÚN
}

\author{
AUTOR: \\ MARIO LEÓN TORRES JARRÍN
}

DIRECTOR:

Prof. Dr. José ANTONio Calvo Gómez

SALAMANCA, 2015 



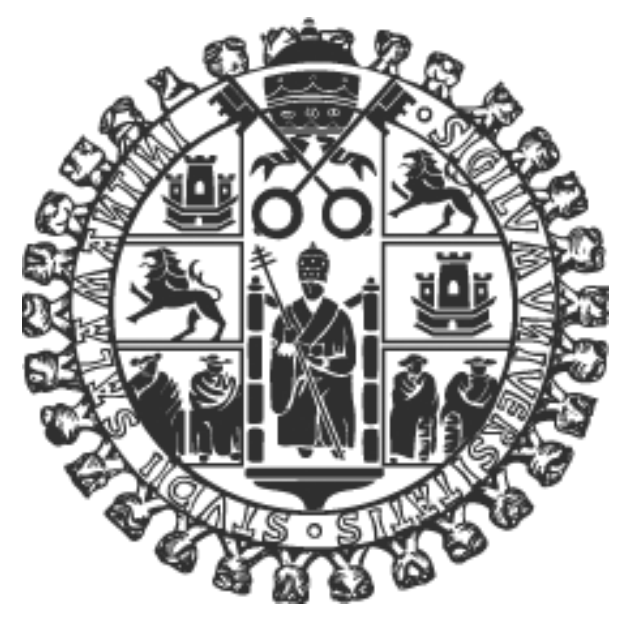

FACUltad de Geografía e Historia

TESIS DOCTORAL

\title{
EL ACERVO INTEGRACIONISTA EN EUROPA Y AMÉRICA: UNA HISTORIA COMÚN
}

\author{
AUTOR: \\ MARIO LEÓN TORRES JARRÍN \\ DIRECTOR: \\ Prof. Dr. José ANTONio CAlvo GómEZ
}





\section{Agradecimientos}

Un buen amigo mío me dijo una vez que "todo trabajo tiene su recompensa". Después de cinco años, la recompensa de mi trabajo es la presente investigación.

Concluir esta tesis doctoral representa una etapa importante en mi vida, la cual inicié hace quince años. El deseo de ser doctor es un sueño que albergué en mi mente durante muchos años, desde que empecé mis estudios de grado. Durante los últimos cinco años, doctorarme ha sido para mí una meta fija a cumplir. Esta tesis ha representado mucho tiempo y sacrificios personales, pero también ha significado un gran aprendizaje en el plano personal y, sin duda alguna, un enriquecimiento en mi vida intelectual.

Deseo iniciar dando las gracias a P. Alfonso Álvarez, ya que sin él nunca hubiese llegado a estudiar en la Universidad de Salamanca, universidad y ciudad donde viví los mejores años de mi vida y donde conocí a los que hoy considero mis amigos.

A mis profesores de la facultad de economía y empresa, facultad de derecho y facultad de geografía e historia de la Universidad de Salamanca, donde he realizado tanto mis estudios de grado como de postgrado. En especial a los profesores Alfredo Ávila de la Torre, Percy Alarcón, Edwin Vílchez, Juan Santos, Luis Norberto Gonzáles, Javier Laso, Araceli Mangas, y en particular a quien fue mi tutor de tesis en el Master de Estudios de la Unión Europea, Prof. Rafael Muñoz Bustillo. A ellos les debo mis conocimientos sobre el proceso de integración regional en Europa.

En cuanto a mi período como doctorando, doy las gracias a mi director de tesis, Prof. José Antonio Calvo, por depositar su confianza en mi persona, por su tiempo, por sus consejos, recomendaciones y palabras de aliento en todo momento, y sobre todo por hacer de mí un investigador concienzudo.

Existen dos profesores que durante el doctorado me han ayudado e inspirado mucho, tanto a través de sus obras como mediante sus conversaciones y debates: El Prof. Francisco Aldecoa (Universidad Complutense de Madrid) de quien aprendí a ser quién soy, un europeísta convencido y de corazón. El Prof. Andrés Rivarola (Universidad de Estocolmo), de quien aprendí la historia de la integración latinoamericana, y junto a quien pude descubrir lo que es América Latina. Para ambos, mi gratitud infinita y amistad incondicional. 
A mis amigos y colegas del Instituto de Estudios Latinoamericanos de la Universidad de Estocolmo: Mona Rosendahl, Magnus Lembke, Margareta Björling, Ann-Marie Lenndin, Thais Machado-Borges, Mirta Osorio, Rickard Lalander y Dag Retsö.

A mi familia y amigos, que mediante sus palabras de aliento han estado en todo momento conmigo apoyándome. Sus ánimos me ayudaban día a día seguir estudiando y trabajando en esta investigación.

Finalmente deseo expresar una mención especial, dedicada a P. Pedro Merino, quién siempre ha estado a mi lado, durante todo el período de mi carrera universitaria, tanto de grado como postgrado (maestría y doctorado), pero sobre todo, acompañándome en cada paso en mi vida. Este doctorado es tuyo, mi querido Pedro, gracias por creer en mí, por tu apoyo incondicional, por estar en los momentos buenos y en los malos, por darme ánimo y aliento cuando más lo necesitaba, por disfrutar conmigo cada uno de mis logros. Sin ti yo no hubiese podido ser el doctor que ahora seré gracias a esta investigación ¡Gracias por todo y por tanto!

Salamanca, 1 de diciembre de 2015. 


\section{- ÍNDICE DE CONTENIDO}

CAPÍTULO I: INTRODUCCIÓN ................................................................................. 13

1.1. JUSTIFICACIÓN DEL TEMA OBJETO DE ESTUDIO.......................................... 14

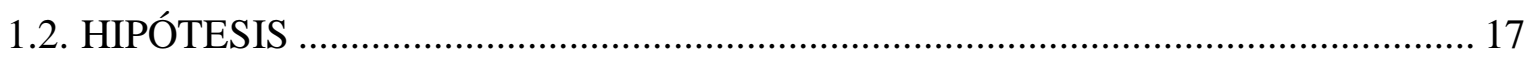

1.3. METODOLOGÍA DE INVESTIGACIÓN ............................................................ 19

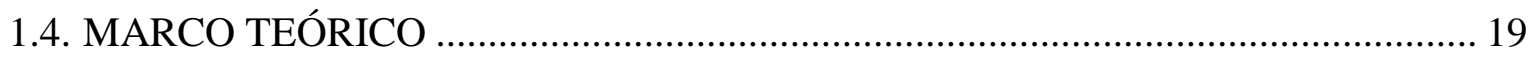

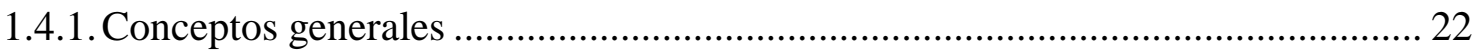

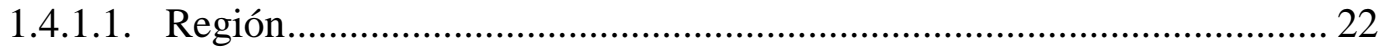

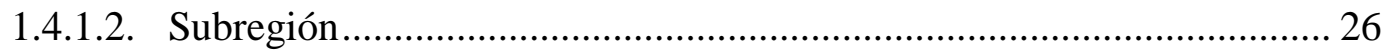

1.4.1.3. Regionalismo y Regionalización ..................................................... 33

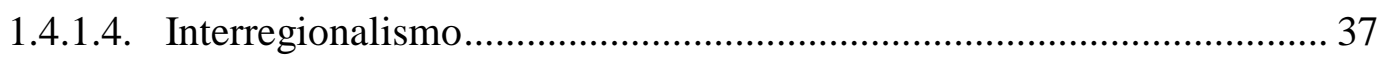

CAPÍtULO II: FUNDAMENTOS HISTÓRICOS DEL ACERVO INTEGRACIONISTA EN LA EUROPA DE LA EDAD MEDIA ................................. 39

2.1. EUROPA: LA HISTORIA DE LA CONSTRUCCIÓN DE UNA REGIÓN .............. 40

2.2. LAS IDEAS INTEGRACIONISTAS DE CARLOMAGNO: LA ACCIÓN EXTERIOR EUROPEA DE CARLOMAGNO …................................................. 45

2.3. LAS IDEAS INTEGRACIONISTAS DE CARLOS V: UNIVERSITAS CHRISTIANA 55

2.4. DE LA UNIVERSITAS CHRISTIANA A LA UNIVERSITAS UNIVERSALIS: EL LEGADO DE CARLOS V HACIA AMÉRICA

CAPÍtULO III: EL ACERVO INTEGRACIONISTA EN EUROPA Y AMÉRICA EN LA MODERNIDAD: UNA HISTORIA EN COMÚN

3.1. LA CONSTRUCCIÓN DE UNA IDEA: LA UNIDAD POLÍTICA DE LOS

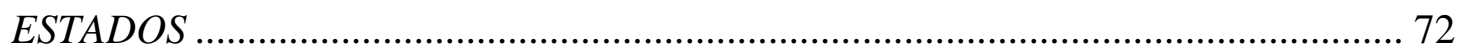

3.2. EL SUEÑO DE LA ANFICTIONÍA: DE EUROPA A AMÉRICA LATINA. 74

3.3. LA BÚSQUEDA DE UNA IDENTIDAD CONTINENTAL: EL PANAMERICANISMO Y EL PANEUROPEÍSMO.... 93 
CAPÍTULO IV: CONSTRUYENDO REGIONES A TRAVÉS DEL DIÁlOGO BI-REGIONAL EN LOS SIGLOS XX-XXI: INSTITUCIONALIZACIÓN DE LAS RELACIONES ENTRE EL PROCESO DE INTEGRACIÓN EUROPEA Y LOS PROCESOS DE INTEGRACIÓN EN AMÉRICA LATINA

4.1. PRIMEROS PASOS HACIA UN DIÁLOGO BI-REGIONAL 102

4.2. EN LA BÚSQUEDA DE UNA SOLA VOZ: LAS COMISIONES Y LOS CONSEJOS DE INTEGRACIÓN REGIONAL

4.3. LA INSTITUCIONALIZACIÓN DE UN DIÁLOGO BI-REGIONAL: LAS BASES DE UNA ACCIÓN EXTERIOR CONJUNTA BI-REGIONAL

4.4. INICIO DE UNA NUEVA ETAPA: HACIA EL DESARROLLO DE UNA ACCIÓN EXTERIOR BIRREGIONAL.

4.5. NEGOCIACIONES PARA UNA ASOCIACIÓN ESTRATÉGICA BIREGIONAL

4.6. UN NUEVO DIÁlOGO BIRREGIONAL PARA EL SIGLO XXI: LAS NEGOCIACIONES UE-CELAC 158

\section{CAPÍTULO V: EL ROL DE LOS PARLAMENTOS SUBREGIONALES Y} REGIONALES: DEMOCRACIA E INTEGRACIÓN.

5.1. LOS PARLAMENTOS SUBREGIONALES Y REGIONALES EN EUROPAAMÉRICA LATINA Y EL CARIBE 170

5.2. EL ROL DEL PARLAMENTO REGIONAL EN LA INTEGRACIÓN DE EUROPA: EL PARLAMENTO DE LA UNIÓN EUROPEA 171

5.3. EL ROL DE LOS PARLAMENTOS SUBREGIONALES Y REGIONALES EN LA INTEGRACIÓN DE AMÉRICA LATINA Y CARIBE 175

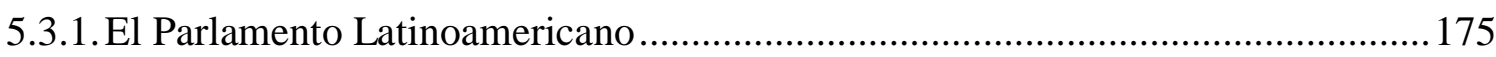

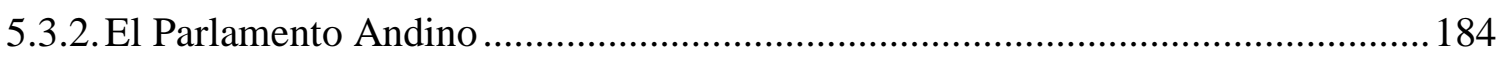

5.3.3. La Asamblea Parlamentaria de la Comunidad del Caribe .................................... 187

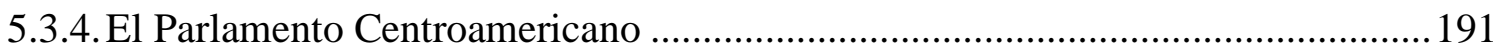

5.3.5.El Parlamento del Mercado Común del Sur........................................................... 194

5.3.6.El Parlamento de la Unión de Naciones Suramericanas ....................................... 198

5.3.7.El Parlamento de la Comunidad de Estados Latinoamericanos y Caribeños........200

5.4. EL DIÁLOGO INTERPARLAMENTARIO BIRREGIONAL: EUROLAT ..............202 


\section{CAPÍtUlo VI: DESARROLlO Y EVOLUCIÓN DE LA ACCIÓN EXTERIOR EN LOS PROCESOS DE INTEGRACIÓN REGIONAL EN LA UNIÓN EUROPEA-AMÉRICA LATINA Y EL CARIBE}

6.1. LA ACCIÓN EXTERIOR: CASO UNIÓN EUROPEA ............................................. 210

6.2. LA ACCIÓN EXTERIOR: CASO AMÉRICA LATINA Y EL CARIBE ................. 221

6.2.1.Los lineamientos para una Política Exterior Común en la Comunidad Andina

6.2.2. La Comunidad Andina como eslabón en la integración regional en América Latina y el Caribe: El interregionalismo latinoamericano y caribeño 235

6.2.2.1. Propuestas para una Acción Exterior Común latinoamericana y caribeña...

6.2.2.2. CAN-MERCOSUR: ¿Convergencia o divergencia?............................ 236

6.2.2.3. UNASUR: ¿Unión regional o foro regional?

6.2.2.4. Institucionalización e implementación de una Acción Exterior Común en el marco de la CELAC: Oportunidades en la Asociación Bi-regional UE-CELAC

6.2.2.5. Los eslabones de la integración en América Latina y el Caribe: eslabón andino-eslabón suramericano-eslabón latinoamericano y caribeño .258

6.2.3. Cambio de percepción de América Latina y el Caribe en el mundo 265

\section{CAPÍTULO VII: EL SERVICIO EUROPEO DE ACCIÓN EXTERIOR Y} LAS RELACIONES UNIÓN EUROPEA-AMÉRICA LATINA Y EL CARIBE ...... 271

7.1. EL SERVICIO EUROPEO DE ACCIÓN EXTERIOR 272

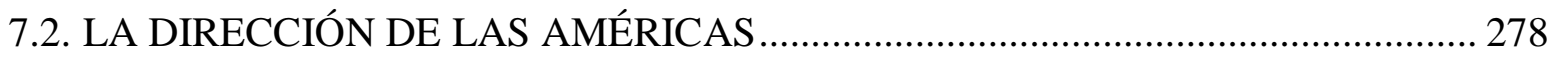

7.3. LA PROGRAMACIÓN REGIONAL PARA AMÉRICA LATINA 2007-2013 ........ 280

7.4. EL PROGRAMA MULTIANUAL INDICATIVO REGIONAL PARA

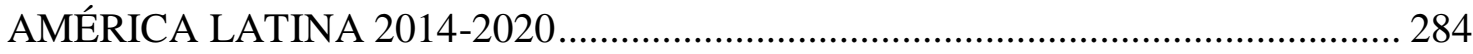

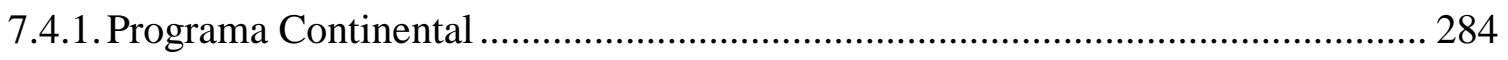

7.4.2. Programa Sub-Regional para América Central ................................................... 288

7.5. EL SEAE EN LOS CONSEJOS Y COMITÉS DE LOS ACUERDOS DE ASOCIACIÓN 290 
7.6. SÍNTESIS DE LAS RELACIONES ENTRE EL SEAE Y AMÉRICA LATINA

CAPÍTULO VIII: EL ROL DE LA ALTA REPRESENTANTE DE LA UNION PARA ASUNTOS EXTERIORES Y POLITICA DE SEGURIDAD EN LAS RELACIONES CON AMÈRICA LATINA Y EL CARIBE: 20102015 .295

8.1. EL ALTO REPRESENTANTE DE LA UNIÓN PARA ASUNTOS

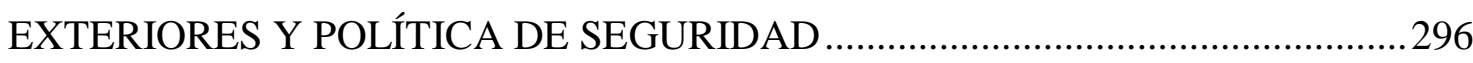

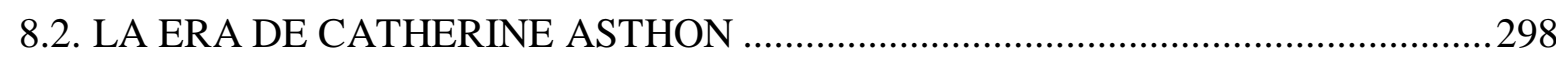

8.3. LA ALTA REPRESENTANTE, EL SERVICIO EUROPEO DE ACCIÓN EXTERIOR Y AMÉRICA LATINA .300

8.4. ASHTON Y AMÉRICA LATINA: UNA ASOCIACIÓN ESTRATÉGICA BIREGIONAL 302

8.5. LA ERA DE FEDERICA MOGUERINI. .306

8.6. MOGHERINI Y AMÉRICA LATINA: UNA ASOCIACIÓN PARA LA PRÓXIMA GENERACIÓN.

8.7. SÍNTESIS DEL ROL DE LA ALTA REPRESENTANTE PARA ASUNTOS EXTERIORES Y POLÍTICA DE SEGURIDAD 316

CONCLUSIONES:

ANEXO: LAS DELEGACIONES DE LA UNIÓN EN LOS PAÍSES DE LA

CELAC

1. RELACIONES DIPLOMÁTICAS ENTRE LA UE Y LOS PAÍSES DE LA CELAC

La UE-Antigua y Barbuda 349

La UE-Argentina 351

La UE-Bahamas .355

La UE-Barbados. 357

La UE-Belice 360

La UE-Bolivia 362

La UE-Brasil 365 


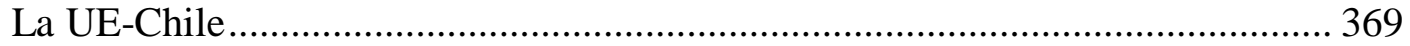

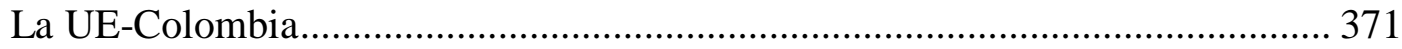

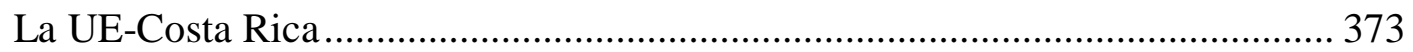

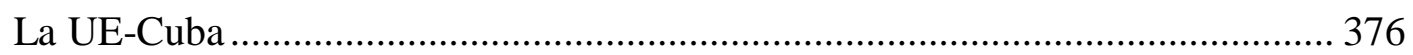

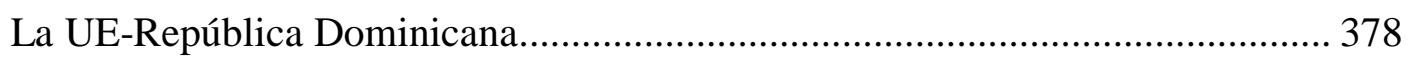

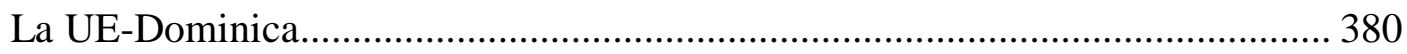

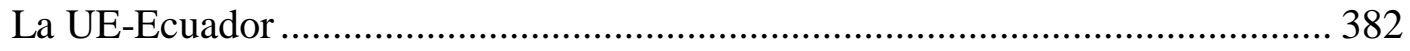

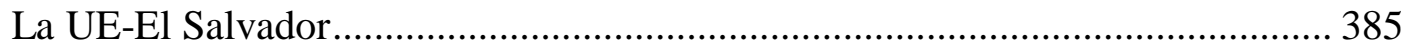

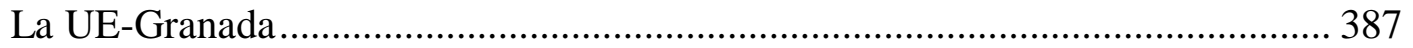

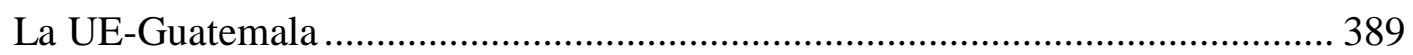

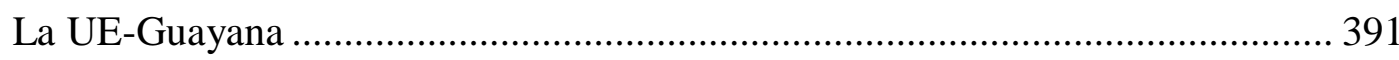

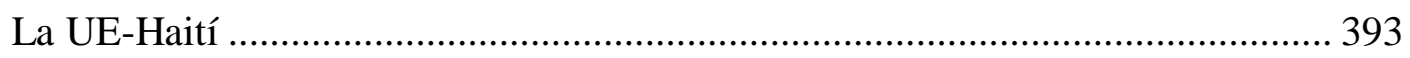

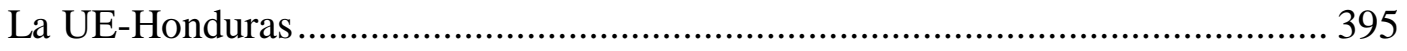

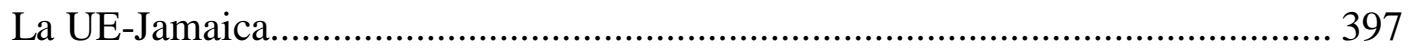

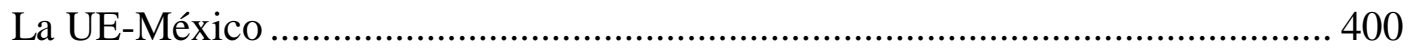

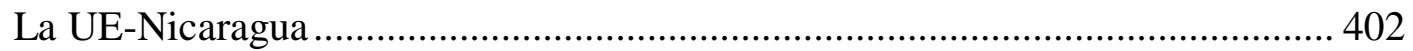

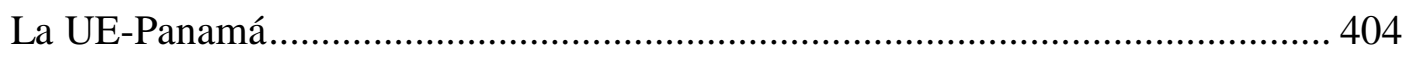

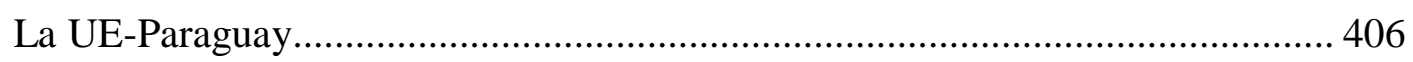

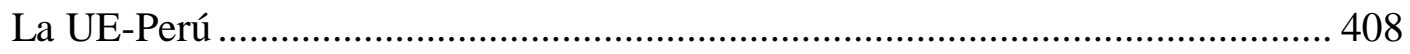

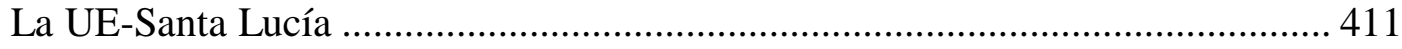

La UE-Federación San Cristóbal y Nieves ....................................................... 413

La UE-San Vicente y las Granadas ...................................................................... 415

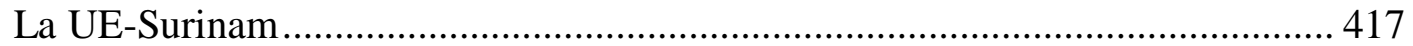

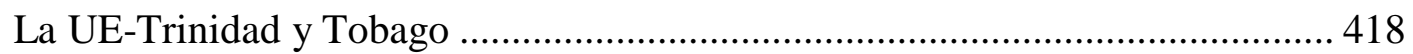

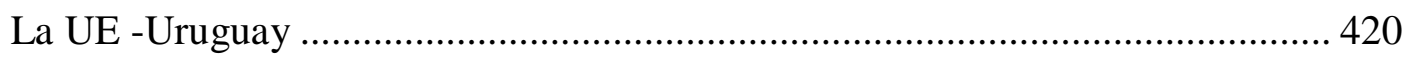

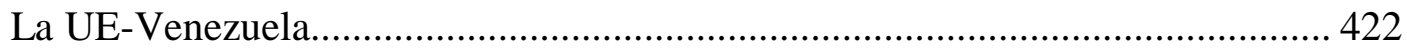

1. RESULTADO DE LAS RELACIONES ENTRE LAS DELEGACIONES DE

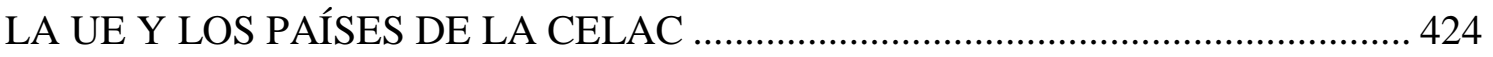

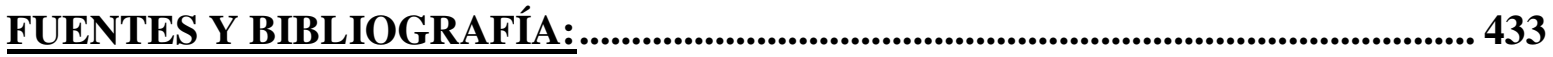


EL ACERVO INTEGRACIONISTA N EUROPA Y AMÉRICA:

UNA HISTORIA COMÚN 
CAPÍTULO I INTRODUCCIÓN 


\subsection{JUSTIFICACIÓN DEL TEMA OBJETO DE ESTUDIO}

Cuando se piensa en los inicios de la historia de la integración regional como fenómeno en las relaciones internacionales, se suele pensar en mediados del siglo XX, tomando como referencia el proceso de integración regional de la Unión Europea. El conjunto de la Academia suele estar de acuerdo con dicha aseveración, por consiguiente, se suelen marcar como punto de partida los Tratados de Roma de 1957, que dan origen a la Comunidad Económica Europea (CEE) y la Comunidad Europea de la Energía Atómica (EURATOM), o en algunos casos, se citan como antecedentes históricos el Convenio Aduanero, firmado en Londres en 1944, que crea el BENELUX, o el Tratado de París de 1951, que constituye la Comunidad Europea del Carbón y el Acero (CECA).

Al período entre 1945-1970 se le define como un "período de integración regional

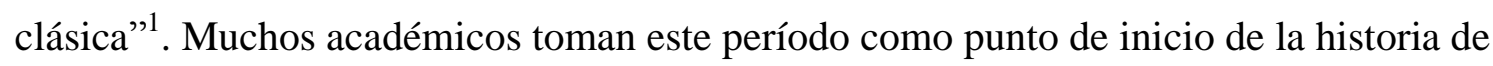
los procesos de integración regional y, sobre el mismo, centran sus investigaciones y teorías. En este orden, se pueden citar los siguientes autores: Mitrany $^{2}$, Viner ${ }^{3}$, Haas $^{4}$,

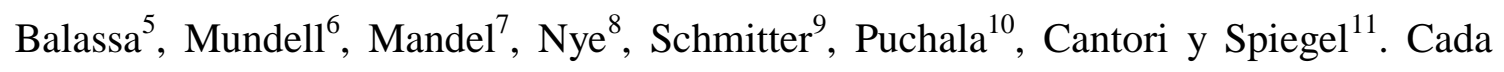
uno de estos autores, desde diferentes perspectivas y disciplinas, ha tratado de estudiar la evolución histórica de los procesos de integración regional y su impacto en las

${ }^{1}$ DE LOMBARDE, P. and SÖDERBAUM, F.: Regionalism: Volumen 1-4, Sage Publications, London, 2013.

${ }^{2}$ MITRANY, D.: The Functional Theory of Politics, Martin Robertson and Co., London, 1975. Ver también: MITRANY, D.: The Progress of International Government, Allen and Unwin, National Peace Council, London, 1944.

${ }^{3}$ VINER, J.: The Customs Union Issue, Carneige Endowment for International Peace, New York, 1950.

${ }^{4}$ HAAS, E.: The Uniting of Europe, Stevens and Sons, London, 1958. Ver también: HAAS, E.: Beyond the Nation State, functionalism and the international organization, Stanford University press, 1964.

${ }^{5}$ BALASSA, B. (Ed): European Economic Integration, North-Holland, Amsterdam, 1975.

${ }^{6}$ MUNDELL, R.: "A Theory of Optimun Currency Area", American Economic Review, 51 (4): 657-665, September, 1961. Ver también: MUNDELL, R.: "International trade and factor mobility", American Economic Review, 47 (2), June/1957.

${ }^{7}$ MANDEL, E.: Europe vs America: Contradictions of Imperialism, Monthly Review Press, New York, 2009.

${ }^{8}$ NYE, J.: "Comparing Common Markets: A Revised Neofunctionalist Model" in LINDEBERG, L. and SCHEINGOLD, S. (Ed): Regional integration: Theory and research, Cambridge University Press, New York, 1971. Ver también: KEOHANE, R. and NYE, J.: Power and Interdependence, Little Brow, Boston, 1977.

${ }^{9}$ SCHMITTER, P.: “A Revised Theory of regional Integration" in LINDEBERG, L. and SCHEINGOLD, S. (Ed): Theory and research, Cambridge University Press, New York, 1971.

${ }_{10}$ PUCHALA, D.: "Integration Studies and the Studies of International Relations, in MENIT, R and RUSSET, B (Eds): From national Development to Global Community-Essays in honour of Karls W Deutsch, Allen and Unwin, London, 1981.

${ }^{11}$ CANTORI, L and SPIEGEL, S.: International Politics of regions: A Comparative Approach, Engelwoods Cliffs, Pretice Hall, New York, 1970. Ver también: CANTORI, L and SPIEGEL, S.: "The Analysis of regional international Politics: The Integration Versus the Empirical Systems Approach", International Organization 27, N 4, 1973. 
relaciones internacionales, analizando para ello sus objetivos, mecanismos e instituciones sobre los cuales nacen, crecen y se desarrollan. Toda idea o proyecto de integración anterior al "período de integración regional clásica" es considerada "sueños de unificación”, “anhelos de unidad" y "utopías de pensamiento", sin embargo, si no hubiesen existido todas estas ideas, sueños y proyectos, la Europa que hoy conocemos no existiría, dado que el grado de institucionalidad existente en el proceso de integración europea, así como sus objetivos, valores y principios han sido resultado de esos sueños, anhelos y utopías integracionistas.

Esta investigación pretende demostrar que existe una historia anterior al período histórico definido como "integración regional clásica". A este período le llamamos "el período del acervo integracionista”, el cual se divide en dos fases. La primera nace en la Edad Media, con las ideas de unificación política de Europa, a través del surgimiento del Sacro Imperio Romano Germánico, que buscaba restaurar la gloria del Imperio Romano, en manos de Carlomagno, quien fue nombrado "Imperator Romanorum en el siglo IX, y a quien se le atribuye el esbozo de una Europa unida. Sin embargo, esta idea quedará frustrada, porque a lo largo de la Edad Media se dará una disputa de poderes en el sistema internacional entre el papado, el imperio y las regiones feudales. Estas últimas a su vez, se integrarán políticamente para formar los futuros EstadoNación en detrimento del poder del papado y del imperio.

La segunda fase parte en los ciernes de la creación de los Estados-Nación en el siglo XVII, mediante el Tratado de Westfalia, el cual estableció un nuevo orden internacional basado en la "soberanía nacional" y, aunque este predominó como modelo político, existieron de manera paralela otros proyectos que proponían la creación de uniones regionales sobre la base de una soberanía compartida o común. En cualquier caso, a pesar de que este último modelo no prevaleció en ese momento, deja como antecedentes históricos dos cuestiones, el desarrollo de ideas integracionistas y el rol que jugarán los Estado-Nación, que inicialmente se independizarán del papado y del imperio, para ser estados soberanos.

En el caso de los países europeos se dan cuenta que como estados soberanos e independientes son tan pequeños en la escena internacional que siglos más tarde retoman las ideas de formar una unión regional para poder tener una mayor presencia en los asuntos internacionales. En esa transición el Estado-Nación aprenderá a conjugar un 
nuevo rol, el de ser un Estado Miembro de una Unión Regional ahora de carácter supranacional y donde la clave no es defender a capa y espada, y de manera irrestricta la soberanía nacional, sino más bien, de una soberanía compartida, y ya no mediante la guerra, sino a través de la defensa de paz y el uso de la diplomacia.

Así mismo hacemos un paralelismo histórico entre Europa y América, estudiando los respectivos procesos de integración regional y su interrelación. Parte de nuestra hipótesis es que con el descubrimiento de América se produce una ampliación del mundo occidental y, con ello, un intercambio de ideas y de experiencias políticas que irán desde Europa hacia América.

El debate sobre qué modelo político tener se dio tanto en los países de Europa como en los de América. En el caso de Europa durante los períodos de los llamados "Sistema de Estados Europeos” o "Sistema Político de Europa" (Congresos de Westfalia 1644-1648) y posteriormente "Concierto Europeo" (Congreso de Viena 1814-1815). Y en el caso de los países americanos, el debate sobre qué modelo político seguir se gesta durante el período de sus independencias y mediante el Congreso de Panamá (1822-1825) donde se discutió la posibilidad de formar una unión regional. No mencionamos el Caribe, dado que la gran mayoría de los países caribeños inician sus independencias en el siglo XX. También excluimos a Canadá y Estados Unidos, en consecuencia cuando hablemos de los países americanos o América, nos referiremos al grupo de países que hoy se denomina “América Latina”, y enfatizamos hoy, por cuanto como veremos a lo largo de este trabajo, no siempre fue llamada así.

Es destacable indicar la constante voluntad de unificación de ambas regiones a lo largo de los siglos, cuya motivación es el deseo de lograr la paz (pactum pacis) y la seguridad en sus respectivas regiones. En el caso de los países europeos era terminar con las constantes guerras fratricidas (guerra intra, podemos decir una guerra intra-regional). En el caso de los países americanos, era terminar con las constantes amenazas de guerra por parte de las potencias extra-regionales (europeas), durante el período de las guerras de independencia, (guerra inter, podemos decir que era una guerra inter-regional).

El riesgo de nuevas guerras es lo que lleva a los estados a unirse para evitar conflictos y establecer una zona de paz y la creación de organizaciones supranacionales que sirvan para mediar, y solucionar conflictos de manera pacífica. Resultado logrado con el 
proceso de integración de la Unión Europea, en la década de los años cincuenta del siglo XX. Quizá por esa razón el conjunto de la academia llega a un consensus al determinar que es el período en la historia en el cual nacen las uniones regionales, por ser esta la década donde se concretiza la creación de organismos de integración regional, algo que no sucedió con anterioridad. Sin embargo, esos hechos no pueden llevar a desconocer, en conjunto y desde una perspectiva histórica, los varios intentos en la búsqueda de la unidad política tanto de los países de Europa como de los de América. A nuestro entender son esos proyectos los que contribuyeron a ir madurando la idea de crear las uniones regionales tal como hoy las conocemos en Europa y América.

\subsection{HIPÓTESIS}

Nuestra pregunta de investigación es: ¿Existe un acervo integracionista común en Europa y América? Para responder a esta pregunta es necesario tener varias consideraciones, sobre las cuales se irá construyendo el hilo conductor de esta tesis.

- ¿Cuándo surge la idea de la integración política regional en Europa?

- ¿Cuándo surge la idea de la integración política regional en América?

- ¿Existe una extrapolación de las ideas de integración regional entre los países de Europa y América?

- ¿Cómo se produce esa extrapolación de ideas?

Para responder todos estos interrogantes, nuestra investigación parte de la hipótesis de que la integración regional no nace en el siglo XX, sino que es una evolución histórica cuyas raíces germinan en la Europa de la Edad Media, por ser este el período en la cual se va a pensar en Europa como una potencia regional diferenciada de otras regiones del mundo, y cuyos cimientos políticos-geográficos se basan en las ciudades feudales, que son las que posteriormente darán nacimiento a las Ciudades-Estados. Ambas son en sí el primer proceso de integración regional, porque serán regiones geográficas unidas por una cultura y lenguas, que se unirán en una alianza política para crear los futuros Estados-Nación. La importancia de este desarrollo es que los últimos serán los futuros miembros (Estados Miembros) de la actual Unión Europea.

La similitud en las ideas, iniciativas y proyectos integracionistas, es algo natural que se da en ambas regiones, a nuestro entender, cuando se habla en la actualidad de que la Unión Europea, América Latina y el Caribe son “aliados naturales unidos por fuertes 
vínculos históricos, culturales y económicos, así como por una convergencia cada vez mayor de valores básicos y principios. Comparten un compromiso común respecto a los derechos humanos, la democracia, la buena gobernanza, el multilateralismo y la cohesión social" $" 12$. No sorprende, dado que ambas regiones comparten ese conjunto de valores y principios, normas y actos jurídicos (tratados y acuerdos) similares, a lo largo de su historia, y que han estado unidos por ese constante intercambio de ideas y de experiencias. Muestra de ello, es esa historia común en sus acervos integracionistas, al fin y al cabo, ambas regiones forman parte de una historia común mayor, que es la historia de Occidente.

Esa América que hoy se encuentra dividida en subregiones, ya sean tres: América del Norte, América Central y América del Sur; o bien cuatro cuando se incluye al Caribe; e incluso dos, América del Norte - América Latina y el Caribe, no se entiende con claridad porque en su división, desde el norte al sur incluido el Caribe, todos los países tiene una misma herencia cultural, que es la europea.

A veces se trata de justificar que América del Norte tiene una herencia anglo-sajona, pero Canadá tiene herencia francófona, y si nos referimos a Estados Unidos, este país también tiene herencia hispánica, no sólo anglo-sajona, y el Caribe, que ahora se considera unida a la llamada América Latina, no es acaso de herencia francófona y anglo-sajona. Si otra variable fueran los aspectos lingüísticos, entre los países de habla inglesa o de habla hispana, tendríamos que recordar que en el Caribe más países hablan inglés que español, y que en Estados Unidos una gran parte de su población habla español, es más, según el Informe 2015 del Instituto Cervantes "El Español: una lengua viva"13 estima que para el 2050 Estados Unidos será el país con más número de habitantes que hablarán español.

Por tanto, si tuviéramos que usar un adjetivo para diferenciar a las Américas, creo que el término de América "Latina" es la más apropiada para toda América, pues al fin y al cabo la gran mayoría de sus lenguas provienen del latín. El latín, esa lengua que se considera muerta y condenada al ostracismo histórico, es lo que mantuvo vivo el nexo

\footnotetext{
12 COMISIÓN EUROPEA: La Asociación estratégica entre la Unión Europea, América Latina y el Caribe: un compromiso común. Comisión Europea. Dirección General de Relaciones Exteriores, Dirección América Latina, Bruselas, 2008. p. 5.

${ }^{13}$ INSTITUTO CERVANTES: Informe 2015, El Español: una lengua viva. Para mayor información puede ver: http://eldiae.es/wp-content/uploads/2015/06/espanol_lengua-viva_20151.pdf [Consulta: 24/10/2015]
} 
entre la el Antiguo Imperio Romano, su conexión con el Edad Media, la Edad Moderna y la Edad Contemporánea. En todos estos períodos se sucederán las ideas integracionistas en ambas regiones, pero con un punto común vincular su modelo y raíces en la herencia greco-romana.

\subsection{METODOLOGÍA DE INVESTIGACIÓN}

Esa tesis estará dividida en tres partes. Una primera que incluirá los fundamentos históricos de la integración regional en Europa de la Edad Media; una segunda, que estudiará el paralelismo histórico de los procesos de integración regional en Europa y América; y una tercera que incluirá las relaciones entre Europa y América en el siglo $X X$ y $X X I$.

Esta investigación se realiza en base a un análisis sincrónico de los diferentes textos publicados en libros, anuarios y archivos, principalmente archivos históricos y archivos diplomáticos, así como revistas especializadas, prensa, internet y documentos como: iniciativas, proyectos, tratados y acuerdos desarrollados en el marco de los procesos de integración regional tanto en Europa como en América Latina y Caribe. Así mismo, se fundamenta en documentos oficiales emanados por los organismos internacionales, organismos regionales y por sus respectivos estados miembros. Por tanto las fuentes utilizadas son de ámbito directo e indirecto, definiendo las fuentes de ámbito directo como los documentos emanados por los propios estados y uniones regionales de nuestro estudio.

\subsection{MARCO TEÓRICO}

Para entender los procesos de integración regional en Europa y América, se hace necesario iniciar con el estudio de las ideas que dan origen a las razones por las cuales un grupo de estados deciden integrarse. Por tal motivo, se hará una búsqueda en la historia de ambas regiones (Europa y América) para identificar cuáles son los puntos de referencia y modelos que toman en consideración para integrarse. Y para poder hacer un estudio comparativo entre ambas regiones, utilizaremos el interregionalismo como marco teórico para explicar cada uno de los procesos de integración regional, así como su interrelación, es decir, su interregionalismo. 
El fenómeno del interregionalismo en las relaciones internacionales ha representado modificaciones en la economía y en la política mundial, generando una transformación estructural del propio sistema internacional ${ }^{14}$, que durante los últimos tiempos ha tenido como actores exclusivos a los Estados-Nación. El surgimiento y participación de las nuevas Uniones Regionales en el sistema internacional y su interrelación (interregionalismo) con otras uniones, ha producido una redistribución y reconfiguración en los centros de poder y en las tomas de decisiones con respecto a la gobernabilidad a nivel global.

La llamada gobernanza global es compartida entre los Estados-Nación y las Uniones Regionales, lo que ha llevado a un nuevo orden mundial, pasando de ser un mundo que tenía un sistema internacional (basado en relaciones interestatales) a un sistema internacional (basado en relaciones interestatales, relaciones interregionales ${ }^{15} \mathrm{y}$ relaciones inter-estatales-regionales), o como Hettne llama "un mundo de regiones"16.

Dentro de este nuevo contexto internacional, los Estados-Nación juegan un doble rol, uno individual como estados y otro como estado miembro de una unión regional. Su membresía y/o adhesión a un proceso de integración regional u organismo de integración lo hace movido por el interés de fortalecer y ampliar su poder político y económico a nivel mundial ${ }^{17}$.

Las investigaciones sobre el desarrollo de las capacidades de las uniones regionales como actores políticos Actorness se centran en la experiencia del proceso de integración de la Unión Europea ${ }^{18}$ y cómo ésta ha desarrollado e implementado una acción exterior común, para consolidar su proceso de integración regional. Para lograr con este objetivo ha utilizado como instrumento el interregionalismo.

Es este el ámbito en el cual se desenvuelven las relaciones interregionales entre Europa y América, concretamente en esta investigación nos centraremos en dos procesos de

\footnotetext{
${ }^{14}$ HETTNE B.: In Search of World Order, in HETTNE, V, and BERTIL O.: Global Governance in the 21st Century: Alternative Perspectives on World Order. Norstedts Tryckeri AB, Stockholm, 2002. p. 6.

${ }^{15}$ HETTNE B., SÖDERBAUM F. and STÅLGREN P.: The EU as Global Actor in the South. Swedish Institute for European Policy Studies, Report N 8, Stockholm, June/2008, p. 21.

${ }^{16}$ HETTNE, B.: Regionalism and World Order, in FARREL M, HETTNE B, and VAN LANGENHOVE, L.: Global Politics of Regionalism, Pluto Press, London, 2005, p. 277.

17 TUSSIE, D: "Regionalism: providing a substance to multilateralism?" in SÖDERBAUM F. y TIMOTHY S.: Theories of New Regionalism: A Palgrave Reader, Basingstoke, Palgrave-McMilan. New York, 2003, pp. 99-116.

${ }^{18}$ BRETHERTON C. and VOGLER, J.: The European Union as a Global Actor, Routledge, London and New York, 2006. pp. 1-10.
} 
integración regional, en el caso de Europa, en el proceso de integración de los países de la Unión Europea; y en el caso de América, en el proceso de integración de los países de América Latina y el Caribe.

Este apartado se inicia definiendo, teóricamente, los términos que se utilizarán a lo largo de esta investigación, los mismos que son parte de nuestras áreas de estudio. El objetivo es tratar de usar con propiedad y con la mayor exactitud posible la verdadera dimensión de cada término, tomando en consideración que en la propia literatura académica existente, no siempre hay una unanimidad, ni tampoco una claridad en las definiciones y en el uso de los términos. Al respecto, Fawcett señala que la dificultad en la falta de definición de los términos es un problema hasta para los propios académicos que trabajan sobre regiones, regionalismo, regionalización ${ }^{19}$.

Este problema se agrava si deseamos realizar un estudio comparativo, pues muchas veces las dimensiones y ámbitos de acción suelen ser distintos entre los diferentes procesos de integración regional que se dan en todo el mundo. Esto tiene que ver con la naturaleza, objetivos y características propias de cada proceso de integración que se desarrolla en el mundo. Nye, por su parte, mencionaba que existen importantes dificultades a la hora de querer teorizar y explicar un proceso de integración regional. El problema se centra en lo difícil que resulta relacionar los conceptos de los diferentes autores, un hecho debido, en gran parte, a que dichos teóricos se han ignorado entre sí, y en otros casos, porque se han confrontado, tratando de defender sus propias teorías y crear sus propias escuelas de pensamiento ${ }^{20}$.

De toda la literatura revisada se expondrán a los autores que son más relevantes en las materias a nivel internacional, y los cuales, se considera, suelen definir con mayor exactitud los términos y conceptos que se usarán a lo largo de esta investigación. A continuación, en el apartado Conceptos Generales se expondrán algunos de los términos que serán más recurrentes en esta investigación, por ser los principales conceptos sobre

\footnotetext{
${ }^{19}$ FAWCETT, L.: Regionalism from an Historical Perspective, in FARRELL, M., HETTNE, B., and VAN LANGENHOVE L. Op. cit. p.23.

${ }^{20}$ NYE, J.: Integración regional comparada: concepto y medición. Revista de Integración, (1969) Vol. 5, Instituto para la Integración de América Latina, Banco Interamericano de Desarrollo, p. 50. Base Bibliográfica del Centro de Documentación INTAL (Instituto para la Integración de América Latina y el Caribe, Banco Interamericano de Desarrollo. www.iadb.org/intal/intalcdi/integ1B.asp?cambio=SI\&ordenX=anioD [Última revisión: 17-11-2012]
} 
los cuales desarrollaremos todo nuestro trabajo, tales como: región, subregión, regionalismo y regionalización e interregionalismo.

\subsubsection{Conceptos generales}

\subsubsection{Región}

Dado que para entender y poder analizar los procesos de integración regional y el interregionalismo, previamente hay que comprender qué es el regionalismo, es primordial, para nuestro estudio, definir ante todo qué es una región, cómo está formada, cuál es su historia y acervo, cuáles son sus límites geográficos o cómo se organiza. Es necesario comprender sus estructuras y analizar si poseen o no instituciones que representen los intereses de dicha región, si esa región tiene o no personalidad jurídica, qué competencias tienen, y si dentro de estas competencias está definida o no su capacidad de acción exterior, que es, en definitiva, lo que le permite proyectarse a nivel internacional como una región diferenciada frente a otras.

Revisando la literatura especializada en estos temas, se observa que hay distintas maneras de definir región, y que todas estas definiciones parten de una base empírica, tomando como referencia la evolución histórica de los procesos de integración que se han dado en las distintas regiones del mundo.

Según Hettne, desde la observación empírica de los diferentes nuevos procesos económicos y políticos que se están desarrollando en diferentes áreas geográficas del mundo, región se define como un grupo de países que comparten, más o menos, un proyecto político compartido ${ }^{21}$. Además agrega que tradicionalmente región era definida como un número limitado de estados que se encontraban vinculados por su proximidad geográfica y por un cierto grado de dependencia mutua, pero que en la actualidad, una región no sólo puede ser definida como un simple conjunto de estados agregados que deciden iniciar un proceso de integración regional. En tal sentido, una región es un conjunto de estados que buscan trascender el estado-central ${ }^{22}$.

\footnotetext{
${ }^{21}$ HETTNE, B., INOTAI, A. AND SUNKEL, O.: Globalism and the new regionalism. Palgrave Macmillan, New York, 2002. p. 1.

${ }^{22}$ HETTNE, B. and SÖDERBAUM: "Theorising the rise of regionness" in BRESLIN, S., HUGHES, C., PHILLIPS, N and ROSAMOND, B.: New regionalisms in the global political economy. Routledge, New York, 2002, p. 37 y 38. Ver también: SÖDERBAUM, F.: The Political Economy of Regionalism. The case of Southern Africa. Palgrave Macmilan, Hampshire, 2004.
} 
Compartiendo la misma visión, expresada en el párrafo anterior, y con el mismo sentido de trascendencia del estado a sus propias fronteras, encontramos a Katzenstein, quien nos dice que las regiones son la creación de un nuevo poder político cuyo propósito es extender el poder de los estados más allá de sus fronteras y para lograrlo lo hacen a través de la combinación de una acción estratégica y su peso total ${ }^{23}$.

Sin embargo, para Fawcett, la proximidad geográfica como elemento para definir una región no es suficiente. Plantea que una simple definición geográfica no basta, y por ello considera que las regiones tienen que ser vistas desde una perspectiva más amplia, tomando como referencia más elementos, y que estos tienen que ser comunes entre las partes que conforman dicha región. Fawcett cree que las regiones son unidades o zonas basadas en un grupo de estados o territorios, cuyos miembros comparten algunos rasgos comunes $^{24}$. Estos elementos comunes pueden ser sistemas políticos o económicos similares, idioma, cultura y religión, entre otros.

Oyarzún, realiza un estudio sobre la naturaleza de la integración regional, en el cual señala el aporte de tres autores que contribuyen a la definición de región, Cantori, Spiegel y Russet. Para Cantori y Spiegel, una región es un territorio geográfico cercano y cuyas políticas exteriores estarían interrelacionadas; y para Russett, una región tiene que cumplir con tres pautas necesariamente: proximidad geográfica (cercanía entre los países que conforman la región), interdependencia (principalmente en términos económicos), y homogeneidad (sistema económico, religión, idioma, historia, etc. $)^{25}$.

Farrell nos dice que la región no es una forma estática, todo lo contrario, es dinámica y abierta a cambios y adaptación, y por ello, su construcción y reconstrucción es parte de un proceso global de transformación ${ }^{26}$.

\footnotetext{
${ }^{23}$ KATZENSTEIN, P. J.: A World of Regions: Asia and Europe in the American Imperium. Cornell University Press, Ithaca, 2005. p. 21.

${ }^{24}$ FAWCETT, L.: Regionalism from an Historical Perspective. En FARRELL, M., HETTNE, B., and VAN LANGENHOVE, L. Op. cit. p.24.

${ }^{25}$ OYARZÚN, L.: Sobre la naturaleza de la integración regional: teorías y debates. Revista de Ciencia política, vol. 28, núm. 2, Pontificia Universidad Católica de Chile, 2008, p.2. Ver también: SAINZ, N.: Tres modelos de cooperación en América: La Organización de Estados Americanos, el Grupo de Río y el Mercado Común del Sur. Documento de Trabajo. Universidad Autónoma de Barcelona, Barcelona, 2000. CANTORI, L. and SPIEGEL, S.: The Analysis of Regional International Politics: The Integration Versus the Empirical Systems Approach. International Organization, Vol. 27, Issue 04,.9.1973, pp. 465-494. RUSSETT, B.: International regions and the international system: a study in political ecology. RandMcNally, Chicago, 1967.

${ }^{26}$ FARREL, M.: The global politics of regionalism: An introduction. En FARRELL, M., HETTNE, B., and VAN LANGENHOVE, L. Op. cit. p. 8.
} 
Sin entrar en el debate de la vigencia o no del sistema internacional conformado por los Estado-Nación, como actores políticos en las relaciones internacionales, lo que sí es cierto, es que en la actualidad está vigente un sistema internacional donde se están dando otras formas de organización diferente que escapan al marco de los estados ${ }^{27}$. Por tanto podemos afirmar que el tradicional modelo del sistema de los Estado-Nación (Sistema de Westfalia) como mínimo ha cambiado, mejor aún, ha evolucionado a un estadio superior, en el cual las uniones regionales son el espacio más idóneo para poder desarrollar una organización política más capaz y eficiente que responda a los retos y desafíos actuales de la globalización.

En este nuevo sistema internacional, el peso y el poder político de un país o una región se mide en dos formas: hard power ${ }^{28}$ y soft power $^{29}$. El primero está representado por el poder económico, es decir en su el peso de mercado y su poder militar ${ }^{30}$. El segundo por la diplomacia, la cultura y/o la historia.

En las últimas décadas se ha dado una proliferación de acuerdos regionales en los cuales ha prevalecido el interés por establecer acuerdos preferenciales comerciales, mercados comunes, uniones aduaneras y/o mercados únicos, para poder ser más atractivos económicamente $^{31}$, lo que ha generado un cambio global en la estructura del sistema internacional. Podemos decir que el cambio gira entorno a la combinación de dos variables: la política y la económica. Hardacre habla del cambio de la geopolítica a la

\footnotetext{
${ }^{27}$ VAN CREVELED, M.: The Rise and Decline of the State. Cambridge University Press, New York, 1999.

${ }^{28}$ CAMPBELL, K and O'HANLON, M.: Hard Power: The New politics of National Security, Basic Books, New York, 2006. GRAY, C.: Hard power and soft power: The utility of military force as an instrument of policy in the $21^{S T}$ Century, Strategic Studies Institute-US Army War College, Pennsylvania, 2011. ILGEN, T.: Hard power, soft power and the future of transatlantic relations, BurlingtonHampshire, Ashgate, 2006.

${ }^{29}$ NYE, J.: Soft power: The means to success in World Politics (Public Affairs, 2004), "Public Diplomacy and Soft Power", The Annals of the American Academy of Political and Social Science, 616, 1 (2008); The future of Power (Public Affairs, 2011). TELÓ, M.: The European Union and Global Governance, Routledge, London, 2009. MELISSEN, J. (Ed): The New Public Diplomacy: Soft Power in International Relations, Palgrave Macmillan, London, 2005. MANNERS, I.: "The Normative Power of the European Union in a Globalized World" in LAIDI, Z.: (Ed): EU Foreign Policy in a Globalized World: Normative Power and Social reference, Routledge, London, 2008.

${ }^{30}$ STRAnGE, S.: The Retreat of the State. The Diffusion of Power in the World Economy. Cambridge University Press, New York, 1996.

31 ORGANIZACIÓN MUNDIAL DEL COMERCIO: Informe sobre el Comercio Mundial 2011. La OMC y los acuerdos comerciales preferenciales: de la coexistencia a la coherencia. Organización Mundial del Comercio, Geneva, 2011. Ver también: WORLD BANK: Global Economic Prospects 2005: Trade, Regionalism and Development. Chapter 2. Regional Trade and Preferential Trading Agreements: A Global Perspective and Chapter 3. Regional Trade Agreements: Effects on Trade. Washington DC, 2005, pp. 27-74. WORLD BANK: Trade Blocs. A World Bank Policy Research Report N 20809. World Bank and Oxford University Press, New York, 2000.
} 
geoeconomía $^{32}$. Lo que evidencia el interés estratégico por poseer un gran mercado en pos de un gran territorio. Si antes las guerras eran por conquistar nuevos territorios, hoy la guerra es por conquistar nuevos mercados.

De ahí la importancia de la visión de la integración regional, que estudiaremos y analizaremos más adelante, cuando aludamos a la Unión Europea-América Latina y el Caribe como uniones regionales y su búsqueda en ser actores globales. Ahora bien, no es lo mismo iniciar y desarrollar un proceso de integración regional con el objetivo de aspirar a una mayor inserción en la economía internacional (caso de América Latina y el Caribe), que aspirar a liderar la economía y escenario internacional (caso de la Unión Europea), para lo que es necesario contar y ejercer un peso político en los foros internacionales. Las uniones regionales brindan la oportunidad a los estados de poder ser oídos con una sola voz; la diferencia radica entre aspirar a ser un participante en la escena global y ser un actor global.

En términos de relaciones internacionales, antes se hablaba de un mundo bipolar, ahora se dice que existe un mundo multipolar. Habría que considerar el peso de los nuevos actores, las uniones regionales, y entonces podemos decir que el poder político y el sistema de gobernanza actual conforman un nuevo orden mundial. Orden que es compartido entre las fuerzas multipolares (los estados tradicionalmente potencias y los estados emergentes) y las fuerzas multiregionales (las uniones regionales).

La cesión de soberanía y la creación de un sistema de competencias a escala regional es un elemento indispensable para crear una unión regional. Lo que décadas atrás fue considerado como un nuevo fenómeno en las relaciones internacionales, el sistema internacional regional ${ }^{33}$, hoy ha creado una gobernanza multinivel ${ }^{34}$. Las uniones regionales tienen cada día más presencia en la toma de decisiones políticas, económicas y de desarrollo de los países, convirtiéndose en los nuevos actores políticos tanto en la esfera nacional como en el ámbito global.

\footnotetext{
${ }^{32}$ HARDACRE, A.: The rise and fall of interregionalismo in EU external relations. International Relations Studies Series. Series Editor Patrick James, University of Southern California, Vol 9. Republic of Letters Publishing BV, Dordrecht, Danvers, 2010. p.1.

${ }^{33}$ HETTNE, B., SÖDERBAUM, F. and STÅLGEN, P. Op. cit., p. 21.

${ }^{34}$ McCORMICK, J.: Understanding the European Union: A concise introduction. Palgrave MacMillan, New York, 2011. pp.2-4.
} 
Como dijera Javier Solana, el sistema de Westfalia tiene sus límites ${ }^{35}$. Una muestra del cambio en la hegemonía ejercida por parte de los estados en las relaciones internacionales son los distintos modelos de política exterior ejercida entre los países y grupos de países, por ejemplo, los Estados Unidos (un Estado-Nación) y la Unión Europea (una unión regional). El primero promueve, dentro de su política exterior, como preferencia, el bilateralismo, como mecanismo de interrelación con terceros; mientras que el segundo fomenta el regionalismo y el interregionalismo en sus relaciones. Ambos casos representan el cambio de modelo dentro de las relaciones internacionales, el modelo neo-Westfalia (Estados Unidos) y el modelo post-Westfalia (Unión Europea) $^{36}$.

Por tanto, en este trabajo cuando se hable del proceso de integración regional, definiremos región como un conjunto de estados que comparten una cierta área geográfica, con raíces históricas, culturales y valores comunes y que sobre esta base aspiran a construir una unidad regional que puede abarcar distintos niveles: económico, político, social y cultural. Pero sobre todo, y lo más importante para nuestro estudio, es cuando esta región se convierte en un sujeto, es decir cuando posee una personalidad jurídica internacional, que le permite desarrollar una acción exterior común, contando con una institucionalidad que le permita negociar y firmar acuerdos internacionales en representación de la unión regional que representa.

\subsubsection{Subregión}

En lo que respecta al término subregión, se comprueba que la literatura académica ha dado poca importancia al término, obviando por completo la definición del mismo. Sin embargo, considero que dicha falta de aclaración no es meramente un tema de forma, pues más bien es de fondo. Para poder entender la evolución histórica e institucional de algunos procesos de integración regional, es necesario poder comprender y deslindar las diferencias entre el término región y subregión. En principio se podría pensar que dicha diferenciación es sólo geográfica, que no es ningún problema teórico, y que daría un poco lo mismo definir un proceso de integración, como regional o subregional. Pero a

\footnotetext{
${ }^{35}$ SOLANA, J.: "Securing Peace in Europe". Symposium on the Political Relevance of the 1648. Peace of Westphalia. Münster, 12.11.1998. http://www.nato.int/docu/speech/1998/s981112a.htm [Última revisión: 02-04-2013]

${ }^{36}$ HETTNE, B.: "Interregionalism and World Order: The Diverging EU and US Models", in TELÓ, M.: European Union and New Regionalism. Regional Actors and Global Governance in a Post-Hegemonic Era, Ashgate Publishing Company, Burlington, 2007. p.107.
} 
mi entender, sí lo es, pues si consideramos la evolución histórica de los procesos de integración regional, tanto en Europa como en América constatamos que muchos de los procesos de integración a escala subregional han servido para profundizar el propio proceso de integración regional en esta parte del mundo.

En el caso de Europa, podemos encontrar, cronológicamente, los siguientes procesos de integración a nivel subregional:

\section{BENELUX (1944) ${ }^{37}$}

2. Unión Europea Occidental (1948) 38

3. Organización Europea de Cooperación Económica (1948) $)^{39}$

4. Comunidad Europea del Carbón y del Acero $(1951)^{40}$

5. Comunidad Económica Europea $(1957)^{41}$

6. Comunidad Europea de la Energía Atómica $(1957)^{42}$

7. Asociación Europea de Libre Comercio $(1960)^{43}$

8. Iniciativa de Europa Central (1989) ${ }^{44}$

9. Acuerdo Centro Europeo de Libre Comercio (1992) ${ }^{45}$

10. Organización de Cooperación Económica del Mar Negro (1992) ${ }^{46}$

37 Convenio Aduanero, firmado en Londres, el 5 de septiembre de 1944. United Nations University. Institute on Comparative regional Integration Studies.

http://www.cris.unu.edu/riks/web/treaties/Benelux.pdf

${ }^{38}$ Tratado sobre la Colaboración Económica, Social y Cultural y de Defensa Colectiva (Tratado de Bruselas), firmado el 17 de marzo de 1948. Wester European Union.

http://www.weu.int/Treaty.htm

39 Convención de la Organización Europea para la Cooperación Económica, firmado en Paris el 16 de abril de 1948. The Organization for Economic Cooperation and Development.

http://www.oecd.org/general/supplementaryprotocolno1 totheconventionforeuropeaneconomiccooperationonthelegalcapacityprivilegesandimmunitiesoftheorganisation.htm

${ }^{40}$ Tratado Constitutivo de la Comunidad Europea del Carbón y del Acero (Tratado de París), 18 de abril 1951. Unión Europea. Europa. Síntesis de la Legislación de la Unión Europea.

http://europa.eu/legislation_summaries/institutional_affairs/treaties/treaties_ecsc_es.htm

${ }^{41}$ Tratado Constitutivo de la Comunidad Económica Europea (Tratados de Roma), 25 de marzo de 1957. Unión Europea. Europa. Síntesis de la Legislación de la Unión Europea.

http://europa.eu/legislation_summaries/institutional_affairs/treaties/treaties_eec_es.htm

42 Tratado de Establecimiento de la Comunidad Europea de la Energía Atómica (Tratados de Roma), 25 de marzo de 1957. Unión Europea. Europa. Síntesis de la Legislación de la Unión Europea.

http://europa.eu/legislation_summaries/institutional_affairs/treaties/treaties_euratom_es.htm

${ }^{43}$ Convención del Establecimiento de la Asociación Europea de Libre Comercio, Estocolmo 4 de enero 1960. World Intellectual Property Organization.

http://www.wipo.int/wipolex/en/other_treaties/details.jsp?treaty_id=439

44 Declaración Conjunta Iniciativa de Europa Central, Budapest 11 de noviembre de 1989. Central European Initiative.

http://www.cei.int/sites/default/files/attachments/publications/booklet\%20final\%20low.pdf

45 Acuerdo Centro Europeo de Libre Comercio, Cracovia diciembre de 1992. World Intellectual Property Organization.

http://www.wipo.int/wipolex/en/other_treaties/details.jsp?treaty_id=391 
11. Comunidad de Estados Independientes $(1991)^{47}$

12. Espacio Económico Europeo (1994) $)^{48}$

13. Áreas de Libre Comercio del Báltico $(1994)^{49}$

14. Comunidad Económica de Eurasia $(2000)^{50}$

Existen otras iniciativas y procesos subregionales, como el Proceso de Cooperación del Sur-Este Europeo (1996), la Iniciativa del Mar Adriático-Jónico (2000), Proceso de Cooperación del Danubio (2002) y el Consejo de Cooperación Regional (2008). Cada uno de estos tratados, acuerdos, convenciones y declaraciones han servido para impulsar procesos de integración a nivel subregional en diferentes ámbitos: comercio, economía, cooperación, seguridad y defensa. Lo que ha servido de acervo integracionista en Europa.

Así, por ejemplo, podemos constatar que los procesos emprendidos en el marco del BENELUX, la Unión Europea Occidental, la Comunidad Europea del Carbón y del Acero, la Comunidad Económica Europea y la Comunidad Europea de la Energía Atómica sirvieron de base tanto en sus ámbitos de acción como modelos institucionales para formar lo que hoy conocemos como la Unión Europea. Si recordamos el Tratado de Bruselas $^{51}$ (Tratado de Fusión) tenía como finalidad fusionar en una única Comisión y un único Consejo la CEE, EURATOM y CECA, primeros pasos del desarrollo del sistema institucional de la unión regional en Europa, a la par que el inicio de un proceso de convergencia institucional entre varios organismos de integración.

Otro ejemplo, es el Tratado sobre la Colaboración Económica, Social y Cultural y de Defensa Colectiva, firmado entre los países del BENELUX, Francia y Reino Unido, que

\footnotetext{
${ }^{46}$ Declaración de la Cumbre sobre la Cooperación Económica del Mar Negro, Estambul 25 de junio de 1992.The Organization of the Black Sea Economic.

http://www.bsec-organization.org/documents/declaration/summit/Reports/Istanbul1992.pdf

47 Acuerdo de Establecimiento de la Comunidad de Estados Independientes, Minsk 8 de diciembre de 1991. Biblioteca Jurídica Virtual Universidad Nacional Autónoma de México. http://biblio.juridicas.unam.mx/libros/2/827/16.pdf

48 Acuerdo sobre el Espacio Económico Europeo, Oporto 2 de mayo 1992. Unión Europea. Europa. Síntesis de la Legislación de la Unión Europea.

http://europa.eu/legislation_summaries/internal_market/living_and_working_in_the_internal_market/em0 024_en.htm

${ }^{49}$ Acuerdo de Libre Comercio del Báltico, Tallin 13 de septiembre de 1993. Banco Mundial. http://wits.worldbank.org/GPTAD/PDF/archive/BAFTA-Indus.pdf

50 Acuerdo sobre la Fundación de la Comunidad Económica de Eurasia, Astana 10 de octubre de 2000. Banco Mundial. http://wits.worldbank.org/GPTAD/PDF/archive/EAEC.pdf

${ }^{51}$ Tratado de Fusión (Tratado de Bruselas), firmado el 8 de abril de 1965 y entró en vigor el 1 de julio de 1967.
} 
un año anterior a la firma de dicho acuerdo, habían firmado el Tratado de Dunquerque $^{52}$, que consistía en un tratado de alianza y asistencia mutua. Acontecimientos que introducen los temas de desarrollo de políticas en seguridad y defensa a escala subregional, sentando las bases para lo que sería la idea de una Unión Europea Occidental. Como señala Mangas "la UEO, ha sido una fuerza motriz de la unidad europea manteniendo un vínculo político con el Reino Unido y tendiendo la mano a los vecinos" $" 53$.

A la vez nos recuerda proyectos europeos como el de W. Churchill, quien propuso ante la Asamblea Consultiva del Consejo de Europa, el 11 de agosto de 1950, la creación de un ejército europeo unificado en el que participaría Alemania; el "Plan Pleven" mediante el cual se preveía la creación de una Comunidad Europea de Defensa o el proyecto de Alcide de Gasperi que propone la creación de una Comunidad Política Europea $^{54}$.

Es verdad que estos proyectos no se llegaron a concretar, pero sin duda sirvieron al acervo integracionista de Europa, y si hoy existe una política exterior y de seguridad común, es gracias a todos estos proyectos e iniciativas que en primera instancia pudieron considerarse como fracasos o duplicación de esfuerzos, tanto en recursos humanos como en recursos financieros.

En materia económica, el Acuerdo sobre el Espacio Económico Europeo, firmado entre los países de la Asociación Europea de Libre Comercio y de la Comunidad Económica Europea, sirvió para fortalecer el Mercado Común. Los otros procesos como la Iniciativa de Europa Central, la Organización de Cooperación Económica del Mar Negro, Comunidad de Estados Independientes y el Área de Libre Comercio del Báltico, han sido creados para promover la cooperación y fomentar la unidad en Europa, a través de acuerdos concretos a menor escala, de hecho muchos de estos procesos sirven para poder acceder a ser futuros candidatos como Estados Miembros de la Unión Europea.

\footnotetext{
${ }^{52}$ Treaty of Alliance and Mutual Assistance Between his Majesty in Respect of the United Kingdom of Great Britain and Northern Ireland and the President of the French Republic, signed at Dunkirk, on 4.3.1947. League of Nations, Treaty Series, Vol ${ }^{\circ}$ CCIV, p.353. http://www.cvce.eu/viewer/-/content/1fb9f4b5-64e2-4337-bc78-db7e1978de09/en.htm [Última revisión: 11-04-2013]

${ }^{53}$ MANGAS, A. y LIÑÁN, D.: Instituciones y Derecho de la Unión Europea, Editorial Tecnos, Madrid, 2006. p. 42

${ }^{54}$ Ibíd. pp. 42 y 43.
} 
Por ello, la Comisión Europea apoya y participa en varios de estos procesos con el fin de fortalecer la integración en estos procesos con miras a una Europa más fuerte a nivel internacional.

Finalmente, hemos incluido en esta lista a la Comunidad Económica de Eurasia porque algunos de sus estados miembros, como Bielorrusia y Ucrania, desean ser candidatos a la Unión Europea. Y por otro lado, porque muestra que los límites de la Europa comunitaria no están cerrados y que su proceso de integración sigue en una construcción constante, y que lo atractivo de ser Estado Miembro de la UE, no es sólo por aspectos económicos, sino por temas de acción exterior, que se traducen en la implementación de una política exterior y seguridad común.

Cottey señala que desde 1990 se ha dado una proliferación de lo que él ha llamado "new sub-regional groups" Centro de Europa, los Balcanes, el Mediterráneo y países de la ex Unión Soviética, sobre todo si tomamos en consideración la importancia de garantizar la paz y la estabilidad en el área Euro-Atlántica ${ }^{56}$.

En el caso de América "Latina" podemos encontrar, cronológicamente, los siguientes procesos de integración subregional:

1. Organización de Estados Centroamericanos $(1951)^{57}$

2. Asociación Latinoamericana de Libre Comercio $(1960)^{58}$

3. Mercado Común Centroamericano $(1960)^{59}$

\footnotetext{
55 COTTEY, A.: "Sub-regional Cooperation in Europe: An Assessment”, Bruges Regional Integration \& Global Governance Papers 3/2009. Joint working paper series of the EU International Relations and Diplomacy Studies Department at the College of Europe and the Comparative Regional Integration Studies Programme of the United Nations University, Bruges. http://www.cris.unu.edu/fileadmin/workingpapers/BRIGG_papers/BRIGG_3-2009_revised_version.pdf [Última revisión: 08-04-2013]

${ }^{56}$ BAILES, A.: "Sub-regional organizations: The Cinderellas of European Security". NATO Review, N 2 Marzo 1997. Vol. 45 pp. 27-31. http://www.nato.int/docu/review/1997/9702-8.htm [Última revisión: 08-04-2013]

${ }^{57}$ Carta de la Organización de Estados Centroamericanos (Carta de San Salvador). 14 de octubre de 1951. Base de datos. Gobierno de Nicaragua. Normas Jurídicas de Nicaragua, Publicado en La Gaceta N ${ }^{\circ} 30$ de 8 de febrero de 1952.

http://legislacion.asamblea.gob.ni/Normaweb.nsf/b92aaea87dac762406257265005d21f7/7185d48372de1 e320625767f005d1fe8?OpenDocument [Última revisión 08-04-2013]

58 Tratado de Montevideo, 18 de febrero 1960. Poder Legislativo. República Oriental del Uruguay. http://www.parlamento.gub.uy/htmlstat/pl/tratados/trat12859.htm [Última revisión: 08-04-2013]

${ }_{59}$ Tratado General de Integración Económica Centroamericana entre los Gobiernos de las Repúblicas de Guatemala, El Salvador, Honduras y Nicaragua. Managua, 13 de diciembre de 1960. Base de datos del
} 
4. Asociación de Libre Comercio del Caribe $(1965)^{60}$

5. Mercado Común del Caribe Oriental $(1968)^{61}$

6. Acuerdo de Integración Subregional Andino (1969) ${ }^{62}$

7. Sistema Económico Latinoamericano y del Caribe $(1975)^{63}$

8. Mercado Común del Sur $(1981)^{64}$

9. Asociación de Estados del Caribe (1994) ${ }^{65}$

10. Comunidad Sudamericana de Naciones $(2004)^{66}$

11. Alianza Bolivariana para los Pueblos de Nuestra América (2006) ${ }^{67}$

12. Comunidad de Estados Latinoamericanos y Caribeños $(2010)^{68}$

13. Alianza del Pacífico (2012) ${ }^{69}$

Sistema de Información sobre Comercio Exterior, Organización de los Estados Americanos. http://www.sice.oas.org/trade/camers.asp [Última revisión: 08-04-2013]

${ }^{60}$ Agreement Establish the Caribbean Free Trade Association. Georgetown 10.12.1966. Caribbean Community (CARICOM) Secretariat, Legal Instruments.

http://www.caricom.org/jsp/secretariat/legal_instruments/agreement_dickensonbay.jsp?menu=secretariat [Última revisión: 08-04-2013]

61 Agreement Establishing the East Caribbean Common Market. Grenada 11.6.1968. Treaties United Nations States. http://treaties.un.org/doc/Publication/UNTS/Volume\%201338/volume-1338-I-22434English.pdf [Última revisión: 08-04-2013]

62 Acuerdo de Integración Subregional Andino (Acuerdo de Cartagena). Cartagena de Indias 26 de mayo de 1969. Secretaría General de la Comunidad Andina. Normativa Andina. Gaceta Oficial del Acuerdo de Cartagena. http://www.comunidadandina.org/Normativa.aspx [Última revisión: 08-04-2013]

${ }^{63}$ Convenio de Panamá Constitutivo del Sistema Económico Latinoamericano. Panamá 17 de octubre de 1975. Secretaría Permanente del Sistema Económico Latinoamericano y del Caribe, Documento Institucional, Caracas, enero 2006.

http://www.sela.org/attach/258/default/T023600000397-0-

Convenio_de_Panama_\%28enero_2006\%29.pdf [Última revisión: 08-04-2013]

${ }^{64}$ Tratado para la Constitución del Mercado Común del Sur entre las Repúblicas de Argentina, Federativa de Brasil, Paraguay y Oriental del Uruguay (Tratado de Asunción). Asunción, 26 de marzo de 1991. Poder Legislativo. República Oriental del Uruguay.

http://www.parlamento.gub.uy/htmlstat/pl/tratados/trat16196.htm [Última revisión: 08-04-2013]

${ }^{65}$ Asociación de Estados del Caribe. Convenio Constitutivo. Cartagena de Indias, 24 de julio de 1994. Banco Interamericano de Desarrollo. Sistema de Información sobre Comercio e Integración.

http://www.iadb.org/int/intradebid/DocsPdf/Acuerdos/AEC\%20-\%20Convenio\%20Constitutivo.pdf

[Última revisión: 08-04-2013]

${ }^{66}$ Declaración del Cusco sobre la Comunidad Sudamericana de Naciones. III Cumbre Presidencial Sudamericana, Cusco 8 de diciembre de 2004. Secretaría General de la Comunidad Andina. Documentos Internacionales.

http://www.comunidadandina.org/documentos/dec_int/cusco_sudamerica.htm [Última revisión: 08-042013]

${ }^{67}$ Acuerdo para la Aplicación de la Alternativa Bolivariana para los Pueblos de Nuestra América y el Tratado de Comercio de los Pueblos. La Habana 29 de abril de 2006. Banco Interamericano de Desarrollo. Sistema de Información sobre Comercio e Integración.

http://www.iadb.org/int/intradebid/DocsPdf/Acuerdos/ALBA\%20alianza_bolivariana.pdf [Última revisión: 08-04-2013]

${ }^{68}$ Declaración de Cancún, 23 de febrero de 2010. Comunidad de Estados Latinoamericanos y Caribeños. Gobierno de Venezuela.

http://www.celac.gob.ve/index.php?option=com_content\&view=article\&id=27\&Itemid=3\&lang=es [Última revisión: 08-04-2013]

${ }^{69}$ Acuerdo Marco de la Alianza del Pacífico. Paranal 6 de junio de 2012. Secretaría de Relaciones Exteriores de los Estados Unidos de México. 
En los procesos de integración subregional desarrollados en América Latina y Caribe, podemos observar tres subregiones: centroamericana, caribeña y suramericana. Es interesante constatar que en los objetivos y fines planteados en los acuerdos y tratados fundacionales, sólo los procesos desarrollados en la subregión suramericana contemplaban la unidad del conjunto de la región latinoamericana.

No son los casos de las subregiones centroamericanas y caribeñas, pues en ambos casos siempre se habla de que los respectivos procesos de integración deben de servir para la integración regional de América Central o el Caribe, es decir, la visión natural de región, con sus respectivas subregiones que son vistas como región en sí mismas, más que una subregión que forma parte de una región más grande. Para ambas subregiones no es siempre la unidad regional de América Latina la prioridad o la aspiración máxima.

Caso contrario a los procesos emprendidos en América del Sur: Comunidad Andina, Mercosur, ALBA, UNASUR y Alianza del Pacífico, todas estas iniciativas, proyectos y procesos buscan la unidad de América Latina, y cronológicamente, irán incluyendo también al Caribe dentro de la definición de región. Así, podemos citar como ejemplos la Asociación Latinoamericana de Libre Comercio, que posteriormente se transformó en la Asociación Latinoamericana de Integración, y la última iniciativa a escala regional, la Comunidad de Estados Latinoamericanos y Caribeños.

Un dato importante a señalar es el papel jugado por México, país que pertenece a América del Norte, geográficamente hablando, pero siempre ha estado ligado a las aspiraciones de unidad de América Latina. El caso del acervo integracionista de México lo veremos con mayor detenimiento más adelante en el apartado que trata sobre el acervo integracionista en Europa y América en la Edad Moderna y Contemporánea.

Es interesante observar cómo la visión geográfica de los países no sólo se limita a sus fronteras nacionales, sobrepasan la escala nacional a subregional, de subregional a regional, e incluso muchas veces y mal utilizada, la idea de continental, cuando quieren definir una región.

Curiosamente las dos regiones de nuestro estudio, son geográficamente subcontinentes, pero muchas veces se definen como continentes propios, error geográfico y políticamente incorrecto. Pues si lo vemos desde el punto de vista geográfico, Europa, 
que muchas veces es definido como un continente, en realidad es un subcontinente, que junto a Asia forma Eurasia $^{70}$, y en el caso de América Latina es un subcontinente ${ }^{71}$ que pertenece al continente llamado América, y aunque a lo largo de su historia de integración ambas regiones han tenido aspiraciones de unidad política a escala continental, sólo han podido concretizar tales aspiraciones y sus sueños de unidad, a través de procesos de integración a escala subregional o regional.

Si hacemos una acotación terminológica la única excepción que podemos citar en términos de unidad continental sería el caso del proceso político emprendido por el conjunto de los países americanos, en la creación y proceso de la Organización de Estados Americanos (OEA), organización que sería la única a escala continental existente y que en sus inicios promovía una unión continental.

\subsubsection{Regionalismo y Regionalización}

Del mismo modo que suele existir una falta de claridad a la hora de definir región, existe también confusión con el nombre que se le asigna al proceso de integración que se da dentro de una región, en términos de objetivos, organización e institucionalización. Al respecto podemos decir que suelen existir dos vías en la construcción de una unión regional. La primeva vía es la del regionalismo y la segunda la regionalización. Ambas son fruto de la globalización de la economía y de la interdependencia existente entre los países ${ }^{72}$.

Dicha interdependencia no es solamente económica, también lo es política. Así, por ejemplo, una crisis política-económica en el país A, repercute también en su vecino, el país B, y esta a su vez a la región 1, formada por los paises A, B, C y D. Y es probable que la crisis de región 1, contagie a una región 2 o 3 formada por otros países. Por tanto,

\footnotetext{
${ }^{70}$ BALDERMANN, A.: ¿La unidad en la diversidad? Visiones de Europa en ensayos alemanes del Romanticismo, en Programa de Estudios Europeos: Europa frente a Europa, Universidad de Concepción, Santiago de Chile, 2011, p. 32. Ver también: BODEMER, K.: Austria, la Unión Europea y América Latina, en FRERES, C. y SANAHUJA, J.: América Latina y la Unión Europea. Estrategias para una asociación necesaria, Icaria Editorial, Barcelona, 2006, p. 253.

${ }^{71}$ VIDAL-FOLCH, X.: Latinoamérica y Europa ante la Agenda Global, en MALLO, T y SANAHUJA, J.A. (Coords.): Las relaciones de la Unión Europea con América Latina y el Caribe, Siglo XXI y Fundación Carolina, Madrid, 2011, p. 33. Ver también: DEL POZO, J.: Historia de América Latina y del Caribe. Desde la independencia hasta hoy, LOM Ediciones, Santiago de Chile, 2009, p.259. ROUQUIÉ, A.: América Latina. Introducción al Extremo Occidente, Siglo XXI, Madrid, 1989, p.20. AYALA, E. y POSADA, E.: Los proyectos nacionales latinoamericanos: Sus instrumentos y articulación 1870-1930. Historia General de América Latina VII, Ediciones UNESCO, Paris, 2008.

${ }^{72}$ STIGLITZ, J.: El Malestar de la Globalización, Taurus, Madrid, 2002, p.309.
} 
podemos decir que existe interdependencia regional. Tal como mencionan Hänggi, Roloff and Rüland, el regionalismo y la regionalización son ahora fenómenos universales $^{73}$. Söderbaum considera necesario hacer distinción entre regionalismo y regionalización ${ }^{74}$, pues aunque parezcan similares, no lo son. Y en muchos casos, hay procesos que suelen estar enmarcados en regionalismo, cuando en realidad son un proceso de regionalización y viceversa.

La misma confusión se da a nivel académico a la hora de estudiar un proceso de integración regional y de querer explicarlo, hecho que se agrava a la hora de desear compararlo con otros procesos llevados a cabo en el mundo.

Söderbaum distingue regionalismo de regionalización. La diferencia está en que el primero es un fenómeno general en el mundo entero, y recoge un conjunto de ideas, ideología e identidades comunes de una región específica, cuya dinámica se desarrolla dentro de un marco formal, es decir, un proyecto de integración regional cuya construcción lleva consigo la creación de una institución supranacional. El segundo es, en cambio, el resultado del regionalismo y además acota que la regionalización puede darse sin necesidad de que exista un proyecto concreto, es decir, sin que exista la voluntad de crear instituciones supranacionales; por tanto los actores pueden comprometerse en el proceso de un modo natural y sin convicción particular ${ }^{75}$.

La regionalización es considerada como un proceso que suele iniciarse desde el interés comercial y económico, es decir des una lógica económica ${ }^{76}$, y en la cual existen diferentes actores, entre los que destaca el papel desempeñado por las empresas. En el desarrollo de relaciones entre las empresas de varios países, los estados en los cuales están dichas empresas, se convierten también en actores promotores del proceso de regionalización, mediante la creación de políticas que faciliten y promuevan un mercado ampliado, es decir, ampliar su mercado nacional a un mercado regional, unificación de mercados, creación de mercados únicos o mercados comunes, para que las empresas tengan y gocen de una libre circulación de bienes, servicios y capitales.

\footnotetext{
${ }^{73}$ HÄNGGI, H, ROLOFF, R and RÜLAND, J.: Interregionalism and International Relations, Routledge, London, 2006, p. 4.

${ }^{74}$ SCHULZ, M., SÖDERBAUM, F. and ÖJENDAL, J.: Regionalization in a Globalizing World. A Comparative Perspective on Forms, Actors and Processes. Zed Book, London, 2001, p. 5.

${ }^{75}$ SÖDERBAUM, F.: The Political Economy of Regionalism. The case of Southern Africa. Palgrave Macmillan, Hampshire, 2004. p.7.

${ }^{76}$ SANTANDER, S.: Le régionalisme sudaméricain, L'Union européenne et les États-Unis, Institut d' Etudes Européennes, Bruxelles, 2008.
} 
En cambio, el regionalismo es una voluntad política cuyos principales actores son los estados y cuyos argumentos no son sólo los aspectos económicos y/o comerciales, sino políticos, sociales y culturales. El desarrollo del regionalismo representa la voluntad expresa por parte de los estados por proyectar a nivel internacional un conjunto de ideas, valores y principios comunes de una subregión o región determinada, y para defenderlos a nivel global. Para Deblock, dentro de las relaciones internacionales el regionalismo es toda forma de cooperación institucionalizada entre dos o varios países $^{77}$. Por tanto, se puede decir que el regionalismo incluye además de la libre circulación de bienes, servicios y capitales, la libre circulación de personas.

Gilson a la hora de definir el comportamiento y la interacción de los estados frente al regionalismo y la regionalización, señala que el regionalismo puede ser visto como un proceso Top-down, es decir, proceso liderado, principalmente, por los estados, los cuales buscan definir una identidad regional y desarrollar instituciones comunitarias que coadyuven a profundizar la integración regional. En cambio, la regionalización es un proceso que se desarrolla Bottom-up ${ }^{78}$, proceso que es liderado por las empresas y cuya participación del estado se circunscribe a facilitar, mediar y crear mecanismos para que exista un mayor intercambio comercial entre las empresas que operan dentro de una región.

En ambos casos podemos ver cómo existe un cambio con respecto a la forma de desarrollarse las relaciones internacionales, en el cual, el poder de los estados y su actuación en pos del desarrollo y aplicación de políticas económicas, comerciales y de desarrollo, ya no son más una competencia exclusiva por parte de los estados.

Este poder es ahora compartido con el poder de las empresas, y más aún si consideramos que el proceso de globalización ha fortalecido el poder de estas últimas. Los mercados ya no sólo buscan satisfacer necesidades de la demanda local y nacional, ahora aspiran a satisfacer necesidades de la demanda a nivel regional y global.

\footnotetext{
77 DEBLOCK, C.: Régionalisme Économique et Mondialisation: Ques nous apprennent les théories?. Cahier de recherche 05-07. Continentalisation. Groupe de recherché sur I'intégration continentale. Centre Études Internationales et Mondialisation, Institutut deétudes internationales de Montréal. Université du Québec à Montréal, Octobre 2005.

http://www.ieim.uqam.ca/IMG/pdf/RegionalismeEcodialisa.pdf [Última revisión: 07-01-2013]

${ }^{78}$ GILSON, J.: Asia meets Europe: Inter-Regionalism and the Asia-Europé Meeting, Edward Elgar Publishing Limited, Glos, 2002. p.3.
} 
El proceso de construcción de una región es cambiante, y por tanto, sus objetivos y sus ámbitos de acción también lo son. La creación o no de un sistema institucional comunitario y de un sistema de competencias en pos de la unión regional, son parte de las decisiones políticas que tienen que tomar los estados nacionales, si desean crear una unión regional fuerte que los represente en los foros internacionales. Muchas veces, la decisión política que toman los estados nacionales a la hora de definir el grado de regionalización o regionalismo, depende de variables económicas.

Tomando en consideración, principalmente, el tamaño óptimo del mercado a desarrollar para satisfacer las necesidades, tanto de la demanda interna como la demanda externa de productos y servicios producidos por los estados que son parte de una unión regional. De ahí que existan procesos que nacen siendo regionales, como la Asociación Latinoamericana de Libre Comercio, y luego se subdividen en procesos de integración subregional, como el Mercado Común Centroamericano o el Acuerdo de Integración Subregional Andino; y viceversa, procesos que tienen un ámbito subregional y pasan a ser regionales, como fue el caso de la Unión Económica de BENELUX, la Comunidad Europea del Carbón y Acero, la Comunidad Económica Europea, los cuales sirvieron de base para construir una unión regional mucho más amplia como es la actual Unión Europea. Citamos estos dos ejemplos tomando como referencia el paralelismo cronológico de los procesos de integración regional emprendidos en ambos lados del Atlántico.

Hoy los países que forman parte de la Unión Europea y la Comunidad de Estados Latinoamericanos y Caribeños buscan desarrollar políticas que les lleven a una "ampliación de mercados" o la creación de "mercado común" o "mercado interior". Desde este punto de vista, la primera región que usa el término de mercado común desde un enfoque de regionalismo es Europa, que a principios de la década de los cincuenta crea la Comunidad Europea del Carbón y del Acero, pues entre sus objetivos estaba señalado que esta nueva Comunidad estaría "basada en mercado común, en objetivos comunes y en instituciones comunes" ${ }^{\text {"79 }}$. En el caso de América Latina se usa el término "mercado común latinoamericano" 80 , a principios de la década de los sesenta, en el marco de la creación de la Asociación Latinoamericana de Libre Comercio.

\footnotetext{
${ }^{79}$ Art. 1 Tratado Constitutivo de la Comunidad Europea del Carbón y del Acero, Paris, 18 de abril de 1951.

${ }^{80}$ Preámbulo. Tratado de Montevideo, Montevideo, 18 de febrero de 1960.
} 
En todos los casos se busca implementar programas de liberación comercial, a través de la creación de sistemas de desgravaciones progresivas con el objetivo de contar, inicialmente, con una zona de libre comercio, para luego poder establecer una unión aduanera y así lograr establecer un mercado común.

Es importante señalar que en todos los procesos, tanto en Europa como en América Latina y el Caribe se ha considerado que cada uno de estos pasos antes mencionados deberá de terminar con la armonización de políticas macroeconómicas, para garantizar el buen funcionamiento de un mercado común.

Sin embargo, en ninguno de los casos, se ha logrado implementar medidas que incluyan la totalidad en la armonización de las políticas macroeconómicas entre los países miembros de uno u otro proceso de integración regional. Aunque la principal diferencia entre un proceso de integración regional y otro es que los países europeos, desde el inicio, apostaron por la creación de instituciones comunes, con carácter supranacional, algo que no hicieron los países latinoamericanos.

\subsubsection{Interregionalismo}

El interregionalismo, al igual que los anteriores conceptos y teorías, nace tomando como referencia el proceso de integración regional de Europa, y concretamente se circunscribe dentro del ámbito de la Acción Exterior de la Unión Europea. Diferentes autores han tratado de explicar los diferentes tipos de relaciones que mantiene la Unión Europea, como nuevo actor político en la escena internacional, con otros actores, sean estos países (UE-USA, UE-RUSIA, UE-CHINA) o con regiones (Asia, África y América Latina). Dichas relaciones se desarrollan en distintos niveles: bilateral, interregional y trans-regional.

El interregionalismo suele ser definido como el diálogo político establecido entre dos regiones del mundo. Sin embargo, a mi modo de ver, la definición en sí misma demuestra una imperfección en el término, pues si se toman como ejemplos las relaciones interregionales de la Unión Europea, esta identifica catorce regiones ${ }^{81}$ :

81 Regiones del Mundo. La Unión Europea en el mundo. Política Exterior y Seguridad. http://eeas.europa.eu/regions/index_es.htm [Última revisión: 18-04-2013] 
1. África

2. Asia

3. Países candidatos y candidatos potenciales

4. Asia Central

5. Países del Golfo, Irán, Iraq y Yemen

6. América Latina y el Caribe

7. Mediterráneo y Oriente Medio

8. América del Norte

9. Otros países europeos

10. Países y Territorios de Ultramar

11. Pacífico

12. Sur del Cáucaso

13. Balcanes Occidentales

14. Europa Occidental

Como se puede ver, de estas catorce "regiones" muchas no lo son, son subregiones, otros continentes y, en otros casos, tan solo un grupo de países.

En esta investigación nos centraremos en la región seis, América Latina y Caribe. Y por tanto cuando se hable de interregionalismo, partiremos de la base que América Latina y Caribe es una región. Y a mi modo de ver, es la única relación que debe ser llamada como relación interregional dentro de las relaciones con América, pues es de región a región, Unión Europea-América Latina y Caribe. Y que por tanto, cuando se mencionan las relaciones interregionales entre la Unión Europea y América Central, Caribe, Comunidad Andina y Mercosur, deberían de ser llamadas relaciones interregiónsubregión. Por otro lado, se puede decir que también existen relaciones intersubregionales, como es el caso de las relaciones entre la Comunidad Andina-Mercado Común del Sur, dado que propiamente dicho, ambas son subregiones. 


\section{CAPÍTULO II FUNDAMENTOS HISTÓRICOS DEL ACERVO INTEGRACIONISTAEN LA EUROPA DE LA EDAD MEDIA}




\subsection{EUROPA: LA HISTORIA DE LA CONSTRUCCIÓN DE UNA REGIÓN}

Este apartado no pretende ser descriptivo, ni sintetizar la evolución histórica de Europa a lo largo de la Edad Media, pero sí busca analizar ciertos períodos de esta para poner en valor, vigencia y en perspectiva histórica muchas de las ideas que algunos personajes realizaron respecto a la idea de unidad de Europa como una entidad política. Para nuestra investigación consideramos importante cada una de las ideas, iniciativas y proyectos que deseaban la integración de Europa, ya que a nuestro entender son las raíces históricas del actual proceso de integración regional que hoy conocemos como Unión Europea.

Hablar de Europa también es hablar de sus relaciones con otras regiones del mundo, y del intercambio de ideas producto de dicha interrelación con otras culturas, relación que podemos decir que es una relación inter-regiones. Por tanto lo que hoy conocemos como interregionalismo, ya tuvo sus antecedentes históricos en las relaciones desarrolladas entre Europa-África; Europa-Asia, y luego entre Europa-América. Nuestra investigación se centrará en el estudio interregional de esta última relación.

La región que hoy entendemos como Europa no nació ni con definición propia, ni en términos culturales, étnicos, lingüísticos, tampoco políticos y ni siquiera con una definición geográfica. La definición de Europa ha sido una definición que se ha ido construyendo en el tiempo, partiendo de una maravillosa narración intemporal, cuyos personajes no son productos de una realidad histórica, sino más bien frutos de una historia ficticia, pero cuyo simbolismo encierra la esencia sobre la cual se ha construido la Europa histórica.

En efecto, Europa nace de un mito, pero crece, se desarrolla y reproduce, como un ser vivo, el cual va teniendo y formando sus propias ideas, pensamientos, carácter, creencias, metas y sueños. Todo esto va ir formando la identidad de la actual Europa. Una Europa que pasa de ser una historia mitológica a una realidad histórica política.

Según la mitología griega, Europa es hija del rey de Tiro, Agenor, y de la ninfa Telfusa, por tanto Europa era princesa de Tiro. En ese entonces Tiro era la ciudad más 
importante de Fenicia $^{82}$ (antigua región que agrupaba un conjunto de territorios ubicados en Asia occidental y el noreste de África, en los actuales territorios de los estados de Israel, Siria y Líbano). Cuenta Hesíodo que Zeus vio a Europa, que recogía flores en un prado acompañado de unas ninfas y se enamoró de ella perdidamente. Zeus bajo del Olimpo, se transformó en un toro y, a modo de aliento, echo de su boca una flor de azafrán y se la dio a Europa para conquistarla. De este modo engaño a Europa y la subió sobre su lomo y la elevo por los aires, transportándola hasta Creta en donde se unió con ella ${ }^{83}$.

Zeus, una divinidad, era el gobernante supremo de los dioses griegos en el Olimpo. Zeus lleva a Europa hacia Creta, la elección de esta ciudad no es mera coincidencia, pues encierra un primer simbolismo. Creta es una ciudad cuyo esplendor máximo fue entre los siglos XVI-XV a.C., es decir, el mismo período en que surge el mito de Europa y que coincide con el período en el cual Egipto extendía su influencia política y militar en la región de Asia menor (península de Medio Oriente que hoy es parte de Turquía) $)^{84}$.

Agenor preocupado por la desaparición de su hija consulta con el Oráculo de Delfos, el cual dice a Cadmo, hermano de Europa, que vaya a Creta y que luego funde una ciudad ahí, la cual será llamada Tebas. En Creta, Europa da a luz a Minos (de quién nacerá la civilización minoica, la misma será la base de la civilización pre helénica); Sarpedón (que será el conquistador de la región de Licia, antigua región de Asia menor, que en la actualidad abarca territorios de Turquía); y Radamantis, rey de Creta, antes que Minos, y de quién se dice dotó de un código de leyes a su propio pueblo, y que se según la leyenda será uno de los tres jueces que juzga a los hombres después de la muerte en el Hades.

Una hipótesis que podemos concluir al darse todas estas ideas y explicaciones, es que el mito trata de decirnos que Europa es descendiente de reyes, que es conquistada por Zeus

\footnotetext{
${ }^{82}$ Fenicia en ese entonces estaba formada por varias Ciudades-Estados cuya actividad principal era el comercio y que tuvo un desarrollo e influencia en la región del Mediterráneo.

${ }^{83}$ Hesíodo, poeta griego que se considera vivió entre los siglos VIII-VII a.C. Para leer algunas de sus obras y sobre la referencia que hemos indicado puede revisarse: HESÍODO: Historia. Gredos, Madrid, 1977. Ver también HESÍODO: Obras y fragmentos. Gredos, Madrid, 1978.

84 TRUJILLO, C.: "La construcción de la idea europea: la perspectiva histórico-cultural, más allá de la identidad. Desafíos, Bogotá (10):64-93, semestre I 2004. p. 67.
} 
y cuyos descendientes evocarán el nacimiento de una nueva civilización, la civilización helena, de espíritu conquistador e impartidor justicia universal.

La primera consideración es el nacimiento de una nueva civilización, la cual representa Minos; la segunda, es que se busca simbolizar el espíritu conquistador de Sarpedón; por último, la personificación de Radamantis, como juez e impartidor de justicia. De acuerdo al mito, Radamantis es uno de los tres jueces que juzgarán a los seres humanos una vez muertos, pero más interesante aún, el mito nos dice que Radamantis será quien juzgará a las personas de Asia, pues a los de Europa los juzgará Eaco, rey de la isla de Egina y que era conocido por su piedad y justicia para con su pueblo. A Minos le fue confiada la misión de pronunciar sentencia definitiva, cuando los otros dos jueces tengan dudas 85 . Platón dice que "Minos y Radamantis (...) han sido los legisladores más perfectos entre los antiguos, regidores y pastores de los hombres"

A nuestro entender estas ideas pretenden resaltar la conquista de Zeus y luego el rapto de Europa a Creta, hecho que simbolizaría el triunfo de la cultura griega sobre la cultura y civilización fenicia, a la vez que se alza por encima de otras civilizaciones, como las asiáticas y africanas, y traslada el centro civilizatorio y poder a Creta (Grecia). Así mimo, entre líneas podríamos incluso entre leer que todo esto ocurre por designio y voluntad divina, la de un único dios, Zeus, afirmando con ello que los dioses griegos son más fuertes y poderosos que los dioses egipcios o fenicios.

La princesa Europa, también representa la evolución superior de su estirpe que por un lado reconoce sus raíces en Asia, pero que al unirse con el dios Zeus, crea una nueva dinastía al unir varias regiones. Por otro lado resalta la supremacía civilizatoria sobre las demás, combinando los tres puntos que antes hemos descrito y concluyendo que Europa es cuna de una civilización, con un espíritu de conquistar territorios, cuya misión y destino es establecer un nuevo orden en el cual será Europa la que legislara e impartirá justicia universal.

Cuando se piensa en la unidad política europea, se piensa inmediatamente en el proceso de integración regional de la actual Unión Europea o en su defecto en las Comunidades Europeas, ambas creadas en el siglo XX. Sin embargo, esta idea de unión política a

\footnotetext{
${ }^{85}$ GARCÍA, F.: Platón. Mitos, Ediciones Siruela, Madrid, 1998, p. 44.

${ }^{86}$ Platón, Minos 318/d.ss, en SANTARCANGELI, P.: El libro de los laberintos. Ediciones Siruela, Madrid, 2002, p.109.
} 
nivel regional ha sido una constante a lo largo de los siglos, la cual ha ido configurando a la propia Europa. Al hablar sobre las ideas y proyectos de integración regionales en Europa, se hace necesario definir qué se entiende por Europa.

Una primera aproximación histórica, sobre la idea de qué se entendía por Europa en la antigüedad, nos la brinda Hesíodo (hacia el año 900 a.C.) y más tarde Hipócrates (hacia el año 400 a.C.), el primero lo hace para establecer la diferencia con la región de Oriente y el segundo con la región de Asia ${ }^{87}$. Ambos provienen de la cultura griega, la cual consideraba que el mundo estaba principalmente dividido en dos partes: los pueblos que formaban Grecia y los pueblos Bárbaros, siendo definidos como pueblos "bárbaros" todo aquel pueblo externo a la civilización griega ${ }^{88}$.

Esta última idea nos hace reflexionar sobre dos aspectos, que nos sirven para explicar y entrelazar la construcción de Europa como una civilización, entre la Edad Antigua y la Edad Media. La idea que podemos destacar es que los griegos aspiran a ser la civilización más avanzada del mundo, y que además, ellos son el centro del mundo. Podríamos decir entonces que la idea que muchas veces se menciona como "eurocentrismo", nace o es herencia directa de la concepción del mundo por parte de los griegos, es decir la existencia de un "grecocentrismo".

Isócrates indica en el Elogio de Helena: "los griegos se pusieron de acuerdo por su causa e hicieron una expedición común contra los bárbaros y que entonces, por primera vez, Europa levantó un trofeo en Asia ${ }^{89}$. Esta afirmación hecha por Isócrates confirma nuestra idea antes descrita sobre la búsqueda de imponer la cultura griega por encima de otras.

Pero Aristóteles nos presenta un debate sobre quienes eran considerados europeos en su época. En su obra Política define "europeos" como aquellos que se caracterizan por su coraje, en lugar que por su inteligencia, caso contrario ocurre con los que él llama "asiáticos", según el pensamiento de Aristóteles, esa falta de coraje por parte de los asiáticos hacía que vivieran en la sujeción y esclavitud. En cambio los "griegos" eran personas inteligentes y con coraje, razones por las cuales eran un pueblo libre y con

\footnotetext{
${ }^{87}$ ROUGEMENT DE, D.: Vingt-huit siécles d'Europé, París, Payot, 1961, pp.87-88.

${ }^{88}$ TRUJILLO, C.: "La construcción de la idea europea: la perspectiva histórico-cultural, más allá de la identidad. Op. cit. p. 72.

${ }^{89}$ ISÓCRATES: Elogio de Helena, en Discursos, Gredos, Madrid, 1979. pp. 182-183.
} 
gobierno, e incluso podrían someter a las demás naciones sí se reunieran en un solo Estado $^{90}$. Con esta afirmación Aristóteles, esboza las ideas de un concepto que muchas veces es utilizado en las relaciones internacionales, el concepto del "destino manifiesto", concepto que inicialmente es vinculado a la historia nacional de Estados Unidos, Manifest Destiny, que defendía la idea que como nación estaba llamada a extenderse o expandirse desde las costas del Atlántico hasta el Pacífico, pero que muchas veces, algunos gobiernos latinoamericanos han creído que esa es la idea de Estados Unidos para expandirse a lo largo del continente, más aún cuando se busca interpretar la frase "América para los americanos". Pero no entraremos en el detalle de este debate.

Posteriormente, con la creación del imperio romano, nacerá una civilización que combinará las herencias e influencias greco-romanas, la misma que se transformará cuando aparezca la religión cristiana, cuyas raíces por otro lado son de características judeo-cristianas. El cristianismo producirá un efecto directo dentro de la vida política del imperio romano. Este efecto se comenzará a materializar cuando el emperador Constantino reconoce al cristianismo como religión, a través del Edicto de Milán en el año 313, y posteriormente se oficializará cuando se da la adopción de la religión cristiana como religión oficial del imperio, mediante la aprobación por parte del emperador Teodosio I.

Todo esto origina un cambio de concepción respecto la civilización griega o grecoromana, que a partir de entonces es sustituida por una civilización cristiana, con la gran diferencia, que la civilización griega o romana, era de ámbito regional, cuyo centro es el Mediterráneo, pero esta nueva religión de concepción católica, es decir "universal" buscará ir más allá de las fronteras regionales, buscando expandirse por todo el orbe.

Otra idea es que partiendo de que los pueblos que forman parte de Grecia son el mundo civilizado, y que todo pueblo externo, es decir, fuera de las fronteras griegas, son pueblos llamados "bárbaros", por ende fuera de la civilización y en consecuencia son pueblos a civilizar. Ambos puntos son interesantes como reflexión, en cuanto a que serán estas mismas ideas, percepciones y conceptos los que se repetirán a lo largo de la

\footnotetext{
90 ARISTÓteles: Política, Capítulo VII. En GINZO, A.: Eneas Silvio Piccolomini (Pío II) y su concepción de Europa, Anales del Seminario de Historia de la Filosofía, Vol. 28 (2011): 71-100.
} 
historia, por ejemplo cuando Carlomagno esboce y justifique su proyecto de unificación política para los pueblos de Europa.

\subsection{LAS IDEAS INTEGRACIONISTAS DE CARLOMAGNO: LA ACCIÓN EXTERIOR EUROPEA DE CARLOMAGNO}

En conexión con el punto anterior, Carlomagno será uno de los precursores de una Europa unida que busca ser centro y civilización del mundo. Pero Carlomagno no hablará sobre la defensa de una civilización griega, sino de una civilización cristiana, y el pueblo externo será aquel pueblo que defenderá el Islam como religión universal. Según Ullmann, la idea de Europa de Carlomagno es una "Europa Latina"91, para Brague, existe una "Cristiandad Latina" 92 . Nótese que ambos autores hacen referencia a la herencia "latina", como fuente de una Europa unida.

Caso similar ocurrirá muchos siglos más tarde, cuando los pueblos de América quieran diferenciarse entre ellos mismos y creen la idea de una América "Latina" para diferenciarse de la América de raíces anglo-sajonas y de religión protestante. Cultura y religión, dos variables importantes a la hora de querer concebir la construcción e identidad de una región determinada y en querer diferenciarse con otra región.

Carlomagno deja como herencia a la historia europea los cimientos de una Europa cuya base la funda sobre la idea de la cristiandad. La religión jugara en esta época un papel muy importante dentro de la política exterior de Carlomagno y en lo que será conocida como la dinastía carolingia. El destino manifiesto de Carlomagno será extender y defender la civilización cristiana frente a los peligros que representaba la creciente influencia del Islam en territorio europeo. En el plano de política interior del imperio, Carlomagno promovió la enseñanza del latín y apoyó la vida monástica como fuente de inspiración y modelo de una vida en términos espirituales, así como un culto por la defensa de las leyes. Con ello buscaba también brindar un modelo de vida en términos civiles a sus súbditos. Por tanto, se puede decir que parte de la ideología de Carlomagno fue la idea de una Europa latina y cristiana.

Carlomagno, nieto de Carlos Martel y primogénito del rey Pipino “el breve” y la reina Bertrada, nació en Aquisgrán, el 2 de abril del 742 o 748, no existe una fecha exacta

\footnotetext{
${ }^{91}$ ULLMANN, W.: Historia del pensamiento político en la Edad Media, Ariel, Barcelona, 1983.

92 BRAGUE, R.: Europa. Eine excentrische Identität, Campus, Frankfurt a.M-New York, 1993.
} 
entre los historiadores. Carlomagno llegó a ser rey de los Francos a muy temprana edad y luego emperador de los Romanos mediante el nombramiento, Imperator Augustus, que le otorgó el Papa León III, el 26 de diciembre del año 800 en Roma. Del imperio de Carlomagno y su dinastía nacería el Sacro Imperio Románico Germánico, el cual duraría hasta su división mediante el Tratado de Verdún en el año 843. Hay que recordar que el rey Pipino, ostentaba el título de Rex Francorum, el cual estaba formado por una diversidad de gentes, tradiciones y lenguas como la germánica, romance, céltica $^{93}$, entre otros.

Para gran parte de la academia el nacimiento de Europa es patrocinado por Carlomagno, y por esa razón es considerado padre de Europa ${ }^{94}$, será el primer monarca que promueva una convergencia europeaen términos políticos ${ }^{95}$. En el año 775 , el sacerdote irlandés Cahtulfo lo alaba como "gloria del Imperio de Europa"; y el poeta francés Angilberto lo exalta como "rey Carlos, cabecera del mundo y cumbre de Europa" 96.

Carlomagno organiza su imperio como una especie de confederación de regiones, a estas regiones les brinda autonomía y competencias jurisdicciones, llamadas "pagos". Nombra a un conde, para que esté a cargo de dicha jurisdicción, le otorga poderes y competencias administrativas y militares. La cercanía de Carlomagno con el Papado, y por ende con la Iglesia de Roma, hace que por encima de los condes estén los obispos o los abades, brindando con ello una representación y protagonismo importante del poder clerical dentro de su imperio, ya que estos ejercerán una tutela frente a los condes, el poder civil.

Carlomagno quiere articular el trabajo entre clérigos y nobles, creando para ello, dentro de las estructuras organizativas del Imperio la figura de los missi dominici (enviados del Señor) que trabajan en dúo, un laico y un clérigo, ambos son los responsables de informar al emperador de la situación y necesidades que demandan las regiones que forman parte de su imperio, los "pagos". Esta figura nos recuerda a la de los cónsules de Roma, que viajan por todo el imperio para administrar, o quizás, se inspiró en Jesucristo

\footnotetext{
${ }^{93}$ VACA, A.: Europa: Proyecciones y perspectivas históricas. Octavas Jornadas de Estudios Históricos organizadas por el Departamento de Historia Medieval, Moderna y Contemporánea, Facultad de Geografía e Historia de la Universidad de Salamanca, Salamanca, 1997. p.23.

${ }^{94}$ MITRE, E.: Una primera Europa. Romanos, cristianos y germanos (400-1000), Ediciones Encuentro, Madrid, 2009, p. 156.

95 Ibíd., p. 149.

96 ANGILBERTO, Versos 92-93; en HALPHEN, L.: Carlomagno y el Imperio carolingio, Akal Universitaria, Madrid, 1992. p. 105.
} 
cuando este envió a sus apóstoles a predicar la palabra de Dios, de dos en dos, siguiendo sus convicciones religiosas y su cercanía con Roma. No extrañaría que haya creado este modelo organización de su imperio tomando referencias bíblicas.

El establecimiento de las regiones imperiales llamadas "pagos" nos hacen pensar sobre lo que hoy es conocido como el principio de subsidiariedad dentro del proceso de integración europea. La idea del emperador era que los "pagos" pudieran resolver sus asuntos de manera autonómica, sin necesidad de recurrir siempre a las instancias imperiales. Haciendo un paralelismo se podría pensar en la relación existente entre un Estado Miembro y las instituciones comunitarias actuales.

Cabe recordar que unas de las iniciativas y herencias que deja el imperio carolingio a Europa es la creación de normas jurídicas comunes para todo el imperio, una especie de supremacía del derecho nacional sobre uno superior, quizás tomando como referencia el modelo del derecho romano. Es decir, un derecho común que sea aplicable y respetado por todos los pueblos que formen parte del imperio, característica similar al actual derecho comunitario europeo, claro está, con las salvedades del caso, entre las diferencias en el sentido temporal y del sentido democrático. La mención del derecho romano sería rescatable, en cuanto a su conexión de relación entre los pueblos que eran parte del imperio, y otro aspecto no menos importante es la idea de ciudadanía desarrollada por los romanos, en el cual no importaba a qué región pertenecieras, porque por encima de todo estaba el tener la "ciudadanía romana", y con ello disfrutar de los beneficios como un ciudadano.

Tenemos los ejemplos de tres emperadores romanos que no fueron de origen romano, y que más bien eran de una región del imperio, pero al ser ciudadanos romanos pudieron llegar a ostentar la máxima jefatura. Tales fueron los casos de los emperadores de origen hispano: Marco Ulpio Trajano, Pulio Elio Adriano y Teodosio I “el Grande”. Sin duda hay una similitud con el concepto de la ciudadanía europea y el acceso a los cargos de las instituciones comunitarias, dado que no importa de qué estado provengas, lo importante es que eres ciudadano europeo.

Volviendo a la idea del principio de subsidiariedad y su toma de referencia del modelo organizacional de la Iglesia Católica y su aplicación al sistema organizacional del imperio, no sería una idea descabellada establecer el paralelismo, dado que en la 
práctica el imperio tiene dentro de su jurisdicción a varios monasterios y abadías, todas ellas instancias que ya practicaban y aplicaban el principio de subsidiariedad. Las independencias jurídicas y administrativas son un carácter propio de las estructuras institucionales de la Iglesia Católica, que a pesar de tener un poder centralizado, el Papado y la Curia Romana, cada una de las diócesis son independientes en su administración y jurisdicción, al igual que ocurre con todas las órdenes religiosas que son parte de la Iglesia y que regentan abadías y/o monasterios.

Si bien es cierto, habrá que esperar algunos siglos hasta que la propia Iglesia recoja de manera explícita este principio dentro de su propia enseñanza y doctrina. Nos referimos a la Doctrina Social de la Iglesia, la cual considera que el principio de subsidiariedad es aquel principio mediante el cual el Estado sólo debe actuar si advierte que las instituciones y/u organismos intermedios pertenecientes al propio estado en cuestión, así como los particulares, no pudieran hacer frente a un problema concreto, siguiendo la praxis ejercida entre la Curia Romana y su diócesis. Al respecto existen muchas encíclicas papales que defienden este principio a favor del interés comunitario, entre ellas podemos mencionar:

- Encíclica del Papa León XII, Rerum novarum (1891)

- Encíclica del Papa Pío XI, Quadragesimo anno (1931)

- Encíclicas del Papa Juan XXII, Mater et Magistra (1961) y Pacem in terris (1963)

- Encíclica del Papa Pablo VI, Populorum Progresiumm (1967)

Muchas de las ideas expresadas en las respectivas encíclicas serán tomadas como inspiración o referencias para quienes serían llamados "los padres fundadores de la Unión Europea", cuya religión, hay que señalar, era la católica, caso de Robert Schuman, De Gasperi y Konrad Adenauer, entre otros. Sin duda, sus concepciones religiosas se vieron reflejadas a la hora de diseñar la integración política de Europa. Por ello se puede decir que el principio de subsidiariedad no nace del "acervo comunitario", del proceso de integración regional de la Unión Europea, sino del catolicismo europeo, cuyas raíces son el tomismo.

Si pensáramos que no existe relación alguna entre las ideas de Carlomagno y los tiempos que acabamos de describir, podríamos citar a dos monarcas europeos que son 
herederos de esa herencia carolingia, el rey de Bélgica, Balduino y el rey de España, Juan Carlos I y que nos recuerda la relación y raíces históricas que existen y unen a la Europa medieval y la contemporánea.

El 24 de mayo de 1961, el rey Balduino realizó una visita oficial a Francia, en ella el general De Gaulle, le ofreció una cena en su honor. En la respectiva cena, el rey de los belgas pronunció las siguientes palabras que evocan tanto a las ideas que promulgaba Carlomagno como a la influencia católica de la integración europea que en ese momento se desarrollaba:

Esa Europa, si quiere ser fiel a su misión propia y desempeñar su papel en el diálogo de los pueblos, no puede limitarse a defender la herencia del pasado. Le incumbe ser la vanguardia del progreso tanto material como espiritual. ¿Acaso la vocación de Europa no es la de ofrecer a los hombres la imagen de una sociedad que respeta las exigencias de la persona humana y a la vez las del bien común? ${ }^{97}$.

Por su parte, el rey de España, Juan Carlos I, el 20 de mayo de 1982, pronunció las siguientes frases en Aquisgrán, el día que recibió el Premio Carlomagno. En ellas evoca su conexión con las ideas que dejó el emperador Carlomagno:

Como rey de España, tiene singular emoción el ser honrado en Aquisgrán, en el lugar en que fue coronado emperador, en 1520, mi antepasado y antecesor en la Corona de España, Carlos I, a quien por esa dignidad se conoció después como Carlos V. [...] Por debajo de la fragmentación, de los intereses particulares, las rivalidades y la lucha por el poder, los elementos han actuado como un factor de unidad y convergencia: la herencia cristiana, el recuerdo de Roma, con su unidad, su lengua universal, convertida en vehículo de la cultura y la liturgia, el derecho romano y el sentido de la autoridad más allá de la fuerza; los impulsos de libertad individual y lealtad personal, aportación germánica a la Edad Media ${ }^{98}$.

Cuando Carlomagno se convierte en emperador busca unificar gran parte de las tierras que se encontraban ubicadas en la parte de la Europa occidental, a la par que pretendía ser el sucesor de los antiguos emperadores romanos, pero siendo el más cristiano de los cristianos. Por esto la diferencia, claro está, es que el imperio carolingio, a diferencia

\footnotetext{
${ }^{97}$ SERROU, R; Balduino, el rey. Ediciones Palabra, Madrid, 2000. p. 152

98 Discurso de Su Majestad el rey de España en Aquisgrán, al recibir el Premio Carlomagno, 20 de mayo de 1982. Puede verse: Los reyes en Europa. 2. El Premio Carlomagno, Editorial Presidencia de Gobierno, Madrid, 1982.
} 
del romano, no sería pagano ni politeísta, más bien sería religioso, y concretamente, cristiano y de carácter monoteísta.

Carlomagno al igual que los griegos, concibe la idea de que su civilización, en este caso la cristiana, está destinada a iluminar el orbe, y por tanto tiene un destino manifiesto, el de proteger y extender la Cristiandad. Para él Europa será igual a la Cristiandad y en apoyar a Roma su expansión a otras regiones del mundo. También igual que los griegos, el imperio carolingio tendrá un pueblo externo a quién civilizar y del cual tiene que defenderse, los pueblos que tenga al Islam como religión.

Erken afirma que la lucha entre los reinos cristianos contra los musulmanes constituyó el referente de unidad política de Europa, a pesar de la gran diversidad cultural que existía en la propia Europa de esos tiempos ${ }^{99}$.

El imperio de Carlomagno abarcaba territorios que hoy son Francia, Alemania, Italia, Bélgica, Luxemburgo, Países Bajos, y Austria. Si extrapolamos dichos territorios al proceso de integración de la Unión Europea iniciado en el siglo XX, podemos decir que son los mismos pueblos los que se integraron en una región-imperio, el carolingio, y luego terminarían formando los pilares del proceso de integración regional de la Unión Europea.

Tras la muerte de Carlomagno se sucedió una partición del imperio carolingio, el Tratado de Verdún repartió el imperio en tres partes, tres grandes regiones que luego serían estados nacionales como Francia, Alemania, Países Bajos, Bélgica y Luxemburgo. El tratado dividió el imperio entre los hijos de Ludovico Pío, por consiguientes los tres nietos de Carlomagno: Lotario I, Luis el Germánico y Carlos el Calvo. El primero hereda los territorios de la región entonces llamada Lotaringia, que comprendía a los actuales estados nacionales de Países Bajos, Bélgica y Luxemburgo; Luis obtuvo los territorios que hoy forman Alemania; y Carlos las tierras que hoy son Francia.

A lo largo de la Edad Media, el poder político en Europa estaba dividido y repartido en tres grandes porciones, el papado, el imperio y los emergentes Estados nacionales que poco a poco irán tomando cada vez más poder político, en detrimento del poder de los

\footnotetext{
99 ERKEN, F-R.: Europa und die osmanische Expansion im ausgehenden Mittelalter, Duncker \& Humblot, Belín,2007. pp. 7-8.
} 
dos primeros. El nacionalismo, jugará un factor importante en todo este juego de poderes. Un proceso que no fue ni breve ni pacífico y que abarcara gran parte de la Alta Edad Media y la Baja Edad Media.

Mientras el Papa y el Emperador se disputan el poder, el liderazgo y la influencia entre los territorios europeos, un nuevo acontecimiento surge, el feudalismo. Este será un fenómeno económico que cambiará no solo las estructuras organizacionales de las monarquías europeas, sino también la del conjunto de los pueblos, ciudades, condados, principados y estados de Europa.

La aparición de reinos emergentes y la consolidación de otros más antiguos reconfiguran el tablero de poder en Europa: los reinos Francos, de Castilla, Aragón, Inglaterra, los Estados Pontificios, Lombardía, entre otros. La creciente economía de ciertas regiones que serán pobladas con nuevas ciudades dará paso a la independencia de varias regiones sobre sus antiguos reinos y se emanciparán como Estado-Nación. La idea de Estado, como hoy lo conocemos, es una idea de la Edad Moderna como respuesta a las fuerzas supraestatales ${ }^{100}$, como eran los casos del Papado y del Imperio.

Sobre nuestra hipótesis que las ideas de unidad europea nacen en la Edad Media, Chabob considera que el concepto de Europa se forma, justamente, por contraposición en cuanto existe algo que no es Europa ${ }^{101}$, concepto que podemos vincularlo con la idea de los griegos. Febvre cree que Europa es una creación de la Edad Media, y que su unidad la debe a las diversidades de anteriores unidades históricas ${ }^{102}$. Le Goff por su parte concuerda con la idea de que en la Edad Media es la época en que apareció y gestó Europa como realidad, aunque indica que a su entender los hombres de esos siglos no albergan la idea o voluntad de construir una Europa unida, pero resalta que existió un hombre que sí tuvo la idea clara de Europa, el Papa Pío II, y que así lo manifestó al escribir su obra titulada Europa ${ }^{103}$, en 1458, y que además escribió otra obra llamada Asia $^{104}$, hecho que según Le Goff evidencia la importancia del diálogo entre ambas regiones $^{105}$. Al mismo tiempo se confirma una idea anteriormente expuesta, en la cual

\footnotetext{
${ }^{100}$ NAEF, W.: La idea de estado en la Edad Moderna, Madrid, Época, 1946.

${ }^{101}$ CHABOD, F.: Historia de la idea de Europa, Norte y Sur, Madrid, 1967. p. 31.

${ }^{102}$ FEBVRE, L.: L'Europé, genese d'une civilisation, París, 1999. p. 67.

${ }^{103}$ ENEAS SILVIO PICCOLOMINI (Pío II): La Europa de mi tiempo, Secretariado de Publicaciones de la Universidad de Sevilla, Sevilla, 1998.

${ }^{104}$ ENEAS SILVIO PICCOLOMINI (Pío II): Asia, Edición de N. Casella, Bellinzona, Casagrande, 2004.

${ }^{105}$ LE GOFF, J.: ¿Nació Europa en la Edad Media? Crítica, Barcelona, 2003, p. 1.
} 
Europa se define en contraposición de otra región, Asia. Basta con recordar el mito de Europa.

Pero ¿quién fue el Papa Pío II? El Papa Pío II, nació siendo Eneas Silvio Piccolomini, el 18 de octubre de 1405 en la región italiana de Corsignano, hoy Pienza. Antes de ser elegido Papa fue secretario del obispo de Fermo, entre los años de 1431 y 1435 , residiendo en la ciudad de Basilea. En varias ocasiones fue enviado en misiones diplomáticas por parte de la Iglesia de Roma y participó en el Concilio de Basilea en 1431. Ambas experiencias lo curtirían en los asuntos de la alta política, tanto dentro de la Iglesia como en los asuntos de la Europa de la época. En 1445 el Papa Eugenio IV lo envía como delegado a la Dieta de Frankfurt y en donde se convertirá en secretario privado del emperador del Sacro Imperio Romano Germánico, Federico III de Habsburgo.

En 1458 es elegido Papa y su pontificado se caracterizará por intentar organizar una cruzada contra el imperio Otomano. Con este objetivo en mente, el ahora Papa Pío II convoca a los príncipes cristianos a la asistencia de un congreso en 1459, en Mantua, para discutir sobre cómo implementar el plan de la cruzada. El Papa Pío II teme ver al continente europeo bajo el imperio turco ${ }^{106}$. Pero al congreso llegan muy pocos participantes, debido a las disputas políticas y doctrinales que tenían entre el propio papa y algunos monarcas europeos respecto a su legitimidad como autoridad suprema. Ante estos hechos el Papa Pío II diría:

\section{La Cristiandad no posee una cabeza a la que todos estén dispuestos a obedecer. Ni al Sumo Pontífice ni al Emperador se les da lo que es suyo. No hay ninguna reverencia, ninguna obediencia: como nombres ficticios, como cabezas pintadas, así consideramos al Papa y al Emperador: cada ciudad tiene su propio rey, hay tantos príncipes como casas. ¿Cómo va a ser posible persuadir a tantas cabezas como rigen el orbe cristiano a que tomen las armas? ${ }^{107}$}

Baldi comenta que en esos momentos Europa vivía "una realidad cada vez más fragmentada, dividida en una multiplicidad de Estados soberanos, gobernados por

\footnotetext{
${ }^{106}$ MANSI, J.D.: Sacrorum Conciliorum: nova et amplissima collectio, vol. 32, Akademische druck u. Verlaganstalt, Graz, 1960. p. 209.

107 Aeneae Silvii Piccolominei Senensis, qui post adeptum Pontificatum Pius eius nominis secundus appellatus est, Opera quae extant omnia, Basilea, per Henric hum Petri, 1551, 656.
} 
soberanos diversos, separados entre ellos por rivalidades políticas y económicas, y la prevalencia de los intereses particulares ${ }^{108}$ ".

El Papa Pío II, en su obra Europa describe las tierras europeas, comenzando por las tierras que están ocupadas por los turcos, las cuales indican que son las que flanquean las dos orillas del Danubio, los Balcanes, las costas orientales del Adriático, así como las regiones que forman Grecia; continúa su descripción mencionado a Lituania, los reinos germánicos, escandinavos, a los Países Bajos y el centro de Europa, así como Inglaterra, incluida Escocia, Francia, y los territorios que forman parte de la Península Ibérica ${ }^{109}$. Hace la misma descripción en su obra Asia, pero en esta enfatiza “¡cuánto ha perdido la república cristiana!" ${ }^{110}$, cuando se recuerda la pérdida de los territorios cristianos en Asia y también en África. Esta idea de "república cristiana" la veremos usar por otros monarcas europeos y también aparecerá en varios proyectos de integración europea en la Edad Moderna.

Ortega y Gasset considera que la aurora de la historia europea se da con Carlomagno ${ }^{111}$, además defiende la idea que las naciones europeas deben de estar unificadas en una unidad política de carácter supranacional, dado que las naciones europeas se han convertido en provincias continentales y corren el riesgo de practicar un nacionalismo hacia dentro, en lugar de ejercitar un nacionalismo hacia fuera, europeo-continental ${ }^{112}$.

La Edad Media tuvo como centro de debate intelectual la búsqueda de la comprensión de Dios y la interpretación del destino, en base a los designios y voluntad de Dios. El desarrollo de la vida de las personas como la de sus gobernantes, y en consecuencia de la sociedad en su conjunto, partían de estas premisas. El pensamiento teológico era monopolio de la Iglesia y con ella la interpretación de las Sagradas Escrituras, hecho que cambiaría cuando el protestantismo plantee traducirlas del latín a las lenguas vernáculas, es decir a las lenguas nacionales, fenómeno que empezará cuando varios estados alemanes abracen algunas de las ramas del protestantismo y se declaren estados

\footnotetext{
108 BALDI, B.: "Enea Silvio Piccolomini e il De Europa: umnesimo, religione e política" en Archivo Storico Italiano 161 (2003). p. 640.

109 Cfr. SANZ, D.: Un texto inédito de Eneas Silvio Piccolomini acerca de Hispania. Exclass 11, Universidad de Huelva, Huelva, 2007. pp. 197-199.

${ }^{110}$ ENEAS SILVIO PICCOLOMINI (Pío II), Descripción de Asia, Servicio de Publicaciones de la Universidad de Sevilla, Sevilla, 1992. p. 257.

111 ORTEGA Y GASSET, J: "De Europa mediatio quaedam”, en Obras completas IX, Madrid, Alianza, 1983. p.261

112 ORTEGA Y GASSET, J. En SEBASTIAN, J.: "La idea de Europa en el pensamiento político de Ortega y Gasset”. Revista de Estudios Políticos (Nueva Época) N 83, Enero-Marzo, 1994. p. 225.
} 
con iglesias nacionales, lo que fomento la idea del Estado-Nación independiente del poder imperial y del papado.

Durante el período de reinado de Carlomagno se produce la fundación de varias escuelas catedralicias, las cuales surgen con la creación de nuevos monasterios que comienzan a sentarse a lo largo del imperio carolingio, justamente como parte del compromiso que tenía el emperador, tanto con la Iglesia como por sus convicciones religiosas de expandir el cristianismo por toda Europa, las cuales marcaron sus decisiones políticas y sus relaciones internacionales. Mediante la edificación de nuevos monasterios e iglesias, se produce la preservación de libros antiguos, de los cuales los frailes traducen y hacen copias, así como comentarios que enriquecen la lectura de dichas obras. Los monjes intentan adaptar la cultura antigua a las necesidades del cristianismo.

Estas actividades han permitido que hoy en día podamos conocer tanto a los autores clásicos como medievales, pero también permitieron la convergencia de varias tradiciones y culturas milenarias dentro de la cultura e identidad europea.

La creación de las universidades jugara un papel fundamental en la formación de una identidad europea. Con la creación de las universidades como centros de saber y de enseñanza se produce un gran salto en el conocimiento y en la vida social y política de los pueblos, sobre todo cuando el modelo de las universidades se traslade hacia América, pues este acontecimiento expandirá la civilización occidental. Este hecho se produce cuando los reinos de España y Portugal se adentran en los mares, en búsquedas de nuevas tierras y riquezas. Ambos objetivos fueron hallados en tierras americanas.

El rey Juan Carlos, también en su discurso al recibir el Premio Carlomagno, que antes hemos mencionado, hace una referencia importante con el punto que estamos describiendo, nos referimos a la expansión del concepto de Occidente: "la Monarquía Española fue pronto la «Monarquía Hispánica», integrada por diversos países en ambos hemisferios, bajo la misma Corona: la primera realización efectiva de Occidente ${ }^{113 \text { ". }}$

\footnotetext{
${ }^{113}$ Discurso de Su Majestad el rey de España en Aquisgrán, Op. cit.
} 
Sobre el tema de la universidad y su relación entre Europa y América volveremos más adelante, cuando hablemos sobre Carlos $\mathrm{V}$, ya que será bajo su período en que se iniciará las primeras fundaciones universitarias en el continente americano.

\subsection{LAS IDEAS INTEGRACIONISTAS DE CARLOS V: UNIVERSITAS CHRISTIANA}

¿Cuáles fueron las ideas integracionistas de Carlos V? ¿Qué era Europa para Carlos V? ¿Fue Carlos V quién inició el movimiento pan-europeo? Estas son algunas de las preguntas que este apartado pretende responder.

Carlos V de Alemania y I de España nació en Gante, el 24 de febrero de 1500. Su nacimiento marcaría un antes y un después dentro de la historia europea y la historia universal. Hijo de reyes y de una dinastía imperial, Carlos representaba en sí mismo la esencia de lo que simboliza Europa, una mixtura cultural de varias culturas y regiones, en sus propias venas corre sangre de distintas parte de la Europa misma; razón por la cual no sería extraño que el propio emperador se haya sentido identificado con el conjunto de las regiones de la cual es parte por sus propias raíces familiares y por las propiedades que hereda, probablemente se habrá sentido el más europeo de los europeos.

Recordemos su familia para ver su proveniencia regional y con ello su herencia patrimonial, que es lo que convierte a Carlos en un rey, un emperador y un césar. De hecho es llamado el último césar, en clara alusión y deseo de vincularse con Roma. Carlos era hijo de Felipe de Habsburgo (conocido como "Felipe el Hermoso") y de Juana I de Castilla (conocida como "Juana la Loca").

Por su lado paterno, su abuelo fue Maximiliano I, emperador del Sacro Imperio Romano Germánico (de quién hereda los territorios de Austria y los derechos sobre todos los estados que formaban parte del imperio); su abuela era María de Borgoña (por quién recibe los territorios de Borgoña y Brabante). Por el lado materno, estaban sus abuelos, los llamados "Reyes Católicos", título que les fue otorgado por el Papa Alejandro VI, mediante la bula Si convenit del 19 de diciembre de 1463. Siendo su abuelo Fernando II de Aragón y V de Castilla (de quién recibe los territorios pertenecientes a las regiones italianas de Sicilia y Nápoles, así como la región española de Aragón. Su abuela, Isabel 
I de Castilla (de quién hereda Castilla, Canarias y todos los territorios del que era llamado "Nuevo Mundo", América).

Todo ello nos permitiría decir que ya en sus venas corría Europa misma. A eso habría que agregarle la influencia que tuvieron en su educación y formación dos grandes personajes de la época vinculados a las ideas europeístas, como fueron Adriano de Utrecht, quién había sido designado por el propio emperador Maximiliano I para educar a Carlos. Adriano de Utrecht fue un gran teólogo holandés, que además fue profesor universitario que incluso llegaría a ser rector de la Universidad Lovaina, y que posteriormente sería nombrado Papa con el nombre de Adriano VI.

El otro gran personaje fue Erasmo de Rotterdam, fraile agustino, teólogo y filósofo holandés, quien entre sus ideas defendía la Philosophia Christi. Sin duda ambos influyeron en el pensamiento de Carlos y sobre su concepción e idea de Europa, concibiéndola como una Europa cristiana y universalista. El actual programa europeo ERASMUS (EuRopean Community Action Scheme for the Mobility of University Students) lleva ese nombre en honor a la figura de Erasmo de Rotterdam.

De las Heras considera que "Carlos V creía que como emperador se debía al conjunto de la cristiandad y no a una parte de la misma. Esta creencia es precisamente la base de su europeísmo"114. Y añade que "desde muy pronto concibió la idea imperial como un proyecto pan-europeo" $" 115$.

Durante su período como rey-emperador, Carlos V tuvo que enfrentar un triple desafío para lograr su sueño de una Europa unida. El primer desafío fue el enfrentar la amenaza turca que se ceñía ante las puertas de propio imperio, los turcos amenazaban la paz y la estabilidad en toda la cristiandad, a la par que disputaban la supremacía política, económica, comercial y militar en la región del Mediterráneo con el imperio de Carlos V. Al igual que Carlomagno, Carlos V tuvo su enemigo externo. La historia se repitió.

Como si no fuera poco, el tener que enfrentar al imperio turco en sus tierras y sus fronteras, el emperador se siente llamado a defender el conjunto de la cristiandad. Pero dos desafíos más se sumaron a los problemas del emperador Carlos V; el primero su

\footnotetext{
${ }^{114}$ DE LAS HERAS, J.: La idea de Europa en Carlos V. Cuadernos del Lazarillo $N^{\mathbf{o}} 18$ Revista literaria y cultural. Enero-Junio 2000. p. 51

${ }^{115}$ De las Heras, Op. cit., p. 52.
} 
rivalidad con Francia, personificada concretamente en la figura del rey Francisco I, competencia que se agravó más aún, cuando el rey francés se presentó como candidato a ocupar el trono imperial de Maximiliano I. Así mismo las peleas constantes entre ambos monarcas por territorios en Italia fue una lucha incesante durante todo el período de sus respectivas monarquías.

El otro asunto que preocupaba a Carlos $\mathrm{V}$ fue el conflicto desatado entre el fraile agustino Martín Lutero y el Papado, conflicto que a su vez desató múltiples frentes por defender. Todos estos problemas estarán presentes a lo largo de todo su período como rey-emperador.

En lo concerniente a su primer desafío, Carlos V convoca y exhorta a todos los monarcas a la unidad política de Europa, a través de su idea de crear una Universitas Christiana. Su idea y propuesta al respecto era que debería de existir una autoridad de carácter imperial (supranacional), para que esta autoridad esté por encima de todos los reyes de la cristiandad, y que se debería diseñar e implementar una política imperial, en términos de defensa común, dado que el enemigo era común. Se puede apreciar, en estas ideas de Carlos, varios esbozos de algunas ideas integracionistas, como son la idea de crear una autoridad supranacional, que adopte decisiones y aplique políticas comunes, como era el caso de la seguridad y defensa, a la par que una policía externa común.

Carlos $\mathrm{V}$ entendió que la cristiandad era un punto en común entre todos los monarcas europeos y que su defensa sería aprobada y respaldada por el conjunto de las poblaciones que formaban parte de Europa, fuera la región que fuese. Además el emperador se percató que en varias regiones europeas existían un descontento por parte de mercaderes, banqueros y nobles que veían sus negocios afectados por el asedio del poder turco en las rutas comerciales entre Europa, África y Asia. El preocuparse por los problemas de sus súbditos era un punto a favor para el emperador, ya que su deseo por solucionar dichos problemas consolidaría su imagen y liderazgo en toda Europa.

En términos políticos, era un buen argumento contra algunos de sus enemigos, por ejemplo, los que estaban en Castilla y Aragón, los mismos que llevaban mucho tiempo luchando por expulsar de la península ibérica a los musulmanes. Gesto que sin duda, generaría un congraciarse con sus enemigos, al mismo tiempo que eliminaba cualquier 
entredicho sobre la defensa de los intereses de sus reinos en Castilla y Aragón, partiendo del hecho que existían facciones de nobles españoles que dudaban que el emperador se preocupara por la defensa de los intereses de los reinos de Castilla y Aragón.

Carlos V emprendió una serie de batallas contra el imperio turco, entre las cuales consiguió victorias pero también muchas derrotas. Entre sus victorias más destacables están las que hicieron retroceder al ejército turco cuando estos lograron llegar invadir Europa central, concretamente Viena en 1532. Otro triunfo fue el desalojo en Túnez del almirante otomano Hizir bin Yakup (más conocido como Barbarroja) en 1535.

Entre sus derrotas se encuentran la de Provenza en 1536 y cuando intentó tomar por asalto el cuartel general de Barbarroja, en Argel, en 1541. El balance fue que Carlos V tuvo que renunciar a sus sueños hegemónicos sobre el Mediterráneo occidental y conformarse con compartir con los turcos la respectiva zona. Al no resolver dicho problema, el imperio tuvo que vivir en una alerta constante ante las varias incursiones de corsarios que asaltaban a las embarcaciones, incidentes que dificultaban el comercio de varios de sus súbditos, y con ello afectaba a la economía de su propio imperio. Muchas veces los corsarios eran apoyados por los turcos, acción que era considerada por el propio emperador como una actitud belicista.

En lo referido a sus relaciones con Francia y sus peleas con el rey francés Francisco I, el emperador propuso la paz entre ambos reinos, tomando como argumentos que ambos eran reinos cristianos, y que por tanto no tenía sentido una guerra entre hermanos. Pero las peleas entre ambos fueron creciendo a tal punto que entrarían en Guerra una y otra vez, durante un largo período que duraría décadas.

Dichas guerras cesarían mediante la firma de los Tratados de Madrid (1526) y el Tratado de Cambay (1529) llamado también el tratado de "la paz de las Damas" en su alusión al proceso de negociación y acuerdos alcanzados por dos damas, de un parte se encontraba Luisa de Saboya, madre de rey Francisco I, y de otra parte, Margarita de Austria, tía del emperador Carlos V. Los acuerdos incluían la renuncia del emperador sobre los derechos del Ducado de Borgoña, y por parte del rey francés su renuncia a los territorios de las regiones de Flandes y Artois, aceptando a su vez abandonar sus pretensiones sobre varias regiones de Italia. 
En el caso de Lutero y por ende su lucha contra el protestantismo, Carlos V buscó inicialmente un acercamiento y diálogo, con el fin de conseguir un acuerdo entre el Papado y Lutero. Pero el problema lejos de solucionarse, se agravó, cuando el príncipe Federico III, Elector de Sajonia (conocido como "Federico el Sabio") decide convertirse al protestantismo y ser protector del propio Martín Lutero.

La situación se tornó más compleja cuando el Papa León $\mathrm{X}$ emite la bula Exsurge Domine el 15 de junio de 1520, la bula papal exigía la retractación de Lutero sobre algunas de tus 95 tesis, las cuales criticaban la corrupción de algunos miembros del clero, sobre todo en el tema de la venta de las indulgencias. Estas circunstancias ponían al Carlos V en un gran conflicto interno con varios de los estados alemanes que apoyaban las ideas reformistas de Lutero y que, a su vez, formaban parte del imperio. Y que por otro lado al ser el emperador del Sacro Imperio Romano Germánico, y en consecuencia fiel defensor del Papa y de la cristiandad, no se podía permitir el lujo de oponerse a la voluntad del Sumo Pontífice, pero tampoco deseaba abrir una brecha interna dentro de su propio imperio. El problema era más que complejo y delicado.

Su respuesta fue impulsar la convocatoria de la Dieta de Worms, que fue una asamblea formada por los príncipes cristianos miembros del imperio en 1521. La asamblea fue presidida por el propio emperador, quién exigió la comparecencia de Lutero y en la cual esperaba la respectiva retractación por parte del fraile agustino, cumpliendo así con el deseo del Papa que había exigido a Lutero se retracte de sus tesis. Pero Lutero lejos de retractarse, refrendó su posición y pidió una vez más la reforma dentro de la Iglesia y condenó la corrupción de la Iglesia en las altas esferas.

Acto seguido la asamblea adoptó la decisión de condena a Lutero y lo declaró culpable de desobediencia, de hereje, de ir contra la Iglesia y lo consideró prófugo, dicha sentencia quedo reflejada mediante el Edicto de Worms, el 25 de mayo de 1521.

Posteriormente la Dieta de Espira de 1526 adoptó la decisión de no forzar el Edicto de Worms, es decir, se propuso que cada príncipe podía decidir sí permitía o no las ideas de Lutero dentro de su territorio. Esta contradicción y ambigüedad originó la expansión del protestantismo en muchos de los estados del imperio, sobre todo por parte de varios estados alemanes, los cuales aprovecharon la tesitura para desconocer la legitimidad y autoridad del Sumo Pontífice de Roma sobre sus territorios, todo ello unido a un 
sentimiento, convenientemente, de nacionalidad se separan primero del poder del papa y posteriormente lo harán del propio emperador.

La Dieta de Espira de 1529 intentó remediar dicha situación, pero el cisma dentro de la cristiandad había comenzado. Muchos estados se declaran soberanos y nacionales, y nacen las iglesias nacionales siendo el rey correspondiente el nuevo jefe supremo de las respectivas iglesias nacionales. El espíritu nacionalista no sólo iba a dividir la cristiandad, sino también al imperio y con ello los sueños de la unidad de Europa. Desde entonces el nacionalismo sería una variable constante en contra de cualquier deseo de unidad política.

En 1546 Carlos V formó una alianza con varios de los príncipes cristianos que aún les eran fiel y declara la guerra a los príncipes insurgentes que habían adoptado el protestantismo. El emperador no estaba dispuesto a permitir una fragmentación dentro del imperio como tampoco iba a permitir diferencias religiosas dentro de su Sacro Imperio.

Las tropas imperiales tuvieron una victoria en la batalla de Muhlberg, el 24 de abril de 1547, este triunfo hizo que Carlos V imponga una solución a este conflicto mediante el Interim de Augsburgo en 1548, la cual quedo manifestada en la "Declaración de su Romana Imperial Majestad sobre la observancia de la religión dentro del Sacro Imperio hasta la decisión del Concilio General”. Dicho concilio había intentado ser convocado por el Papa Paulo III en Mantua en 1537, posteriormente se buscó convocarlo en Vicenza en 1538. Pero en ese entonces se negociaba en Niza un tratado de paz entre el emperador y el rey francés. Después de estos retrasos el concilio general se llegó a realizarse en Trento, pero este duraría muchos años, entre 1545-1563. Entre los temas tratados estuvieron la reforma protestante, los sacramentos, la Eucaristía o el Canon de las Sagradas Escrituras.

Entre los preparativos y la realización del concilio general se produce la "guerra de los príncipes" en 1552, dando como resultado el tratado de "Paz de Augsburgo" llamado también el tratado de "Paz de las Religiones". El tratado divide el imperio en dos confesiones (luterana y católica) que fue como acabamos de indicar la potestad de los príncipes de escoger qué religión adoptar dentro de sus reinos. 


\subsection{DE LA UNIVERSITAS CHRISTIANA A LA UNIVERSITAS UNIVERSALIS: EL LEGADO DE CARLOS V HACIA AMÉRICA}

A finales de la Baja Edad Media, grandes ciudades europeas como Múnich, Liverpool, París, Manchester, entre otras, surgieron debido al establecimiento de comunidades de agustinos, benedictinos, cistercienses, dominicos, entre otras tantas órdenes religiosas que contribuyeron al desarrollo de Europa intelectual. Así mismo, las primeras universidades en el mundo nacieron bajo el auspicio y dirección de la Iglesia Católica, que en sus inicios comenzaron siendo centros de estudios, colegios mayores y posteriormente universidades, tales como: Salamanca (España), Oxford, Cambridge (Gran Bretaña), Boloña (Italia), La Sorbona de París (Francia). Siendo estas ciudades los primeros focos intelectuales y verdaderos polos de desarrollo en sus respectivas regiones.

Salamanca es un claro ejemplo de este hecho cultural. La llamada "Escuela de Salamanca", donde la figura de Francisco de Vitoria (religioso dominico) es dinamizadora de un proceso cuyas aportaciones iusnaturalistas sirvieron para resolver problemas derivados de la expansión europea y la colonización en territorios americanos, tales como: la naturaleza del poder y de la justicia, los derechos de la persona y del Estado, la regulación del orden de la comunidad internacional, el derecho de gentes y la búsqueda de la solución pacífica de los conflictos internacionales. También podemos señalar el pensamiento teológico y filológico de Fray Luis de León (religioso agustino), que junto a la figura de Vitoria y otros religiosos contribuyeron a la riqueza cultural de la Escuela de Salamanca cuyo modelo organizativo se proyectó al otro lado del mundo, en las futuras universidades americanas.

Muchas veces cuando se piensa en el período de la Conquista Española en territorios americanos se piensa mayormente en las injusticias ocasionadas hacia los pueblos originarios, explotaciones de recursos naturales e imposición cultural que hizo la Corona española en estos territorios. La historia de la humanidad nos demuestra que estas acciones no son exclusividad de un pueblo o cultura, como también nos enseña que es algo que lamentablemente se repite una y otra vez a lo largo del tiempo e indistintamente del continente, e incluso entre pueblos del propio continente. Desgraciadamente todo imperio siempre ha oprimido a otro, sea mediante la imposición de una cultura o la región, y sea en Europa o América. Sin embargo, la historia también 
nos confirma que lo que en principio se da como una imposición de una cultura sobre otra, muchas veces, dicho proceso termina por producir una convergencia cultural, que enriquece a las culturas que se enfrentan, pasando del enfrentamiento a la convergencia, dando como resultado la creación de una nueva civilización aún más rica culturalmente hablando.

Para muchos académicos la construcción y definición de Occidente se produce y materializa en la diferenciación con Oriente, y la gran mayoría establece como puntos de partida dos acontecimientos históricos; el primero se origina en el marco del imperio romano, cuando el emperador hispánico Teodosio I reparte el imperio entre sus dos hijos en el año 395 d.C. Honorio, quién hereda Occidente y Arcadio que recibe Oriente $^{116}$.

Otros consideran que la división entre Occidente y Oriente se produce con la división de la cristiandad, entre la iglesia de Oriente de rito ortodoxo y la iglesia de Occidente de rito católico en el año $1054^{117}$, aunque más que católico era llamado rito latino, el uso del término católico que significa universal comienza a encontrarse justamente después de los conflictos con el protestantismo, lo que a nuestro entender se utiliza dicho término, porque el termino cristiandad o latino, ya no era un término que representaba y englobaba la unidad de la cristiandad, una manera de diferenciarse, a la vez que buscaba prevalecer la supremacía de poder sobre otras iglesias cristianas reformistas, al anunciarse como católica, es decir, universal dejaba a la protestante como poca legitima o un poder parcial. Ginzo define la tensión entre Occidente y Oriente como la tensión entre Latinos y Bizantinos ${ }^{118}$. En cualquier caso, todos los hechos sitúan a Occidente en territorios de Europa. Pero a nuestra consideración este Occidente se expandió hacia al otro lado del Atlántico cuando se produce el descubrimiento de América.

Según Romeu "occidentalización es el proceso en que los pueblos no europeos adoptan, trasplantan e imitan las instituciones, creencias y códigos distintivos del orden de la sociedad y el modo político y económico de Occidente" ${ }^{119}$, definiendo que Occidente, en la actualidad, está formado por Europa y Estados Unidos. Pero dicha

\footnotetext{
${ }^{116}$ BETANCOURT, F.: Derecho Romano Clásico, Universidad de Sevilla, Sevilla, 2007, p. 86.

${ }_{117}$ BINNS, J.: Las iglesias cristianas ortodoxas, Cambridge University Press, Cambridge, 2004, p. 231.

118 GINZO, A.: Eneas Silvio Piccolomini (Pío II) y su concepción de Europa, Anales del Seminario de Historia de la filosofía, Vol. 28 (2011), p. 80

119 ROMEU, G.: Valores socioculturales en México y América Latina, Palilibro, Bloomington, 2011, p.17.
} 
occidentalización no se produce en la actualidad, se genera durante el periodo del Sacro Imperio Romano Germánico, y concretamente en los tiempos del emperador Carlos V, ya que será dentro de su período en el cual se llegan a erigir, en América, las primeras universidades, siendo este sin duda uno de los más grandes legados que deja el emperador a este continente, dado que serán en estas universidades donde se debatirá el futuro político y económico de las colonias, en primera instancia, y en segundo término la creación de las nuevas repúblicas independientes, que serán los actuales estados nacionales.

En relación con este último punto la Universidad de Salamanca jugará un rol fundamental en las nuevas universidades americanas, pues muchas de ellas se crearán tomando como modelo la universidad salmantina y los debates intelectuales que en ella se realizan y propugnan se trasladan de Europa hacia América. Recordemos que es justamente en el siglo XVI cuando Salamanca está en su máximo esplendor, como centro académico y foco intelectual.

Águeda nos dice en ese momento Salamanca representa el cerebro de la nación y la máxima cátedra del saber europeo, citando como momento principal la renovación producida en la Facultad de Teología con Francisco de Vitoria a la cabeza, y que en ese instante Salamanca supera a la de París como referencia en la vanguardia de ideas ${ }^{120}$. Estas ideas fueron proyectadas desde Salamanca al nuevo continente creando un mapa de universidades de Hispanoamérica, la cual se transformará un día en el mapa de las naciones libres de América ${ }^{121}$.

Las primeras universidades en América fueron iniciativas y fundaciones de la Orden de los Predicadores, más conocida como Los Dominicos, posteriormente le seguirían, la Orden de San Agustín y la Orden de la Compañía de Jesús, llamados también agustinos y jesuitas.

En 1548 los dominicos realizaron un Capítulo en su convento en Cusco (Perú), en dicho capítulo se discutió la conveniencia de crear una universidad en el Virreinato del Perú. Esta iniciativa tuvo una gran acogida por parte del Cabildo de Lima, que en 1550

${ }^{120}$ RODRÍGUEZ, A.: La proyección de la Universidad de Salamanca en Hispanoamérica: modelo institucional y pedagógico de las Universidades Hispanoamericanas, revista de Educación de Extremadura N 4-2012, Ediciones Universidad de Extremadura, p. 41.

${ }^{121}$ Ibíd., p. 45. 
designa a dos Procuradores, un eclesiástico y un laico, que en nombre de la ciudad gestionarían el permiso de apertura de la universidad ante el emperador Carlos V, los procuradores nombrados fueron fray Tomás de San Martín (representado al clero) y el capitán jerónimo de Aliaga (como laico).

La Real Cédula del 12 de mayo de 1551 firmada por Carlos V, Emperador del Sacro Imperio Románico Germánico y I de Castilla, supone la fundación oficial en el Virreinato del Perú, de la Real y Pontificia Universidad de la Ciudad de los Reyes de Lima. El reconocimiento eclesiástico fue dado el Papa Pío V quién le otorgó el Breve Exponi Nobis, el 25 de julio de $1571^{122}$. A continuación un extracto de la cédula mencionada:

Don Carlos por la Divina Clemencia, Emperador siempre Augusto, rey de Alemania, Doña Juana su Madre, y el mismo Don Carlos por la gracia de Dios, reyes de castilla, de León, de Aragón, de las dos Cicilias, de Jerusalén, de Navarra, de Granada, de Toledo, de Valencia, de Galicia, de Mallorcas, de Sevilla, de Cerdena, de Córdoba, de Córcega, de Murcia, de Jaén, de los Algarves, de Algeriza, de Gibraltar, de las Islas Canarias, de las Indias, Islas, é Tierra Firme del Mar Océano, Conde de Flandes, y de Tirol, \&. Por quanto Fray Thomas de Sant-Martín de la Orden de Santo Domingo, Provincial de la dicha Orden en las Provincias del Perú, nos ha hecho relación, que en la Ciudad de los Reyes de las dichas Provincias está hecho, y fundado un Monasterio de su Orden en el cual ay buen aparejo para hazer Estudio General en qual sería muy provechoso en aquella tierra: porque los hijos de los Vecinos de ella, serían doctrinados, y enseñados, y cobrarían abilidad, é nos suplicó fuessemos servidos de tener por bien, que en el dicho Monasterio oviesse el dicho Estudio General con los privilegios, franquezas, y libertades, que ha, y tiene el Estudios y Universidad de la Ciudad de Salamanca [...] Dada en la Villa de Valladolid a doce dia del mes de Mayo de mil quinientos cincuenta y un años ${ }^{123}$.

Siguiendo los pasos del Perú, en México se funda la Universidad de San Pablo, mediante la Real Cédula, firmada en Toro el 21 de septiembre de 1551, por su parte el

\footnotetext{
${ }^{122}$ Breve de Pío V para la Universidad de San Marcos, Lima. Ms. Archivo central de la Universidad de San Marcos. Ver también Breve de Pío V para la Universidad de Lima, Sevilla, Ms. Archivo general de Indias, Patronato, Estante 2, cajón 2, Legajo 7, N 12.

${ }^{123}$ Real Cédula de Fundación de la Universidad de San marcos, Ms. Archivo general de Indias, Audiencia de Lima, Legajo 566, tomo 6. También puede verse: Libro de Cédulas y Fundación de/la real Universidad de S. Marcos, Lima Ms. s XVI-XVII. ACUSM, t. I, N 697
} 
Papa Clemente VIII otorgó la bula que le da la ratificación académica ecuménica, el 7 de octubre de 1595. Así se crea la primera universidad en el Virreinato de Nueva España (México) ${ }^{124}$. Esta universidad al igual que la del Virreinato del Perú tomaría como inspiración el modelo institucional y administrativo, así como académico de la Universidad de Salamanca.

El 23 de febrero de 1558, el rey Felipe II firma en Valladolid la Real Cédula por la cual queda instituía, de manera formal, la Universidad de Santiago de la Paz, en Santo Domingo en la Isla Española (República Dominicana); enfatizamos el término formal, porque el proyecto de la universidad fue iniciado en 1537, dado que recibió el reconocimiento como universidad pontificia en $1538^{125}$, y se estipuló que seguiría los modelos de las universidad de Salamanca y Alcalá de Henares. Pero de acuerdo a los procedimientos de la época una universidad no quedaba formalmente reconocida hasta el momento que contara con los das autorizaciones correspondientes, esto quiere decir que tenía que contar con la autorización del papa y la del rey.

Águeda nos indica que entre el período de 1538 y 1821 en América se funda unas treinta universidades ${ }^{126}$. Un punto interesante es ver el desarrollo político y geográfico de las colonias en América, las cuales nacen bajo dos grandes y principales virreinatos (el Virreinato de Nueva España y el Virreinato del Perú), posteriormente se subdividen en más partes, pasando de dos virreinatos a cuatro (el Virreinato de Nueva Granada, el Virreinato de la Plata, más los dos anteriores); finalmente existirán cuatro virreinatos más cuatro capitanías generales: Venezuela, Cuba, Guatemala, Santiago. ¿Por qué es interesante? Porque dichas divisiones políticas-geográficas coinciden con el establecimiento de universidades en los respectivos territorios, y más curioso aún es notar que antes de iniciarse el proceso de independencias en América, ya existe casi una universidad por cada nueva capital de las futuras repúblicas americanas. En

\footnotetext{
${ }^{124}$ Para mayor información puede revisarse: Reales Cédulas de la real y Pontificia universidad de México de 1551 a 1816. Versión Paleográfica y nota de Jhon Tate Lanning, estudio preliminar de Rafael Heliodoro Valle. México, Imprenta Universitaria, 1946. MENDOZA, V.: Vida y costumbres de la Universidad de México. Imprenta Universitaria, México, 1950. También ver: La primera universidad de América. Orígenes de la Antigua real y Pontifica Universidad de México. Imprenta Universitaria, México, 1940.

${ }_{125}$ Para mayor información puede verse: GARCíA, J.: Compendio de la Historia de Santo Domingo, Santo Domingo, 1890. También ver: La universidad de Santo Domingo. Reseña Histórica. La Ciudad Universitaria, Cuadro cronológico. Anuario de la Universidad de Santo Domingo, Vol. XXXI. Ciudad Trujillo, 1944-45.

126 RODRÍGUEZ, A.: La proyección de la Universidad de Salamanca en Hispanoamérica: modelo institucional y pedagógico de las Universidades Hispanoamericanas, Op. cit., p. 29.
} 
consecuencia podemos establecer que existe una correlación directa entre la creación de los centros de enseñanza superior y la formación de los futuros estados nacionales en América una vez independizadas de la Corona Española.

El siguiente cuadro incluye, de manera cronológica, por un lado la jurisdicción política en cada una de las colonias de la Corona Española en América, su respectiva universidad, año de fundación y el nombre del futuro y actual Estado-nación. 
Cuadro N 1. Universidades en América

\begin{tabular}{|c|c|c|c|}
\hline \multicolumn{4}{|c|}{ UNIVERSIDADES EN AMÉRICA } \\
\hline Jurisdicción & Nombre de la Universidad & $\begin{array}{c}\text { Año de } \\
\text { fundación }\end{array}$ & $\begin{array}{l}\text { Actual Estado- } \\
\text { Nación }\end{array}$ \\
\hline Virreinato del Perú & San Marcos & 1521 & Perú \\
\hline Virreinato de Nueva España & San Pablo & 1521 & México \\
\hline $\begin{array}{l}\text { Virreinato del Perú / Real } \\
\text { Audiencia de la Plata de las } \\
\text { Charcas }\end{array}$ & De la Plata & 1552 & Bolivia \\
\hline $\begin{array}{l}\text { Virreinato de Nueva España } \\
\text { /Isla Española }\end{array}$ & Santiago de la Paz & 1558 & $\begin{array}{c}\text { República } \\
\text { Dominicana }\end{array}$ \\
\hline $\begin{array}{l}\text { Virreinato del Perú/ Real } \\
\text { Audiencia de Santafé de } \\
\text { Bogotá }\end{array}$ & Santo Tomás & 1580 & Colombia \\
\hline $\begin{array}{l}\text { Virreinato del Perú/ Real } \\
\text { Audiencia de Quito }\end{array}$ & San Fulgencio & 1586 & Quito \\
\hline $\begin{array}{l}\text { Virreinato del Perú/ Real } \\
\text { Audiencia de Chile }\end{array}$ & $\begin{array}{c}\text { La de Nuestra Señora del } \\
\text { Rosario }\end{array}$ & 1619 & Chile \\
\hline $\begin{array}{l}\text { Virreinato de Nueva España / } \\
\text { Capitanía de Guatemala }\end{array}$ & San Carlos & 1676 & Guatemala \\
\hline $\begin{array}{l}\text { Virreinato de Nueva España/ } \\
\text { Capitanía General de Cuba }\end{array}$ & La Habana & 1721 & Cuba \\
\hline $\begin{array}{l}\text { Virreinato de Nueva Granda / } \\
\text { Capitanía General de } \\
\text { Venezuela }\end{array}$ & Caracas & 1721 & Venezuela \\
\hline Virreinato de la Plata & Buenos Aires & 1778 & Argentina \\
\hline Virreinato de Nueva Granada & Francisco Javier de Panamá & 1749 & Panamá \\
\hline Virreinato de la Plata & Asunción & 1733 & Paraguay \\
\hline $\begin{array}{l}\text { Capitanía General de } \\
\text { Guatemala }\end{array}$ & León & 1812 & Nicaragua \\
\hline
\end{tabular}

Elaboración propia.

Hay que tener en cuenta que durante la fundación de las primeras universidades, muchas de ellas, fueron creadas cuando sólo existían jurídicamente dos Virreinatos, los cuales se dividían en reales audiencias y que luego algunas serían transformadas en 
capitanías generales o virreinatos. De ahí que en el cuadro aparezcan que muchas están dentro de la jurisdicción del Virreinato de Nueva España (1535-1821) y del Virreinato del Perú (1542-1824) por haber sido fundadas dentro de su período como virreinatos correspondientes. En los inicios de la conquista el Virreinato del Perú cubrió prácticamente toda la actual América del Sur partiendo desde el Istmo de Panamá, pasado por las actuales Argentina, Bolivia, Colombia, Chile, Ecuador, Argentina, Uruguay, Paraguay, la región oeste y sur de Brasil, exceptuando los territorios que hoy ocupan Venezuela por pertenecer al Virreinato de Nueva España.

Finalmente, a modo de conclusión y partiendo desde el primer al cuarto punto de este apartado, se puede decir que la Edad Media aporta al acervo integracionista de Europa varias ideas y conceptos, que luego serán retomados en la Edad Moderna cuando se formen los Estados nacionales, pero que como veremos también, existirán de manera paralela proyectos de integración a nivel europeo. Entre las ideas a rescatar podemos resaltar el deseo de establecer como referencia y modelo a seguir primero la cultura griega, en segundo lugar la cultura greco-romana, para posteriormente vincularla con la herencia cristiana, todo ello con el objeto siempre de crear una identidad supra, cuyos valores, principios y creencias sean comunes por el conjunto de las naciones que forman parte de una región.

Otro aspecto interesante es cómo en la idea de integración, tanto en la Edad Media como incluso hasta en los actuales procesos de integración, siempre se da como un factor importante una variable exógena, un enemigo externo, que hace que una a varias naciones en una unidad política para hacer frente a dicho enemigo común, y es en ese interés común, donde las distintas partes suelen encontrar que tienen más puntos en común que puntos divergentes, más cuando reflejan frente al espejo de ese enemigo externo. La idea de república cristiana, que menciona el Papa Pío II, también será un concepto usado en varios proyectos de unificación política en Europa como veremos en los siguientes apartados.

Con respecto al último punto, podemos decir que de acuerdo a nuestro sujeto de estudio que son los procesos de integración regional, las divisiones territoriales de la América "Española", tanto los virreinatos como las capitanías generales, coinciden por un lado con las actuales repúblicas existentes, así como con los procesos de integración subregional en América, por un lado México y Chile como países, Centro América 
coincidiendo con los países que fueron miembros de la Capitanía de Guatemala, el proceso de integración andina entre el Virreinato de Nueva Granada y el Virreinato del Perú, los países del MERCOSUR, siguiendo el esquema del Virreinato de la Plata y Venezuela como bisagra entre los países andinos y los del MERCOSUR. Quizás la unión de estos países encuentra sus raíces más en la época de la Corona, que en la de sus pueblos originarios. Y sin querer entrar en dicho debate, lo que sí parece evidente viendo los mapas, es que la América llamada Latina, que hoy conocemos, tiene el mismo mapa de división jurisdiccional que en la época de la Colonia en términos de procesos de integración subregional en marcha. 
EL ACERVO INTEGRACIONISTA N EUROPA Y AMÉRICA:

UNA HISTORIA COMÚN 


\title{
- CAPÍTULO III
}

\section{EL ACERVO INTEGRACIONISTA EN EUROPA Y AMÉRICA EN LA MODERNIDAD:}

\author{
UNA HISTORIA EN COMÚN
}




\subsection{LA CONSTRUCCIÓN DE UNA IDEA: LA UNIDAD POLÍTICA DE LOS ESTADOS}

Se suele decir que el acervo comunitario de la Unión Europea (UE), por consiguiente su acervo integracionista, es el conjunto de principios y objetivos políticos emanados de los diferentes tratados, legislación derivada de dichos tratados y la jurisprudencia del Tribunal de Justicia de la UE, de las declaraciones y resoluciones adoptadas en el marco de la acción exterior de la Unión, así como de los acuerdos internacionales celebrados tanto por la UE como de sus Estados miembros ${ }^{127}$.

Sin embargo, considero que dicha conceptualización es parcial e incompleta. Se debería de considerar cada una de las iniciativas y proyectos que contemplaban la unificación de los países europeos, antes de los tratados mencionados, a pesar de no haber prosperado, muchos son proyectos y tratados desarrollados en el marco de los estados y todos ellos tenían como objetivo la unidad política de Europa.

Del mismo modo ocurre con los procesos de integración regional en América, en los que de ahora en adelante nos centraremos, la integración regional de una parte de América, la región llamada América Latina y Caribe, región que también cuenta con su propio acervo integracionista. Nótese que no hemos dicho acervo comunitario, porque en el caso del proceso de integración latinoamericana-caribeña (de ahora en adelante para simplificar se usará el término latinoamericana/latinoamericano), no podemos hablar de comunitario, dado que el concepto comunidad, a nuestro entender sólo debe de ser usado cuando existe una puesta en común, es decir existe un grado de "soberanía común" o una "soberanía compartida".

Hechos e ideas inexistentes en cada una de las propuestas desarrolladas en el marco del proceso latinoamericano $^{128}$, aspecto contraproducente, si pensamos que siempre aspiran a la unidad política y que muchos de sus procesos utilizan el nombre de comunidad, sin tener en consideración ni anhelo de establecer una "soberanía común” o una "soberanía compartida". A lo largo del proceso integracionista latinoamericano, el tema de la

\footnotetext{
127 Definición de Acervo Comunitario. Glosario. Síntesis de la Legislación de la Unión Europea. http://europa.eu/legislation_summaries/glossary/community_acquis_es.htm [Última revisión: 20-042013]

${ }^{128}$ Cabe señalar que cada vez que se use, en este artículo, el término América Latina, quedará implícito, la definición de América Latina y Caribe.
} 
defensa al respeto e inviolabilidad de la soberanía ha sido una "variable constante" en cada una de las propuestas de unificación planteadas hasta la fecha.

Para entender los conceptos de estados nacionales y soberanos, es necesario regresar en el tiempo hasta los inicios de la Edad Moderna, tomando como referencia el Primer Congreso diplomático celebrado en Europa, el cual dio origen al sistema internacional, basado en la soberanía nacional de los estados, nos referimos a los Tratados Osnabrück y Münster, llamados también como los Tratados de Westfalia, firmados en 1648. Desde los Tratados de Westfalia a los Tratados fundacionales de la Unión Europea, ha pasado trescientos años y desde entonces ha ocurrido un cambio significativo en las relaciones internacionales, pasando de un sistema internacional fundado en la soberanía nacional a otro tipo de sistema, que cuenta con un nuevo actor que posee una soberanía común, las uniones regionales.

Lo interesante es notar cómo paralelamente que se pensaba en la organización de un sistema internacional basado en los estados nacionales y soberanos, se pensaba también en un sistema internacional basado en unidades territoriales más grandes, lo que a nuestro modo de ver, es el germen político de lo que vendrían hacer las organizaciones de integración regional, de ahí que existieran diferentes iniciativas y proyectos de unidad diseñados por varios estados europeos ya en ese entonces.

Es relevante señalar que es Europa la que crea el sistema internacional basado en estados nacionales, y será la misma Europa la que creará un nuevo sistema internacional tres siglos más tarde, redefiniendo la manera de concebir las relaciones internacionales al iniciar su proceso de integración regional y creando las primeras organizaciones de carácter regional. Así lo que históricamente fue llamado "sistema de Estados Europeos" o "Sistema Político de Europa" (Congresos de Westfalia 1644-1648) y posteriormente “Concierto Europeo" (Congreso de Viena 1814-1815), son hechos que demuestran los intentos por la búsqueda de una organización política idónea por parte de los estados europeos $^{129}$. Y será la misma Europa la que originará, nuevamente, un nuevo orden mundial, un nuevo sistema, el "mundo de las regiones"130.

129 TRUYOL Y SERRA, A.: La integración Europea. Idea y Realidad. Discurso de recepción del Académico de Número. Academia de Ciencias Morales y Políticas, Madrid, 1972. p. 14.

130 HETTNE, B.: Regionalism and World Order, in FARREL M, HETTNE B, and VAN LANGENHOVE, L. Op, cit. p. 277. 
Cabe indicar que no es el objetivo central de este trabajo el defender o acometer en contra de la vigencia de los estados nación, pero sí se busca enfatizar el paralelismo histórico entre el desarrollo de un sistema internacional organizado sobre la base de los estado nación y un sistema organizado en uniones regionales. Es destacable la constante voluntad de unificación de ambas regiones a lo largo de los siglos, cuya motivación es el deseo de lograr la paz (pactum pacis) y la seguridad en sus respectivas regiones. En el caso de Europa era terminar con las constantes guerras fratricidas (guerra intra, podemos decir una guerra intrarregional).

En el caso de América Latina, era terminar con las constantes amenazas de guerra por parte de las potencias extra regionales (europeas), durante el período de las guerras de independencia, (guerra inter, podemos decir que era una guerra interregional).

Por tanto, el riesgo de nuevas guerras es una de las motivaciones que lleva a los estados a unificarse para evitar conflictos y establecer una zona de paz. Resultado logrado con el proceso de integración de la Unión Europea, en la década de los años cincuenta. Quizá por esa razón, es que el conjunto de la academia llega a un "consenso" al determinar que es la fecha de partida en la historia de las uniones regionales, por ser esta la década de inicio en que comienzan a materializarse y concretarse la creación efectiva de organismos e instituciones regionales, dándose un cumplimiento y respeto por los tratados internacionales firmados en estas materias, algo que no sucedió con anterioridad.

Sin embargo, esos hechos no pueden llevar a desconocer, en conjunto, y desde una perspectiva histórica los varios intentos en la búsqueda de la unidad política tanto en Europa como en América Latina y el Caribe, pues a nuestro entender son esas ideas e intentos lo que contribuyeron a ir madurando la idea de crear las uniones regionales tal como hoy las conocemos.

\subsection{EL SUEÑO DE LA ANFICTIONÍA: DE EUROPA A AMÉRICA LATINA}

Anfictionía es una palabra que proviene del griego y que etimológicamente quiere decir "fundación conjunta". Tradicionalmente, es asociada a la historia de la Confederación de los antiguos pueblos griegos. Cuya identidad común era su religión, razón por la cual 
se reunían en el santuario de Deméter, en Antela. Por ese entonces, el oráculo de Delfos era un santuario más famoso que el de Deméter y estaba cercano al Istmo de Corinto, que une el Peloponeso con Hélade, la Grecia continental. Su ubicación estratégica a nivel regional era una de las razones por las cuales servía de punto de referencia para centrar las grandes decisiones políticas.

El istmo es flanqueado por el mar Jónico y el mar Egeo, otro motivo por el cual las reuniones de las anfictiónicas fueron trasladas al oráculo de Delfos. Estos hechos históricos, aunque lejanos en el tiempo, servirán de fuente de inspiración para construir la idea de una fundación conjunta entre los pueblos de Europa, y posteriormente, servirán de referencia e inspiración ideológica entre los pueblos de la América, concretamente con los de América Latina. No es casualidad que los primeros proyectos de unión tanto en Europa como en América Latina enarbolan la anfictionía griega.

En 1648, el mismo año en que se celebró los congresos de Westfalia, muere Emery de la Croix, más conocido como Émeric Crucé, un sacerdote, escritor y político francés que en 1623 escribió Le nouveau Cynée: Ou discours des occasions et moyens d'establir une paix generale \& la liberté du commerce par tout le monde ${ }^{131}$. Esta es la primera obra, en el génesis de la historia del estado nación, que proponía un proyecto de paz general y establecía el libre comercio como argumento político central, el mismo argumento principal a la hora de iniciar un proceso de integración regional en la actualidad.

Crucé propone la creación de una corte internacional permanente, compuesto por embajadores y establecía un tribunal internacional con sede en Venecia, por ser este un territorio neutral. La vía para conseguir y mantener esa paz general y perpetua, sería a través del fomento del comercio internacional ${ }^{132}$, pues se consideraba que éste podría ser el medio para evitar futuras guerras. La interdependencia generada por las relaciones comerciales evitaría una guerra, dado el conjunto de intereses creados por el comercio.

\footnotetext{
${ }^{131}$ Émeric Crucé, Le nouveau Cynée: Ou discours des occasions et moyens d'establir une paix generale \& la liberté du commerce par tout le monde. Aux monarques \& souverains de ce temps, Villery, Paris, 1623. Una versión electrónica puede encontrarse en la web de la Biblioteca Nacional de Francia: http://www.patrimoine.edilivre.com/le-nouveau-cynee-ou-discours-d-estat-representant-les-occasions-etmoyens-d-establir-une-paix-generalle-et-la-liberte-du-commerce-par-tout-le-monde-aux-monarques-etsouverains-de-ce-temps-em-cr-par-la-croix-emeric-de-1590-1648-ark-12148-bpt6k823107.html [Última revisión: 22-04-2013]

132 BALCH, T.: "The Proposed International Tribunal of Arbitration of 1623", Proceedings of the America Philosophical Society, Vol. 46 N 186, April-September, 1907. p. 304. http://www.jstor.org/stable/983742 [Última revisión: 21-04-2013]
} 
Esta propuesta también contemplaba la necesidad de crear una moneda común. Si bien es cierto que Crucé contempla una unión universal, ésta la establece sobre la base del liderazgo de las potencias europeas y bajo la dirección del Papa y el Rey de Francia. Otro aspecto importante de la propuesta de Crucé, de cara a nuestra investigación, es que su proyecto de unión universal lo divide tomando en consideración grandes territorios geográficos, lo que hoy entenderíamos como "regiones". Así Crucé sugiere que en dicha unión deberían de estar representados los siguientes territorios: Persia, China, Etiopia, Las Indias Orientales, las Indias Occidentales, en definitiva el mundo entero $^{133}$.

Si hacemos un paralelismo histórico con la Antigua Grecia, fundadora de la idea de la Anfictionía, la propuesta de Crucé corrió el mismo destino que la propuesta de paz hecha por el protagonista de su obra, Cynée, pues ambas fueron rechazadas. Cuenta la historia que en el siglo III a.C. una vez ganada la guerra por parte de los griegos a los romanos, Pirro, rey de Epiro, envía a su ministro Cineas (Cynée en francés) como embajador ante el senado romano a exponer las condiciones de un tratado de paz.

Cineas era un fiel defensor de la paz, fue discípulo de Demóstenes y era conocido por su elocuencia y oratoria, tanto que el propio Pirro confesaba “que debía más ciudades a su palabra que a su misma espada"134. Sin embargo, el senador romano Apio Claudio, apodado "El Ciego", rechazó cada una de las condiciones expuestas por Cineas, su negativa la efectúo realizando un discurso patriótico y nacionalista, en favor de la grandeza del pueblo de Roma.

En 1638, Maximilien de Bérthume, el Duque de Sully, publica sus Memorias en las cuales propone la creación de una Confederación a escala europea. El Duque de Sully describe cómo esta confederación, formada por una unión de quince estados, que sería regido por un consejo, llamado "Consejo de Europa", el mismo que se dividiría en un consejo regional y un consejo general. Este consejo formaría "un cuerpo común de República Cristiana siempre pacífica en ella misma que esté compuesta de todos los estados, reinos, repúblicas y señoríos que hagan profesión de fe cristiana en Europa"135.

\footnotetext{
${ }^{133}$ Ibíd. pp. 305-306.

${ }^{134}$ CANTÚ, C.: Historia Universal. Tomo II, Gaspar y Roig Editores, Madrid, 1866, p. 28

135 MAXIMILIEN DE BÉTHUMEN, Duque de Sully, Mémoires des sages et royales a économies d'Estat, domestiques, politiques et militaires de Henri le Grand, l'exemple des rois, le prince des vertus, des armes et des lois et le père en effet de ses peuples francais ; Et les Sertitudes utiles, obéissances convenables et administrations loyales de Maximilien de Béthune, l'un des plus confidents, familiers et
} 
De la Reza enfatiza que a pesar que el proyecto se sienta sobre bases ecuménicas, se excluye a Turquía y Rusia, el primero por albergar a los "enemigos de la ley" y ocupar Tierra Santa, y Rusia por encontrarse mayoritariamente en Asia, además de incorporar naciones paganas y por profesar un rito cristiano distinto al europeo ${ }^{136}$. Del mismo modo describe que Sully concibe dos proyectos concernientes a la forma de cómo implementar la confederación. La primera propuesta incluía un congreso o consejo que estaría compuesto por 66 diputados, distribuidos de la siguiente manera:

- 4 representantes por cada potencia mayor (Papado, Francia, Gran Bretaña, Dinamarca, Suecia, Polonia y el Señorío de Venecia).

- 2 representantes por cada potencia media (Hungría, Bohemia, Nápoles, Sicilia y Cerdeña, los cantones de Suiza, Los Países Bajos, los ducados de Florencia, Milán, Saboya, Mantua, Parma, Moderna y Génova $)^{137}$.

La segunda propuesta contemplaba la institución de un Consejo General formado por 40 representantes divididos entre dos mitades, formadas por las grandes potencias y potencias medias. Las funciones de este Consejo General serían atender a las reclamaciones de todos los estados miembros y seis asambleas "particulares" o “regionales". Poseería competencias en temas de asuntos internos de la confederación, así como autorizar su participación en el diseño de la política exterior ${ }^{138}$.

En 1676 Gottfried Wilhelm Leibniz, filósofo, jurista, político y diplomático alemán, propone la creación de una República Cristiana, buscando la reconciliación entre católicos y protestantes, de la misma forma que lo hizo Sully. Curiosamente Leibniz y el Duque de Sully eran protestantes, y sin embargo, ambos en sus respectivos proyectos sugerían la intervención y liderazgo del Papa, y por consiguiente el de la Iglesia Católica Apostólica y Romana. No es de extrañar, si se considera el poder e influencia de la Iglesia Católica en las relaciones internacionales y porque ambos servían a sus respectivos señores que eran católicos, Enrique IV y el Duque de Brunswick Johann Friedrich. Leibniz propone redefinir el concepto de soberanía, considerando que todo

utiles soldats et serviteurs du Grand Mars des Français, Tomos I-II, Paris, Michaud y Poujoulat, Vol. III, 1837. En DE LA REZA, G.: Las Memorias del duque de Sully (o los avatares del primer proyector de unión europea). Revista Brasileira de Política Internacional, Vol. 52 N² 2, 2009, Instituto Brasileiro de Relaciones Internacionales, p. 104.

136 Ibíd.

${ }^{137}$ Ibíd. p. 106

${ }^{138}$ Ibíd. pp. 105-106. 
soberano se debía a un soberano universal, como era el Sacro Imperio Romano o el Papado. Leibniz considera que todos los estados cristianos constituyen un solo cuerpo, del cual el Papa es el jefe espiritual y emperador terrenal, y que por ello, éste debería de ejercer una jurisdicción universal ${ }^{139}$. Como vemos la idea medieval de la "República Cristiana" se vuelve a retomar como proyecto para redefinir los asuntos internacionales de época.

En 1693 William Penn, cuáquero inglés y fundador del Estado de Pensilvania, escribe An Essay towards the Present and Future Peace of Europe, by the Establishment of an European Diet, Parliament or States ${ }^{140}$. En este ensayo expone varias ideas de unidad europea como una Dieta Europea, es decir un Parlamento Europeo, e inclusive llega a sugerir la creación de un Estado de Europa (idea similar expondría siglos más tarde otro inglés al proponer la creación de los Estados Unidos de Europa, ese inglés sería, Winston Churchill). Esta Dieta Europea soberana, estaría formada por delegados de los estados miembros que la formen, y cuya función sería la de establecer reglas de justicia comunes y de resolver, de manera pacífica, los conflictos entre las partes. Penn propone que cada miembro deberá de contribuir a la Dieta de acuerdo a su tamaño y riqueza, y en tal sentido sugiere la siguiente formación ${ }^{141}$ :

1. Imperio de Alemania: 12

2. France: 10

3. España: 10

4. Italia: 8

5. Inglaterra: 6

6. Portugal: 3

7. Suecia: 4

8. Dinamarca: 3

9. Polonia: 4

10. Venecia: 3

\footnotetext{
139 JOLleY, N.: The Cambridge Companion to Leibniz, The Press Syndicate of the University of Cambridge, Cambridge, 1995. p. 28.

${ }^{140}$ PENN, W.: An Essay towards the Present and Future Peace of Europe, by the Establishment of an European Dyet, Parliament or States, 1693. Georg Olms AG, 1983. Nachdruck der Ausgabe London 1693. Printed Germany. Versión electrónica en EEBO Early English Book On line: http://eebo.chadwyck.com/search/full_rec?SOURCE=pgthumbs.cfg\&ACTION=ByID\&ID=36272868\&F ILE=../session/1366984333_16384\&SEARCHSCREEN=CITATIONS\&SEARCHCONFIG=var_spell.cf g\&DISPLAY=AUTHOR

${ }^{141}$ PENN, W. Op., cit. Section VII. Of the Composition of the Imperial States. pp. 16-18.
} 
11. Siete Provincias: 4

12. Trece Cantones y los pequeños soberanos vecinos: 2

13. Los ducados de Holstein y Courland: 1

Del mismo modo señala que si los turcos y moscovitas se adhieran. Tendrán 10 delegados cada uno, haciendo un total de 90. Pero estos dos últimos sólo pondrán sentarse, es decir, Penn considera que estos deberán de tener representación dentro de la Dieta Europea, pero no voto.

Como mencionan Salmon (Profesor del Colegio de Europa) y Nicoll (exdirector general en el Consejo de las Comunidades Europeas), el ensayo de Peen es un ejemplo más de los diferentes planes, propuestas y reflexiones sobre la integración de Europa ${ }^{142}$. Es importante destacar la idea de Penn, pues posteriormente, cuando se realizan las gestas de las guerras de independencia en América, y en el caso concreto, en la formación de los Estados Unidos de América, se verá esta unión como referencia para la creación de una nueva visión de unidad y gobernabilidad política, lo que promoverá a la reflexión sobre el modelo federal. Quizás por eso Winston Churchill propuso la creación de los Estados Unidos de Europa, mezclando las ideas de Penn y extrapolando a la realidad de ese momento, el modelo de la nueva superpotencia mundial, los Estados Unidos de América.

Pero sigamos con nuestra cronología de proyectos integracionistas.La visión de una Europa unida políticamente hablando, sería compartida y defendida por europeos como el francés Marie-Joseph Paul Yves Roch Gilbert du Motier, Marqués de Lafayette, y el lituano Andrzej Tadeusz Bonawentura Kosciuszko. Posteriormente esas ideas serán retomadas por los franceses Claude-Henri de Rouvroy, Conde de Saint-Simon; Charles Lemonnier, discípulo de Saint-Simon (que fundó el periódico de la Liga: Les États Unis d'Europe y la asociación defensa del federalismo europeo); Pierre-Joseph Proudhon que publicó su libro El principio federativo (1863) en el cual exponía una visión de una Europa como una confederación de confederaciones ${ }^{143}$; y Víctor Hugo que también enarbolaría la defensa de una unión política de Europa, a través de la creación de los Estados Unidos de Europa.

${ }^{142}$ SALMON, T. and NICILL, W.: Building European Union. Manchester University Press, Manchester, 1997. p. 3.

${ }^{143}$ GIL, J: Historia de la Integración Europea. Universidad Nacional de Educación a Distancia, Madrid, 2012. p. 14. 
Como señalara Viviane Reding, Vice presidenta de la Comisión Europea y Comisaria Europea de Justicia, Derechos Fundamentales y Ciudanía, en 2012, en una conferencia titulada: ¿Por qué necesitamos ahora unos Estados Unidos de Europa? y realizada en el Centro de Derecho Europeo de la Universidad de Passau:

Son muchas las personalidades que a lo largo de la historia han hecho referencia a los Estados Unidos de Europa y se han rendido a este sueño, desde George Washington hasta Richard Coudenhove-Kalergi, pasando por Napoleón Bonaparte o Giuseppe Mazzini. La visión más clara y más concreta, sin embargo, es la que formuló en su día el escritor francés Víctor Hugo ${ }^{144}$.

En efecto, Víctor Hugo, pasa a la historia de las ideas de la integración europea con su discurso en favor de unos Estados Unidos de Europa, cuando participó en el Congreso Internacional de la Paz en 1849, en el pronunció una de sus más famosas frases: “Llegará el día en el cual se verán estos dos grupos inmensos, los Estados Unidos de América y los Estados Unidos de Europa, situados uno frente al otro, tendiéndose la mano por encima de los mares, intercambiando sus productos, su comercio y su industria" $" 145$.

Muchos consideran que con esta frase Víctor Hugo profetiza la creación de los Estados Unidos de Europa, pero también podríamos hacer otra interpretación, que está anunciando la importancia que tendría en el futuro las relaciones internacionales, las relaciones transatlánticas, con ello, las ideas del interregionalismo o si se quiere, del intercontinentalismo.

En 1713 Charles Irénée Castel de Saint-Pierre, más conocido como el Abad de SaintPierre, presenta su obra Projet pour rendre la paix pérpetuelle en Europe ${ }^{146}$ el cual contempla una confederación o liga europea, libre de fronteras, con un senado y una unión económica, inspirándose en el proyecto de Enrique IV y su ministro Sully.

\footnotetext{
${ }^{144}$ Discurso de Viviane Reding, Vicepresidenta de la Comisión Europea y Comisaria Europea de Justicia, Derechos Fundamentales y Ciudadanía, 8 de noviembre de 2012, Centro de Derecho Europeo de la Universidad de Passau. Europa Press releases Rapid. http://europa.eu/rapid/press-release_SPEECH-12-796_es.htm [Última revisión: 27-04-2013]

${ }^{145}$ Víctor Hugo, discurso pronunciado en el Congreso Internacional de la Paz, Paris, 21 de agosto de 1849. En PASCUAL RUIZ MACIÁ, J.: Los cimientos de los Estados Unidos de Europa, Netbiblio S.L., La Coruña, 2007, p. XI.

${ }^{146}$ ABBÉ DE SAINT-PIERRE: Projet pour rendre la paix perpétuelle en Europe, Ed. facsímil de S. Goyard-Fabre, Garnier, Paris, 1981. En ROUSSEAU, J.J.: Escritos Políticos. Editorial Trotta, Madrid, 2006, pp. 13-57.
} 
Décadas más tarde Rousseau se encargaría de retomar dicha propuesta, buscando actualizar el proyecto del Abad de Saint-Pierre realizando un resumen del proyecto, versión de la cual extraemos las líneas maestras del mismo. La confederación se formarían mediante una alianza perpetua e irrevocable; la confederación estaría compuesta por plenipotenciarios nombrados por las partes firmantes y se establecería un congreso permanente, en el cual ejercería de tribunal donde las partes contrayentes podrán acudir a resolver sus diferencias y conflictos. Se establece un sistema de votación y se afirma que la confederación garantizará a cada de sus miembros su soberanía.

Se menciona una defensa común contra una amenaza extranjera y se propone un contingente al servicio de la confederación. Así mismo la confederación buscará promover el comercio, la agricultura, las artes y las inversiones. Inclusive se llegó a plantear la creación de fondos comunes de ahorro ${ }^{147}$. La composición de esta confederación, que Rousseau llamaría República Europea, estaría formada por diecinueve miembros, que representarían a:

1. Emperador de los romanos

2. Emperador de Rusia

3. Rey de Francia

4. Rey de España

5. Rey de Inglaterra

6. Los Estados Generales

7. Rey de Dinamarca

8. Rey de Suecia

9. Rey de Polonia

10. Rey de Portugal

11. Soberano de Roma

12. Rey de Prusia

13. Elector de Baviera y sus co-asociados

14. Elector Palatino y sus co-asociados

15. Los suizos y co-asociados

16. Electores eclesiásticos y sus asociados

${ }^{147}$ ROUSSEAU, J.J.: Resumen del Proyecto de Paz Perpetua del Abate Saint-Pierre. Escritos Políticos, en CARRACEDO, J. R., Editorial Trotta, Madrid, 2006, pp. 29-39. 
17. República de Venecia y sus co-asociados

18. Rey de Nápoles

19. Rey de Cerdeña

Se menciona que los soberanos menos importantes, como la República de Génova o los Duques de Módena y de Parma, como cualquier otro soberano excluido de la lista principal, pueden adherirse en forma de asociados ${ }^{148}$. Otro aspecto a tener en cuenta es que Rousseau sigue con la idea de una República, pero esta vez, no mantendrá las ideas de que exista una República Cristiana, sino que defiende la idea de una República Europea. Quizás para separar la Iglesia del Estado.

En 1734 el Barón de Montesquieu escribe Reflections sur la monarchie universelle en esta obra dice: "Europa constituye ahora sólo una nación integrada por varias; Francia e Inglaterra necesitan la riqueza de Polonia y de Rusia así como sus propias provincias se necesitan las unas a las otras"149. En 1771-1772 Rousseau exhortara la idea de unidad europea en su obra Constitución Polaca: "Hoy ya no hay ni franceses ni alemanes ni españoles y ni siquiera ingleses, por más que se diga lo contrario; sólo hay europeos" ${ }^{" 150}$.

Gracias a la obra de Jean-Jacques Rousseau, Immanuel Kant (filósofo prusiano) conoce el proyecto del Abad de Saint-Pierre y desarrolla dichas ideas en su libro Hacia la paz perpetua. Un esbozo filosófico, publicado en 1795. En él propone una "federación de pueblos" basada en la paz "foedus pacificum", el derecho de gentes "ius gentium", el Estado de derecho y el republicanismo como forma de gobierno. Este último punto es importante, por cuanto será un punto que se destacará constantemente en las propuestas de integración en las nacientes repúblicas de la América Española, hoy conocida como América Latina. Así como el concepto de ius gentium que fue defendido y promovido por la Escuela de Salamanca, como antes se ha indicado.

De toda la propuesta de Kant, lo más novedoso es lo que establece en su artículo segundo, en el que esboza lo que en la actualidad conocemos como los conceptos de supranacionalidad e intergubernamentalidad. Kant menciona que dicha federación

\footnotetext{
${ }^{148}$ Ibíd. pp. 31-32.

${ }^{149}$ CORRAL, L.: Génesis de la Unión Europea. Cuadernos de Estudios Empresariales. Nº, Universidad Complutense, Madrid, 1998, pp. 55-56.

${ }^{150}$ Ibíd., p. 56
} 
pretende mantener y garantizar la libertad de un Estado para sí mismo y, simultáneamente, la de otros Estados federados ${ }^{151}$. Y enfatiza:

Resulta compresible que un pueblo diga: «No debe haber entre nosotros ninguna guerra, pues queremos formar un Estado, es decir, queremos imponernos a nosotros mismos un poder supremo legislativo, ejecutivo y judicial que dirima nuestros conflictos pacíficamente». Pero si este Estado dice: «No debe haber ninguna guerra entre mí y otros Estados aunque no reconozco ningún poder legislativo supremo que asegure mi derecho y al que yo asegure su derecho», no puede entenderse en absoluto dónde quiero basar entonces la confianza en mi derecho, si no es en el sucedáneo de la federación de las sociedades civiles, es decir, en el federalismo libre ${ }^{152}$.

Posteriormente, las ideas y propuestas de Kant sirven al francés Claude-Henri de Rouvroy, más conocido como el Conde de Saint-Simon, que conjuntamente con el historiador francés Jacques Nicolás Agustín Thierry, escriben en 1814 De la organización de la sociedad europea ${ }^{153}$. En esta obra se reflexiona también sobre la necesidad de hacer de Europa una unidad, es decir un solo cuerpo. Saint-Simon propone a los parlamentos de Francia e Inglaterra formar un núcleo que sirva de base para formar una confederación que reunifique a Europa, lo que hoy llamaríamos un "eje" franco-británico ${ }^{154}$.

Ideas que serán retomadas siglos más adelante, por Jean Monnet y que se tradujo en el Comité de Coordinación durante la Segunda Guerra Mundial, y que posteriormente Monnet, quiso extrapolar proponiendo la unificación de los dos parlamentos (francés y británico) y crear un solo gobierno, propuesta que fue rechazada, paradójicamente por la propia Francia $^{155}$.

\footnotetext{
${ }^{151}$ KANT, I.: Hacia la paz perpetua. Un esbozo filosófico. Editado por Jacobo Muñoz, Biblioteca Nueva, Madrid, 1999, p. 91.

${ }^{152}$ Ibíd. p. 92. Ver también: O'NEAL J. and RUSSETT, B.: The Kantian Peace: The Pacific Benefits of democracy, Interdependence, and International Organizations, 1885-1992, World Politics, Vol. N 52, Issue 01,.10. 1999, pp. 1-37.

${ }^{153}$ Para mayor información ver: SAINT-SIMON, C.-H.: De la organización de la sociedad europea, Círculo de Bellas Artes, Madrid, 2011. También: Henri Saint-Simon 1760-1825. Selected Writings on Science, Industry and Social Organisation, Keith Taylor, Croom Helm Ltd, London, 1975.

${ }^{154}$ CASSEN, B.: Una Europa cada vez menos europea. Le Monde Diplomatique, Edición española, $\mathrm{N}^{\circ}$ 87, enero 2003. Versión electrónica: http://monde-diplomatique.es/2003/01/cassen.html Última revisión: 28-04-2013.

${ }^{155}$ MONNET, J.: Memorias, Instituto Universitario de Estudios Europeos y Ediciones Encuentro, Madrid, 2010.
} 
El 26 de diciembre de 1805 se firma el Tratado de Presburgo, llamado también el "Tratado de Dominación del Emperador del Sacro Imperio Romano Germánico", terminando con los Estados alemanes, por destacar el triunfo de Napoleón sobre el Emperador Francisco II del Sacro Imperio Romano Germánico. Este tratado no sólo puso fin a la guerra entre Austria y Francia, sino también el fin del Sacro Imperio Romano Germánico, Napoleón reduce de 360 estados a 39 estados, y crea la Confederación del Rin. Esta confederación dura hasta 1815, cuando Napoleón pierde en la Batalla de Waterloo. Luego, el Congreso de Viena disuelve la confederación de 39 estados y nombra al Emperador de Austria nuevamente jefe.

Lo descatable de este proyecto confederativo es el sistema que ideó e implementó Napoleón en 1806, el llamado "sistema continental” sobre el cual establecía una unión aduanera continental, y que excluía a Inglaterra de esta, un claro boicot de los productos ingleses y acertando un golpe económico a los mismos ${ }^{156}$. Lo que manifestaba las disputas entre ambas potencias. A su vez, dicha experiencia serviría para que entre 1818-1834 se diera la unificación alemana, con ello, la creación de la unión aduanera y la unificación económica. Un precedente histórico, que la academia suele nombrar como reseña histórica a la hora de explicar de cómo se forman las uniones aduaneras, pero no se suele tomar en cuenta, ni se menciona que dicha experiencia surge de la confederación y del sistema continental, ambas ideadas por Napoleón, es decir, Francia.

Paralelamente a los acontecimientos desarrollados en Europa, encontramos, en plena efervescencia, el proceso de independencias de las colonias en la América, o si se quiere, la América Española, posteriormente llamada Hispanoamérica y hoy conocida como América Latina. Interesante que la primera iniciativa que se encuentra dentro del acervo integracionista en esta región tenía carácter confederativo y continental. Clara muestra de la transferencia de ideas entre los países de Europa y América. No es de extrañar, si tomamos en cuenta que muchos de los grandes intelectuales, militares, políticos y diplomáticos que participaron en las guerras de independencia fueron educados en Europa. De ahí que exista en el ideario del acervo integracionista latinoamericano las ideas de anfictionía, liga, confederación, federación, continentalismo y republicanismo; y para implementarlas organizaban congresos, (como lo habían sido antes Westfalia o Viena) en dónde se discutía la forma de organizar

\footnotetext{
${ }^{156}$ LANDAU, E.: Napoleon Bonaparte. Twenty-First Century Books, Mineapolis, 2006, p. 83.
} 
políticamente y administrativamente el nuevo orden político, tanto interno (por país), como externo (relaciones internacionales) dentro y fuera de su región. Y en donde sin duda el rol de las universidades americanas jugó un papel importante, ya que sin ellas no hubiese existido ese canal de intercambio de conocimientos entre ambos continentes, ni el fermento de una masa crítica, intelectual y política.

Aunque muchas veces, en el mundo académico, se suele considerar el Congreso Anfictiónico de Panamá como punto de partida y referencia principal de los proyectos de integración en América Latina, con este trabajo también se busca subrayar que dicha afirmación es incorrecta, por que existieron nueve proyectos antes del Congreso de Panamá.

Así el primer proyecto de unificación política para las futuras colonias hispanoamericanas la encontramos en el Pacto de París, del 27 de diciembre de $1797^{157}$. Dicho pacto fue propuesto por Francisco de Miranda, militar, político y diplomático venezolano, quién propone la idea de una Unión de los Pueblos del Continente Americano del Sur, o también llamada América Meridional. Tal es su convicción de éxito en la lucha por la libertad e independencia de las colonias americanas, que diseña un futuro político común para las nuevas repúblicas. Miranda considera que, una vez independizadas las colonias, éstas deberían de unirse para ser más fuerte en la arena internacional, y por eso se debería de firmar un acuerdo con otras grandes potencias de la época, con el fin de equipararse a ellas e insertarse en el sistema internacional. Con este fin, Miranda propone firmar una alianza defensiva entre los Estados Unidos de América, Inglaterra y la América Meridional ${ }^{158}$.

Las ideas expuestas por Miranda responden a un conocimiento vivencial y de constatación personal, Miranda fue un gran personaje que formó parte de los tres más grandes acontecimientos de la historia universal de su época, la independencia de los Estados Unidos de América, la Revolución Francesa y la independencia de Hispanoamérica. Hechos que lo llevaron recorrer el mundo entero y a establecer y desarrollar relaciones con diferentes gobernantes, políticos e intelectuales de su época, por tanto, poseía un buen conocimiento acerca del funcionamiento de las relaciones internacionales y el sistema internacional de la época.

${ }^{157}$ El Pacto de Paris. Francisco de Miranda, Colombeia, Primera Sección, Miranda (1750-1780) T. I, Presidencia de la República, Caracas, 1978, p. 51.

${ }^{158}$ Ibíd. p. 53. 
Otro aspecto a considerar es la idea que en los dos casos, proceso de integración en Europa y América Latina, hayan sido dos abades los principales artífices y promotores de la unificación de estados, el Abad peruano (Viscardo y Guzmán) y el Abad francés (Saint-Pierre). Una posible respuesta sería, que debido a su formación y su pertenencia a la Iglesia Católica desarrollan esa visión universal, donde la defensa de los nacionalismos no tiene sentido alguno, y en donde es más importante defender principios y valores universales como la paz, la defensa de justicia y los derechos humanos, la cooperación y la solidaridad entre los pueblos, que defender la idea de una soberanía nacional, que solo contempla el interés particular (un estado) en lugar de un interés general (el mundo).

El Abad Juan Pablo Viscardo y Guzmán, escribe en 1799 la Carta Dirigida a los Españoles Americanos ${ }^{159}$, en ella exhorta a los "españoles americanos"160, que tras la independencia de España, se deberá de formar un solo cuerpo, basado en la identidad, historia, destino y futuro común del conjunto de los pueblos de la América Española, formando de esta una "grande familia de hermanos"161. Como hombre de iglesia, destaca conceptos como "familia", para simbolizar la unidad indisoluble, y la "hermandad" entre los pueblos, para establecer la paz sobre la base de una confianza mutua entre hermanos, en clara alusión a las "guerras fratricidas". La idea de "grande familia", es un llamado a formar un solo cuerpo, todos ellos pensamientos sobre el cual debe regirse la unificación de los pueblos. Miranda toma las ideas y el pensamiento del Abad Viscardo y Guzmán y redacta la Proclamación a los pueblos del continente colombiano, alias Hispanoamérica, dado que en la carta del Abad encuentra gran parte de sus planteamientos ideológicos respecto de la emancipación hispanoamericana ${ }^{162}$.

\footnotetext{
159 VISCARDO Y GUZMÁN, J. P.: “Carta Dirigida a los Españoles Americanos”. Archivo General de Indias, Sevilla, 1799, Filadelfia, pp. 6 y 7. Cabe señala que la carta fue escrita originalmente en francés publicado por Simmons y posteriormente fue traducida al inglés por P. Boyle Vine Street, Picadilly en 1801, finalmente se tradujo al español realizada por Francisco Miranda.

${ }^{160}$ El término "españoles americanos" era de uso común para designar a los habitantes de los reinos transoceánicos de la Corona española. Miguel Batllori en su libro "El abate Viscardo" menciona que en 1811 Manuel García de Serna dedicaba a los habitantes de la Costa Firme su traducción de varias piezas de Thomas Paine, llamándolos "americanos españoles". "La independencia de la Costa Firme justificada por Thomas Paine treinta años ha", publicación n ${ }^{\circ} 5$ del Instituto Panamericano de Geografía e Historia, Comité de orígenes de la emancipación, Caracas, 1949, p. 33, en BATLLORI, M.: "El Abate Viscardo". Editorial Mapfre, Madrid, 2005.

${ }^{161}$ VISCARDO Y GUZMÁN, J. P.: “Carta Dirigida a Los Españoles Americanos”. Op. cit.

162 GUTIÉRREZ, A.: Juan Pablo Viscardo y su "Carta Dirigida a los Españoles Americanos". Araucaria, Vol. 9, $\mathrm{N}^{\circ}$ 17, Revista Iberoamericana de Filosofía, Política y Humanidades, Universidad de Sevilla, Sevilla, 2007, p. 326.
} 
La segunda y tercera propuesta provienen de Chile, una la realiza el gobierno chileno, en 1810, en la cual propone la creación de una Confederación de los Pueblos del Pacífico. La otra propuesta la efectúa Bernardo O’Higgins, militar y político chileno, quién sugiere la creación de una Confederación Sudamericana ${ }^{163}$.

Un cuarto proyecto es elaborado por el Reino de Brasil en manos de Heliodoro Jacinto de Araújo Carneiro, médico, político y diplomático portugués, en 1818, quién propone la Alianza de Naciones de América ${ }^{164}$. En ese mismo año se produce una quinta iniciativa, la plantea José de San Martín, militar y político argentino, quién proclama la necesidad de un Congreso Central que siente las bases de una alianza y federación perpetua de los pueblos de América ${ }^{165}$.

Con relación a la idea de una Unión Americana propuesta por O’Higgings, existen dudas si fue él o Bolívar, quién lo expuso primero. Seijas en su obra El Derecho Internacional Hispano Americano subraya ${ }^{166}$ : "En caso de estribar la duda en mejor apoyo, la reseña misma del general O’Leary la refuta. No sólo nos dice que Bolívar presentó oficialmente el proyecto a Buenos Aires en 1818, sino que también escribió de él a un amigo, en Jamaica, el año de $1815^{\prime \prime 167 . ~}$

Aunque consideramos que es un dato irrelevante, quién fue el primero de los dos, caso O’Higgings o Bolívar, lo que sí es importante, es describir que existieron hechos históricos que corroboran la existencia de un acervo integracionista latinoamericano ya en los ciernes de la independencia. Por otro lado, como diría el escritor Ignacio Quiroz “es preciso reconocer que fue Bolívar quien consagró grandiosas y constantes energías a la realización de este proyecto que constituyó el ideal máximo de su vida"168.

Un sexto proyecto se efectúa en 1819 y viene nuevamente desde Brasil, esta vez la efectúa el Almirante Rodrigo Pinto Guedes, militar portugués, quién plantea la creación de una Liga Americana. Así mismo, Brasil en 1822, presenta un séptimo proyecto, a

\footnotetext{
${ }^{163}$ GARCIA, F.: La creación de un continente, Fondo Editorial del Congreso del Perú, Lima, 2001, p. 61. Fue publicado por primera vez en 1912.

${ }^{164}$ LYRA, H.: Ensaios diplomáticos, Monteiro Lobato LC. Sâo Paulo 1922, pp.180-181, en BRANDI, J.

C: O Brasil e o Congreso Anfictiónico do Panamá, Revista Brasileña de Política Internacional año/vol. 43, No 002, Instituto Brasileño de Relaciones Internacionales, Brasilia, 2000, p. 171.

165 GARCIA, F.: La creación de un continente, Op. cit., p. 61

${ }^{166}$ SEIJAS, R.: El derecho internacional Hispano-americano, El Monitor, Caracas, 1884.

${ }^{167}$ SEIJAS, R en Archivo Histórico Diplomático Mexicano, Op. cit., p. IV.

${ }^{168}$ QUIROZ, I.: El Congreso de Panamá y algunos otros proyectos de Unión Hispano-Americana Op. cit, p. IV.
} 
través de Silvestre Pinheiro Ferreira, político y filósofo portugués, último ministro de Negocios Extranjeros nombrado por el Rey de Portugal João VI, quién sugiere firmar un Tratado de Confederación y Mutua Garantía de Independencia ${ }^{169}$.

El octavo proyecto lo efectúa José Cecilio del Valle, abogado, filósofo y político hondureño, quién en 1822 publicó El Proyecto de Confederación Americana. Soñaba el Abad de San Pedro: y Yo también sé soñar ${ }^{170}$. En dicho proyecto, existe por un lado, una clara alusión al Proyecto del Abad de San Pierre como modelo para una confederación a escala americana, y por otro lado, expone como deberá de estructurarse dicha confederación:

- Convocar a un Congreso General, en la provincia de Costa Rica o de León, para formar la "Federación Americana".

- Al congreso asistirá un representante de cada provincia de América.

- Las competencias de la federación abarcarán aspectos como: política, economía, fiscalidad y militar. A la par que mediar jurisdiccionalmente, para poder resolver los posibles conflictos de manera pacífica y a nivel regional, sin intervención extranjera.

- Tratado General de Comercio.

- Tratado o Pacto Solemne de socorrerse unos a otros, ante invasiones extranjeras $^{171}$.

Finalmente, la novena propuesta viene de Argentina. Bernardo Monteagudo en 1824 publica su Ensayo sobre la necesidad de una Federación General entre los Estados Hispanoamericanos y Plan de su organización ${ }^{172}$. Al respecto, García Laguardia, escribe que Monteagudo conoció los escritos de Del Valle, cuando visitó Guatemala en 1823, cumpliendo una misión encargada por Bolívar, y a quién le comentó sobre el proyecto de Valle y por ello deseaba imprimir su artículo sobre la Federación Americana y que Bolívar estaba de acuerdo con la idea ${ }^{173}$.

\footnotetext{
${ }^{169}$ BRANDI. A.: O Brasil e o Congreso Anfictiónico do Panamá, Op.cit. p.174.

${ }^{170}$ Publicado en El Amigo de la Patria, $\mathrm{N}^{\circ}$ 24, Guatemala, 1 de marzo de 1822 en GARCÍA, M.: José Cecilio del Valle, Biblioteca de Ayacucho, N $^{\circ}$ 96, Caracas, 14 de junio de 1982.

${ }^{171}$ GARCÍA, M.: José Cecilio del Valle, Op, cit., pp. 233-234.

172 MONTEAGUDO, B.: Sobre la necesidad de una Federación General entre los Estados HispanoAmericanos y Plan de su organización, Obra póstuma, Imprenta del Estado, Lima, 1825.

${ }^{173}$ GARCÍA, M.: José Cecilio del Valle, Op, cit., p. XIV.
} 
Destacamos que de estos primeros nueve proyectos de integración, 6 promotores fueron hispanoamericanos (Abad Juan Pablo Viscardo y Guzmán, Francisco de Miranda, Bernardo O’Higgins, José de San Martín, Del Valle y Monteagudo) y tres provinieron de Brasil, sin embargo, en los tres casos fueron portugueses los promotores (Heliodoro Jacinto de Araújo Carneiro, Silvestre Pinheiro Ferreira y Rodrigo Pinto Guedes).

El hecho que Brasil fue hasta ese entonces un reino y posteriormente un imperio, en manos de un poder extraregional, la Corona de Portugal, puede explicar la falta de aceptación general de sus iniciativas por parte de los nacientes estados hispanoamericanas, quienes desde el inicio buscaban eliminar cualquier tipo de injerencia extranjera, principalmente europea en la región, y por otro lado, defendían la idea de republicana como forma de gobierno. Además otro aspecto en contra, pudo haber sido la diferencia de idioma, y en consecuencia una diferencia de mentalidades y concepción de ideas.

Después de estos nueve proyectos integracionistas, llega la convocatoria al Congreso Anfictiónico de Panamá, que efectúa Simón Bolívar, militar y político venezolano, el 7 de diciembre de 1824. Como señala De la Reza, este congreso es "uno de los portentos diplomáticos de su época y principal heredero de los proyectos confederativos del Duque de Sully, el Abate de Saint-Pierre y Juan Jacobo Rousseau, se origina en la obra intelectual, estratégica y estadista de Simón Bolívar"174.

Lo que reafirma nuestra teoría de ese constante intercambio y transferencias de ideas entre una región y otra, lo que llamamos “acervo integracionista común”.

Bolívar realiza dicha convocatoria desde y en nombre de la República de Perú, y argumenta:

Entablar aquel sistema y consolidar el poder de este gran cuerpo político, pertenece al ejercicio de una autoridad sublime que dirija la política de nuestros gobiernos [...]. Profundamente penetrado de estas ideas, invité en 1822, como presidente de la república de Colombia, a los gobiernos de México, Perú, Chile y Buenos Aires, para que formásemos una confederación y reuniésemos, en el Istmo de Panamá u otro punto elegible a pluralidad, una asamblea de plenipotenciarios de cada estado «que nos sirviese de consejo en los grandes conflictos, de punto de

${ }^{174}$ DE LA REZA, G.: Documentos sobre el Congreso Anfictiónico de Panamá, Fundación Biblioteca Ayacucho y Banco Central de Venezuela, Caracas, 2010, p. IX. 
contacto en los peligros comunes, de fiel intérprete en los tratados públicos cuando ocurran dificultades, y de conciliador, en fin, de nuestras diferencias» $[\ldots] .{ }^{175}$.

Las reflexiones expuestas por Bolívar en el siglo XIX sobre la forma de organizar, actuar y relacionarse en el sistema internacional, serán en cierto modo, una mezcla de ideas de la Edad Antigua, Edad Media y Edad Moderna desarrollada principalmente en Europa, pero por otro lado, sus ideas también serán visionarias y embrionarias con respecto a las futuras ideas del panamericanismo y paneuropeísmo:

1. Establecer una confederación que buscara crear intereses comunes del conjunto de los estados de la región. (ideas del modelo de integración de la Unión Europea y CELAC)

2. La confederación será sentada sobre las bases del republicanismo y por ello utiliza el término "Repúblicas Americanas". (ideas del modelo de la Unión Internacional de Repúblicas Americanas, hoy conocida como la Organización de Estados Americanos).

3. La confederación será una autoridad política máxima por encima de los estados y que dirija al conjunto las políticas de todos sus gobiernos. (esbozos del concepto de supranacionalidad)

4. La confederación poseerá capacidades de: mediar y solucionar conflictos, y crear un sistema de garantías en la defensa de la paz. (Tribunales de Justicias a escala regional: Corte Interamericana de Justicia, Tribunal de Justicia de la Unión Europea)

5. La confederación tendrá entre sus funciones la interpretación de los tratados, en casos de controversia. (Comisión Europea)

6. Crear una Asamblea General. (Parlamentos regionales: Parlamento Latinoamericano, Parlamento Europeo)

No decimos que hay una relación directa del pensamiento de Bolívar con cada una de las instituciones mencionadas, pero la idea es comparar y demostrar la vigencia de esas

\footnotetext{
175 Circular de su Excelencia, El Libertador de Colombia y Encargado del Supremo Mando de la República del Perú, Simón Bolívar, invitando a los Gobiernos de las demás Repúblicas de Colombia, México, Río de la Plata, Chile y Guatemala a enviar a sus Representantes al Istmo de Panamá con el fin de celebrar una Asamblea General. Lima, 7 de diciembre de 1824, en Archivo Histórico. Ministerio del Poder Popular para Relaciones Exteriores "De Panamá a Panamá. Acuerdos de Integración Latinoamericana", Caracas, 2010, p.55.
} 
ideas en la actualidad. Aunque en el caso de las organizaciones americanas sí hay una relación directa a las ideas de Bolívar, por cuanto en muchos de estas organizaciones se menciona la idea de Bolívar como la idea base para crearlas.

Durante el período de 1822 a 1825 se firman cinco tratados bilaterales que sirven de base jurídica para lo que luego serán los Tratados de Panamá, cuatro de ellos serán tratados de unión, liga y confederación, y un tratado de amistad firmado entre Colombia y Argentina.

A continuación presentamos los cinco tratados bilaterales preparatorios del Congreso de Panamá $^{176}$ :

1. Tratado de Unión, Liga y Confederación entre Colombia y Perú, firmado el 6 de julio de 1822 .

2. Tratado de Unión, Liga y Confederación entre Colombia y Chile, firmado el 21 de octubre de 1822 .

3. Tratado de amistad entre Colombia y Argentina, firmado el 8 de mayo de 1823.

4. Tratado de Unión, Liga y Confederación entre Colombia y México, firmado el 3 de octubre de 1823.

5. Tratado de Unión, Liga y Confederación entre Colombia y Centro América, firmado el 5 de mayo de 1825 .

Cada uno de estos tratados comparten los objetivos y disposiciones, y en la mayoría de los casos comparten el mismo tenor en el texto con el fin de facilitar su homologación en el futuro acuerdo único ${ }^{177}$, o lo que podríamos llamar Acta Única, los tratados del Congreso de Panamá. Por otro lado, cada uno de estos tratados van sentando las bases de lo que nosotros consideramos es parte del acervo integracionista latinoamericano.

En referencia a la participación de los gobiernos de los Estados Unidos y Brasil, las instrucciones dadas por el nuevo Ministro de Relaciones Exteriores del Perú, Hipólito Unánue, propone que si los ministros plenipotenciarios de los Estados Unidos forma parte de la asamblea, se seguirán las instrucciones generales, y si los Estados Unidos no formarán parte de la asamblea y llegarán con una propuesta de alianza, casus foederis,

\footnotetext{
${ }^{176}$ DE LA REZA, G.: El Congreso de Panamá de 1826 y otros ensayos de integración latinoamericana en el siglo XIX, Op. cit., p. 17. 177 Ibíd.
} 
para defender contra España o cualquier otro estado europeo, podrán entablar tratados de paz, amistad y alianza ofensiva y defensiva con Estados Unidos ${ }^{178}$. En el caso de Brasil, se considera que si el Emperador enviara ministros plenipotenciarios, se procederá del mismo modo que con los Estados Unidos, y si en la asamblea Brasil proponía tratar el tema de los límites, en este caso se dirigirán dichos temas al Gobierno para que la decisión sea tomada en común acuerdo entre ambos estados ${ }^{179}$.

Algo novedoso e importante son los resultados tangibles de las negociaciones de los tratados de Panamá. Son las que señala el entonces Ministro de Relaciones Exteriores del Perú, Tomás de Heres, quién menciona que una vez ratificados los tratados, que se celebren en el Gran Congreso Federal de los Estados Americanos, se declarará un Código de Derecho Público Americano, obligatorio a todos los Estados que han tenido parte en el Congreso ${ }^{180}$. Lo que hoy es conocido como derecho comunitario, dentro de un proceso de integración regional, como es el caso de la Unión Europea.

Los azares del destino quisieron que la historia se repitiese una y otra vez, y al igual que ocurrió con Cineas y con Crucé en Europa, posteriormente sucedió con Simón Bolívar, en las nacientes independientes repúblicas americanas, cuando convoca al Congreso Anfictiónico en el Istmo de Panamá, al igual que el discurso patriótico de Apio Claudio, frustró el tratado de paz entre griegos y romanos, el proyecto de Bolívar sería frustrado por el discurso patriótico y nacionalista de las repúblicas americanas, que prefirieron separarse a formar una unión de estados. Probablemente porque las élites de cada una de las nuevas repúblicas vieron la oportunidad de establecer sus parcelas de poder, algo difícil de tener y controlar, si se creaban instituciones supranacionales y donde el poder político es compartido. Al igual que hoy lo hacen los discursos nacionalistas de algunos países tanto en los procesos de integración regional en Europa como en América Latina y el Caribe.

\footnotetext{
${ }^{178}$ Ibíd. p. 95.

179 Ibíd.

${ }^{180}$ Primeras instrucciones del Ministro de Relaciones Exteriores del Perú, Tomás de los Heres, a los ministros plenipotenciarios, Documento 6, en DE LA REZA. Op,cit., p 87.
} 


\subsection{LA BÚSQUEDA DE UNA IDENTIDAD CONTINENTAL: $E L$ PANAMERICANISMO Y EL PANEUROPEÍSMO}

El término doctrina es definido por la Real Academia Española como "el conjunto de ideas u opiniones religiosas, filosóficas y políticas sustentadas por una persona o grupo". Por consiguiente, podemos decir, que el desarrollo del panamericanismo y del paneuropeísmo, son en sí, una doctrina, cuyo objetivo era crear una identidad supra, es decir una identidad continental, que se sumen a la identidad nacional.

En el caso de América, después del fallido intento en Panamá se suceden múltiples iniciativas y proyectos integracionistas, todas desarrolladas como: asambleas, conferencias y congresos. Todas estas reuniones invocaban a la unidad de los estados, pero sin conseguirla. Entre los más destacados encontramos una mezcla de propuestas gubernamentales e iniciativas personales por parte de diferentes intelectuales, políticos y diplomáticos:

1. Conferencia entre los Plenipotenciarios de Colombia, Centro América y Estados Unidos Mexicanos (1828) ${ }^{181}$.

2. Asamblea General Americana iniciada por México $(1831)^{182}$.

3. Protocolos del Congreso de Lima. Tratado de Confederación por Perú, Bolivia, Chile, Colombia y Ecuador (1848) ${ }^{183}$.

4. Tratado de Unión Continental, propuesta por el Gobierno de Chile, firmado por Chile, Perú y Ecuador (1856) ${ }^{184}$.

5. Tratado de Confederación y Alianza entre Venezuela, Nueva Granada, Guatemala, El Salvador, Costa Rica, México y Perú $(1856)^{185}$.

\footnotetext{
${ }^{181}$ Protocolo de la conferencia verbal tenida entre los Plenipotenciarios de Colombia, Centro América y Estados Unidos Mejicanos, en villa de Tacubaya, el 9 de octubre de 1828. Archivo Histórico Diplomático Mexicano, $\mathrm{N}^{\circ} 19$, pp. 142-149, Secretaría de Relaciones Exteriores, México DF, 1926.

${ }_{182}$ Asamblea General Americana iniciada por México, 2 de noviembre de 1831, Guatemala. Archivo Histórico Diplomático Mexicano, № 19, pp. 151-157, Secretaría de Relaciones Exteriores, México DF, 1926.

${ }^{183}$ Tratado de Confederación firmado en Lima por los delegados de Perú, Bolivia, Chile, Colombia y Ecuador. Lima, 8 de febrero de 1848. Protocolos del Congreso de Lima. Tratado de Confederación. Documento $\mathrm{N}^{\circ}$ 54. Archivo Histórico. Ministerio del Poder Popular para Relaciones Exteriores de Venezuela "De Panamá a Panamá. Acuerdos de Integración Latinoamericana", Caracas, 2010, p.358-369. ${ }^{184}$ Tratado de Unión Continental, firmado 15 de septiembre de 1856, Santiago de Chile. Archivo Histórico. Ministerio del Poder Popular para Relaciones Exteriores de Venezuela. Op. cit., p.380-385. Ver también: Bases para la Unión de los Estados Americanos propuesta por el Gobierno de Chile. Documento $\mathrm{N}^{\circ}$ 10. Archivo Histórico. Ministerio del Poder Popular para Relaciones Exteriores de Venezuela. Op. cit., p.412-428.
} 
6. Congreso de Plenipotenciarios de los Estados Hispano-Americanos, propuesta de México (1857) ${ }^{186}$.

7. Proyecto de Asamblea General Americana para la Defensa Común de los Pueblos Americanos contra las Agresiones Extranjeras (1862) ${ }^{187}$.

8. Tratado sobre conservación de la paz entre los Estados de América contratantes, suscrito por Venezuela, Colombia, Ecuador, Perú, Bolivia, Chile y El Salvador $(1865)^{188}$.

9. Junta de Ministros Hispano-Americanos en Paris. Conveniencia de la Reunión de un Congreso en Panamá, propuesta de Bolivia $(1886)^{189}$.

10. Congreso Republicano de América, propuesta de Ecuador (1895) ${ }^{190}$.

Entre el período de las dos últimas propuestas, surge una iniciativa presentada por los Estados Unidos de América (EE.UU.) hacia los estados hispanoamericanos. La propuesta consiste en crear una unión continental, rescatando el anhelo de unificación de Bolívar. Con esta aspiración los EE.UU. convoca a la Primera Conferencia Internacional Americana en Washington DC, del 2 de octubre de 1889 al 19 de abril de 1890, el objetivo era establecer un tribunal de arbitraje que pueda solucionar, de manera pacífica, los desacuerdos y cuestiones que puedan darse entre los países americanos.

Así mismo, busca fomentar las relaciones comerciales entre los estados participantes y asegurar con ello la creación de mercados más amplios. En dicha conferencia se crea la Unión Internacional de Repúblicas Americanas, posteriormente se cambia el nombre a

\footnotetext{
185 Tratado de Confederación y Alianza entre las Repúblicas de Venezuela, Nueva Granada, Guatemala, El Salvador, Costa Rica, México y Perú, firmado en Washington, 8 de noviembre de 1856. Documento $\mathrm{N}^{\circ}$ 2. . Archivo Histórico. Ministerio del Poder Popular para Relaciones Exteriores de Venezuela. Op. cit., p.476-480.

${ }^{186}$ Memoria reservada sobre la necesidad de un Congreso de Plenipotenciarios de los diversos Estados Hispano-Americanos 1857. Archivo Histórico Diplomático Mexicano, N 19, pp. 161-189, Secretaría de Relaciones Exteriores, México DF, 1926.

${ }^{187}$ Proyecto de una Asamblea General Americana que se reunirá en Panamá con objeto de concertar las medidas que deberán tomarse para la Defensa Común de los Pueblos Americanos contra las Agresiones Extranjeras. Archivo Histórico Diplomático Mexicano, N 19, pp. 193-205. Secretaría de Relaciones Exteriores, México DF, 1926.

${ }^{188}$ Tratado sobre conservación de la paz entre los Estados de América contratantes, suscrito entre Venezuela, Colombia, Ecuador, Perú, Bolivia, Chile y El Salvador, firmado el 23 de enero de 1865 en Lima, en el marco del Congreso Americano. Archivo Histórico. Ministerio del Poder Popular para Relaciones Exteriores de Venezuela. Op. cit., p. 693-696.

189 Junta de Ministros Hispano-Americanos en Paris. Conveniencia de la Reunión de un Congreso en Panamá. Legación de los Estados Unidos Mexicanos en Francia. Reservada, Número 18. Reunión citada por el Ministro de Bolivia, Paris, 11 de octubre de 1886. Archivo Histórico Diplomático Mexicano, $\mathrm{N}^{\circ}$ 19, pp. 211-212. Secretaría de Relaciones Exteriores, México DF, 1926.

Congreso Proyectado por el Gobierno del Ecuador 1895-1896. Archivo Histórico Diplomático Mexicano, N 19, pp. 323-325. Secretaría de Relaciones Exteriores, México DF, 1926.
} 
Unión Panamericana, y finalmente, en 1948 en el marco de la Novena Conferencia Internacional Americana, se decide cambiar el nombre por la Organización de Estados Americanos (OEA), mediante la firma de la Carta de la Organización de Estados Americanos, así mismo se firma el Tratado Americano de Soluciones Pacíficas (Pacto de Bogotá) y la Declaración Americana de los Derechos y Deberes del Hombre. Convirtiéndose en el primer organismo de integración regional, a escala continental del mundo y siendo este la base sobre el cual se construirá el sistema interamericano que hoy conocemos.

Los aspectos de identidad como un factor social y cultural de los países será una idea desarrollada y expuesta por José Enrique Rodó Piñeyro, escritor y político uruguayo, quien escribe la obra Ariel en 1900, dedicada "A la juventud de América". Rodó busca remover conciencias y propone crear valores espirituales propios, a los que llamó "el genio de su raza". A la vez, deja apreciar ese constante intercambio de ideas y pensamientos entre Europa y América, una vez más.

Muestra de ello es su gusto por la tradición greco-romana, por sus pensadores y escritores como Joseph Ernest Renán y William Shakespeare. La influencia de éstos fue tanta que se inspira en los personajes de sus obras para crear su propia obra Ariel: Próspero, Ariel Calibán, caso de Shakespeare; y en el caso de Renán, lo incluye también en la misma obra citando su pensamiento, a la hora de definir y explicar por qué se dirige a la juventud: "Yo os digo con Renán: «La juventud es el descubrimiento de un horizonte inmenso, que es la Vida»" ${ }^{191}$. Este libro servirá de inspiración para promover la idea de una identidad latinoamericana, basada en la diferenciación sociolingüística-cultural entre dos subregiones del continente americano, dividiéndolo en dos: un mundo anglosajón y un mundo hispanoamericano que será llamado latinoamericano. Un ejemplo de la influencia de Rodó en el mundo político es Manuel Ugarte, político y diplomático argentino, quien será uno de los políticos que promueva la idea de una identidad latinoamericana y para ello defenderá la idea de crear una Nación Latinoamericana ${ }^{192}$.

Pero nótese que Rodó no escribe a la "juventud latinoamericana", escribe "a la juventud americana”. Al igual que todas las iniciativas que hemos visto, es América la que se

\footnotetext{
${ }^{191}$ RODÓ, J.: Ariel, Editorial Kapelusz, Buenos Aires, 1962, p. 9.

${ }^{192}$ GALASSO, N: Manuel Ugarte. La Nación Latinoamericana. Biblioteca de Ayacucho, $\mathrm{N}^{\circ}$ 45. Caracas, 1978.
} 
resalta, pero a la hora recuperar esa idea de unidad americana, se cambia por latinoamericana, se entiende que es por diferenciarse de "esa otra América", la América del Norte, que en teoría tiene diferencias raíces y herencias, pero como ya hemos explicado, no las tiene, toda América tiene las mismas herencia, y por eso volvemos a insistir, sí se habla de América "Latina", "Latina" en origen es toda América.

En el caso de Europa, en 1923, Richard N. Coudenhove-Kalergi, político austríaco, hace un llamado a "La juventud de Europa"193 en su obra Pan-Europa. En este caso, existe una clara similitud entre la idea de Rodó y Coudenhove-Kalergi, pues ambos hacen el llamado a la unión del continente por medio de la juventud. No tenemos indicios sobre si Coudenhove-Kalergi leyó o no los escritos de Rodó, pero lo que si hay constancia es que él tomo el modelo del panamericanismo para proponer y promover sus ideas de un paneuropeísmo. Así deja constancia en la parte introductoria de su libro Paneuropa:

Mientras estoy escribiendo estas líneas, se reúne en Chile la V Conferencia Panamericana. [...] Entretanto, Europa va dando tumbos, sin guía y sin plan, de una crisis a otra. [...] Es la juventud europea a quién corresponde modificar este estado de cosas. La juventud europea está llamada a levantar una nueva Europa sobre las ruinas de la antigua: a sustituir la Europa anárquica por una Europa organizada ${ }^{194}$.

Pero a diferencia de Rodó, que explica de manera poética y metafórica los problemas y soluciones para América, Coudenhove-Kalergi explica de manera política, económica y geopolítica los asuntos europeos y sobre sus relaciones con otras regiones del mundo.

Coudenhove-Kalergi nos describe el declive de la hegemonía mundial de Europa, donde "la proclamación de la doctrina de Monroe significó la declaración de independencia del continente americano respecto del europeo" ${ }^{\text {"195; }}$ la constitución, fuera de Europa, de un imperio británico mundial, lo que él llamó "reino federal intercontinental”; la creación de un imperio mundial ruso, la emancipación de Asia y el auge de América. Con esto, Coudenhove-Kalergi se declara admirador de América, de sus ideas, pensamientos y avances políticos, y destaca entre los mayores logros de este continente, que América

\footnotetext{
193 COUDENHOVE-KALERGI, R.: Pan-Europa.Verlag GmbH, Augsburg y Ediciones Encuentro. Instituto Universitario de Estudios Europeos-Universidad San Pablo, Madrid, 2010.

${ }^{194}$ Ibíd. pp. 9 y 11.

195 Ibíd. p. 15.
} 
haya sido el "primero en introducir el nuevo método de la organización entre Estados: el sistema de asociaciones pacíficas de Estados, que desembocó en la Unión Panamericana y en la idea de la Sociedad de Naciones" ${ }^{\prime 196}$. Finalmente, Coudenhove-Kalergi, nos habla que tras el paso del antiguo sistema de las grandes potencias, se dio el paso a un nuevo sistema de potencias mundiales, que él llama: la agrupación de Estados.

La visión de Coudenhove-Kalergi nos habla de una nueva estructura del sistema internacional, dividido en grandes regiones, lo que a su entender, se organizarán por medio de los panismos:

1. Pan-América, comunidad promovida por el movimiento panamericano.

2. El Imperio del Sur, situado en el océano Índico, es el núcleo del Imperio británico, comprendido por África Oriental, los mundos árabe e hindú y Australia (El Cabo, Suez, Calcuta, Singapur, Sídney) y cuyos límites son el Mediterráneo y el Himalaya.

3. El Imperio del Norte, Imperio ruso, cuyos límites al oeste con Europa, al sur con el mundo británico y al este con el Extremo Oriente.

4. Los Imperios del Este, China y Japón, y de los cuales destaca que son países que aunque están separados políticamente, están unidos por la comunidad de raza, escritura y civilización.

5. Los Estados Occidentales, formados por Europa y sus colonias africanas ${ }^{197}$.

El gran aporte de Coudenhove-Kalergi al acervo integracionista europeo, será el movimiento paneuropeo "Unión Paneuropea", movimiento que buscará crear esa identidad común, Europa, y hacer crecer entre su población, la idea de ser ciudadanos europeos. Para lo cual fomentará el pro-europeísmo. Dicha idea será promovida por políticos, diplomáticos e intelectuales de toda Europa, muchos de ellos tomarán la posta en esa carrera de crear una unión regional en Europa.

Entre los más destacados podemos mencionar Aristide Briand, Konrad Adenauer, Charles de Gaulle, George Pompidou, Salvador de Madariaga, Thomas Mann. En 1927 será Aristide Briand, quién siendo ministro de asuntos exteriores de Francia y presidente de la Unión Paneuropea, concibe la idea de crear un plan de acción política para la unificación de Europa. En 1929 Briand, como presidente de Francia, propone la idea de

\footnotetext{
${ }^{196}$ Ibíd. p.22.

${ }^{197}$ Ibíd. p 26.
} 
una Liga a la que nombró "Unión Europea", Briand llamo a la gente de Europa a pensar y crear un "Unión Federal", siendo esta la primera propuesta oficial realizada por un gobierno europeo, la cual la efectuó el gobierno francés a veintiséis gobiernos de Europa, en mayo de 1930, a través de la publicación del Mémorandum sur l'organisation d'un régime d'union fédérale européenne ${ }^{198}$.

Está debe de basarse en la reconciliación franco-alemana para garantizar la paz en el continente y así convocar a una Conferencia Europea, que estaría compuesta por representantes de todos los países. El Memorándum de la Unión Federal Europea define como campos de acción las siguientes áreas temáticas:

1. Economía general

2. Infraestructura

3. Comunicaciones y tránsito

4. Finanzas

5. Trabajo

6. Salud

7. Cooperación intelectual ${ }^{199}$

Finalmente todas estas ideas llegarían a Jean Monnet, político francés, uno de los "Padres de Europa" y quien ideó el Plan Schuman, documento base de lo que hoy conocemos como la Unión Europea. Monnet expone:

No habrá paz en Europa si los Estados se reconstruyen sobre la base de soberanía nacional [...] Los países de Europa son demasiado pequeños para asegurar a sus pueblos la prosperidad y los avances sociales indispensables. Esto supone que los Estados de Europa se agrupen en una federación o «entidad europea» que los convierta en una unidad económica común ${ }^{200}$.

\footnotetext{
198 SIDJANSKI, D: The Federal future of Europe. From the European Community to the European Union, University of Michigan, Michigan, 2000, p. 9.

${ }^{199}$ M. Briand, Foreign Minister of France, "Memorandum on the Organization of a Regimen of European Federal Union Addressed to Twenty-Six Governments of Europe" 1930. En SALMON, T. and NICOLL, W.: Building European Union, Op. cit., pp. 10-16. Ver también NÉRE, J: The Foreign Policy of France from 1914 to 1945, Routledge, London, 2002. KLEINSORGE, T.: Council of Europe, Klumer Law International, The Netherlands, 2010.

${ }^{200}$ Estudios de Política Exterior. Cuadernos pedagógicos sobres la Unión Europea. El porqué y el cómo de la Unión Europea, Madrid, 2010, p. 15.
} 
Si bien, al otro lado del Atlántico, existe un movimiento panamericano, este se da sólo a escala de políticos, diplomáticos y empresarios, es decir, no llega a trasladarse a la población, por lo que esta parte de la sociedad, los ciudadanos, no sienten identificación alguna con el respectivo movimiento. Todo lo contrario, cierta parte de la sociedad, principalmente los partidos de tendencia política de izquierda, critican el panamericanismo por considerar que el panamericanismo es un proyecto promovido e impulsado por los Estados Unidos.

La desconfianza proviene de las sospechas de vínculos entre el gobierno estadounidense y algunos regímenes militares y golpes de estado que se producen en ese período a lo largo del continente americano. Lo que produce críticas sobre la posible injerencia de los Estados Unidos en la política interna de varios países americanos. Como respuesta a ello, muchos partidos políticos de izquierda en los países americanos comienzan a hablar de América Latina como una región aparte, dentro del continente americano. Dejando de lado el término americano, por evitar confusión y/o diferenciarse con el estadounidense, que suele ser identificado como americano. Sin embargo, la propuesta estadounidense contribuirá al acervo de integración en la región, con la idea del panamericanismo como idea integradora de los pueblos, en términos diplomáticos, políticos y económicos, más que social o cultural.

A modo de conclusión, se destaca la constancia de los estados, tanto en Europa como en América, por persistir a lo largo del tiempo en la presentación de proyectos de integración. Si bien es cierto, no hemos entrado a analizar a fondo cada proyecto, ni tampoco nos hemos detenido a estudiar el contexto político de cada propuesta, ni si contaron o no con apoyo o detractores. Dado que no era nuestro objetivo, lo que se ha buscado en todo momento es dejar constancia de la existencia de los innumerables intentos que han existido y que éstos forman parte del acervo integracionista en ambas regiones y de su interrelación.

Por tanto la similitud en las ideas, iniciativas y proyectos integracionistas es algo natural, pues a nuestro entender cuando se habla, en la actualidad, de que la Unión Europea y América Latina y el Caribe son "aliados naturales unidos por fuertes vínculos históricos, culturales y económicos, así como por una convergencia cada vez mayor de valores básicos y principios. Comparten un compromiso común respecto a los derechos 
humanos, la democracia, la buena gobernanza, el multilateralismo y la cohesión social" ${ }^{201}$.

No sorprende, dado que ambas regiones comparten una historia común, y que no es sólo la historia de la integración regional, pues al fin y al cabo, ambas regiones forman parte de una historia común mayor, que es la historia de Occidente.

En las últimas décadas tanto los estados europeos como latinoamericanos y caribeños han ido creando organismos de integración regional, y aunque existe diferencias entre unos y otros, en cuanto a objetivos, competencias y método de trabajo (supranacional e intergubernamental), lo importante es que la actuación de los estados está pasando de la esfera nacional a la regional, los estados ya no son los únicos actores políticos en la escena internacional, ahora también lo son las uniones regionales que buscan el desarrollo de su población.

Las experiencias de integración regional de los países europeos, latinoamericanos y caribeños pueden ser un modelo para otras regiones del mundo y su diálogo birregional puede sentar las bases de un reordenamiento de un nuevo sistema internacional.

201 COMISIÓN EUROPEA: La Asociación estratégica entre la Unión Europea, América Latina y el Caribe: un compromiso común. Comisión Europea. Dirección General de Relaciones Exteriores, Dirección América Latina, Bruselas, 2008. p. 5. 


\section{- CAPÍTULO IV}

\section{CONSTRUTENDO REGIONES A TRAVÉS}

DEL DIÁLOGO BI-RREGIONAL EN LOS

SIGLOS XX-XXI:

INSTITUCIONALIZACIÓN DE LAS

RELACIONES ENTRE EL PROCESO DE INTEGRACIÓN EUROPEA Y LOS PROCESOS DE INTEGRACIÓN EN AMÉRICA LATINA 


\subsection{PRIMEROS PASOS HACIA UN DIÁLOGO BI-REGIONAL}

Siguiendo con el orden cronológico de la historia de los procesos de integración regional en los países de Europa y América, iniciaremos este apartado examinando los primeros documentos oficiales que marcan el inicio de las relaciones entre los primeros organismos e instituciones de carácter regional creados por los países de EuropaAmérica entre los siglos XX y XXI ${ }^{202}$. Nos centraremos en las relaciones desarrolladas por el proceso de integración europea y los diferentes procesos de integración desarrollados, principalmente, entre los países de América Latina.

Marcando como primer documento oficial, el "Informe Martino" (1963-1964), y como último la "Declaración de Santiago" (2013). Período que estará comprendido entre 1963 y 2013, desde entonces han transcurrido cincuenta años. Ya desde el inicio de este período, 1963, observaremos como se ha dado de forma paralela la creación de mecanismos e instrumentos que han contribuido al desarrollo de una acción exterior a nivel regional, primero en el diseño, elaboración y puesta en marcha de una acción exterior en plano intra-regional, y a continuación su implementación en el plano extraregional. Veremos cómo dichas relaciones ayudaron a fortalecer los lazos interregionales, a la par, que contribuyó al fortalecimiento de los respectivos procesos de integración en ambas regiones, ayudando a los respectivos procesos a identificarse y desarrollarse como actores políticos regionales en el ámbito internacional.

Después de la Segunda Guerra Mundial los países europeos deciden apostar por la paz y por no tener más guerras y no más divisiones dentro de Europa, sino más bien, buscan unificarla y hacer de ella un nuevo actor político en la escena internacional.

Resueltos que la integración será el instrumento que garantizará la paz en la región y evitará posibles futuros conflictos, inician un proceso que terminará con la creación de una Unión Europea, a la que los Estados miembros atribuyen competencias para

\footnotetext{
${ }^{202}$ DÍAZ, C., FERNÁNDEZ, C. y ZAPATERO, M.: Perspectivas sobre las relaciones entre la Unión Europea y América Latina. Universidad Carlos III de Madrid. Boletín Oficial del Estado, Madrid, 2008. JARA, E.: La Unión Europea, los países de América Latina y el Caribe. Una relación con pasado, presente y futuro. Fundación Manuel Giménez Abad, Zaragoza, 2011. PEÑA, F. y TORRENT, R.: Hacia una etapa en las relaciones Unión Europea-América Latina: Un diagnóstico inicial. Universidad de Barcelona, Observatorio Relaciones Unión Europea-América Latina, Barcelona, 2005. FRERES, C. y SANAHUJA, J. (Coord): América Latina y la Unión Europea. Estrategias para una asociación necesaria. Icaria, Barcelona, 2006. MALLO, T. y SANAHUJA, J. (Coord): Las relaciones de la Unión Europea con América Latina y el Caribe. Fundación Carolina, Siglo XXI, Madrid, 2011.
} 
alcanzar sus objetivos comunes ${ }^{203}$. Convencidos que la unión regional de estados es un buen modelo de desarrollo deciden comenzar a interactuar y promover dicha idea a otras regiones del mundo. Estas acciones representan los inicios de lo que hoy conocemos como "Diálogo Birregional”. Entendiéndose como el diálogo, al proceso iniciado por dos grupos de países, que se presentan e identifican como una región y dan a esta un sentido de actor político, que buscar representar los intereses comunes de los estados que integran dicha región.

El diálogo birregional puede darse de dos formas. Una forma, es un "diálogo informal", creando para ello foros políticos donde intercambian ideas y discuten problemas comunes, es decir de ámbito regional y acordar una posición concertada o común frente a los desafíos a nivel mundial, es decir de ámbito global. La realización de dichos foros pueden ser esporádicos o regulares, y no se suelen crear órganos o instancias permanentes que sirvan para coordinar y trabajar lo acordado.

Otra forma, es un "diálogo formal”, donde se institucionaliza dicho diálogo, para el cual se efectúan reuniones regulares, se suelen crear órganos o instancias permanentes para continuar el trabajo acordado y desarrollar los temas que han sido tratados en las reuniones. Se firman acuerdos entre las partes y pueden existir varios tipos de acuerdos, por ejemplo, acuerdos de cooperación o acuerdos de asociación. El objetivo de estos acuerdos es dotar de un marco jurídico a dichas relaciones. Este último es el caso del diálogo que se da entre los países europeos, latinoamericanos y caribeños.

Con el fin de la Segunda Guerra Mundial también se crea la Naciones Unidas, y se pretende que éste sea el principal organismo que vele por la paz y la seguridad internacional, así mismo, se buscará fomentar la cooperación entre los países y promover un desarrollo armónico y equilibrado entre los pueblos, con el fin de que existe un orden en el sistema internacional. Mencionamos a las Naciones Unidas porque será el marco en donde se desarrollara una conferencia mundial, que buscará promover el comercio y el desarrollo, será esta la oportunidad que utilizarán tanto los países europeos como los países latinoamericanos para organizarse y actuar como bloque.

${ }^{203}$ Art. 1. Título I. Disposiciones comunes. Tratado de la Unión Europea. 
Como se leerá a continuación, se expondrán las reuniones y documentos que tuvieron ambas regiones. Así como se podrá ver cuáles fueron los temas de interés que les llevó a establecer dicha relación.

El primer antecedente lo encontramos a inicios de los años sesenta, cuando la Comunidad Europea reconoce la necesidad de elaborar una política común respecto a los países de América Latina. Así en 1962 la Comunidad Europea transmite al Consejo de Ministros de Asuntos Exteriores una "Nota relativa a los componentes de una programa de acción comunitaria respecto de América Latina”, a la que posteriormente se suma una "Comunicación" dirigida al Consejo. Dichos documentos servirían de base para que el Parlamento Europeo (PE) elabore futuros informes y desarrolle los lineamientos que marcarán las relaciones birregionales.

El 24 de septiembre de 1964 la Comisión de Comercio Exterior del Parlamento Europeo presentó a la Comisión Europea y al Consejo de Ministros de Asuntos Exteriores de la Comunidad Europea el Informe sobre las relaciones entre la Comunidad Europea y América Latina, llamado también "Informe Martino", por ser el nombre del relator del respectivo documento. Parte del informe era el resultado de las visitas efectuadas, entre el 27 de febrero y el 17 de marzo de 1963, por parte de una delegación del propio Parlamento Europeo a varios países latinoamericanos: Argentina, Brasil, Colombia, Chile, Perú y Uruguay.

Un dato muy importante en este informe es el que tiene relación justamente con la búsqueda de establecer relaciones formales, institucionalizadas entre ambas regiones, dicha mención la encontramos en el interés manifestado por parte, de la entonces, Comunidad Europea del Carbón y del Acero (CECA) por establecer un diálogo con una institución par en América Latina, para ello identifica como pares al Instituto Latinoamericano de Hierro y del Acero (ILAFA) y la Comisión Económica para América Latina y Caribe (CEPAL) ${ }^{204}$. El informe también señala que la CECA desea abrir una oficina de enlace en la región de América Latina, pudiendo ser la ciudad de Santiago de Chile, la sede de dicha oficina.

\footnotetext{
${ }^{204}$ Informe sobre las relaciones entre la Comunidad Europea y América Latina. En Europa-América Latina: 20 años de documentos oficiales (1976-1996). Instituto de Relaciones Europeo-Latinoamericanas, Madrid, 1996, p.7.
} 
Punto relevante y no meramente circunstancial, si consideramos que tanto la sede de ILAFA como de la CEPAL estaban en Santiago de Chile, por tanto decisión y acción estratégica que facilitaría el diálogo entre dichas instituciones.

El Informe remarca que la fecha de las visitas de la delegación del Parlamento Europeo:

...fue escogida de forma que los contactos pudiesen tener lugar antes de la apertura de la Conferencia Mundial sobre Comercio y Desarrollo en Ginebra y durante los debates que la CECLA (Comisión Especial de Coordinación para América Latina) había organizado en Alta Gracia con la intención de coordinar las posiciones de los países latinoamericanos ${ }^{205}$.

En efecto, para el año 1964, en el marco de la Tercera Reunión del Consejo Internacional Económico Social (CIES) y aprovechando la reunión de los ministros de economía de 19 países latinoamericanos, se decide constituir formalmente la CECLA (Comisión Especial de Coordinación Latinoamericana), ésta buscaba ser un organismo permanente con carácter de foro político, que usarán los países para realizar los primeros intentos de acción exterior común como grupo de países, en la defensa de sus intereses en las negociaciones de la Conferencia de las Naciones Unidas sobre Comercio y Desarrollo (UNCTAD), que se celebraría en ese mismo año, 1964, en la ciudad de Ginebra.

Los antecedentes de la CECLA se remontan tres años atrás, cuando en el marco del CIES, institución perteneciente al sistema de la Organización de Estados Americanos (OEA), se decide crear la CECLA. El encuentro se realizó en Punta del Este, entre el 5 y 17 de agosto de 1961. En el mencionado encuentro se firma la Carta de Punta del Este, la cual, por un lado, crea la Alianza del Progreso ${ }^{206}$, y por otro lado, sirve de documento base para establecer los lineamientos de "esfuerzos coordinados y conjuntos" y para "procurar que se dé término acuerdos preferenciales y otras medidas que limitan el consumo mundial de productos primarios latinoamericanos y su acceso a los mercados internacionales, en especial con aquellos países que están en proceso de

\footnotetext{
205 Ibíd. pp. 7 y 8.

${ }^{206}$ La Alianza del Progreso fue una iniciativa de los Estados Unidos para ayudar al desarrollo económico y social de los países de América Latina, contaba con un presupuesto de 20000 millones de dólares. Podemos decir que es un plan parecido al Plan Marshall diseñado para los países europeos.
} 
integración económica en Europa Occidental y de los países de economía centralmente planificada" 207.

Hasta aquí podemos resaltar dos puntos, primero el aporte del Parlamento Europeo en el acercamiento hacia la región, que será la base política para el diálogo institucionalizado entre ambas regiones; y en segundo lugar el aporte de la OEA, por ser dentro del marco del sistema interamericano el marco en el cual los países latinoamericanos deciden crear un mecanismo que busca articular y coordinar la defensa de sus intereses comunes como región. Como podemos ver, ambos puntos hacen que los países latinoamericanos comiencen a pensar en una acción exterior coordinada frente a terceros y en los foros internacionales.

Los tratados fundacionales de la CEE incluían la formación de una Unión Aduanera lo que a su vez representaba el establecimiento de un Arancel Externo Común; el establecimiento de una Política Agrícola Común y el conjunto de ventajas que se establecían para un grupo de países, muchos de ellos ex colonias de varios Estados miembros, como Bélgica, Francia, Italia y Países Bajos ${ }^{208}$, los territorios ubicados en África y el Pacífico tendrían beneficios de acceso al mercado común europeo; lo que afectaba al intercambio comercial entre los países latinoamericanos hacia los europeos, que hasta ese momento exportaban principalmente productos agrícolas y cárnicos.

En estos momentos los países latinoamericanos se preguntan hacia dónde deben priorizar sus relaciones comerciales y por consiguiente si debería, o no, diversificar sus mercados, una clara opción era acercándose más a su socio, geográficamente natural, Estados Unidos, o intentar negociar mejores condiciones con otros socios en otras regiones del mundo. Esa opción pasaba por identificar como socios a los países europeos. Lo cierto es que las estadísticas demuestran que durante los años 1958 a 1963, las importaciones de la Comunidad Económica Europea procedentes de América Latina habían aumentado lejos de disminuir, así los países de América Latina registraban un $38 \%$ frente al $25 \%$ de los países africanos y el $17 \%$ de los países de

\footnotetext{
${ }^{207}$ Capítulo II. Medidas de Cooperación Internacional. Carta de Punta del Este. Establecimiento de la Alianza para el Progreso dentro del marco de la Organización Panamericana. Alianza para el Progreso, Documentos Básicos. Biblioteca Nacional de Chile, p. 31. http://www.memoriachilena.cl/602/w3-article-94594.html [Última revisión: 21-02-2014]

${ }^{208}$ Art. 131. Tratado Constitutivo de la Comunidad Económica Europea, Roma, 25 de marzo de 1957.
} 


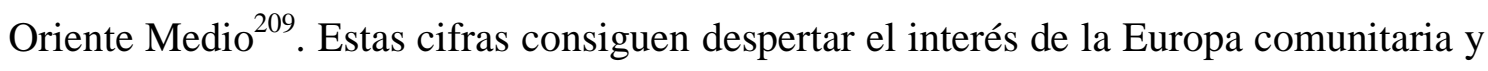
por eso el "Informe Martino" remarca la necesidad de crear un programa de acción comunitario respecto a América Latina ${ }^{210}$.

Pero muchas de las recomendaciones sugeridas en el Informe no se concretaron a nivel del Consejo de Ministros, la única recomendación que prospero fue la que planteaba la organización de un grupo de contacto entre los servicios competentes del Ejecutivo (es decir de la CEE) y los embajadores de los Estados de América Latina acreditados ante la Comunidad en Bruselas ${ }^{211}$, el llamado GRULAC. Posteriormente, este tipo de reuniones diplomáticas, de carácter informal, efectuadas dentro del GRULAC, se efectuarían de manera cada vez más periódicas en Bruselas para tratar diferentes temas y con el fin de encontrar puntos comunes entre europeos y latinoamericanos.

Hasta este momento se puede decir que en ambas regiones comienzan a contar con ciertos mecanismos similares de diálogo político. Por un lado, el Grupo de Embajadores Latinoamericanos (GRULAC) ${ }^{212}$, mecanismo de carácter informal y no institucionalizado en el proceso de integración regional latinoamericana. Por otro lado, el Comité de Representantes Permanentes de la CEE (COREPER) ${ }^{213}$, mecanismo formal e institucionalizado dentro del proceso de integración regional europea. Mientras que el COREPER se ha incorporado como institución formal y ha ampliado sus capacidades desde su creación, coordinando su trabajo con otras instancias comunitarias, que también coordinan la acción exterior de la Europa Comunitaria; el GRULAC en cambio, sigue siendo un mecanismo informal de consulta entre los países latinoamericanos, cuyos acuerdos y decisiones no son vinculantes, a la par que sigue sin estar institucionalizado y sin ser considerado como un órgano o institución dentro del proceso de integración regional de América Latina.

\footnotetext{
${ }^{209}$ LERMAN, A.: Evolución histórica de las relaciones comerciales entre América Latina y la CEE. Comercio Exterior, Vol. 41, N 2, México, febrero de 1991, p.180.

${ }^{210}$ Informe sobre las relaciones entre la Comunidad Europea y América Latina. Op. cit., p.14.

${ }^{211}$ Ibíd. p. 16

${ }^{212}$ El GRULAC es el Grupo de Embajadores de América Latina y Caribe que sirve como mecanismo de diálogo y concertación entre los embajadores de esta región acreditados en un país. No es una institución, no es formal y sus decisiones no son vinculantes, pero sirve como mecanismos de acción coordinada entre los diferentes países a la hora de presentar un pedido ante el país u organismo internacional que estuvieran acreditados.

${ }^{213}$ SMITH H.: Actually existing foreign policy - or not? The EU in Latin and Central America. En PETERSON J. and SJURSEN H.: A Common Foreign Policy for Europé. Competing visions of the CFSP. Routledge, London and New York, 1998, p.158.
} 
Ahora bien, cabe hacer un inciso al explicar el GRULAC, pues a pesar de no haber sido incorporado formalmente dentro del proceso de integración regional de América Latina, en lo que respecta a las relaciones con las Comunidades Europeas, primero, y luego con la Unión Europea, es el que hace el seguimiento en Bruselas de todo lo que se acuerda en las Cumbres de Jefe de Estado y Gobierno en la actualidad. El GRULAC nace de la necesidad de dialogar y coordinar las posiciones de los países latinoamericanos, luego se incorporarán los países caribeños (pasando a llamarse el Grupo de Embajadores Latinoamericanos y Caribeños) en el marco de las reuniones convocadas por Naciones Unidas y sus funciones, no reguladas, se han extendido a otros ámbitos de las relaciones internacionales, sus decisiones no son vinculantes, y su máxima instancia son las reuniones de embajadores.

Sus reuniones no cuentan con una periodicidad establecida y no tienen competencias establecidas de manera concreta, es decir sus funciones no se encuentran recogidas en ningún tratado, acuerdo o reglamento de funcionamiento. A pesar de ello, los países latinoamericanos y caribeños suelen utilizar este mecanismo, a través de sus delegaciones diplomáticas, para expresar e intentar defender sus intereses ante los diferentes foros y organismos internacionales existentes.

La praxis del GRULAC demuestra que ésta pudo y puede servir de base para el desarrollo de una diplomacia a nivel regional (América Latina y el Caribe) y por ende pensar en la creación de un futuro órgano que articule una acción exterior regional, con una política exterior común, tal como lo desarrollaron los países europeos al crear el COREPER y cuyo objetivo fue contar un una institución que coordine sus intereses comunes como región, al tiempo que obtienen una representación ante los foros y organismos internacionales.

El COREPER, a diferencia del GRULAC, nace de la necesidad de dialogar y coordinar las posiciones de los seis miembros de la CECA, la idea de contar con un órgano que escoja, prepare y debata los temas de la agenda común era imprescindible dentro de la Comunidad. Por lo que en febrero de 1953 se crea el Comité de Coordinación (COCOR), formado por embajadores de los Estados miembros, en principio, éste órgano no fue constituido de manera permanente, pero fue su efectividad y funcionalidad la que demostró su extrema utilidad, hecho que llevó a los países miembros de la CECA a definir su funcionamiento. Así el Consejo de la Comunidad 
Económica Europea pudo prever la creación de un Comité de con estas características. Lo refleja el Artículo 151 del Tratado Constitutivo de la Comunidad Económica Europea: "El Consejo establecerá su reglamento interno. Dicho reglamento podrá prever la constitución de un Comité compuesto por representantes de los Estados miembros. El Consejo determinará la misión y la competencia de dicho Comité"214.

Dentro de este marco jurídico, los Estados miembros, el 25 de enero de 1958, deciden institucionalizar de manera permanente el Comité, llamándolo Comité de Representantes Permanentes (COREPER) ${ }^{215}$, cuya misión será el coordinar y dialogar sobre los temas de interés común que posteriormente será discutido en las reuniones del Consejo de la Comunidad.

En 1965 se la firma del Tratado de Bruselas, llamado también el Tratado de Fusión, por ser el que fusiona en una única Comisión y en un único Consejo el de las tres Comunidades Europeas existentes hasta ese momento: La Comunidad Europea del Carbón y del Acero, la Comunidad Económica Europea y la Comunidad Europea de la Energía Atómica. Siendo este tratado en el que el COREPER quedará incorporado en el derecho comunitario mediante el Artículo 4: "Un Comité composé des représentants permanents des États membres a pour tâche de préparer les travaux du Conseil et d'exécuter les mandats qui lui sont confiés par celui-ci”,216.

A continuación, las funciones del COREPER se irían ampliando cada vez más. Por ejemplo, sería el Tratado de Ámsterdam el que amplió las capacidades de la COREPER: “El Comité podrá adoptar decisiones de procedimiento en los casos establecidos en el reglamento interno del Consejo" 217 . Finalmente, con la entrada en vigor del Tratado de Lisboa, es el Artículo 240, el que regula las funciones del respectivo Comité: “Un

\footnotetext{
214 Tratado Constitutivo de la Comunidad Económica Europea. Sección Segunda. El Consejo. Artículo 151. Roma, 25 de marzo de 1957.

215 Acta de la sesión inaugural de los Consejos de la CEE y la CEEA, celebrada en Bruselas el 25 de enero de 1958. (CM2 20/1958), p. 10. En CONSILIUM. El Consejo de la Unión Europea. 1952-2012: Sesenta años de actividad legislativa y toma de decisiones. Consilium, Bruselas, julio de 2013.

216 Article 4. Traité Intituant un Conseil Unique et Une Commission Unique des Communautés Européennes. Chapitre I. Le Conseil des Communautés Européennes. Journal Officiel des Communautés Européennes, 13 Juillet 1967. Edition de Langue Francaise 10 Année N 152.

http://eur-lex.europa.eu/LexUriServ/LexUriServ.do?uri=OJ:P:1967:152:FULL:FR:PDF_ [Última Revisión: 24-02-2014]

217 Artículo 4. Tratado de Ámsterdam por el que se modifican el Tratado de la Unión europea, los Tratados Constitutivos de las Comunidades Europeas y determinados Actos conexos. Diario Oficial N C 340 de 10 de noviembre de 1997. http://eur-lex.europa.eu/es/treaties/dat/11997D/htm/11997D.html [Última Revisión: 24-02-2014]
} 
Comité compuesto por Representantes Permanentes de los Gobiernos de los Estados miembros se encargará de preparar los trabajos del Consejo y de realizar las tareas que éste le confié. El Comité podrá adoptar decisiones de procedimiento en los casos establecidos por el reglamento interno del Consejo" ${ }^{218}$.

El COREPER fue en gran medida el germen de lo que hoy es la diplomacia europea en manos del Servicio Europeo de Acción Exterior de la Unión Europea. Razón por la cual, nos hace pensar que el GRULAC tiene el potencial institucional para seguir los pasos del COREPER y se una instancia que incentive el desarrollo de una diplomacia regional en América Latina y el Caribe.

\subsection{EN LA BÚSQUEDA DE UNA SOLA VOZ: LAS COMISIONES Y LOS CONSEJOS DE INTEGRACIÓN REGIONAL}

Volviendo a las relaciones entre la CEE y la CECLA, el 17 de octubre de 1969 el Consejo de las CEE emite una declaración sobre las relaciones entre la CEE y AL, en la respectiva declaración los países europeos expresan su voluntad e interés de intensificar las relaciones no sólo económicas-comerciales con América Latina, sino también en términos políticos.

Este mismo año, será en el cual se firma el Acuerdo de Integración Subregional Andino y con éste se da inicio al proceso de integración de los países andinos. Será el segundo proceso de integración a nivel subregional que se da dentro de América Latina, si consideramos como primero el proceso de integración subregional centroamericano, iniciado en 1951, curiosamente es el mismo año de la firma del Tratado de Paris, celebrado en 1951, tratado que creó la CECA. Lo importante de estas dos experiencias subregionales a este apartado es el hecho que ambas crean instituciones comunes, tomado como modelo la experiencia europea, al crear sus propios consejos y comisiones. Retomaremos este punto más adelante con el fin de seguir con la cronología de las relaciones entre Europa y América Latina como regiones.

Por su parte América Latina a través de la CECLA emite la Declaración de Buenos Aires, en la cual por un lado, los países reafirman su compromiso de hacer de CECLA:

\footnotetext{
${ }^{218}$ Artículo 240. Tratado de Funcionamiento de la Unión Europea. Lisboa, 13 de diciembre de 2007.
} 
Una expresión vigorosa de su unidad, que permite proyectarse hacia otras áreas del mundo como una sola voz y promover un diálogo franco responsable capaz de establecer fórmulas y mecanismos eficientes a fin de lograr una más justa y equitativa cooperación internacional. [...] Reafirman que la CECLA es el foro para coordinar y aunar ante las Comunidades Europeas los intereses de los países que la integran sin perjuicio de las negociaciones bilaterales, subregionales o regionales que se estime conveniente realizar ${ }^{219}$

Por otro lado, examinan las relaciones entre América Latina y las Comunidades Europeas. Relaciones que se consideran necesario "institucionalizar a alto nivel político, el diálogo entre América Latina y las Comunidades Europeas con el objeto de: i) Analizar y decidir sobre los asuntos que se refieran a sus relaciones, y permitir así alcanzar los objetivos mutuamente concertados del sistema que se propone crear. ii) Establecer un marco de referencia que facilite el desarrollo dinámico de las relaciones bilaterales, subregionales y regionales entre América Latina y las Comunidades Europeas, y iii) Convenir soluciones, incluyendo la conclusión de acuerdos sectoriales o globales en materia de comercio, financiamiento, transporte y cooperación científica y tecnológica ${ }^{220 "}$.

Las Comunidades Europeas, por su parte, habían reconocido la gran importancia política y económica que reviste el desarrollo de sus relaciones con América Latina, muestra de ello eran las distintas decisiones y recomendaciones emitidas al respecto hasta el momento, tanto en el marco del Consejo de Ministros de Asuntos Exteriores, como a nivel de la Comisión y del Parlamento Europeo. Siguiendo en la línea de fortalecer las relaciones entre ambas regiones.

El 18 de junio de 1971 la CEE y la CECLA crean un mecanismo de diálogo con el objetivo de regular los temas de interés birregional. Entre los temas de interés común estaban el deseo de lograr avances respecto la promoción del comercio entre los países en vías de desarrollo-productores de materias primas (Estados miembros de CECLA) y los países desarrollados o industrializados (países CEE). Parte de la mencionada promoción consistía en establecer un sistema de estabilización de precios y eliminar las barreras arancelarias.

\footnotetext{
${ }^{219}$ Declaración de Buenos Aires. Documentos. CECLA: América Latina ante la Comunidad Económica Europea. Comercio Exterior, Vol. XIX, N 6, junio de 1969, pp. 617-618.

${ }^{220}$ Declaración de Buenos Aires, Op. cit., p. 618.
} 
La idea era que todas estas cuestiones sean debatidas a nivel birregional para luego ser tratadas a nivel multilateral, como era el caso de las negociaciones desarrolladas en el marco de la Conferencia de las Naciones Unidas sobre Comercio y Desarrollo (UNCTAD) y el GATT (conocido por sus siglas en inglés General Agreement on Tariffs and Trade). No hay que olvidar que uno de los principales logros de la UNCTAD fue crear el "Sistema Generalizado de Preferencias" en 1971, y es en el marco del acuerdo del GATT en el que se establece el principio de la "Nación Más Favorecida".

Ambos instrumentos serán referencia para los distintos modelos de integración regional en el mundo y un tema de suma importancia en los diálogos birregionales, más aún cuando se tengan que considerar las distintas asimetrías en los niveles económicos de los países que forman parte del diálogo birregional.

En el año 1972 se celebra en Santiago de Chile la Tercera Conferencia de las Naciones Unidas sobre Comercio y Desarrollo, en ella no se logran avances significativos con respecto a los objetivos deseados. En esta conferencia los países latinoamericanos actúan coordinando posiciones comunes, así lo refleja la Declaración conjunta de la Segunda Reunión Ministerial del Grupo de los 77, celebrada en Lima del 25 de octubre al 7 de noviembre de 1971, en esa reunión se había acordado armonizar posiciones para la tercera reunión de la UNCATD. Los países latinoamericanos, el 23 de octubre de 1971, habían aprobado su posición común en la XII Reunión de la CECLA, a la que llamaron Consenso de Lima ${ }^{221}$.

Por el lado de la CEE, el Parlamento Europeo considera que los resultados de la respectiva conferencia sólo podrán ser apreciadas de manera definitiva "a la luz de los órganos de UNCATD y del GATT”,222. Con relación a estos temas, el PE había deplorado vivamente que el Consejo de Ministros no haya aceptado, varias propuestas que le habían sido presentadas por parte de la Comisión ${ }^{223}$, las cuales según

\footnotetext{
221 Consenso de Lima, 23 de octubre de 1971. XII Reunión de la CECLA (MM/77/II/MISC.3CECLA/XII/DC/29/Rev.1) en Actas de la conferencia de las Naciones Unidas sobre comercio y desarrollo, tercer período de sesiones, Santiago de Chile, 13 de abril-21 de mayo de 1972. Vol. I. Informes y Anexos. Naciones Unidas, New York, 1973, p. 400.

${ }^{222}$ Resolución sobre los resultados de la Tercera Conferencia de la UNCTAD, (Santiago de Chile, 13 de abril-21 mayo de 1972) 26 de julio de 1972. En Europa-América Latina: 20 años de documentos oficiales. Op. cit., p. 40.

${ }^{223}$ Resolución relativa al estado de las relaciones de la Comunidad Europea con América Latina y al resultado de las misiones de estudio y de información realizadas en 1971 en determinados países
} 
consideraciones del PE habían facilitado, en el plano económico, el incremento del comercio exterior entre ambas partes, y en el plano político, reforzar las relaciones entre las dos regiones. A la par que creaban las condiciones necesarias para seguir avanzando sobre posibles acuerdos conjuntos entre ambas regiones y así ir de manera coordinada, mediante posiciones conjuntas, a las múltiples conferencias y foros internacionales.

A lo largo de la década de los setenta la Comunidad Económica Europea firma varios acuerdos de diferente tipo, todos de forma bilateral con un tercer país:

- Acuerdo Comercial entre CEE-Argentina (8 de noviembre de 1971), el acuerdo concede de manera recíproca el trato de "Nación Más Favorecida" y establecía una Comisión Mixta para consolidar y ampliar las relaciones económicas y comerciales entre las partes.

- Acuerdo Comercial entre CEE-Uruguay (6 de noviembre de 1973) y Acuerdo Comercial entre CEE-Brasil (19 de diciembre de 1973), ambos acuerdos tenías las mismas características que el firmado con Argentina.

- Acuerdo Comercial entre la CEE-México (15 de julio de 1975) mediante el cual ambas partes contratantes se conceden el trato de "Nación Más Favorecida".

Otra vez hacemos un alto para indicar los tres primeros acuerdos firmados con Argentina, Uruguay y Brasil. Como bien sabemos, estos tres países luego iniciarán un proceso de integración subregional, teniendo como objetivo una unión aduanera, estableciendo como base un arancel externo común y teniendo como fin la creación de un mercado común, el MERCOSUR, siguiendo la experiencia europea, tal como lo hicieron los procesos de integración andina y centroamericana. Por tanto podemos decir que hasta esta década, los setenta, la CEE ya estaban fomentando las uniones regionales y con ello el mundo de regiones, de la que tanto nos habla Hettne.

Continuando, en 1975 la CECLA se transforma en el Sistema Económico Latinoamericano (SELA) y entre sus objetivos está el promover la cooperación e integración económica entre los 25 países de América Latina y el Caribe, implementando un sistema que les permita a los países de la región coordinar y concertar posiciones comunes ante otros grupos de estados, organismos internacionales y foros internacionales. Al respecto, el PE emite una resolución en la cual: 
...felicita la firma del acuerdo constitutivo de SELA y considera que éste podría servir de marco de referencia para la cooperación entre la Comunidad y América Latina [...]. Sugiere la creación de un centro financiero entre las dos regiones y la extensión gradual de las intervenciones del Banco Europeo de Inversiones para cubrir operaciones que impulsen la integración regional e intensifiquen los intercambios entre la Comunidad y América Latina ${ }^{224}$.

En la misma resolución enfatiza que todo ello ha sido posible gracias a que desde 1971 los contactos han sido regulares entre las dos regiones, las "cuales permiten dos veces al año el estudio de los principales problemas económicos entre ambas partes, y que espera que estos contactos prosigan" ${ }^{225}$. Es decir, se había dado el inicio de un diálogo birregional, formal e institucionalizado.

Con la transformación de CECLA en SELA, los países de esta región incluyen dentro de su proceso de integración un nuevo instrumento de acción conjunta a nivel político, crean el Consejo Latinoamericano del SELA, que sustituye de manera formal al Comisión (CECLA). El Consejo Latinoamericano tiene similitudes con el Consejo de la Comunidad Económica Europea, principalmente en las siguientes funciones y capacidades:

${ }^{224}$ Resolución sobre el estado actual de las relaciones económicas entre la Comunidad Europea y América Latina. 8 de marzo de 1976. Europa-América Latina: 20 años de documentos oficiales (19761996). Op. cit., p.57.

225 Ibíd., p. 56 
Cuadro $N^{\circ}$ 1. Consejos Regionales en Europa y América Latina

\begin{tabular}{|l|l|l|}
\hline Consejo Comunidad Económica Europea & Consejo Latinoamericano-SELA \\
\hline $\begin{array}{l}\text { Objetivos: El Consejo "asegurará la } \\
\text { coordinación de las políticas económicas } \\
\text { generales de los Estados miembros"226 }\end{array}$ & $\begin{array}{l}\text { Objetivos: El Consejo "establecer las políticas } \\
\text { generales del SELA"227. Entre las que se } \\
\text { encuentra "Aprobar posiciones y estrategias } \\
\text { comunes de los Estados miembros sobre temas } \\
\text { económicos"228 }\end{array}$ \\
\hline $\begin{array}{l}\text { Estructura: "Compuesto por representantes } \\
\text { de los Estados miembros"229 }\end{array}$ & $\begin{array}{l}\text { Estructura: "Estará integrado por un } \\
\text { representante de cada Estado miembro"230 }\end{array}$ \\
\hline $\begin{array}{l}\text { Autonomía de competencias: "Establecerá su } \\
\text { reglamento interno"231 }\end{array}$ & $\begin{array}{l}\text { Autonomía de competencias: "Aprobar su } \\
\text { reglamento"232 }\end{array}$ \\
\hline
\end{tabular}

Elaboración propia

Hecho que evidencia la referencia tomada de la experiencia y modelo europeo en la creación de instituciones en el proceso de integración regional de América Latina. Otras similitudes institucionales entre la CEE y el SELA, pueden ser observadas entre la Comisión de la CEE y la Secretaría Permanente del SELA. Así por ejemplo podemos ver que la primera "ejercerá las competencias que el Consejo le atribuya para la ejecución de las normas ${ }^{233}$ ", la segunda, tiene entre sus atribuciones "ejercer las funciones que le encomiende el Consejo Latinoamericano y, cuando corresponda, poner en ejecución sus decisiones ${ }^{234}$,"

\footnotetext{
${ }^{226}$ Art. 145. Tratado Constitutivo de la Comunidad Económica Europea, Roma, 25 de marzo de 1957.

${ }^{227}$ Art. 15. 1) Convenio de Panamá Constitutivo del Sistema Económico Latinoamericano. Panamá 17 de Octubre de 1975.

${ }^{228}$ Art. 15. 11) Convenio de Panamá Constitutivo del Sistema Económico Latinoamericano. Panamá 17 de Octubre de 1975.

${ }_{229}$ Art. 146. Tratado Constitutivo de la Comunidad Económica Europea, Roma, 25 de marzo de 1957.

${ }^{230}$ Art. 9. Convenio de Panamá Constitutivo del Sistema Económico Latinoamericano. Panamá 17 de Octubre de 1975.

${ }^{231}$ Art. 151. Tratado Constitutivo de la Comunidad Económica Europea, Roma, 25 de marzo de 1957.

${ }^{232}$ Art. 15. 3) Convenio de Panamá Constitutivo del Sistema Económico Latinoamericano. Panamá 17 de Octubre de 1975.

${ }^{233}$ Artículo 155. Sección Tercera. La Comisión. Tratado Constitutivo de la Comunidad Económica Europea, Roma, 25 de marzo de 1957.

${ }^{234}$ Art. 31.1. Convenio de Panamá Constitutivo del Sistema Económico Latinoamericano. Panamá 17 de Octubre de 1975.
} 
Así mismo, la coincidencia en el uso de la posibilidad que contemplan ambos tratados fundacionales con relación a la creación de "Comités", es sin duda un dato a considerar, contra quienes consideren que el modelo europeo no contribuyó al desarrollo institucional de la integración regional en América Latina. Tal es el caso del Artículo 151 del Tratado Constitutivo de la CEE, el cual servirá de base jurídica para la creación del COREPER, y en el caso del SELA, la base jurídica será el Artículo 20 de su tratado constitutivo, el cual menciona la posibilidad de crear "Comités de Acción" con la finalidad de "preparar y adoptar posiciones negociadoras conjuntas de interés",235.

Entre el 30 de mayo y el 1 de junio de 1977 se celebra en Paris la Conferencia sobre la Cooperación Económica Internacional, llamada también "Diálogo Norte-Sur", a la cual el SELA fue invitado a participar como "Observador Permanente" de la conferencia, junto a organismos como la Secretaría General de las Naciones Unidas, la UNCTAD, la Organización de Naciones Unidas para la Alimentación y la Agricultura (FAO), el Banco Mundial (BM) y el Fondo Monetario Internacional (FMI). Siendo el SELA el único organismo regional que participó en esa calidad en la Conferencia ${ }^{236}$.

En este mismo año la Comisión Económica para América Latina de las Naciones Unidas (CEPAL) subrayaba los avances logrados por el SELA desde su creación y recomendaba que siga siendo el instrumento para canalizar el esfuerzo de la región, reforzar los procesos de integración y reafirmar la necesidad de un desarrollo integrado $^{237}$. No hay que olvidar el contexto de ese momento, la Conferencia sobre la Cooperación Económica Internacional, la misma que surge en respuesta a la crisis energética de 1973, cuando la Organización de Países Exportadores de Petróleo (OPEP) decide no exportar más petróleo a Estados Unidos y a varios países europeos, por ser países que habían apoyado a Israel, durante la guerra del "Yom Kippur".

La respuesta a esta decisión, por parte de los países europeos, cuya idea fue promover un diálogo entre los países industrializados y los países productores de petróleo, dicha

\footnotetext{
${ }^{235}$ Art. 20. Convenio de Panamá Constitutivo del Sistema Económico Latinoamericano. Panamá 17 de Octubre de 1975.

${ }^{236}$ Anónimo.: EL SELA frente al diálogo Norte-SUR. Nueva Sociedad, N 31-32, julio-octubre 1977, p. 306.

http://www.nuso.org/revista.php?n=31 [Última revisión: 06-03-2014]

${ }^{237}$ SECRETARÍA PERMANENTE DEL SELA: Asuntos considerados por el Consejo Latinoamericano desde su creación. Selección 1975-2001 (SP/CL/XXVIII.O/Di N 11-02) XXVIII Reunión Ordinaria del Consejo Latinoamericano, Caracas, 7-9 de abril de 2003. p.3.
} 
idea fue desarrollada en el marco de la Cumbre Europea de Copenhague de diciembre de 1973. Sin embargo un grupo de países, como Argelia, lidiaron por una ampliación del diálogo entre países del Norte y del Sur. Estos acontecimientos evidencian como los organismos de integración regional van tomando cada vez más espacio en la toma de decisiones a nivel internacional y como son utilizados por los países para poder posicionarse o resolver los asuntos internacionales.

Otro acontecimiento importante que se efectuó en la década de los setenta, y que contribuyó a afianzar las bases para la relación birregional, es la realización de la Primera Conferencia Interparlamentaria, entre el Parlamento Europeo y el Parlamento Latinoamericano, celebrada en Bogotá los días 15 al 17 de julio de 1974. Hecho que pone de manifiesto que la CEE no sólo buscaba promover una integración de carácter económico-comercial, sino también político, desde el inicio de sus relaciones. Ahondaremos más sobre este asunto, en un apartado más adelante, cuando tratemos el tema del rol de los Parlamentos Regionales dentro de los procesos de integración regional.

Pero antes, es necesario destacar el rol del Parlamento Europeo en favor del fortalecimiento en las relaciones entre ambas regiones, su papel ha sido un factor importante a tener en cuenta. Un ejemplo de ello fue la resolución que emite acerca del estado de las relaciones económicas entre la CEE y América Latina en marzo de 1976, documento que servirá para argumentar la asistencia financiera y técnica hacia América Latina dentro del presupuesto comunitario, ampliando así la perspectiva de un diálogo birregional donde prevalecía los temas políticos, económicos y comerciales, para incluir otros temas, como la cooperación al desarrollo. Así el 15 de marzo de 1976, la CEE incluye, por primera vez, en su presupuesto una línea de cooperación para los países no asociados en vías de desarrollo, entre los que incluye a los países de dos regiones Asia y América Latina, la línea presupuestaria del Primer Programa de Asistencia Financiera y Técnica.

La década de los setenta terminará con la creación de dos nuevos actores en la escena subregional latinoamericana, nos referimos al Parlamento Andino, que fue creado el 25 de octubre de 1979, y al Consejo Andino de Ministros de Relaciones Exteriores del Acuerdo de Cartagena. Ambas instituciones buscaban el fortalecimiento institucional del proceso de integración de los países andinos. Los países andinos tomarán como 
modelo organizacional, las instituciones europeas, creando así sus primeras instituciones: una Comisión, un Parlamento, un Tribunal de Justicia, y como máximo órgano del proceso de integración, un Consejo Andino de Ministros de Relaciones Exteriores, cuyas funciones son también parecidas a las de sus pares institucionales europeos. Lo importante a considerar para este apartado es el hecho que este nuevo Consejo Andino de Ministros de Relaciones Exteriores busca ser el órgano de dirección política en el proceso de integración de los países andino, a la vez que busca tener una voz común a través del ejercicio de una representación y acción exterior común ante los principales foros, conferencias y organismos internacionales.

La década de los ochenta se inicia con la firma del Acuerdo de Cooperación entre CEEBrasil (18 de septiembre de 1980) $)^{238}$. A continuación, el 17 de febrero de 1981 el Consejo aprueba el primer reglamento de asistencia financiera y técnica a países en vías de desarrollo no asociados (Asia y América Latina), el Consejo delega en la Comisión la gestión de la respectiva asistencia. En el Art. 2 del Reglamento No 442/81, se acentúa que "es conveniente garantizar una presencia comunitaria en las grandes regiones del mundo en vías de desarrollo, tendiendo a un equilibrio geográfico razonable entre las mismas" 239 .

Del mismo modo se indica que la ayuda de la Comunidad adoptará la forma de ayudas no reembolsables ${ }^{240}$. Con este marco referencial, se produce los primeros acercamientos con grupos subregionales de América Latina, como fueron los casos con los países andinos, Acuerdo entre CEE-Grupo Andino, el 17 de diciembre de 1983 y el Acuerdo Marco de Cooperación entre CEE-Centroamérica, el 12 de noviembre de $1985^{241}$, a nuestro entender por ser los modelos de integración más próximos al modelo de la CEE.

\footnotetext{
${ }^{238}$ Para más información acerca de las relaciones entre CEE-Brasil puede verse en: AYLLÓN, B.: "España ante la segunda cumbre entre la Unión Europea y América Latina y el Caribe. Encuentros y desencuentros en las relaciones de Brasil con la Comunidad Económica Europea (1957-2000). Revista CIDOB D'AFERS INTERNATIONALS 54-55, pp. 165-177, Fundación CIDOB, Barcelona, 2001. También revisar: COSTA, M.: "Las relaciones comerciales de la UE con Brasil". Boletín Económico de ICE N 3054, Agosto, Madrid, 2014.

${ }^{239}$ Art. 2. Reglamento (CEE) $\mathrm{N}^{\circ} 442 / 81$ del Consejo, de 17 de febrero de 1981, relativo a la ayuda financiera y técnica en favor de los países en vías de desarrollo no asociados. DO L 48 de 21.2.1981, p.8/10. Edición especial en español: Capítulo 11 Tomo 14 p. 146-148. Eur-lex:

http://eur-lex.europa.eu/LexUriServ/LexUriServ.do?uri=CELEX:31981R0442:ES:NOT [Última revisión: 02-03-2014]

240 Art. 5 Reglamento (CEE) $\mathrm{N}^{\circ}$ 442/81 del Consejo, de 17 de febrero de 1981, relativo a la ayuda financiera y técnica en favor de los países en vías de desarrollo no asociados. Op. cit., Ibíd.

${ }^{241}$ Es importante señalar que en el caso del proceso de integración en Centroamérica, existe un antecedente en las relaciones con la Comunidad Económica Europea. Nos referimos al Proyecto de
} 
Con la firma de los acuerdos antes mencionados se inician también los acuerdos llamados de segunda generación, los cuales se diferencian de los firmados en los años setenta por incluir más temas. Los acuerdos de primera generación tienen como principales características tres puntos:

\section{Interés comercial}

2. Interés por determinados países

3. Se privilegia los acuerdos bilaterales: CEE-Argentina ${ }^{242}$, CEE-Uruguay, CEEBrasil; CEE-México.

Los acuerdos de segunda generación cumplen con los siguientes puntos:

1. Interés comercial + interés político y de cooperación

2. Interés por firmar acuerdos con grupos subregionales de integración: CEEGrupo Andino y CEE-Centroamérica.

3. La cooperación se convierte en tema principal en las relaciones entre la CEE y AL.

Con la firma de ambos acuerdos subregionales la UE abre un nuevo capítulo en sus relaciones con terceros, a la par que promueve la formación, acción y representación exterior de otros organismos de integración regional y/o subregional. Así consta en Reglamento (CEE) $\mathrm{N}{ }^{\circ}$ 2955/85, en el cual, el Título Primero, titulado "Cúmulo regional y atribución del origen", menciona que se entenderá por "grupo regional" a los siguientes organismos:
a) Asociación de Naciones del Asia Central (ASEAN)
b) Mercado Común de América Central (MCAC)
c) Grupo Andino 243

exposición del Mercado Común Centroamericano a la Comunidad Económica Europea, presentado en el marco de la reunión de la Secretaría Permanente del Tratado General de Integración Económica Centroamericana, realizada en Tegucigalpa, del 18 al 24 de septiembre de 1967.

${ }^{242}$ ARMAS, C. y PFIRTER, F.: "El acuerdo comercial de la Comunidad Económica Europea con la Argentina y su correlación con los celebrados en otros países latinoamericanos". Revista de Instituciones Europeas, 1976, Vol. 3 N 3, pp. 627-656.

${ }^{243}$ Reglamento (CEE) $N^{\circ} 2955 / 85$ del Consejo por el que se establecen excepciones, para los países de la Asociación de Naciones del Asia Sudoriental, para los países del Mercado Común de América Central y para los países signatarios del Acuerdo de Cartagena (Grupo Andino), al Reglamento (CEE) N $^{\circ} 3749 / 83$ Relativo a la definición de la noción de productos originarios para la aplicación de preferencias arancelarias concedidas por la Comunidad Económica Europea a determinados productos de países en vías de desarrollo. 22 de octubre de 1985. Portal de la Legislación de la Unión Europea. EUR-LEX: 
El proceso de integración europea ha creado y ha ido definiendo una serie de términos y conceptos, a través de sus documentos oficiales y de trabajo que han tenido incidencia en la historia de la integración regional de los países de Europa y América. Lo que hoy en día parece evidente, no siempre fue así. Por ejemplo, hoy en día es normal, y se sabe lo que significa, cuando se quiere decir "grupo regional" o "actor global".

Sin embargo, es interesante constatar que no es la academia la cual ha definido estos conceptos, sino ha sido la vida política y la acción diplomática del proceso de integración europea la que ha ido generando y creando conceptos que atañen directamente a las relaciones internacionales. El ejemplo del Reglamento (CEE) $\mathrm{N}^{\circ}$ 2955/85, antes mencionado, es el que define y reconoce, como "grupo regional", a los procesos de integración en marcha hasta esa época; y más importante aún, sí se hace relación, que será cuando veinticuatro años más tarde, en 2009, sea la UE mediante otro documento oficial, el que definirá y reconocerá a América Latina como “Actor Global",244.

Siguiendo en la década de los ochenta, se produce otro hecho significativo que contribuirá de manera muy especial en las relaciones birregionales. Nos referimos a la Primera Conferencia Ministerial del "Proceso de San José" (28-29 de septiembre de 1984), cuya finalidad era apoyar la pacificación en Centroamérica. Esta conferencia tiene como logro el resultado de poder haber formalizado reuniones frecuentes y periódicas a nivel de Ministros de Asuntos Exteriores, en este caso, entre países miembros de la Comunidad Europea, América Central y el Grupo de Contadora.

Hacemos un énfasis en este punto, pues será el Grupo de Contadora, el mecanismo sobre el cual, durante las próximas tres décadas siguientes, servirá de base para crear lo que hoy se conoce como la Comunidad de Estados Latinoamericanos y Caribeños (CELAC), por tanto su experiencia como mecanismo de integración es importante a tener en cuenta, y no caer en el error de pensar que es su obsolescencia lo que da paso a la CELAC, sino que es su acervo integracionista lo que contribuye a crearla.

http://eur-lex.europa.eu/legal-content/EN/TXT/?qid=1395830449557\&uri=CELEX:31985R2955 [Última revisión: 26-03-2014]

${ }^{244}$ Comunicación de la Comisión al Parlamento Europeo y al Consejo. La Unión Europea y América Latina: Una asociación de actores globales, COM (2009) 495/3. Comisión Europea, Bruselas, 30 de septiembre de 2009. 
No hay que olvidar que el Grupo Contadora se estableció como un mecanismo de acción conjunta para promover la paz en Centroamérica, aquí otra vez, otro punto de coincidencia con el proceso de integración regional en Europa, el cual también tuvo el mismo objetivo, promover la paz en la mencionada región. Posteriormente.

Al Grupo de Contadora se sumará a los esfuerzos por la paz, el Grupo de Apoyo de Contadora, que conjuntamente formarían el Grupo de los Ocho, que sucesivamente pasarían a formar el Grupo de Río, y que finalmente será la institución sobre la cual se fundará la CELAC. Y como veremos más adelante, será inicialmente el Grupo de Río y luego la CELAC los interlocutores que representan a América Latina en el diálogo birregional con la Unión Europea primero usando el marco de las celebraciones de las cumbres Grupo de Rio-UE y posteriormente usando el marco de las cumbres UECELAC.

Pero antes de terminar este apartado, es sustancial, también indicar la experiencia que brinda el Tratado de Montevideo de 1980 al acervo integracionista latinoamericano, en lo referente a la construcción de un sistema político institucional organizado piramidalmente, y en cuya cúspide está un órgano máximo que buscará promover la integración regional, ya no sólo a nivel económico, sino también a nivel político, con implicancias en representación y acción exterior a nivel regional. Nos referimos a la Asociación Latinoamericana de Integración (ALADI) y a su antecesora la Asociación Latinoamericana de Libre Comercio (ALALC).

Si revisamos sus tratados fundacionales podemos observar cómo se da una evolución en lo que respecta al sistema institucional del proceso de integración regional latinoamericano. Los países de esta región se van dando cuenta a lo largo de sus negociaciones con terceros, que para conseguir una integración económica, es necesario no sólo desarrollar políticas comunes en dicha materia, sino que también es indispensable e imprescindible implementar, paralelamente, una política exterior común, o al menos, una política exterior coordinada o concertada. Los argumentos para dicha aseveración los podemos encontrar en los siguientes artículos de sus respectivos tratados: 
Cuadro $\mathrm{N}^{\circ}$ 2. Cambios en el sistema organizacional ALALC-ALADI

\begin{tabular}{|c|c|c|}
\hline Organización & $\begin{array}{l}\text { Asociación } \\
\text { Latinoamericana de Libre } \\
\text { Comercio }\end{array}$ & $\begin{array}{l}\text { Asociación } \\
\text { Latinoamericana de } \\
\text { Integración }\end{array}$ \\
\hline Tratado Fundacional & $\begin{array}{l}\text { Tratado de Montevideo } \\
\text { (1960) }\end{array}$ & $\begin{array}{l}\text { Tratado de Montevideo } \\
\text { (1980) }\end{array}$ \\
\hline Estructura organizacional & $\begin{array}{l}\text { Establece como máximos } \\
\text { órganos de la } \\
\text { Asociación }{ }^{245} \text { : } \\
\quad \text { - La Conferencia } \\
\text { - El Comité }\end{array}$ & $\begin{array}{l}\text { Establece como máximos } \\
\text { órganos políticos de la } \\
\text { Asociación }{ }^{246} \text { : } \\
\begin{array}{l}\text { - El Consejo } \\
\text { - La Conferencia } \\
\text { - Comité }\end{array}\end{array}$ \\
\hline Representación & $\begin{array}{l}\text { El Comité será "un órgano } \\
\text { permanente } 247, \text { y el } \\
\text { encargado de "representar } \\
\text { a la Asociación ante } \\
\text { terceros países y } \\
\text { organismos o entidades } \\
\text { internacionales, con el } \\
\text { objeto de tratar asuntos de } \\
\text { interés común }{ }^{248 ",}\end{array}$ & $\begin{array}{l}\text { El Comité será un "órgano } \\
\text { permanente } 249 " \text { el } \\
\text { encargado de "representar } \\
\text { a la Asociación ante } \\
\text { Terceros } \\
250,\end{array}$ \\
\hline Personalidad jurídica: & $\begin{array}{l}\text { "La Asociación } \\
\text { Latinoamericana de Libre } \\
\text { Comercio gozará de } \\
\text { completa personalidad } \\
\text { jurídica } 251 ",\end{array}$ & $\begin{array}{l}\text { "La Asociación gozará de } \\
\text { completa personalidad } \\
\text { jurídica }{ }^{252, "}\end{array}$ \\
\hline
\end{tabular}

Elaboración propia. Fuente: Tratados fundacionales de la ALALC y ALADI.

Cómo se puede observar en el cuadro superior, se da una evolución respecto al grado de institucionalidad en el proceso organizacional de la Asociación, al crear el Consejo, y al poner a éste como máximo órgano, dándole un carácter político más que económico. El máximo órgano estaría constituido por los Ministros de Relaciones Exteriores de los

\footnotetext{
${ }^{245}$ Art. 33. Tratado Constitutivo de la Asociación Latinoamericana de Libre Comercio, Montevideo, 18 de febrero de 1960. Base de datos del Poder Legislativo, República Oriental del Uruguay. http://www.parlamento.gub.uy/htmlstat/pl/tratados/trat12859.htm\#art4 [Última revisión: 22-03-14]

${ }^{246}$ Art. 28. Tratado de la Asociación Latinoamericana de Integración, Montevideo, 12 de Agosto de 1980. Base de datos de Normas Institucionales de la Asociación Latinoameriana de Integración. http://www.aladi.org/nsfaladi/juridica.nsf/vtratadoweb/tm80 [Última revisión: 22-03-14]

${ }^{247}$ Art. 39. Tratado Constitutivo de la Asociación Latinoamericana de Libre Comercio. Ibíd., Op. cit.

${ }^{248}$ Art. 39. Apartado C. Tratado Constitutivo de la Asociación Latinoamericana de Libre Comercio. Ídem, Op. cit.

${ }^{249}$ Art. 35. Tratado de la Asociación Latinoamericana de Integración. Ibíd., Op. cit.

${ }^{250}$ Art. 35. Apartado i) Tratado de la Asociación Latinoamericana de Integración. Ibíd., Op. cit.

251 Art. 46. Tratado Constitutivo de la Asociación Latinoamericana de Libre Comercio. Op. cit.

${ }^{252}$ Art. 52. Tratado de la Asociación Latinoamericana de Integración. Op. cit.
} 
países miembros ${ }^{253}$, en un claro ejemplo de querer ejercer una acción exterior coordinada a nivel internacional como región, y de ahí la importancia de seguir apostando por contar con un Comité de carácter permanente, de manera que exista una institución que ejecute lo acordado a nivel ministerial y así dé continuidad a dichas políticas regionales. La representación delegada al Comité, ante terceros países y organismos internacionales, con una personalidad jurídica es a nuestro entender un gran avance.

El 17 de diciembre de 1983, la CEE centra su labor en una subregión en concreto, con la idea de promover la integración regional como modelo, con estas metas firma en Cartagena de Indias, el Acuerdo de Cooperación entre el Acuerdo de Cartagena y sus Países Miembros ${ }^{254}$, la Comunidad Económica Europea y la Comunidad Europea del Carbón y del Acero, el texto del acuerdo fue previamente adoptado en Bruselas el 28 de octubre del mismo año. Con este acuerdo las Comunidades Europeas buscan "fomentar la creación y el fortalecimiento de organizaciones regionales destinadas a promover el crecimiento económico, el progreso social y el desarrollo cultural, introduciendo un factor de equilibrio en las relaciones internacionales" ${ }^{\prime 255}$. Entre los principales objetivos, acordados en el presente acuerdo, se destacarán los siguientes:

- En materia de cooperación económica:

- Abrir nuevas fuentes de abastecimiento y nuevos mercados.

- Intercambio de información relativa a la cooperación económica así como el desarrollo de contactos y de actividades de promoción entre las empresas y organizaciones de las dos regiones.

- Relaciones más estrechas entre sus respectivos sectores económicos, industriales, agropecuarios y mineros.

- Cooperación en los campos de las ciencias y de las técnicas, del desarrollo industrial, agroindustrial y agropecuario, minero, de la pesca, de la infraestructura, de los transportes y comunicaciones, del medio ambiente, de la energía y del turismo.

\footnotetext{
${ }^{253}$ Art. 31 Tratado de la Asociación Latinoamericana de Integración. Ibíd., Op. cit.

${ }^{254}$ Los Países Miembros del Acuerdo de Cartagena en esos momentos era: Bolivia, Colombia, Ecuador, Perú y Venezuela.

${ }^{255}$ Acuerdo de Cooperación entre el Acuerdo de Cartagena y sus Países Miembros, la Comunidad Económica Europea y la Comunidad Europea del Carbón y del Acero. Documento de la Secretaría General de la Comunidad Andina. 39 Período de Sesiones Extraordinarias de la Comisión del 7 al 9 de noviembre de 1983. Decisión 190. Lima, 9 de noviembre de 1983.
} 
- Las relaciones entre sus respectivos empresarios y empresas, entre otras, bajo la forma de empresas conjuntas ${ }^{256}$.

- En materia de cooperación para el desarrollo:

- La Comunidad se esforzará por coordinar sus actividades y las de sus Estados Miembros en materia de cooperación para el desarrollo en la Subregión Andina, particularmente en lo que concierne a los proyectos de integración de esta Subregión ${ }^{257}$.

- En materia de cooperación comercial:

- Aproximar a los agentes económicos de ambas regiones con el fin de diversificar e incrementar las corrientes comerciales

- Se conceden, para sus importaciones y exportaciones de mercancías, el régimen de la nación más favorecida ${ }^{258}$.

Así mismo, la Comunidad emite la Declaración relativa al Régimen del Sistema Generalizado de Preferencias para los Países del Acuerdo de Cartagena, confirmando su compromiso con lo instituido en la Resolución $N^{\circ} 21$ (II) de la Segunda Conferencia de las Naciones Unidas sobre Comercio y Desarrollo.

A mediados de los años ochenta se producen dos hechos más para la consolidación y proyección internacional de América Latina, como región. El primer hecho sería que la Comisión Económica para América Latina (CEPAL), que había sido creada en el marco de las Naciones Unidas, mediante la Resolución 106 (VI) del Consejo Económico y Social, el 25 de febrero de 1948, modificaría su nombre, a través de la Resolución 1984/67, emitida el 27 de julio de 1984, el Consejo decidió que de ahora en adelante pasaría a llamarse la Comisión Económica para América Latina y el Caribe.

Lo relevante en términos internacionales, son dos aspectos, el primero que amplía la concepción del ámbito geográfico de América Latina como región, incluyendo ahora al Caribe; y segundo punto, en base a esa nueva definición y concepción geográfica como región, es sobre la que se pensará políticamente, en América Latina y Caribe como una región. Muestra de ello, es cuando los países del conjunto de esta región formen la

\footnotetext{
${ }^{256}$ Art. 1. Acuerdo de Cooperación entre el Acuerdo de Cartagena y sus Países Miembros, la Comunidad Económica Europea y la Comunidad Europea del Carbón y del Acero. . Op. cit., p. 6.

${ }^{257}$ Art. 2. Acuerdo de Cooperación entre el Acuerdo de Cartagena y sus Países Miembros, la Comunidad Económica Europea y la Comunidad Europea del Carbón y del Acero. . Op. cit., p. 8.

${ }^{258}$ Art. 3. Acuerdo de Cooperación entre el Acuerdo de Cartagena y sus Países Miembros, la Comunidad Económica Europea y la Comunidad Europea del Carbón y del Acero. . Op. cit., p. 9.
} 
Comunidad de Estados Latinoamericanos y Caribeños (CELAC) y deseen presentarse al mundo como una sola región ante otras regiones. Y como veremos más adelante será en el marco de las negociaciones con la Unión Europea, en la que la CELAC se presente como un actor regional.

Finalmente, destacar que la CEPAL ha jugado un papel importante en la integración latinoamericana, por un lado ha servido como secretaría técnica en muchos de los procesos de integración emprendidos por los países de América Latina, tanto en los proyectos de ámbitos subregionales como en los proyectos a escala regional. La CEPAL fue una de las primeras organizaciones internacionales en saludar la creación de CELAC y desde su inicio ha apoyado con asistencia técnica a la reciente comunidad.

La CEPAL ha acompañado a lo largo de estas décadas a los países de esta región en el proceso de su integración económica y política. Un dato por señalar es el siguiente, nadie cuestiona el apoyo y el rol de la CEPAL durante éstos años en favor de la integración latinoamericana ${ }^{259}$, sin embargo, parece que nadie sabe, que existen miembros fuera de la región, concretamente países europeos que son miembros de la CEPAL. La CEPAL cuenta con cuarenta y cuatro miembros, de los cuales, doce son miembros asociados, y de los cuales treinta y dos son miembros plenos, entre los cuales están el conjunto de la región, los países de América Latina y el Caribe, y doce miembros son extra regionales: Alemania, Canadá; España, Estados Unidos, Francia, Italia, Japón, Países Bajos, Portugal, Reino Unido, Irlanda y la República de Corea. De estos doce países, ocho países son europeos. $\mathrm{P}$

or tanto se puede decir que la contribución de los países europeos por la integración regional de América Latina y el Caribe, se da a través de diferentes mecanismos, uno a través del diálogo birregional y otro a través del apoyo de organismos internacionales, como es el caso de la CEPAL, al estar ésta dentro ámbito de las Naciones Unidas. Y lo que nos puede hacer pensar que los esfuerzos que realizo la CEE, CE y hoy la UE en favor de la integración regional de ALC, también lo hace dentro del marco de la CEPAL.

${ }^{259}$ BRICEÑO, J., QUINTERO, M., y RUIZ, D.: "El pensamiento estructuralista de la CEPAL sobre el desarrollo y la integración latinoamericana. Reflexiones sobre su vigencia actual". Revista Aportes para la integración Latinoamericana, Año XIX N 28/junio 2013, pp. 1-34 
El otro acontecimiento internacional, es el desarrollado en el seno de la construcción regional europea el mismo que marcaría, un antes y un después en las relaciones entre América Latina y la Unión Europea. En 1985, se produce la firma de adhesión de España y Portugal a la Comunidad Económica Europea, y eleva a doce el número de Estados miembros de la Comunidad. Con el ingreso de España se produce una intensificación de las relaciones entre Europa y América Latina, así queda constancia en el documento titulado: "Declaración Común de Intenciones Relativa al Desarrollo y a la Intensificación de las Relaciones con los Países de América Latina”. En dicho documento se confirma la voluntad de la CEE por querer reforzar sus relaciones económicas, comerciales y de cooperación con esta región:

\begin{abstract}
La Comunidad: Confirma la importancia que atribuye a los lazos tradicionales que mantiene con los países de América Latina y a la estrecha cooperación que ha desarrollado con estos países, recuerda, en este contexto, el reciente encuentro ministerial de San José en Costa Rica, reafirma, con ocasión de la adhesión de España y Portugal, su voluntad de extender y de reforzar sus relaciones económicas, comerciales y de cooperación con estos países ${ }^{260}$.
\end{abstract}

También en 1985 se firma el Acuerdo Marco de Cooperación entre la Comunidad Europea y los países centroamericanos más Panamá, el cual considera una amplia gama de temas: cooperación económica, comercial, financiera, inversiones, técnica y social.

Para 1987 la Comisión Europea emitirá una Comunicación al Consejo sobre el estado actual de las relaciones con América Latina, en el comunicado menciona que en “Aspectos Institucionales, se han celebrado acuerdos dos subregiones en vías de integración económica o que esperan conseguirla, el Pacto Andino y América Central y con Brasil, México y Uruguay [...] son "acuerdos marco de cooperación" no preferenciales"261.

Con el objeto de promover las relaciones entre ambas regiones y crear líneas de acción concretas, y teniendo en cuenta la iniciativa de España y Portugal, por profundizar dichas relaciones, la Comisión Europea envía, el 21 de enero de 1987, una Comunicación al Consejo sobre la situación en América Latina, con el fin de evaluar el

\footnotetext{
${ }^{260}$ Declaración de Intenciones sobre América Latina, Tratado de Adhesión de España y Portugal a la Comunidad Europea, 12 de junio de 1985.

${ }^{261}$ Comunicación de la Comisión al Consejo sobre las relaciones con América Latina, 27 de enero de 1987.
} 
estado actual de las relaciones y explorar nuevas perspectivas. El 23 de enero de ese mismo año, el Parlamento Europeo aprueba una resolución sobre las relaciones económicas entre la Comunidad Europea y América Latina.

El Parlamento Europeo señala que es importante avanzar en la liberalización de los intercambios comerciales entre ambas regiones y que para ello es necesario contribuir al desarrollo de dichos países. Para lo cual considera imprescindible institucionalizar las relaciones sobre las bases de: las VI y VII Conferencias interparlamentarias Comunidad Europea-Latinoamérica ${ }^{262}$, resoluciones sobre relaciones económicas y comerciales así como sobre la cooperación entre la Comunidad Europea y Latinoamérica ${ }^{263}$, el Acuerdo Marco entre la CEE y los países del Acuerdo de Cartagena ${ }^{264}$, el Acuerdo de Cooperación entre la CEE y los países centroamericanos y Panamá ${ }^{265}$, las reuniones entre los Ministros de Asuntos Exteriores de la CE y los Ministros de Asuntos Exteriores del Mercado Común Centroamericano y de los cuatro países del Grupo de Contadora $^{266}$, la Resolución sobre la deuda de los países latinoamericanos y la reunión de los Siete en Bonn ${ }^{267}$; la Resolución sobre la situación política en Sudamérica ${ }^{268}$ y la Declaración común de intenciones relativa al desarrollo y la intensificación de las relaciones con los países de Latinoamérica ${ }^{269}$.

Concluye que:

- Considera necesario institucionalizar las relaciones con Latinoamérica mediante una concertación permanente a nivel político, e insiste en que la Comisión

\footnotetext{
${ }^{262}$ La VI Conferencia interparlamentaria fue celebrada en Bruselas del 13 al 16 de junio de 1983 y la VII Conferencia se efectuó en Brasilia del 16 al 20 de junio de 1985.

${ }^{263}$ Resolución sobre las relaciones económicas y comerciales. DO n C 307 de 14.11.1983. Resolución sobre la cooperación entre la Comunidad Europea y Latinoamérica. DO n ${ }^{\circ} \mathrm{C} 175$ de 15.7.1985.

${ }^{264}$ Resolución relativa a la conclusión del Acuerdo Marco de cooperación entre la Comunidad Económica Europea y el Acuerdo de Cartagena. DO n ${ }^{\circ}$ C 127 de 14.5. 1984.

${ }^{265}$ Resoluciones sobre la conclusión del Acuerdo de cooperación entre la Comunidad Económica Europea y los países del Tratado General de Integración Económica Centroamericana así como Panamá. DO n C 148 de 16.6.1986.

${ }^{266}$ Comunicado Conjunto de la Reunión Ministerial de San José, San José, Costa Rica, 1984. Comunicado Político Conjunto de la Conferencia Ministerial de Luxemburgo sobre diálogo político y la cooperación económica entre los países de la Comunidad Europea, España, Portugal y los Países de América Central y de Contadora, 11 y 12 de noviembre de 1985. Ver en: Las Conferencias Ministeriales del Diálogo de San José (1984-2002). Oficina de la Delegación de la Comisión Europea en Costa Rica, San José, abril de 2003.

${ }^{267}$ Resolución sobre la deuda de los países latinoamericanos y la reunión de los Siete en Bonn. DO ${ }^{\circ}$ C122 de 20.5.1985.

${ }^{268}$ Resolución sobre la situación de Sudamérica. DO n ${ }^{\circ} 36$ de 17.2.1986.

${ }^{269}$ Declaración común de intenciones relativa a desarrollo y la intensificación de las relaciones con los países de Latinoamérica, ver anexo Acta final relativa a la Adhesión de España y Portugal a la CE. DO n ${ }^{\circ}$ C 302 de 15.11 .1985
} 
estudie con carácter de urgencia la creación de un acuerdo político y económico más amplio $[\ldots]$

- [...] incrementar los esfuerzos de la Comunidad en lo que respecta a la liberalización en el ámbito comercial y la intensificación y diversificación de los intercambios

- Pide a la Comisión que aumente sus delegaciones en Latinoamérica ${ }^{270}$.

Este último punto es resaltante en cuanto ha servido para que la Unión Europea pueda estrechar los lazos con América Latina en términos diplomáticos, en la actualidad la existen 15 delegaciones de la UE en la región y esto ha contribuido a poder diseñar e implementar muchos de los proyectos y programas existentes entre ambas regiones, a la par que cumplir con cada uno de los objetivo que han sido contemplados en los diferentes presupuestos plurianuales UE-AL.

Dentro de este contexto, el 31 de enero de 1990 el Comité Económico y Social de la Comunidad Europea presenta un dictamen sobre la cooperación económica y social entre la CE y AL. En el dictamen se solicita ampliar los niveles de cooperación y se hace hincapié de crear programas regionales de fomento al proceso de integración regional. La mayoría de los programas regionales serán fruto, justamente, del diálogo entre ambas regiones, los cuales son pruebas palpables y hechos concretos que se irán desarrollando y ampliando en la diversidad de temas comunes, y que se darán cada vez a más alto nivel, hasta llegar a las reuniones Cumbre entre la UE-ALC, como veremos más adelante.

Haremos un inciso para destacar que desde entonces hasta la actualidad se ha implementado varios programas que cubren una serie de áreas temáticas de cooperación. Entre los principales programas podemos mencionar:

1. AL-INVEST (cooperación económica entre empresas)

2. ALFA y ALBAN (cooperación académica e investigación)

3. @LIS (sociedad de la información)

4. ALURE (energía)

5. URB-AL (desarrollo urbano)

6. EUROsociAL (cohesión social)

\footnotetext{
${ }^{270}$ Resolución sobre las relaciones económicas entre la Comunidad Europea y Latinoamérica, 23 de enero de 1987. Conclusiones puntos: 37,38 y 39.
} 
7. Observatorio para las relaciones Unión Europea-América Latina-OBREAL (centro que estudia y analiza las relaciones entre ambas regiones)

8. EUROsolar (energía renovable)

Como señalaran Rouquayrol y Herrero, estos programas responden a las prioridades políticas e intereses comunes y favorecen la regionalización a través de distintos estamentos de la sociedad civil $^{271}$.

Cerramos este apartado haciendo referencia a lo que consideramos un punto de inflexión en las relaciones entre los países europeos y latinoamericanos, el punto será la Declaración de Roma, del 20 de diciembre de 1990, en la cual ambas regiones inician un mecanismo de diálogo político regular sobre temas una base de una agenda birregional que incluye abordar cuestiones internacionales de mutuo interés y en la cual se decide que se celebrarán Reuniones Ministeriales Institucionalizadas entre los Cancilleres de la Unión Europea y el Grupo de Río.

\subsection{LA INSTITUCIONALIZACIÓN DE UN DIÁLOGO BI- REGIONAL: LAS BASES DE UNA ACCIÓN EXTERIOR CONJUNTA BI-REGIONAL}

Desde la Declaración de Roma realizada entre Comunidad Europea-Grupo de Río hasta la Declaración de Santiago firmada entre la Unión Europea-Comunidad de Estados Latinoamericanos, han pasado treinta y cuatro años. Estas relaciones han estado marcadas por encuentros y desencuentros en algunos temas, pero siempre se ha mantenido el deseo de desarrollarlas, fortalecerlas y profundizarlas.

La Declaración de Roma, marca cuatro objetivos, que para nuestra investigación son relevantes, pues darán como resultado las bases para futuras acciones conjuntas:

\footnotetext{
${ }^{271}$ ROUQUAYROL, L y HERRERO, S.: Guía sobre la Cooperación Unión Europea-América Latina, Asociación CEFICALE, Francia, 2007, p.54
} 
Cuadro $^{\circ}$ 3. Objetivos y Acciones Conjuntas:

Comunidad Europea-América Latina

\begin{tabular}{|c|c|}
\hline Objetivos & Acciones Conjuntas \\
\hline 1. Visión y misión & $\begin{array}{l}\text { Elaboración de una Agenda Birregional } \\
\text { sobre los temas de interés común }\end{array}$ \\
\hline $\begin{array}{l}\text { 2. Colaboración común en los foros } \\
\text { internacionales }\end{array}$ & $\begin{array}{l}\text { Proponer políticas internacionales sobre } \\
\text { temas globales }\end{array}$ \\
\hline $\begin{array}{l}\text { 3. Mecanismos de coordinación } \\
\text { comunes }\end{array}$ & Crear instituciones birregionales \\
\hline 4. Participación conjunta & Acción Exterior Birregional Conjunta \\
\hline
\end{tabular}

Elaboración propia.

Fuente: Declaración de Roma.

El primer punto tiene que ver con la visión respecto a la misión que pueden desarrollar de manera conjunta ambas regiones a escala global, "La Comunidad Europea y América Latina están llamadas a jugar conjuntamente un papel activo en la reconstrucción de la sociedad internacional del futuro" ${ }^{272}$.

Importante, en cuanto los países europeos, que siempre han querido y han jugado un papel activo en la sociedad internacional, desean hacerlo contando con América Latina, claro está que es por su afinidad cultural, además de sus lazos históricos, y por ello entre los Objetivos Globales que señala la Declaración de Roma, se encuentran otros tres puntos. El de colaborar para mantener los propósitos y principios de la Carta de las Naciones Unidas en los diferentes foros de manera conjunta ${ }^{273}$, y para ello se contempla la necesidad de establecer los medios y mecanismos necesarios para mejorar su

\footnotetext{
${ }^{272}$ Apartado 3. Declaración de Roma sobre las relaciones entre el Grupo de Río y la Comunidad Europea, Roma, 20 de diciembre de 1990. Ver en: Acervo Histórico Grupo de Río. Declaraciones Grupo de RíoUnión Europea. Comunidad de Estados Latinoamericanos y Caribeños.http://celacppt.altavoz.net/grupode-rio-union-europea/celac/2013-04-26/181347.html [Última revisión: 11-06-14]

273 Ibíd. Apartado 4.
} 
coordinación entre ambas regiones, para luego poder participar conjuntamente dentro de los organismos internacionales ${ }^{274}$. Para lograrlo ambas regiones acordaron:

- Celebrar una conferencia anual a nivel ministerial;

- Realizar reuniones de expertos;

- Reunirse a nivel ministerial, durante la Asamblea General de las Naciones Unidas;

- Realizar consultas sobre temas de interés común;

- Compromiso de trabajar conjuntamente sobre propuestas específicas ${ }^{275}$.

Cada uno de estos puntos antes mencionados nos podría hacer pensar sobre la idea e intención de desarrollar una Acción Exterior Birregional a nivel internacional sobre determinados temas y en determinadas áreas y organismos concretos. Sabemos que la Unión Europea es una promotora de la integración y de un sistema internacional basado en una cooperación multilateral que contribuya a una buena gobernanza mundial ${ }^{276}$.

Lo cual no es extraño que promueva también el desarrollo de una acción exterior a nivel regional, en este caso en América Latina, y para ayudarla a realizarla le propone hacerla de manera conjunta. A nuestro entender esta es una intención clara y el punto de partida sobre el interés que tiene la Unión Europea en América Latina, y así constará en los sucesivos documentos oficiales que emitirán las distintas instituciones comunitarias: Consejo de la Unión, Comisión Europea y Parlamento Europeo.

La idea de una asociación y posteriormente de una asociación estratégica, e inclusive el término que usará la UE para hablar sobre el papel de ambas regiones, “Actores Globales", da una idea de la coherencia del interés primero por parte de la UE a la hora de buscar profundizar cada vez más las relaciones con ALC. Sin embargo, ALC no parece creer en que eso es verdad o no termina por creer que puede realmente ejercer una participación activa y aspirar a liderar a nivel internacional, en ciertos temas y áreas como lo hace la Unión Europea, y lo que a nuestro parecer se suma la falta de definición acerca de qué es integración regional, y su no, ceder competencias comunitarias, por no dejar su visión de soberanía nacional en pos de una soberanía común o compartida. Si

\footnotetext{
${ }^{274}$ bíd. Apartado 41.

275 Ibíd. Apartado 48.

${ }^{276}$ Art. 21. Título V. Disposiciones generales relativas a la acción exterior de la Unión y disposiciones específicas relativas a la política exterior y de seguridad común. Tratado de la Unión Europea.
} 
pensamos que la UE es la única que se beneficia de esta relación, por consolidar su Política Exterior y por consiguiente su Acción Exterior, América Latina y el Caribe también puede beneficiarse de ello, si realmente aprovecha y potencializa su relación con la UE.

Como se observa a lo largo de este apartado, se menciona como evidencia, los distintos documentos que tienen relación con esta idea. Idea que en principio podría sonar a un sueño lejano y utópico. Pero para ello están los documentos que declaran la intención de querer hacerlo, la propia UE, desde su nacimiento fue tildada de un sueño y utopía, y se decía que dicho proceso integrador estaba condenado a morir, sin embargo, no sólo existe, sino que conforme pasa el tiempo, se fortalece como una unión regional tanto interna como externamente.

Si revisamos desde la primera acta de las reuniones ministeriales entre la Comunidad Económica Europea y el Grupo de Río de abril de 1991 hasta la Declaración de Praga de mayo de 2009, constatamos que existieron catorce reuniones ministeriales institucionalizadas, en las cuales se van desarrollando distintos temas que van a ser parte de lo que hoy conocemos como la agenda de la asociación estratégica birregional. Y si tuviéramos que pensar en los pilares de dicha Asociación Estratégica Birregional, el desarrollo de una acción exterior birregional es explícito, pues todas las acciones comprendidas en el proceso de negociaciones entre ambas regiones hablan sobre ello.

Es verdad que no se llega a usar el término para los conceptos y acciones para desarrollar una Acción Exterior Birregional, pero en la praxis se dan en los objetivos de dicha Asociación. Todo ello es lo que nos hace pensar que la institucionalización de este mecanismo de consulta permanente a nivel ministerial entre ambas regiones, ha servido para fortalecer sus relaciones, a la par que desarrollar una agenda con puntos en común, puntos que a su vez América Latina y el Caribe han ido incorporando en su propio proceso de integración.

Lamentablemente no ha logrado entender la importancia de desarrollar una acción exterior a nivel regional, pues no la ha desarrollado, y por tanto tampoco se ha podido avanzar más en las relaciones con los países europeos al respecto. Pero las bases están para poder ser desarrolladas en un futuro. 
En el marco temporal entre 1991- 2009 se desarrollan catorce reuniones ministeriales institucionalizadas entre la Comunidad Económica Europea, después la Unión Europea y el Grupo de Río, que después se transformará en CELAC:

1. Luxemburgo, 1991

2. Santiago de Chile, 1992

3. Copenhague, 1993

4. Sao Paulo, 1994

5. Paris, 995

6. Cochabamba, 1996

7. Noordwijk, 1997

8. Panamá, 1998

9. Vilamoura, 2000

10. Santiago de Chile, 2001

11. Atenas, 2003

12. Luxemburgo, 2005

13. Santo Domingo, 2007*

14. Praga, 2009

Si comparamos la primera declaración (Luxemburgo-1991) con la última (Praga-2009) observamos varios aspectos importantes, los cuales podemos concentrarlos en dos:

1. Términos teóricos: Creación de conceptos

2. Términos prácticos: Elaboración de una Agenda Común y la ejecución de Acciones Comunes

Como se ha mencionado anteriormente, varios conceptos y acciones que hoy en día damos por sentado y que se maneja en la literatura académica de manera natural, antes no existían y de ahí el aporte de las relaciones entre ambas regiones durante éstas décadas. Usualmente no reparamos en ellos y eso puede hacer que muchas veces veamos o consideremos que el proceso de Asociación Birregional parezca lento o que está estancado. A nuestro juicio, todo lo contrario, el intercambio de ideas, visión, conceptualización y creación de acciones conjuntas, es el mayor legado que deja el proceso de las negociaciones de la Asociación Estratégica Birregional, para ambos procesos de integración regional. 
A continuación examinaremos de manera sucinta, las catorce declaraciones conjuntas entre ambas regiones, a la par que indicaremos los conceptos y temas que van naciendo y que se irán incorporando, tanto en la agenda compartida (Unión Europea-Grupo de Río), como en las respectivas agendas de sus respectivos procesos de integración regional, tanto en la Unión Europea como en América Latina y Caribe. Finalmente, se realizará una conclusión sobre los temas y conceptos mencionados. Todo bajo la perspectiva teórica de la integración regional y la construcción de actores regionales y su participación en la arena internacional.

La Primera Declaración Conjunta sentará los cimientos para ir desarrollando la definición geográfica y política de América Latina y Caribe como región. La Declaración de Luxemburgo destaca que por primera vez se da la presencia de los representantes de los países de América Central y de la Comunidad del Caribe en el seno de Grupo de Río ${ }^{277}$, y que es gracias a las relaciones que el Grupo de Río establece con la, entonces, Comunidad Económica Europea, que se da el marco para que esas dos subregiones se adhieran al proceso del diálogo político entre los dos conjuntos regionales.

Al respecto "los Ministros de la Comunidad Económica Europea se declararon dispuestos a prestar su asistencia a los países del Grupo de Río en los aspectos teóricos y prácticos de la integración, a nivel regional, subregional y bilateral" ${ }^{278}$. Sin embargo hasta ese momento América Latina y el Caribe siguen siendo tratados como dos regiones distintas.

Otro punto son las menciones que se hacen al compromiso y apoyo, por parte de ambas regiones, a las Naciones Unidas y la Organización de Estados Americanos. "Los ministros reafirmaron su apoyo a las Naciones Unidas y a la Organización de Estados Americanos" ${ }^{, 279}$ ¿ ¿Por qué es resaltante este punto? Por dos razones, primero porque las Naciones Unidas promueve el trabajo y la organización de regiones, muestra de ello es

\footnotetext{
277 Apartado 3. Cooperación en el proceso de integración regional y subregional Acta de la Primera Reunión Ministerial Institucionalizada entre la Comunidad Económica Europea y el Grupo de Río, Luxemburgo, 26 de abril de 1991. Ver en: Acervo Histórico Grupo de Río. Declaraciones Grupo de RíoUnión Europea. Comunidad de Estados Latinoamericanos y Caribeños. http://celacppt.altavoz.net/grupo-de-rio-union-europea/celac/2013-04-26/181347.html [Última revisión: 11-06-14]

${ }^{278}$ Ibíd. Apartado D.

${ }^{279}$ Ibíd. Apartado 4.
} 
que desde sus inicios, la ONU, trabajará a través de Comisiones Regionales ${ }^{280}$, para promover el desarrollo y la paz a nivel mundial, aquí otro hecho que constata la idea de Hettne sobre un mundo de regiones. Así, dentro de la ONU tenemos a: Comisión Económica para Europa (CEE, creada en 1947), Comisión Económica y Social para Asia y el Pacífico (CESPAP, creada en 1947), Comisión Económica para América Latina y el Caribe (CEPAL, creada en 1948), Comisión Económica para África (CEPA, creada en 1958), Comisión Económica y Social para Asia Occidental (CESPAO, creada en 1973).

Cabe recordar que la CEPAL nació llamándose Comisión Económica para América Latina, y que es recién en 1984 que Naciones Unidas, incluye dentro de su área de trabajo al Caribe dentro de América Latina. Pero la CEPAL no es en sí un proceso de integración, por lo que la definición de región como actor político será resultado de las relaciones con otro proceso de integración, el de la UE. Si comparamos Declaración de Luxemburgo con la Declaración de Praga (2009), observaremos que ya se usa el término América Latina y el Caribe ${ }^{281}$.

Con respecto a la Organización de Estados Americanos, veremos que el apoyo a su gestión y trabajo es agradecido en las primeras declaraciones, pero ya no se hacen ninguna mención en las últimas. Incluso la Declaración de Praga enfatiza que el rol a jugar para enfrentar los desafíos mundiales es un trabajo de dos organizaciones: la UE y el Grupo de Río. Así consta en la declaración: "los Ministros reiteraron su compromiso con la Carta de Naciones Unidas [...] y subrayaron la importancia del diálogo entre la Unión Europea y el Grupo de Río, así como la necesidad imperiosa de trabajar conjuntamente, en particular para hacer frente a los desafíos mundiales. ${ }^{282}$.

Lo que demostraría el reconocimiento y respeto por el deslinde político que tratan de realizar los países latinoamericanos, ya por ese entonces, y su búsqueda de establecer un nuevo equilibrio en sus relaciones con el organismo continental, la OEA. Es decir, quizás los países europeos, en una primera instancia, a la hora de iniciar las relaciones

\footnotetext{
${ }^{280}$ Naciones Unidas. Comisiones Regionales. Departamento de Asuntos Económicos y Sociales. http://www.un.org/es/development/desa/regions.shtml [Última revisión: 10-06-2014]

${ }^{281}$ Apartado 15. Declaración Conjunta Unión Europea-Grupo de Río, Praga, 13 de mayo de 2009. Ver en: Acervo Histórico Grupo de Río. Declaraciones Grupo de Río-Unión Europea. Comunidad de Estados Latinoamericanos y Caribeños.

http://celacppt.altavoz.net/grupo-de-rio-union-europea/celac/2013-04-26/181347.html [Última revisión: 11-06-14]

${ }^{282}$ Ibíd. Apartado 2.
} 
institucionalizadas con los países latinoamericanos, decidieron incorporar continuas menciones a la OEA, y por tanto manifestar el apoyo y respeto al trabajo del organismo continental en la región de ALC, pero también se podría pensar que era por no entrar en un conflicto directo con su otro socio, los Estados Unidos (en términos a los intereses de Estados Unidos en la región de ALC), que además de ser, para ese entonces, el principal socio para ambas regiones, tanto político como comercial, es el país que lidera el organismo continental de la OEA. Más aún si consideramos que los objetivos que se buscaban establecer mediante el diálogo político permanente entre europeos y latinoamericanos-caribeños, son parecidos, a los objetivos de la OEA, que también buscaba promover e incentivar el diálogo político y la cooperación a nivel continental. Actitud que pudo haber sido vista por parte de los Estados Unidos como una injerencia respecto a sus intereses en el continente, en términos políticos, económicos, comerciales e inversión.

Pero no es nuestro interés entrar en este debate, pero si lo consideramos interesante señalar, pues a nuestro entender, puede ser una de las razones por la cual los países de la región ALC, han preferido desarrollar relaciones con los países europeos, y el fortalecimiento de estas relaciones ha dado paralelamente un debilitamiento en las relaciones entre los países de ALC con la OEA, y por consiguiente con los Estados Unidos, o viceversa.

En todo caso parece que la UE supo esperar pacientemente que ese tema fuera resuelto internamente, es decir, intracontinentalmente entre los Estados Unidos y América Latina-Caribe. Las últimas décadas han servido de mucho para la UE, el desinterés por parte de ALC hacia Estados Unidos, ha sido el mismo que el desinterés de Estados Unidos hacia esta región, prefiriendo enfocar su acción exterior e intereses en Medio Oriente y en Asia, lo que ha dado como resultado, un alejamiento entre los países latinoamericanos y caribeños con respecto a los Estados Unidos.

Lo cierto es que en la última declaración ya no se le menciona al organismo continental, la OEA. Y como bien se sabe, muchos países de América Latina y Caribe trataron de crear sus propios espacios de coordinación y concertación política, durante la última década, sus intentos han ido desde el plano subcontinental o si se quiere, regional, y de ahí su apuesta por crear UNASUR y la CELAC. UNASUR fue en cierta medida una 
iniciativa alternativa al ALCA, al igual que la CELAC una propuesta alternativa a la OEA.

En la Segunda Declaración Conjunta (Santiago de Chile, 28-29 de mayo de 1992), se expresa la satisfacción por la celebración de la Primera Cumbre Iberoamericana de Jefes de Estado y de Gobierno realizada en Guadalajara, en 1991, el mecanismo iberoamericano será desde entonces incluido en cada una de las declaraciones siguientes. No es de extrañar si recordamos la Adhesión de España y Portugal a las CEE, que contemplaba la voluntad de intensificar y reforzar las relaciones económicas, comerciales y de cooperación con América Latina ${ }^{283}$.

No cabe duda que la consideración de la puesta en valor de la Comunidad Iberoamericana es el resultado de los esfuerzos diplomáticos por parte de España y Portugal de fortalecer el interés por la región de América Latina dentro de la agenda comunitaria europea. A su vez, este mecanismo iberoamericano es importante en cuanto los países latinoamericanos van encontrando, a lo largo de la década de los noventas, otros organismos de diálogo político distintos a la OEA. Lo que también, a nuestro entender, representa un factor que se sumaría al desinterés por parte de varios países latinoamericanos por debatir sus asuntos dentro del organismo continental, la OEA, en favor de encontrar convergencias políticas en otros organismos, como la Comunidad Económica Europea y la Comunidad Iberoamericana.

Otro constante factor es el apoyo por parte de los europeos en la promoción del diálogo político intrarregional, es decir entre dos subregiones la latinoamericana y la caribeña: "Los Ministros de la Comunidad decidieron apoyar los esfuerzos de la integración de América Latina"284; y por eso destaca el dinamismo de los procesos de integración a nivel subregional como el Grupo Andino, MERCOSUR, G3, Mercado Común Centroamericano, CARICOM y los acuerdos dentro del marco de ALADI. Lo que evidencia el interés de la CEE por ver a América Latina unificada en una sola región

\footnotetext{
${ }^{283}$ Declaración Común de intenciones relativa al desarrollo y a la intensificación de las relaciones con los países de América Latina, 12 de junio de 1985. En Instituto de Relaciones Europeas-Latinoamericanas: Europa-América Latina: 20 años de documentos oficiales, Op. cit. p. 55

${ }^{284}$ Apartado 5. Cooperación en el proceso de integración regional y subregional Acta de la Primera Reunión Ministerial Institucionalizada entre la Comunidad Económica Europea y el Grupo de Río, Luxemburgo, 26 de abril de 1991. Ver en: Acervo Histórico Grupo de Río. Declaraciones Grupo de RíoUnión Europea. Comunidad de Estados Latinoamericanos y Caribeños.

http://celacppt.altavoz.net/grupo-de-rio-union-europea/celac/2013-04-26/181347.html [Última revisión: 11-06-14]
} 
desde el inicio de sus relaciones permanentes. Interés que fue visto con desconfianza por parte de los Estados Unidos, dado que esto dificultaría desarrollar relaciones bilaterales, modelo de relaciones internacionales, aplicado y defendido por los Estados Unidos a la hora de querer firmar acuerdos de libre comercio con los países de la región ALC.

Otros aspectos relevantes de la declaración es la mención a los principios y valores universales que comparten ambas regiones, las cuales luego pasaran a ser considerados piedra angular de la Asociación Birregional. Las partes se adhieren a los principios de la democracia representativa ${ }^{285}$, Estado de Derecho, justicia social y el respeto por los Derechos Humanos. Establecen que existe un nexo entre la democracia, derechos humanos y desarrollo sostenible, como camino para el desarrollo.

Así mismo, brindan su apoyo al papel constructivo en la solución de conflictos regionales e internacionales por parte de las Naciones Unidas ${ }^{286}$. Destacan el Diálogo de San José (entre Centroamérica y la Comunidad Europea) y cómo éste diálogo contribuye no sólo con la paz en la región centroamericana sino también con la estabilidad y la paz en el conjunto de la región ${ }^{287}$. Con estos esfuerzos la Comunidad promueve la creación de una zona de paz dentro de la región.

En lo que respecta a al futuro de las "Acciones Conjuntas" a nivel Birregional, los primeros pasos lo darán ambas regiones al acordar reunirse previamente en el marco de la 47 Asamblea General de las Naciones Unidas ${ }^{288}$, a celebrarse en la ciudad de Nueva York, para fijar posiciones comunes, esta práctica se volverá habitual hasta la actualidad, y será justamente, porque sus relaciones se basan sobre valores y principios comunes.

Finalmente los apartados 35 y 37 de la declaración mencionan dos puntos que servirán para ampliar la futura cooperación hacia la región de los países del conjunto de ALC. Estos puntos tienen que ver con la creación de programas de formación empresarial de

\footnotetext{
285 Apartado 5.1. Declaración Conjunta, Reunión Ministerial Institucionalizada Comunidad EuropeaGrupo de Río, Santiago de Chile, 28-29 de mayo de 1992. Ver en: Acervo Histórico Grupo de Río. Declaraciones Grupo de Río-Unión Europea. Comunidad de Estados Latinoamericanos y Caribeños. http://celacppt.altavoz.net/grupo-de-rio-union-europea/celac/2013-04-26/181347.html [Última revisión: 11-06-14]

${ }^{286}$ Ibíd. Apartado 9.

${ }^{287}$ Ibíd. Apartado 12.1.

${ }^{288}$ Ibíd. Apartado 41.1.
} 
carácter regional y de formación, información y sensibilización sobre los procesos de integración regional, con ello nace la idea de crear un Centro Regional para la formación y asistencia técnica en este ámbito. ¿Por qué es interesante este último punto? porque con eso se busca profundizar en el concepto y visión de la integración, si no se piensa a nivel regional, no se podrá diseñar, elaborar, desarrollar y ejecutar políticas de integración regional, de ahí de la importancia que se creen estos programas.

Una principal diferencia entre ambos procesos de integración regional, se dan de una manera bastante asimétrica en cuanto a nivel de desarrollo institucional, sino también político, pues mientras que dentro del proceso de integración regional europeo existen: partidos políticos europeos, movimientos sociales europeos y un sentido empresarial a escala europea; en los países que participan en los procesos de integración regional de América Latina sólo se piensa en integración a nivel de los gobiernos, y no a todos los niveles de la administración pública, salvo en ciertas y escasas direcciones ministeriales relacionadas con los asuntos exteriores, economía, comercio y finanzas. Este punto será estudiando cuando analicemos los servicios de acción exterior de los países latinoamericanos y caribeños.

La Tercera Declaración Conjunta (Copenhague, 23-24 de abril de 1993) los ministros de ambas regiones siguen expresándose "en América Latina y en el Caribe, predominan la paz y la democracia, y están consolidándose la libertad económica y la apertura de mercados [...] desarrollo de procesos de integración regional y subregional"289 ${ }^{2}$. Nótese que dice en América Latina y en el Caribe; y también señala el desarrollo de integración regional y subregional. Lo que confirma nuestra teoría que la idea de una América Latina y Caribe, unida como una sola región es fruto de la insistencia europea por tratar de negociar con un par regional, igual que ella en términos políticos, y de ahí que la importancia del desarrollo de conceptos. Y cuándo la Comunidad Europea saluda y apoya el nacimiento de un nuevo proceso de integración en América Latina y Caribe, rápidamente enfatiza que es un proceso de integración subregional pues la región es América Latina y Caribe, de ahí que se esfuercen por dejarlo claro en cada una de estas declaraciones.

\footnotetext{
${ }^{289}$ Apartado 5.1. Declaración Conjunta, Reunión Ministerial Institucionalizada Unión Europea-Grupo de Río, Copenhague, 23-24 de abril de 1993. Ver en: Acervo Histórico Grupo de Río. Declaraciones Grupo de Río-Unión Europea. Comunidad de Estados Latinoamericanos y Caribeños.

http://celacppt.altavoz.net/grupo-de-rio-union-europea/celac/2013-04-26/181347.html [Última revisión: 11-06-14]
} 
Tratando de cumplir con este objetivo integrador regional, los ministros de la UE deciden intensificar la cooperación al Grupo Andino, MERCOSUR, ALADI, Mercado Común Centroamericano, CARICOM y Grupo de los $\operatorname{Tres}^{290}$, y establecen tres tipos de cooperación a diferentes niveles: regional, subregional y bilateral ${ }^{291}$. Tomando así en consideración los diferentes tipos de intereses y niveles de integración a que aspira cada grupo de países o países individualmente. Así para el MERCOSUR, por ejemplo, diseñan programas de cooperación en temas aduaneros, normas técnicas y agricultura.

En cambio para los países centroamericanos y andinos, se plantean programas de cooperación en integración regional, financiamiento de comercio, agricultura e industrialización. Con Chile se acuerda crear una fundación empresarial Comunidad Europea-Chile para desarrollar el comercio entre ambas partes. Como se puede ver existen diferentes propuestas de acuerdo a los intereses de la contraparte latinoamericana.

En la declaración antes mencionada, se anuncia también las negociaciones para firmar acuerdos marcos de cooperación con Centroamérica y los países andinos. Se empieza con estos dos esquemas de integración, por cuanto son los dos únicos esquemas de integración que conciben la integración a través de la óptica supranacional y porque ambos tienen un sistema institucional parecido al de la UE, de hecho es prácticamente una copia exacta del sistema institucional comunitario de la UE.

Lo que probablemente la UE consideraba podría beneficiar a la hora de realizar una convergencia de todos los procesos de integración subregional a escala regional. Motivo por el cual quizá decide iniciar firmar acuerdos con estas dos subregiones antes que con otros procesos de integración.

La Cuarta Declaración Conjunta (Sao Paulo, 22-23 de abril de 1994) menciona que la cooperación entre ambas regiones se basa en el principio de solidaridad, en apoyo al desarrollo social y regional, cuyos objetivos deben incluir la lucha contra la pobreza y la protección de los menos favorecidos. Por primera vez la declaración comienza a dividirse en áreas temáticas, lo que demostraba que se iban creando los temas para una futura agenda común, éstas son las mismas que años más tarde serán parte de los planes de acción entre la UE-ALC y luego entre la UE-CELAC. En esta declaración se

\footnotetext{
${ }^{290}$ Ibíd. Apartado 23.

${ }^{291}$ Ibíd. Apartado 27.
} 
destacan dos apartados. El primer apartado se titula: "Principios y valores compartidos” ${ }^{, 292}$, entre los que se mencionan, ya los antes indicados, pero esta vez se agrupan en dos grupos:

1. Democracia representativa y el Estado de Derecho

2. Respeto a los Derechos Humanos y de las Libertades Fundamentales

El segundo apartado se llama: "Medidas Conjuntas", las cuales a su vez están subdivididas en ${ }^{293}$ :

1. Aspectos políticos (Naciones Unidas, Desarrollo Social, Cooperación Iberoamericana, Lucha contra el racismo y la xenofobia, terrorismo, drogas, desarme y no proliferación)

2. Aspectos Económicos y de Cooperación

Entre las "Medidas Conjuntas" se habla sobre seguir coordinando posiciones previas antes de las Asamblea General de Naciones Unidas, y acuerdan intensificar el diálogo actual en el Naciones Unidas, para lo cual consideran que los temas a desarrollar de manera común pueden ser los siguientes:

- La Iniciativa del Programa para el Desarrollo y del Programa de Paz

- La reforma de la Carta de las Naciones Unidas y el perfeccionamiento de los métodos de trabajo de la organización

- La aplicación de los acuerdos de la Conferencia de las Naciones Unidas sobre el Medio Ambiente y el Desarrollo

- La Tercera Conferencia Internacional sobre Población y Desarrollo

- La Conferencia Mundial de Pekín sobre la Mujer

- Apoyo a la Declaración de los Derechos del Niño de las Naciones Unidas

- El refuerzo del papel de las Naciones Unidas en la defensa y el fomento de los derechos humanos, y el apoyo al Alto Comisionado para los Derechos Humanos

292 Principios y Valores Compartidos. Declaración de Sao Paulo, IV Reunión Ministerial Institucionalizada Unión Europea-Grupo de Río, Sao Paulo, 22-23 de abril de 1994. Ver en: Acervo Histórico Grupo de Río. Declaraciones Grupo de Río-Unión Europea. Comunidad de Estados Latinoamericanos y Caribeños.

http://celacppt.altavoz.net/grupo-de-rio-union-europea/celac/2013-04-26/181347.html [Última revisión: 11-06-14]

${ }^{293}$ Ibíd. Medidas Conjuntas. 
- La protección de los derechos de las comunidades indígenas y de su patrimonio cultural

- A todo ello, vuelven a reconocer la importancia de la cooperación Iberoamericana, dado que dichos esfuerzos acerca cada vez más a la región ALC a Europa, en comparación a otras regiones del mundo.

La Quinta Declaración (Paris, 17 de marzo de 1995), deja como contribución a la agenda común tres temas, que resumen y evalúan el avance de las relaciones entre ambas regiones. A saber:

\section{Desarrollo Social}

2. Integración Regional

3. Futuro de las relaciones entre el Grupo de Río y la Unión Europea

El primer tema fue abordado desde la perspectiva de comprometerse a poner en práctica la Declaración y el Programa de Acción, adoptados durante la Cumbre Mundial sobre Desarrollo Social (Copenhague, 1995) ${ }^{294}$. Lo que demuestra el cumplimiento de sus acciones conjuntas ante los foros internacionales. A ello se agrega la intención de examinar juntos la definición de una Estrategia Común para la cooperación interregional en materia de Desarrollo Sostenible, cumpliendo también con ello sus compromisos en el marco de los mandatos de las Naciones Unidas.

En materia de integración regional las partes reafirman su convicción de que la integración regional es la mejor vía para garantizar el entendimiento político entre los Estados, a la par que permite un mejoramiento en los niveles de competitividad y una mayor integración en la economía mundial.

Con respecto a éste último punto, ambas regiones expresaron su satisfacción por la creación de la Organización Mundial de Comercio, pues se esperaba que al ser jurídicamente una organización internacional podrá facilitar un trabajo más estructurado y planificado en el tiempo, a la vez que establecer una normativa internacional vinculante para todos los que decidan ser miembros de ésta. Se congratulan por los

\footnotetext{
294 Apartado 2. Declaración Conjunta. V Reunión Ministerial Institucionalizada, Paris, 17 de marzo de 1995. Ver en: Acervo Histórico Grupo de Río. Declaraciones Grupo de Río-Unión Europea. Comunidad de Estados Latinoamericanos y Caribeños.

http://celacppt.altavoz.net/grupo-de-rio-union-europea/celac/2013-04-26/181347.html [Última revisión: 11-06-14]
} 
avances conseguidos en "vasto proceso de integración regional en América Latina y el Caribe sobre la base de un regionalismo abierto". El porqué de enfatizar esta frase es por cuanto a que hace una ligera observación y crítica, a nuestro modo de ver, a los esfuerzos que hacen los países latinoamericanos y caribeños por avanzar en su integración regional, pero a la vez representa un dispersión de esfuerzos, cuando menciona el término vasto proceso, esta dispersión de esfuerzos tiene un doble efecto, en recursos humanos y financieros, por tener tantos procesos parecidos en marcha, en lugar de apostar por una convergencia de los procesos de integración subregionales existentes en uno solo, tal como lo hizo la Unión Europea.

Subsiguientemente se rescata las recomendaciones dadas por la CEPAL hacia los países latinoamericanos y caribeños con relación a establecer una integración regional sobre la base de un regionalismo abierto. Idea que a nuestro entender ha sido mal interpretada por cierto grupo de países que vieron en esta idea un camino de escape para poder iniciar acuerdos bilaterales en contra de promover acuerdos regionales.

La idea de establecer un regionalismo abierto debió haber sido considerada como un mecanismo de cooperaciones reforzadas por los países que sí deseaban una integración regional con características comunitarias, como eran los casos centroamericano y andino, y no por abrir procesos de negociación a nivel bilateral con los hicieron varios países de la región. Por todo ello, la UE apuesta por intensificar el diálogo y la cooperación entre la UE y el Grupo de Río conjuntamente con el Grupo Andino, América Central, MERCOSUR y CARICOM.

Continuando con el tema de integración regional consideran positivo la entrada en vigor del establecimiento de las uniones aduaneras constituidas dentro de la Comunidad Andina y en el MERCOSUR. De igual modo, destacan los avances logrados en las negociaciones de Chile y Bolivia con el MERCOSUR.

Un punto no menor, y que de hecho será importante en el futuro, será las decisiones adoptadas en la Cumbre de Cumana. En ella los países andinos, firmes en su visión de que el fin último es la integración regional y no la integración subregional, en consonancia con la idea de la UE, la Comunidad Andina propone iniciar negociaciones para acercarse al MERCOSUR, el primer paso para un proceso de convergencia entre dos procesos subregionales, y que luego será la plataforma para crear la UNASUR. Esta 
propuesta andina, dejaría entredicho la teoría, que muchas veces se piensa, sobre que la idea de una convergencia sudamericana fue una iniciativa brasileña, o un impulso por parte de los países del MERCOSUR por integrar América del Sur. Esta decisión adoptada en la Cumbre de Cumana deja evidencia que dichas afirmaciones son incorrectas e imprecisas.

Volviendo al punto de integración descrito en la Declaración de París, los ministros de manera conjunta felicitan, también, la entrada en vigor del Tratado de Libre Comercio del Grupo de los Tres ${ }^{295}$, por cuanto dentro de sus objetivos está la integración de América Latina y ampliar la cooperación con los países de América Central y el Caribe. Lo que afianza la idea de ir formando una sola región.

$\mathrm{Si}$ analizamos las ideas de este proyecto, coincide con las ideas que al otro lado del Atlántico se acaban de efectuar, por ese entonces se terminaba de negociar el Tratado de Maastricht que crea la Unión Europea y al mismo tiempo amplió el proceso de integración europea hacia los países de Europa Central, Europa Oriental y el Mediterráneo, lo que se traducirá en términos efectivos en la transformación de una Unión Europea de doce a quince Estados miembro.

Los ministros europeos evalúan los resultados de los programas de formación en materia de integración regional que fueron efectuados por el Centro de Formación para la Integración Regional (CEFIR), con sede en Montevideo, y auspiciado por la UE para que los países desarrollen una visión regional. Según datos de 2009, el CEFIR contaba con más de 300 egresados $^{296}$. Parece mucho, pero si comparamos con los 33.039 funcionarios que trabajan en las instituciones europeas, según cifras oficiales de la Dirección General de Recursos Humanos de la Comisión Europea ${ }^{297}$, podemos ver la diferencia.

\footnotetext{
295 Durante la V Conferencia Ministerial de los Países de América Central, Comunidad Económica Europea y el Grupo de Contadora, celebrada en San Pedro Sula (Honduras), en febrero de 1989, Colombia, México y Venezuela anunciaron la creación del llamado Grupo de los Tres. El 12 de marzo de 1989 en Guyana, firman el Plan de Acción, el cual tiene entre sus objetivos crear un mecanismo e integración económica trilateral que desarrollen acciones conjuntas en favor de la integración de América Latina, en los ámbitos de: económicos, culturales, científicos y técnicos hacia Centro América y el Caribe. Las mismos ámbitos desarrollados en el marco de las relaciones entre la CEE-Grupo de Río.

${ }^{296}$ Centro de Formación para la Integración Regional. Red Alumni. http://www.formacioncefir.org/redalumni/ [Última revisión: 11-06-2014]

${ }^{297}$ Comisión Europea. Personal en cifras. Ver ficha estadística de la Dirección General de Recursos Humanos.

http://ec.europa.eu/civil_service/about/figures/index_es.htm [Última revisión: 11-06-2014]
} 
Y aquí nos detenemos para tratar el tema de la importancia de formar funcionarios, en los diferentes niveles: altos funcionarios y administrativos formados en materia de integración regional. Algo que los procesos de integración subregional y regional en América Latina y Caribe parece no haber tomado en consideración o no darle la importancia debida como un aspecto fundamental en el desarrollo efectivo de sus procesos de integración.

Aspecto que a nuestro entender marca la diferencia a la hora de querer pensar regionalmente, ni que decir, la diferencia entre pensar en los futuros proyectos, iniciativas, políticas o leyes de ámbito regional. Muchos de los funcionarios que trabajan en las organizaciones subregionales y regionales de América Latina y Caribe provienen de sus Estados nacionales con las ideas nacionales o una visión nacionalista, visión contrapuesta si se quiere pensar regionalmente.

Otra consideración que vemos es que la ayuda y cooperación dada en este tema ha sido sólo un esfuerzo unilateral, es decir, desde la UE hacia ALC, sin que ésta última haya tomado medidas para corregir un tema capital para el desarrollo y evolución de sus respectivo proceso integrador. Al respecto, Alberto Hasson, Jefe de la Unidad de la Dirección General IX (Personal y Administración) de la Comisión Europea, en 1995 ya resaltaba este punto como un tema central para el éxito de un proceso de integración regional: "la formación de los funcionarios nacionales en los asuntos europeos constituyen incluso una condición previa para el éxito"298.

Hasson menciona, por ejemplo, que hasta ese momento (1995) se habían tenido que elaborar cerca de 290 directivas comunitarias para armonizar las legislaciones nacionales a la normativa comunitaria y que para eso era imprescindible trabajar paralelamente en la formación de cuadros no sólo internamente, es decir, en las instituciones comunitarias, sino también en los cuadros de funcionarios y administrativos de las instituciones públicas de cada Estado miembro, pues de lo contrario, no se podría entender lo que se quería hacer a nivel regional. La formación europea, fue una apuesta de modernización de las administraciones nacionales, enfatizaba Hasson.

\footnotetext{
${ }^{298}$ HASSON, A.: La formación de cuadros en el marco de la integración regional, en Documento de Trabajo 12/1995. Centro de Formación para la Integración Regional, Montevideo, 1995. pp. 15-22
} 
La UE presentó una iniciativa para ampliar los esfuerzos del CEFIR, con el proyecto FORCE RIO ${ }^{299}$, que incluía la formación de empresarios, en materia de integración regional como fue el Programa FORCE en la Unión Europea, y así complementar los esfuerzos del CEFIR que lo hacía en la misma materia pero destinado a funcionarios que trabajan con temas de integración regional en los países que formaban parte del Grupo de Río.

En el tema sobre el futuro de las relaciones entre el Grupo de Río-Unión Europea, se hacía evidente un cambio de perspectiva, puesto que con la entrada en vigor del Tratado de Maastricht se creaba la UE, y ello llevaba a una redefinición de sus objetivos, dada la amplitud de sus competencias, sobre todo en temas de acción exterior por parte de la UE. Por lo que los ministros de ambas regiones manifiestan el interés común de poner en práctica una "Asociación Nueva", ampliando sus relaciones sobre la base de los acuerdos existentes hasta la fecha, acuerdos que por otro lado eran acuerdos de tercera generación firmados entre la CE y los países y grupo regionales y subregionales de América Latina y del Caribe.

Deciden evaluar los programas comunitarios de inversión implementados en la región como AL-INVEST y ECIP, ambos creados para promover la creación de empresas comunes, con especial énfasis a las PYMES, por ser éstas, en ambas regiones, las principales generadoras de puestos de trabajo y ser el gran sustento de las economías en términos de su contribución en sus respectivos Productos Interior Bruto (PIB). En relación a esto temas, destacan el desempeño realizado por el Banco Europeo de Inversiones $(\mathrm{BEI})$ en el contexto de la integración regional y la promoción de inversiones europeas hacia AL, y el programa de co-financiamiento de proyectos entre el BEI y el Banco Interamericano de Desarrollo (BID) ${ }^{300}$.

Finalmente reafirman la voluntad de realizar Acciones Conjuntas y diseñar una Estrategia a mediano y largo plazo y para ello la UE propone una cooperación regional que contenga una Programación Plurianual, con el fin de hacer un trabajo a mediano y largo plazo, más que a corto plazo, que contengan temas como: reforma social,

\footnotetext{
${ }^{299}$ Declaración Conjunta. V Reunión Ministerial Institucionalizada, Paris, 17 de marzo de 1995. Ver en: Acervo Histórico Grupo de Río. Declaraciones Grupo de Río-Unión Europea. Comunidad de Estados Latinoamericanos y Caribeños.

http://celacppt.altavoz.net/grupo-de-rio-union-europea/celac/2013-04-26/181347.html [Última revisión: 11-06-2014]

${ }^{300}$ Ibíd. Apartado 12.
} 
fortalecimiento de la sociedad civil, modernización del Estado, fortalecimiento de la capacidad de acción del sector privador de la región, educación, ciencia y tecnología ${ }^{301}$.

La Sexta Declaración (Cochabamba, 15-16 de abril de 1996), aporta al acervo integracionista birregional, la acción conjunta, el incremento de la participación del diálogo político a nivel interparlamentario para consolidar la democracia dentro del respectivo proceso de negociaciones ${ }^{302}$. Así como la intención de seguir trabajando conjuntamente para fijar posiciones antes de la 51 Asamblea General de Naciones Unidas, para lo que se decide reunirse en Nueva York para los trabajos preparatorios respectivos $^{303}$.

\subsection{INICIO DE UNA NUEVA ETAPA: HACIA EL DESARROLLO DE UNA ACCIÓN EXTERIOR BIRREGIONAL}

Con la Sexta Reunión Ministerial Institucionalizada y su respectiva Declaración Conjunta, se abre una nueva etapa en las relaciones entre ambas regiones, las novedades que trae dicha declaración es la incorporación de dos nuevos conceptos teóricos y acciones conjuntas en materia de acción exterior a nivel birregional. Analicemos el contenido de esta declaración.

Los ministros apuestan por seguir desarrollando un diálogo, dentro del marco de Naciones Unidas, acercando posturas de ambas regiones y cooperar en asuntos de interés mutuo en este organismo y otros foros internacionales, para lo cual acuerdan reunirse una vez más en el marco de la 52 Asamblea General de Naciones Unidas.

Otro aspecto novedoso, es que es será la primera vez que se mencionen dos nuevos conceptos, el uso de América Latina y el Caribe, como una sola región y el término Comercio Birregional. En relación al primer punto, los ministros mencionan “de los avances logrados en el proceso de integración económica y cooperación política tanto

\footnotetext{
${ }^{301}$ Ibíd. Apartado 14.

302 Apartado 32. Declaración Conjunta. VI Reunión Ministerial Institucionalizada, Cochabamba, 15-16 de abril de 1996. Acervo Histórico Grupo de Río. Declaraciones Grupo de Río-Unión Europea. Comunidad de Estados Latinoamericanos y Caribeños.

http://celacppt.altavoz.net/grupo-de-rio-union-europea/celac/2013-04-26/181347.html [Última revisión: 11-06-2014]

${ }^{303}$ Ibíd. Apartado 37.
} 
en América y el Caribe como en Europa" ${ }^{304}$. Obsérvese que se dice tanto en América Latina y el Caribe como en Europa, es decir divide en dos, ya no en tres partes, como antes se decía. Para reafirmar esta teoría, y no pensar que es sólo, quizás, una forma de abreviar o de redacción, se menciona que el "en relación con el comercio birregional, constataron con satisfacción el hecho de que América Latina y el Caribe en su conjunto ha surgido como uno de los mercados más dinámicos para la Unión Europea. Asimismo, la Unión Europea sigue siendo uno de los mercados más importantes para América Latina y el Caribe" 305.

Ambos aspectos influirán en el cambio de dirección de las relaciones entre ambas regiones que terminarán con la creación de un diálogo político birregional que terminará en la futura Asociación Birregional, tal como hoy la conocemos.

La Octava Declaración (Panamá, 11-12 de febrero de 1998) remarca la importancia de del Diálogo Político que fortalezca las relaciones birregionales ${ }^{306}$, y para ello consideran necesario que ese diálogo político también incorporé un Diálogo Político Interparlamentario entre ambas regiones y subraya los resultados derivados de la XIII Conferencia Interparlamentaria Unión Europea-América Latina (Parlamento EuripeoParlamento Latinoamericano), celebrado en Caracas en 1997.

Otro tema que entra en la agenda, y que había sido ya tratada antes pero no a este nivel, es el tema de la Lucha Contra las Drogas, tema de trascendencia, por cuanto será uno de los argumentos para que varios procesos de integración subregional, por ejemplo en de la Comunidad Andina, acceda al Sistema de Preferencias Generalizadas. La Unión Europea invita a todos los países de América Latina y el Caribe a participar en el mecanismo de cooperación entre la UE-ALC, cuya primera reunión estaba prevista para marzo de 1998, y en la cual se espera identificar de manera conjunta mecanismos e

\footnotetext{
${ }^{304}$ Declaración Conjunta. VII Reunión Ministerial Institucionalizada, Noordwijk, 7-8 de abril de 1997. Acervo Histórico Grupo de Río. Declaraciones Grupo de Río-Unión Europea. Comunidad de Estados Latinoamericanos y Caribeños. http://celacppt.altavoz.net/grupo-de-rio-union-europea/celac/2013-04-26/181347.html [Última revisión: 11-06-14]. Apartado 11.

305 Ibíd. Apartado 23.

${ }^{306}$ Declaración Conjunta. VIII Reunión Ministerial Institucionalizada, Panamá, 11-12 de febrero de 1998. Acervo Histórico Grupo de Río. Declaraciones Grupo de Río-Unión Europea. Comunidad de Estados Latinoamericanos y Caribeños.

http://celacppt.altavoz.net/grupo-de-rio-union-europea/celac/2013-04-26/181347.html [Última revisión: 11-06-14]. Apartado 2.
} 
instrumentos que permitan desarrollar una mayor cooperación en la lucha contra las drogas.

Acordaron seguir acordando posturas sobre temas globales con miras a defenderlos en el marco de Naciones Unidas ${ }^{307}$. Y expresan su satisfacción por la próxima celebración de la I Cumbre de Jefes de Estado y de Gobierno de la Unión Europea-América Latina y el Caribe ${ }^{308}$, a celebrarse en Río de Janeiro en 1999, con lo que abren otra etapa en las relaciones entre ambas regiones. Convinieron que los temas a ser tratados en la próxima cumbre birregional serán: asuntos políticos, económicos-comerciales, culturaleseducativos y humanos.

En materia de cooperación, se incorpora otro concepto, el de Socios Privilegiados, significativa definición, porque de ella se desprenderá el concepto de futuros Socios Estratégicos, que más adelante desarrollarán ambas regiones. La Declaración menciona que "los ministros subrayaron su voluntad de actuar como socios privilegiados en la cooperación birregional y manifestaron su interés en profundizarla"309. A este nuevo concepto se suma el concepto de Valor Estratégico. El Apartado 30 señala: "los ministros reconocen el valor estratégico de la cooperación en las relaciones entre la Unión Europea-Grupo de Río"310. Por lo que apuestan a seguir con la cooperación de formación regional tanto en los ámbitos empresariales como en el de funcionarios, pero además agregan que estos esfuerzos deberán de ampliarse a los ámbitos de la educación; y destacan el aporte dado hasta ahora de los siguientes programas y la implementación de otros nuevos como:

\section{FORCE RÍO}

2. AL-INVEST

3. ECIP (conocido por sus silgas en inglés: European Community Investment Partners)

4. AL-URE (Utilización Racional de la Energía)

5. Programa URBANO

6. CEFIR

7. Formación Académica

\footnotetext{
${ }^{307}$ Ibíd. Apartado 16.

${ }^{308}$ Ibíd. Apartado 18.

309 Ibíd. Apartado 28.

${ }^{310}$ Ibíd. Apartado 30.
} 
Con relación al punto siete, la declaración menciona la importancia de reforzar la cooperación birregional científica de excelencia, en el contexto del V Programa Marco Europeo de Investigación y Desarrollo 1998-2002 311 , con el objeto de favorecer la inclusión de América Latina y el Caribe dentro del mismo.

\subsection{NEGOCIACIONES PARA UNA ASOCIACIÓN ESTRATÉGICA BI-REGIONAL}

La celebración de la I Cumbre de Jefes de Estado y de Gobierno de la Unión EuropeaAmérica Latina y el Caribe, maca una nueva etapa en las relaciones entre ambas regiones porque pasa de ser del Grupo de Río a ser con el conjunto de América Latina y el Caribe, con este hecho se ven materializados los esfuerzos de la Unión Europea de ver a América Latina y el caribe como una sola región.

Una debilidad, que es importante señalar es que a pesar que la UE ve a ALC como una región y la trata como igual, estas relaciones nos son iguales, pero no en trato, sino porque una cuenta con una representatividad e instituciones comunitarias y cuya acción exterior es institucionalizada, salvaguardada y definida a través de los tratados europeos, cosa que no ocurre con América Latina y el Caribe. Tema que hasta el día de hoy sigue siendo un tema pendiente por parte de los países de la región latinoamericana y caribeña.

Esta I Cumbre estaría llamada a escribir una nueva etapa en la historia de las relaciones entre los países europeos-latinoamericanos y caribeños, pues marca un punto de inflexión, por cuanto va a desarrollar la idea de crear una Asociación Estratégica ${ }^{312}$, asociación que contemplará no solo los ámbitos económicos, comerciales, sino también políticos, sociales, ambientales, educativos, humanos, técnicos y científicos, lo que hace que sea una agenda ambiciosa a cubrir, pero también demuestra el acercamiento ideológico entre los países de ambas regiones y el deseo de ejecutarla de manera conjunta. Por eso, los países reafirman su compromiso de actuar conjuntamente,

\footnotetext{
${ }^{311}$ Ibíd. Apartado 32.

312 Declaración Conjunta. IX Reunión Ministerial Institucionalizada, Vilamoura, 24 de febrero de 2000. Acervo Histórico Grupo de Río. Declaraciones Grupo de Río-Unión Europea. Comunidad de Estados Latinoamericanos y Caribeños. Apartado 3.

http://celacppt.altavoz.net/grupo-de-rio-union-europea/celac/2013-04-26/181347.html [Última revisión: 11-06-2014]
} 
alentando los trabajos del Grupo Birregional de Seguimiento, cuyo objetivo será darle continuidad y ejecución de las decisiones adoptadas en las cumbres de jefes de estado y de gobierno.

A esta nueva etapa se suman Costa Rica, El Salvador, Guatemala, Honduras, Nicaragua y República Dominicana como parte del Grupo de Río ${ }^{313}$ para participar como representantes de ALC como región. Este es otro avance para la integración de dicha región, y resaltamos nuestra teoría que la integración de esta región avanza, más que por sus propios esfuerzos e intereses de ser una región, por participar en las negociaciones con la Unión Europea.

Es el proceso de las negociaciones con la Comunidad Económica Europea, luego con la Comunidad Europea y finalmente con la Unión Europea, lo que lleva a los países de la región de ALC profundizar y avanzar en su proceso de integración para tener una representación, unido a ello, al constante apoyo político y financiero de la Unión Europea de hacer de América Latina y el Caribe, una región y como veremos más adelante, un Actor Global.

Curiosamente, la UE considera y cree que ALC está llamado a ser un Actor Global, pero parece ser que ALC aún no lo cree. Pues será sólo en los documentos emitidos por parte de las instituciones comunitarias europeas, donde se resalta el papel a jugar de ALC como Actor Global, término que no es usado en ninguno de los documentos oficiales de los procesos de integración subregional o regional en ALC como objetivo ni final, ni a corto o a largo plazo. ALC en sus documentos oficiales sólo menciona las potencialidades que tiene como región y su papel de participante en el escenario internacional en términos económicos, comerciales y en recursos naturales. Por otro lado, es entendible, partiendo que si no tiene una institución que pueda representarla como actor regional, políticamente hablando, es un hecho que es una debilidad.

A pesar de todo ello, la UE apuesta por ALC como un socio estratégico con el cual contar en el escenario internacional. Las partes se comprometen a seguir profundizando sus relaciones a través del proceso de negociaciones, ahora, birregional, y alientan a la implementación de instrumentos y mecanismos establecidos por los acuerdos existentes. Se resalta la convergencia en los puntos de vista por ambas partes respecto a un número

\footnotetext{
${ }^{313}$ Ibíd. Apartado 4.
} 
significativo de temas de interés global y acuerdan incluir dentro de sus debates, la reforma del Sistema de Naciones Unidas, y la búsqueda conjunta de un nuevo equilibrio entre sus órganos principales por que deciden reunirse para coordinar posiciones en la 55 Asamblea General de Naciones Unidas ${ }^{314}$.

Otro avance es el reconocimiento del principio de responsabilidad común y compartida para enfrentar la lucha contra las drogas ilícitas y delitos conexos, y acuerdan de manera conjunta la ejecución del Plan Global en Materia de Drogas entre la UE-ALC, aprobado en Panamá en abril de 1999, plan que busca el control de precursores químicos, cooperación judicial, policial y aduanera, prevención, fortalecimiento institucional, y el desarrollo alternativo como eje central de la cooperación interregional ${ }^{315}$.

Entre los nuevos conceptos aportados por la UE, estará el de Prevención Desastres Naturales, que es el resultado del Grupo Ad hoc sobre desastres naturales del Grupo de Río $^{316}$, y deciden incorporar el tema en el trabajo conjunto.

Entre las acciones externas conjuntas acuerdan apoyar la aplicación del Protocolo de Kioto $^{317}$; defender conjuntamente la liberalización del comercio, mediante normas y directivas, en el marco de la Organización Mundial del Comercio ${ }^{318}$; y defender en los diferentes foros internacionales una nueva arquitectura financiera internacional ${ }^{319}$.

El tema energético será otro tema que se incorpora a la agenda birregional, y se destaca los progresos realizados en la búsqueda de la integración energética de $\mathrm{ALC}^{320}$, por que se decide apoyar a dicho esfuerzo e incluir el uso de energías alternativas. Una idea que refleja la intención de combinar esfuerzos entre el uso de recursos y el uso de energías alternativas para lograr un desarrollo sostenible, algo que ambas regiones tienen y pueden verse beneficiadas si deciden crear programas de desarrollo conjuntos en estas áreas. Para lo cual el intercambio de tecnologías y experiencia será un valor agregado a tener en consideración entre ambas regiones.

\footnotetext{
314 Ibíd. Apartado 9.

315 Ibíd. Apartado 12.

316 Ibíd. Apartado 15.

${ }^{317}$ Ibíd. Apartado 16.

318 Ibíd. Apartado 17.

319 Ibíd. Apartado 21.

${ }^{320}$ Ibíd. Apartado 27.
} 
La Décima Declaración (Santiago de Chile, 28 de marzo de 2001) deja como principal aporte otro concepto, una Visión Común, así como la incorporación de nuevos temas: el empleo, el buen gobierno, sociedad civil, seguridad ciudadana y el tráfico de armas. Los debates se inician esta vez, mediante ejes temáticos, algo que comenzará a ser una constante práctica en las reuniones sucesivas y que serán también extrapoladas a las cumbres de jefes de estado y de gobierno UE-ALC, así como en sus respectivas cumbres a nivel regional. Una idea de focalizar e ir precisando las acciones a desarrollar más allá de las declaraciones de intenciones.

La Declaración de Santiago por tanto presenta dos ejes temáticos, el primero es propuesta por el Grupo de Río la cual se titula: "Nueva Economía, Brecha Tecnológica y Empleo"; y por parte de la UE el tema presentado fue: "La Sustentabilidad de la Democracia, el Buen Gobierno y el Alivio de la Pobreza" ${ }^{\text {321 }}$. El resultado es una convergencia sobre ambos temas y acuerdan defenderlos en los foros internacionales de manera conjunta. Los ministros saludan la entrada de vigor de los Acuerdos de Asociación entre México-Unión Europea y ven avances en las negociaciones con Chile y MERCOSUR.

Tal como se ha indicado anteriormente, comparten la idea de profundizar la cooperación en materia de seguridad ciudadana, combatir la lucha del tráfico ilícito de armas pequeñas y apoyarán los trabajos del Comité Preparatorio de la Conferencia de las Naciones Unidas sobre el Comercio Ilícito de Armas Ligeras y de Pequeño Calibre ${ }^{322}$. Así mismo condenan de manera conjunta, y de forma enérgica toda forma de crimen internacional organizado y el terrorismo.

En materia de sociedad civil consideran necesario intensificar el intercambio y la cooperación entre las sociedades civiles de $\mathrm{ALC}_{-} \mathrm{UE}^{323}$, este punto será uno de los argumentos para lo que luego será la Fundación EU-LAC, que tendrá entre sus principales objetivos dar a conocer la importancia de la Asociación Estratégica

\footnotetext{
${ }^{321}$ Apartado 4. Declaración Conjunta, X Reunión Ministerial Institucionalizada, Santiago de Chile, 28 de marzo de 2001. Acervo Histórico Grupo de Río. Declaraciones Grupo de Río-Unión Europea. Comunidad de Estados Latinoamericanos y Caribeños.

http://celacppt.altavoz.net/grupo-de-rio-union-europea/celac/2013-04-26/181347.html [Última revisión: 11-06-2014]

${ }^{322}$ Apartado 14. Declaración Conjunta, X Reunión Ministerial Institucionalizada, Santiago de Chile, 28 de marzo de 2001. Ibíd.

${ }^{323}$ Apartado 20. Declaración Conjunta, X Reunión Ministerial Institucionalizada, Santiago de Chile, 28 de marzo de 2001. Ibíd.
} 
Birregional, y para lo cual buscará justamente promover el intercambio de experiencias e incentivar la cooperación entre los diferentes actores de las sociedad civil entre ambas regiones.

Los ministros reiteran su "visión común del papel de la integración regional como un factor para el desarrollo económico y social como consolidación de la posición de sus respectivas regiones en la escena internacional ${ }^{\text {} 324}$. Con este aparado se busca resaltar la idea de la integración regional como modelo de desarrollo y como mecanismo de acción exterior en la arena internacional.

La Décimo Primera Declaración (Atenas, 28 de marzo de 2003) como no podía ser de otra manera, por haber sido realizada en Atenas, se resalta en primer orden de los temas, que la relación privilegiada que se da a América Latina y el Caribe, es porque esta se funda sobre la base de una historia y cultura comunes, así como en los valores y principios compartidos ${ }^{325}$. Este punto tiene relación con nuestro apartado anterior sobre el acervo integracionista, que trata justamente sobre la historia y cultura en común, tan común que se desarrollan historias y procesos de unificación política paralelamente, y ambas tomando como base y punto de partida las experiencias desarrolladas en la Antigua Grecia.

Siguiendo con la práctica de tener reuniones temáticas, el Grupo de Río presenta "Los aspectos generales y perspectivas de las relaciones UE-Grupo de Río" y por parte de la UE se presenta "Cohesión Social y Gobernanza Democrática en un nuevo entorno económico". Se resalta el Principio de Solidaridad ${ }^{326}$, tan arraigado y defendido en el proceso de integración europea, principio que también será recogido por los diferentes procesos de integración en ALC.

Entre los temas relacionados con las acciones conjuntas se plantean fortalecer la cooperación birregional en los ámbitos de la democratización y los derechos humanos; y reafirmar su compromiso por hacer cumplir las negociaciones de la Agenda de

\footnotetext{
${ }^{324}$ Apartado 21. Declaración Conjunta, X Reunión Ministerial Institucionalizada, Santiago de Chile, 28 de marzo de 2001. Ibíd.

325 Apartado 3. Declaración Conjunta, XI Reunion Ministerial Institucionalizada, Atenas, 28 de marzo de 2003. Acervo Histórico Grupo de Río. Declaraciones Grupo de Río-Unión Europea. Comunidad de Estados Latinoamericanos y Caribeños.

http://celacppt.altavoz.net/grupo-de-rio-union-europea/celac/2013-04-26/181347.html [Última revisión: 11-06-2014]

${ }^{326}$ Ibíd. Apartado 5.
} 
Desarrollo de Doha ${ }^{327}$, para que esta concluya con éxito. Se pronuncian sobre el respeto de las resoluciones emitidas por las Naciones Unidas sobre la crisis de Irak, y el conflicto Palestino-Israelí, con relación a este último, apoya los trabajos del Cuarteto ${ }^{328}$, establecido entre la Unión Europea, Rusia, Naciones Unidas y los Estados Unidos. Las regiones comienzan a expresarse cada vez más sobre asuntos globales, lo que constata la intención de su acción exterior o posición birregional a nivel internacional.

La Décimo Segunda Declaración (Luxemburgo, 27 de marzo de 2005) presenta como temas: el futuro de las relaciones UE-Grupo de Río, la integración y la cooperación regionales, la cooperación internacional con Haití, la creación de empleo para luchar contra la pobreza y fortalecer la gobernanza democrática ${ }^{329}$.

En materia de acciones conjuntas, discuten sobre las posiciones a presentar ante la 60 Asamblea General de Naciones Unidas que se llevará a cabo en septiembre de 2005; su compromiso con los Objetivos del Desarrollo del Milenio y reforma de las Naciones Unidas $^{330}$ y de sus respectivos órganos, en particular, la Asamblea General, el Consejo de Seguridad y el Consejo Económico y Social.

Es la primera vez que se establece como objetivo de acción conjunta, defender cambios tan ambiciosos, la idea es consolidar y mejorar una mayor representatividad, transparencia y eficacia del Sistema de Naciones Unidas, así como la Comisión de Derechos Humanos. Esta acción marca también la primera vez que defienden una idea en contra de las ideas de unos de sus principales socios para ambas regiones, los Estados Unidos, que desea mantener el statu quo del sistema internacional. Se aprueba también el apoyo a las Naciones Unidas de establecer el $0.7 \%$ del PIB para la Ayuda Oficial al Desarrollo ${ }^{331}$, compromiso que fue adquirido en Monterey en 2002. También se brinda el respaldo a las Naciones Unidas en la propuesta sobre la No Proliferación de Armas de Destrucción Masiva, así como el control de armamento y desarme ${ }^{332}$.

\footnotetext{
${ }^{327}$ Ibíd. Apartado 7.

${ }^{328}$ Ibíd. Apartado 13.

${ }^{329}$ Apartado 3. Declaración Conjunta. XII Reunión de Ministros Institucionalizada, Luxemburgo, 27 de marzo de 2005. Acervo Histórico Grupo de Río. Declaraciones Grupo de Río-Unión Europea. Comunidad de Estados Latinoamericanos y Caribeños.

http://celacppt.altavoz.net/grupo-de-rio-union-europea/celac/2013-04-26/181347.html [Última revisión: 11-06-2014]

${ }^{330}$ Ibíd. Apartado 10.

${ }^{331}$ Ibíd. Apartado 13.

332 Ibíd. Apartado 14.
} 
Nos detendremos en examinar al detalle el Apartado 7, por cuanto indica lo siguiente, que "toman conocimiento de la Comunidad Sudamericana de Naciones (CSN) 333 " y de los objetivos que esta nueva comunidad pretenden desarrollar. Por qué resaltamos este punto, porque entre los objetivos de la CSN, creada en 2004, se plantea ejerza de mecanismo de coordinación política y de la integración económica, social y cultural que permitirá impulsar sus intereses en los foros internacionales.

Obsérvese que usan los términos "toman nota" no dicen "saludan", "congratulan" ni mucho menos mencionan "progreso en la integración regional", cada uno de estos términos han sido usados cada vez que se hablaban de la creación de los otros procesos de integración subregional (Sistema de Integración Centroamericano, CARICOM, CAN, MERCOSUR), porque se cuidan en no usar esos términos, acaso no es una alegría que se hable de una posible convergencia entre dos esquemas de integración subregionales como son el MERCOSUR y la CAN, pues así fue anunciada CSN.

Nuestra teoría es que quizás la UE no vio con buenos ojos, la creación de UNASUR, por cuanto representa una dispersión de esfuerzos, primero porque se crea otro organismo de integración más, a todos los existentes, porque este podría entorpecer la integración regional, en lugar de afianzarla. Pues como dice sus objetivos, pretende ser un mecanismo de coordinación política que impulse los intereses de los suramericanos en los foros internacionales, todos los esfuerzos de la UE por ver a una ALC unida y defendiendo ante los foros internacionales como una sola región ante los foros internacionales, se vería debilitada al ser representada a escala subregional a nivel suramericana.

A esto habría que sumarle las contradicciones antes mencionadas entre el enfoque sobre la integración desarrollada entre los países andinos y los de MERCOSUR. La CSN más allá de representar un avance en el proceso de integración regional podría representar, en este sentido una fractura del proceso de integración entre una nueva subregión, la suramericana, y la centroamericana y la caribeña. Es verdad que no ha existido nunca un pronunciamiento en contra por parte de la UE sobre CSN, que luego se transformara en UNASUR, pero la prueba de una posible desconfianza de este nuevo proceso es que nunca han establecido relaciones formales, como lo ha hecho la UE con los otros procesos de integración a nivel subregional. O quizás, simplemente no tomó

\footnotetext{
${ }^{333}$ Ibíd. Apartado 7.
} 
importancia, por cuanto la CSN no definía con claridad sus objetivos, entre los cuales se entremezclaban conceptos como el de aspirar ser un foro regional o ser un proceso de integración, sobre la convergencia de CAN y MERCOSUR. La realidad ha demostrado que la CSN, hoy UNASUR, ha terminado siendo sólo un foro político y no un proceso de convergencia.

La Décimo Tercera Declaración (Santo Domingo, 20 de abril de 2007), es prácticamente una reunión de evaluación de las últimas reuniones y por ello se limita a repasar los temas antes tratados: Haití, energía, medio ambiente, cambio climático, los países de renta media y la lucha contra la pobreza, fortalecimiento del multilateralismo y el diálogo entre la UE-Grupo de Río ${ }^{334}$.

La Décimo Cuarta Declaración (Praga, 13 de mayo de 2009) se centra en la crisis financiera internacional que empezó en el 2008, y que de hecho, si observamos, no se realizó una reunión en ese año. Por ello todos los temas se enfocaron en la recuperación de la estabilidad financiera y crecimiento de la economía mundial, tal como consta en la Parte Segunda de la Declaración. Crisis que según los ministros necesita "una respuesta concertada global de la comunidad internacional [...] las economías emergentes y en desarrollo, incluidas las más pobres, deben de tener más voz y más representación”,335.

La crisis, lejos de apartar a ambas regiones por la diferencias de cómo enfrentaron la misma, las une en la idea de que es necesario tener más voz y mayor representación en la escena internacional, y para ello la respuesta es una acción conjunta que estimule a la comunidad internacional, la reflexión de una nueva arquitectura financiera internacional fue la respuesta, que por otro lado era algo que ya se venía tratando en las anteriores reuniones ministeriales. También sirve para ampliar su campo de acción exterior conjunta, como es el caso de defender la visión común sobre las soluciones a la crisis en el foro internacional de la Cumbre del $\mathrm{G} 20^{336}$.

\footnotetext{
${ }^{334}$ Declaración de Santo Domingo, XIII Reunión Ministerial Institucionalizada, Santo Domingo, 20 de abril de 2007. Acervo Histórico Grupo de Río. Declaraciones Grupo de Río-Unión Europea. Comunidad de Estados Latinoamericanos y Caribeños. http://celacppt.altavoz.net/grupo-de-rio-union-europea/celac/2013-04-26/181347.html [Última revisión: 11-06-2014]

335 Apartado 11. Declaración de Praga, XIV Reunión Ministerial Institucionalizada, Praga, 13 de mayo de 2009. Acervo Histórico Grupo de Río. Declaraciones Grupo de Río-Unión Europea. Comunidad de Estados Latinoamericanos y Caribeños.

http://celacppt.altavoz.net/grupo-de-rio-union-europea/celac/2013-04-26/181347.html [Última revisión: 11-06-2014]

${ }^{336}$ Ibíd. Apartado 13.
} 
Entre las propuestas debatidas como posibles soluciones se trataron temas como reforzar los trabajos que lleven a la conclusión acertada y equilibrada en la Ronda de Doha de la OMC, para lo que consideran vital rechazar el proteccionismo en todas sus formas $^{337}$.

Aquí podemos hacer un alto, para mencionar que para que esta propuesta prospere antes deberán de hacer cambios estructurales en sus políticas, nos referimos a la Política Agraria Común por parte de la UE, que es un mecanismo de protección y subvención a este sector, que se contradice con el discurso de la UE de promover un libre comercio y sin restricciones. Y por parte de ALC el proteccionismo ejercido por Brasil y por algunos países que comienzan a querer volver implementar medidas proteccionistas, principalmente los que se identifican con el movimiento bolivariano. En ambos casos se produce un doble discurso, y mientras siga existiendo y no adopten medidas para corregirlo, será un tema sin resolver no sólo en el marco de la OMC, sino también para avanzar en las negociaciones comerciales, entre ambas regiones y con terceros países y regiones en el mundo. Como una respuesta alternativa se alienta a la cooperación sursur y triangular ${ }^{338}$.

\subsection{UN NUEVO DIÁLOGO BIRREGIONAL PARA EL SIGLO XXI: LAS NEGOCIACIONES UE-CELAC}

La Declaración de Santiago tituló su primer apartado "El nuevo diálogo CELAC-UE", como bien hemos visto anteriormente, el diálogo no es nuevo, pues llevan tiempo trabajando de manera conjunta ambas regiones, pero es nuevo en el sentido a la dimensión que cobra el diálogo, ya que será la primera vez que América Latina y el Caribe se presentaba con un solo mecanismo que busca ser representativo de toda esta región. Tal como se menciona en la Declaración de Santiago, de ahora en adelante será la CELAC la que sostendrá el diálogo birregional con la Unión Europea. Esto es un paso adelante para ALC, que hasta ahora se presentaba como una "región" y negociaba como tal sin tener un organismo, institución o mecanismo permanente que la representara en su conjunto. Es verdad que la CELAC no ha desarrollado aún una institucionalidad, y que al día de hoy trabaja mediante el sistema de trabajo de la Troika CELAC.

\footnotetext{
${ }^{337}$ Ibíd. Apartado 14.

${ }^{338}$ Ibíd. Apartado 18.
} 
No cabe duda que ALC cuente con un mecanismo representativo y permanente como región es un avance significativo, pero poco sustancial, si no le brinda personalidad jurídica, y por tanto institucionalidad. También es verdad, que los países son libres de no querer hacerlo, como son libres de seguir o no los pasos o modelo institucional de la UE o crear uno propio.

Pero lo cierto es, que sí han decidido dar pasos para profundizar su integración regional creando este mecanismo que agrupe al conjunto de las subregiones y países sueltos (México y Chile) y quieren tener una mejor capacidad de negociación como región, si es esta la dirección que desean tomar, tendrán entonces que desarrollar instrumentos jurídicos para ello, e instituciones para ejecutarlas y que velen por el cumplimiento de las normas y políticas comunitarias o regionales que se decidan adoptar. Quedará por ver si la CELAC adopta o no estas medidas. Pero mientras la UE posee una política exterior común, instituciones para ejecutarla, e incluso un Alta Representante de la Unión para Asuntos Exteriores y Política de Seguridad. Ni que decir ya del Presidente del Consejo Europeo y del Presidente de la Comisión Europea. Es difícil ver que la CELAC como una contraparte formal e institucional en un diálogo birregional o cualquier otro diálogo a nivel internacional; y nos referimos a las intenciones y proyectos que comienzan a desarrollar con China o la Unión Africana, por citar unos ejemplos.

La CELAC carece de personalidad jurídica para negociar y representar a la región. Ello muestra la falta de representatividad por parte de ALC como un actor regional, y la constatación que los países no desean dar, ni un milímetro en cesión de algunas de sus competencias nacionales, ni que decir sobre la idea de contar con una soberanía común.

En el caso que nos compete en este apartado, podemos citar la experiencia que deja el sistema de cumbres CELAC-UE. En el marco de este sistema de cumbres, en Santiago se celebraron cuatro cumbres y una asamblea parlamentaria birregional. En todos los casos, la ausencia de una representante o figura a nivel regional por parte de la CELAC fue una prueba de que los países no tienen la intención de desarrollar esa representatividad a nivel institucional, hecho que dificulta la visibilidad regional de ALC, a la par resta efectividad en la capacidad de negociación. 
En lo que respecta a la Cumbre de Santiago UE-CELAC, se desarrollaron cuatro tipos de cumbres:

En los actos de apertura y clausura de la Cumbre de Jefes de Estado y de Gobierno UECELAC (26-27 de enero de 2013), participaron como representantes regionales los siguientes: representando a ALC, el Presidente de Chile, Sebastián Piñeira, en su calidad de Presidente Pro-témpore de la CELAC. Representando a la UE, estaban el Presidente del Consejo Europeo, Herman Van Rompuy y el Presidente de la Comisión Europea, José Manuel Durao Barroso.

A la IV Cumbre Empresarial CELAC-UE (25 de enero de 2013) representando a los países de la CELAC estaba el Presidente de Chile y el Presidente de la Confederación de la Producción y del Comercio, Lorenzo Constans. Representando a la UE, se encontraba el Presidente del Consejo Europeo.

En la I Cumbre Académica CELAC-UE (22-23 enero de 2013) intervinieron en los actos de apertura, el Ministro de Relaciones Exteriores de Chile, Alfredo Moreno, y los embajadores de Chile, Emb. Rodrigo Gaete y Emb. Daniel Carvallo. Como participantes y representando a la UE, estuvieron el Ministerio de Asuntos Exteriores de Francia, por ser la iniciativa de la Cumbre Académica una idea de Francia y Chile, también estuvieron representantes de la Fundación EU-LAC y EUROLAT. El objetivo de esta cumbre es trabajar sobre los temas de educación, ciencia, tecnología e innovación ${ }^{339}$, a la par que se busca desarrollar un espacio de educación superior común entre ambas regiones ${ }^{340}$.

Cabe señalar que la Fundación EU-LAC nace con la vocación de promover la participación activa de la sociedad civil de ambas regiones y contribuir con ello a un mejor entendimiento y fortalecer la Asociación Estratégica Birregional, y que ésta, nace siendo, en una primera instancia, como una fundación birregional, pero está llamada a convertirse en la primera organización de carácter birregional. Lo que hace que su participación en este tipo de foros sea relevante e imprescindible de cara a consolidar dicha Asociación Estratégica Birregional.

\footnotetext{
339 LEIVA. P. (Ed): Hacia un espacio eurolatinoamericano para la educación superior, ciencia, tecnología e innovación. Foro Académico Permanente ALC-UE. Universidad Central, Santiago de Chile, 2013.

340 CENTRO LATINOAMERICANO DE RELACIONES EUROPA AMERICA LATINA. Revista EUROLAT, N 84, AÑO 18, Santiago de Chile, agosto 2012.
} 
La inauguración y apertura de la I Cumbre Judicial CELAC-UE (10-11 de enero de 2013), estuvo a cargo por parte de CELAC, el Presidente de Chile, el Ministro de Relaciones Exteriores de Chile, el Presidente de la Corte Suprema de Chile, Rubén Ballesteros y el Ministro de la Corte Suprema de Chile y coordinador general de la Cumbre, Sergio Muñoz. Por la representación de la UE, estuvo el Presidente de la Red de Presidentes de las Cortes Supremas Judiciales de la UE, Geert Costens.

En la VI Asamblea EUROLAT (23-25 de enero de 2013), asamblea que reúne a los dos parlamentos de carácter regional, Parlamento Latinoamericano y el Parlamento Europeo $^{341}$. Intervinieron por parte de ALC el Ministro de Relaciones Exteriores de Chile y por parte de la UE, la Alta Representante de la Unión para Asuntos Exteriores y Política de Seguridad, Catherine Ashton.

Como se puede ver, por el lado europeo siempre hay un representante o representantes de la Unión, como región, mientras que en ALC, no se da ese caso, el protagonismo siempre lo cobra el país que ejerce la presidencia pro- témpore, no está mal, pero no sería mejor contar con representantes regionales? Más aún si cuando fue fundada tiene dicho objetivo y más cuando se dice que será el par de la UE dentro del diálogo birregional. Para ser un par, es necesario ser iguales institucionalmente.

El mecanismo de la coordinación y representación en $\mathrm{CELAC}^{342}$, funciona a través de la Troika. Recordemos que el sistema de Troika es ejercido por tres países, el que ejerció la presidencia pro-témpore, el que ejerce y el que ejercerá la presidencia, siguiendo un orden determinado por los estados miembro de la organización en cuestión. Lo que significa un trabajo de coordinación a tres bandas a nivel de los ministerios de relaciones exteriores de los respectivos países.

Pensemos por un momento en la desventaja de este sistema, sistema que justamente abandonó la UE y sustituyó por instituciones comunitarias permanentes con funciones y

\footnotetext{
341 AJENJO, N. y STAVRIDIS, S.: La Asamblea Parlamentaria EUROLAT: ¿Un modelo de relación entre bloques de integración regional? Working Paper N31, Programa de América Latina, Centro Argentino de Estudios Internacionales, Buenos Aires, 2011. Ver también: VITTINI, I.: La Asamblea Euro-Latinoamericana EUROLAT. Antecedentes y su importancia para la promoción de la comunidad de valores. Programa de Estudios Europeos: Europa América Latina. Dos caminos, ¿Un destino común? Universidad de Concepción, Chile, 2012.

${ }^{342}$ ROJAS, F.: Nuevo espacio de concertación regional: La CELAC, en ROJAS, F. (Ed) América Latina y el Caribe: Relaciones Internacionales en el siglo XXI. Diplomacia de Cumbres y espacios de concertación regional y global. FLACSO, AECID, TESEO, Buenos Aires, 2012.
} 
capacidades para su acción exterior de manera comunitaria. Imaginemos en tres escenarios ejercidos como Troika:

Escenario A, los tres países que coinciden son pro integración regional y deciden preparar una agenda que incluya políticas regionales, proyectos e iniciativas que promuevan una mayor profundización en su proceso de integración y que deseen dar un paso más profundo y quieran dar mayor visibilidad a su proceso creando para ello instituciones regionales permanentes con competencias e independencia supranacional.

Escenario B, tres países de los cuales son intergubernamentalitas, anti integración y deseen romper todos los tratados firmados sobre esta materia.

Escenario C, que combina varias posturas, un país integracionista, otro en contra de la integración y un tercer país que está de acuerdo con la integración pero que no sabe que es lo mejor, si aplicar un modelo federalista, supranacional o intergubernamental.

Si a todo esto le agregamos que existe diferencias en la visión y la conceptualización de lo que significa un proceso de integración regional, y le sumamos las ideologías políticas, las diferencias sobre materia económica, el tema se complejiza aún más. A todo ello, habrá que sumarle otra ausencia, el tema de la integración regional, en los planes políticos por parte de los partidos políticos y la ausencia de partidos políticos regionales, a escala de ALC. Por lo que este sistema para ALC se hace ineficiente.

Si observamos la Troika de la CELAC, esta estuvo formada por Chile, Cuba y Costa Rica, los tres países con distintas manera de pensar y ver la integración, y con modelos económicos diferentes. En lo concerniente a lo político, Chile estaba gobernado por el partido Alianza, de tendencia centro-derecha; Cuba, por el Partido Comunista, y Costa Rica por el Partido Acción Ciudadana, socialdemócrata progresista.

El primer y último país con más aperturistas desde el punto de vista económico, Cuba, no lo es, la pregunta cae por su propio peso: ¿Qué acuerdos lograron? Al mínimo de los consensos. Si a todo ello, le añadimos que no todos los ministerios de exteriores cuentan con direcciones generales sobre ALC, de manera exclusiva, o con unidades exclusivamente para tratar los asuntos de integración regional, el tema se va agravando más y más. Muchas veces los temas de integración están, en parte, en las direcciones de multilaterales o a nivel continental. Hecho que dificulta también la manera de trabajar y 
de tratar de organizar un trabajo regional de manera coherente e integrado, con una visión estratégica y a largo plazo.

$\mathrm{Si}$ tuviéramos que evaluar las relaciones entre ambas regiones, podríamos partir diciendo que desde que ambas regiones deciden reunirse a nivel presidencial a través de la organización de Cumbre de Jefes de Estado y de Gobierno, se han realizado siete cumbres $^{343}$ :

1. I Cumbre entre los Jefes de Estado y de Gobierno de la Unión Europea-América Latina y el Caribe (Río de Janeiro 1999).

2. II Cumbre entre los Jefes de Estado y de Gobierno de la Unión EuropeaAmérica Latina y el Caribe (Madrid 2002)

3. III Cumbre entre los Jefes de Estado y de Gobierno de la Unión EuropeaAmérica Latina y el Caribe (Guadalajara 2004)

4. IV Cumbre entre los Jefes de Estado y de Gobierno de la Unión EuropeaAmérica Latina y el Caribe (Viena 2006)

5. V Cumbre entre los Jefes de Estado y de Gobierno de la Unión EuropeaAmérica Latina y el Caribe (Lima 2008)

6. VI Cumbre entre los Jefes de Estado y de Gobierno de la Unión EuropeaAmérica Latina y el Caribe (Madrid 2010)

7. VII Cumbre entre los Jefes de Estado y de Gobierno de la Unión EuropeaAmérica Latina y el Caribe y I Cumbre Unión Europea-Comunidad de Estados Latinoamericanos y Caribeños (Santiago de Chile 2013).

De las cuales se ha hecho teniendo como representación regional por parte de ALC, inicialmente al Grupo de Río y ahora a la CELAC como mecanismos de representación de acción exterior conjunta o concertada ante Europa, que en principio actuó con la Comunidad Económica Europea, luego como Comunidad Europea y ahora como Unión Europea.

La evolución de los países europeos respecto a su acción exterior ha estado marcada por una mayor profundización de su propio proceso de integración, a través de sus tratados, que ha sido reformados una y otra vez, pero siempre dando más competencias a sus instituciones comunitarias y con el claro objetivo estratégico de brindar una mayor voz

\footnotetext{
${ }^{343}$ Para mayor información sobre las declaraciones de las cumbre puede ver en la Fundación EU-LAC: http://eulacfoundation.org/es/content/documentos-alc-ue [Última revisión: 11-06-2014]
} 
en el escenario internacional. Lo que le ha llevado a contar con un Presidente del Consejo Europeo, un Presidente de la Comisión y crear el cargo de un Alto Representante para los asuntos exteriores y dotarle de un Servicio Europeo de Acción Exterior. Mientras la UE ha tomado un camino de crear instituciones comunitarias, ALC se ha quedado rezagada, contando para su acción exterior, sólo con mecanismos de coordinación o de concertación como dicta muchos de sus tratados fundacionales de los diferentes organismos subregionales o regionales que han creado. Quedará por ver cómo resuelve ALC el tema de su acción y representación exterior, y si crea o no, instituciones que se encarguen de manera conjunta o comunitaria estos temas.

Para finalizar este apartado, se desea indicar que podemos resumir distinguiendo tres etapas en las relaciones entre los países europeos, latinoamericanos y caribeños, las respectivas etapas están marcadas por el cambio de mecanismo de representación que han ejercido una y otra región:

I. Primera Etapa: Relaciones Grupo de Río-Comunidad Europea / Relaciones Grupo de Río-Unión Europea.

II. Segunda Etapa: Relaciones América Latina y Caribe-Unión Europea

III. Tercera Etapa: Relaciones Comunidad de Estados Latinoamericanos y Caribeños-Unión Europea.

Como acervo integracionista birregional podemos decir que las relaciones entre ambas dejan las declaraciones conjuntas a nivel ministeriales institucionalizadas, las declaraciones presidenciales y dos planes de acción a nivel birregional (Plan de Acción Madrid 2010-2012 344 y el Plan de Acción Santiago 2013-2015). Agenda de trabajo común sobre temas en ocho grandes áreas de trabajo como:

1. ciencia, tecnología e innovación;

2. desarrollo sostenible, medio ambiente, cambio climático, biodiversidad y energía;

3. integración regional e interconectividad y promoción de la cohesión e inclusión social;

4. migración;

\footnotetext{
${ }^{344}$ Más información ver: Plan de Acción de Madrid 2010-2012, Consejo Europeo de la Unión Europea, Madrid, 18 de mayo de 2010. Prensa, Bruselas, 15 de noviembre de 2010. 10449/1/10 REV 1 PRESSE 150.
} 
5. educación y empleo,

6. el problema mundial sobre drogas;

7. género;

8. inversiones y espíritu empresarial para el desarrollo sostenible ${ }^{345}$.

Si se piensa que estos temas sólo son una declaración de intenciones y retórica, se tendrá que defender la idea que no lo es, pues llevan décadas trabajando para haber llegado a constituir esta agenda, por tanto no es un punto de partida, sino un punto de llegada, después de tantas décadas de diálogo.

Como muestra del deseo por cumplir con todos estos objetivos, los planes de acción contemplan para cada uno de estos temas, un método, el diálogo birregional ya institucionalizado, y actividades e iniciativas concretas a desarrollar e implementar, con objetivos claros y señalados para cada uno de los temas considerados. A todo ello habría que sumarle, como principales resultados, la existencia y trabajo actual desarrollado en tres programas birregionales:

\section{Programa EUrocLIMA}

2. Programa EUROsocial

3. Mecanismo de Inversión en América Latina

4. Mecanismo de Cooperación y coordinación en materia de drogas

5. Programa COPOLAD

6. Foro sobre Cooperación técnica, energía renovables y eficiencia energética UEALC

7. Foro de Cohesión Social UE-ALC

8. Diálogo estructurado y completo sobre migración

9. El Proyecto de Asociación de administraciones públicas, como cooperación interinstitucional birregional.

Sin dejar al lado, lo que tanto se ha remarcado a lo largo de este apartado, como es el trabajo de acciones conjuntas antes foros internacionales, resaltando el trabajo efectuado ante las Naciones Unidas, coordinando las posiciones en las asambleas generales y defender conjuntamente la reforma del sistema de las Naciones Unidas y su compromiso de contribuir con los Objetivos del Milenio a nivel global.

345 Más información ver: EU-CELAC ACTION PLAN 2013-2015. Council of the European Union, Santiago, 27.1.2013. 5748/13, Press, Brussels, p.1. 
Durante la Cumbre CELAC-UE, Karel De Gucht, Comisario Europeo de Comercio señaló la importancia de trabajar juntos, a través de la Asociación, indicó que el intercambio de conocimiento y tecnología entre ambas regiones, sólo puede traer beneficios mutuos y que esto puede significar un crecimiento comercial para todos. Recordó el punto señalado por la CEPAL que decía "las dos terceras partes de todos los proyectos de investigación y desarrollo en esta región se origina en Europa" ${ }^{\text {\#46 }}$. Lo que hace vigente el interés de seguir profundizando las relaciones con la UE.

Todo ello no hace pensar que el resultado de una acción exterior conjunta a nivel internacional es beneficioso para ambas regiones, y que su voz es más fuerte si actúan de manera conjunta a nivel internacional. Queda esperar si CELAC desarrolla mecanismos e instrumentos para poder ejercer una acción exterior conjunta o común como región, no sólo para facilitar las negociaciones con la UE, sino también para que pueda hacerlo con terceros.

Para finalizar este apartado, se puede decir que el beneficio del diálogo a nivel birregional ha sido beneficioso para ambas partes. El acercamiento de los países europeos hacia los países de América Latina y el Caribe, ha servido, entre otras cosas, para ir perfeccionando su propia acción exterior como una unión regional, políticamente hablando, ante el mundo. Y por su parte, América Latina y Caribe, ha obtenido como beneficio, de dicha relación, profundizar en su propio proceso de integración regional.

En las últimas décadas tanto los estados europeos como latinoamericanos han ido creando organismos de integración regional, y aunque existe diferencias entre unos y otros, en cuanto a objetivos, competencias y método de trabajo (supranacional e intergubernamental), lo importante es que la actuación de los estados está pasando de la esfera nacional a la regional, los estados ya no son los únicos actores políticos en la escena internacional, ahora también lo son las uniones regionales.

Las experiencias de integración regional de los países europeos y latinoamericanos pueden ser un modelo para otras regiones del mundo y su diálogo birregional puede sentar las bases de un nuevo sistema internacional.

\footnotetext{
${ }^{346}$ DE GUCHT, K.: Trade, Investment and Sustainable Prosperity. Summit of the European Union and the Community of Latin American and Caribbean States, Santiago de Chile, 26.1.2013, Documento de la Comisión Europea, p.2.
} 
Es verdad que el conjunto de los países de América Latina y Caribe (ALC) siempre han enarbolado el discurso de la "unidad política" desde el período de sus independencias, promoviendo iniciativas y proyectos de integración tanto a nivel subregional como regional por cuenta propia, como lo hemos visto en el apartado anterior, sin embargo, los hechos históricos demuestran que cada paso que han dado los países de ALC en favor de su integración, lo han hecho ante una respuesta de acción exterior común ejecutada por los países europeos hacia ALC, y por consiguiente ante los principales foros, organismos y conferencias internacionales. Es decir, ALC ha ido creando mecanismos e instrumentos de acción exterior no de manera pro-activa, sino de manera reactiva, es decir reaccionando ante una determinada situación o circunstancia, en este caso ante las negociaciones con los países europeos.

Dejaremos en análisis de la última cumbre UE-CELAC celebrada en Bruselas en 2015, porque será incluida dentro del punto Perspectivas de las Relaciones entre Europa y las Américas en un apartado posterior. 
EL ACERVO INTEGRACIONISTA N EUROPA Y AMÉRICA:

UNA HISTORIA COMÚN 
- CAPÍTULO V

EL ROL DE LOS PARLAMENTOS SUBREGIONALES Y REGIONALES: DEMOCRACIA E INTEGRACIÓN 


\subsection{LOS PARLAMENTOS SUBREGIONALES Y REGIONALES EN EUROPA-AMÉRICA LATINA Y EL CARIBE}

Todo proceso de integración regional que conlleve a la unión o comunidad de estados tiene que considerar un aspecto fundamental, la participación de sus ciudadanos. La participación, activa o pasiva, de la población dentro del proceso de integración puede representar el impulso, estancamiento o declive del mismo. Para ello el sistema democrático y la participación democrática de los ciudadanos en los procesos de integración regional, juegan un rol importante en la construcción de dichas uniones y/o comunidades de estados, por eso no es extraño ver en los tratados fundacionales, de las uniones regionales, la mención explícita a la promoción y defensa de los principios y valores democráticos.

En tal sentido, la creación de una asamblea o parlamento dentro de un proceso de integración resultaría algo natural y evidente, el tener este tipo de institución simboliza, por un lado, que la toma de decisiones en el proceso de integración es de manera democrática y que los ciudadanos participan y respaldan las decisiones tomadas por sus gobernantes. A la par que dicha participación ciudadana da garantías de legitimidad democrática, pues deja de ser un proyecto liderado por políticos, diplomáticos o los gobernantes de turno, para pasar a ser un proyecto de estado donde los ciudadanos son parte imprescindible.

Este apartado busca mencionar de manera sistemática la existencia de estos nuevos parlamentos, a escala subregional y regional, desarrollados en los diferentes procesos de integración regional llevados en Europa y América Latina y Caribe. Se aclara que no entraremos en la valoración detallada de sus actividades y su efectividad, este apartado se centrará en mencionar su existencia, sus competencias y funciones determinadas en sus acuerdos, tratados o protocolos fundacionales y la relación que éstos tienen entre sí, a través del establecimiento de diálogos interparlamentarios a niveles inter-subregional como inter-regional $^{347}$.

\footnotetext{
347 STAVRIDIS, S. and IRRERA, D.(Eds): The European Parliament and its International Relations. Routledge, London-Ney York, 2015. ALDECOA, F. and KEATING, M.(Eds): Paradiplomacy in Action: The Foreign Relations of Subnational Governments. Hove, Sussex: Psychology Press/Taylor \& Francis Group, 1999. COSTA, O and DRI, C. and STAVRIDIS, S. (Eds): Parliamentary Dimensions of regionalization and Globalization, Palgrave Mac Millan, Bakingstoke, 2013.
} 
El apartado se divide en tres ejes temáticos, el primero describe el rol del Parlamento Europeo dentro del proceso de integración de la Unión Europea; el segundo versará sobre el rol de los parlamentos regionales en América Latina y el Caribe, y su interrelación; finalmente, el tercer eje temático se centrará en el diálogo interparlamentario birregional llevado a cabo por el Parlamento Europeo y el Parlamento Latinoamericano (EUROLAT).

\subsection{EL PARLAMENTO REGIONAL EN LA INTEGRACIÓN DE EUROPA: EL PARLAMENTO DE LA UNIÓN EUROPEA}

La experiencia de tener un parlamento regional en Europa se da dentro del proceso de integración de la Unión Europea ${ }^{348}$. Así el actual Parlamento Europeo que hoy conocemos, fue inicialmente fundado en 1952 como la Asamblea Común de la Comunidad del Carbón y del Acero; posteriormente la Asamblea sería renombrada conforme se fueron reformando los tratados. Así mediante la firma de los Tratados de Roma se constituyen, la creación de las Comunidades Europeas y la Asamblea Parlamentaria Europea. Asamblea que en 1962 se convirtió en el Parlamento Europeo, el cual realizará sus primeras elecciones mediante sufragio directo en 1979.

Cada reforma de los tratados ha representado para el proceso de integración europea más democracia, pues cada nuevo tratado brindaba mayores capacidades legislativas y de control al Parlamento Europeo.

Entre las más destacables podemos mencionar, por ejemplo: en 1975 el Tratado de Bruselas otorgó al Parlamento Europeo el derecho de control sobre las cuentas de la Comunidad; en 1986 el Acta Única Europea estableció la obligación de aprobación por parte del PE para la candidatura y adhesión de un nuevo estado a la Unión; en 1997 el Tratado de Ámsterdam reforzó la función del PE en el procedimiento de codecisión con el Consejo Europeo; finalmente, mediante la entrada de vigor del Tratado de Lisboa, en 2009, la UE ve ampliada sus competencia exclusiva en materia de comercio exterior e incluye en el tema de la inversión extranjera directa ${ }^{349}$, que antes no estaba contemplada. El tratado también confiere al Parlamento una ampliación de sus

${ }^{348}$ CRAIG, P. and BÚRCA, C.: EU Law. Text, cases and materials, Oxford University Press, New York, 2011.

${ }^{349}$ Art. 207 Tratado de Funcionamiento de la Unión Europea, el cual indica que la Política Comercial Común es competencia exclusiva de la Unión. 
competencias, confiriéndole una papel más activo en los procesos de negociación y ratificación de los acuerdos comerciales firmados entre la UE con terceros países y regiones del mundo.

La acción exterior de la Unión Europea no fue una competencia prevista en sus tratados fundacionales. Sin embargo, será a través del transcurrir de las décadas del proceso de integración regional, en que los países europeos irán desarrollando un sistema informal, que poco a poco, se va ir regulando e institucionalizando, creando mecanismos de coordinación y acción conjunta entre sus Estados miembros y las instituciones comunitarias, y en donde la jurisprudencia del Tribunal de Justicia de la Unión Europea y los informes del Parlamento Europeo en favor de una unión cada vez más fuerte y representativa ha significado un paso importante en la consolidación de una UE más fuerte en el mundo.

Se estima que 126 son los temas que forman parte del sistema de competencias que posee la Unión Europea ${ }^{350}$, sobre estos la UE puede regular y legislar, y de estas 126 competencias, 100 de estas competencias son reguladas por el Parlamento Europeo. Sin embargo, la Política Exterior y Seguridad Común (PESC) queda excluida de las competencias comunitarias.

El Art. 24 del Tratado de la Unión Europea, afirma que si bien la UE es competente en todos los ámbitos de la PESC y a pesar que puede definir y aplicar dicha política a través del Presidente del Consejo Europeo y del Alto Representante de la Unión Europea para Asuntos Exteriores y Política de Seguridad, la UE no puede legislar sobre este ámbito y también queda excluido el Tribunal de Justicia de la UE, por considerarse que tampoco tiene competencias para hacerlo en este tema.

Esto representa una clara limitación para el Parlamento Europeo. Algo que podría ser considerado como la defensa del poder de los Estados miembros sobre las instituciones comunitarias o la limitación expresa del poder de éstas última de mano de los Estados miembros, principalmente de los que consideran que la UE ya posee demasiadas competencias. El Reino Unido propone una descomunitarización de competencias para que vuelvan a ser nacionales y al amparo de su país, al considerar que así cada país

\footnotetext{
${ }^{350}$ TUSSEAU, G.. Theoretical deflation: The EU order of competences and power-conferring norms theory in AZOULAI, L.: The Question of Competence in the European Union, Oxford University Press, New York, 2011
} 
podría tener mayor libertad a la hora de diseñar políticas de desarrollo en favor de su país, en lugar de esperar que dichas políticas sean decididas en Bruselas. Lo que se ha buscado al traer este hecho como ejemplo, es la vigencia del Parlamento Europeo y su rol activo en las decisiones de la UE, y esto lo hace porque tiene competencias para hacerlo.

Es cierto que las competencias de la UE se han ido incrementando, y podemos decir dos supuestos diferentes, el primero, es que los Estados miembros han querido hacerlo de manera deliberada en pos de una mayor integración política, y otro supuesto, es que los Estados no tenían previsto que la UE tuviera tantas competencias, y que el incremento de estas competencias se ha producido, gracias a la interpretación extensiva de competencias, realizada por el Tribunal de Justicia de la UE. Weiler dice que la interpretación extensiva realizada por el Tribunal está fundada sobre una interpretación teleológica de los tratados, y que está basada en los principios de efecto útil y efecto necesario $^{351}$.

Para la legislatura 2014-2019, el Parlamento Europeo cuenta con la representación de trece partidos políticos:

1. Partido Popular Europeo

2. Partido Socialista Europeo

3. Alianza de Liberales y Demócratas por Europa

4. Verdes

5. Alianza de Conservadores y Reformistas Europeos

6. El Partido de la Izquierda Europea

7. Movimiento para una Europa de Libertades y Democracia

8. Partido Demócrata Europeo

9. Alianza Libre Europea

10. Alianza Europea para la Libertad

11. Alianza de los Movimientos Nacionales Europeos

12. Movimiento Político Cristianos Europeos

13. EU Demócratas

${ }^{351}$ WEILER, J.: Europa, fin, en Il Sistema comunitario europeo. Structura giuridica e processo político. Bolonia. II Mulino, 1985. Ver: CANCELA, C.: El proceso de constitucionalización de la Unión Europea. De Roma a Niza, Universidad Santiago de Compostela, 2001; CHARLESWORTH, A.-GUILLEN, H.: European Community Law, London, Pitman, 1994; MARTÍN Y PÉREZ DE NANCLARES, J.: El sistema de competencias de la Comunidad Europea, McGraw-Hill, Madrid, 1997. 
Después de las elecciones europeas de mayo, el Parlamento Europeo ${ }^{352}$ está formado por 751 eurodiputados que representan a los 28 Estados miembros de la Unión y a una población de 503, 7 millones de habitantes. Cuenta con veinticinco comités de trabajo, lo que demuestra las competencias delegadas a la Unión:

1. Asuntos Exteriores

2. Derechos humanos

3. Seguridad y defensa

4. Desarrollo

5. Comercio internacional

6. Presupuestos

7. Control presupuestario

8. Asuntos económicos y monetarios

9. Empleo y asuntos sociales

10. Medio ambiente, salud pública y seguridad alimentaria

11. Industria, investigación y energía

12. Mercado interior y protección al consumidor

13. Transporte y turismo

14. Desarrollo regional

15. Agricultura y desarrollo rural

16. Pesca

17. Cultura y educación

18. Asuntos legales

19. Libertades civiles, justicia y asuntos interiores

20. Asuntos constitucionales

21. Derechos de la mujer e igualdad de género

22. Peticiones

23. Comité de retos políticos

24. Crisis financiera, económica y social

25. Crimen organizado, corrupción y lavado de dinero

Finalmente destacamos que entre las funciones más importantes del PE en favor de la integración regional de Europa, está el poder de legislar para el conjunto de la UE, el

352 JUDGE, D. and EARNSHAW: The European Parliament. Palgrave Macmillan, Basingstoke-New York, 2008. 
poder de codecisión que comparte con el Consejo Europeo: aprobar el presupuesto comunitario, efectuar el control democrático de la toma de decisiones dentro de la UE, y en especial sobre la Comisión Europea, que es el órganos ejecutivo de la Unión. No olvidemos que es el Parlamento el que aprueba o desaprueba el nombramiento de los comisarios europeos y su presidente, y es el que da el visto bueno en los tratados internacionales que firma la Unión. Poderes que no cuentan los parlamentos regionales en América Latina y Caribe, que son los parlamentos que a continuación estudiaremos.

\subsection{EL ROL DE LOS PARLAMENTOS SUBREGIONALES Y REGIONALES EN LA INTEGRACIÓN DE AMÉRICA LATINA Y CARIBE}

En la actualidad la región de América Latina y Caribe cuenta con cinco parlamentos subregionales, cada uno responde a un proceso de integración llevado por un grupo de países: el Parlamento Latinoamericano, Parlamento de la Comunidad Andina, Asamblea Parlamentaria de la Comunidad del Caribe, Parlamento Centroamericano y Parlamento del Mercado Común del Sur. Y dos procesos de creación en marcha uno a escala subcontinental, el Parlamento de UNASUR y otro a escala regional, el Parlamento de la CELAC. Nótese que consideramos al Parlamento Latinoamericano (Parlatino) como un proceso subregional, ya que si somos estrictos en el uso del término y definición de América Latina y Caribe como región, el Parlatino no incluye a los países del Caribe. Estos parlamentos son nuevas formas de concertación regional ${ }^{353}$ en América Latina.

\subsubsection{El Parlamento Latinoamericano}

La iniciativa de crear un Parlamento Latinoamericano provino de Andrés Townsend Ezcurra, abogado, político y escritor peruano, quien propuso organizar y fundar un Parlamento para América Latina. Dos datos relevantes sobre el proyecto de Townsend, primero que se inspira en las ideas de Bolívar, dotando a dicha propuesta de fundamento histórico para tratar de crear una identidad común en el conjunto de los países de América Latina; un segundo aspecto, y en relación con el anterior punto, promueve y defiende los valores y principios rectores de su partido político, la Alianza Popular

\footnotetext{
353 VACCHINO, JM.: Organismos latinoamericanos de Integración: Evolución y perspectivas, en TOMASSINI, L. (Ed): Nuevas formas de concertación regional en América Latina, grupo Editor Latinoamericano, Buenos Aires, 1990.
} 
Revolucionaria Americana (APRA), este partido tiene como doctrina defender la democracia, la justicia social y la integración de los pueblos de América Latina. Este ideario hace que Towsend decida plantear la creación de un órgano político organizado que ayude a promover la integración, sobre la base de un sistema democrático a través de la creación de un Parlamento ${ }^{354}$.

Hay que señalar que el APRA a pesar de tener dentro de sus principios la promoción la integración regional, nunca llegó a ser un partido pan-latinoamericano, o un movimiento panamericano. No obstante, el proyecto de Towsend se vio cristalizado mediante la Declaración de Lima, aprobada en la ciudad de Lima, el 10 de diciembre de 1964, por la Asamblea Constitutiva del Parlamento Latinoamericano. En esta misma asamblea Townsend fue elegido por unanimidad primer secretario general, cargo que ostentaría hasta 1991, año en el cual pasa a ser miembro del Consejo Consultivo, y en el cuál desarrollo otra idea, el proyecto de las bases políticas de la Comunidad Latinoamericana de Naciones. En 1993 con motivo de los actos de inauguración de la sede permanente del Parlamento Latinoamericano en Sao Paulo, se le rindió homenaje como promotor e impulsor del organismo.

Las primeras sesiones parlamentarias se desarrollaron, inicialmente en Lima (I Asamblea Ordinaria) en julio de 1965, seguidas de la II Asamblea Ordinaria en Montevideo y la III Asamblea Ordinaria en Brasilia, los años siguientes. Los gobiernos latinoamericanos estaban convencidos que para profundizar en una integración era necesario contar con un parlamento, y por esa razón lo crearon para que sea un mecanismo de consulta y concertación política. La Declaración de Lima expuso como principales argumentos los siguientes puntos, que consideramos más relevantes destacar:

Persuadidos de que los pueblos latinoamericanos están llamados a formar, en un próximo futuro, una Comunidad de Naciones [...] permita presentar a la faz del mundo, una América Latina unida, solidaria, progresiva y fuerte. [...]. Los Parlamentos de América Latina deben de concurrir al éxito de la integración a través de la movilización de la opinión pública, proponiendo y propiciando, en cada país, las leyes y reformas que democráticamente conduzcan a su realización.

\footnotetext{
354 TOWNSEND A.: Patria Grande, pueblo, parlamento e integración, Fondo Editorial del Congreso, Lima, 1991. Ver más obras de TOWSEND: Bolívar, alfarero de Repúblicas (1973) y Las ideas de Bolívar en la integración de los pueblos latinoamericanos (1975).
} 
[...]. El Parlamento Latinoamericano, [...], será la institución democrática de carácter permanente, representativa de todas las tendencias políticas existentes en nuestros cuerpos legislativos; y estará encargada de promover, armonizar y canalizar el movimiento hacia la integración ${ }^{355}$.

La III Asamblea Ordinaria, celebrada en Brasilia, el 22 de junio de 1968, aprobó la Carta Magna de los Pueblos de América Latina, así fue declarada la carta fundacional del Parlamento Latinoamericano, la cual indicaba que "El Estado y el Derecho son los medios indispensables para realizarlos ${ }^{356,}$.

El 1987, los países miembros del Parlatino firman el Tratado de Institucionalización, en Lima, el tratado fue suscrito por: Argentina, Bolivia, Brasil, Colombia, Costa Rica, Cuba, Ecuador, El Salvador, Guatemala, Honduras, México, Nicaragua, Panamá, Paraguay, Perú, República Dominicana, Uruguay y Venezuela. Cada uno de estos países designa en sus respectivos parlamentos nacionales la delegación que los representará en las asambleas ordinarias, excepto Venezuela que hoy lo hace mediante sufragio universal.

El Parlatino tendrá como principales objetivos y principios la defensa de la democracia y la promoción de la integración en la región. Sin embargo, a diferencia del Parlamento Europeo, no posee capacidad legislativa y sus declaraciones no son vinculantes, por consiguiente, muchas veces no son consideradas por los propios países. Una clara debilidad.

Por otro lado, los representantes que van al Parlatino, son parlamentarios de los países miembros, elegidos a nivel nacional, es decir, no son elegidos para ser representante del Parlatino. Algo que marca una diferencia de fondo y de forma, de fondo porque si algo carece los procesos de integración regional en América Latina y Caribe es la falta de partidos políticos pan-latinoamericanos, que incluyan entre sus objetivos, la integración regional, un tema ausente y carente en cada elecciones generales e incluso en el debate y en la agenda política a nivel nacional. Por consiguiente, la ausencia de debate en los propios parlamentos nacionales, a la hora de discutir los temas de integración regional

\footnotetext{
${ }^{355}$ Declaración de Lima, aprobada el 10 de diciembre de 1964. Archivo del Parlamento Latinoamericano. http://parlatino.org/archivo/res/document/lima.php [Última revisión: 8-5-2014]

${ }^{356}$ Carta Magna de los Pueblos de América Latina, aprobada en la III Asamblea Ordinaria del Parlamento Latinoamericano, Brasilia, 22 de junio de 1968. Archivo del Parlamento Latinoamericano. http://parlatino.org/archivo/res/document/lima.php [Última revisión: 8-5-2014]
} 
es un hecho que permite ver la importancia que tiene la integración regional dentro de las agendas políticas a nivel regional. Importancia nula.

En la mayoría de los casos, la integración regional, suele ser discutida como tema en las comisiones de exteriores de los parlamentos nacionales. Los parlamentarios carecen de formación y de conocimientos sobre las relaciones internacionales, la gobernanza global, integración regional e interregionalismo ${ }^{357}$, todos ellos temas claves para poder analizar la conveniencia o no de firmar acuerdos regionales e internacionales o de iniciar, evaluar o reprobar los procesos de integración en marcha, todo esto da como resultado la falta de una visión estratégica a nivel regional.

Cada partido político piensa en sus intereses partidistas y defienden los intereses nacional, sin tomar en consideración las ventajas de fortalecer los procesos de integración regional como un mecanismo de una mejor acción exterior, que defienda tanto sus interés nacionales como los del conjuntos de sus socios en cada uno de los procesos de integración que son parte a nivel internacional ${ }^{358}$. Todo ello, redunda en una completa ausencia de propuestas por parte de los parlamentos nacionales a nivel de los parlamentos regionales existentes, y en este caso concreto, en el Parlatino.

Otra gran carencia, es la no existencia de partidos de ámbito regional, y tampoco existen mecanismos de coordinación entre los partidos políticos de uno y otro país, formalmente no existen movimientos, uniones o federaciones que puedan agrupar a las familias políticas, como sucede en el proceso de integración regional europea, con el Partido Popular Europeo o el Partido Socialdemócrata, por poner como ejemplo, las familias políticas más representativas del Parlamento Europeo.

Quienes se pregunten: ¿Por qué se tiene que comparar con la UE? o ¿Por qué siempre tendríamos que hacer lo que hace Europa? Nuestras respuestas son, si comparamos, es porque los objetivos que tienen cada proceso de integración subregional y regional en América Latina y Caribe, tienen en su gran mayoría los mismos objetivos planteados que el de la Unión Europea; y en segundo lugar, porque su acción busca también

\footnotetext{
${ }^{357}$ PANAIA, M.: Políticas públicas educativas e integración regional. La construcción de una política regional, en PINTO, J. (Comp): Entre la integración y la fragmentación regional: El desafío político de nuestro tiempo, Eudeba, Buenos Aires, 2009.

358 AHCAR, S., GALOFRE, O. and GONZÁLES, R.: "Procesos de integración regional en América Latina: Un enfoque político". Revista de Economía del caribe, N 11, enero-junio 2013. Universidad del Norte, Colmbia, Colmbia, 2013.
} 
hacerlo como la UE, sin tener en consideración, previa, la creación de normas e instituciones para ejecutarla. Por tanto, si tomamos como referencia la experiencia integracionista de Europa, se hace con la idea de poder saber cuáles son las dificultades que podrían ser evitadas y como debería de ser pensadas las políticas, y no por hacer lo mismo que Europa, si no por aprender de un proceso de integración que está en un nivel más avanzado de integración regional, y donde el Parlamento Europeo juega un rol ${ }^{359}$ decisivo, tanto en la legislación, como en el control del proceso y haciendo el llamado de atención a los Estados miembro que podrían perjudicar el proceso de integración.

Cada país es libre de participar o no en un proceso de integración, un grupo de países es libre de poder establecer las metas y aceptarlas o no, y si lo hace, creemos que lo mínimo que pueden hacer, por respeto a su ciudadanía y por el respeto con el derecho internacional, es cumplir los objetivos firmados.

La idea del panamericanismo, a nivel de partidos políticos es una tarea pendiente. A los países que no compartan la idea de un pan-americano y quieran defender la idea "Patria Grande" podrían fundar un pan-latinoamericano, si desean diferenciarse o dejar fuera a Estados Unidos, como muchos países defienden hoy en día. Al respecto, se puede decir que es válido que cada país pueda escoger sus socios, pero si vemos la geografía, algo que no se puede escoger, son los países vecinos.

Los países latinoamericanos, y ahora latinoamericanos y caribeños creen que pueden desarrollarse dejando de lado a Estados Unidos, su vecino y para muchos países su principal socio comercial, hecho que consideramos un error de base y políticamente incorrecto. Estados Unidos es para América Latina y Caribe, lo que es Reino Unido para Europa, un vecino que estará ahí siempre, que puede ser euroescéptico, que muchas veces prefiere una actuación al margen de la UE, del cual es miembro, sin embargo, es un Estado del cual no se puede prescindir a la hora de diseñar un plan de desarrollo para el conjunto de Europa como región.

De igual modo, es el caso de Estados Unidos respecto a ALC. Demás estar decir, la relación estrecha que tienen, económicamente y comercialmente hablando, entre Estados Unidos-Centroamérica, Estados Unidos-Caribe y Estados Unidos-México. Y

359 LINDEBERG, B. RASMUSSEN, A. and WARNTJEN, A.: The role of political parties in the European Union. Routledge, New York, 2010. RIPOLL, A.: Institutional and Policy Change in the European Parliament. Deciding on freedom, security and justice, Palgrave Macmillan, New York, 2010. 
que en suma, es gran parte de los países que conforman la región. ¿Se puede realmente pensar en una estrategia de desarrollo latinoamericano sin contar con Estados Unidos? A nuestro modo de ver, la respuesta es: No. Y no nos referimos a que ALC tenga que pedir el consentimiento u aprobación del gobierno estadounidense a la hora de diseñar sus planes de desarrollo, nos referimos que no se puede evitar considerar a un mercado grande que está de vecino, y la política exterior que éste adopta o desarrolla, es inevitable que sus decisiones y acciones afectarán al conjunto de la región de una manera u otra.

A quienes argumenten el grado de asimetrías económicas o las ventajas competitivas y comparativas a favor de los estadounidenses, podemos argumentar, que no son problemas, son retos a superar por los latinoamericanos y caribeños. ¿Acaso, la economía de Austria no es asimétrica con respecto a la de Alemania, o Estonia con Finlandia, o Luxemburgo con Francia, y porque estos países no hablan de asimetrías? Será porque de lugar de contar los problemas buscan encontrar soluciones, y por ello, y de lugar de sentirse débiles dentro de la UE, se sienten más fuertes dentro de ella. En lugar de ver obstáculos, crean soluciones que acorten dichas diferencias, crean fondos de desarrollo para las regiones del interior de los Estados, ayudas para infraestructuras, ayudas para la producción agrícola, crean marcos jurídicos para promover la creación de empresas europeas conjuntas, nombran capitales europeas a diferentes ciudades de Europa para promover el turismo, abren los espacios aéreos para que exista una mayor competencia, y así bajen los precios en favor del consumidor.

Cada una de estas políticas pueden hacer reflexionar sobre "el problema de las asimetrías" entre los países, a nuestro modo de ver, es una excusa por parte de algunos países para no integrarse o defender exclusivamente su interés nacional, el cual es legítimo, pero no lo es cuándo participa en un proceso de integración regional.

El victimismo, y el argumento de amenaza constante por terceros países, siempre es un argumento de los nacionalismos, los cuales, no permitirán nunca la integración en ALC o como ahora parece querer hacerlo los partidos nacionalistas con la UE. Una vez más, la defensa de la soberanía es el tema estrella en ambos casos. Parece que en ALC no hay una definición clara de integración, ni tampoco la visión de qué quieren como región. Esto seguirá así, como cuestión sin resolver, mientras nos existan partidos políticos a 
nivel regional. Y cuándo los partidos políticos pasen de tener un espíritu nacionalistas a un espíritu regionalistas.

A pesar de todo, hay que destacar la experiencia y el ejercicio de que exista el Parlatino como mecanismo permanente, y reafirmamos el término mecanismo, porque no se puede decir que es una institución, cuando esta carece de competencias y poder de legislar y control, un proceso de integración necesita la legitimidad democrática, y dicha legitimidad democrática no es sólo exclusividad de los gobiernos de turno que negocian, acuerdan y firman los tratados, se hace necesario el involucramiento del conjunto de la sociedad en dichos procesos, y mediante elecciones directas con una representación permanente y exclusiva por parte de los parlamentarios en dicho órgano, en lugar de enviar sus parlamentarios nacionales a reuniones de coordinación y más aún cuando sus resoluciones carecen de carácter vinculante y por decir más, no legislan solo realizan declaraciones sin efecto ninguno.

Es destacable, mencionar los esfuerzos de del Parlatino por querer profundizar la integración en América Latina y ahora incluyendo al Caribe, por primera vez en su proceso de integración regional, al amparo de la CELAC, pero como trataremos en un apartado más adelante, esta también es un mecanismo más que una institución. Entre los esfuerzos del Parlatino podemos decir que está su deseo de establecer y mantener un diálogo interparlamentario con otras regiones del mundo, y paradójicamente, lo hace tomando como par, al Parlamento Europeo.

El Parlatino cuenta con trece comisiones de trabajo, y en teoría cada una de ella tiene sus objetivos y áreas de trabajo definidas, en sus declaraciones comprobamos que en muchos casos, tratan temas distintos a su competencias, en algunos casos tomando como marco el país anfitrión que muchas veces marca los temas de su interés nacional, y en otros casos dependiendo del tema internacional del momento, es decir, no existe una agenda de trabajo organizada, coordinada y con objetivos claros.

A continuación daremos algunos ejemplos, pero primero nombraremos las trece comisiones permanentes que trabajan en el Parlatino:

1. Agricultura, ganadería y pesca

2. Asuntos económicos, deuda social y desarrollo regional

3. Asuntos políticos, municipales y de la integración 
4. Derechos humanos, justicia y políticas carcelarias

5. Educación, cultura, ciencia, tecnología y comunicación

6. Energía y minas

7. Equidad de género, niñez y juventud

8. Laborales, previsión social y asuntos jurídicos

9. Medio ambiente y turismo

10. Pueblos indígenas y etnias

11. Salud

12. Seguridad ciudadana, combate, prevención al narcotráfico, terrorismo y crimen organizado

13. Servicios públicos y defensa del usuario y el consumidor

Como podemos ver, los temas son diversos y muchos de ellos superpuestos. Pero bien, no entraremos en ese detalle, pero sí entraremos a ver, como algunas comisiones emiten declaraciones o resoluciones, todas ellas no vinculantes para los países miembros, que suelen ser distintas a su área de trabajo. Muchas veces la agenda nacional se superpone al desarrollo de una agenda que defienda los temas de interés común.

En 2008, la Comisión sobre Asuntos políticos, municipales y de la integración, incentiva la Declaración N 9 sobre Derecho Internacional Humanitario en Colombia, y esta es aprobada en el marco de la XXIV Asamblea Ordinaria del Parlamento Latinoamericano, en Panamá. ¿Este tema no sería más propio de la comisión sobre Derechos humanos, justicia y políticas carcelarias o por la comisión sobre Seguridad ciudadana, combate y prevención al narcotráfico, terrorismo y crimen organizado?

En 2009, la comisión permanente de Laborales, previsión social y asuntos jurídicos promueve una iniciativa, Resolución Condena al bloqueo comercial, económico y financiero del Gobierno de Estados Unidos contra Cuba, dicha resolución fue aprobada en el marco de la XII Reunión de Comisiones Permanentes (2 y 8). No discrepamos del tema de la resolución, pues al fin y al cabo está dentro de los objetivos del Parlatino el defender los intereses del conjunto de sus miembros, pero la pregunta es: ¿Qué opinión tiene que dar la comisión permanente sobre asuntos laborales, previsión social y asuntos políticos en este tema? No sería más propio que este tema sea trabajado, de acuerdo a sus funciones, exclusivamente por la comisión de asuntos económicos, deuda social y 
desarrollo regional. ¿Tendrá que ver que la reunión que aprobó dicha resolución fue aprobada en Cuba?

También en 2009, la comisión sobre Salud elaboró un proyecto de declaración sobre la Crisis Financiera Global, el proyecto fue aprobado en Cuba. ¿Por qué la comisión de Salud trata este tema? No es que le quede del todo ajeno, ni mucho menos, probablemente tiene una incidencia en la salud, pero no sería más competencia de la comisión de asuntos económicos, la de energía y minas o la de asuntos laborales la que preparen mejor este tipo de declaración.

En 2010, la comisión de Servicios públicos y defensa del usuario y el consumidor defiende la iniciativa de resolución sobre la Situación del Sahara Occidental, la cual fue aprobada como Resolución Legisladores del Parlamento Latinoamericano, en Montevideo. ¿Por qué el Parlatino se pronuncia sobre el Sahara Occidental? ¿Tiene competencias para ello? En este mismo marco, la comisión que se dedica a Medio Ambiente y Turismo promueve la Declaración de Buenos Aires sobre el Año del Bicentenario de la Revolución de Mayo de 1810. A la vez, las comisiones de Medio Ambiente y Turismo conjuntamente con la comisión de servicios públicos y defensa del usuario y el consumidor, promueven dentro de la declaración de Buenos Aires, el Rechazo a la explotación hidrocarbuífera en las Islas Malvinas y reafirmación de la soberanía argentina. ¿Quizás tendrá que ver con el hecho de que la declaración fue firmada en Buenos Aires?

También en 2010, la comisión sobre Pueblos indígenas y etnias trabajó sobre una declaración en contra de la Ley SB-1070, más conocida como la "Ley Arizona", que trataba sobre una ley estadounidense sobre la inmigración. ¿Acaso este tema no sería más acorde con las funciones de las comisiones de laborales, prevención social y asuntos jurídicos o la comisión sobre asuntos económicos o incluso la comisión sobre derechos humanos?

Es evidente que no existe una clara definición de roles y competencias, a pesar que en teoría cada comisión se ocupa de cada una de las áreas comprendidas en su tema y que tiene relación con el nombre de sus comisiones, pero en la prácticas esto no sucede.

En relación a la acción exterior, consideramos positivo que la Asamblea General del Parlatino haya buscado pronunciarse sobre temas internacionales como el Sahara 
Occidental (2010), la Declaración del Parlatino sobre el conflicto en la Franja de Gaza, en enero de 2009, y en temas de defensa de los intereses de sus países haciéndolos regionales (Declaración Islas Malvinas en maro de 2007, en apoyo a Argentina y la Declaración sobre las reformas a las leyes estadounidense de migración, en mayo de 2006). Estos últimos, son una manifestación de querer tocar temas internacionales y adoptar una posición común frente a los mismos.

\subsubsection{El Parlamento Andino}

Los orígenes del Parlamento Andino se encuentran en el mismo ordenamiento jurídico del Acuerdo de Cartagena, firmado el 26 de mayo de 1969. Pero serán los instrumentos como la Declaración de Bogotá de 1978, el Mandato de Cartagena de 1979 y la Declaración de los Presidentes de Quito en 1979, las que apoyen la creación del Parlamento Andino, como órgano representativo, de deliberación y de control de la Comunidad Andina.

El Tratado Constitutivo del Parlamento Andino fue firmado el 25 de octubre de 1979, en la Paz, y entró en vigencia en 1984, tiene su sede en Lima, lugar donde también se encuentra la Secretaría General de la Comunidad Andina. A pesar de haber sido concebido como un órgano legislativo, su misión no es legislar, sino brindar consejos y dar su opinión sobre algún tema que afecte a cualquier Estado miembro de la Comunidad. Es el órgano encargado de velar por el proceso de integración subregional y representa los intereses de los ciudadanos andinos.

Entre 1984 y 1996 los parlamentarios andinos eran delegados que representaban a los parlamentos nacionales de cada Estado miembro de la CAN. En 1997 en la IX Reunión del Consejo Presidencial Andino se aprueban dos nuevos acuerdos, el primero sería el Tratado Constitutivo del Parlamento Andino, acuerdo que reemplaza al firmado en 1979, siguiendo la conformidad del Acta de Trujillo ${ }^{360}$, Protocolo Modificatorio del Acuerdo de Integración Subregional Andino, que cambia de Grupo Andino a Comunidad Andina, por otro lado el Acta de Trujillo busca adecuar su proceso de integración subregional con su tiempo y sus necesidades, por lo que crea el sistema andino de integración, es decir su sistema institucional de carácter comunitario. Y el

\footnotetext{
${ }^{360}$ Acta de Trujillo fue firmada el 10 de marzo de 1996. http://www.comunidadandina.org/documentos/actas/act10-3-96.htm [Última revisión: 18-5-2014]
} 
segundo documento será el Protocolo Adicional sobre elecciones directas y universales de sus representantes ${ }^{361}$. Mediante este Protocolo, los parlamentarios son elegidos por un período de cinco años, a través de elección directa, en los casos de Colombia, Ecuador y Perú, en el caso de Bolivia recién lo tiene establecido en 2015.

Podríamos hablar más sobre el Parlamento Andino, sin embargo, consideramos que no es tan importante, puesto que en el proceso de reingeniería que lleva a cabo la Comunidad Andina, el Parlamento Andino desaparece, con el fin de desarrollar un proyecto de convergencia con el Parlamento del MERCOSUR al amparo del Parlamento de UNASUR. Así queda reflejado en la Propuesta sobre la nueva visión, lineamientos estratégicos y priorización de los ámbitos de acción de la Comunidad Andina, de julio de 2013, la cual en el punto dos, que trata sobre los criterios de análisis acerca del fortalecimiento del marco institucional de la Comunidad Andina, se "plantea la migración del Parlamento Andino hacia la esfera Suramericana"362.

Pero si nos interesa resaltar dos aspectos de la experiencia de integración andina, el primero es la importancia que le da al método de trabajo comunitario, al establecer instituciones supranacionales y por ello, es interesante ver que el Capítulo Primero del Tratado Constitutivito del Parlamento Andino menciona que éste parlamento es parte de un sistema institucional comunitario y por eso el parlamento andino es dentro del sistema el órgano deliberante común ${ }^{363}$. Otro aspecto que tiene relación con la acción exterior regional, es un tema que también forma parte del acervo integracionista andino, nos referimos a la Política Exterior Común que cuenta la Comunidad Andina. Tema que trataremos en el apartado correspondiente.

En la experiencia del proceso de integración de la Comunidad Andina, el Parlamento Andino desarrolló cinco comisiones de trabajo, las cuales son:

1. Política exterior y relaciones interinstitucionales

2. Educación, cultural, ciencia, tecnología y comunicación

\footnotetext{
361 Tratado Constitutivo del Parlamento Andino y Protocolo Adicional sobre elecciones directas y universales de sus representantes. Sucre, 23 de abril de 1997, Secretaría General de la Comunidad Andina.

http://www10.iadb.org/intal/intalcdi/PE/2011/07343.pdf [Última revisión: 24-5-2014]

${ }^{362}$ Documento Final. Propuesta sobre la nueva visión, lineamientos estratégicos y priorización de los ámbitos de acción de la Comunidad Andina, Lima, 12 de julio de 2013.

${ }^{363}$ Capítulo I: de la creación, composición y sede del Parlamento Órgano Deliberante Común. Tratado Constitutivo del Parlamento Andino. Secretaría General de la Comunidad Andina. http://www10.iadb.org/intal/intalcdi/PE/2011/07343.pdf [Última revisión: 24-5-2014]
} 
3. Seguridad regional y desarrollo sustentable

4. Asuntos económicos y turismo

5. Asuntos sociales y desarrollo humano

De estas cinco comisiones no centraremos en las funciones descritas para la comisión primera, la de Política exterior y relaciones interinstitucionales. Entre las cuales se encontraban las siguientes:

1. Realizar el seguimiento a la política exterior común formulada por el Consejo Andino de Ministros de Relaciones Exteriores. El Parlamento Andino participaba de manera comunitaria en los distintos foros y organismos internacionales en los que la Comunidad asistía.

2. Efectuar el seguimiento a los distintos procesos de integración que existían dentro de la región (América Latina y Caribe) y a nivel extra regional (principalmente con la Unión Europea).

3. Evaluar el proceso de negociaciones de la Comunidad Andina con otros procesos de integración y con terceros países.

4. Elaborar propuestas que busquen una aproximación entre las legislaciones nacionales en temas relacionados con los intereses de la Comunidad.

Estas funciones son importantes, a pesar que no tienen carácter vinculante para los Estados miembro de la Comunidad, lo rescatable es que es uno de los únicos procesos de integración en ALC que desarrolla este punto, claro está que tiene una relación directa con el hecho que también es el único proceso que cuenta con el diseño de una Política Exterior Común, experiencia que puede servir para nuevos esquemas como el de UNASUR o el de la CELAC.

En relación entre las relaciones con la Unión Europea y la Comunidad Andina podemos decir que sus relaciones datan desde la propia creación del proceso de integración andina, cuándo se firmó el entonces llamado Acuerdo de Cartagena en 1969. Hecho que sirvió para dos aspectos, que el proceso de integración andina tomará como referencia directa la experiencia europea, y de ahí su semejanza tanto a nivel de instituciones, como la creación de un Tribunal de Justicia donde el derecho comunitario tiene supremacía sobre el derecho nacional y la creación de una Política Exterior Común, pues no hay en otro proceso de integración subregional o regional en América Latina y 
Caribe que haya desarrollado todos estos temas en conjunto. Un principal argumento de todas estas acciones, puede ser la relación estrecha que tienen los países andinos desde su nacimiento con las instituciones europeas. Un hecho significante de las buenas relaciones entre ambas partes es que en 1983, la entonces Comunidad Europea, firma el primer acuerdo de cooperación con una subregión en América Latina y Caribe, la andina.

A partir de ese primer acuerdo de cooperación, vendrá un Acuerdo Marco de Cooperación en 1993. Diez años ha de pasar para que en 2003, firmen un Acuerdo de Diálogo Político y Cooperación, sin embargo, este acuerdo aún no ha entrado en vigor del todo, y las negociaciones sobre un acuerdo de asociación, que se iniciaron en 2007, se terminó cuando los países andinos deciden no firmar en conjunto, ante el abandono de Venezuela, en 2006, a la Comunidad Andina y posteriormente la negativa de Bolivia y Ecuador a firmar dicho acuerdo.

En 2010 Colombia y Perú inician las negociaciones para firmar un Acuerdo Comercial Multilateral, el cual fue firmado en junio de 2012 y ratificado por el Parlamento Europeo en diciembre de ese mismo año. El acuerdo entró en vigor el 1 de marzo de 2013 en Perú y el 1 de Agosto de ese mismo año en Colombia. En noviembre de 2013, Bolivia anuncio el inicio de las negociaciones para adherirse al acuerdo con la Unión Europea, del mismo modo, en enero de 2014, Ecuador anuncio el inicio de la negociaciones para firmar también su adhesión al acuerdo.

\subsubsection{La Asamblea Parlamentaria de la Comunidad del Caribe}

La idea de crear una Asamblea Parlamentaria dentro del proceso de integración de los países del Caribe proviene del Primer Ministro de Barbados, Erskine Sandifordin, quien en 1987 propuso como proyecto, establecer un parlamento para la región. Esta propuesta irá madurando en las siguientes conferencias de Jefes de Gobierno, entre la Octava Conferencia de Jefes de Gobierno de la Comunidad del Caribe desarrollada en Santa Lucía entre el 29 de junio y el 3 julio de 1987 y la Décima Conferencia, celebrada entre el 3 y 7 de julio de 1989, los Estados miembros de la Comunidad determinan establecer una Asamblea Parlamentaria de la Comunidad del Caribe, como cuerpo deliberante para profundizar el movimiento de la integración. 
En el Art. 4 del tratado fundacional de la Asamblea, se establece sus objetivos, entre los que destacamos los siguientes: involucrar a la población en el proceso de integración regional de la Comunidad del Caribe, a través de la participación de sus representantes en los parlamentarios nacionales de cada Estado miembro de la Comunidad; hacer de la Asamblea un foro en el cual las personas puedan participar dando a conocer sus opiniones sobre el proceso de integración; establecer un mecanismo de control de las políticas de la Comunidad; proveer el intercambio de oportunidades para la coordinación de políticas exteriores de los Estados miembros; finalmente defender los valores y principios que defiende la Comunidad y alentar la adopción de una política común sobre asuntos económicos, sociales, culturales, científicos y legales ${ }^{364}$.

Sus funciones y poderes se encuentran recogidos en el Art. 5 del Tratado fundacional ${ }^{365}$, el cual describe que la Asamblea será, un órgano deliberante y un cuerpo consultivo para las discusiones sobre las políticas, programas y otros asuntos de interés de la Comunidad y que estén comprendidos dentro de los tratados fundacionales. La Asamblea puede realizar recomendaciones a la Conferencia de Jefes de Gobierno, al Consejo de Ministros de Asuntos Exteriores y a las otras instituciones parte del sistema de integración caribeño. Sin embargo, la asamblea no puede pronunciarse sobre asuntos internos de cualquier Estado miembro.

Los Estados Miembros son: Antigua y Barbuda, Las Bahamas, Barbados, Belice, Dominica, Granada, Guyana, Jamaica, Montserrat, San Kitts y Nevis, Santa Lucía, San Vicente y las Granadinas, Trinidad y Tobago.

Las relaciones desarrolladas entre la Unión Europea respecto a los países del Caribe, pudo haber sido un argumento por el cual los países latinoamericanos invitan a participar a los países caribeños en su proceso de integración regional. Si tomamos en consideración las relaciones entre la Unión Europea y la Comunidad del Caribe nacen de las relaciones existentes entre algunos de los Estados miembros de la Unión y algunos territorios caribeños. Relaciones que fueron institucionalizadas y reguladas por diferentes acuerdos, entre ellos: el Acuerdo de Cotonú, firmado en 2000, entre setenta y

\footnotetext{
${ }^{364}$ Art. 4 Agreement for the Establishment of an Assembly of Caribbean Community Parliamentarians. El acuerdo fue firmado en diferentes fechas, dependiendo del Estado miembros de la Comunidad, la franja fué entre 1992 y 1996.

http://www.caricom.org/jsp/secretariat/legal_instruments/agreement_accp.jsp [Última revisión: 18-52014]

${ }^{365}$ Ibíd. Art. 5.
} 
nueve países de África, del Caribe y del Pacífico, los llamados países ACP, y el Acuerdo de Asociación Económica entre la Unión Europea-CARIFORUM ${ }^{366}$, firmado en 2008. CARIFORUM es el principal mecanismo para el diálogo birregional con la Unión, y de sus dieciséis miembros, catorce son Estados miembro de CARICOM, más República Dominicana y Cuba que goza de un estatuto especial.

Cada uno de los datos mencionados nos puede hacer pensar y realizar las siguientes preguntas: ¿Es la incorporación del Caribe una iniciativa de los países latinoamericanos para fortalecer su proceso de integración regional? ¿Es la importancia que da la Unión Europea al Caribe lo que hace que los países latinoamericanos consideren sumar esta subregión en su proceso de integración? ¿Puede ser que la relación entre la UE y AL haya hecho que se incluya el Caribe dentro del proceso de integración regional y así poder facilitar las negociaciones con esta zona del mundo?

En todo caso, no es extraño que la UE haya saludado y visto con buenos ojos, desde el inicio, la idea de crear la CELAC, al fin y al a cabo, las reuniones cumbres entre UEALC han sido sustituidas por UE-CELAC para facilitar el diálogo birregional. Inclusive, nos puede hacer pensar que la participación de Cuba dentro de la CELAC, pudo haber sido resultado del deseo de la UE en establecer relaciones con Cuba, a través de la Posición Común emitida por el Consejo, el cual marca un punto de partida para un apoyo al proceso democrático a escalas y coadyuvar a la apertura de la economía cubana nivel internacional. Como acabamos de ver, la UE ya mantenía ciertas relaciones formales con Cuba, ya que este país participaba dentro del CARIFORUM.

Tomando en cuenta las siguientes fechas, en 1996 el gobierno español promueve la iniciativa de un cambio en las relaciones entre la UE hacia Cuba, en noviembre de ese mismo año en el marco de la Cumbre Iberoamericana de Viña del Mar, el gobierno español lanza la propuesta de celebrar la primera Cumbre América Latina y Caribe, y en diciembre de ese mismo año el Consejo de la UE aprueba la Posición Común respecto a $\mathrm{Cuba}^{367}$. La primera Cumbre entre América Latina y Caribe-Unión Europea, se realiza en Río de Janeiro en 1999, a propuesta del gobierno español y francés, siendo esta la

\footnotetext{
${ }^{366}$ CARIFORUM, siglas en inglés de Caribbean Forum of African, Caribbean and Pacific States, es un foro politico que busca promover el diálogo politico, la cooperación y la integración entre sus miembros.

${ }^{367}$ Consejo Europeo, Posición Común sobre Cuba, 2 diciembre de 1996.

http://eur-lex.europa.eu/LexUriServ/LexUriServ.do?uri=CELEX:31996E0697:ES:HTML_[Última revisión: 24-5-2014]
} 
primera vez que América Latina y el Caribe se presenta conjuntamente como una sola región incorporando a los países caribeños.

Particularmente, considero que la incorporación del Caribe al proceso de integración regional de América Latina, es una decisión apresurada, pues si no existe todavía una misma visión de la integración, ni tampoco hay una agenda común que combina los intereses nacionales con los intereses del conjunto de la región latinoamericana, por consiguiente si no se da aún un consenso entre los propios países latinoamericanos, que comparten unas mismas raíces, la cultura iberoamericana, y citamos iberoamericana por las relaciones históricas, culturales, lenguas y administración política, herencias de España y Portugal hacia los países de América Latina, imagínense tener que incorporar y compaginar la cultura, lenguas y administración política de los países del Caribe, los cuales son distintos.

No cabe duda que representa un reto, y aplaudimos la incorporación del Caribe, puesto que son vecinos y socios naturales en el espacio geográfico del Continente Americano o para nuestro caso de estudio concreto en la región de América Latina. Sin embargo, considero que esto puede representar una dificultad más que una ventaja, al menos en el corto plazo, más aún si no se decide crear instituciones supranacionales que busquen velar por los intereses generales de la región, más que los intereses nacionales o subregionales por encima de los de la Comunidad de Estados Latinoamericanos y Caribeños.

Se puede entender que desde una perspectiva geopolítica es conveniente incorporar al Caribe dentro del proceso de integración regional, pero quizás no era el momento adecuado. Si hacemos un paralelo con el proceso de integración regional de la UE, podemos decir que la incorporación del Caribe con el proceso de integración regional de América Latina, representa lo mismo que representó la incorporación de los países de la Europa de Este a la UE. Necesario, sí, importante, también, pero en todos los casos, representó un reto. Con la clara diferencia que la UE contaba con instituciones comunitarias, con fondos de cohesión y mecanismos que contemplaban la convergencia económica de los nuevos Estados Miembros (ampliación de 2004) con el conjunto de la UE. Instituciones y mecanismos que ALC no cuentan. 


\subsubsection{El Parlamento Centroamericano}

El Parlamento Centroamericano (Parlacen) nace en el mismo año que la Asamblea Parlamentaria de la Comunidad del Caribe, en 1987. Su tratado constitutivo se firmó el 8 de octubre de 1987 y entró en vigencia el 28 de octubre de 1991, cuando se instaló por primera vez de manera oficial la primera asamblea en Guatemala.

Los antecedentes históricos del Parlacen se remontan a la reunión del 28 y 29 de septiembre de 1984, en San José, cuando se reunieron doce ministros de asuntos exteriores de la entonces Comunidad Económica Europea, España, Portugal, cinco países centroamericanos y los cuatro países miembros del Grupo de Contadora. Que dio como resultado no sólo la paz en América Central, sino que sirvió para sentar las bases para una reflexión mayor, que fue el incorporar a su proceso de integración, un parlamento.

Así lo recoge la Declaración de Esquipulas I, firmada el 25 de mayo de 1986: "Numeral 3: es necesario crear y complementar esfuerzos de entendimiento y cooperación con mecanismos institucionales que permitan fortalecer el diálogo, el desarrollo conjunto, la democracia y el pluralismo como elementos fundamentales para la paz en el área y para la integración de Centroamérica. Es por ello que conviene crear el Parlamento Centroamericano"

Durante 1986 y 1987, Marco Vinicio Cerezo, presidente de Guatemala promoverá el Acuerdo Esquipulas II "Procedimiento para establecer las paz firme y duradera en Centroamérica"; y quién afirmará que: "nuestro ideal de logar alguna vez la unidad política Centroamericana $^{369 "}$. Por consiguiente, podemos decir que las relaciones con el proceso de integración regional europea han contribuido e influido también en el proceso de integración centroamericana. Basta con ver el sistema institucional y el método de trabajo que prevalece en las toma de decisiones en Centroamérica.

\footnotetext{
368 Declaración de Paz de Esquipulas, firmado el 24-25 de mayo de 1986 en Guatemala. Parlamento Centroamericano:

http://www.parlacen.int/Informaci\%C3\%B3nGeneral/MarcoPol\%C3\%ADticoyJur\%C3\%ADdico/Esquip ulasI.aspx [Última revisión: 19-5-2014]

${ }^{369}$ Discurso de Marco Vinicio en la toma de posesión como Presidente de la República de Guatemala, enero de 1986. Parlamento Centroamericano, Historia del Parlamento:

http://www.parlacen.int/Informaci\%C3\%B3nGeneral/HistoriadelParlamento.aspx [Última revisión: 19-52014]
} 
En un documento de la Asamblea Nacional de Nicaragua sobre el Parlacen indica que este: "promueve una concepción comunitaria de la integración centroamericana y rechaza la tendencia de realizarla como un proceso intergubernamental ${ }^{370,}$.

El Parlacen no sólo sirvió para fortalecer y darle mayor legitimidad democrática a su proceso de integración, sino que además deja como experiencia al conjunto de la región, el interés manifiesto de querer trabajar de manera comunitaria en la toma de decisiones, hecho que da una mayor capacidad de negociación y una mayor fortaleza en el deseo de desarrollar una acción exterior como organismo regional.

Dentro de las competencias del Parlacen se encuentren recogidos en el Art. 5 del Tratado Fundacional del Parlacen:

- Proponer legislación en materia de integración regional

- Iniciativas para ampliar y profundizar la integración centroamericana

- Ser el único foro político regional ${ }^{371}$

- En el Art. 29 de este mismo tratado también encontramos:

- Control parlamentario sobre las instituciones comunitarias centroamericanas, a través de la presentación de informes por partes de las instituciones comunitarias dirigidas al Parlacen, a la par que el parlamento deberá de conocer la elección de sus ejecutivos y sus respectivos presupuestos ${ }^{372}$.

Cada una de estas competencias se asemeja a las competencias del Parlamento Europeo, clara evidencia que los centroamericanos toman como referencia el proceso de integración regional europea. Del mismo modo ocurre con sus comisiones permanentes, cuya temática y organización también se parece al del Parlamento Europeo.

\footnotetext{
${ }^{370}$ Parlamento Centroamericano. Documento: Foros Internacionales, Asamblea Nacional de Nicaragua, p. 20, en: www.asamblea.gob.ni\%2Fediciones\%2Sinopsis-Foros. [Última revisión: 19-5-2014]

371 Para mayor información puede revisar el Art. 5 Atribuciones del Parlamento Centroamericano, Tratado fundacional del Parlamento Centroamericano. http://www.parlacen.int/InformaciónGeneral/MarcoPolíticoyJurídico/TratadoConstitutivo.aspx [Última revisión: 19-5-2014]

${ }^{372}$ Para mayor información puede revisar el Art. 29 Informe de los organismos de la integración centroamericana, Tratado fundacional del Parlamento Centroamericano.

http://www.parlacen.int/InformaciónGeneral/MarcoPolíticoyJurídico/TratadoConstitutivo.aspx [Última revisión: 19-5-2014]
} 
Para el período 2013-2014 existen las siguientes comisiones permanentes del Parlacen $^{373}$ :

1. Política y de asuntos partidarios

2. Paz, seguridad ciudadana y derechos humanos

3. Asuntos monetarios y financieros

4. Educación, cultura, deporte, ciencia y tecnología

5. Integración, comercio y desarrollo económico

6. Asuntos agropecuarios, pesca, medio ambiente y recursos naturales

7. De la mujer, niñez, juventud y familia

8. Desarrollo municipal y participación ciudadana

9. Salud, seguridad social, población y asuntos laborales y generales

10. Asuntos jurídicos, derechos comunitario e institucionalidad regional

11. Relaciones internacionales y asuntos migratorios

12. Turismo

13. Pueblos indígenas y afrodescendientes

14. Y una comisión especial que es la encargada de coordinar y desarrollar las acciones con el Parlamento Europeo dentro del marco de EUROLAT

\section{Comisión EUROLAT}

El Parlacen es el único parlamento de un proceso de integración en América Latina que cuenta con partidos políticos que se agrupan por "familias políticas", es decir de acuerdo a su ideología. Hecho que hace que su experiencia, pueda ser considerada como un modelo a seguir por otros procesos de integración en América Latina y Caribe.

Para establecer un grupo parlamentario se hacen necesario como mínimo diez miembros y una representación mínima de dos estados miembros. Para el período 2013-2014 se encontraban registrados cuatro grupos parlamentarios dentro del Parlacen ${ }^{374}$ :

1. Integración Centro-Democrático (CD): conformado por partidos moderados, en particular de centro-izquierda, de centro y centro derecha.

\footnotetext{
373 Listado general de las comisiones del Parlamento Centroamericano, período 2013-2014. http://www.parlacen.int/Funcionamiento/Comisiones2013-2014.aspx [Última revisión: 24-5-2014]

${ }^{374}$ Grupos Parlamentarios en el Parlamento Centroamericano.

http://www.parlacen.int/Funcionamiento/GruposParlamentarios2013-2014.aspx [Última revisión: 24-52014]
} 
2. Alianza Democrática Centroamericana (ADC): partidos conservadores y de derecha

3. Grupo Parlamentario de Izquierda (GPI): partidos de izquierda revolucionaria

4. Grupo Innovador Centroamericano y del Caribe

Con todo lo expuesto antes, Centroamérica es la primera subregión en América Latina y Caribe que firmó un Acuerdo de Asociación con la UE, pues existe una visión común sobre lo que significa y representa una integración regional de Estados. Este tipo de organizar el agrupamiento de familias políticas es similar al efectuado en el Parlamento Europeo $^{375}$, la idea es que no se agrupen por su nacionalidad, sino por sus ideas políticas y puedan éstas ser defendidas ya no a nivel nacional, sino a nivel regional, de esta manera pueden desarrollar propuestas que interesen al conjunto de la población de la región o subregión que representan y con ello desarrollar una agenda común de intereses.

El 7 de abril de 2014, el Comité Consultivo del Sistema de la Integración Centroamericana (SICA) conjuntamente con el Comité Económico Social de la Unión Europea, efectuaron una propuesta para trabajar con el Parlacen, para crear un Comité Consultivo Conjunto que ayude a analizar, apoyar y desarrollar con mayor eficacia los objetivos planteados en el Acuerdo de Asociación entre UE-AC, en el cual además invitarán a participar a los sectores productivos y de la sociedad civil. La importancia de este paso versa sobre el hecho que es el Comité Económico Social de la UE emite dictámenes dirigidos tanto a la Comisión Europea como al Parlamento Europeo.

\subsubsection{El Parlamento del Mercado Común del Sur}

El Parlamento del Mercado Común del Sur fue constituido el 6 de diciembre de 2006, en el marco del proceso de integración subregional del MERCOSUR, este parlamento sustituyó a la Comisión Parlamentaria Conjunta, la cual ejercía como órgano representativo de los ciudadanos de los Estados Partes del MERCOSUR. Enfatizamos el término Estados Partes, pues de todos los procesos de integración existentes en

\footnotetext{
${ }^{375}$ ULLOA, F.: Los partidos políticos actores de la institucionalización democrática en Centroamérica. Theorethiko, Revista de la Universidad Francisco Gavidia, Año V, N 001, Enero - Junio 2001. El Salvador. http://www.ufg.edu.sv/ufg/theorethikos/enero2001/analisis03.htm [Última revisión: 24-5-2014]
} 
América Latina y Caribe, MERCOSUR es el modelo intergubernamental por excelencia, y en donde los países a pesar de aspirar y defender una unión política en los diferentes organismos de integración en los cuales participan (MERCOSUR, UNASUR y CELAC), siempre reafirman, una y otra vez, la defensa de su soberanía nacional, por consiguiente no comulgan con la idea de crear instituciones supranacionales, mucho menos de carácter comunitarios, razón por la cual nunca mencionan el término Estado Miembro, sino más bien, Estado Parte, por ser el término correcto en el argot del derecho internacional, el cual utiliza el término Partes Contratantes a la hora de firmar un acuerdo.

En tal sentido, no es de extrañar que su máximo objetivo, más que una unión política, sea el de una unión de mercados, una unión comercial, y a pesar de tener dentro de su nombre y objetivo el crear un Mercado Común, no han logrado crear políticas comunes, sino ciertas políticas concertadas a nivel intergubernamental. Estableciendo para eso como máximo órgano del MERCOSUR, el Consejo de Ministros de Economía y Ministros de Relaciones Exteriores ${ }^{376}$, siendo este consejo el que define y conduce la política $^{377}$ del proceso de integración, a diferencia de otros procesos cuyo máximos órganos ejecutivos son ejercidos y dirigidos por el Consejo de Ministros de Relaciones Exteriores o un Consejo Presidencial, lo que evidencia la preminencia en el MERCOSUR de los objetivos únicos y finales de ese proceso, cooperación comercial.

Los inicios de la creación del Parlamento del MERCOSUR se encuentran recogidos en el propio tratado fundacional, Tratado de Asunción (1991), en el su artículo 24 señala el "establecimiento de la Comisión Parlamentaria Conjunta del MERCOSUR 378 , siendo el fin el de insertar al Poder Legislativo en el proceso de integración.

En 1994, el Protocolo de Ouro Preto, crea la estructura institucional del MERCOSUR, el cual crea la Comisión Parlamentaria Conjunta, obsérvese que no usa el término

${ }^{376}$ Art. 9 Tratado para la Constitución de un Mercado Común, Asunción, 26 de marzo de 1991. Para mayor información ver MERCOSUR, tratados y protocolos en:

http://www.mercosur.int/t_generic.jsp?contentid=3862\&site=1\&channel=secretaria\&seccion=3 [Última revisión: 20-5-2014]

377 Art. 10. Tratado para la Constitución de un Mercado Común, Asunción, 26 de marzo de 1991. Para mayor información ver MERCOSUR, tratados y protocolos en:

http://www.mercosur.int/t_generic.jsp?contentid=3862\&site=1\&channel=secretaria\&seccion=3 [Última revisión: 20-5-2014]

${ }^{378}$ Art. 10. Tratado para la Constitución de un Mercado Común, Asunción, 26 de marzo de 1991. Ver MERCOSUR, tratados y protocolos en:

http://www.mercosur.int/t_generic.jsp?contentid=3862\&site=1\&channel=secretaria\&seccion=3 [Última revisión: 20-5-2014] 
común, sino conjunta (modelo intergubernamental). Entre 1994 y 2006 el órgano parlamentario conjunto fue integrado por delegados, no representantes, de los parlamentos nacionales de cada Estado parte. Acotamos en el término que son delegados y no representantes, porque los primeros, quiere decir, que son enviados por sus parlamentos nacionales a defender los intereses nacionales al parlamento regional; los segundo serían que representan a sus estados, pero que irán al parlamento regional para defender los intereses comunes, como también los intereses nacionales. Lo que enfatiza con denominar delegados, es justamente, la definición clara del mandato de los delegados, representar sólo los intereses nacionales a escala regional.

En 2003 la Comisión Parlamentaria Conjunta celebró con el Consejo del Mercado Común un Acuerdo Interinstitucional, en el que el Consejo aprueba un programa de trabajo 2004-2006, que previó en el Capítulo MERCOSUR Institucional, proponía la constitución del Parlamento del MERCOSUR.

En 2005 se firma el Protocolo Constitutivo del Parlamento de MERCOSUR y en él se deja estipulados varios temas que hacen pensar que el MERCOSUR pudo haber querido sentar algunas bases para ir hacia una integración política, sin embargo, también se deja ver, que el protocolo es fruto de una negociación de países que conciben de manera diferente la integración con respecto a los países andinos o centroamericanos. Entre las competencias designadas al parlamento se mencionan, que este "estará integrado por representantes electos por sufragio universal, directo y secreto, de acuerdo con la legislación interna de cada Estado parte [...] El Parlamento será un órgano

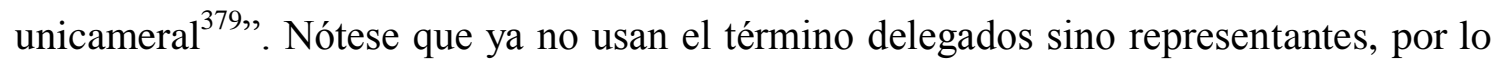
que buscan darle legitimidad y mayor autonomía tanto a los parlamentarios como al propio parlamento.

Entre los propósitos del Parlamento de MERCOSUR están el de "representar a los pueblos del MERCOSUR; asumir la promoción y defensa permanente de la democracia, la libertad y la paz; contribuir a consolidar la integración latinoamericana mediante la profundización y ampliación del MERCOSUR"380. Aquí un aspecto importante, si

\footnotetext{
${ }^{379}$ Art. 1. Protocolo Constitutivo del Parlamento del MERCOSUR, Montevideo, 9 de diciembre de 2005. Ver MERCOSUR, tratados y protocolos: http://www.mercosur.int/t_generic.jsp?contentid=3862\&site=1\&channel=secretaria\&seccion=3 [Última revisión: 20-5-2014]

${ }^{380}$ Art. 2. Protocolo Constitutivo del Parlamento del MERCOSUR, Montevideo, 9 de diciembre de 2005. Ver MERCOSUR, tratados y protocolos:
} 
observamos el último punto, dice que buscan contribuir a la integración latinoamericana mediante la profundización y ampliación del MERCOSUR, no habla de convergencia o acercamiento con otros procesos de integración o unir esfuerzos o experiencias, hablan de que la integración latinoamericana será mediante la profundización y ampliación de su propio esquema.

Por tanto quedaría hacerse varias preguntas: ¿Qué tipo de integración están pensando los países del MERCOSUR para América del Sur o América Latina y Caribe? ¿Un proceso de integración donde prevalezca sólo una unión comercial o económica? ¿Aspiran realmente estos países a una unión política para América Latina y Caribe? Desean acaso que prevalezca el método intergubernamental dentro del proceso de integración regional de América Latina y Caribe en detrimento del método comunitario, marginando así el proceso y acervo creado por los otros procesos de integración en el resto de la región y que además son una mayoría que sí apuestan por una integración política de carácter comunitario.

Las ideas del tipo de integración que aspiran los países del MERCOSUR son válidas y legítimas, pero esto deja en evidencia la diferencias que existen sobre qué es integración regional, qué método de trabajo y toma de decisiones aplicar en el proceso de integración regional de ALC. Diferencias que llevarán a encuentros y desencuentros, pero en que en todo caso, se hace necesario que se haga, de lo contrario será un diálogo entre sordos, porque cada proceso defenderá su visión de integración, este es un claro motivo del porque no se produce la integración en América Latina y Caribe, porque a nuestro entender muchos países confunden y usan el término integración regional, cuando en verdad lo que están pensando y aspirando es a una cooperación regional.

Entre las competencias dadas al Parlamento se mencionan "velar por la preservación del régimen democrático en los Estados parte; elaborar y publicar informes sobre Derechos Humanos; efectuar pedidos de informes u opiniones a los órganos decisorios del MERCOSUR; emitir declaraciones, recomendaciones e informes sobre cuestiones vinculadas al desarrollo del proceso de integración, por iniciativa propia o a solicitud de otros órganos del MERCOSUR ${ }^{381}$ ". Un aspecto positivo es que le da poder de iniciativa

http://www.mercosur.int/t_generic.jsp?contentid=3862\&site $=1 \&$ channel=secretaria\&seccion=3 [Última revisión: 20-5-2014]

381 Art. 4. Competencias del parlamento. Protocolo Constitutivo del Parlamento del MERCOSUR, Montevideo, 9 de diciembre de 2005. Ver MERCOSUR, tratados y protocolos: 
para pronunciarse sobre cuestiones que afecten a la integración, pero tampoco le da poder de legislar y enfatiza que sus principales temas de trabajo son la democracia y los derechos humanos, por lo que hace pensar que el hecho que pueda pronunciarse sobre cualquier otro tema, es un aspecto más declarativo que potestativo.

El 7 de mayo de 2007, en Montevideo, lugar sede del parlamento, se realizó la sesión de instalación. El Parlamento se organiza a través de comisiones permanentes y temporales, tal como:
1. Economía
2. Asuntos jurídicos
3. Derechos humanos
4. Desarrollo regional
5. Educación

\subsubsection{EI Parlamento de la Unión de Naciones Suramericanas}

UNASUR fue lanzado como un proyecto ambicioso y nuevo en la escena política de América del Sur, ambicioso porque pretende la unión sudamericana, basada en el proceso de convergencia de los procesos de integración subregionales como la CAN y MERCOSUR, como se ha mencionado anteriormente estos dos grupos de países tienen diferencias respecto a la visión y objetivos de la integración regional. Nuevo por cuanto pretende presentar a América del Sur como una región unificada a nivel internacional, casi a la par que lo está haciendo el conjunto de los otros procesos de integración subregionales para fortalecer a América Latina y Caribe. Lo que hace pensar que si dentro de los objetivos de MERCOSUR estaban, como hemos visto anteriormente, que para profundizar la integración latinoamericana hay que ampliar el MERCOSUR y si tomamos en cuenta que ambos proyectos, tanto MERCOSUR como UNASUR son iniciativas de Brasil, entonces podemos afirmar dos cosas, el primero que UNASUR es una especie de MERCOSUR Plus, y segundo lugar, quizás como sugiere Sanahuja, UNASUR “es el resultado de una política geopolítica brasileña”382, hecho que puede hacernos pensar que UNASUR, no pretende ser una unión que sirva para unir y

http://www.mercosur.int/t_generic.jsp?contentid=3862\&site=1\&channel=secretaria\&seccion=3 [Última revisión: 20-5-2014]

382 SANAHUJA, J. A.: UNASUR "La construcción de una región: Sudamérica y el regionalismo posliberal", en CIENFUEGOS, M. y SANAHUJA, J.A. (Editores): Una región en construcción. UNASUR y la integración en América del Sur, Barcelona, Fundación CIDOB, 2010, p. 102. 
fortalecer a los estados miembro, sino ser un mecanismo que sirva como instrumento que busca defender exclusivamente los intereses de un solo país, a través de este fortalecer a un solo estado, Brasil. Por consiguiente, UNASUR Plus, sería el incorporar a los demás países de la región de manera que sea este el órgano que incluya a toda la región, y cuyo eje político sea el propio Brasil.

Entre los grandes objetivos planeados por UNASUR está crear una moneda, unión monetaria y un parlamento ${ }^{383}$. Para ello plantea, ir un paso más delante de lo que habían ido con la idea de crear un Mercado Común, justamente con MERCOSUR. Argumento que cobra sentido y lógica, más aún si vemos los problemas y consecuencias que ha representado para la UE el haber creado un Mercado Común y una Moneda Común sin haber tomado en cuenta una política económica y fiscal común. Bien, en tal sentido UNASUR considera imprescindible, que para contar con una unión monetaria en América del Sur, es necesario dar un primer "paso inicial es sin duda una política económica y programa económico comunes en América del Sur [...] para lo que resulta indispensable: crear un Parlamento Sudamericano"384.

En la actualidad los países de UNASUR siguen discutiendo sobre la creación del respectivo parlamento, para eso se ha creado un equipo técnico y político integrado por los parlamentos nacionales de los países integrantes de UNASUR. La última reunión de este equipo se realizó en Cochabamba, el 15 de julio de 2015, y se llamó II reunión de la Mesa de Diálogo y Convergencia de Parlamentos de UNASUR, en la que se acordó seguir trabajando para poder elaborar una propuesta de Protocolo Adicional que sirva de acta constitutiva para el parlamento suramericano, a la vez que queda integrado dentro del cuerpo jurídico en el conjuntos de los acuerdos de UNASUR.

Se espera que el Parlamento Suramericano se la instancia deliberativa en donde participen los doce países de UNASUR, entre sus funciones estarán velar por la defensa de la democracia, establecer relaciones de cooperación entre sus miembros, emitir declaraciones y recomendaciones, fomentar el desarrollo de la democracia representativa y ejercer el control político de las instituciones del UNASUR.

\footnotetext{
383 Art. 17 Tratado Constitutivo de UNASUR

384 LOVEDAY J.: Hacia una Unión Monetaria Sudamericana, en Documento de Trabajo 17. La coordinación macroeconómica y la cooperación monetaria, sus costos, beneficios y aplicabilidad en acuerdos regionales de integración. Washington, Abril 2004, Banco Interamericano de Desarrollo, División de Integración, Comercio y Asuntos Hemisféricos del Departamento de Integración y Programas Regionales y el Instituto para la Integración de América Latina y Caribe, p. 162.
} 
Este parlamento estará formado por noventa y nueve miembros, cada país delegará cinco parlamentarios, más algunos representantes del Parlamento Andino, Parlamento del MERCOSUR y de los parlamentos de Guyana y Surinam. Se espera que sesiones dos veces al año, y que su organización sea mediante la creación de comisiones, subcomisiones, presidencias y vicepresidencias, secretarías y subsecretarías. Entre los primeros desafíos que espera al futuro parlamento suramericano estarán el establecer la reglamentación para una ciudadanía suramericana y una moneda en común.

\subsubsection{El Parlamento de la Comunidad de Estados Latinoamericanos y Caribeños}

La CELAC contempla la creación de un parlamento a escala regional. Pero dicha idea no ha sido aún desarrollada y se desconoce cómo será su funcionamiento, organización y competencias. Todo parece indicar que el Parlatino podría ser una plataforma para tomar de base, o sencillamente, incorporarla dentro del sistema institucional de la CELAC como un órgano. Esta última propuesta podría ser una buena alternativa, sobre todo, porque este mecanismos ya funciona en coordinación con los parlamentos nacionales, algo que puede servir de mucho, a la hora de pensar en el futuro trabajo del parlamento regional, no hay que crear canales, pues ya existen, y eso es un punto a favor, en lo que sería el sistema organizacional del futuro Parlamento de la CELAC.

Como se ha indicado, el futuro de cómo se organizará el Parlamento de la CELAC, es aún una incógnita, por tanto, todo lo que se pueda decir al respecto son especulaciones, pues no existe nada oficial aún. Sin embargo podemos analizar algunas declaraciones de ciertos funcionarios latinoamericanos. Cierto es que la CELAC necesita en su andamiaje institucional contar con un órgano que represente a los ciudadanos, y hacer que éstos se sientan realmente representados en dicho órgano y más aún que se sientan partícipes del proceso de integración regional en marcha.

Partiendo de estas premisas, el 19 de diciembre de 2012, el Secretario General de la Asociación Latinoamericana de Integración, Carlos Álvarez afirmó que "la futura CELAC requiere de un brazo político como el Parlamento Latinoamericano (Parlatino) para su desarrollo ${ }^{385 \%,}$, destacó que este nuevo proceso a diferencias de los anteriores

\footnotetext{
385 ÁLVAREZ, C.: "La CELAC requiere de un brazo político como el Parlatino", publicado en CELAC, Centro de Noticias del Parlamento Latinoamericano, Panamá, 19 de diciembre de 2012.
} 
realizados, tiene que tener un nuevo enfoque, en el cual el rol a jugar por parte de un órgano de carácter legislativo, es importante, y que "la integración no pude depender exclusivamente de la tecnocracia de las cancillerías, que es necesaria e indispensable, pero no suficiente ${ }^{386,}$.

El 5 de diciembre de 2011, durante la XXVII Asamblea del Parlatino, su presidente, Elías Castillo, señaló que el Parlatino se proyecta como el órgano legislativo de la integración regional, apeló a la historia, vocación, trayectoria y objetivos desarrollados por el Parlatino a lo largo de estas décadas. Por lo que terminó enfatizando que:

La creación de la CELAC establece la creación de una Secretaría General y permanente, por ello el Parlatino ofrece, en la estructura que está construyéndose un espacio, de manera que Panamá siga manteniendo ese centro que representó el Congreso Anfictiónico a inicios del siglo XVIII [...] hemos venido trabajando a lo largo de todos estos años con la promoción de la Comunidad Latinoamericana de Naciones $(\text { CLAN })^{387}$.

En esta misma reunión se tocaron como temas centrales la interacción que podría tener el Parlatino dentro de la estructura institucional de la CELAC, Por su parte, el Vicepresidente del Parlatino, Juan Carlos Varela, manifestó que el Parlatino puede contribuir en la consolidación y vigencia de la democracia en América Latina y a su unidad de acción política hacia otras regiones". Con esta última afirmación podemos observar la mirada puesta en el deseo de crear una acción exterior, políticamente unificada frente a otras regiones, o al menos el ir dotando al parlamento regional esa competencia de acción exterior frente a terceros, de hecho el Parlatino ya lo hace como lo veremos a continuación en su diálogo birregional parlamentario con el Parlamento Europeo.

Si este nuevo parlamento regional, encarna, el mismo deseo, compromiso e impulso que dio el Parlamento Europeo en la construcción de una Unión Europea como Actor Global, diseñando y elaborando legislación comunitaria, velando por el cumplimiento

http://www.parlatino.org/cdn/component/k2/itemlist/category/268-celac.html [Última revisión: 7-72014]

${ }^{386}$ Ibíd.

${ }^{387}$ PARLAMENTO LATINOAMERICANO: PARLATINO celebra conformación de la CELAC, Centro de Noticias del Parlamento Latinoamericano, Panamá, 5 de diciembre de 2011.

http://www.parlatino.org/cdn/component/k2/item/2344-parlatino-celebra-conformación-de-la-celac.html [Última revisión: 7-7-2014] 
de los compromisos asumidos por parte de los Estados miembros, sancionando si se incumpliesen dichos compromisos, y siendo el garante democrático de las tomas de decisiones a nivel regional, será un avance más que significativo, no sólo en términos de integración para la región, sino también en términos democráticos y de desarrollo.

En términos democráticos a nivel regional, existe una carencia total, no sólo porque no existe un proceso de elecciones a nivel regional, sino porque no existe una cultura de democracia a nivel regional, ni instituciones que la ejerzan, pues todos los parlamentos de los procesos de integración existentes, carecen de poderes y competencias, efectivas, decimos efectivas a poder diseñar, elaborar y dictar normas legislativas a nivel regional.

En la actualidad todos los parlamentos subregionales y regionales existentes se limitan a realizar resoluciones o declaraciones, pero que no son vinculantes, y carece de obligatoriedad tanto jurídica como política, y los procesos que tiene contemplados desarrollar dichas funciones, en la práctica aún no lo ha hecho. Decimos desarrollo, porque faltan órganos regionales que piensen regionalmente, y por tanto, puedan diseñar leyes pensando en el conjunto de intereses de la ciudadanía latinoamericana y caribeña, y no sólo en el conjunto de los intereses de ciudadanos nacionales.

Muchos de los proyectos de desarrollo o de infraestructura a nivel subregional o regional son desarrollados mediantes acuerdos internacionales de carácter bilateral o ante organismos multilaterales, y todos ellos, suelen ser refrendados por los parlamentos nacionales, y en cierto momento pueden ser apoyados y respaldados por los mismos, en una siguiente legislatura pueden ser desacreditados y pedir su cancelación, debido a los cambios de partidos políticos tanto en el gobierno como en sus respectivos parlamentos nacionales. Quedará por ver como los países de la región resuelve la institucionalidad de su respectivo parlamento.

\subsection{EL DIÁLOGO INTERPARLAMENTARIO BIRREGIONAL: EUROLAT}

La Primera Conferencia Interparlamentaria entre el Parlamento Latinoamericano y el Parlamento Europeo, fue celebrada en Bogotá, entre el 15 y 17 de julio de 1974. Pero es en el marco de EUROLAT como Asamblea Parlamentaria Euro-Latinoamericana, que 
se convierte en un mecanismo de consulta permanente y formal, y en la cual se tratan temas de interés común dentro de la Asociación Estratégica Birregional (AEB).

EUROLAT fue establecida como tal en junio de 1999 en el marco de la Cumbre Unión Europea-América Latina y Caribe. El 8 y 9 de noviembre de 2006, se efectuó su sesión constitutiva y tuvo lugar en Bruselas.

EUROLAT adopta y presenta declaraciones y brinda recomendaciones a las instituciones, organismos y grupos ministeriales encargados del desarrollo e implementación de la Asociación Estratégica Birregional. La Asamblea Parlamentaria Birregional (APB) está compuesta por representantes de ambas regiones, 75 representantes por región, con un total de 150 representantes. Por la parte europea, los 75 representantes pertenecen al Parlamento Europeo, en el caso de América Latina y Caribe, sus 75 representantes, se dividen entre representantes del Parlamento Latinoamericano, Parlamento Andino, Parlamento Centroamericano, Parlamento del MERCOSUR y representantes de los parlamentos nacionales de México y Chile.

EUROLAT, es parte de ese acervo comunitario integracionista que se ha ido forjando en ambas regiones y que les ha llevado al actual diálogo birregional. Sus antecedentes se remonta a las primeras resoluciones, en 1972, de ambos parlamentos regionales, que para ese entonces eran el Parlamento Latinoamericano y la Asamblea de las Comunidades Europeas, que posteriormente con la reformas de los tratados europeos pasaría a estar representando por el Parlamento Europeo, desde 1979 los países europeos realizan elecciones directas a dicha asamblea y como tal comienza a ejercer y establecer relaciones interinstitucionales.

Posteriormente el Acta Única Europea (1987) y el Tratado de la Unión Europea (Tratado de Maastricht en 1992), que incluyen los temas de política exterior común y enfatizan la importancia de estrechar relaciones con otras regiones del mundo con el fin de promover la integración regional, se hace más que evidente la necesidad de seguir profundizando el diálogo con el Parlatino, ya que este se presentaba como un mecanismo de diálogo político permanente que buscaba ayudar a la integración regional de América Latina.

Por su parte, el Parlatino se institucionalizó a partir de 1987 y en 1992, establece una sede permanente con el objeto de darle una mayor representatividad al mismo. Como 
podemos observar las fechas, 1987 y 1992, sirven a ambas asambleas como referencia para realizar cambios en su funcionamiento y representación exterior. Ambas asambleas deseaban estrechar lazos con el fin de coadyuvar tanto en la mayor profundización de sus respectivos procesos de integración regional, así como en el acercamiento con otras regiones del mundo que justamente estaban llevando procesos de integración regional, una forma de darle más visibilidad a sus respectivos procesos y darle un respaldo democrático a los mismos. Al ser la experiencia europea, pionera en desarrollar este tipo de proceso de integración, América Latina se vuelca a intercambiar impresiones, experiencias e información con los países europeos con la idea de establecer una agenda de trabajo común.

Como hemos visto a lo largo de este trabajo, el Parlamento Europeo jugó un papel importante en las relaciones con ALC, que constantemente emitía documentos con recomendaciones y líneas de trabajo a considerar en el fortalecimiento de las relaciones entre ambas regiones. Se puede decir que el trabajo y esfuerzo desarrollado por ambas partes no era en vano, todo lo contrario, servía para reflexionar e introducir temas en la agenda de las reuniones tanto a nivel de jefes de estado y de gobierno como ministerial.

Los días 15 al 17 de julio de 1974, en la ciudad de Bogotá se efectúa la primera Conferencia Interparlamentaria, y se establece que esta tenga carácter permanente y con una periodicidad bienal, con una alternancia de celebración entre una y otra región. Las lenguas oficiales son las de los países que participan, pero se seleccionaron como lenguas de trabajo cinco lenguas: español, inglés, francés, alemán y el portugués. Desde entonces, 1974, hasta 2015, han transcurrido 41 años de este mecanismo de consulta, realizándose XVI Conferencias Interparlamentarias, en el marco de las reuniones entre el Parlatino y el Parlamento Europeo, desde la I Conferencia Interparlamentaria de Bogotá en 1974 hasta la XVI Conferencia Interparlamentaria de Bruselas en 2003. Posteriormente, el marco jurídico de las relaciones entre ambas cámaras de representantes sería EUROLAT.

Desde la Sesión Constitutiva de EUROLAT, en Bruselas, noviembre de 2006, se han realizado siete Sesiones Plenarias Ordinarias, siendo la última en Bruselas, en junio de 2015. En tal sentido, siguiendo con sus funciones de mecanismo consultivo, ha participado en la última reunión entre la UE-ALC, esta vez, en el marco de la II Cumbre 
UE-CELAC, que marca una nueva etapa en la profundización de las relaciones entre ambas partes, en la búsqueda de establecer un nuevo diálogo birregional.

Como se comprueba EUROLAT ha acompañado a los países de ambas regiones durante su evolución de sus relaciones, incluso cuándo deciden cambiar de marco jurídico, del Grupo de Río-UE a las Cumbres UE-ALC, EUROLAT estaría presente en ellas en dos ocasiones, y cuándo ambas regiones deciden cambiar otra vez su marco jurídico de sus relaciones, al pasar de las cumbres ALC-UE a CELAC-UE, EUROLAT también ha estado presente.

EUROLAT se estructura mediante una Asamblea Plenaria, formada por los parlamentos regionales, a trabaja a través de una Mesa Directiva. EUROLAT tiene dos Copresidentes junto a catorce Co-vicepresidentes (7 representantes de cada lado), este órgano supervisa el trabajo de la asamblea y mantiene relaciones con las instituciones que llevan a cabo el trabajo de la Cumbre CELAC-UE, así mismo mantiene relaciones con la Fundación UE-ALC, las conferencias interministeriales y los Grupos de Altos Funcionarios y Embajadores.

En la actualidad EUROLAT tiene cuatro comisiones permanentes:

1. Asuntos Políticos

2. Asuntos Económicos

3. Asuntos Sociales

4. Desarrollo Sostenible

Y cuenta con un Grupo de Trabajo sobre "Migraciones Unión Europea-América Latina y el Caribe".

Las Comisiones y la Mesa Directiva se reúnen, por lo menos dos veces al año. De los acuerdos alcanzados en las diferentes comisiones, se elevan como propuestas a la Asamblea, y esta emite resoluciones y recomendaciones sobre los temas planteados. El sistema de votación es por mayoría simple.

$\mathrm{Si}$ analizamos las últimas resoluciones de EUROLAT se pude ver que tiene una correlación directa con los temas que son tratados en las Cumbres de Jefes de Estado y de Gobierno de ambas regiones y que a su vez, dichos temas son los tratados en sus respectivos procesos de integración. Entre los más resaltantes podemos señalar: 
- Resolución sobre participación ciudadana y democracia en la Unión Europea y América Latina y el Caribe, marzo de 2014.

- Resolución sobre comercio de materias primas entre la UE-ALC, marzo de 2014.

- Resolución sobre educación formal e informal y educación continua en Europa y América Latina, marzo de 2014.

- Resolución sobre la lucha contra el narcotráfico y la delincuencia organizada, enero de 2013.

- Resolución sobre Globalización y la Crisis financiera, enero de 2013.

- Resolución sobre desastres naturales en Europa y América Latina, mayo de 2011.

- Resolución sobre las perspectivas para las relaciones comerciales entre la UEALC, mayo de 2011.

- Resolución sobre una Carta Euro-Latinoamericana para la paz y seguridad, abril de 2009.

Podemos decir que el trabajo desempeñado por EUROLAT a lo largo de estas décadas ha contribuido a sentar como principales principios y valores comunes la defensa de la democracia, la defensa y promoción de los derechos humanos, la solución pacífica de conflictos, lo que se puede traducir e interpretar, como la preminencia de la "fuerza de la diplomacia" sobre el ejercicio de la "fuerza militar" ante posibles conflictos. Algo que la Unión Europea siempre defiende y promueve a nivel global y que ha puesto en marcha en sus relaciones interregionales con América Latina.

Entre sus principales esfuerzos podemos indicar su apuesta por el fortalecimiento de las instituciones democráticas, buscando además que estas sean cada vez más representativas, la promoción de mecanismos de participación de la sociedad civil dentro de los procesos de integración, así como en las negociaciones entre ambas regiones, otra forma de legitimar justamente los mencionados procesos. Y resaltando sobre todo, encontramos el apoyo y fomento de la integración regional como modelo de paz y de desarrollo entre los pueblos, lo que representa una clara apuesta por un nuevo sistema internacional basado en la participación activa de las regiones como actores globales.

Para lograr tales fines se hace necesario, cada vez más, seguir profundizando en esa visión multidimensional que tiene que tener la integración regional, que debe de incluir otros ámbitos además de lo económico y comercial. Esa visión multidimensional de la 
integración tiene que estar basada en tratar de cubrir todos los ámbitos de la sociedad, si se desea logar un desarrollo integral de la población, abarcando para ello los ámbitos: político, económico, social y cultural. Esta visión multidimensional de la integración regional es lo que hace común el diseño, elaboración, desarrollo e implementación de todos los diferentes proyectos y programas que están en marcha entre ambas regiones. Todo esto, es lo que en resumen podemos decir que es el mayor activo que podemos destacar del trabajo desempeñado por EUROLAT en favor de la construcción de una Asociación Estratégica Birregional. 
EL ACERVO INTEGRACIONISTA N EUROPA Y AMÉRICA:

UNA HISTORIA COMÚN 
- CAPÍTULO VI

DESARROLLO Y EVOLUCIÓN DE LA ACCIÓN EXTERIOR EN LOS PROCESOS DE INTEGRACIÓN REGIONAL EN LA UNIÓN EUROPEA-AMÉRICA LATINA Y EL CARIBE 


\subsection{LA ACCIÓN EXTERIOR: CASO UNIÓN EUROPEA}

La acción exterior de una Comunidad o Unión de Estados se hace posible y efectiva a través del desarrollo e implementación de una política exterior común, ello permite poder expresarse y actuar como una región a través y sobre la base de un ordenamiento jurídico que determina objetivos, metas y delimita las acciones a desarrollar.

En el caso de la integración europea, la Unión Europea ha ido desarrollando los instrumentos necesarios para poder articular una política comunitaria en el ámbito de la acción exterior, y poco a poco, ha ido incluyendo dentro de las competencias comunitarias la creación de una política exterior común. El Tratado de Lisboa contempla algunos elementos que le son de gran ayuda para lograr de manera efectiva esa visibilidad externa, que tanto deseaba tener la UE, a la par que aumentar su peso internacionalmente. La UE ha ido tomando cada vez más mayores pasos hacia una mayor integración política, lo que ha permitido que la Unión pueda presentarse ante los principales organismos, foros y conferencias internacionales con una sola voz.

Al respecto el Tratado de Lisboa tiene como novedades la figura del Alto Representante de la Unión para Asuntos Exteriores y Política de Seguridad y dota a este mismo con la creación de un cuerpo comunitario que le servirá de apoyo y asistencia, nos referimos al Servicio Europeo de Acción Exterior. Estas novedades significaban un cambio en la forma de trabajar y cooperar entre los estados, por tanto representó un cambio en las tradicionales relaciones internacionales, que eran predominantemente ejercida por los estados, de manera bilateral o multilateral; con la Comunidad Económica Europea se rompe esta tradicionalidad de relaciones entre los estados para pasar a desarrollar relaciones entre región-estado, región-región, región-organismos internacionales; la creación de un Servicio Europeo de Acción Exterior es otro gran cambio que contribuirá, a un más, a la modificación de la tradicional forma de concebir las relaciones internacionales.

La elaboración, desarrollo e implementación de una Política Exterior Común es sin duda el primer paso político que tiene que dar una región si realmente desea ser un actor político importante y relevante en la arena internacional.

El Servicio Europeo de Acción Exterior y la Política Exterior y de Seguridad Común han sido concebidos para reforzar la acción exterior de la diplomacia europea, siendo su 
principal objetivo permitir a la UE expresarse y actuar con personalidad jurídica propia en el escenario internacional. No olvidemos que la acción de la UE siempre se basa en la diplomacia, y por tanto, no tiene sentido que piense en una acción exterior sin considerar el desarrollo de una diplomacia común. Diplomacia que ha ido creando conforme han transcurrido los años de su proceso de integración regional.

Con el transcurrir del tiempo, los Estados miembros del proceso de integración de la UE se va dando cuenta, conforme va desarrollando sus relaciones con terceros, que las negociaciones comerciales, económicas y de cooperación al desarrollo, que sus acciones en materia de acción exterior tienen que estar articuladas mediante un marco jurídico, llegando a la conclusión que el mejor marco jurídico es el desarrollar una política exterior común, que combine los intereses nacionales de sus Estados miembros con los intereses generales de la Unión. Sólo así podrían conseguir mejores negociaciones y tener una voz relevante en ellas, al igual que en la toma de decisiones en los grandes foros, conferencias y organismos internacionales.

Quienes critican el desarrollo de estas competencias comunitarias en detrimento de las competencias nacionales, se adhieren a la idea que la política exterior es el máximo baluarte de la soberanía nacional de un Estado, por tanto, quienes están en contra de ello, dicen que la diplomacia sólo debe de ser ejercida por los Estados, y critican que la diplomacia que desea implementar la UE es una "diplomacia sin los Estados" ${ }^{388}$, sin embargo a estos mismos detractores se les podría decir que tampoco se esperaba que la UE iba a evolucionar tanto y que iba cambiar la manera de concebir las relaciones internacionales, pues como argumenta Macarena Esteban, la UE constituye la excepción en un mundo en el que impera la diplomacia estatal ${ }^{389}$.

Por otro lado, en ese momento, los Estado no estaban preparados para delegar funciones diplomáticas en órganos comunitarios ${ }^{390}$. Lo cierto es, que estando de acuerdo o en desacuerdo con el rumbo tomado por la Unión, el SEAE está creado y aprobado y ya es un hecho, y con ello la puesta en marcha de una diplomacia regional europea.

\footnotetext{
388 JÖNSSON, C. and HALL, M.: Essence of Diplomacy, Basingstoke, Palgrave Mcmillan, Hampshire 2005 , p. 154.

${ }^{389}$ ESTEBAN, M.: Los inicios del Servicio Europeo de Acción Exterior, Documento de Trabajo, Serie Unión Europea, N 52/2011, Instituto Universitario de Estudios Europeos, Universidad San Pablo CEU, Madrid, 2011, p. 29.

390 JÖNSSON, C. and HALL, M.: Essence of Diplomacy, Op, cit., p. 151.
} 
Sin embargo el camino para llegar hasta la creación del SEAE no ha sido tarea fácil, de hecho ha estado lleno de continuos "fracasos" y ponemos entre comillas, pues a nuestro entender cada uno de esos fracasos han permitido ir introduciendo dentro de la agenda de la integración europea ese tema, hasta llegar a su implementación.

A nuestro modo de ver, no era un camino claro, pero sí ha sido el resultado del tratar que la UE posea una voz fuerte en el concierto internacional, y para que esta pueda desarrollar negociaciones que se le representaran más beneficiosas, y que de hacerlo como países separados, en lugar de realizarlas como Estados miembros de la UE, no hubiesen conseguido las ventajas que han conseguido en conjunto, si tenemos que pensar cuáles han sido esas ventajas o los beneficios obtenidos, tendríamos que pensar en que la UE, hoy por hoy, representa uno de los mayores mercados a nivel mundial, en términos económicos, y en términos políticos es un actor a tener en cuenta en la escena global, cosa que no sería si cada uno de los países europeos operarán de manera unilateral, su fortaleza negociadora y política radica justamente en ser una unión de estados.

El camino hasta llegar a contar con un SEAE no ha estado exento de dificultades y trabas por parte de los mismos estados miembros, que siempre han pugnado por mantener ciertas competencias inherentes a los estados nacionales soberanos, y por consiguiente, el tema de compartir una soberanía común como hoy se tiene, no ha sido una tarea ni fácil, como tampoco ha sido de la noche a la mañana. A continuación realizaremos una recapitulación histórica del desarrollo de la acción exterior de la UE.

Iniciaremos poniendo como punto de partida la propia Declaración Schuman (1950) la cual, si bien es cierto, proponía una integración partiendo de la base económica, pero su visión y voluntad era establecer un una unión política. Es verdad que esos primeros intentos de integración dejaban de lado el tema de la política exterior, un tema que era materia exclusiva de los Estados y que buscaban que sea mantuviera así, motivo por el cual se optó, inicialmente, porque sea esta desarrollada de manera intergubernamental, hasta llegar en cierto modo una política comunitaria, y decimos en cierto modo, porque aún con el Tratado de Lisboa se reserva ciertas prerrogativas en la toma de decisión a los Estados miembros en esta área. Pero también es cierto que los Estados han ido cediendo poco a poco hasta llegar a desarrollar una acción exterior de ámbito europeo. Ello ha sido posible gracias al trabajo de interpretación teleológica de los tratados 
fundacionales por parte del Tribunal de Justicia de la Unión Europea, así como por parte del Parlamento Europeo.

Partiendo de los deseos expresado en la Declaración Schuman porque Europa sea una unidad política, se dan los primeros pasos hacia esa dirección cuando el 24 de octubre de 1950, René Prevén, a instancias de Jean Monnet, propone la creación de un ejército europeo, con ello introduce en el proceso de integración europea el tema de defensa, tema que siempre fue una competencia exclusiva de ámbito nacional, pero que con dicha iniciativa se busca extrapolarla a una escala regional europea.

La idea en ese momento era crear una Comunidad Europea de Defensa, y con ello se marca un punto de partida sobre lo que también sería en el futuro la Política Exterior y de Seguridad Común de la UE. En esta misma década, en 1954 Jean Monnet, se convierte en el presidente de la Alta Autoridad de la Comunidad Europea del Carbón y del Acero, ese mismo año la CECA emite su primer boletín titulado Hacia un Gobierno Federal de Europa, acto seguido abre una representación oficial de enlace en Santiago de Chile para América Latina y su primera misión diplomática en Londres en 1956. En 1958 abren una representación en Washington ${ }^{391}$. Barbé destaca que la propuesta francesa tenía como objetivo "erosionar el liderazgo de los Estados Unidos en el terreno diplomático, mediante la creación de una «segunda voz» en el bloque occidental» ${ }^{, 392}$.

En 1960 el Presidente Kennedy escribió a Jean Monnet “América y Europa trabajan en una asociación plena y efectiva [...] y fue el Presidente Kennedy quién en su discurso visionario [...], el 4 de julio de 1962, propuso el concepto de asociación transatlántica y de una declaración de interdependencia entre el nuevo mundo y la nueva Europa"393. Se trae a colación este tema, dada las actuales negociaciones entre los Estados Unidos y la Unión Europea respecto al Acuerdo Transatlántico de Comercio e Inversiones, para que quienes piensen que dicha propuesta responde a una coyuntura actual, pues no hay que olvidar que las relaciones entre ambas partes datan desde el inicio del proceso de integración de la misma UE como se puede apreciar.

\footnotetext{
${ }^{391}$ EUROPEAN COMMISSION: Taking Europe to the world. 50 years of the European Commsion's External Service, Luxemburgo, 2004, p. 12.

392 BARBÉ, E.: Política exterior y de seguridad común: de Luxemburgo a Ámsterdam, Política y Sociedad, 28, Madrid, 1998, p. 30.

393 "A letter from America", Günter Burghardt, Head of Delegation, Washington, in EUROPEAN COMMISSION: Taking Europe to the world. 50 years of the European Commsion's External Service, Op. Cit., pp.13-14
} 
La Primera Conferencia de París, en febrero de 1961, buscaría crear los medios adecuados para organizar una cooperación política europea más estrecha en las áreas de política exterior y de seguridad ${ }^{394}$. De esa conferencia saldría el Informe Fouchet, que contemplaba una unión de estados basada en la premisa de una cooperación a nivel intergubernamental y regulada a través de tratados de carácter comunitario, entre las áreas propuestas estaban la política exterior y de defensa, ciencia, cultura y los derechos humanos.

Se plantea la necesidad que para que exista una mayor cooperación política era necesario que se creara, en el futuro inmediato, un Consejo de Jefes de Estado para que regule los temas comunes a tratar, y que éste se reúna de manera periódica para intercambiar impresiones y coordinar un trabajo conjunto. Las decisiones sería tomadas mediante votación de unanimidad, a su vez se contempla la idea de que el Consejo sea asistido por una Comisión formada por diplomáticos de los países, de tal manera que quedara garantizada la defensa de los intereses de cada estado dentro del marco europeo.

La Cumbre de la Haya en 1969, sentará las bases para adoptar una decisión mediante la cual se dota a la Comunidad de recursos financieros propios, para desarrollar una cooperación en materia de política exterior (Informe Davignon, 1970). En este mismo año, en octubre de 1970, los seis Estados miembros aprueban el Informe de Luxemburgo, mediante el cual deciden crear un mecanismo de coordinación diplomática, este nuevo mecanismo tendría tres grandes funciones:

1. Desarrollar una red de información

2. Armonizar los puntos de vista de los Estados

3. Concertar posiciones comunes

Todas estas acciones fueron llamadas, por un sector de la academia, como: communauté $d^{\prime}$ information, communauté de vues y communauté $d^{\prime}$ action ${ }^{395}$. Durante la misma década de los setenta, en 1974, en la Cumbre de París se crea el Consejo Europeo como un órgano permanente, hecho que daría un nuevo impulso a la unidad política europea. La primera reunión dentro de este nuevo órgano se realiza en Dublín, en marzo de 1975.

\footnotetext{
394 Más información ver: CONSEJO EUROPEO. Cincuenta años de conferencias en la Cumbre, Secretaria General del Consejo Europeo, Bruselas, 2012.

395 DE SCHOUTHEETE, P.: La Coopération Politique Européenne, Labor, Bruselas, 1986, p. 49.
} 
Sin embargo, hasta ese momento, el Consejo carece de base jurídica por no estar recogida su existencia ni funcionamiento en un tratado.

En junio de 1984, el Consejo Europeo de Fontainebleau, encarga la creación de un Comité Especial, el Comité Dooge-Spaak II (el cual fue establecido en la Conferencia de Messina en 1955) para que se den las sugerencias sobre cómo mejorar el funcionamiento de la cooperación europea en dos ámbitos, a nivel comunitario y en cooperación política. Un año más tarde se debatió al respecto en el Consejo Europeo de Milán, junio de 1985, en el mismo la mayoría de los estados deciden, por mayoría, convocar a una Conferencia Intergubernamental para revisar los tratados y con ella evaluar el funcionamiento de las instituciones comunitarias existentes hasta la fecha, así como el tema de la libre circulación, así como las tareas encomendadas a elaborar un texto sobre la política exterior y de seguridad común. En ese mismo año, 1985, se efectúa el Consejo Europeo de Luxemburgo, que consigue un acuerdo político que abre paso para la futura adopción del Acta Única Europea (AUE), la cual comprendía modificaciones respecto a las normas de funcionamiento de las instituciones europeas y ampliaba las competencias comunitarias, la AUE contribuirá en el crecimiento del acervo comunitario la incorporación de la reglamentación jurídica sobre la cooperación europea en el tema de la política exterior ${ }^{396}$.

El Tratado de Maastricht del 7 de febrero de 1992, crea la Unión Europea y con el mismo se establece tres pilares, el primero de carácter comunitario y el segundo y tercero de ámbito intergubernamental:

1. Comunidad Europea y la EURATOM (primer pilar)

2. Política Exterior y de Seguridad Común (segundo pilar)

3. Cooperación judicial y de asuntos interiores (tercer pilar)

En el período previo al Tratado de Maastricht, ocurren dos acontecimiento de escala global que modifica la arena internacional, nos referimos a la caída del Muro de Berlín (1989) y la disolución de la Unión Soviética (1991), por consiguiente generó la reunificación alemana, estos hechos hacen que Europa reoriente parte su política exterior, tanto intracomunitariamente como extracomunitariamente, se comienza a mirar

\footnotetext{
${ }^{396}$ El Acta Única Europea incluía en su Título III. Disposiciones sobre la Cooperación Europea en materia de Política Exterior. El AUE fue firmada en Luxemburgo el 17 de febrero de 1986 y entró en vigor el 1 de julio de 1987.
} 
hacia el Este y las nuevas repúblicas nacientes de dicha disolución, como bien sabemos posteriormente la mayoría de estas nuevas repúblicas pasarán a ser parte de la UE.

La UE decide apostar por la vía diplomática antes que por la vía militar para solucionar los conflictos internacionales. Barbé llama a este período la "europeización de las relaciones internacionales" término que emplea para explicar un mayor desarrollo de la diplomacia, las relaciones económicas y culturales en contra del desarrollo y aplicación de la capacidad militar ${ }^{397}$. Para hacer una conexión con nuestra otra región de estudio, ALC, cabe señalar también que la incorporación de España y Portugal en 1986, fortalece la idea de priorizar las relaciones con ALC, como hemos señalado antes.

En 1995 la ampliación de la UE con la incorporación de Austria, Suecia y Finlandia y posteriormente con la firma del Tratado de Ámsterdam, el 2 de octubre de 1997, se introduce la creación del Espacio de Libertad, Seguridad y Justicia Común, hecho que afecta a la política exterior.

En 1999 se firma los acuerdos con Noruega e Islandia. Las negociaciones para llegar al Tratado de Ámsterdam dejan varios puntos claves en favor del desarrollo de una Política Exterior Común a nivel europeo. El eje franco-alemán propone la idea de una "cooperación reforzada" para aquellos Estados miembros que deseen avanzar en el terreno de una unión política, y concretamente en el tema de la política exterior común, así queda reflejado en el Tratado de Ámsterdam que contempla el voto por mayoría cualificada en vez de la unanimidad.

Se considera que el sistema de la presidencia rotatoria no favorece a un buen funcionamiento para desarrollar políticas comunitarias, y es en ese momento que el gobierno francés propone la creación de un nueva figura política, cuya funciones serían destinadas a representar a la Unión, quería darle una personificación a la acción exterior europea, la UE debería de contar con un Alto Representante.

La idea de tener esta nueva figura despertó muchos recelos por parte de Estados que no estaban de acuerdo con una federalización del proceso de integración, por el contrario ellos apostaban por defender los nacionalismos y por tanto seguir trabajando, cooperando, utilizando el método intergubernamental. Uno de los principales

\footnotetext{
${ }^{397}$ BARBÉ, E y GRASA, R.: La Comunitat Europea i la Nova Europa, Fundación Bofill, Barcelona, 1992, pp. 133-172.
} 
detractores a esta propuesta fue el Reino Unido. El Tratado consiguió una medida intermedia, que la presidencia seguirá desempeñando las funciones de representación de la Unión ${ }^{398}$, pero esta será asistida por el Secretario General del Consejo, que ejercerá las funciones de Alto Representante de la Política Exterior y de Seguridad Común ${ }^{399}$. Además señala que, los Estados miembros apoyarán activamente y sin reservas la política exterior y de seguridad de la Unión, con espíritu de lealtad y solidaridad mutua $^{400}$. A continuación, la definición de los objetivos de la PESC en el Tratado de Ámsterdam:

“La Unión definirá y realizará una política exterior y de seguridad común, que abarcará todos los ámbitos de la política exterior y de seguridad y cuyos objetivos serán los siguientes:

- La defensa de los valores comunes, de los intereses fundamentales y de la independencia e integridad de la Unión, de conformidad con los principios de la Carta de Naciones Unidas;

- Fortalecimiento de la seguridad de la Unión en todas sus formas;

- El mantenimiento de la paz y el fortalecimiento de la seguridad internacional, de conformidad con los principios de la Carta de Naciones Unidas, con los principios del Acta Final de Helsinki y con los objetivos de la Carta de Paris, incluidos los relativos a las fronteras exteriores;

- El fomento de la cooperación internacional;

- El desarrollo y la consolidación de la democracia y del Estado de Derecho, así como el respeto a los derechos humanos y de las libertades fundamentales ${ }^{401}$,.

El español Javier Solana fue designado como Secretario General del Consejo y con eso el primer Alto Representante para Asuntos Exteriores y de Seguridad Común, A su vez, ejercería el cargo de Secretario General de la Unión Europea Occidental (UEO). La designación de Solana fue una propuesta del Gobierno español (Gobierno de Felipe Gonzales) que coincidentemente encontró el respaldo y apoyo internacional,

\footnotetext{
398 Art. J. 8.1. Disposiciones relativas a la Política Exterior y de Seguridad Común. Tratado de Ámsterdam, firmado el 2 de octubre de 1997.

399 Art. J. 8.3. Disposiciones relativas a la Política Exterior y de Seguridad Común. Tratado de Ámsterdam, firmado el 2 de octubre de 1997.

${ }^{400}$ Art. J2. Disposiciones relativas a la Política Exterior y de Seguridad Común. Tratado de Ámsterdam, firmado el 2 de octubre de 1997.

${ }^{401}$ Art. J1. Disposiciones relativas a la Política Exterior y de Seguridad Común. Tratado de Ámsterdam, firmado el 2 de octubre de 1997.
} 
principalmente por parte del Gobierno estadounidense (Gobierno de Bill Clinton), por haber sido, Solana, Secretario General de la OTAN, seguramente surge la pregunta y qué relación tiene, pues mucha, ya que era importante que la persona que ocupara el cargo de Alto Representante supiera compatibilizar las relaciones establecidas entre la UE, la UEO, Estados Unidos y la OTAN.

Hasta ahora, no la hemos mencionado a la UEO para seguir un orden cronológico y centrarnos exclusivamente en el desarrollo de la PESC, pero su relación es relevante y su existencia como organización fue importante, por cuanto ayudó a sentar las bases para pensar en temas de seguridad y defensa a nivel regional. Si bien es cierto, que la UEO se disolvió el 31 de marzo de 2010, tras la entrada en vigor del Tratado de Lisboa. Sin embargo, como veremos, sus funciones tienen relación en la implementación de la PESC. Así lo refleja el Tratado de Ámsterdam:

“La Unión Europea Occidental es parte integrante del desarrollo de la Unión y
proporciona a la Unión el acceso a una capacidad operativa [...]. La UEO
secunda a la Unión en la definición de los aspectos de defensa de la política
exterior y de seguridad común [...]. La Unión, en consecuencia, fomentará
relaciones institucionales más estrechas con la UEO con vistas a la posibilidad de
la integración de la UEO en la Unión. [...]. La Unión [...] respetará las
obligaciones derivadas del Tratado del Atlántico Norte para determinados Estados
miembros que consideran que su defensa común se realiza dentro de la OTAN y
será compatible con la política común de seguridad y de defensa establecida en
dicho marco".402.

La UEO fue una organización de defensa y seguridad de ámbito regional europeo, formada por los Estados miembros de la UE y los miembros europeos de la OTAN. La UEO se creó mediante el Tratado de Bruselas de 1948, y fue creada originariamente con el respaldo de Francia, Bélgica, Reino Unido y Países Bajos, su objetivo era defensivo, y por consiguiente tenía como meta asistir a cualquiera de sus miembros en caso de una eventual agresión. Pero con la incorporación de los temas de seguridad dentro del marco del proceso de integración de la UE, con la existencia de la UEO representó una duplicidad de funciones y por tanto era ineficiente. Como se ha indicado, con la entrada

\footnotetext{
${ }^{402}$ Art. J. 7. Disposiciones relativas a la Política Exterior y de Seguridad Común. Tratado de Ámsterdam, firmado el 2 de octubre de 1997.
} 
en vigor del Tratado de Lisboa que contemplaba una política exterior y de seguridad común, la UEO dejó de existir.

Muchas veces las crisis, lejos de debilitar a la UE, la fortalecen. Y así ocurrió cuándo también durante la década de los noventa se da la Guerra de la Antigua Yugoslavia y el conflicto de los Balcanes, que da pie a que la UE pueda crear el cargo de Alto Representante para la Política Exterior y de Seguridad Común, que a su vez ejercerá como Secretario General del Consejo de la Unión Europea, hecho que contribuyó para que se acelerara la idea de articular y profundizar tanto en el tema de la política exterior como el de la política de seguridad común dentro del seno de la UE. Estos acontecimientos darían la oportunidad de implementar un mecanismo, la Unidad de Planificación de Política y de Alerta Rápida (UPPAR).

El Tratado de Niza, firmado el 26 de febrero de 2001, reforma los lineamientos de la PESC, este tratado crea cambios respecto a las "cooperaciones reforzadas", estableciendo un mínimo de ocho Estados miembros para tenerla.

En ese mismo año se emite la Declaración de Laeken, 2001, por la cual se establecerá una Convención que será la encargada de elaborar una Constitución Europea, esta fue firmada el 24 de octubre de 2004 en Roma, y aunque no llegó a ver la luz. La nonata Constitución Europea, deja al acervo comunitario muchos de los lineamientos que hoy se encuentran recogidos en el Tratado de Lisboa, con lo que respecta a la acción exterior de la UE, sólo que cambia un poco la terminología, pero en esencia mantiene las ideas y los fines para seguir avanzando en esta materia

Así podemos encontrar la figura del Ministro de Asuntos Exteriores de la Unión, el cual sería el encargado de realizar propuestas relacionadas con la política exterior y de seguridad común, a la par que presidiría el Consejo de Ministros de Asuntos Exteriores, al igual que sería el depositario de ejecutar las decisiones adoptadas por el Consejo de Ministros de Asuntos Exteriores y del Consejo Europeo. Entre sus funciones también estaba el representar a la Unión y dirigir el diálogo político con terceros en nombre de la Unión, y sería el encargado de expresar la posición común de la UE en los foros, conferencias y organismos internacionales. Del mismo modo se establecía que el Ministro contara con el apoyo de un Servicio Europeo de Acción Exterior para que pudiera ejercer con eficiencia y eficacia sus funciones. 
Volviendo al Tratado de Lisboa, este recoge prácticamente las mismas funciones y misiones que las contempladas en la Constitución Europea, salvo que le cambia el nombre de Ministro por el de Alto Representante de la Unión para Asuntos Exteriores y Política de Seguridad.

Quecedo y Gerardo y Becerril Atienza, afirman que "desde 1950 la actividad externa de la Comunidad se ha extendido continuamente. Por muchos años que la actividad estuvo centrada sobre el campo económico y en particular sobre la política comercial y de ayuda al desarrollo, pero gracias a la dinámica de la Comunidad y al establecimiento de la Unión Europea con su Política Exterior y de Seguridad Común, se ha ido pasado del principio de naturaleza estrictamente económico a involucrarse cada vez más a las esferas políticas y diplomáticas" ${ }^{403}$.

La idea de contar con un Alto Representante de la Unión en materia de política exterior y de seguridad común, a la par que contar con un Servicio Europeo de Acción Exterior, es dar mayor visibilidad a la UE en el escenario internacional, dotar de credibilidad y coherencia en su Acción Exterior, ampliar su capacidad negociadora a nivel internacional y realizar con eficacia una unión política a nivel regional. Por estas razones, las funciones que designa el Tratado de Lisboa para el Alto Representante son:

- Mayor visibilidad de la UE y ampliar su capacidad negociadora: contar con un Alto Representante de la Unión para Asuntos Exteriores y de Seguridad Común

- Dotar de credibilidad y coherencia en su acción exterior: unir en el cargo del Alto Representante, lo que antes era el cargo de Comisario de Asuntos Exteriores, Vice presidencia de la Comisión y Presidente del Consejo de Ministros de Asuntos Exteriores de la UE.

\footnotetext{
${ }^{403}$ QUECEDO, G. and BECERRIL, B.: "Towards a Common European Diplomacy.Analysis of the European Parliament Resolution on Establishing a Common Diplomacy (A5-0210/2000)" Madrid: Serie de Documentos de Trabajo del Instituto de Estudios Europeos, 2001, p.4 (traducción propia), en ESTEBAN, M.: Los inicios del Servicio Europeo de Acción Exterior, Op. cit., p.30.
} 


\subsection{LA ACCIÓN EXTERIOR: CASO AMÉRICA LATINA Y EL CARIBE}

\subsubsection{Los lineamientos para una Política Exterior Común en la Comunidad Andina}

Desde hace décadas se habla del fallecimiento de la CAN, pero de la misma forma se habla de la UE u otros procesos de integración, y sin embargo, a pesar de dichas críticas aún persisten y existen. Es verdad que la CAN ha tenido problemas y podemos hablar de los constantes incumplimientos por parte de sus Países Miembros hacia la propia CAN. Pero no es nuestra intención entrar en ese debate o evaluación de su proceso, como tampoco es la intención de defender su existencia, vigencia o caducidad como proceso.

Lo que se desea rescatar en este apartado es el acervo integracionista de la CAN y cómo sus lineamientos sobre Política Exterior Común, puede servir como experiencia para que América Latina y el Caribe se conviertan en un Actor Global y en consecuencia cuente con una acción exterior jurídicamente e institucionalmente incorporada dentro de su proceso de integración. Por qué se desea defender esta posición, porque ya hemos visto como de manera externa, las relaciones desarrolladas con la Unión Europea han servido para tratar de impulsar a que América Latina y el Caribe sea una región, y como hemos visto también en los documentos de la UE, ALC es para la UE un Actor Global con el que desea contar en los asuntos de la gobernanza global. Pero si la UE para lograr ser un Actor Global ha tenido que fortalecer su voz común creando instituciones, normas y políticas comunitarias, del mismo modo tendría que hacerlo ALC.

Si se piensa que no es posible establecer una Política Exterior Común en ALC, dada las diferencias que existen entre los países y subregiones con respecto a la visión y forma de integración regional, podemos responder, que ya existen unos primeros pasos, por tanto ya hay una primera base sobre la que se puede trabajar y pensar que sí es posible pensar en ello.

El proceso de convergencia propuesta por la propia CAN hacia MERCOSUR dentro del marco de UNASUR, y se combinara los temas comunes como la política exterior común, las política de defensa y comercial común de la CAN, unida a la política 
comercial común del MERCOSUR y los temas desarrollados en UNASUR como son los temas de seguridad y defensa, todo ello puede servir para pensar sobre una Política Exterior y de Seguridad Común a nivel Suramericana y luego extrapolarla a nivel regional, es decir a nivel de la CELAC.

El proceso de integración de los países andinos nace con vocación regional, y a diferencia de otros procesos de integración su idea de integración siempre tuvo como primer y máximo objetivo la integración política, de ahí su defensa por el concepto de comunidad de naciones, es decir el deseo de trabajar comunitariamente, por ello, es en este esquema de integración se desarrollara un sistema institucional comunitario de carácter supranacional, un derecho comunitario y una Política Exterior Común, tema que atañe a este apartado. Por todo eso, es de nuestro especial interés, rescatar que el proceso de integración andina es el más avanzado de todos los existentes en América Latina y el Caribe, en términos de integración política, en lo que respecta a su desarrollo institucional y normativa comunitaria, pilares e instrumentos indispensables para una región que aspire a ser un actor político y fuerte, con voz única en el escenario internacional.

Analicemos ese acervo comunitario andino, examinando los pasos dados por la Comunidad Andina desde su fundación hasta la fecha, haciendo hincapié en los temas que están relacionados con la acción exterior y la política exterior común de los países andinos. Los países andinos inician su proceso de integración firmando en mayo de 1969 el Acuerdo de Integración Subregional Andino (llamado el Acuerdo de Cartagena y conocido también como el Grupo Andino), su primer artículo deja desde el principio claro el camino y destino de este nuevo esquema: "el presente Acuerdo tiene por objetivos promover el desarrollo equilibrado y armónico de los Países Miembros [...]; facilitar su participación en el proceso de integración regional, con miras a la formación gradual de un mercado común latinoamericano" ${ }^{, 404}$.

En 1979 los países andinos crean tres instituciones comunitarias: el Tribunal de Justicia Andino (28 de mayo de 1979), el Parlamento Andino (25 de octubre de 1979) y el Consejo Andino de Ministros de Relaciones Exteriores (12 de noviembre de 1979). Diez años más tarde, el 17 de diciembre de 1989, los presidentes andinos aprueban el

\footnotetext{
404 Art. 1. Acuerdo de Integración Subregional Andino, Secretaria General de la Comunidad Andina. Normativa Andina. Tratados y Protocolos. http://www.comunidadandina.org/Normativa.aspx?link=TP [Última revisión: 22-6-2014]
} 
Diseño Estratégico en Galápagos. Este Diseño Estratégico busca resolver dos asuntos pendientes en el proceso de integración subregional, el primero era consolidar el espacio económico andino, y el segundo era el mejorar la capacidad de negociación en el escenario internacional. Ambos consideraciones estaban unidas a otro gran objetivo, reforzar su contribución a la unidad latinoamericana ${ }^{405}$.

El 22 de mayo de 1990 se crea el Consejo Presidencial Andino (CPA). El CPA se constituye en el máximo órgano del Sistema Andino de Integración (conjunto de instituciones comunitarias andinas), y es la encargada de ejercer la dirección política de la Comunidad, emite directrices, las mismas que posteriormente deberán de ser instrumentadas por las instituciones comunitarias. Entre sus objetivos están el definir las políticas de integración subregional, orientar e impulsar las acciones en temas de interés común. Con dichas funciones y competencias designadas al CPA, este aprueba el Protocolo de Trujillo, el 10 de marzo de 1996, por el cual se modifica la naturaleza jurídica del proceso, creándose la Comunidad Andina de Naciones (CAN).

Dentro de las novedades del Protocolo de Trujillo se contemplaba la creación de una Secretaría General permanente, con sede en Lima. Entre las funciones y competencias otorgadas a la Secretaría General de la Comunidad Andina (SGCAN), se encuentran presentar al Consejo Andino de Ministros de Relaciones Exteriores (CAMRE) y a la Comisión Andina propuestas de Decisión. El CPA y la Comisión Andina pueden delegar a la SGCAN la reglamentación de Decisiones. Corresponde a la SGCAN velar por el cumplimiento de los tratados y acuerdos, así como mantener vínculos con todas las instituciones comunitarias, así como con los órganos ejecutivos de los organismos regionales de integración y cooperación, organismos internacionales, entre otros.

Finalmente, es la secretaría la que ejerce la reunión de representantes de las instituciones comunitarias que forman parte del SAI. Como se puede observar existe similitud entre las funciones de la SGCAN y la Comisión Europea, como representar y defender los intereses del conjunto de los Estados miembro, poder de iniciativa y ejercicio de representación al exterior. Así el 25 de junio de 1997, se elige al Embajador de Venezuela, Sebastián Alegrett Ruiz, primer Secretario General de la Comunidad Andina, para el período (1997-2002), sucesivamente le seguirán en orden cronológico,

405 Comunidad Andina, Secretaría General. Documentos de las Reuniones del Consejo Presidencial Andino 1989-2002. http://www.comunidadandina.org/public/Presidentes.pdf [Última revisión: 22-62014] 
el colombiano Guillermo Fernández de Soto (2002-2004), el Embajador de Perú Allan Wagner Tizón (2004-2006), el colombiano Alfredo Fuentes (2006-2007), el ecuatoriano Freddy Ehlers (2007-2010), el boliviano Adalid Contreras (2010-2013) y desde 2013 hasta la actualidad, el también boliviano Pablo Guzmán Laugier.

Al respecto se puede decir que la SGCAN, y sus respectivos secretarios generales, han cumplido con ejercer y cumplir los mandatos designados para su cargo, pero los gobiernos de los Países Miembros, no siempre han cumplido con sus compromisos de Estado, como es la integración política de la Comunidad. Uno de los secretarios generales, el Embajador del Perú, Allan Wagner reflexionó con respecto a dicho punto, y señalo: "es conveniente distinguir entre objetivos de Estado y objetivos de Gobierno"406. Señalando con eso, las divergencia que existían a la hora de querer profundizar o avanzar en el proceso integrador desde el punto de vista político.

El mismo 25 de junio de 1997 se firma el Protocolo de Sucre, el cual incorporó el Capítulo de las Relaciones Exteriores de la Comunidad Andina, dentro del acervo comunitario andino. Dos años más tarde, el 25 de mayo de 1999 los países andinos aprueban los Lineamientos de la Política Exterior Común, mediante la Decisión 458. En ella se menciona los principios, objetivos, criterios, mecanismos, modalidades de acción y las áreas de acción de la nueva Política Exterior Común (PEC). Entre los puntos y aspectos más resaltantes de esta Decisión podemos resaltar lo siguiente:

Considerandos: "Que la formulación de una PEC constituye un elevado grado de cooperación política y marca el inicio de una nueva etapa en el proceso de integración andino; [...] Que la PEC contribuirá a fortalecer la identidad y cohesión de la Comunidad Andina, le proporcionará una mayor presencia e influencia internacional y propiciará su articulación y convergencia con los demás procesos de integración existentes en América Latina y el Caribe" ${ }^{407}$.

La idea de formular una PEC representa no sólo una nueva etapa en el proceso de integración andino, sino también en el latinoamericano y caribeño, por cuanto pone sobre mesa una política que tradicionalmente es manejada, y símbolo de la soberanía

\footnotetext{
${ }^{406}$ WAGNER, A.: Una conceptualización de las relaciones políticas externas de la Comunidad Andina, en SECRETARÍA GENERAL COMUNIDAD ANDINA: Hacia una Política Exterior Común Andina, Santa Fe de Bogotá, 1999. p. 51

${ }^{407}$ Decisión 458. Lineamientos de la Política Exterior Común. Comunidad Andina, Consejo Andino de Ministros de Relaciones Exteriores, Cartagena de Indias, 25 de mayo de 1999. p. 1.
} 
nacional, de cualquier Estado, la política exterior. En este caso, los países andinos deciden crear una PEC a nivel subregional, lo que a nuestro entender deja la posibilidad de pensar en desarrollar una futura Política Exterior Común Latinoamericana y Caribeña. Pues el acervo de la CAN deja esta experiencia.

Con respecto al proceso de convergencia a nivel regional, la CAN ha propiciado y fomentado la convergencia con los diferentes procesos de integración en toda la región, convirtiéndose en un eslabón de la integración latinoamericana y caribeña, primero con MERCOSUR en el marco de ALADI, luego entre CAN y MERCOSUR en el marco de UNASUR, y que fue participe del proceso de creación la CELAC y por eso participa activamente en las reuniones de Mecanismos regionales y subregionales de integración, durante el 2014 se celebrará la IV Reunión; así quedó estipulado en el Plan de Acción de la CELAC $2014^{408}$.

En alusión a la CELAC, el ex secretario general de la CAN, Adalid Contreras, dijo: “estamos forjando la Patria Grande Latinoamericana y Caribeña a los que los andinos aspiramos institucionalmente desde los inicios de nuestro proceso"409. En otras declaraciones, llegó a mencionar que la CELAC "representaba un oportunidad histórica para que la tradicional integración subregional derive en una integración continental" ${ }^{410}$, uniendo las experiencias de MERCOSUR, SICA, CARICOM, ALBA y Alianza del Pacífico.

Es interesante notar cómo el deseo de esa integración continental permanece en las ideas y en el espíritu de las instituciones y dirigentes andinos, a pesar que pasan los años, y decimos esto porque el primer secretario general, Sebastián Alegrett llego a decir que "existe en la Comunidad Andina la posibilidad de ampliarse no sólo en el ámbito latinoamericano y en el ámbito inmediato sudamericano, sino dentro de lo que

\footnotetext{
${ }^{408}$ Mayor información ver: Plan de Acción de la CELAC, II Cumbre CELAC, La Habana, 28-29 de enero de 2014.

409 CONTRERAS, A.: Secretario General de la CAN afirma que con la CELAC estamos forjando la Patria Grande Latinoamericana y Caribeña. Secretaria General de la Comunidad Andina. Notas de Prensa, http://www.comunidadandina.org/prensa/notas/np5-12-11.htm [Última revisión: 22-6-2014]

${ }^{410}$ CONTRERAS, A.: CAN: Oportunidad histórica para la integración continental. Boletín sobre integración de América Latina y el Caribe, Secretaría General Permanente del SELA, Convenio UNESCO-SELA "Comunicación para la integración de América Latina y el Caribe, N 182, 29 de enero 2013.

http://www.sela.org/attach/258/EDOCS/SRed/2013/03/T023600005059-0-

Boletin_de_Integracion_de_America_Latina_y_el_Caribe_No._182.pdf [Última revisión: 22-6-2014]
} 
sería el proceso de integración continental"411. Aunque también es interesante notar, que a nuestro entender, para Alegrett, la integración continental, era en el sentido hemisférico, así consta en el apartado donde tomamos su frase, lo que nos hace pensar que quizás su enfoque de integración continental abarcaba toda la América, y de ahí que haga el énfasis en cuatro ámbitos: andino, sudamericano, latinoamericano y continental.

Mientras que Contreras claramente habla de integración continental, tomando como ámbito máximo la CELAC, es decir, para él continental es América Latina y el Caribe. Para Alegrett, en cambio sería el ámbito continental la Organización de Estados Americanos. Y en el estricto uso de los términos, si se desea hablar de integración continental, la referencia tiene que ser la OEA, pues es el único organismo continental, tal como hemos mencionado antes, y cuándo se quiera referirse a la totalidad de ALC, lo máximo que se puede decir es regional, pues en todo caso ALC es una región e incluso si se quiere, podríamos decir que es una subregión de América, partiendo de la base que hay una América del Norte, una América Central y una América del Sur, que es como tradicionalmente se divide el continente americano. En todo caso, la consolidación de la integración latinoamericana, es uno de los principios de la PEC y así consta en la Decisión 458 . Entre los once objetivos ${ }^{412}$ de la PEC destacamos cinco:

- El fortalecimiento de la paz y seguridad en la Comunidad Andina;

- El incremento de la capacidad de negociación internacional de los Países Miembros de la Comunidad Andina;

- La consolidación y profundización del proceso de integración subregional y el afianzamiento de la identidad, solidaridad y cohesión de la Comunidad Andina;

- La participación activa de la Comunidad Andina en el proceso de integración latinoamericana y el fomento de la estabilidad, la paz y la solidaridad de la región;

- El reforzamiento del multilateralismo y la democratización de las relaciones internacionales.

Así mismo, en la Decisión 458 se determina que el mecanismo a ejecutar las acciones de la política exterior comunitaria será la Comisión de la Comunidad Andina en

\footnotetext{
411 ALEGRETT, S.: Hacia la integración sudamericana, latinoamericana y hemisférica. Las relaciones externas de la Comunidad Andina, en SECRETARÍA GENERAL COMUNIDAD ANDINA: Hacia una Política Exterior Común Andina, Op. cit., p.12

${ }^{412}$ Decisión 458. Principios. Lineamientos de la Política Exterior Común. Comunidad Andina, Consejo Andino de Ministros de Relaciones Exteriores, Cartagena de Indias, 25 de mayo de 1999.
} 
coordinación con el Consejo Andino de Ministros de Relaciones Exteriores. Estableciendo como modalidades de acción tres tipos ${ }^{413}$ :

1. Posiciones comunes, acciones conjuntas y vocerías únicas, incluyendo la concertación de votaciones y candidaturas;

2. Coordinación regular entre las Misiones Diplomáticas y Representaciones de los Países Miembros ante terceros países y en organismos internacionales; y

3. Representaciones diplomáticas conjuntas.

Dentro de las áreas de acción destacamos dos, la unidad regional y las relaciones extraregionales. La primera por cuanto tiene como fin contribuir a la unidad regional mediante mecanismos de consulta y concertación política con los otros países de la región. La segunda acción porque establece la creación de mecanismos de diálogo y consulta con otros países y regiones para fortalecer la proyección internacional de la CAN. Y de ahí la base jurídica que posteriormente servirá para firmar el Acuerdo de Diálogo Político y Cooperación con la Comunidad Europea. Destacable también la idea de contar con misiones diplomáticas conjuntas, algo similar como las delegaciones de la Comisión Europea, que luego pasarán a ser misiones diplomáticas de la Unión Europea.

El 3 de febrero de 2000 el Consejo Andino de Ministros de Relaciones Exteriores aprueba la Decisión 475. Directiva $\mathrm{N}^{\circ} 1$ Sobre Política Exterior Común, en el cual queda regulado cuáles serán las instituciones comunitarias que estarán a cargo de la formulación y ejecución de la PEC, tareas que corresponderá al Consejo Presidencial Andino, Consejo Andino de Ministros de Relaciones Exteriores y Reunión de Viceministros de Relaciones Exteriores o de Funcionarios de Alto Nivel. Siendo la Comisión quién ejecutará las acciones de su competencia en el marco de la PEC, aprobada previamente por el CAMRE. En lo referido a la representación de la Comunidad Andina en materia de PEC estará a cargo de quién ejerza la Presidencia del CAMRE, y será la que expresará la posición de la CAN ante terceros países o en organismos y conferencias internacionales ${ }^{414}$.

\footnotetext{
${ }^{413}$ Decisión 458. Modalidades de Acción. Lineamientos de la Política Exterior Común. Comunidad Andina, Consejo Andino de Ministros de Relaciones Exteriores, Cartagena de Indias, 25 de mayo de 1999. p. 3.

${ }^{414}$ Decisión 475. Directiva $\mathrm{N}^{\circ} 1$ Sobre Política Exterior Común. Consejo Andino de Ministros de Relaciones Exteriores. Comunidad Andina, Lima, 3 de febrero de 2000.
} 
El 27 de abril de 2000 el CAMRE aprueba la Decisión 476 "Seguimiento de la Política Exterior Común" seguimiento de la PEC. Se dispone que cada Ministerio de Relaciones Exteriores de cada País Miembro designe a un funcionario de Alto Nivel para que realice la función de coordinar la ejecución de las acciones y negociaciones de la agenda de la PEC en su respectivo país. A la vez, los respectivos funcionarios efectuarán conjuntamente con la Secretaría Pro- Témpore del CAMRE y en colaboración con la SGCAN, el seguimiento de la PEC, haciendo, si es necesario, recomendaciones a sus respectivos ministerios para que éstos tomen las medidas necesarias para alcanzar con los objetivos fijados por el Consejo Andino.

El 13 de mayo la CAN emite la Resolución 528 que trata los "Criterios y pautas para la formulación y ejecución de la Política Exterior Común" (Texto Unificado de la Directiva $\mathrm{N}^{\circ} 1$ de la PEC), el objetivo de esta Resolución es establecer un conjunto de criterios y pautas para la programación y ejecución de la PEC y para que las Misiones Diplomáticas de los Países Miembros tengan un marco de actuación coordinada o conjunta en los Estados y Organismos Internacionales ante los cuales están acreditados. Un punto resaltante de la Resolución 528 es la representación, sobre la que menciona que el ejercicio de vocerías únicas, representaciones y gestiones diplomáticas serán ejecutadas por la representación delegada en el país que ejerce la Presidencia del CAMRE.

Sobre la actuación de las misiones diplomáticas y representaciones andinas destaca que deberán de realizar reuniones periódicas de coordinación, de intercambio de información y/o de opinión sobre asuntos de interés común, y que las mismas deberán de informar a sus respectivos ministerios de relaciones exteriores. En cumplimiento con lo dispuesto, enfatiza que "las embajadas andinas ante los Estados Unidos y la Unión Europea, así como las Representaciones Permanentes andinas ante la Organización de Naciones Unidas, la Organización de Estados Americanos, la Organización Mundial del Comercio y ante los Organismos Internacionales con sede en Ginebra y Viena, establecerán un mecanismo de reuniones de coordinación, intercambio de información y de opinión sobre los temas de la agenda de la Política Exterior Común en sus

\footnotetext{
415 Decisión 476 “Seguimiento de la Política Exterior Común”. Consejo Andino de Ministros de
} Relaciones Exteriores. Comunidad Andina, Lima, 27 de abril de 2000. 
respectivos ámbitos de competencia" ${ }^{\natural 16}$. Indica que dichas reuniones deberán de ser trimestrales y que deberán de mantener permanentemente informando al CAMRE, a través de la Secretaría Pro-Témpore. Finalmente también contempla que el CAMRE podrá encomendar a las Misiones Diplomáticas y Representaciones Permanentes andinas la realización de cualquiera de las modalidades operativas previstas en el Capítulo II de la Resolución que trata sobre los criterios generales.

El 22 de junio de 2001 el CAMRE y la Consejo Andino aprueba la Decisión 499”Actualización de la Directiva $N^{\circ} 1$. Entre las novedades de esta Decisión versan sobre el período de actualización de la Agenda, sobre la cual se menciona que ésta deberá de ser aprobada anualmente y actualizada trimestralmente en Reuniones de Funcionarios de Alto Nivel de los Ministerios de Relaciones Exteriores, o en su defecto en las reuniones extraordinarias si fuera el caso necesario de hacerlo, dando cuenta siempre al Consejo.

Otra novedad es la mayor participación y coordinación entre las instituciones comunitarias andinas "la Secretaría Pro-Témpore desarrollará conjuntamente con los funcionarios responsables de la coordinación y seguimiento de la PEC, designados por cada Ministerio de Relaciones Exteriores conforme a la Decisión 476 y con el apoyo de la Secretaría General, un sistema efectivo de comunicación, consulta e intercambio de información a fin de garantizar el cumplimiento de la agenda de la PEC y para considerar situaciones o asuntos que requieran atención prioritaria"417.

El 17 de junio de 2002 el CAMRE y los Ministros de Defensa de la Comunidad Andina aprueban la Carta Andina para la Paz y la Seguridad. Esta Carta servirá de modelo para que luego en el marco de UNASUR se apruebe también a América del Sur como una zona de paz, así mismo será el germen de la futura idea sobre la creación de una Escuela de Defensa Sudamericana de UNASUR, que dentro de sus fines está el consolidar a la región en una zona de paz. La Escuela fue creada el 9 de mayo de 2013.

\footnotetext{
${ }^{416}$ IV. Actuación de las Misiones Diplomáticas y Representaciones Permanentes Andinas. Resolución 528. Criterios y pautas para la formulación y ejecución de la Política Exterior Común (Texto Unificado de la Directiva $\mathrm{N}^{\circ} 1$ de la Política Exterior Común), Secretaria General de la Comunidad Andina, Lima, 13 de julio de 2001.

${ }^{417}$ Decisión 499 “Actualización de la Directiva $\mathrm{N}^{\circ} 1$ sobre formulación y ejecución de la Política Exterior Común”. Consejo Andino de Ministros de Relaciones Exteriores, Caracas, 22 de junio de2001.
} 
El 15 de diciembre de 2003 se suscribe la Declaración de Roma, Acuerdo de Diálogo Político y Cooperación entre la Comunidad Andina y la Comunidad Europea. El acuerdo se firma cumpliendo los criterios y objetivos estipulados en la PEC. Ese mismo año, el 16 de diciembre la CAN en el marco de la ALADI, firma el Acuerdo de Complementación Económica con el MERCOSUR, siendo el objetivo establecer una Zona de Libre Comercio ${ }^{418}$.

Cumpliendo con la idea de incorporar el tema de seguridad dentro de la agenda de la Comunidad Andina y buscar relacionarla con la PEC, tal como sucede en la UE (Política Exterior y de Seguridad Común de la Unión Europea), aprueban el 11 de julio de 2004 los Lineamientos de la Política de Seguridad Externa Común. Esta idea también servirá de referencia para perfeccionarla dentro de UNASUR, pero en este caso darán un paso más, al crear un Consejo de Defensa.

Siguiendo con el mandato de contribuir a la integración de los países de la región, el 7 de julio de 2005, se aprueba la norma andina mediante la cual se otorga a los Miembros Asociados de la CAN a los países del MERCOSUR. Una de las bases jurídicas para luego desarrollar el proceso de convergencia dentro de UNASUR.

Durante el 2010 se dan muchos avances, el 5 de febrero el CAMRE en una reunión ampliada con la Comisión de la CAN aprueban la Agenda Estratégica Andina; el 15 de julio entra en vigencia el Pasaporte Andino, paso importante para fortalecer la idea de una identidad común andina y que contribuirá a una mayor coordinación en temas de asuntos consulares, como la atención consular por parte de cualquier ciudadano andino en el exterior, pudiendo el ciudadano solicitar asistencia consular a cualquier País Miembro de la CAN en el exterior, si su país no tuviera una representación diplomática en el país que se encuentra. Además de contribuir con la libre circulación de personas dentro del espacio andino. El 22 de julio se aprueba la norma comunitaria que regula la figura del País Observador de la Comunidad Andina, especialmente para los países no Asociados a la CAN, los primeros países que se incorporan como Países Observadores serán México y Panamá.

\footnotetext{
${ }^{418}$ El Acuerdo de Complementación Económica N 59 (ACE 59) establece que la zona de libre comercio deberá de entrar en vigor a más tardar el 1 de Julio de 2004. En el caso de la CAN la zona de libre comercio queda completada el 1 de enero de 2006, pero no se llega a hacer efectiva la zona con el MERCOSUR.
} 
El 14 de julio de 2011 la CAN aprueba el Plan de Implementación de la Agenda Estratégica Andina. El 22 de agosto de ese mismo año España solicita ser País Observador de la CAN. Del mismo modo, el 9 de diciembre de 2011, Marruecos solicita oficialmente ser también País Observador del proceso de integración andino.

El 23 de enero de 2012 la CAN completa el proceso de ratificación del Acuerdo de Diálogo Político y Cooperación con la Unión Europea. El 20 de junio de ese mismo año la Organización Internacional para las Migraciones se convierte en el primer organismo internacional que pide ser formalmente ser Observador de la CAN. En un acto de buenas prácticas y de un buen trabajo comunitario, los países de la CAN realizan una promoción comercial conjunta en la Feria Alimentaria en China, del 14-16 de noviembre de 2012.

Finalmente, durante el 2013 se dan cuatro acontecimientos, el primero se produce el 26 de enero, cuando la CAN, MERCOSUR, UNASUR y ALADI se reúnen para reflexionar sobre el proceso de convergencia de los citados organismos, hecho que contribuirá a fortalecer el proceso ya emprendido dentro del marco de la CELAC. El 21 de febrero, la CAN aprueba el Reglamento "Garantía de Asistencia Consular a los Ciudadanos Andinos en Terceros Países".

El 15 de junio, el CAMRE aprueba la Decisión 791 por la cual crea un Grupo de Trabajo para realizar una Reingeniería del Sistema Andino de Integración. Esta Decisión es tomada tomando como referencias las reuniones del Consejo Presidencial Andino, de Lima (28 de julio de 20012) y la de Bogotá (8 de noviembre de 2011), en las cuales se decidió renovar el proceso de integración andino, y con ello la reforma del Sistema Andino de Integración para evitar duplicidades de esfuerzos y recursos tanto humanos como financieros, tomando en cuenta, la existencia de los nuevos procesos de integración en marcha, principalmente el de UNASUR y CELAC donde los países andinos son miembros y participantes activos.

Mediante la Decisión 773 la Comunidad Andina encargó una consultoría para el Proceso de Reingeniería del Sistema Andino de Integración a la CEPAL y a la Fundación Getulio Vargas, y se estableció un Comité Coordinador del proceso. Los trabajos del Comité terminaron y sus resultados fueron presentados durante la XXXVI 
Reunión de CAMRE ampliada con los representantes de la Comisión Andina el 15 de junio de 2013.

El 19 de septiembre de 2013 en la XXXVII Reunión del CAMRE y la Comisión Andina se emite la Decisión 792 por la cual se aprueba la Implementación de la Reingeniería del Sistema Andino de Integración. Su artículo primero estipula conformar un Grupo de Alto Nivel para la revisión del marco institucional, el acervo jurídico comunitario y el sistema de solución de controversias de la $\mathrm{CAN}^{419}$. Con el deseo de realizar las reformas necesarias para brindar una visión, nuevos lineamientos estratégicos y una priorización de ámbitos de acción de la CAN. El 12 de julio de 2013 se presenta un Documento Final titulado: "Propuesta sobre la Nueva Visión, Lineamientos Estratégicos y Priorización de los Ámbitos de Acción de la Comunidad Andina”. Que a continuación pasamos a analizar las principales reformas:

1. La Nueva Visión de la CAN: Pretende buscar un mejor relacionamiento con otros espacios económicos regionales y mundiales. Nótese que se dice espacios económicos, pues UNASUR se define como un espacio económico con claro énfasis en lo económico y comercial, de ahí que otras de las recomendaciones sea profundizar la integración comercial.

2. La reforma del Sistema Andino de Integración: de las catorce instituciones que forman el SAI quedan sólo ocho: el Consejo Presidencial Andino, el Consejo Andino de Ministros de Relaciones Exteriores, la Comisión Andina, la Secretaría General, el Tribunal de Justicia de la Comunidad Andina, la Universidad Andina Simón Bolívar, el Consejo Consultivo Empresarial y el Consejo Consultivo Laboral. Es decir, desparecen seis instituciones: El Parlamento Andino, que migra al Parlamento de UNASUR; la Corporación Andina de Fomento, hoy llamada Corporación Andina de Fomento-Banco de Desarrollo para América Latina y el Caribe que pasa a ser un organismo independiente y al servicio de toda la región; el Fondo Latinoamericano de Reservas; el Organismo Andino de Salud, que quizás migre también a UNASUR; el Consejo Consultivo de los Pueblos Indígenas y a Mesa Andina para la Defensa de los Derechos del Consumidor.

\footnotetext{
${ }^{419}$ Art. 1 Decisión 792 "Implementación de la Reingeniería del Sistema Andino de Integración, XXXVII Reunión del Consejo Andino de Ministros de Relaciones Exteriores y la Comisión Andina, Lima, 19 de septiembre de 2013.
} 
3. Los aspectos sociales de la integración: Seguir profundizando la Libre Circulación de Personas, creando más políticas comunitarias que permitan a los ciudadanos andinos viajar, trabajar, estudiar y residir en cualquier país andino sin discriminación de su nacionalidad (similar a la Libre Circulación de Personas de la UE). Promover la identidad andina.

4. Los aspectos comerciales: internacionalización de las PYMES, crear mecanismos para incrementar el comercio intracomunitario, exportaciones con valor agregado y encadenamientos productivos y promoción comercial conjunta, quizás tomando como referencia MERCOSUR. Pues la convergencia y complementariedad comercial está orientada a la integración suramericana.

5. Energía: interconexión eléctrica y la interconexión con otros países de la región, quizás tomando en consideración la demanda por varios países de MERCOSUR que son deficitarios en materia energética y lo cual representa un potencial mercado para los países andinos.

Con ello muchos temas antes trabajados en la CAN migran al marco de UNASUR:

- Seguridad y defensa

- Democracia y asuntos electorales

- Derechos humanos

- Desarrollo social

- Educación

- Ciencia y tecnología

- Telecomunicaciones

- Políticas macroeconómicas, entre ellas la política fiscal, política cambiaria y la política monetaria, pues recordemos que dentro de los planes de UNASUR está el crear una moneda única.

- Cooperación judicial

- Política antidrogas, esta tiene sentido por cuanto estaría dentro de seguridad y defensa

- Dada la convergencia, quedan suprimidos los siguientes temas en la Comunidad Andina:

- Arancel Externo Común

- Defensa comercial frente a terceros países

- Negociaciones conjuntas con terceros

- Política anticorrupción

- Desarrollo municipal 
Lejos de las críticas que se podría hacerse a la CAN, su experiencia como proceso, su vocación integracionista y su acervo comunitario tanto jurídico como institucional hacen de la Comunidad Andina un modelo a considerar, tomando en cuenta que para poder tener una voz fuerte en el escenario internacional, se hace necesario desarrollar e implementar una Política Exterior Común para poder realizar una acción exterior efectiva y eficiente en las negociaciones ante terceros, sea con países u otros procesos de integración, así como participar como un actor regional o global fuerte ante los principales organismos, foros y conferencias internacionales.

La PEC de la CAN puede ser un modelo a tomar en cuenta para poder hacer de América Latina y el Caribe un Actor Global. Ya lo dice el presidente de la CAF (Corporación Andina de Fomento), Enrique García: "resulta fundamental que todos los actores retomemos la concepción de que la integración no es un lujo, sino una necesidad, si queremos alcanzar una verdadera presencia internacional y actuar como un jugador global con el peso que se requiere" ${ } 420$. A lo que Adalid Contreras, Secretario General de la CAN agregaba que es "precisamente, el desafío central que tiene la CAN: consolidarse como un eslabón importante del fortalecimiento de la UNASUR y de la CELAC, a partir de las convergencias con MERCOSUR y otros mecanismos de integración, provocando un sistema multipertenencias" ${ }^{\text {,21 }}$.

No hay que olvidar que la CAF fue una de las razones para iniciar la cooperación subregional andina, y fue uno de las primeras instituciones que dieron origen al sistema andino de integración, y que ha servido como una de las principales piedras angulares en el desarrollo de los países andinos, no sólo por ser la institución financiera de los países andinos y por canalizar dichos recursos a los proyectos de desarrollo de esta subregión, sino porque es otra muestra de los aspectos positivos que deja la experiencia y el acervo integracionista andino a la región, motivo por el cual hoy la CAF ha pasado de ser un banco de desarrollo de escala subregional (Comunidad Andina) a cumplir con su vocación integracionista regional, por ello la CAF en la actualidad se llama CAFBanco de Desarrollo para América Latina y el Caribe.

\footnotetext{
${ }^{420}$ Esta frase se encuentra recogida en el Discurso del Secretario General de la Comunidad Andina, Adalid Contreras con ocasión de la presentación de su informe de gestión mayo 2010-febrero 2013. Más información en: Discursos. Secretaría General de la Comunidad Andina, Lima, 18 de febrero de 2013. http://www.comunidadandina.org/Prensa.aspx?id=3344\&accion=detalle\&cat=DI\&title=comunidadandina-integracion-desarrollo-y-democracia [Última revisión: 24-6-14]

${ }^{421}$ Ibíd.
} 
Si comparamos la experiencia andina con la europea, en su empeño por desarrollar una acción exterior y una política exterior común, existe una historia similar. Pues lo que fueron considerados como intentos fallidos en el caso del proceso de integración de la UE, y nos referimos a los proyectos de la Comunidad Europea de Defensa, la Comunidad Política Europea, los Planes Fouchet o inclusive la nonata Constitución Europea, se puede decir que cada una de esos proyectos fracasados, sirvieron para contar con lo que hoy se conoce como la Acción Exterior de la Unión Europea, y con ella la política exterior y de seguridad común, una alto representante para estos asuntos, y un cuerpo diplomático común, como es el Servicio Europeo de Acción Exterior.

Si la Unión Europea tomó estas decisiones para buscar tener una mayor voz y actuar como región siendo un Actor Global, y si ALC también aspira a los mismos objetivos, como dice tener, entonces el camino está trazado y las experiencias realizada para poder desarrollar las acciones conducentes a hacer de ALC un Actor Global.

\subsubsection{La Comunidad Andina como eslabón en la integración regional en América Latina y el Caribe: El interregionalismo latinoamericano y caribeño}

\subsubsection{Propuestas para una Acción Exterior Común latinoamericana y caribeña}

Si ALC desea tener una presencia y una participación más activa en la escena internacional, esta región deberá de desarrollar una acción exterior común, y para ello se hace necesaria la implementación de una política exterior común a escala regional y contar con instituciones comunitarias, de carácter supranacional, que dirija dicha acción exterior. Para lograr esos objetivos, los actuales y diferentes procesos de integración, en marcha, deberán de iniciar un proceso de convergencia institucional, establecer una agenda común y ejecutarla de manera comunitaria.

Este momento no es lejano, partiendo del hecho que la convergencia iniciada entre la Comunidad Andina y el Mercado Común del Sur, en el marco del proceso de integración de la Unión de Naciones Suramericanas, ya está en marcha, convergencia que puede ser la piedra angular para avanzar en el proceso de integración regional de ALC. Siendo, claro está que la integración suramericana es un paso intermedio. 
Para poder pensar en el desarrollo de una Acción Exterior Común en el marco de la

CELAC, se hace necesario previamente considerar las siguientes etapas:

- Primera Etapa: Propuesta de la CAN ante el MERCOSUR, para incluir dentro de la agenda de convergencia institucional, el tema de establecer lineamientos de una acción exterior común, tomando como base el acervo andino.

- Segunda Etapa: Incluir del tema de seguridad y defensa desarrollado por UNASUR dentro de los lineamientos de una acción exterior común suramericana

- Tercera Etapa: Propuesta suramericana ante la CELAC para la Institucionalización e implementación de una Acción Exterior Común en el marco de la CELAC.

Este último punto, tendría como primer escenario de trabajo la Asociación Estratégica UE-CELAC.

\subsubsection{CAN-MERCOSUR: ¿Convergencia o divergencia?}

El Acuerdo Marco para la creación de la Zona de Libre Comercio entre MERCOSUR y la Comunidad Andina, es el punto de partida en las relaciones entre ambos bloques subregionales en 1998. Sin embargo la Declaración sobre la Convergencia de los procesos de Integración en América del Sur es la que establece el punto de inflexión en las negociaciones entre MERCOSUR y CAN, dado que cambia la idea de cooperación estrecha por una convergencia entre ambos organismos, esta se realiza dentro del marco de la creación de un espacio común sudamericano, UNASUR.

El acercamiento y la coordinación estrecha entre las principales secretarías generales de los organismos subregionales y regionales de América del Sur, es uno de los primeros pasos tangibles que se dan para conseguir la tan ansiada unión política suramericana. Destacable es, a favor de UNASUR como organismo, que sea este el marco sobre el cual se hagan los respectivos trabajos de convergencia.

Las convocatorias de participación por parte de las principales secretarías han sido fundamentales para lograr la coordinación entre todas y definir qué sentido quieren darle a la integración de sus países. Así fueron convocadas las secretarías de: ALADI, 
MERCOSUR, CAN, CARICOM, más a los gobiernos de Chile, Guyana y Surinam ${ }^{422}$ para cumplir con dicha tarea. Los países suramericanos se dan cuenta que para crear una Comunidad Suramericana necesitan la asociación recíproca de los Estados miembros del MERCOSUR y $\mathrm{CAN}^{423}$. He aquí el que puede ser el primer paso hacia la consecución de la integración en América Latina y el Caribe, porque si funciona UNASUR, no sólo se abra consolidado el proceso de integración en los países de América del Sur, sino también abra dado un gran paso hacia la integración regional.

Así como la Comunidad Andina puede aportar su acervo integracionista (sistema institucional, supranacionalidad y método de trabajo comunitario, derecho comunitario y el desarrollo de políticas comunitarias), la contribución del acervo del MERCOSUR es su éxito en materia comercial y económica, el desarrollo de su política comercial, la reducción de los aranceles y su unión aduanera son las mejores credenciales del Mercado Común del Sur.

Pues a pesar de todos los problemas del MERCOSUR, hay que destacar que a diferencias de los andinos, siempre han ido con una sola voz a negociar acuerdos comerciales. Y no lo han hecho separado, por países, como es el caso de Colombia y Perú, dejando a la CAN al lado. Pero, no debemos de confundir, si bien estos son los éxitos más destacables del MERCOSUR, podemos también afirmar que su método intergubernamental en la toma de decisiones a escala subregional es contrario a lo que se pretende crear en UNASUR, por tanto el método más indicado sería el de la CAN, el método comunitario bajo los principios de la supranacionalidad.

Si el proceso de integración de UNASUR se lleva bajo el sistema intergubernamental que utiliza MERCOSUR, poco le servirá a UNASUR para la consecución de sus objetivos, entre ellos el de ser una unión de estados, pues lo que necesitaría es implementar un sistema comunitario en la cual el sistema de toma de decisiones, tanto a nivel interno (regional suramericano) como externo (internacional) sea bajo un sistema de toma de decisiones a nivel comunitario. Aquí uno de los principales problemas que tendrán que solucionar los países suramericanos. La disyuntiva de qué método de trabajo aplicar: Intergubernamental vs. Comunitario.

\footnotetext{
${ }^{422}$ Declaración sobre la Convergencia de los Procesos de Integración en América del Sur. I Reunión de Jefes de Estado de Comunidad Sudamericana de Naciones, Op. cit.

${ }_{423}$ Declaración Presidencial y Agenda Prioritaria. I Reunión de Jefes de Estado de la Comunidad Sudamericana de Naciones, Brasilia, 30 de septiembre de 2005.
} 
Dentro de América del Sur, se dan dos procesos de integración (CAN y MERCOSUR), ambos poseen distintos puntos de vista acerca de la visión de la integración regional. MERCOSUR ve la integración regional como una alternativa al desarrollo y por ende considera a la integración como un mecanismo de cooperación intergubernamental; la CAN ve a la integración regional como un proceso de unión política entre sus estados, motivo por el cual establece una serie de mecanismos e instituciones de carácter comunitario, desarrollando e implementando políticas y acciones comunes, donde la supranacionalidad juega un rol primordial.

Ambos esquemas de integración nacieron con la voluntad de establecer una unión aduanera, pero desde sus inicios el enfoque acerca del nivel de integración que querían establecer los países dentro de sus respectivos esquemas fue diferente. Para entender su concepción de ambos bloques regionales, es necesario entender su contexto histórico y términos de referencia a nivel internacional.

La Comunidad Andina fue concebida en la década de 1960, contexto en el cual se estaba desarrollando el proceso de integración europea y por tanto era el modelo de integración regional de referencia y el modelo a seguir. El modelo europeo establecía un sistema de atribución de competencias a favor de la Comunidad Europea, la cual se dotaba cada vez más de mayores poderes en la toma de decisión de la vida política, económica, social y cultural de sus países, pensando que así podría tener una mayor presencia, con una voz única, internacionalmente hablando. La CAN al igual que UE, deseaba crear una comunidad de naciones, buscando crear las bases para lograr una unión política de sus miembros.

En cambio el Mercado Común del Sur surge en la década de 1990, cuando el modelo de integración era considerado como un mecanismo de cooperación intergubernamental y en el tiempo en que el modelo a seguir es el modelo de integración estadounidense, el cual se desarrollaba mediante tratados de libre comercio, NAFTA (siglas en inglés del Tratado de Libre Comercio de América del Norte), es un claro ejemplo, en donde prevalecía la idea de la integración de países bajo el esquema de un bloque comercial regional, no una comunidad de naciones que buscaba una unión política.

Nótese que cuando se quiere enfatizar la primacía del aspecto económico y/o comercial en un esquema de integración se les define como un bloque regional, cuya finalidad es 
facilitar la creación de un mercado más extenso ${ }^{424}$ (caso NAFTA) o espacio regional integrado $^{425}$ (caso de UNASUR), prevaleciendo aspecto económico sobre el político. El uso de los términos bloque o espacio regional dejan claro que lo que esperan los países es promover una cooperación más estrecha, pero no buscan una integración en el sentido de querer ser una unidad política.

Es importante señalar que el método de trabajo del MERCOSUR, el intergubernamental, fue preservado en el diseño institucional de UNASUR, en detrimento de la supranacionalidad que ha prevalecido históricamente en la experiencia de la Comunidad Andina. Este hecho se da, dado que el impulsor de la idea es Brasil, siendo este país un fiel defensor del intergubernamentalismo, método que ya ha defendido dentro del MERCOSUR y que sigue manteniéndolo en el UNASUR.

Esta distinta visión de la integración es algo que se deja entrever en los distintos documentos de UNASUR, desde el Comunicado de Brasilia, en donde parte de la idea de crear un espacio de integración suramericano y no una unión, y en donde especifican que serán un espacio de integración y una unión, en lo cultural, social, económico y político $^{426}$. En ningún momento se dice que será una unión regional en lo político, económico, social y cultural. Lo cual remarca la importancia a una cooperación intergubernamental más que comunitaria.

Sin embargo hay que destacar un aporte que ha dado UNASUR, que en su corta andadura ha logrado, este ha sido en la resolución de varios conflictos en la región, como el golpe de Honduras, las crisis internas suscitadas en Bolivia y Ecuador y el conflicto entre Colombia y Venezuela ${ }^{427}$. Si UNASUR pretende fortalecer el multilateralismo para lograr un mundo multipolar, equilibrado y justo en el que prime la cultura de paz $^{428}$, entonces la primera acción que se nos viene a la mente, sería ¿Por qué el Consejo de Defensa Sudamericano no ha buscado tener una mayor participación e influencia por encontrar una solución del conflicto en Colombia?

\footnotetext{
${ }^{424}$ Tratado de Libre Comercio de América del Norte. Fue firmado en Ottawa, 11 de diciembre de 1992 y entro en vigor el 1 de enero de 1994.

${ }^{425}$ Tratado Constitutivo de la Unión de Naciones Suramericanas, Brasilia, 23 de mayo de 2008.

${ }^{426}$ Tratado Constitutivo de la Unión de Naciones Suramericanas, Op. cit.

427 GUALDONI, F.: Entrevista: María Emma Mejía, Secretaria General de la UNASUR. "Veo a los Ejércitos sudamericanos protegiendo los recursos naturales”. El País, Madrid, 23 de junio de 2011.

${ }^{428}$ Tratado Constitutivo de la Unión de Naciones Suramericanas, Op. cit.
} 
Los Estados miembros no sólo deberían de pronunciarse al respecto, tendrían que tomar medidas decisorias comunes para terminar con este problema que acosa por décadas a Colombia y por ende es un problema que afecta a la región. Más aún si consideramos que parte del problema es el narcotráfico, lucha que todos los países afirman querer hacer, y suscriben todos los acuerdos internacionales y regionales para combatir ese flagelo, sin embargo, es un tema inexistente en las agendas de los procesos de integración, en términos de acciones conjuntas, ya que declarativas hay muchas. Si algunos países no están de acuerdo con el apoyo que brindan otras potencias extrarregionales (Estados Unidos) a Colombia, entonces este apoyo debe de venir de la región misma.

Se suele hablar siempre de la injerencia que representa para el conjunto de los intereses de la región el Plan Colombia y de las bases militares de Estados Unidos en territorio colombiano, pero ningún país hasta ahora se ha ofrecido para brindarle ayuda militar, ya no digamos financiera, que también deberían hacerlo, en favor y cumplimiento a esa cooperación de solidaridad entre sus pueblos ${ }^{429}$. Por qué no formar un ejército suramericano que vaya a Colombia y que apoye al ejército colombiano en su lucha contra las guerrillas. Por tanto la convergencia tiene que darse en todos los planos, dicha expansión tiene que crear una red de intereses recíprocos ${ }^{430}$. ¿Para qué existe entonces un Consejo Suramericano de Defensa?

Otra novedad de este proceso, es que es liderado por Brasil, el gigante de la región y la sexta potencia económica mundial, país emergente que se ha hecho espacio por si sólo dentro del escenario internacional y en donde su participación y opinión dentro de los foros internacionales políticos y económicos es ya de por sí relevante.

El hecho de que una potencia como Brasil lidere el proceso es una garantía de continuidad en el mismo, sin embargo al ser Brasil Estado miembro de MERCOSUR, hemos podido comprobar el sistema que emplea, el intergubernamental, veremos a ver si cambia dicha idea. Podemos destacar que a nuestro entender, para Brasil la integración regional, es un eje principal en su Política Exterior ${ }^{431}$, y que este país sabe

\footnotetext{
${ }^{429}$ Comunicado de Brasilia. I Reunión de Presidentes de América del Sur, Brasilia, 1 de septiembre de 2000 . ${ }^{430}$ Ibíd.

${ }^{431}$ D’ ESCRAGNOLLE, J.: O sentido da integração sul-americana. Secretaria General de la Comunidad Andina. Valor Econômico, 26 de junio de 2007.
} 
que su desarrollo y consolidación como potencia en América del Sur y en el mundo pasa por fortalecer su presencia dentro de UNASUR. Sin embargo, lejos de querer lograr buscar un consenso, busca que prevalezca su manera de concebir la integración y a pesar de enunciar su apoyo a la integración latinoamericana, lo que parece buscar es una suramericanización de la integración latinoamericana, pues como veremos a continuación, el tratado de UNASUR invita a que los países de la región se adhieran al proceso integrador de UNASUR, y no que UNASUR se adhiera al proceso integrador latinoamericano. El enfoque es distinto.

\subsubsection{UNASUR: ¿Unión regional o foro regional?}

Si se tuviese que fijar un punto de referencia del proceso de convergencia suramericana, desde el punto de vista del derecho internacional, el Tratado de Brasilia ${ }^{432}$ fue el tratado constitutivo de la Unión de Naciones Suramericanas (UNASUR), esta unión nació llamándose Comunidad Sudamericana de Naciones $(\mathrm{CSN})^{433}$, el cambio de nombre se produjo en el marco de la I Cumbre Energética Suramericana, en la cual los Jefes de Estado y de Gobierno deciden nombrar al esfuerzo integrador de Suramérica como la Unión de Naciones Suramericanas ${ }^{434}$.

UNASUR nace con el objetivo de fortalecer el proceso de integración regional en América del Sur. A diferencia de los anteriores procesos y organismos subregionales de integración existentes en América del Sur, UNASUR nos buscaba o pretendía empezar de cero, partía sobre la base de los vínculos institucionales entre la Comunidad Andina (CAN) y el Mercado Común del Sur (MERCOSUR), promoviendo un mecanismo de asociación recíproca entre los Estados miembros de los dos organismos, más la participación de Chile, Guyana y Surinam ${ }^{435}$. Es decir, se inicia un proceso de convergencia entre dos procesos de integración subregional, entre la CAN y el MERCORSUR, dentro del marco de UNASUR.

Este hecho representa realmente un avance significativo en el proceso de integración de los países suramericanos y de América Latina, y decimos América Latina, porque si

\footnotetext{
${ }^{432}$ Tratado Constitutivo de la Unión de Naciones Suramericanas, Brasilia, 23 de mayo de 2008.

${ }^{433}$ Declaración del Cusco sobre la Comunidad Sudamericana de Naciones. III Cumbre Presidencial Sudamericana, Cusco, 8 de diciembre de 2004.

${ }^{434}$ Decisiones del Diálogo Político entre los Jefes de Estado y de Gobierno. I Cumbre Energética Suramericana. Isla de Margarita, 16 de abril de 2007.

${ }_{435}$ Programa de Acción. Primera reunión de Jefes de Estado de la Comunidad Sudamericana de Naciones, Brasilia, 30 de septiembre de 2005.
} 
bien es cierto que UNASUR sólo agrupa a los países de América del Sur, su Tratado Constitutivo, también determina que la UNASUR contribuirá al fortalecimiento de la unidad de América Latina y el Caribe ${ }^{436}$. En este sentido, sirve de eslabón en la integración regional. A partir del quinto año de la entrada en vigor del Tratado Constitutivo $^{437}$, es decir en el año 2016, todos los países de América Latina y el Caribe tendrán derecho a solicitar su ingreso a UNASUR, con lo que la organización subregional (suramericana) podría adquirir una dimensión regional (latinoamericana) con un valor estratégico importante en el escenario internacional político, económico e incluso militar ${ }^{438}$.

En efecto los Estados de América Latina y el Caribe pueden solicitar su participación en UNASUR, inicialmente como Estados Asociados ${ }^{439}$, transcurridos cuatro años los Estados Asociados pueden solicitar su ingreso como miembros de pleno derecho, es decir como Estados miembro ${ }^{440}$ de UNASUR. Con el mismo propósito de fortalecer la unidad de América Latina y el Caribe, en la Primera Reunión de Jefes de Estado de la Comunidad Sudamericana de Naciones, realizada en Brasilia el 30 de septiembre de 2005, se decidió solicitar a las secretarías generales de ALADI, MERCOSUR, CAN y CARICOM, con la concurrencia de Chile, Guyana y Surinam, que elaborarán estudios sobre la convergencia de los acuerdos de complementación económica entre los países de América del Sur ${ }^{441}$.

La creación de UNASUR demuestra dos puntos nuevos dentro de la historia de la integración en la respectiva región, América Latina y el Caribe, el primero, el lanzamiento de nuevo proceso de integración que parte sobre la base del acervo integracionista existente y no queriendo crear uno nuevo o deseando desplazar o duplicar los ya existentes. Por lo que se acuerda tener en cuenta el acervo integracionista de la CAN y del MERCOSUR. El segundo punto, la búsqueda de la convergencia de dos organismos subregionales (CAN y MEROSUR) para construir un

\footnotetext{
${ }^{436}$ Preámbulo. Tratado Constitutivo de la Unión de Naciones Suramericanas, Op. cit.

${ }^{437}$ Resolución del Consejo de Ministros de Relaciones Exteriores de UNASUR sobre la entrada en vigencia del Tratado Constitutivo. Quito, 11 de marzo de 2011.

${ }^{438}$ VELIT. E.: Los desafíos de la Unión Sudamericana. Secretaria General de la Comunidad Andina. Observatorio UNASUR. El Comercio, Lima, 29 de mayo de 2008.

http://www.comunidadandina.org/prensa/articulos/elcomercio29-5-08.htm

${ }_{439}$ Art. 19. Estados Asociados. Tratado Constitutivo de la Unión de Naciones Suramericanas. Op. cit.

440 Art. 20. Adhesión de Nuevos Miembros. Tratado Constitutivo de la Unión de Naciones Suramericanas. Op. cit.

${ }^{441}$ Declaración sobre la Convergencia de los Procesos de Integración en América del Sur. Reunión de Jefes de Estado de la Comunidad Sudamericana de Naciones, Brasilia, 30 de septiembre de 2005.
} 
organismo subregional más grande que agrupe al conjunto de todos los estados suramericanos con el fin de tener una mejor acción y representación en el plano internacional. Los países de América del Sur parten de la premisa que la integración suramericana debe ser alcanzada a través de un proceso innovador, pero que incluya los avances y los logros alcanzados por los procesos de MERCOSUR, y la CAN, así como la experiencia de Chile, Guyana y Surinam, y deseando ir más allá de la convergencia de los mismos ${ }^{442}$. La pregunta es: ¿Qué definen por un proceso innovador?

Hasta ahora hemos resaltado los puntos destacables y positivos de la creación de UNASUR, ahora analizaremos los puntos negativos y contradictorios del mismo. Por un lado, UNASUR despierta cierto grado de escepticismo acerca del nivel de integración al que aspiran tener los países de América del Sur.

El escepticismo no está basado en argumentos subjetivos, sino más bien desde argumentos objetivos, como son los hechos históricos que demuestran que cada proceso de integración emprendido por los países de América de Sur no ha tenido continuidad en el tiempo y sobre todo por la falta de voluntad política expresada por sus gobiernos, que muchas veces cobran gran impulso y apoyo en sus etapas iniciales y luego a la hora de desarrollar y profundizar su integración sus objetivos quedan sólo como objetivos declarativos y no se llegan a traducir en planes de acción.

A todos estos hechos habría que agregar la proliferación constante de nuevas organizaciones e instituciones de ámbito subregional y/o regional existentes, principalmente durante las últimas décadas, que paradójicamente todas tienen como objetivo máximo, la unión de América Latina. La dispersión de los esfuerzos integracionistas desarrollados por los países suramericanos ha debilitado su propio proceso, ninguno ha sabido profundizar en cada uno de los organismos en los cuales eran Estados Miembros, entre las causas, la múltiple y simultánea participación en otros organismos también de carácter subregional y/o regional.

Otra causa del escepticismo se sustentaría en las diferencias ideológicas, principalmente en materia de política exterior y política económica, que separan a los gobiernos de los países suramericanos, así por ejemplo en el gobierno venezolano ha precisado y advertido que en la región hay "una mayoría de gobiernos autónomos, soberanos,

\footnotetext{
${ }^{442}$ Preámbulo. Tratado Constitutivo de la Unión de Naciones Suramericanas, Op. cit.
} 
progresistas y populares", dando a entender que hay gobiernos que no lo son ${ }^{443}$. Estos son los tipos de desafíos que han de enfrentar los Estados miembros de UNASUR si desean efectivamente concretar tal aspiración y deseo integrador.

El incumplimiento de las obligaciones internacionales contraídas por parte de cada uno de los países suramericanos, es un hecho irrefutable en el tiempo y es algo que no se deben permitir en este nuevo proceso de integración. Tendría que existir un Tribunal de Justicia Suramericano que controle y vele por el cumplimiento de las normas establecidas, en los acuerdos y tratados firmados, y que sancione al Estado que incumpla con sus obligaciones. Competencias que los estados soberanos suramericanos no desean ceder y de ahí la constante contradicción en objetivos, pues quedaría la pregunta de cómo desean contar con un organismo regional que los represente en la acción exterior si no crean instituciones que posean tales competencias.

El incumpliendo de las obligaciones internacionales ha sido un común denominador en la gran mayoría de los procesos de integración tanto en América del Sur como en el conjunto de América Latina y el Caribe. Existen tratados y acuerdos que son firmados y luego no son cumplidos por las partes, dejando sin efecto los compromisos adquiridos.

Ni que decir de los acuerdos y tratados que fueron negociados y firmados, y luego no han sido ratificados por los parlamentos nacionales o por los propios gobiernos, sea porque ocurre un cambio de gobierno o por la falta del tema de integración en las diferentes agendas de los partidos políticos, por tanto, a esta carencia se suma que la integración regional no suele ser ni discutida ni incorporada dentro de los planes electorales de los partidos políticos de los países de la región.

Tenemos varios ejemplos de incumplimiento a los acuerdos firmados entre los países andinos, entre ellos, el incumplimiento a la norma que regula la libre circulación de mercancías dentro de la zona de libre comercio andina. Durante la década de los años ochenta cuando se implementa la Zona de Libre Comercio y el proyecto de un Arancel Externo Común surge uno de los primeros incumplimientos de obligaciones internacionales, por parte de los países firmantes al Acuerdo de Integración Subregional Andino, pues a pesar de haber sido negociado tanto la Zona de Libre Comercio como la

443 TOBÓN. G.: Persiste el sueño de una integración latinoamericana. Secretaria General de la Comunidad Andina. Observatorio UNASUR. Portafolio de Colombia, Bogotá 29 de mayo de 2008. http://www.comunidadandina.org/prensa/articulos/portafolio29-5-08.htm 
adopción de un Arancel Externo Común por el conjunto de los países andinos, sólo es adoptado por Venezuela, Colombia y Ecuador, manteniéndose al margen Perú y Bolivia $^{444}$. Dicho incumplimiento iba en contra del Acuerdo de Cartagena, que incluía un Programa de Liberalización del intercambio comercial más avanzado que los compromisos del Tratado de Montevideo, como era la ampliación de mercados a nivel regional $^{445}$, o la implementación de un Arancel Externo Común ${ }^{446}$, cada uno de estos pasos representaban un paso adelante en la constitución de un mercado común andino y a favor de un mercado común latinoamericano, en el cual los países miembros establecían una área de preferencias económicas, compuesta por un sistema de preferencias arancelarias, tanto de alcance regional y parcial $^{447}$.

Otro tipo de incumplimiento o retraso, si se desea, aconteció con los objetivos de crear un Mercado Común Latinoamericano, propuesto por la Asociación Latinoamericana de Libre Comercio que luego se convirtió en la Asociación Latinoamericana de Integración, del mismo modo, acaeció con el MERCOSUR que incluía tener un mercado común, y apenas llega a tener una unión aduanera imperfecta, decimos imperfecta porque no llega a la totalidad de los productos, pues los llamados productos sensibles, principalmente los agrícolas y ganaderos quedan excluidos de la negociación.

Uno de los grandes problemas de la integración latinoamericana, y por ende suramericana, es la defensa irrestricta de su soberanía nacional y su autodeterminación, lo que representa muchas veces una disputa entre sus intereses nacionales sobre los intereses generales planteados en los acuerdos de integración, ya que los intereses nacionales están por encima de los intereses comunes. A lo que cabe preguntar, entonces para qué inician un proceso de integración regional con carácter político. Por lo que surge otra cuestión, hasta qué punto esta vez están dispuestos los países avanzar en el proceso de integración. Para que funcione tendrían que implementar un sistema de competencias a nivel comunitario en favor de UNASUR, algo que hasta ahora no se ha hecho en términos efectivos.

\footnotetext{
${ }^{444}$ GÓMEZ. M.: La integración andina en tela de juicio. La Prensa, La Paz, 27 de noviembre de 2005. http://www.integracionsur.com/comunidadandina/AndinosCrisisIntegracionGomezB.htm [Última revisión: 31 de agosto de 2011]

445 Art. 3. Tratado Constitutivo de la Asociación Latinoamericana de Integración. Montevideo, 12 de agosto de 1980.

${ }_{446}$ Art. 3. Acuerdo de Integración Subregional Andino. Cartagena, 26 de mayo 1969.

${ }^{447}$ Art.4. Tratado Constitutivo de la Asociación Latinoamericana de Integración, Op. cit.
} 
La CAN los ha hecho parcialmente, ya que posee un sistema institucional comunitario avanzado en términos comparativos con los otros procesos de integración en marcha; el SAI (Sistema Andino de Integración), es el más desarrollado de América Latina y el Caribe. Ya que posee el Tribunal de Justicia de la Comunidad Andina, que a diferencia del Tribunal Permanente de Revisión del MERCOSUR, sus decisiones tienen efecto directo, aplicación inmediata y supremacía del derecho comunitario andino sobre el derecho nacional de los Estados miembros de la CAN. Lo que marca una diferencia jurídica importante a la hora de querer velar por el cumplimiento de los objetivos trazados y por los compromisos asumidos por parte de los Estados miembros de un esquema de integración.

Como comentó Mangas en un artículo sobre UNASUR en 2008:

Los dirigentes de aquel continente crean, ingresan, simultanean y se retiran de unas y otras organizaciones con facilidad. Despilfarran sus energías con floridas palabras sin dar pruebas de voluntad real de compartir soberania [...]. Su concepción de la soberanía es la que circuló entre la Edad Media al siglo XIX. [...]. Los repetitivos ensayos integracionistas nacen muertos por la persistente tendencia a ignorarlos al día siguiente aferrándose a la irrestricta soberanía e independencia, eje central del nuevo Tratado UNASUR ${ }^{448}$.

En efecto, soberanía, todo proceso de integración que aspire ser una unión política regional tiene que contar con un sistema de competencias compartidas y/o comunes donde la cesión de la soberanía nacional y el ejercicio de una soberanía común es la piedra angular del proceso de integración.

UNASUR tiene previsto en su tratado constitutivo "construir una identidad y ciudadanía suramericana y desarrollar un espacio regional integrado en lo político, económico, social, cultural, ambiental, energético y de infraestructura"449; así como fortalecer "el diálogo político entre los Estados miembros que aseguren un espacio de concertación para reforzar la integración suramericana y la participación de UNASUR en el escenario internacional $^{450}$. Hemos resaltado espacio regional integrado y espacio de concertación

\footnotetext{
${ }^{448}$ MANGAS, A.: ¿Es creíble una Unión Suramericana de Naciones? Publicado en El Mundo, 2 de junio de 2008.

http://reggio.wordpress.com/2008/06/02/\%C2\%BFes-creible-una-union-suramericana-de-naciones-dearaceli-mangas-martin-en-el-mundo/ [Última revisión: 19-8-2011].

${ }_{449}$ Preámbulo. Tratado Constitutivo de la Unión de Naciones Suramericanas, Op. cit.

${ }^{450}$ Art. 3. a. Tratado Constitutivo de la Unión de Naciones Suramericanas, Op. cit.
} 
para analizarlo posteriormente y conjuntamente con los otros conceptos que describimos a continuación. Los Estados de América del Sur "ratifican que tanto la integración como la unión suramericanas se fundan en los principios rectores de: irrestricto respeto a la soberanía, integridad e inviolabilidad territorial de los Estados; autodeterminación de los pueblos" "451. Agregando que "conscientes de que este proceso de construcción de la integración y la unión suramericanas es ambicioso en sus objetivos estratégicos, que deberá de ser flexible y gradual en su implementación, asegurando que cada Estado adquiera los compromisos según su realidad"452.

Finalmente, menciona que:

Unión de Naciones Suramericanas tiene como objetivo construir, de manera participativa y consensuada, un espacio de integración y unión en lo cultural, social, económico y político entre sus pueblos, otorgando prioridad al diálogo político, [...] fortalecer la democracia y reducir las asimetrías en el marco del fortalecimiento de la soberanía e independencia de los Estados ${ }^{453}$.

Analicemos, si UNASUR pretender ser el organismo subregional por excelencia que buscará una mayor profundización en el proceso de integración en América del Sur, entonces UNASUR debería de buscar ser una verdadera unión de países, en la cual sus Estados miembros debieran ceder ciertas competencias nacionales a favor de la unión, de manera que esta pueda desarrollar una política comunitaria; pero este no parece ser el caso, expresada la idea de crear un espacio regional integrado, no deja claro la voluntad de crear una unión regional, sino más bien dice, espacio regional integrado.

No dice crear un espacio común, por tanto no pretende ser una organización regional, la cual lleve de manera comunitaria las políticas de desarrollo de los países, más bien siguen siendo los Estados miembros soberanos los que tienen las competencias únicas y exclusivamente, en todo caso más que crear políticas comunitarias, serán políticas de cooperación intergubernamental a nivel regional. O en el peor de los caso, deja la duda si lo que realmente quieren es extrapolar los intereses nacionales a escala regional.

El hecho de que los países de América del Sur busquen crear una integración regional sobre las bases de unos principios rectores, los cuales son el irrestricto respeto a la

\footnotetext{
${ }^{451}$ Preámbulo. Tratado Constitutivo de la Unión de Naciones Suramericanas, Op. cit. 452 Ibíd.

${ }^{453}$ Art. 2. Tratado Constitutivo de la Unión de Naciones Suramericanas, Op. cit.
} 
soberanía, su integridad e inviolabilidad territorial y además la autodeterminación de los pueblos, son la prueba que no se dará el desarrollo de políticas comunitarias bajo ningún término, en todo caso intergubernamentales, más aún si resaltan la idea de la supremacía de la soberanía nacional, entonces dejan entrever, que el método de trabajo y sistema a desarrollar será el de la cooperación intergubernamental en lugar del comunitario. Lo que da por pensar que si existe una confusión a la hora de hablar de integración, cuando realmente lo que quieren es crear un organismo de cooperación regional, más que crear un organismo de integración regional.

Si UNASUR pretende dar un mayor ímpetu para la construcción de la identidad suramericana y promover aún más la integración del continente suramericano ${ }^{454}$, primero tiene que ceder su soberanía nacional en pos de una soberanía compartida, es decir una soberanía común suramericana. Segundo, dotar de competencias exclusivas a la nueva unión regional. Los países suramericanos deberían de crear un sistema de competencias comunitario, con competencias exclusivas y otras compartidas entre los Estados miembros, establecer normas y políticas comunitarias que permitan el desarrollo de una acción exterior.

Carlos Piñeiro Iñiguez propone en su libro La Nación Sudamericana, la creación de una nueva nacionalidad, la sudamericana, y dice que esta debe de estar fundamentada sobre el principio de la supranacionalidad ${ }^{455}$. Compartimos la idea en que dicha supranacionalidad conlleva la transferencia de competencias estatales a un organismo supranacional comunitario, el mismo que se encargará de dictar las normas al conjunto de los Estados miembros ${ }^{456}$ para tener una mejor voz en el escenario internacional. Si se espera que UNASUR cree una identidad suramericana, debiera entonces de implementar el principio de supranacional, y por ende, tendría que cambiar su método de trabajo, implementando la creación de instituciones comunitarias de carácter supranacional.

\footnotetext{
${ }^{454}$ Resolución del Consejo de Ministros de Relaciones Exteriores de UNASUR sobre la entrada en vigencia del Tratado Constitutivo, Quito 11 de marzo de 2011.

${ }^{455}$ PIÑEIRO. C.: La Nación Sudamericana, en MAÍZ. C.: Unir lo diverso. Problemas y desafíos de la integración latinoamericana. Universidad Nacional de Cuyo, Mendoza, 2010. p. 102.

${ }^{456}$ TÉLLEZ. C.A.: La integración energética en el marco de UNASUR, en LONDOÑO. B. y GÓMEZ. D. M.: Diez años de investigación jurídica y socio-jurídica en Colombia: balances desde la Red Sociojurídica, tomo II. Universidad Colegio Mayor de Nuestra Señora del Rosario y la Universidad de La Sabana, Bogotá, 2010. p. 203.
} 
El énfasis que han dado los países suramericanos en los documentos de UNASUR, en donde destacan que se respetará la autodeterminación de los pueblos, es un obstáculo a superar, no sólo políticamente, sino también mentalmente, mientras los políticos nacionales sigan pensando de manera nacional y no se preocupen por incluir dentro de sus planes de gobierno, la integración regional, los países no podrán avanzar, porque sus dirigentes políticos solo pueden ver a nivel nacional, a nuestro criterio es porque no entienden el concepto de la integración regional confundiéndolo una vez más con el concepto de cooperación.

La autodeterminación de los pueblos, ciertamente, es un derecho por el cual un pueblo decide sus formas de gobierno, y dicho derecho está recogido en la Carta de Naciones Unidas $^{457}$, sin embargo, los países no pueden querer construir una unión regional si los propios países siguen con esa vieja idea de la autodeterminación de los pueblos, esta tiene que cambiar a favor de una gobernanza suramericana. Muchas veces se habla de las asimetrías de desarrollo o tamaño de mercado como un principal obstáculo, pero lo mismo podría haber pensado Luxemburgo, Holanda o Bélgica a la hora de ceder soberanía a la Unión Europea, pero sabemos que no fue así, estos países entendieron que sus intereses nacionales podrían ser mejor desarrollados y defendidos a una escala europea, en la cual podrían tener una mayor capacidad de negociación frente a terceros que haciéndolos unilateralmente.

La crisis financiera que azotó a Estados Unidos, Europa y otras regiones del mundo no ha afectado el crecimiento económico de los países latinoamericanos, principalmente los países de América del Sur, en conjunto la región registro un crecimiento del seis por ciento, promedio, durante este período.

Dentro del marco de UNASUR se ha podido ver un avance en su política, dado que los Estados miembros han decidido fortalecer sus economías y prever futuras crisis, creando el Consejo Sudamericano de Economía, dicho organismo tiene como función incentivar el comercio en la región, coordinar el uso de las reservas monetarias y fortalecer las instituciones financieras de la región ${ }^{458}$. Decidieron crear el Banco de Sur,

\footnotetext{
${ }^{457}$ Carta de Naciones Unidas, San Francisco 26 de junio de 1945.

458 REBOSSIO. A.: América del Sur hace frente común contra la crisis. La amenaza al crecimiento económico impulsa la ansiada integración regional. El País, Entrevista Digital, Buenos Aires, 14 de Agosto de 2011.

http://www.elpais.com/articulo/internacional/America/Sur/hace/frente/comun/crisis/elpepiint/20110814el pepiint_10/Tes [Última revisión: 22-6-14]
} 
este nuevo banco con vocación regional, puede ayudar financieramente a desarrollar los proyectos como de infraestructura, comunicación y proyectos de industrialización, ciencia y tecnología en los países miembros, conjuntamente con otros entes financieros de la región como son la Corporación Andina de Fomento (CAF), el Fondo Latinoamericano de Reservas y el Banco Interamericano de Desarrollo (BID), los dos primeros son parte del acervo institucional que tiene el proceso de integración andina, los cuales pueden ser un núcleo financiero impulsor de la integración suramericana y en América Latina y el Caribe.

El BID es resultado del sistema interamericano creado por la OEA. La CAF ha cambiado su denominación y ahora suma su nombre: CAF-Banco de Desarrollo de América Latina y el Caribe, muestra de su crecimiento, fortaleza financiera y capacidad de poder servir al conjunto de la región y no sólo a la subregión andina, como se indicó anteriormente. En el mejor de los casos, podemos decir que la región contaría con bancos de desarrollo de escala regional y un fondo de reservas.

UNASUR prevé por primera vez un punto en común estratégico más allá del económico y comercial, la infraestructura, todos los países necesitan desarrollar sus infraestructuras de lo contrario no podrán optimizar los beneficios del espacio común creado, sin infraestructura no podrá ser factible el crecimiento del comercio intrarregional, que es muy bajo en comparación al europeo. Dentro de sus objetivos está el de desarrollar una infraestructura para la interconexión de la región, del mismo modo la integración energética para el aprovechamiento integral, sostenible y solidario de los recursos de la región $^{459}$.

Se prevé que el Fondo Latinoamericano de Reservas, pueda rescatar a países en dificultades financieras. Como hemos mencionado anteriormente, este fondo nace dentro del proceso de integración andina, pero su vocación desde su nacimiento, como dice su propio nombre, era regional.

El grado de interdependencia en el que vivimos es tal, que es imposible pensar en el desarrollo de los países sin considerar el desarrollo de sus países vecinos, las economías están interrelacionadas entre sí y cualquier acontecimiento en el mundo afecta a la economía regional. La Comisión Económica para América Latina (CEPAL) considera

\footnotetext{
${ }^{459}$ Art. 3. Tratado Constitutivo de la Unión de Naciones Suramericanas, Op. cit.
} 
que ha habido avances en los procesos de integración de América Latina ${ }^{460}$, estos han sido positivos y significativos, pero que aún falta mucho para que los países latinoamericanos logren una unión política o económica a escala regional latinoamericana. UNASUR puede ser la respuesta para integrar no sólo a América del Sur sino también al conjunto de la región, siendo ese eslabón entre lo suramericano y lo latinoamericano-caribeño. Como lo está haciendo la CAN, al ser el eslabón andino hacia el suramericano.

Si se tiene en cuenta el desarrollo de una política exterior andina, y que está pueda servir de base para desarrollar una política exterior suramericana, se podrá pensar en una futura acción exterior y política exterior latinoamericana-caribeña, tarde o temprano si los países suramericanos están pensando en la unidad de América Latina y el Caribe este es el paso a seguir, implementar una política exterior suramericana.

Si se pensara que esto no es necesario, entonces surge la pregunta ¿Cómo desean cumplir su objetivo de unidad política y ejercer una voz fuerte en la arena internacional? El sistema de presidencia Pro-témpore, es un paso intermedio, no un fin mismo. A quienes opinen que no es necesario, y que dicho sistema es eficaz y suficiente, se podría responder, por qué entonces la Unión Europea abandonó dicho sistema y creó instituciones comunitarias que ejerzan su acción exterior. La respuesta es coherencia y eficacia, tener capacidad de negociación frente a terceros y una mejor acción y representación exterior. ¿Por qué no aprender de la experiencia europea?

La Unión de Naciones Suramericanas tendrá que cambiar los conceptos a sus Estados miembros y decirles que el viejo concepto de la soberanía nacional, al igual que la autodeterminación de los pueblos, no sirven en este mundo multipolar, un mundo donde las uniones regionales se han constituido en nuevos agentes políticos en la escena política y económica a nivel global. El desarrollo de una política común es lo que beneficiaría al conjunto de los países suramericanos, por tanto si los países suramericanos pretenden profundizar su proceso de integración y ser una unión regional entonces deben de formular políticas de integración suramericana ${ }^{461}$, y para ello deberán de cambiar su sistema de gobierno, compartiendo su sistema de competencias con la

${ }^{460}$ LOPÉZ. A.: CAN, MEROCSUR y UNASUR ¿Tiene sentido la convergencia? En Secretaria General de la Comunidad Andina. Revista de integración No 2. La Construcción de la integración Suramericana, Lima, julio de 2008. p. 78.

${ }^{461}$ Tratado Constitutivo de la Unión de Naciones Suramericanas, Brasilia, Op. cit. 
creación de un sistema de competencias comunitarias, transformando su idea de gobernanza, del plano nacional hacia un gobierno comunitario, de carácter supranacional, más no un intergubernamental, pues la propia UE se dio cuenta que el intergubernamentalismo no es suficiente a la hora de responder los desafíos de la globalización; es la única manera en que UNASUR pueda formular políticas de integración suramericana ${ }^{462}$.

El sistema institucional de UNASUR es insipiente para las metas que tiene previstas desarrollar, la creación de un Consejo de Jefes de Estado y Jefes de Gobierno, un Consejo de Ministros de Relaciones Exteriores, un Consejo de Delegados y una Secretaría General ${ }^{463}$; están bien para una organización internacional, pero no para una organización regional cuya meta es la integración y la convergencia de los procesos de integración en uno sólo.

Más aún si desean sumar a esta unión política, una Unión Interparlamentaria Sudamericana, conformada por reuniones conjuntas con la Comisión Parlamentaria Conjunta del MERCOSUR, el Parlamento Andino y representantes del Congreso de Chile ${ }^{464}$ como se está pretendiendo hacer. Surge entonces otra pregunta: ¿Para qué crear un parlamento subregional si este no posee competencias subregionales? El desarrollo de un trabajo comunitario es el camino para poder desarrollar una agenda común que combine los intereses nacionales con los intereses comunitarios, donde el conjunto de la población obtenga un crecimiento y desarrollo económico y social ${ }^{465}$.

Sin duda el rol a jugar por parte de este nuevo parlamento subregional será importante, no sólo en términos de legitimidad democrática, sino también para darle sustento normativo al propio proceso, dotando de instrumentos jurídicos en todas las áreas que pretender desarrollar. En el actual contexto mundial es necesario sobrepasar la realidad del Estado nacional ${ }^{466}$ es necesario tener una unión regional fuerte.

\footnotetext{
${ }^{462}$ Art. 3. Tratado Constitutivo de la Unión de Naciones Suramericanas, Op. cit.

463 Art. 4. Tratado Constitutivo de la Unión de Naciones Suramericanas, Op. cit.

${ }^{464}$ Declaración de Ayacucho, 9 de diciembre de 2004.

465 Consenso de Guayaquil sobre Integración, Seguridad e Infraestructura para el Desarrollo. II Reunión de Presidentes de América del Sur, Guayaquil, 26 y 27 de julio de 2002.

${ }^{466}$ PINEDA, J. C.: UNASUR: Más allá de la CAN y MERCOSUR. Secretaria General de la Comunidad Andina. Observatorio UNASUR. El Universal (Venezuela), 3 de setiembre de 2009.

http://www.comunidadandina.org/prensa/articulos/eluniversal3-9-09.htm
} 
Es necesario que los países de UNASUR se aclaren antes de proseguir, definiendo primero qué tipo de integración quieren realizar en América del Sur, y definir qué quieren decir con ser un proceso innovador ${ }^{467}$, también tendrían que dilucidar su rol como organismo subregional, haciendo frente y resolver las diferencias entre sus Estados miembros respecto al enfoque y visión de integración.

Mientras un grupo de países aspiren a crear un esquema de integración, que sólo busca la confluencia de los procesos de integración existentes y en el que solo se añade nuevos campos de acción, en comparación a otro grupo de países que piensan en una progresiva construcción de una Comunidad de Estados, análoga a la europea, e incluso en una suerte de federalismo ${ }^{468}$ a nivel suramericano, poco podrán avanzar los países suramericanos, mientras no aclaren primero hacia dónde quiere ir y qué quieren hacer, no pueden volver a caer en la retórica y en la exposición de grandes ideas, metas e ideales que no podrán cumplirse, si no se debate y discute sobre ello.

\subsubsection{Institucionalización e implementación de una Acción Exterior} Común en el marco de la CELAC: Oportunidades en la Asociación Bi-regional UE-CELAC

El fomento de la integración regional constituye una de las principales actividades de la acción exterior de la Unión Europea en el mundo, para que las regiones participen más activamente en los asuntos mundiales ${ }^{469}$. La Unión Europea busca en las relaciones con América Latina y Caribe, una relación de socios, considera a esta región, muy próxima al compartir una historia, cultura, principios y valores comunes, por tales motivos, no duda en poner a ALC en primer lugar ${ }^{470}$ a la hora de construir alianzas. Es la región más próxima ideológicamente hablando.

El inconveniente de esta consideración es que la UE parte del principio que ALC es en sí misma una región política y organizada, pero no lo es, no se puede negociar ni llegar a un acuerdo, si el interlocutor que se tiene no posee ni personalidad jurídica, ni

\footnotetext{
${ }^{467}$ Tratado Constitutivo de la Unión de Naciones Suramericanas, Brasilia, Op. cit.

468 VALENCIA, J.: Integración en la UNASUR. Secretaria General de la Comunidad Andina. Observatorio UNASUR. Hoy (Ecuador) 13 de agosto de 2009.

http://www.comunidadandina.org/prensa/articulos/hoy13-8-09.htm

${ }^{469}$ Comisión Europea: La Unión Europea y el mundo. Serie: Europa en movimiento, Bruselas, 2001.

${ }^{470}$ Comunicación de la Comisión al Consejo y al Parlamento Europeo: Una asociación reforzada entre la Unión Europea y América Latina, COM (2005) 636 final. Dirección General de Relaciones Exteriores, Comisión Europea, Oficina de publicaciones oficiales de las Comunidades Europeas, Luxemburgo, 2006. p. 5 .
} 
capacidad de negociar, tampoco tiene una voz, y por no tener, no tiene claro qué tipo de integración quiere tener, caso CELAC.

Dentro de los objetivos y los planes de la UE están el ser un Actor Global y consolidarse como tal, a través del ejercicio de un liderazgo activo en cada uno de los foros y organismos internacionales. Para lograr tal objetivo, aplica el interregionalismo como parte de su estrategia dentro de su Acción Exterior, a través de su Política Exterior y de Seguridad Común, la cual contempla la celebración de acuerdos internacionales, con el objeto de establecer acciones comunes ${ }^{471}$.

La UE busca, a través de las relaciones con ALC, que esta región se desarrolle como unión regional para que pueda actuar como un actor global, y juntas, ambas regiones puedan unir sus fuerzas y adoptar posiciones comunes en los diferentes foros internacionales, de manera que puedan ser un contrapeso frente a otras regiones del mundo o países de dimensiones regionales como por ejemplo Estados Unidos, Rusia, China e India, cuyo peso económico y político en la escena internacional, determinan el reparto del poder, y en consecuencia determinar quiénes participan y quiénes no, en la toma de decisiones de las políticas de desarrollo a nivel global.

Mientras que para la UE es claro que el mejor camino emprendido para el desarrollo de los países, es a través de la integración regional, formando uniones regionales, que cuenten con instituciones comunitarias fuertes, con un sistema de competencias supranacionales, lo que significa que los Estados atribuyen competencias ${ }^{472}$, cediendo parte de su soberanía nacional en pos de una soberanía común.

En el otro lado del Atlántico, ALC sigue dudando sobre las ventajas de formar una unión política regional, a pesar de sus múltiples intentos, no han logrado todavía definir qué tipo de integración va a desarrollar en su proceso de integración.

Los países de ALC siempre anteponen sus intereses nacionales, argumentado la defensa de la soberanía nacional, sobre los intereses comunes. ALC no está a favor de la creación de instituciones comunitarias, porque eso significaría ceder competencias nacionales y aplicar un método de trabajo comunitario. Prefirieren aplicar en sus

\footnotetext{
${ }^{471}$ Art. 217 Título V. Acuerdos Internacionales, Tratado de Funcionamiento de la Unión Europea.

472 Art. 1. del Tratado de la Unión Europea señala: "Unión, a la que los Estados miembros atribuyen competencias para alcanzar sus objetivos comunes”.
} 
procesos de integración, el método de intergubernamental, pues tienen miedo a perder el control y a ser controlados por órganos comunitarios.

Se puede llegar a la conclusión que ALC busca, más que desarrollar y crear organismos de integración regional, crear mecanismos de cooperación a escala regional. Su proceso de integración regional tiene más características a una regionalización que a un regionalismo. La prueba de ello, es que todos sus procesos de integración a escala subregional emprendidos, que han buscado desarrollar e implementar instituciones comunes y políticas comunitarias, han sido rechazados, como es el caso de la Comunidad Andina, que lejos de fortalecerse con el pasar de los años, se ha ido debilitando. Siendo abandonada por sus Estados miembros.

La carencia de un debate concienzudo sobre integración, la ausencia del tema de la integración en los planes y agendas de los partidos políticos, evidencian el verdadero desinterés por parte de los gobiernos por desarrollar el tema y la carencia de visión a largo plazo. Si a todo esto, le sumamos que en la mayoría de los países se aplica el presidencialismo, y que es sobre la figura del presidente en la que recae la responsabilidad de diseñar e implementar la política exterior de un país, y que la misma, se realiza, tomando en consideración no lo intereses nacionales, sino muchas veces los intereses del partido político que está en el gobierno de turno, los planes y la visión son sólo a corto plazo, pues viven a expensas de buscar una relección, más que de velar un proyecto a largo plazo.

Lo que da como resultado, no defender la integración regional, más aún si esta involucra una posible cesión de soberanía, hecho que recortaría sus poderes y poder de influencia a nivel nacional, y el deseo expreso de no querer discutir con terceros sus planes políticos, ni que decir que no desean crear instituciones comunitarias, pues eso significaría más control y menos margen de actuación en la implementación de las políticas de desarrollo, algo que desean guardarse para sí mismo, para poder mostrar a sus votantes que si hay un avance es gracias a un gobierno nacional y no a un gobierno comunitario.

La mezquindad y ambición política, a nivel nacional, hace que la integración sea contraria a sus intereses de partido. Si Europa avanzó en su proceso de integración fue porque hubo consenso entre sus diferentes partidos, y porque estos tuvieron la altura de 
poder mirar más allá de sus intereses partidistas e intereses nacionales para poder construir una región no sólo de paz, sino también de prosperidad y bienestar. Para todo esto se necesita consenso, desarrollar una visión y planes estratégicos a largo plazo, no a corto plazo.

Pero en ALC, es mejor no tener ese consenso, porque parece no ser conveniente, y es mejor deshacer todo lo que el gobierno anterior realizó, incluyendo los compromisos asumidos en materia de acuerdos internacionales, como son los casos de incumplimiento a cada uno de los tratados y acuerdos de integración subregional y regional firmados y que contemplan entre sus objetivos y metas desde la creación de mercados únicos hasta una mayor integración política a través justamente de la creación de instituciones comunitarias.

Muchos partidos políticos gastan la mitad de su tiempo de gobierno, en desacreditar al partido que gobernó anteriormente y si es de un pensamiento político distinto, mejor argumento aún. No acaban de entender que la integración está por encima de pensamientos e ideologías políticas, y que por consiguiente no es sólo grandes discursos de unidad, ALC llevan siglos con ese discurso, la integración en ALC jamás será efectiva mientras primero no exista un consenso a nivel nacional por parte de los partidos políticos, y mientras, estos no incluyan un verdadero debate sobre la integración, y que luego este, concluya con la incorporación de la unidad regional en las agendas de los partidos políticos a escala regional. Como ocurren con las "familias de partidos políticos" a nivel europeo.

El proceso de integración en Centro América y el de los países andinos, son una clara muestra de dicha afirmación, son los dos únicos esquemas que tienen contemplados dentro de sus objetivos el desarrollo de políticas comunitarias y la instauración de instituciones comunitarias, pues MERCOSUR, como su propio nombre lo indica nació para ser un mercado común, jamás aspiró a más, y muestra de ello es que su método de trabajo es de carácter intergubernamental y por ello su máximo órgano es un Consejo de Mercado Común ${ }^{473}$, y no un Consejo Presidencial. Su extrapolación a la nueva UNASUR, pone de manifiesto la misma tendencia, a pesar de usar el término unión de naciones, en cada uno de sus documentos se deja claro que es un espacio de integración

\footnotetext{
473 Art. 9 del Tratado de Asunción, 26 de marzo de 1991 y el Art.1 del Protocolo de Ouro Preto, 17 de diciembre de 1994 regulan la estructura institucional del Mercado Común del Sur.
} 
integrado $^{474}$ y que busca ser un mecanismo de cooperación, con principal énfasis en términos comerciales y económicos. Como bien hemos descrito anteriormente.

El mismo caso ocurre con CELAC que a pesar de usar la palabra comunidad, y sin tener ningún tipo de institucionalidad, hasta ahora sólo es una instancia de concertación ${ }^{475}$ y cuya representación a nivel exterior son las presidencia Pro-témpore, no es una instancia comunitaria que sirva de órgano de representación a nivel exterior.

Lo paradójico y a la vez rescatable, es que a pesar que a nivel intrarregional, los países de ALC no logran ponerse de acuerdo sobre qué proceso fortalecer y cómo lo van hacer, en las relaciones entre la UE y esta región se han mantenido y cada vez a más alto nivel político. Las relaciones de la CELAC con la UE son un ejercicio de acción exterior común o concertada entre sus estados miembros frente a la UE. La pregunta entonces que surge es si dicha acción exterior es consciente, y es resultado de una madurez en su proceso de integración regional interna o más bien es resultado de una dinámica que se ha venido dando como producto de las relaciones desarrolladas con la Unión Europea.

Lo que sí es claro, es que las negociaciones entre la UE-ALC, desde 1991 hasta la fecha, han servido para tratar de posicionar a ALC como un actor global en el escenario internacional. El reto de ser una unión regional con peso propio en la escena internacional es ahora responsabilidad política por parte de los países de ALC.

Si el anuncio de creación de la CELAC fue un símbolo de una buena dirección en favor de la integración política a nivel regional, más aún lo es, que exista una Cumbre de Jefes de Estado y de Gobierno UE-CELAC, porque exigirá la adopción de una posición común por parte de los países de la CELAC en el proceso de las negociaciones, lo que acarrea la necesidad de crear un plan de trabajo conjunto (una agenda común) y con ello, la necesidad de iniciar una convergencia entre los procesos subregionales existentes hacia la construcción de una unión regional, para evitar duplicidades de esfuerzos y recuerdos humanos y financieros.

La aplicación de una agenda común requiere, necesariamente, una acción exterior común, y ésta exige la elaboración e implementación de una política exterior común, sin

\footnotetext{
474 Tratado Constitutivo de la Unión de Naciones Suramericanas, Brasilia, 8 de diciembre de 2004.

475 Declaración de Cancún señala: "la región requiere de una instancia de concertación". Cancún 23 de febrero de 2010 .
} 
ésta, América Latina y el Caribe jamás podrá aspirar a ser un interlocutor parejo frente a la UE y un verdadero actor global.

\subsubsection{Los eslabones de la integración en América Latina y el Caribe: eslabón andino-eslabón suramericano-eslabón latinoamericano y caribeño}

Desde la reunión en Río de Janeiro, en 1999, los Estados miembros de la Unión Europea (UE) y los países de América Latina y Caribe (ALC) han establecido mecanismos de cooperación conjunta, a través de diferentes foros sectoriales, bilaterales, birregionales y multilaterales, en una amplia gama de áreas temáticas, todas ellas enfocadas a cumplir con el compromiso de la UE con el fortalecimiento de la integración regional de ALC, mediante el establecimiento de Acuerdos de Asociación y/o Acuerdos Comerciales.

Desde entonces, la relación entre ambas regiones ha pasado de ser nombrada desde una asociación reforzada $(2005)^{476}$, una asociación estratégica $(2008)^{477}$, a una asociación de actores globales (2009) ${ }^{478}$. Nótese que se hace una diferenciación en el uso de los términos entre Estado miembros, en el caso de la UE, y países, en el caso de ALC, pues se parte de la base que la UE es una unión regional, es decir una región que cuenta con un organismo regional que posee personalidad jurídica, según el derecho internacional. En el caso de ALC, no se puede decir lo mismo, pues a pesar de ser considerada una región, en términos económicos, históricos y culturales, no lo es en lo político, desde el estricto punto del derecho internacional, no posee personalidad jurídica como tal.

Por tal razón cuando se hable del conjunto de países de una región u otra, cada vez que se utilice el término "Estado miembro" será en clara alusión a la UE, y cuando se use el término "países" será en referencia a ALC. La aclaración no es de forma, es de fondo, pues en la política y en la diplomacia, las palabras son importantes, y la utilización de un término u otro, pueden desvelar las intenciones, lo que se quiere conseguir y el camino a seguir.

\footnotetext{
${ }^{476}$ Ibíd.

${ }^{477}$ Comisión Europea: La asociación estratégica entre la Unión Europea, América Latina y Caribe: Un compromiso común. Dirección General de Relaciones Exteriores, Comisión Europea, Oficina de publicaciones oficiales de las Comunidades Europeas, Luxemburgo, 2008.

${ }^{478}$ Comunicación de la Comisión al Parlamento Europeo y al Consejo. La Unión Europea y América Latina: Una asociación de actores globales, COM (2009) 495/3. Comisión Europea, Bruselas, 30 de septiembre de 2009.
} 
En el caso de la integración regional, en Europa, sus Estados Miembros han sido claros respecto al tipo de integración querían tener, con sus éxitos y fracasos, con sus avances y estancamientos, más nunca retrocesos, los europeos han apostado siempre a un solo proceso de integración, el de la Unión Europea, en la cual, son "Estados miembro", han formado una unión que cuenta con un sistema de competencias, cedidos por sus "Estados miembros", porque en el fondo saben, que en el mundo en el que vivimos, es mejor actuar unidos que por separado, más aún si se es tan pequeño, y se desea ser un actor activo, buscando un liderazgo, deseando ser un primer actor en el escenario internacional y no un segundo actor, es decir un mero actor pasivo u observador global.

En cambio ALC desvela a través de sus múltiples procesos en marcha, la falta de claridad de objetivos, existe una confusión, si se analiza todos los tratados fundacionales de los distintos organismos subregionales o regionales que existen en ALC, la duda surge respecto a que si realmente aspiran a tal anhelada y constante mencionada "unidad regional”, dicha duda es una duda válida y vigente.

A mi modo de ver, los países de ALC confunden, integración con cooperación, organización regional con mecanismo de coordinación regional, unión y comunidad de estados con espacio integrado de estados. ALC despliega un discurso político de unión política regional, cuando en realidad sus objetivos son sólo las de crear un mercado regional. Por tanto la pregunta: ¿Qué tipo de proceso se desarrolla en ALC, regionalismo o regionalización? Es legítima si se desea resolver esa falta de claridad por parte de los gobiernos de ALC.

En términos teóricos Söderbaum distingue regionalismo de regionalización, el primero lo define como un fenómeno general en el mundo entero. El regionalismo recoge un conjunto de ideas, ideología e identidades comunes de una región específica, cuya dinámica se desarrolla dentro de un marco formal, es decir, un proyecto de integración regional, cuya construcción lleva consigo la creación de una institución supranacional. El segundo, puede ser o no, resultado del regionalismo, y además acota que la regionalización puede darse sin necesidad de que exista un proyecto concreto, es decir, sin que exista la voluntad de crear instituciones supranacionales. Por tanto, los actores pueden comprometerse en el proceso de un modo natural y sin convicción particular ${ }^{479}$,

\footnotetext{
${ }^{479}$ SÖDERBAUM, F.: The Political Economy of Regionalism. The case of Southern Africa. Hampshire:
} Palgrave Macmillan, 2004, p.7. 
diferenciando así que la regionalización es más un proceso en términos comerciales y económicos que políticos. Tomando como referencia este marco teórico, se puede cuestionar la idea que los países de ALC busquen o estén realizando un proceso de regionalismo, más bien, se podría pensar que se inclinan por un proceso de regionalización.

Revisando los tratados fundacionales de los principales organismos subregionales y/o regionales existentes, encontramos las palabras que usan los países a la hora de definir como se desarrollara la integración en los respectivos organismos creados:

\section{Cuadro $\mathbf{N}$ Membresías de los países en los organismos de integración regional en} América Latina y el Caribe

\begin{tabular}{|c|c|c|c|}
\hline $\begin{array}{c}\text { Nombres de los } \\
\text { procesos de } \\
\text { integración }\end{array}$ & $\begin{array}{c}\text { Descripción y forma } \\
\text { de participación }\end{array}$ & Objetivos & Método de trabajo \\
\hline $\begin{array}{c}\text { Integración regional } \\
\text { Centroamericana }\end{array}$ & Estados Miembro & $\begin{array}{c}\text { Organización de } \\
\text { Estados } \\
\text { Centroamericanos }\end{array}$ & Comunitario \\
\hline Comunidad Andina & Países Miembro & Comunidad de Estados & Comunitario \\
\hline ALADI & Partes Contratantes & Mercado Común & Intergubernamental \\
\hline MERCOSUR & Estados Parte & Mercado Común & Intergubernamental \\
\hline CARICOM & Miembros de una & Comunidad de Estados & Intergubernamental \\
\hline UNASUR & Estados Parte & $\begin{array}{c}\text { Espacio regional } \\
\text { integrado económico }\end{array}$ & Intergubernamental \\
\hline CELAC & Estados o Estados & $\begin{array}{c}\text { Mecanismo regional } \\
\text { de integración Espacio } \\
\text { latinoamericano y }\end{array}$ & Intergubernamental \\
& Soberanos & caribeño & \\
\hline
\end{tabular}

Elaboración propia.

\section{Fuentes Tratados fundacionales de los procesos de integración en América Latina y el Caribe}

Como se puede observar, los dos únicos procesos de integración que usan los términos "Estados miembro" son aquellos que se definen como una organización de estados o comunidad de estados y que además trabajan de manera comunitaria, ambos tienen un 
Sistema de Integración, es decir poseen un sistema institucional de carácter comunitario y supranacional. Ambos poseen un derecho comunitario; sin embargo, de los dos, sólo la CAN cuenta con lineamientos para el desarrollo de una Política Exterior Común, la misma que establece los parámetros y criterios de la acción exterior de la CAN frente a terceros países y/o grupos de países, es decir otras regiones. Así lo refleja los distintos documentos y normas comunitarias de la CAN: Decisión 458 Lineamientos de la Política Exterior Común (1999) ${ }^{480}$, Decisión 475-Directiva $N^{\circ} 1$ sobre Política Exterior Común (2000) ${ }^{481}$, Decisión 476 Seguimiento de la política Exterior Común $(2000)^{482}$, Decisión 499 Actualización de la Directiva $\mathrm{N}^{\circ} 1$ sobre formulación y ejecución de la Política Exterior Común $(2001)^{483}$, Resolución 528 Criterios y pautas para la formulación y ejecución de la Política Exterior Común-Texto unificado de la Directiva $\mathrm{N}^{\circ} 1$ de la Política Exterior Común $(2001)^{484}$, Decisión 741 Observadores de la Comunidad Andina (2010) ${ }^{485}$.

A pesar de tales avances las diferencias ideológicas de los últimos gobiernos de algunos países Miembros de la CAN han generado diferencias respecto a la conducción y fin último del proceso de integración de la CAN, siendo el incumplimiento de sus responsabilidades y obligaciones contraídas por los tratados y normas comunitarias algo recurrentes.

La crisis de la CAN se agudizó en el 2006 con la salida de Venezuela, ese mismo año Venezuela firma el Protocolo de Adhesión como miembro del MERCOSUR, hecho que estanca el proceso de integración andina de manera interna y de manera externa, estancó

480 Decisión 458 Lineamientos de la Política Exterior Común. Consejo Andino de Ministros de Relaciones Exteriores, Cartagena de Indias, 25 de mayo de 1999. Normativa Andina. Gaceta Oficial del Acuerdo de Cartagena http://www.comunidadandina.org/Normativa.aspx

${ }^{481}$ Decisión 475-Directiva $\mathrm{N}^{\circ} 1$ sobre la Política Exterior Común. Consejo Andino de Ministros de Relaciones Exteriores, Lima, 3 de febrero de 2000. Normativa Andina. Gaceta Oficial del Acuerdo de Cartagena http://www.comunidadandina.org/Normativa.aspx

${ }^{482}$ Decisión 476 Seguimiento de la Política Exterior Común. Consejo Andino de Ministros de Relaciones Exteriores, Lima, 27 de abril de 2000. Normativa Andina. Gaceta Oficial del Acuerdo de Cartagena http://www.comunidadandina.org/Normativa.aspx

${ }^{483}$ Decisión 499 Actualización de la Directiva $\mathrm{N}^{\circ} 1$ sobre formulación y ejecución de la Política Exterior Común. Consejo Andino de Ministros de Relaciones Exteriores, Valencia, 22 de junio de 2001. Normativa Andina. Gaceta Oficial del Acuerdo de Cartagena http://www.comunidadandina.org/Normativa.aspx

${ }^{484}$ Decisión 528 Criterios y pautas para la formulación y ejecución de la Política Exterior Común (Texto unificado de la Directiva $\mathrm{N}^{\circ} 1$ de la Política Exterior Común), Secretaría General de la Comunidad Andina, Lima 13 de mayo de 2001. Normativa Andina. Gaceta Oficial del Acuerdo de Cartagena http://www.comunidadandina.org/Normativa.aspx

${ }^{485}$ Decisión 741 Observadores de la Comunidad Andina, Consejo Andino de Ministros de Relaciones Exteriores, Lima 22 de julio de 2010. Normativa Andina. Gaceta Oficial del Acuerdo de Cartagena http://www.comunidadandina.org/Normativa.aspx 
las negociaciones con la UE, que se estaban realizando de bloque a bloque y pasan a ser de manera bilateral, Colombia y Perú firmaron un Acuerdo Comercial con la UE (2012). Ha todo esto se suma la doble personería de integración que pretende ejercer Bolivia, al presentar también su solicitud de ingreso como miembro de pleno derecho al MERCOSUR y seguir en la CAN, camino que parece querer seguir Ecuador. Bolivia firmó en 2012 el Protocolo de Adhesión al MERCOSUR. Y a esto se complejiza aún más al manifestar, Bolivia, que mantendrá una doble membresía con la CAN y el MERCOSUR. La pregunta es si esta posición es válida en cuanto están, supuestamente, en un proceso de convergencia CAN-MERCSUR, en marcha.

La CAN y la UE comparten un objetivo común en materia de política exterior, su compromiso con la integración regional de ALC. Muestra de ello, es el acuerdo fundacional de la CAN, el cual se establece, como Acuerdo de Integración Subregional Andino, nótese que no dice regional, dice subregional, pues su objetivo final, es la formación gradual de un mercado común latinoamericano.

En el caso de la UE los distintos documentos y comunicaciones antes señalados demuestran su compromiso con la integración regional de ALC. La CAN a pesar de su crisis institucional, sigue aspirando por forjar la "Patria Grande Latinoamericana y Caribeña", tal como afirmase, en su momento, el Secretario General de la Comunidad Andina, Adalid Contreras, al destacar la creación de la CELAC ${ }^{486}$.

Cabe señalar que la CAN participa en el marco de UNASUR y a través de una agenda de trabajo desarrollada de manera conjunta con MERCOSUR y ALADI, con el fin de sentar las bases de una convergencia de dichos bloques. La convergencia de ambos procesos, puede servir para optimizar recursos y evitar duplicidad o multiplicidad de esfuerzos integradores desplegados en tantas iniciativas, centrando todo el trabajo y esfuerzo en uno sólo.

El Secretario General de la Comunidad Andina, Adalid Contreras, en una entrevista realizada el 29 de enero de 2013, sostenía que la participación de la Comunidad Andina, en la construcción y consolidación de los espacios más amplios de integración, como UNASUR y la CELAC, puede ser dinamizando estrategias de convergencia y

\footnotetext{
${ }^{486}$ CONTRERAS, A.: Comunidad Andina destaca creación de la CELAC como mecanismo de unidad. Secretaria General de la Comunidad Andina. Noticias. Lima, 6 de diciembre de 2011. http://www.comunidadandina.org/prensa/noticias/6-12-11.htm [Última revisión: 11-08-2013]
} 
complementariedad con MERCOSUR ${ }^{487}$. Dentro de este marco, en el 2005, en Lima, se realiza una Reunión de las Secretarías Técnicas de las Instituciones Regionales y Subregionales de la Comunidad Sudamericana de Naciones (hoy UNASUR), en la cual se busca definir una agenda común que incluya las áreas prioritarias para todas las partes, así se incluyen:

- Integración comercial y complementación económica (crear una zona de libre comercio a nivel suramericano)

- Infraestructura y desarrollo descentralizado

- Medio Ambiente

- Integración energética

- Financiación regional

- Cohesión y Justicia social

- Asimetrías ${ }^{488}$

Es en el 2005 se dan varios avances respecto al tema de la convergencia subregional a escala suramericana, se celebra una reunión ampliada del Consejo de Ministros de Relaciones Exteriores de la Comunidad Andina, en la que se adopta la Decisión $613^{489}$, la cual otorga la condición de Miembro Asociado a los Estados Parte de MERCOSUR y la par que se definen los términos de su participación dentro de la Comunidad Andina. En el marco de ALADI, se suscriben los Acuerdos de Complementación Económica $\mathrm{N}^{\circ}$ 36,58 y $59^{490}$.

\footnotetext{
${ }^{487}$ Entrevista a Adalid Contreras, Secretario General de la Comunidad Andina: "Es la oportunidad histórica para la integración continental en base a la convergencia de los sistemas subregionales y regionales". Secretaria General de la Comunidad Andina. Noticias. Lima, 29 de enero de 2013.

http://www.comunidadandina.org/Prensa.aspx?bloqAct $=1 \&$ PageNumber $=9 \&$ busca $=\&$ mes $=01 \& a n i o=201$ 3\&tema=TI\&cat=RD\&accion=buscar [Última revisión: 11-08-2013]

${ }^{488}$ Reunión de las Secretarías Técnicas de las Instituciones regionales y Subregionales de la Comunidad Sudamericana de Naciones. Bases para un plan de trabajo conjunto. Secretaría General de la Comunidad Andina, Lima 30 y 31 de mayo de 2005.

489 Decisión 613. Consejo de Ministros de Relaciones Exteriores de la Comunidad Andina sobre la Asociación de la República de Argentina, de la República Federativa de Brasil, de la República de Paraguay y de la República de Uruguay, Estados Parte de MERCOSUR, a la Comunidad Andina, Lima 7 de julio de 2005. Secretaría General de la Comunidad Andina. Tratados y Legislación. http://www.comunidadandina.org/ingles/normativa/D613e.htm [Última revisión: 11-08-2013]

${ }^{490}$ Para mayor información sobre los acuerdos de complementación económica, revisar la web de la Secretaría General de la Comunidad Andina y su sección Relaciones Exteriores-MERCOSURDocumentos Básicos:

http://www.comunidadandina.org/Seccion.aspx?id=111\&tipo=TE\&title=mercosur [Última revisión: 1108-2013]
} 
En septiembre, se realiza la primera Reunión de Jefes de Estado de la Comunidad Sudamericana de Naciones, en la ciudad de Brasilia, en la cual se decide promover la convergencia de los Acuerdos de Complementación Económica entre los países de América del Sur, con el objetivo de conformar gradualmente una zona de libre comercio $^{491}$.

En todos los casos se busca implementar programas de liberación comercial, a través de la creación de sistemas de desgravaciones progresivas con el objetivo de contar, inicialmente, con una zona de libre comercio, para luego poder establecer una unión aduanera y así lograr establecer un mercado común. Tanto en Europa como en América Latina se ha considerado que cada uno de estos pasos antes mencionados deberá de terminar con la armonización de políticas macroeconómicas, para garantizar el buen funcionamiento de un mercado común.

Sin embargo, en ninguno de los casos, se ha logrado implementar medidas que incluyan la totalidad en la armonización de las políticas macroeconómicas entre los países miembros de uno u otro proceso de integración regional.

La experiencia andina que surge a mediados de la década del sesenta, y que a nuestro entender es una experiencia a considerar a la hora de querer contar con ALC como un Actor Global. Como se ha visto en este apartado la CAN ha jugado como un eslabón que articula el trabajo en los diferentes procesos de integración en la región de América Latina y el Caribe.

ALC podría combinar el acervo andino en materia de acción exterior y por ende el diseño de política exterior, y combinarla con la experiencia de la política comercial del MERCOSUR y articularla con los esfuerzos que se llevan a cabo en el marco de UNASUR, sumando además el tema de defensa y seguridad que se da dentro del UNASUR, todo ello podría generar las bases para diseñar una Política Exterior y de Seguridad Común a nivel suramericano que luego puede ser expuesta y extrapolada a nivel de la CELAC, ya que éste nuevo organismo pretender ser la voz única que representa a ALC a nivel internacional.

\footnotetext{
491 Declaración sobre la Convergencia de los Procesos de Integración en América del Sur. Primera Reunión de Jefes de Estado de la Comunidad Sudamericana de Naciones, Brasilia, 30 de septiembre de 2005 .
} 


\subsubsection{Cambio de percepción de América Latina y el Caribe en el mundo}

Durante las últimas décadas, el crecimiento y desarrollo económico de los países de América Latina y Caribe (ALC), han hecho de esta región, una región con grandes potencialidades de un desarrollo sostenible y sustentable en el tiempo. Si en décadas anteriores ALC fue una de las regiones considerada como principal destino de la Ayuda Oficial para el Desarrollo por terceros países, hoy en día, es una de las principales regiones destino de Inversión Extranjera Directa. Lo que demuestra un cambio de percepción respecto al resto del mundo hacia ALC. Existe más confianza a la hora de invertir en la región y en realizar proyectos a largo plazo.

La consolidación de la democracia ha sido un punto a favor de la región conjuntamente con el respeto a las reglas de juego, jurídicamente hablando, no suelen cambiar cada vez que hay cambios de gobierno.

La apuesta por el sistema democrático, la estabilidad jurídica y política, y continuidad en las políticas económicas, por parte de la mayoría de los gobiernos de la región, han hecho de esta, una región estable, con tasas de altas de crecimiento y desarrollo. La muestra de ello, es la reducción de los niveles de pobreza, el incremento de políticas sociales y cohesión social.

En términos económicos, el incremento de su comercio y la diversificación en su oferta exportable, que ya no sólo se limita a exportaciones de recursos naturales, sino también a la exportación de productos con valor agregado, son pasos y signos positivos que permiten pronosticar un desarrollo armónico y estable en la región. Dentro de este contexto, ALC busca hacerse un espacio dentro de la arena internacional, y la apuesta por crear organismo de integración de carácter subregional y regional, es una evidente muestra que los gobiernos de la región han entendido que el mundo ha cambiado, y con ello, su sistema internacional, donde se tiene que buscar ser un Actor Global, más que un Observador Global.

La multipolaridad ha generado una nueva dinámica, que ha hecho que pequeños países busquen tener una participación en la toma de decisiones políticas y económicas a nivel 
internacional, a través de su membresía de dichos organismos de integración, para tener una voz y presencia significativa dentro de este nuevo escenario global.

En la década de los ochenta, cuando el escritor colombiano, Gabriel García Márquez, recibió el Premio Nobel de Literatura habló sobre "la soledad de América Latina"492, en clara alusión a los problemas políticos y conflictos sociales en que vivía la región. Esa misma década fue llamada, por analistas políticos y económicos, como la "década perdida de América Latina”.

Desde entonces, muchos cambios se han producido, el mundo ha cambiado y América Latina también lo ha hecho. Hoy en día, se habla en cambio de la "década de América Latina"493 e inclusive del "siglo de América Latina"494, curiosamente, ambas afirmaciones también provienen de dos colombianos, es decir de los países andinos, esta vez del ámbito económico internacional y político, Luis Alberto Moreno, presidente del Banco Interamericano de Desarrollo (BID) y de Juan Manuel Santos, presidente de Colombia, éste último recoge la idea del líder chino Deng Xiaoping, quién dijo que "el siglo XXI va ser la era de América Latina"495.

Por tanto la percepción positiva del futuro de la región, no es sólo desde la visión intrarregional, lo es también fuera de ella, es decir extrarregional. Pero China no es la única que considera importante establecer relaciones con América Latina y Caribe, la India también ha visto el potencial de la región, la Unión Europea lleva décadas madurando dicha relaciones, y por ello considera que sus relaciones con ALC son estratégicas.

Tales pensamientos demuestran el cambio de percepción sobre el presente y el futuro de América Latina y el Caribe en comparación a décadas anteriores. Sin embargo la falta de peso político a escala internacional debilita la posición de ALC en los foros internacionales.

\footnotetext{
492 MARQUÉZ, G.: La soledad de América Latina. Discurso de aceptación del Premio Nobel de Literatura 1982.Centro Virtual Cervantes, Instituto Cervantes. http://cvc.cervantes.es/actcult/garcia_marquez/audios/gm_nobel.htm [Última revisión: 10-08-2013]

${ }^{493}$ MORENO, L.: La década de América Latina y el Caribe, una oportunidad real. Banco Interamericano de Desarrollo, Washington, mayo de 2011.

${ }^{494}$ SANTOS, J. M.: Palabras del Presidente de la República de Colombia, Juan Manuel Santos. Al instalar la VII Cumbre de la Alianza del Pacífico. Presidencia de la República de Colombia, Cali, 23 de mayo de 2013.

http://wsp.presidencia.gov.co/Prensa/2013/Mayo/Paginas/20130523_02-pacifico.aspx [Última revisión: 11-08-2013]

495 Ibíd.
} 
La estructura de la economía mundial ha experimentado grandes cambios, y más aún con la reciente crisis financiera internacional desatada en 2008. Alicia Bárcenas en sus constantes discursos afirman que mientras Estados Unidos, Japón y la Unión Europea han perdido peso relativo en la economía mundial, las economías emergentes se han visto beneficiadas en relación a un incremento de su peso.

Para el 2016 las economías de los países emergentes representarán el $53 \%$ del PIB mundial. Para el 2020 la suma de la actividad económica entre las regiones de AsiaPacífico y América Latina significará el 60 \% y las exportaciones Sur-Sur superarán a las exportaciones Norte-Norte. El 50 \% de los flujos de la Inversión Extranjera Directa estarán en los países en vías de desarrollo. En casi una década, entre el 2000 y 2011 , Asia aumentó su relevancia en el PIB mundial de 7 al $16 \%$, con China como principal protagonista. Entre el mismo período, América Latina y el Caribe incrementaban su participación del PIB mundial del 6,4\% al 8,1\%. Es destacable señalar que 1998 la economía china era equivalente a la mitad de la de América Latina y el Caribe, en 2008 la economía china ya era similar a la de la región, y para 2011 la superaba en un $30 \%$.

Anteriormente, en cada crisis internacional que se daba, América Latina era parte del problema, ahora ALC es parte de la solución. Y mientras varias regiones en el mundo se encuentran con recesión y estancamiento económico, ALC crece.

ALC tiene la oportunidad de aprovechar esta coyuntura económica positiva y hacer de esta una coyuntura política favorable, no sólo para consolidarse económicamente, sino políticamente. Al fin y al cabo, la crisis económica-financiera internacional, es el resultado de una crisis política. ALC no debe dormirse en los laureles, pensando que dicha bonanza será siempre eterna, pues como bien relata la historia económica de los países, la economía es cíclica, y por tanto el auge de los precios de las materias primas, que hoy gozan de precios altos y de una gran demanda y que es fruto del crecimiento económico de muchas de las economías de la región, no será algo ni eterno, ni sostenible en el tiempo. De hecho durante el 2015 la tendencia de los precios de las materias primas está siendo a la baja, lo que afectará los ingresos de varios países de ALC.

La necesidad de diseñar e implementar una estrategia y una política industrial y de comercio internacional, que incluyan exportaciones con valor agregado, es sin duda, un 
discurso bien conocido y recurrente por los países de ALC, pero que sin embargo, no se termina de aplicar. Pues no es lo mismo, crecimiento que desarrollo, y la región debe de implementar políticas de desarrollo, de lo contrario, las buenas cifras macroeconómicas jamás llegarán al plano microeconómico, que es la población.

Nuevamente, es la Secretaría Ejecutiva de la CEPAL, Alicia Bárcena, quién sostiene que dicho crecimiento se debe a que los países de la región han aprendido a ser "prudentes en lo macroeconómico y progresistas en lo social"496. Las políticas adoptadas por los países de ALC han sido acertadas y se han traducido en una disminución de la pobreza y en un incremento en los ingresos de la población. Desde 1999 la pobreza acumulada se ha reducido 13,4 puntos porcentuales y la indigencia 5,8 puntos. Sin embargo, quedan desafíos por superar, pues aún existe un 30,4 \% de la población pobre en la región que representan a 174 millones de personas. América Latina y el Caribe sigue siendo la región más desigual del mundo. Para eso es necesario que haya más inversión. ALC destina el $20 \%$ de su PIB en inversión, mientras que Asia canaliza el $40 \%$ de su PIB. ALC necesita un mercado interior fuerte y para eso necesita implementar políticas que profundicen sus procesos de integración regional con el fin de contar con un mercado común sólido.

Si tomamos como referencia otras regiones y otros procesos de integración regional, podemos comparar el peso que ocupa el comercio intrarregional en cada región, así por ejemplo, mientras que para Europa representa el 54 \% y en la región Asia-Pacífico un $48 \%$, en América Latina y el Caribe apenas alcanza un $19 \%$. El peso y el poder político de un país o una región se miden en el peso de mercado ${ }^{497}$.

En las últimas décadas se ha dado una proliferación de acuerdos regionales ${ }^{498}$ ha cambiado el mapa económico del mundo. Hardacre habla del cambio de la geopolítica a

\footnotetext{
${ }^{496}$ BÁRCENAS, A.: Palabras de Alicia Bárcenas, Secretaria Ejecutiva de la Comisión Económica para América Latina y el Caribe, en ocasión de la VI Cumbre de las Américas de Jefes de Estado y de Gobierno, Cartagena de Indias, 14 de abril de 2012. Comunicados de prensa de la Comisión Económica para América Latina y Caribe.

http://www.eclac.cl/prensa/noticias/discursossecretaria/5/46375/DiscursoABICartagenaFinal_14-rev3.pdf [Última revisión: 11-08-2013]

${ }^{497}$ STRANGE, S.: The Retreat of the State. The Diffusion of Power in the World Economy. Cambridge University Press, New York, 1996.

${ }^{498}$ ORGANIZACIÓN MUNDIAL DEL COMERCIO: Informe sobre el Comercio Mundial 2011. La OMC y los acuerdos comerciales preferenciales: de la coexistencia a la coherencia. Organización Mundial del Comercio, Geneva, 2011. Ver también: WORLD BANK: Global Economic Prospects 2005: Trade, Regionalism and Development. Chapter 2. Regional Trade and Preferential Trading Agreements: A Global Perspective and Chapter 3. Regional Trade Agreements: Effects on Trade. Washington DC,
} 
la geoeconomía ${ }^{499}$. Hecho que evidencia el interés estratégico por poseer un gran mercado en pos de un gran territorio.

$\mathrm{Si}$ antes las guerras eran por conquistar nuevos territorios, hoy la guerra es por conquistar nuevos mercados. De ahí la importancia de la visión de la integración regional y de desarrollar una acción exterior a nivel regional. Pues no es lo mismo, iniciar y desarrollar un proceso de integración regional con el objetivo de aspirar a una mayor inserción en la economía internacional (caso de América Latina y el Caribe) y otra cosa es aspirar liderar la economía internacional (caso de la Unión Europea), y para ello es necesario contar y ejercer un peso político en los foros internacionales con una sola voz, la diferencia radica entre aspirar ser un participante en la escena global y otra el ser un actor global.

En términos de relaciones internacionales, antes se hablaba de un mundo bipolar, ahora se dice que existe un mundo multipolar, habría que considerar el peso de los nuevos actores, las regiones, y entonces podemos decir que el poder político y el sistema de gobernanza actual conforma un nuevo orden mundial. Orden que es compartido entre las fuerzas multipolares (los estados tradicionalmente potencias y los estados emergentes) y las fuerzas multiregionales (las uniones regionales). Tomando en consideración, para ello, sólo las regiones que hayan desarrollado una acción exterior con una política exterior común.

La cesión de soberanía y la creación de un sistema de competencias, entre ellas la política exterior, en pos del fortalecimiento de los nuevos organismos de integración regional, constituyen la evidencia en que la gobernanza mundial ya no es solamente ejercida por los estados, y lo que décadas atrás fue considerado como un nuevo fenómeno en las relaciones internacionales, el sistema internacional regional ${ }^{500}$, hoy ha creado una nueva forma de gobernar, la gobernanza multinivel ${ }^{501}$.

2005, pp. 27-74. WORLD BANK: Trade Blocs. A World Bank Policy Research Report N 20809. World Bank and Oxford University Press, New York, 2000.

${ }^{499}$ HARDACRE, A.: The rise and fall of interregionalismo in EU external relations. International Relations Studies Series. Series Editor Patrick James, University of Southern California, Vol 9. Republic of Letters Publishing BV, Dordrecht, Danvers, 2010, p.1.

${ }^{500}$ HETTNE, B., SÖDERBAUM, F. and STÅLGREN, P.: The EU as Global Actor in the South. Swedish Institute for European Policy Studies, Report $N^{\circ}$ 8, Stockholm, June/2008, p. 21.

${ }^{501}$ McCORMICK, J.: Understanding the European Union: A concise introduction. Palgrave MacMillan, New York, 2011, pp.2 - 4. 
Las uniones regionales toman cada día más presencia en la toma de decisiones políticas, económicas y de desarrollo de los países, convirtiéndose en los nuevos actores globales. Como dijera Javier Solana, el sistema de Westfalia tiene sus límites ${ }^{502}$.

Una muestra del cambio en la hegemonía ejercida por parte de los estados en las relaciones internacionales son los distintos modelos de política exterior ejercida entre los Estados Unidos (un estado-nación) y la Unión Europea (una unión regional formada por estados nacionales), por otro lado, el primero promueve dentro de su política exterior el bilateralismo, mientras que el segundo fomenta el regionalismo, el interregionalismo y el multilateralismo por igual. Ambos casos representan el cambio de modelo dentro de las relaciones internacionales, el modelo neo-Westfalia (Estados Unidos) y el modelo post-Westfalia (Unión Europea) ${ }^{503}$.

La transformación estructural del sistema internacional ${ }^{504}$ y por consiguiente en la gobernanza global, ha creado un nuevo orden mundial, basado en un sistema internacional regional ${ }^{505}$ o como Hettne llama "un mundo de regiones"506.

\footnotetext{
${ }^{502}$ SOLANA, J.: "Securing Peace in Europe". Symposium on the Political Relevance of the 1648. Peace of Westphalia. Münster, 12.11.1998.

http://www.nato.int/docu/speech/1998/s981112a.htm [Última consulta: 02-04-2013]

${ }^{503}$ HETTNE, B.: "Interregionalism and World Order: The Diverging EU and US Models", en TELÓ, M.: European Union and New Regionalism. Regional Actors and Global Governance in a Post-Hegemonic Era, Ashgate Publishing Company, Burlington, 2007, p.107.

${ }^{504}$ HETTNE B.: In Search of World Order, in HETTNE, V, and BERTIL O.: Global Governance in the 21 st Century: Alternative Perspectives on World Order. Norstedts Tryckeri AB, Stockholm, 2002, p. 6.

${ }^{505}$ HETTNE B., SÖDERBAUM F, and STÅLGREN P.: The EU as Global Actor in the South. Swedish Institute for European Policy Studies, Report $\mathrm{N}^{\circ}$ 8, Stockholm, June/2008, p. 21.

506 HETTNE, B.: Regionalism and World Order, in FARREL M, HETTNE B, and VAN
} LANGENHOVE, L.: Global Politics of Regionalism, Pluto Press, London, 2005, p. 277. 


\section{- CAPÍTULO VII}

\section{EL SERVICIO EUROPEO DE ACCIÓN EXTERIOR Y LAS RELACIONES UNIÓN EUROPEA-AMÉRICA LATINA Y EL \\ CARIBE}




\subsection{EL SERVICIO EUROPEO DE ACCIÓN EXTERIOR}

Este apartado busca responder a la pregunta ¿Qué cambios ha representado en las relaciones entre la UE y ALC la creación del Servicio Europeo de Acción Exterior?

Tomando en consideración como marco teórico, dos teorías: el poder normativo y el interregionalismo. La primera teoría consiste en el poder normativo desarrollado por la Unión Europea, para lo cual usaremos las teorías desarrolladas por Ian Manners ${ }^{507}$, Richard G. Whitman ${ }^{508}$, Mai`a Davis Cross y Jan Melissen ${ }^{509}$.

La segunda teoría se enfoca en analizar como la Unión Europea se inter-relaciona con otras regiones del mundo, concretamente con América Latina y el Caribe, y lo hará aplicando el interregionalismo, el cual es un mecanismo de acción exterior que le permite desarrollar alianzas y asociaciones estratégicas con terceros.

Dentro de este contexto internacional, la diplomacia ya no es un privilegio y monopolio de los Estados soberanos y la prueba de ello es el proceso de integración europea ${ }^{510}$, que mediante la reforma de sus tratados ha creado el Servicio Europeo de Acción Exterior (SEAE). El Tratado de Lisboa (TdL) introduce grandes novedades al proceso de la integración regional europea, en materia de las relaciones exteriores de la Unión Europea (UE).

La puesta en marcha del SEAE busca brindar coherencia y eficiencia en las relaciones de la Unión, algo que hasta la fecha no había hecho con mucho éxito y eficacia. Según David O’Sullivan, Director de Operaciones del SEAE, la necesidad para tener una política exterior a nivel de la UE demuestra una carrera entre la irrelevancia e integración $^{511}$. El SEAE representa un nuevo paso en el proceso de integración europea,

\footnotetext{
507 MANNERS, I., LYNGGAARD, K., LÖFGREN K.: The European Union in Global Politics: Normative power and longitudinal interpretation, Basingstoke, Palgrave Macmillan, 2014.

508 WHITMAN, R.G.: Normative Power Europe: Empirical and Theoretical Perspective, Basingstoke, Palgrave Macmillan, 2011.

509 DAVIS CROSS, M.: The European Diplomatic Corps: Diplomats and International Cooperation from Westphalia to Maastricht, Basingstoke, Palgrave Macmillan, 2007. DAVIS CROSS, M and MELISSEN, J.: European Public Diplomacy: Soft Powers at work, Basingstoke, Palgrave Macmillan, 2013.

${ }^{510}$ PLANTEY, A.: Principes de Diplomatie. Editions A. Pedone. 2000.

https://ghum.kuleuven.be/ggs/publications/working_papers/new_series/wp61-70/wp62.pdf_[Última revisión: 11-08-2013]

511 O'SULLIVAN, D.: The Global Positioning of the EU: Where Next?, speech, Bruges, College of Europe, 18.3.2014, in SCHMIDT, J.: Between Irrelevance and Integration? New Challenges to Diplomacy in the $21^{\text {st }}$ Century and the Role of the EEAS, Department of EU International Relations and Diplomacy Studies, College of Europe, EU Diplomacy Paper 08/2014, p. 4.
} 
y mediante el cual convierte a la UE en un "Actor Diplomático Sui Generis" "512 que interactuará a nivel internacional ${ }^{513}$. El TdL también considera la creación de la figura del Alto Representante de la Unión para los Asuntos Exteriores y la Política de Seguridad (AR), que conjuntamente con el SEAE buscan ser la voz común de la UE.

El 23 de octubre de 2009 el Consejo de la UE emitía un reporte al Consejo Europeo sobre el Servicio Europeo de Acción Exterior ${ }^{514}$, en el mencionaba que de acuerdo al Artículo 27.3 del Tratado de la Unión Europea (Tratado de Lisboa):

En el ejercicio de su mandato, el Alto Representante se apoyará en un servicio europeo de acción exterior. Este servicio trabajará en colaboración con los servicios diplomáticos de los Estados miembros y estará compuesto por funcionarios de los servicios competentes de la Secretaría del Consejo y de la Comisión y por personal en comisión de servicios de los servicios diplomáticos nacionales ${ }^{515}$.

Mediante la Decisión del Consejo Europeo de 1 de diciembre de 2009 se nombra a la Baronesa Catherine Margaret Asthon of Upholland, Alta Representante de la Unión para Asuntos Exteriores y Política de Seguridad para el período comprendido entre el 1 de diciembre de 2009 y el 1 de diciembre de 2014, fecha que coincide con el final del mandato del conjunto de la Comisión Barroso ${ }^{516}$. Una vez nombrada la AR, Catherine Ashton se encargó en elaborar su propuesta de establecimiento y organización del SEAE, que fue presentada el 25 de marzo de 2010 ante el Consejo, siguiendo el procedimiento marcado.

Todos estos pasos fueron materializando poco a poco la idea de una diplomacia sui generis para una institución sui generis ${ }^{517}$. El SEAE se convierte así en la base de una

512 WOUTERS, J., and DUQUET, S.: The EU, EEAS and Union Delegations and International Diplomatic Law: New Horizons. Working Paper N 62 Leuven Centre for Global Governance Studies, Katholieke Universiteit Leuven, May 2011.

${ }^{513}$ LEGUEY-FEILLEUX, J.-R.: The dynamics of diplomacy. Boulder: Lynne Rienner Publishers. 2009.

514 COUNCIL OF THE EUROPEAN UNION: Presidency report to the European Council on the European External Action Service. Note from Presidency to Council/European Council, Brussels, 23.10. 2009.

515 Art. 27.3. Tratado de la Unión Europea.

516 Decisión del Consejo Europeo adoptada con el acuerdo del Presidente de la Comisión de 1 de diciembre de 2009 por la que se nombra a la Alta Representante de la Unión para Asuntos Exteriores y Política de Seguridad (2009/880/UE). Diario Oficial de la Unión Europea L315/49. 2.12.2009.

517 LEFEBVRE, M., and HILLION, C.: The European External Action Service: towards a common diplomacy? Swedish Institute for European Policy Studies. June 2010. 
diplomacia común europea, cuya novedad es unir en una sola visión y acción, los esfuerzos y trabajos que hasta ahora realizaban los servicios de acción exterior de los Estados Miembros de la Unión, por un lado; y los servicios exteriores de las instituciones comunitarias, por otro, la acción coordinada en materia de acción exterior es en favor del conjunto de todos los países que forman parte de la Unión.

El establecimiento del SEAE también tuvo detractores, quienes consideraban que la UE ha actuado por encima de las competencias que le fueron conferidas, y que sólo busca ampliar su poder en detrimento de la soberanía nacional de los Estados. Entre las críticas y observaciones al desarrollo de una diplomacia común europea, están que la Unión no ha logrado hablar al mundo con una sola voz, ni asumir su papel político sólido en la escena internacional ${ }^{518}$; y que la diplomacia de la UE es una diplomacia sin un estado 519 .

Teniendo en cuenta todas estas críticas, el TdL buscaba conciliar las posturas entre los que deseaban el modelo comunitario y los que preferían un modelo intergubernamental, a través de la puesta en marcha de un modelo de federalismo intergubernamental ${ }^{520}$, el cual pretende regular con eficacia todas las áreas de acción de la Unión. El Tratado de Funcionamiento de la Unión (TFUE), regula el funcionamiento de esa Unión en sus diversos aspectos ${ }^{521}$. Las funciones asignadas al AR y al SEAE permiten "asegurar la consistencia y mejor coordinación de la acción exterior de la Unión",522.

Con estas regulaciones jurídicas la Unión trató de resolver la falta de visibilidad en la arena internacional, así como hacer valer su rol como un actor global, el cual se ha incrementado en las últimas décadas ${ }^{523}$. Dicha aspiración ya había quedado reflejada en el Consejo Europeo de diciembre de 2001, cuando se emitió la "Declaración sobre el futuro de la Unión Europea”: "el papel que debe desempeñar es el de una potencia que

518 ESTEBAN, M.: Los inicios del Servicio Europeo de Acción Exterior. Documento de Trabajo. Documento de Trabajo Serie Unión Europea N 52 Instituto Universitario de Estudios Europeos. 2011.

519 JÖNSSON, C., and HALL, M.: Essence of Diplomacy. Palgrave Macmillan, New York, 2005.

${ }^{520}$ ALDECOA, F.: La diplomacia europea como diplomacia común. In La diplomacia común europea: el servicio europeo de acción exterior. Marcial Pons, Madrid, 2011.

${ }^{521}$ MARTÍN Y PÉREZ DE NANCLARES, J., and URREA CORRES, M.: Estudio Preliminar al Tratado de Lisboa. Real Instituto Elcano, Madrid, 2008.

522 COUNCIL OF THE EUROPEAN UNION: Presidency report to the European Council on the European External Action Service. Note from Presidency to Council/European Council, Brussels, 23 October 2009.

${ }_{522}$ Art. 27.3.Tratado de la Unión Europea.

${ }^{523}$ EUROPEAN PARLIAMENT: Resolution of 22.10.2009 on the institutional aspects of setting up the European External Action Service (2009/2133(INI)). 
lucha decididamente contra cualquier violencia, terror y fanatismo, pero que tampoco cierra los ojos ante las injusticias flagrantes que existen en el mundo. En resumen, una potencia que quiere hacer evolucionar las relaciones en el mundo de manera que no sólo beneficien a los países ricos sino también a los más pobres. Una potencia que quiere enmarcar éticamente la mundialización, es decir, ligarla a la solidaridad y al desarrollo" ${ }^{\natural 24}$. Es decir, el principio normativo de la solidaridad en la política de desarrollo de la Unión ${ }^{525}$.

Son estos principios normativos que la UE busca extender a través de sus relaciones con terceros, sean con regiones, subregiones y a nivel bilateral con la idea de crear un mundo mejor. Y es bajo estos principios normativos en que desarrolla sus relaciones con América Latina y el Caribe.

\section{**La estructura del SEAE: La administración central y las delegaciones de la Unión}

El 26 de julio de 2010 el Consejo de la Unión Europea emite una decisión que establece la organización y funcionamiento del SEAE, después de haber sido sometida a la opinión del Parlamento Europeo y obtenido el consenso de la Comisión Europea, la estructura del SEAE estaría formada por una administración central y por las Delegaciones de la Unión ante terceros países y organismos internacionales ${ }^{526}$. Siendo su máxima autoridad la AR, la cual es asistida por una Secretaría General, dos Vice Secretarios Generales, y Direcciones Generales.

Las direcciones generales cubren áreas geográficas que incluyen a todos los países y regiones del mundo, así como áreas temáticas y de multilaterales ${ }^{527}$. Según estas consideraciones el SEAE cuenta con siete direcciones generales, que a su vez se dividen en dos partes, cinco direcciones generales con carácter geográfico y dos direcciones de carácter temático:

\footnotetext{
524 CONSEJO EUROPEO: "Declaración sobre el futuro de la Unión Europea", Conclusiones de la Presidencia, Laeken, 11 y 12 de diciembre de 2001.

${ }^{525}$ MANNERS, I.: EU Foreign Policy in a Globalized World. Normative power and social preferences. In Z. LAÏDI (Ed.), EU Foreign Policy in a Globalized World: Normative Power and Social Preferences. Routledge, London, 2008.

526 COUNCIL OF THE EUROPEAN UNION: Council Decision of 26.7.2010 establishing the organization and functioning of the European External Actions Service (2010/427/EU). Official Journal of the European Union L 201/30. 3.8.2010.

527 COUNCIL OF THE EUROPEAN UNION 8029/10: Proposal from the High Representative for Foreign Affairs and Security Policy Council. Draft Council decision establishing the organization and functioning of the European External Action Service, Brussels, 25.3.2010, p.4.
} 
1. Dirección General Asia y el Pacífico

2. Dirección General África

3. Dirección General Europa y Asia Central

4. Dirección General África del Norte, Medio Oriente, Península Arábica, Irán e Iraq

5. Dirección General de las Américas

6. Dirección General Asuntos Globales y Multilaterales

7. Dirección General Gestión de crisis y coordinación operacional

En el caso de las direcciones generales geográficas se subdividen en subregiones o grupos de países. Y en el caso de la dirección de Asuntos Globales y Multilaterales se divide en dos grandes temas:

- Derechos Humanos y Democracia

- Relaciones Multilaterales y Asuntos Globales

Entre las principales funciones que tiene asignadas el SEAE está el ser el coordinador con las otras instancias comunitarias que tengan temas relacionados con las relaciones exteriores $^{528}$, como las instancias que se encargan de asistencia externa. Por ello, el SEAE se encarga de la elaboración de los documentos de programación multianual regionales, subregional y por país ${ }^{529}$. Dichos documentos contemplan las líneas maestras de actuación de la Unión en la región.

El SEAE también incluye dentro de su organización las Delegaciones de la Unión, las cuales sirven de plataforma para la proyección internacional de los intereses comunes europeos $^{530}$. Las respectivas delegaciones tienen un Jefe de Delegación, quién recibe instrucciones directas del AR y de la administración central del SEAE, por tanto, es el responsable de ejecutar dichas instrucciones y mandatos.

Las antiguas Delegaciones de la Comisión Europea, con la puesta en marcha del SEAE pasan a ser llamadas Delegaciones de la Unión, el cambio es más que sustancial, dado que las primeras representaban a la Comisión, es decir a una parte de la Unión. De

\footnotetext{
${ }^{528}$ HADFIELD, A., \& FIOTT, D.: Europe and the rest of the World. Journal of Common Market Studies, 51, 168-182. 2013

${ }^{529}$ Art. 9. Council Decision of 26.7.2010 establishing the organization and functioning of the European External Actions Service (2010/427/EU). Official Journal of the European Union L 201/30. 3.8.2010. ${ }^{530}$ Ibíd.
} 
hecho la parte comunitaria de la UE, ahora al tener el título de Delegaciones de la Unión, representa a toda la Unión, tanto a la parte comunitaria como la intergubernamental.

Las antiguas delegaciones al ser representaciones de la Comisión Europea, pertenecían a la estructura de la Comisión; y sus funciones estaban dirigidas a:

- Presentar, explicar e implementar la política de la Unión Europea

- Analizar y reportar sobre las políticas y desarrollo de los países ante los cuales estaban acreditados

- Conducir negociaciones de acuerdo al mandato asignado ${ }^{531}$

A todas las funciones anteriores se suman, las nuevas funciones que reciben las Delegaciones de la Unión:

- Responder a las necesidades de otras instituciones de la Unión, en particular al Parlamento Europeo, en sus contactos con organizaciones internacionales o terceros países ante los cuales las delegaciones son acreditadas

- Representar a la Unión, el Jefe de la Delegación tiene el poder de representar a la Unión en el país donde la Delegación esté acreditada

- Trabajar en cercana colaboración e intercambiar información con los servicios diplomáticos de los Estados Miembros

- Apoyar a cualquier Estado Miembro en sus relaciones diplomáticas y en su rol de proveer protección consular a los ciudadanos de la Unión en terceros países sobre una base de recurso-neutral ${ }^{532}$.

Esta ampliación de funciones de las delegaciones de la UE ha brindado un mayor reforzamiento político para las mimas, permitiendo que la UE gane más visibilidad e impacto en terceros países y en organizaciones internacionales ${ }^{533}$. Se considera que la Unión debe de velar por mantener una coherencia entre los distintos ámbitos de su

${ }^{531}$ EUROPEAN COMMISION: Taking Europe to the world. 50 years of the European Commission's External Service. Office for Official Publications of the European Communities, Luxembourg, 2004, p. 6. ${ }_{532}$ Art. 5. Council Decision of 26.7.2010 establishing the organization and functioning of the European External Actions Service (2010/427/EU). Official Journal of the European Union L 201/30. 3.8.2010.

${ }^{533}$ SANTOS, J.: EU representation to international organizations: A challenging task for the EEAS. In GONZÁLEZ, L. (Ed.): Between autonomy and cooperation: shaping the institutional profile of the European External Action Service. Cleer Working Paper 2014/6. The Hague: Centre for the Law of EU External Relations. ASSER Institute Centre for International \& European Law. 2014. 
acción exterior y sus demás políticas ${ }^{534}$, para lo cual la coordinación entre las distintas partes de la UE es importante.

El SEAE ha estimulado y promovido una mayor cooperación entre las diferentes instancias de la Unión, como el Consejo, la Comisión y el $\mathrm{AR}^{535}$. El personal del SEAE responde a un proceso de negociación entre el Consejo de la Unión, la Comisión Europea y el Parlamento. Entre los acuerdos alcanzados: deberá de existir un equilibrio geográfico y de género, a la par que mantener un equilibrio de porcentajes entre las “instituciones fuentes de personal”: el Consejo, la Comisión Europea y los Estados Miembros.

De los dos primeros, concretamente de las secretarías generales, que son las que tenían unidades relacionadas a las relaciones exteriores, y en el caso de los Estados Miembros, de los servicios diplomáticos. La incorporación de personal proveniente del Consejo fue sin duda el mejor argumento para poder contar con el apoyo de los Estados Miembros, sobre todo, de aquellos Estados Miembros que consideraban que la UE tenía demasiadas competencias cedidas, y que quizás era hora de descomunitarizar la Unión. Lejos de ese objetivo, el acuerdo alcanzado permitió una extensión lógica de la acquis communautaire en la esfera de las relaciones exteriores de la Unión ${ }^{536}$.

\subsection{LA DIRECCIÓN DE LAS AMÉRICAS}

La Dirección General de las Américas fue asignada a Christian Leffler (Suecia) como director general; es asistido por un director, Roland Shäfer, y un Jefe de División, Manfredo Fanti. Esta dirección se divide en cinco divisiones:

1. Estados Unidos y Canadá

2. México y América Central

3. América del Sur, que a su vez se subdivide en la subdivisión para los Países Andinos (que también se ocupa de las relaciones con Chile) y MERCOSUR

4. El Caribe

5. Asuntos Regionales

\footnotetext{
${ }_{534}^{53}$ Art. 23.3. Tratado de la Unión Europea.

535 Art. 3. Council Decision of 26.7.2010 establishing the organization and functioning of the European External Actions Service (2010/427/EU). Official Journal of the European Union L 201/30. 3.8.2010.

${ }^{536}$ EUROPEAN PARLIAMENT Resolution of 22.10.2009 on the institutional aspects of setting up the European External Action Service (2009/2133(INI)).
} 
A estas divisiones se agregan dos departamentos que antes pertenecían a la Secretaría del Consejo: COTRA, que se encarga de las relaciones transatlánticas y coordinaba con la división de Estados Unidos y Canadá), a cargo de Alenka Zajc Freudenstein (Eslovenia); y AMLAT/COLAT (AMLAT se ocupaba de asuntos económicos, comerciales y de cooperación; COLAT en cambio se encargaba de temas políticos en América Latina), el cual está dirigido por Francisco Acosta Soto.

Para entender las relaciones entre UE y ALC, es necesario entender que aunque las relaciones tengan un contenido político y económico, el núcleo y nexo de las mismas es la cooperación al desarrollo, razón por la cual, la base legal sobre la cual se desarrolla todas las acciones hacia ALC, es mediante el Instrumento de Financiación de la Cooperación al Desarrollo (ICD).

Este instrumento financia la cooperación geográfica con los países en desarrollo, existiendo una lista que detalla los países que pueden ser beneficiarios. Toma en cuenta la política de cooperación de la Unión, la cual es guiada por los Objetivos de Desarrollo del Milenio.

EL ICD tiene una programación multianual y de acuerdo a él se diseñan los documentos de programación regional, subregional y país. Dentro del período de la Era Ashton, el ICD vigente era el programado para el período 2007-2013, este fue elaborado en su totalidad por la Comisión Europea; en cambio el Programa Regional Indicativo Multianual para América Latina 2014-2020 fue elaborado por el SEAE en colaboración con la Dirección General para la Cooperación y el Desarrollo de la Comisión Europea, por ser la institución comunitaria que se encarga del ICD.

Las unidades que concretamente se centran en el trabajo con los países de América Latina y el Caribe, dentro de la Dirección de las Américas son las siguientes subdivisiones:

\section{Subdivisión México y América Central}

2. Subdivisión América del Sur

3. Subdivisión Caribe

Para el período 2007-2013 la Comisión elaboró los programas multianuales para el conjunto de los países de América Latina y el Caribe: 
- Documento de Programación Regional 2007-2013

- Documento de Estrategia Regional-América Central 2007-2013

- Documento Estratégico Regional-MERCOSUR 2007-2013

- Documento Estratégico Regional-Comunidad Andina 2007-2013

- Documento Estratégico Regional-Región Caribe 2007-2013

Con la puesta en marcha del SEAE serán las Delegaciones de la Unión las encargadas de vigilar y controlar la ejecución de los mismos, antes los hacían las Delegaciones de la Comisión Europea, las cuales coordinaban exclusivamente con la misma, ahora las Delegaciones de la Unión dependen exclusivamente del SEAE y coordina con las otras instancias comunitarias.

Hay temas que aunque tienen una repercusión externa, siguen siendo competencias de la Comisión, como es el caso de la cooperación y el desarrollo, conjuntamente con cambio climático, comercio y ayuda humanitaria. Ahora bien, es cierto que la Comisión mantiene dichas competencias, pero también lo es que el SEAE las coordina. Si revisamos la composición de las Delegaciones de la Unión comprobamos que éstas se encuentran dividas en cuatro secciones:

1. Sección Política, Prensa e Información

2. Sección Económica y Comercio

3. Sección Cooperación

4. Sección Administración

Esta estructura interna habilita los canales de coordinación entre los servicios centrales del SEAE y las instituciones comunitarias, como las direcciones generales que tienen funciones de ámbito exterior.

\subsection{LA PROGRAMACIÓN REGIONAL PARA AMÉRICA LATINA 2007-2013}

El Documento de Programación Regional para América Latina 2007-2013, contempló un presupuesto indicativo de 556 millones de Euros ${ }^{537}$, se enmarcó dentro del ICD y respondió a los compromisos asumidos por la Cumbre de Guadalajara (2004) y la Cumbre de Viena (2006). De la primera se desprende la importancia de proyectar

\footnotetext{
537 EUROPEAN COMMISSION: Latin America Regional Programming Document 2007-2013.
} 12.07.2007 (e/2007/1417) p. 20 
acuerdos entre los países de la UE-ALC, para que éstos sirvan de base para la asociación estratégica birregional ${ }^{538}$, con la finalidad de que dicha asociación le sirva a la Unión para intensificar sus esfuerzos en los diferentes foros y conferencias internacionales como las que se desarrollan dentro del marco de las Naciones Unidas ${ }^{539}$. Ya la Comunicación de la Comisión en 2005 se había pronunciado al respecto, indicando que uno de los aspectos fundamentales de la asociación UE-ALC es la voluntad de concertación en temas de interés común, en particular en el marco de las Naciones Unidas ${ }^{540}$. Esta asociación es conducida y coordinada a distintos niveles: regional, subregional y bilateral.

El programa 2007-2013 fue elaborado, principalmente por dos direcciones generales de la Comisión Europea, la Dirección General RELEX (Relaciones Exteriores) y la Dirección General AIDCO (Oficina de Cooperación EuropeAid). Esta oficina era la responsable de todas las fases de la cooperación, con respecto a los programas y proyectos, la oficina se encarga de la identificación, evaluación, preparación de financiación, aplicación y evaluación final de los programas y proyectos aprobados por las Direcciones Generales de Relaciones Exteriores y Desarrollo de la Comisión Europea. Las razones de por qué estas direcciones son las que intervinieron, fue porque la base jurídica era el ICD, el cual es administrado y ejecutado por la Comisión Europea, y porque ambas tenías unidades que incluían tanto América Latina como el Caribe.

Hoy existe una Dirección General para la cooperación internacional y el desarrollo, la cual agrupa a las antiguas direcciones de desarrollo y la que incluía la Oficina de Cooperación. Anteriormente, la dirección que comprendía desarrollo se ocupaba de los países ACP, por lo tanto se ocupaba de las relaciones con los países del Caribe, y RELEX se encargaba de las otras regiones del mundo (RELEX tenía una Dirección América Latina).

Hoy RELEX no existe, ha pasado a ser parte del SEAE, pero la Dirección General para la Cooperación Internacional y el Desarrollo, cuenta con ocho direcciones geográficas,

\footnotetext{
538 Declaración de Guadalajara. $\mathrm{N}^{\circ}$ 51. III Cumbre América Latina y el Caribe-Unión Europea, Guadalajara, 28 y 29 de Mayo de 2004.

${ }^{539}$ Declaración de Viena. $\mathrm{N}^{\circ} 3$. IV Cumbre Unión Europea-América Latina y el Caribe, Viena, 12 de mayo de 2006.

540 COMISIÓN EUROPEA: Una asociación reforzada entre la Unión Europea y América Latina. COM (2005) 636 final. II-1. Combinar las fuerzas de dos actores mundiales, p. 7.
} 
entre las cuales existe la Dirección G América Latina y el Caribe. Nótese que antes el Caribe y América Latina eran vistos como dos regiones separadas. Este hecho queda reflejado también en el presente programa 2007-2013, dado que el Caribe tiene su propia programación regional, por otro lado los fondos para el Caribe tienen otra base jurídica, como son los acuerdos firmados entre la Comunidad Europea y los países ACP, así como los recursos provenientes del Fondo Europeo de Desarrollo (FED).

El documento de la programación regional 2007-2013, define a América Latina como una región compuesta por grupos subregionales, entre los que se encuentran países y subregiones, tales como:

- México

- América Central

- El Caribe

- América del Sur (comprendida en Comunidad Andina y MERCOSUR)

- Chile

El documento incluye al Caribe dentro de América Latina, pero lo deja al margen del programa 2007-2013, dado que el Caribe, como se ha mencionado anteriormente, goza de sus propios instrumentos de cooperación y financiación.

Volviendo al programa 2007-2013, éste establece tres grandes áreas de trabajo a realizar durante el período 2007-2013:

1. Cohesión social

2. Integración regional y cooperación económica

3. Recursos humanos y entendimiento mutuo entre la Unión Europea y América Latina

Para lograr el primer punto se establecieron los programas europeos: URB-AL y EUROsociAL. En el caso de la segunda área de trabajo fueron los programas ALINVEST y @LIS. En la tercera área estaban los programas ALFA y ERASMUS MUNDUS. Siendo los beneficiarios directos: las administraciones públicas, empresas, universidades, organizaciones no gubernamentales, profesores y estudiantes universitarios ${ }^{541}$.

541 EUROPEAN COMMISION: Latin America Regional Programming Document 2007-2013. 12.07.2007 (e/2007/1417) p. 10. 
Las tres áreas de trabajo respondían a los objetivos de la Unión Europea recogidos en los Tratados de las Comunidades Europeas, en su artículo 177, el cual prevé que "la política de la Comunidad en este ámbito contribuirá al objetivo general de desarrollo y consolidación de la democracia y del Estado de derecho, así como al objetivo de respeto de los derechos humanos y de las libertades fundamentales" ${ }^{\text {542 }}$. Cumpliendo a la vez con lo establecido en el Consenso Europeo sobre Desarrollo (2006): "El objetivo primordial y horizontal de la cooperación para el desarrollo de la UE es la erradicación de la pobreza en el contexto del desarrollo sostenible, incluido el empeño en la realización de los Objetivos de Desarrollo del Milenio" ${ }^{\$ 43}$.

El documento introduce tres tipos de conceptos sobre las cuales define sus relaciones con los países de ALC: asociación, red de acuerdos, tipos de relaciones (regional, subregional y bilateral). La “Asociación" regional, no es posible sino existe una "red de acuerdos", y para que ésta red se produzca se tiene que estructurar en varios niveles: regional, subregional y bilateral. El poder normativo de la Unión, se desarrolla mediante la introducción de conceptos. También podemos mencionar otros conceptos: “cooperación regional horizontal ${ }^{544 \text { ", "socios estratégicos }}{ }^{545 "}$ y “actores globales ${ }^{546 "}$ ".

En la actualidad, la Comunidad de Estados Latinoamericanos y Caribeños (CELAC) es el interlocutor para la UE, por parte de los países de la región de ALC. Con la creación de la CELAC se da por primera un proceso de institucionalización que se espera agrupe a la región, y la proyecte exteriormente como un Comunidad.

A nuestro modo de ver, la CELAC no hubiese sido posible, sin la ayuda de la Unión Europea, y no sólo nos referimos a la cooperación brindada a la institucionalización de los diferentes procesos de integración en la región (SICA, CAN, CARICOM y

\footnotetext{
${ }^{542}$ Art. 177.2. Tratados de las Comunidades Europeas. Título XX Cooperación al desarrollo.

${ }^{543}$ El Consenso Europeo sobre el Desarrollo. Declaración conjunta del Consejo y de los Representantes de los Gobiernos de los Estados miembros reunidos en el seno del Consejo, del Parlamento Europeo y de la Comisión sobre la política de desarrollo de la Unión Europea titulada "El consenso europeo sobre el desarrollo". Diario Oficial de la Unión Europea C 46/1. 24.2.2006.

${ }^{544}$ El Documento de programación para América Latina 2007-2013 dice: "the concept of regional horizontal cooperation and most programmes had already been introduced by the early 1990s before the 2002-2006 regional programming document was draw up". Para mayor información, ver en: EUROPEAN COMMISSION: Regional Programming Document Latin America 2007-2013. (E/2007/1417) 12.07.2007. p. 9.

${ }^{545}$ Así lo refleja y establece el Documento de la COMISIÓN EUROPEA: La Asociación estratégica entre la Unión Europea, América Latina y el Caribe: Un compromiso común. Bruselas, 2008

${ }^{546}$ Este concepto es usado en la Comunicación de la Comisión al Parlamento y al Consejo. "La Unión Europea y América Latina: Una asociación de actores globales". Comisión de las Comunidades Europeas, COM (2009) 495/3, Bruselas, 30.09.2009.
} 
MERCOSUR), sino al diálogo que siempre ha buscado tener la UE con ALC como una sola región, hechos que a nuestro modo de ver, han sido los que ha llevado a los países de ALC trabajar juntos para interactuar con la UE.

La programación para América Latina 2007-2013 contemplaba apartados específicos para dicho fin, el punto 4. Estrategia de respuesta para 2007-2013 en su aparado (b) integración regional define la importancia de promover el diálogo y el desarrollo de capacidades institucional a nivel político, promover la cooperación, el diálogo regional y el intercambio de experiencias y buenas prácticas, o la promoción y profundización de entendimiento entre los países de América Latina y la Comunidad ${ }^{547}$. Estas líneas servirán de base para la implementación de los otros programas a nivel subregional: MERCOSUR, COMUNIDAD ANDINA, CARIBE y AMERICA CENTRAL. Además de la programaciones bilaterales en los casos de México y Chile.

\subsection{EL PROGRAMA MULTIANUAL INDICATIVO REGIONAL PARA AMÉRICA LATINA 2014-2020}

Coincidiendo, en el mismo mes en que Federica Mogherini asume su mandato como AR, el 19 de noviembre de 2014, la UE presentó el programa indicativo plurianual 2014-2020 para América Latina y el Caribe, a los Embajadores del GRULAC (Grupo Latinoamericano y Caribeño) en Bruselas, el programa contaba con una asignación indicativa de 925 millones de Euros. Si se compara con el presupuesto asignado en la programación regional anterior, 2007-2013, cuyo monto fue de 556 millones de Euros, existe que un incremento del presupuesto hacia la región de un $45 \%$. Esta vez, el programa contempla dos componentes:

1. Actividades a nivel continental

2. Programa Subregional para América Central

\subsubsection{Programa Continental}

En el primer componente está diseñado para promover iniciativas regionales abiertas a todos los países de América Latina, estableciendo como países elegibles: Argentina, Bolivia, Brasil, Chile, Colombia, Costa Rica, Cuba, Ecuador, El Salvador, Guatemala,

\footnotetext{
547 EUROPEAN COMMISION: Latin America Regional Programming Document 2007-2013.
} 12.07.2007 (e/2007/1417) p. 17 
Honduras, México, Nicaragua, Panamá, Paraguay, Perú, Uruguay y Venezuela. De los 925 millones de Euros, como presupuesto indicativo, 805 irán destinados para el Componente 1 y 120 millones de Euros estarán destinados para el Componente 2. Pudiendo ser beneficiarios un total de 24 países latinoamericanos.

Lo novedoso de esta programación plurianual es que la UE deja de lado la cooperación que brindaba a los procesos de integración subregional como MERCOSUR, CAN; y sólo se queda con el proceso centroamericano. Opta por una cooperación de líneas temáticas. Interesante notar que el primer componente lo denomina "actividades a nivel continental", y no usa el término regional, quizás la UE trata de introducir un nuevo concepto, el de continental o quizás se deba a una nueva reconfiguración en sus relaciones transatlánticas en la cual contempla incluir a América Latina y el Caribe, no sería nada raro partiendo de la base que su dirección es llamada Las Américas.

En cualquier caso, la UE busca con estas dos líneas de trabajo impulsar una agenda que en ciertos puntos parecía más que estancada, el caso de las negociaciones entre el MERCOSUR-UE con los antecedentes de los resultados del proceso de negociación entre la CAN-UE, en el cual los países andinos terminaron firmando acuerdos bilaterales, en lugar de hacerlos en conjunto, lo que parece demostrar que la realidad suramericana es distinta a la centroamericana, la cual, sí logró firmar un acuerdo de asociación como bloque subregional, en comparación a los otros dos procesos suramericanos. Si miramos los temas que tiene el Componente 1, podemos ver que las líneas de cooperación son horizontales, con el fin de que se incentive la cooperación y el diálogo a nivel continental ${ }^{548}$.

Es probable que el relanzamiento de las negociaciones que quiere efectuar la AR/VP, tiene que ver con la nueva realidad económica de América Latina y el Caribe como región, dado que muchos de sus países han dejado de ser "países de ingreso bajo" para pasar a ser considerados "países de ingreso mediano". Lo que hace que muchos no entren ya en el marco de países receptores de la Ayuda Oficial para el Desarrollo.

${ }^{548}$ EUROPEAN EXTERNAL ACTION SERVICE AND EUROPEAN COMMISSION-DIRECTORATE GENERAL FOR DEVELOPMENT AND COOPERATION-EUROPEAID. Development Cooperation Instrument (DCI) 2014-2020 Multiannual Indicative Regional Programme for Latin America, p.5. http://eeas.europa.eu/la/docs/mip_alr_vf_07_08_14_en.pdf [Última revisión: 22-03-2015] 
Si se tiene en cuenta los pronósticos de crecimiento de los países de la región, se estima que muchos pasarán a ser, en el corto plazo, "países de ingreso alto". Esta nueva situación hace que la ayuda vía cooperación para el desarrollo de la UE hacia región, tiene que cambiar, de cooperación para el desarrollo a la cooperación técnica.

Según el Banco Mundial, existen varias categorías de países, de acuerdo a su tipo de ingresos, y dependiendo de este punto, muchos de los países desarrollados y organismos internacionales establecen una lista de países beneficiarios. De acuerdo a esta clasificación el Banco Mundial estima que los países de la región de ALC se encuentran dentro de la clasificación de "Países de ingreso mediano alto", con ingresos de US.\$ $9.536^{549}$.

\section{Cuadro N. Grupo de Países/Clasificación de Ingresos}

\begin{tabular}{|l|l|}
\hline Grupo de países según & Nivel de Ingresos según INB per cápita 2008 \\
\hline Países de ingreso bajo & US.\$975 o menos \\
\hline Países de ingreso mediano: & \\
- Países de ingreso mediano bajo & US.\$976 a US.\$ 3.855 \\
- Países de ingreso mediano alto & US.\$3.856 a US.\$11.905 \\
\hline Países de ingreso alto & US.\$11.906 a más \\
\hline
\end{tabular}

Elaboración propia.

Datos obtenidos del Banco Mundial

Según la OCDE (Organización para la Cooperación y el Desarrollo), Chile y México, ambos con ingresos per cápita de US.\$ $15.230^{550}$ y US.\$9.940 551 respectivamente, permite que ambos países sean miembros de la organización, con la diferencia que Chile está en el grupo de "países de ingreso ato" y México está en "países de ingresos mediano alto". Brasil es país candidato a convertirse miembro de la $\mathrm{OCDE}^{552}$ con un

\footnotetext{
${ }^{549}$ BANCO MUNDIAL: Indicadores de Desarrollo Mundial. http://datos.bancomundial.org/tema/economia-y-crecimiento\#tp_wdi [Última revisión: 22-03-2015]

${ }^{550}$ BANCO MUNDIAL: Países de Ingreso Alto. Países Miembros de la OCDE. http://datos.bancomundial.org/income-level/OEC [Última revisión: 22-03-2015]

551 BANCO MUNDIAL: México http://datos.bancomundial.org/pais/mexico [Última revisión: 22-03-2015]

552 ORGANIZACIÓN PARA LA COOPERACIÓN Y EL DESARROLLO: Países en adhesión y cooperación reforzada.

http://www.oecd.org/centrodemexico/paisesmiembros.htm [Última revisión: 22-03-2015]
} 
ingreso per cápita de US.\$11.690 553 . A ello se agregarían tres países más: Colombia (US.\$ 7.590 554 ) y Costa Rica (US.\$ 9.550 555 ), que iniciaron las negociaciones de adhesión anunciadas por la OCDE en $2013^{556}$; y Perú (US. $\$ 6.270^{557}$ ), los cuales se espera sean también miembros de la OCDE antes del $2021^{558}$, es decir cuando pasen la meta de los US.\$11.906. ¿Por qué son importantes estas cifras y el hecho que varios países latinoamericanos formen parte de la OCDE? Porque uno de los objetivos de la OCDE es contribuir al desarrollo de los países, y por eso sus miembros pasan a tener agencias de cooperación internacional para ayudar a terceros países.

En los casos de Chile y México, miembros de pleno derecho de la OCDE, cuenta con sus respectivas agencias, la Agencia de Cooperación Internacional de Chile y la Agencia Mexicana de Cooperación Internacional para el Desarrollo, es decir, ambos países latinoamericanos han pasado de ser, países receptores a ser también países emisores de ayuda al desarrollo. Ahí la importancia de la membresía de la OCDE.

La UE en su "Programa Continental" menciona que, dado el fuerte crecimiento económico y la estabilidad macroeconómica que viven los países de América Latina y el Caribe, cree necesario realizar cambios, partiendo de la base de que la cooperación de la UE responde a un valor añadido, como puede es el intercambio de conocimientos y el aprendizaje entre iguales, que contribuyan al fortalecimiento de la integración regional $^{559}$, en la región.

Entre las áreas de cooperación identificadas a desarrollar dentro del Programa Continental están 4 áreas prioritarias:

${ }^{553}$ BANCO MUNDIAL: Brasil

http://datos.bancomundial.org/pais/brasil [Última revisión: 22-03-2015]

${ }^{554}$ BANCO MUNDIAL: Colombia

http://datos.bancomundial.org/pais/colombia [Última revisión: 22-03-2015]

${ }^{555}$ BANCO MUNDIAL: Costa Rica.

http://datos.bancomundial.org/pais/costa-rica [Última revisión: 22-03-2015]

556 ORGANIZACIÓN PARA LA COOPERACIÓN Y EL DESARROLLO: La OCDE amplía su proyección global iniciando conversaciones de adhesión con Colombia y Letonia, seguidos de otros países.

http://www.oecd.org/centrodemexico/la-ocde-amplia-su-proyeccion-global-iniciando-conversaciones-deadhesion-con-colombia-y-letonia-seguidos-de-otros-paises.htm [Última revisión: 22-03-2015]

${ }_{557}^{55}$ BANCO MUNDIAL: Perú http://datos.bancomundial.org/pais/peru [Última revisión: 22-03-2015]

${ }^{558}$ CENTRO DE PLANEAMIENTO ESTRATÉGICO: PERÚ 2021: País OCDE.

http://www.ceplan.gob.pe/sites/default/files/Documentos/peru_2021_-_pais_ocde-

_espanol_impresion_09-02-2015_final.pdf [Última revisión: 22-03-2015]

559 EUROPEAN EXTERNAL ACTION SERVICE AND EUROPEAN COMMISSION-DIRECTORATE GENERAL FOR DEVELOPMENT AND COOPERATION-EUROPEAID. Development Cooperation Instrument (DCI) 2014-2020 Multiannual Indicative Regional Programme for Latin America, pp.4-5. http://eeas.europa.eu/la/docs/mip_alr_vf_07_08_14_en.pdf [Última revisión: 22-03-2015] 
- El nexo entre seguridad y desarrollo

- Buen gobierno, rendición de cuentas y equidad social

- Crecimiento sostenido e inclusivo para el desarrollo humano

- Desarrollo sostenible y cambio climático

- Programa Erasmus +

De los 805 millones de Euros, destacan tres puntos, por la cantidad de recursos invertidos, el primero de ellos es "desarrollo sostenible y cambio climático" con una asignación de 300 millones de Euros, seguido de "crecimiento sostenido e inclusivo para el desarrollo humano" para el cual se destinan unos 215 millones de Euros, y finalmente, en tercer lugar, es para el "programa Erasmus +" con una dotación de 163 millones de Euros. Juntos suman un total de 678 millones de Euros, más de la mitad del presupuesto, casi dos terceras partes.

\subsubsection{Programa Sub-Regional para América Central}

En el caso del segundo componente podrán participar: Costa Rica, El Salvador, Guatemala, Honduras, Nicaragua y Panamá. El programa tiene un presupuesto indicativo de 120 millones de Euros. Dentro de las áreas de trabajo se encuentran:

- Integración económica regional

- Seguridad y Estado de Derecho

- Cambio climático y gestión de desastres

- Medidas de apoyo

Esta programación tiene una triple justificación y coherencia, la primera es que es el único proceso de integración subregional con el cual la UE pudo negociar y firmar un acuerdo de asociación. La segunda, la base del propio acuerdo con los centroamericanos. Y una tercera, es que la mayoría de los países centroamericanos siguen siendo "países de ingresos bajo" o "ingreso mediano bajo" por lo que ayuda al desarrollo en esta subregión es justificable.

Siguiendo con los esfuerzos de apoyar la integración regional, se encuentra el rubro “integración económica regional” que estipula como objetivo específico el apoyo a las instituciones del Sistema de Integración Centro Americano (SICA), en este caso al 
SIECA (Secretaría de Integración Económica Centroamericana) con una partida de 40 millones de Euros.

En el segundo punto "seguridad y Estado de derecho" se dota con un presupuesto de 40 millones, con el fin de reforzar la capacidad de la región para lograr una disminución del crimen transnacional, mejorar la seguridad y brindar mejores servicios de justicia.

En lo que respecta a "cambio climático y gestión de desastres" se considera unos 35 millones de Euros, para apoyar el establecimiento de una Estrategia Regional para el Cambio Climático. A continuación un resumen esquemático del presupuesto para América Latina para el período 2014-2020: 
Cuadro N. Programación presupuestaria por partidas del Programa Regional para América Latina período 2014-2020

\begin{tabular}{|c|c|c|}
\hline PARTIDAS & $\begin{array}{c}\text { MONTO } \\
\text { PRESUPUESTARIO }\end{array}$ & TOTAL \\
\hline Programa Continental & & 805 \\
\hline $\begin{array}{l}\text { El nexo entre seguridad y } \\
\text { desarrollo }\end{array}$ & 70 & \\
\hline $\begin{array}{l}\text { Buen gobierno, rendición de } \\
\text { cuentas y equidad social }\end{array}$ & 42 & \\
\hline $\begin{array}{l}\text { Crecimiento sostenido e } \\
\text { inclusivo para el desarrollo } \\
\text { humano }\end{array}$ & 215 & \\
\hline $\begin{array}{l}\text { Desarrollo sostenible y } \\
\text { cambio climático }\end{array}$ & 300 & \\
\hline Programa Erasmus + & 163 & \\
\hline Medidas de Apoyo & 15 & \\
\hline $\begin{array}{l}\text { Programa Sub-Regional } \\
\text { para América Central }\end{array}$ & & 120 \\
\hline $\begin{array}{l}\text { Integración económica } \\
\text { regional }\end{array}$ & 40 & \\
\hline $\begin{array}{l}\text { Seguridad y Estado de } \\
\text { Derecho }\end{array}$ & 40 & \\
\hline $\begin{array}{l}\text { Cambio climático y gestión } \\
\text { de desastres }\end{array}$ & 35 & \\
\hline Medidas de apoyo & 5 & \\
\hline Total & & 925 \\
\hline
\end{tabular}

Elaboración propia.

Datos obtenidos del SEAE y la Comisión Europea.

\subsection{EL SEAE EN LOS CONSEJOS Y COMITÉS DE LOS ACUERDOS DE ASOCIACIÓN}

Con el establecimiento del SEAE también se vio modificada la participación institucional de la Unión ante terceros, como en los casos de su representación en los Consejos y Comités de los Acuerdos de Asociación. Cada uno de estos acuerdos 
contemplaba el establecimiento de órganos encargados de velar por el fiel cumplimiento de los objetivos y compromisos asumidos.

Pongamos como ejemplo, el Acuerdo de Asociación UE-Chile de 2002, es decir, antes del Tratado de Lisboa, para entonces la UE contemplaba que el Consejo de Asociación, estaría integrado por un miembro del Consejo de la UE y un miembro del Ministerio de Relaciones Exteriores de Chile. Este Consejo de Asociación se reuniría como mínimo cada dos años, de manera ordinaria, y de manera extraordinaria, cuando lo requiera cualquiera de las partes.

El Consejo tendría un presidente y dos secretarios; en el caso de las presidencia esta sería ejercida por turnos y por períodos de 12 meses, en el caso de la UE, la presidencia sería ocupada por un miembro del Consejo de la UE, y en el caso de Chile, por el Ministro de Relaciones Exteriores de Chile ${ }^{560}$. En el caso de las Secretarías, serían ocupadas por un funcionario de la Secretaría General del Consejo de la UE y por un funcionario del Ministerio de Relaciones Exteriores de Chile, quienes ejercerán conjuntamente las funciones de Secretarios del Consejo de Asociación ${ }^{561}$.

Por otro lado, estaba un Comité de Asociación ${ }^{562}$, cuya función es asistir al Consejo de Asociación en el fiel cumplimiento de sus funciones y velar por la aplicación general de los asuntos establecidos en el Acuerdo. El Comité estaba compuesto por representantes de los miembros del Consejo de la UE y representantes de la Comisión de las Comunidad Europeas, llamada así por ese entonces.

A la vez, entre las funciones asignadas al Comité estaban el de preparar las reuniones del Consejo, supervisar la aplicación de las decisiones y recomendaciones dadas por el Consejo de Asociación. El Comité tenía dos secretarías, las cuales eran ocupadas por un funcionario de la Comisión Europea y un funcionario del Ministerio de Relaciones Exteriores de Chile. Nótese que siempre la contraparte chilena es un representante del ministerio de relaciones exteriores y no de otro ministerio, a pesar que el reglamento

\footnotetext{
${ }^{560}$ Art. 1 Presidencia. Decisión N 1/2003 del Consejo de Asociación UE-Chile de 27 de marzo de 2003 relativa a la adopción de los reglamentos internos del Consejo de Asociación, del Comité de Asociación y de los Comités Especiales. Diario Oficial de la Unión Europea L95/46 11.4.2003.

561 Art. 5. Presidencia. Decisión N 1/2003 del Consejo de Asociación UE-Chile de 27 de marzo de 2003 relativa a la adopción de los reglamentos internos del Consejo de Asociación, del Comité de Asociación y de los Comités Especiales. Diario Oficial de la Unión Europea L95/46 11.4.2003.

562 Art. 14. Presidencia. Decisión N 1/2003 del Consejo de Asociación UE-Chile de 27 de marzo de 2003 relativa a la adopción de los reglamentos internos del Consejo de Asociación, del Comité de Asociación y de los Comités Especiales. Diario Oficial de la Unión Europea L95/46 11.4.2003.
} 
interno del Consejo y del Comité, sólo dice que deberá de ser a escala ministerial, pero no específica que en exclusividad deberá de ser siempre el ministerio de relaciones exteriores. Sin embargo, este hecho evidencia que dichas relaciones tienen el rango de relaciones diplomáticas.

Cuando se crea el SEAE, el Consejo de Asociación y el Comité del Acuerdo de Asociación UE-Chile pasa a estar formado de la siguiente manera:

\section{Cuadro N. EI SEAE en los Acuerdos de Asociación}

\begin{tabular}{|c|c|}
\hline Consejo de Asociación & Comité de Asociación \\
\hline $\begin{array}{l}\text { En el caso de Chile: } \\
\text { - } \quad \text { Por el Ministro de Relaciones Exteriores }\end{array}$ & $\begin{array}{l}\text { En el caso de Chile: } \\
\text { - Vice Ministro de Relaciones Exteriores } \\
\text { - Director General Económico del } \\
\text { Ministerio de Relaciones Exteriores } \\
\text { - Director de la Agencia de Cooperación } \\
\text { Internacional } \\
\text { - Otros representantes de organismos } \\
\text { estatales }\end{array}$ \\
\hline $\begin{array}{l}\text { En el caso de la Unión Europea: } \\
\begin{array}{l}\text { - } \\
\text { Por el Presidente del Consejo Europeo } \\
\text { y la Alta Representante de la Unión } \\
\text { para Asuntos Exteriores y Política de } \\
\text { Seguridad/Vice Presidenta de la } \\
\text { Comisión }\end{array}\end{array}$ & $\begin{array}{l}\text { En el caso de la Unión Europea: } \\
\begin{array}{c}\text { - } \\
\text { - Secretaría General del SEAE } \\
\text { - } \quad \text { DG Comercio } \\
\text { - } \quad \text { DG DEVCO EuropeAid } \\
\text { - } \quad \text { Otras direcciones generales }\end{array}\end{array}$ \\
\hline
\end{tabular}

Fuente: CEPAL y AECID: Ricardo Herrera: "El pilar de cooperación en el acuerdo de asociación política, económica y de cooperación entre Chile y la Unión Europea. Santiago de Chile 2011, p. 15.

En la última reunión del Comité de Asociación UE-Chile (XII Reunión) celebrada en Santiago de Chile, el 7 de noviembre de 2014, el Comité de Asociación estuvo presidido por el Director General Adjunto para Asuntos Bilaterales del Ministerio de Relaciones Exteriores de Chile y el Director de la Dirección de las Américas, Roland Schäfer. 
En la reunión evaluaron los 12 años del acuerdo de asociación, llegando a la conclusión que los resultados han sido positivos, y entre los cuales, destacaron la liberalización de casi el $98 \%$ del universo arancelario, un incremento del doble en lo que respecta al intercambio comercial y el flujo de inversiones, con respecto al período anterior al acuerdo. Hablaron sobre la posibilidad de actualizar el acuerdo con nuevas metas, entre las que acordaron temas como: educación, energía, responsabilidad social empresarial o corporativa, seguridad y defensa, pequeñas y medianas empresas, y clúster ${ }^{563}$.

En el caso de las relaciones con subregiones, por ejemplo, América Central, ocurre lo mismo en cuanto a la representación por parte de la Unión, participando los mismos representantes de la UE que en el caso de Chile. Ahora bien, se supondría que el acuerdo al ser firmado con una región o subregión, América Central, sería algunas de sus organizaciones del sistema de integración quienes representarían a la subregión centroamericana y por ende debería de ser la contraparte de la Unión.

Sin embargo, esto no es así, la representación es ejercida por cada uno de los estados centroamericanos. Así queda evidenciado en el Comunicado Conjunto de la reunión de la Comisión Mixta UE-Centroamérica, celebrada el 17 de octubre de 2014, donde los representantes de la UE fueron miembros del SEAE y de la DG DEVCO, y en el caso de América Central sus representantes fueron los representantes de cada país, es decir de Belice, Guatemala, El Salvador, Honduras, Nicaragua, Costa Rica, Panamá ${ }^{564}$.

Si bien es verdad que se dice que la Secretaría General del Sistema de Integración Centroamericano participó también en la reunión, bien claro dice el comunicado que ésta lo hizo en "acompañamiento" de los países, y que la Vocería la tuvo en este caso, por el sistema de rotación que existe de las presidencia pro témpore, Honduras, quiere decir, que ni siquiera la vocería conjunta, común o concertada, fue ejercida por el organismo regional.

563 PARLAMENTO EUROPEO: XII Comité de Asociación Chile-Unión Europea: Hacia la modernización del Acuerdo de Asociación.

http://www.europarl.europa.eu/meetdocs/2014_2019/documents/d-

cl/dv/51_22_comite_asociacion_chile/51_22_comite_asociacion_chilees.pdf [Última revisión: 22-032015]

564 EUROPEAN EXTERNAL ACTION SERVICE: Comunicado Conjunto Primera Reunión de la Comisión Mixta entre Centroamérica y la Unión Europea, Tegucigalpa, 17 de octubre de 2014. http://eeas.europa.eu/statements/docs/2014/141020_05_es.pdf [Última revisión: 25-03-2015] 


\subsection{SÍNTESIS DE LAS RELACIONES ENTRE EL SEAE Y AMÉRICA LATINA}

El establecimiento del Servicio Europeo de Acción Exterior ha logrado establecerse con menor dificultad política de lo que se pudo pensar, lo que se puede traducir, en dos puntos, el primero es que el conjunto de los países de la Unión, han visto los beneficios de tener una institución permanente y articuladora, con poder y funciones específicas, para coordinar el trabajo entre los servicios de acción exterior de los Estados Miembros y los servicios exteriores centrales dentro de la Unión. Un segundo punto, es que mediante el SEAE, la representación exterior de la Unión se ha visto más unificada. Estos dos puntos, han tenido incidencia directa en las relaciones con América Latina y el Caribe.

La Dirección de las Américas, encargada de las relaciones con esta región ha sido la responsable de articular todos los ámbitos relacionados entre la UE y la región latinoamericana y caribeña, buscando una mayor optimización de los recursos, tanto humano con financieros.

El nuevo contexto internacional, en el cual, muchos de los países de América Latina y el Caribe, cuentan con ingresos medios, harán replantear las relaciones entre la UE y dicha región. El nacimiento de la Comunidad de Estados Latinoamericanos y Caribeños (CELAC) como nuevo organismo que busca ejercer y ser una voz conjunta que represente los intereses de la región ante terceros, representa también un doble desafío, uno interno, por cuanto quedará por ver si lograr convertirse en el organismo articulador de las demandas e intereses del conjunto de los países y logre establecer una agenda común. Y en segundo lugar, que sea, en efecto, el interlocutor regional que logre acuerdo con la UE, en temas de interés común, como son los asuntos de la gobernanza global. La próxima reunión en París, la Conferencia sobre Cambio Climático de Naciones Unidas y la Agenda de Desarrollo Post-2015, son las dos primeras pruebas de fuego para la relación de ambas regiones, y comprobar si verdaderamente es una relación efectiva o solo sobre el papel. 


\section{- CAPÍTULO VIII}

EL ROL DE LA ALTA REPRESENTANTE DE LA UNION PARA ASUNTOS EXTERIORES Y POLITICA DE SEGURIDAD EN LAS RELACIONES CON AMÈRICA LATINA Y EL CARIBE: 2010-2015 


\subsection{EL ALTO REPRESENTANTE DE LA UNIÓN PARA ASUNTOS EXTERIORES Y POLÍTICA DE SEGURIDAD}

El Tratado de la Unión Europea (TUE), más conocido como el Tratado de Lisboa (TdL) introdujo grandes novedades en el funcionamiento de la Unión Europea (UE), sobre todo en las áreas relacionadas con la representación y acción exterior. Entre las novedades están la no elección de una presidencia rotatoria del Consejo Europeo, por lo que el cargo de Presidente del Consejo Europeo, cargo que pasó de ser un cargo oficioso (que era desempeñado por los jefes de estado y/o gobierno del Estado Miembro que ejercía la presidencia rotatoria del Consejo de la Unión) a un cargo permanente y a tiempo completo.

Entre sus funciones está representar a la UE en el exterior para cuestiones de política exterior y de seguridad ${ }^{565}$, trabajo que desarrollara conjuntamente con una nueva figura, la del Alto Representante de la Unión para los Asuntos Exteriores y la Política de Seguridad (AR). Esta nueva figura conllevaba a la vez una doble función, la de ejercer como Vicepresidente de la Comisión Europea (VP) con el objetivo de agrupar, coordinar y dirigir en conjunto todos los ámbitos exteriores de la UE. Finalmente, se crearía un Servicio Europeo de Acción Exterior, que asistiría al AR.

El 23 de octubre de 2009, el Consejo de la UE emitió un reporte al Consejo Europeo sobre el SEAE ${ }^{566}$, de acuerdo al Artículo 27.3 del TUE:

en el ejercicio de su mandato, el Alto Representante se apoyará en un servicio europeo de acción exterior. Este servicio trabajará en colaboración con los servicios diplomáticos de los Estados miembros y estará compuesto por funcionarios de los servicios competentes de la Secretaría del Consejo y de la Comisión y por personal en comisión de servicios de los servicios diplomáticos nacionales $^{567}$.

\footnotetext{
${ }^{565}$ Las funciones del Presidente del Consejo de la Unión está recogidos en el art.15 del Tratado de la Unión Europea, y entras las cuales están: dirigir la labor del Consejo Europeo; impulsar la cohesión y el consejo en el Consejo Europeo, y representar a la UE en el exterior para cuestiones de política exterior y de seguridad.

566 COUNCIL OF THE EUROPEAN UNION: Presidency report to the European Council on the European External Action Service. Note from Presidency to Council/European Council, Brussels, 23.10.2009.

${ }^{567}$ Art. 27.3. Tratado de la Unión Europea.
} 
La nueva arquitectura de la UE en materia de acción exterior representó una remodelación interna de varias unidades y direcciones generales pertenecientes a la Secretaría General del Consejo y la Comisión, las cuales pasaron a formar parte del SEAE. La Decisión del Consejo del 26 de julio de 2010, sobre el establecimiento de la organización y funcionamiento del Servicio Europeo de Acción Exterior, cuenta con un anexo, el cual específica las transferencias antes mencionadas, entre ellas:

\section{Por parte de la Secretaría General del Consejo:}

- Unidad política. Estructura de gestión de crisis y la Política Común de Seguridad y Defensa (con excepción del personal de apoyo a la Autoridad de Acreditación de Seguridad del Centro Conjunto de Situación para el Análisis de la Inteligencia (SITCEN sus siglas en inglés) y la Dirección General E (entre las que se encontraban la Dirección para las Américas y las Naciones Unidas)

- Oficiales de la Secretaría General del Consejo sobre adscripción a las Representaciones Especiales de la Unión Europea y a las misiones de la Política de Seguridad y Defensa Común.

Por parte de la Comisión Europea (incluyendo sus delegaciones):

- Dirección General para las Relaciones Exteriores

- Servicio Exterior

- Dirección General para el Desarrollo

EL SEAE tiene como máxima autoridad a la AR, debajo de ella existe una Administración Central, la cual está constituida de la siguiente manera:

- Secretario General Ejecutivo, Pierre Vimont (Francia)

- Jefe Interino de Operaciones, Patrick Chield (Reino Unido) y antes estuvo David O’Sullivan (Irlanda)

- Secretario General Adjunto-Director Político, Helga María Schimid (Alemania)

- Secretario Adjunto, Maciej Popowski (Alemania)

Existen también siete direcciones generales, entre los cuales está la Dirección de las Américas. Dentro de las transferencias de unidades y direcciones, antes mencionadas, se produjo una fusión de dos direcciones, la Dirección General para las Relaciones Exteriores que incluía la Dirección C (América del Norte, Asia Oriental, Australia, Nueva Zelanda, Áreas Económica Europea, Asociación Europea de Libre Comercio, San Marino, Andorra y Mónaco) y la Dirección G (América Latina). Ambas direcciones 
se fusionaron en una, dentro del SEAE, y crearon una Dirección General de las Américas, agrupando parte de la Dirección C, en el caso de América del Norte, y en la Dirección G que tenía a América Latina.

\subsection{LA ERA DE CATHERINE ASTHON}

El 19 de noviembre de 2009, la británica, Comisaria de Comercio de la UE, Catherine Margaret Ashton, fue elegida como AR/VP, asumiendo la responsabilidad tanto de la Política Exterior y Seguridad Común como la Política de Seguridad y Defensa Común. Además ejercería como presidente del Consejo de Ministros de Asuntos Exteriores de la Unión y como Vice Presidenta de la Comisión Europea, y como tal es la encargada de coordinar todos los aspectos de las relaciones exteriores de la UE. El 1 de diciembre de 2009 mediante la Decisión del Consejo Europeo se nombra a la Baronesa Catherine Margaret Asthon of Upholland, AR/VP para el período 1/12/09-1712/14, fecha que coincidía con el final del mandato de la Comisión Barroso ${ }^{568}$.

El proceso de nombramiento de Ashton estuvo lleno de cuestionamientos y sorpresas. La primera sorpresa fue su propia designación para ocupar dicho cargo, la propuesta fue hecha por el gobierno británico, en ese momento dirigido por Gordon Brown, quién la escogió para sustituir al también británico, Peter Mandelson, que hasta ese momento ocupaba un cargo comunitario en nombre del gobierno británico, el cargo de Comisario de Comercio, bajo la presidencia de José Manuel Durao Barroso. Ashton pasaba así de la política nacional británica a la europea, dejando su cargo de líder de la Cámara de los Lores y de presidente del Consejo.

Las críticas estaban en el escepticismo sobre el rol que podía cumplir Ashton como AR, dada su poca experiencia en los asuntos europeos e internacionales, comparando a sus competidores en el cargo, entre ellos: el ex primer ministro y ex ministro de asuntos exteriores de Italia, Massimo D’Alema, el ex ministro de relaciones exteriores de Francia, Bernard Kouchner, el ex vice canciller y ex ministro de relaciones exteriores de Alemania, Joschka Fischer; el presidente de Estonia, Toomas Ilves; el ex primer ministro y ex ministro de relaciones exteriores de Suecia, Carl Bildt; el ex ministro de asuntos exteriores de España, Miguel Moratinos; la ex ministra de asuntos exteriores de

\footnotetext{
${ }^{568}$ Decisión del Consejo Europeo adoptada con el acuerdo del Presidente de la Comisión de 1 de diciembre de 2009 por la que se nombra a la Alta Representante de la Unión para Asuntos Exteriores y Política de Seguridad (2009/880/UE). Diario Oficial de la Unión Europea L315/49. 2.12.2009.
} 
Austria, Ursula Plassnik; el Comisario Europeo de Asuntos Económicos y Monetarios, el finlandés Ollin Rehn; o su propio compatriota el Secretario de Estado para asuntos exteriores, David Miliband ${ }^{569}$.

Pero a pesar de no ser conocida en el ambiente europeo, se entendía que el puesto se le daba al candidato que el Reino Unido presentara, en compensación al creciente escepticismo europeísta británico y a sus constantes reclamos de renacionalizar competencias europeas. El apoyo al nombramiento de la británica al cargo de AR, se puede ver como una concesión o gesto de buena voluntad y vecindad, si se quiere expresar en términos diplomáticos, hacia el Reino Unido. Por otro lado, se buscaba logar un balance entre el poder político de las dos grandes familias políticas europeas (Partido Socialista Europeo y el Partido Popular Europeo).

El nombramiento de Van Rompuy como Presidente Permanente del Consejo Europeo, satisfacía la cuota de poder de los populares europeos, por lo que Ashton, cubría la cuota de los socialdemócratas europeos dentro del gobierno comunitario. A pesar que los principales candidatos para ser AR eran el español Moratinos y el italiano D’Alema, se tenía que tener en cuenta varias consideraciones, que el cargo, ahora extinto con el Tratado de Lisboa, de Alto Representante para la Política Exterior y de Seguridad Común (PESC) había sido ejercido, durante casi 10 años, por el español Javier Solana, por tanto, el candidato italiano era una buena alternativa, pero este no consiguió los apoyos necesarios.

La experiencia de Ashton como activista pacifista en organismos no gubernamentales, que promovía una Campaña para el Desarme Nuclear en el Reino Unido o en la ONG London First; su membresía en el Consejo Central para la Educación y la Formación en Trabajo Social ${ }^{570}$; y su trabajo en la Cámara de los Lores y Lord Presidente del Consejo de Gabinete de Gordon Brown, le brindaba experiencia como una coordinadora y mediadora nata entre dos poderes, el ejecutivo y el legislativo, que era lo que le esperaba en su nuevo cargo como AR.

${ }^{569}$ BARCELONA CENTRE FOR INTERNATIONAL AFFAIRS. Catherine Ashton. Biografías Líderes Políticos. Las personas en el centro de las relaciones internacionales.

http://www.cidob.org/es/documentacio/biografias_lideres_politicos/europa/reino_unido/catherine_ashton [Última revisión: 14-03-2015]

${ }^{570}$ Ibíd. Para más información también ver: EUROPEAN EXTERNAL ACTION SERVICE. The High Representative of the Union for Foreign Affairs and Security Policy. Political Career in the United Kingdom.

http://eeas.europa.eu/archives/ashton/index_en.htm [Última revisión: 14-03-15] 
Entre las tareas asignadas a Asthon estaban el implementar el SEAE, al respecto se fijó tres prioridades para su mandato:

1. El establecimiento y puesta en marcha del Servicio Europeo de Acción Exterior

2. Fomentar una profunda relación con los países vecinos

3. Construir una fuerte alianza estratégica con los socios existentes y los emergentes actores globales ${ }^{571}$.

4. Dentro del tercer punto, incluye una lista de 10 países, a los cuales los considera estratégicos para los fines e intereses de la Unión:

5. Estados Unidos

6. Rusia

7. China

8. India

9. Brasil

10. Sudáfrica

11. Japón

12. Corea del Sur

13. Canadá

14. México

Sólo hay dos países de ALC dentro de esta lista, y como se puede constatar se dio un especial énfasis a negociaciones de carácter bilateral más que inter-regional.

\subsection{LA ALTA REPRESENTANTE, EL SERVICIO EUROPEO DE ACCIÓN EXTERIOR Y AMÉRICA LATINA}

Dentro de la Administración Central del SEAE la AR cuenta con una Dirección de las Américas, que estaba a cargo del Embajador sueco Christian Leffler, y que es la que cubre América Latina y el Caribe. En el gabinete personal de Ashton existían 4 personas que trataban los asuntos de la región en diferentes ámbitos ${ }^{572}$ :

1. Asesor de la AR para las Américas, Christophe Parisot

571 EUROPEAN EXTERNAL ACTION SERVICE: 2011 Annual Activity Report, p. 6. http://eeas.europa.eu/background/docs/20121017_eeas_aar_2011_en.pdf [Última revisión: 24-2-2015]

EUROPEAN EXTERNAL ACTION SERVICE. CABINET OF CATHERINE ASHTON: http://eeas.europa.eu/archives/ashton/team/index_en.htm [Última revisión: 24-02-15] 
2. Miembro del Gabinete de la AR, Suvi Seppäläinen, cuyas responsabilidades son:

- África

- Américas

- Caribe

- Desarrollo

- Prevención de Conflictos/Mediación

- Derechos Humanos

- Desarrollo

- Sahel

- Justicia

- Asuntos Internos

- Agenda Digital

- Educación y Cultura

3. Portavoz de la AR, Maja Kocijancic, cuyas responsabilidades son ${ }^{573}$ :

- Europa (Estados No Miembros de la Unión Europea, Los Bacanes Occidental y Turquía)

- Rusia, Asociación Oriental, Asia Central

- Proceso de Paz en Medio Oriente

- Asia (con algunas exepciones)

- América Latina y el Caribe

- Asuntos Horizontales (derechos humanos, no proliferación de armas, etc...)

4. Encargado de Prensa, Iulia Costea, encargada de:

- África

\section{- América Latina y el Caribe}

Como se puede apreciar las áreas de responsabilidades son muy amplias y diversas. Por lo que se puede deducir que ALC no era una región o tema prioritario dentro de su mandato, y por tanto, no era necesario contar con expertos exclusivos para dicha región. ALC es más bien un tema más, dentro de una gran agenda global.

${ }^{573}$ EUROPEAN EXTERNAL ACTION SERVICE. Spokenspersons: http://eeas.europa.eu/archives/ashton/spokespersons/index_en.htm [Última revisión: 14-3-2015] 
Christian Leffler como director general, es asistido por un director Roland Shäfer y un Jefe de División, Manfredo Fanti. La Dirección de las Américas se divide en cinco divisiones:

1. Estados Unidos y Canadá, Fernando Andresen Guimaräes

2. México y América Central, Kenneth Bell

3. América del Sur, que a su vez se subdivide en la subdivisión para los Países Andinos (que también se ocupa de las relaciones con Chile) y MERCOSUR, ésta subdivisión está a cargo de Adrianus Koetsenruijter (Países Bajos).

4. Caribe, Ioannis Kalogirou

5. Asuntos Regionales, Manfredo Fanti

A estas divisiones se agregan dos departamentos que antes pertenecían a la Secretaría del Consejo: COTRA, que se encarga de las relaciones transatlánticas y coordina con la división de Estados Unidos y Canadá), a cargo de Alenka Zajc Freudenstein (Eslovenia); y AMLAT/COLAT (AMLAT se ocupa de asuntos económicos, comerciales y de cooperación; COLAT en cambio se encarga de temas políticos en América Latina), el cual está dirigido por Francisco Acosta Soto.

\subsection{ASHTON Y AMÉRICA LATINA: UNA ASOCIACIÓN ESTRATÉGICA BI-REGIONAL}

En 2009 la Comisión Europea emite una comunicación que señala las relaciones con América Latina como una "Asociación de Actores Globales" "574, siendo uno de los principales objetivos establecer posiciones comunes en los principales foros internacionales.

Sin embargo paralelamente a este deseo, se produce un abandono de las negociaciones a nivel regional y subregional por la parte de los países latinoamericanos, concretamente con los países andinos, que abandonan las negociaciones con la UE, como Comunidad Andina, y terminan firmando acuerdos bilaterales (casos Colombia y Perú).

Por otro lado se profundiza el estancamiento en las relaciones entre la UEMERCOSUR, y el ingreso de Venezuela y Bolivia, complejiza aún más las

${ }^{574}$ COMISIÓN DE LAS COMUNIDADES EUROPEAS: Comunicación de la Comisión al Parlamento Europeo y al Consejo. La Unión Europea y América Latina: Una asociación de actores globales. Bruselas, 30 septiembre de 2009. COM (2009) 495/3. 
negociaciones entre ambas partes, por cuanto su adhesión plena no está aún finalizada. La comunicación de 2009 resalta como principales logros en las con ALC los siguientes puntos:

Cuadro. Principales resultados de las relaciones entre la UE-ALC

\begin{tabular}{|c|c|}
\hline Cumbres & Principales resultados respecto a América Latina \\
\hline Río de Janeiro & $\begin{array}{l}\text { - Puesta en marcha de la Asociación Estratégica } \\
\text { UE/ALC } \\
\text { - } \quad \text { Apertura de las negociaciones UE-MERCOSUR }\end{array}$ \\
\hline Madrid 2002 & $\begin{array}{l}\text { - Anuncio del Acuerdo de Asociación UE-Chile } \\
\text { - Puesta en marcha del Programa ALBAN } \\
\text { - Puesta en marcha del concepto de espacio } \\
\text { único UE-ALC de la Enseñanza Superior y el } \\
\text { Conocimiento }\end{array}$ \\
\hline Guadalajara 2004 & - Puesta en marcha del Programa EUROsociAL \\
\hline Viena 2006 & $\begin{array}{l}\text { - Inicio de las negociaciones UE-América Central } \\
\text { para un Acuerdo de Asociación } \\
\text { - Apertura de las negociaciones para un Acuerdo } \\
\text { de Asociación entre la UE y la CAN } \\
\text { - Creación de una asamblea parlamentaria a } \\
\text { nivel birregional, EUROLAT }\end{array}$ \\
\hline Lima 2008 & $\begin{array}{l}\text { - Puesta en marcha de EUrocLIMA } \\
\text { - Concepto de una fundación } \boldsymbol{U E}-\boldsymbol{A L C} \\
\text { - Decisión de entablar un diálogo estructurado y } \\
\text { global sobre migración }\end{array}$ \\
\hline
\end{tabular}

Fuente: Comunicación de la Comisión al Parlamento Europeo y al Consejo. COM (2009) 495/3.

La UE a través de su cooperación al desarrollo hacia la región, introduce su poder normativo, mediante conceptos y mecanismos institucionalizados. Conceptos como el espacio único en educación superior, asamblea parlamentaria bi-regional y una fundación bi-regional, la se convertirá en un organismo internacional, tal como fue 
acordado por los jefes de estado y de gobierno en la última II Cumbre UE-CELAC, evidencia el cumplimiento del objetivo de la Unión en promover la integración regional a nivel mundial.

Cuando comienza el mandato de Ashton, en 2010, las prioridades políticas que tiene la UE hacia ALC se centran en:

- Profundizar el diálogo político a tres niveles: bilateral, subregional y regional

- Fortalecer las relaciones bilaterales existentes con los países de ALC en pos de una integración regional conjunta

- Cumplir sus compromisos internacionales a través del cumplimiento de los Objetivos de Desarrollo del Milenio, a través de sus relaciones con ALC

Todas estas acciones se encuentran recogidas en los documentos de programación a nivel regional, subregional y estrategia país (2009-2013), los mismos que pasaron a ser parte de las funciones de la Administración Central del SEAE, así como la supervisión y control por parte de las nuevas Delegaciones de la Unión Europea, antiguas Delegaciones de la Comisión Europea, y todo bajo la dirección del AR.

Durante su período como AR, Ashton visito cuatro veces América Latina:

- Brasil: 6 y 7 de febrero de 2012

- México: 8-10 de febrero de 2012

- Perú: 22 de enero de 2013

- Chile: 26 y 27 de enero de 2013

En el caso de Brasil, Ashton trató temas relacionados con los asuntos globales: crisis financiera, la Conferencia de las Naciones Unidas sobre Desarrollo Sostenible, cambio climático, derechos humanos, el proceso de paz en Medio Oriente, y las negociaciones concernientes a lograr un acuerdo de Asociación con el MERCOSUR ${ }^{575}$. En el caso de México, la agenda incluyó casi los mismos temas, exceptuando el tema de MERCOSUR. Al analizar la temática de la agenda de la AR en Brasil y México, se

${ }^{575}$ MINISTERIO DE RELACIONES EXTERIORES DE BRASIL: Relaciones Exteriores: "Visita ao Brasil de Alta Representante para Relacoes Exteriores e Política de Seguranca da União Europeia Catherine Ashton", Brasilia y Sao Paulo, 6 y 7 de febrero de 2012.

http://www.itamaraty.gov.br/index.php?option=com_content\&view=article \&id=2944\&catid=42\&lang=pt -BR\&Itemid=280 [Última revisión: 6-4-2015] 
deduce el interés por llevar a cabo una reforma del sistema financiero internacional, contando con el apoyo de ambos países dentro del G-20, dado que si se suma los países de la UE más Brasil y México, suman una tercera parte de los votos. En los otros temas como cambio climático, derechos humanos y desarrollo sostenible, la UE buscaba concertar posiciones apoyos para concertar una posición en las distintas conferencias y foros internacionales.

En el tema del conflicto con Medio Oriente, era para tocar la posición de los países latinoamericanos respecto al conflicto. Recordemos en durante el 2010 una muchos países latinoamericanos emitieron distintas declaraciones en favor del reconocimiento de Palestina como un Estado ${ }^{576}$.

Este apoyo se vio respaldado por parte de los países latinoamericanos hacia Palestina, cuando Palestina fue aceptada, el 31 de octubre de 2011, como miembro de la $\mathrm{UNESCO}^{577}$; y posteriormente el 29 de noviembre de 2012, cuando fue aceptada como un "Estado Observador no miembro" 578 , en el marco de la Asamblea General de las Naciones Unidas. Brasil apoya a Palestina en su reconocimiento como estado independiente y además defiende la postura de defender el trazado de las fronteras antes de la Guerra de 1967.

En el caso de México, no reconoce a Palestina como estado independiente, pero ha votado a favor, en el caso de su admisión en organismos internacionales como fue el caso de la UNESCO y como "Estado Observador no miembro".

Durante su gira por Brasil y México, Ashton declaró:

La Unión Europea se ha comprometido con el fortalecimiento de la asociación estratégica con Brasil y México. Espero que la visita fortalezca nuestros vínculos políticos y económicos y crear oportunidades para las sinergias en el enfoque regional y los desafíos globales. La UE sigue con interés la dinámica de América

\footnotetext{
${ }^{576}$ Entre los países de América Latina y el Caribe estaban: Argentina, Antigua y Barbuda, Bolivia, Cuba. Costa Rica, Dominica, Ecuador, Nicaragua, San Vicente y las Granadinas, Venezuela, Chile, Perú, el Salvador, Paraguay, Surinam, Uruguay y Honduras. La mayoría de los estos países apoyan la postura de reconocer las fronteras definidas antes de la Guerra de 1967.

${ }^{577}$ La admisión de Palestina como miembro de la UNESCO fue aprobada en la Sesión Plenaria de la 36 reunión de la Conferencia General de la UNESCO, Paris, 31 de octubre de 2011. Su admisión fue efectuada con 107 votos a favor, 14 votos en contra y 52 abstenciones.

${ }^{578}$ Resolución de las Naciones Unidas: NNUU A/RES/67/19.
} 
Latina y creo que tenemos que encontrar aún más maneras ambiciosas de trabajar juntos $^{579}$.

En el caso de Perú, la agenda de la AR se centró en reforzar el compromiso que tiene la UE con el país andino en materia de cooperación, participó en un evento del programa EUROPAN, el cual es un programa para reducir la desnutrición infantil. Durante su visita Ashton declaró:

\begin{abstract}
Aunque ya hemos recorrido un largo camino juntos, nuestras relaciones con Perú siguen teniendo un gran potencial. Nos congratulamos de los importantes avances que el país ha logrado en materia de inclusión social. Estamos dispuestos a proseguir nuestros esfuerzos conjuntos en la lucha contra la producción ilegal de drogas y el apoyo al desarrollo alternativo. Valoramos positivamente el compromiso de Perú a escala regional, como demuestra el hecho de que ostente la presidencia de UNASUR y estoy segura de que será una voz muy constructiva en la próxima cumbre UE-CELAC $C^{580}$.
\end{abstract}

La mención que realiza sobre UNASUR, es una de las pocas que ha efectuado algún alto funcionario de la Unión, quizás se deba que el nacimiento de UNASUR, fue visto desde Bruselas como un mecanismo más de los tantos existentes que crean los países latinoamericanos, en vez de verlo como una mecanismo que pretender realizar una convergencia $^{581}$ de varios procesos de integración en marcha en América del Sur. Lo cierto es, que también puede verse, como una distracción de los esfuerzos por parte a la ayuda y asistencia que brinda la UE a los dos procesos de integración subregional en América del Sur, Comunidad Andina y el MERCOSUR, justamente, los dos procesos sobre los cuales pretende fortalecerse la Unión de Naciones Suramericanas (UNASUR).

En el caso de Chile, viajó para asistir a la I Cumbre UE-CELAC, que se desarrolló el 26 y 27 de enero de 2013, y cuyo título fue "Alianza para el desarrollo sostenible: fomento

\footnotetext{
579 DELEGACIÓN DE LA UNIÓN EUROPEA ANTE BRASIL: Catherine Ashton visita Brasil. http://www.uebrasilrtd.org/noticias/visualizar/noticia/==AUVZ0cWxGZhJlRaNVTWJVU [Última revisión: 28-2-2015]

${ }^{580}$ EUROPEAN COMMISION: Press release. Catherine Ashton viaja a Latinoamérica. Bruselas, 21 de enero de 2013.

http://europa.eu/rapid/press-release_IP-13-29_es.htm [Última revisión: 24-2-2015]

${ }^{581}$ COMUNIDAD ANDINA: Art. 3 Objetivos Específicos. Tratado Constitutivo de la Unión de Naciones Suramericanas, Cusco, 8 de diciembre de 2004.
} 
de las inversiones de calidad social y medio ambiental" ${ }^{582}$; también participó en la Asamblea Birregional Parlamentaria (EUROLAT) y presidió la Reunión Birregional de los Ministros de Asuntos Exteriores UE-CELAC, el lema de esta reunión birregional a nivel ministerial fue "Trabajar juntos hacia el crecimiento y la estabilidad". Ashton en su intervención en EUROLAT, señala como áreas de trabajo: la cooperación al desarrollo, las inversiones y el esfuerzo conjunto en la defensa y promoción del multilateralismo. E indica que la UE hasta el 2013 había realizado inversiones por un monto de 300 billones de euros, y la inversión realizada en la región es mayor que la de Rusia, China e India juntos; a nivel multilateral, la cooperación y el trabajo conjunto realizado en el marco de las Naciones Unidas en los temas de la defensa de los derechos humanos o la presión ejercida por las dos regiones en la abolición de la pena de muerte y la promoción por los derechos del niño ${ }^{583}$.

Son hechos que evidencian una relación estratégica operativa y un trabajo conjunto en la arena internacional.

\subsection{LA ERA DE FEDERICA MOGUERINI}

Federica Moguerini toma el cargo de AR/VP mediante la Decisión del Consejo Europeo de 30 de agosto de 2014, y sus funciones serán hasta el 31 de octubre de $2019^{584}$. El nombramiento simboliza un giro político con respecto a este cargo. El 1 de noviembre, día en que Federeica Mogherini toma el cargo como AR/VP recibe una "Carta de Misión”, de parte del Presidente de la Comisión, esto es un hábito usual, en la cual se detalla los lineamientos y objetivos de su mandato. Si se compara la carta que envió José Manuel Barroso a Catherine Ashton, el 27 de noviembre de 2009. Además de los 27 días de diferencia de envío, partiendo que el 1 de noviembre es el mismo día en que

\footnotetext{
582 PARLAMENTO EUROPEO: Declaración de la Cumbre de Jefes de Estado y de Gobierno Unión Europea-Comunidad de Estados Latinoamericanos y Caribeños (UE-CELA) "Declaración de Santiago". Santiago de Chile, 26 y 27 de enero de 2013. http://www.europarl.europa.eu/intcoop/eurolat/key_documents/summits_eu_alc/1_celacue_2013/santiago _declaration_es.pdf [Última revisión: 24-2-2015].

${ }^{583}$ COMISIÓN EUROPEA: Press realease. Palabras de Catherine Ashton, Alta Representante de la Unión para Asuntos Exteriores y Política/Vice Presidenta de la Comisión, en la sesión inaugural de la Sexta Asamblea Parlamentaria EUROLAT. http://europa.eu/rapid/press-release_SPEECH-13-52_en.htm?locale=en [Última revisión: 28-2-2015]

${ }^{584}$ CONSEJO EUROPEO: Decisión del Consejo Europeo de 30 de agosto de 2014 por la que se nombra Alto Representante de la Unión para Asuntos Exteriores y Política de Seguridad (2014/639/UE). DO L 328 de 15.12 .2009 p.69
} 
tanto Ashton como Mogherini formalmente toman en cargo como AR/VP, también existe una diferencia sustancial en las directrices que reciben.

En la carta enviada de Barroso a Ashton ${ }^{585}$, de una página, habla de la importancia de “trabajar juntos como un Colegio", que su "misión como Comisión es promover y defender los intereses comunes europeos" y resalta la idea de que "una Comisión efectiva debe formar también una asociación exitosa con los Estados Miembros y las otras instituciones, y en particular con el Parlamento Europeo”. En cambio, Jean-Claude Juncker en su "Carta de Misión" a Mogherini ${ }^{586}$, de cinco páginas, y dividida en cuatro apartados, explica, con detalle, lo que espera de ella La carta se divide:

1. Una nueva manera de trabajar

2. El portafolio de la Alta Representante/Vice Presidenta de la Comisión Europea

3. Nuestros principios: ética y transparencia

4. Trabajando en asociación por Europa

Juncker inicia su carta resaltando la dificultad de la situación geopolítica por la que atraviesa Europa y los estragos de la crisis económica en la población y remarcando cómo iba a ser su período como Presidente de la Comisión: "Yo quiero la nueva Comisión sea un equipo fuerte y político [...] Yo quiero la Comisión Europea sea grande y ambiciosa sobre las cosas grandes, y pequeña y modesta sobre las cosas pequeñas ${ }^{587,}$.

En relación con esta afirmación en su primer apartado, describe que siguiendo los "Lineamientos políticos" presentados por él ante la Unión, propone una reforma estructural de la misma Comisión, la cual se traduce con una agrupación de los

${ }^{585}$ EUROPEAN COMMISIÓN: President of European Commission, Jose Manuel Barroso "Letter Mission" to Baroness Catherine Ashton, Brussels, 27 November 2009.

http://ec.europa.eu/archives/commission_2010-

2014/mission_letters/pdf/ashton_high_representative_en.pdf

Para más información sobre las "Cartas Misión”, también puede verse en: Mission letters from President Barroso the Commisioners designate:

http://ec.europa.eu/archives/commission_2010-2014/mission_letters/index_en.htm [Última revisión: 213-2015]

${ }^{586}$ EUROPEAN COMMISSION: Jean-Claude Juncker, President of the European Commission "Mission Letter" to Federica Mogherini High Representative of the Union for Foreign Policy and Security/VicePresident of the European Commission. Brussels, 1 November 2014.

http://ec.europa.eu/commission/sites/cwt/files/commissioner_mission_letters/mogherini_en.pdf [Última revisión: 21-3-2015]

${ }^{587}$ EUROPEAN COMMISSION: Jean-Claude Juncker, President of the European Commission "Mission Letter" to Federica Mogherini High Representative of the Union for Foreign Policy and Security/VicePresident of the European Commission. Brussels, 1 November 2014. pp. 1-2. 
comisionados bajo unas determinadas vicepresidencias, con el fin de facilitar una mayor coordinación y brindar efectividad en trabajo. Mogherini en su calidad de AR/VP presidirá un Grupo de Comisionados sobre Acción Externa para desarrollar un enfoque conjunto. Mogherini tiene bajo su responsabilidad siete $\operatorname{comisionados}^{588}$ :

1. Política Europea de Vecindad y Negociaciones de Ampliación

2. Cooperación Internacional y Desarrollo

3. Acción Climática y Energía

4. Ayuda Humanitaria y Gestión de Crisis

5. Comercio

6. Transporte

7. Migración, Asuntos Internos y Ciudadanía

Lo que significa la responsabilidad de cuatro comisionados más a su cargo, si comparamos con los tres que tenía dentro de sus roles Catherine Ashton: cooperación internacional y desarrollo, comercio y ayuda humanitaria y gestión de crisis $^{589}$.

La elección de Moguerini al igual que en el caso de Ashton, fue un juego de equilibrio de poder entre las dos grandes familias políticas europeas, el Partido Popular Europeo (PPE) y el Partido Socialista Europeo (PSE), los cuales tenían que considerar variables políticas, geográficas y de género a la hora de configurar el gobierno comunitario. Al ganar las elecciones el PPE, su candidato es elegido como Presidente de la Comisión Europeo, el ex primer ministro de Luxemburgo y ex Presidente del Eurogrupo, JeanClaude Juncker (Partido Popular Social Cristiano de Luxemburgo). Su oponente, el alemán, Martin Schulz (Presidente de la Alianza Progresista de Socialistas y Demócratas de Europa y ex europarlamentario), y miembro de PSE, pasa a ser Presidente del Parlamento Europeo.

En este juego de ajedrez político europeo, se nombra como Presidente del Consejo Europeo al ex Primer Ministro de Polonia, Donald Tusk, líder del Partido Plataforma Cívica (partido político de centro derecha) que pertenece a la familia del PPE, lo que se

\footnotetext{
${ }^{588}$ EUROPEAN COMMISSION: The Commission's Structure: http://ec.europa.eu/about/structure/index_en.htm\#ta [Última revisión: 21-3-2015]

589 EUROPEAN EXTERNAL ACTIONS SERVICE: High Representative of the Union for Foreign Affairs \& Security Policy/Vice-President of the European Commission. "As EU Foreign Affairs chief her portfolio includes a wide variety of roles: coordination other foreign policy tools-development assistance, trade, humanitarian aid and crisis response".

http://www.eeas.europa.eu/archives/ashton/index_en.htm [Última revisión: 21-3-2015]
} 
hacía necesario, un contrapeso, en el cual, Moguerini cumplía con varias de las variables antes mencionados.

En términos políticos, era de la familia socialdemócrata europea, en términos geográficos, era italiana, es decir del sur de Europa, jugando con el equilibrio del reparto de poder entre los Estados Miembros, Luxemburgo y Alemania, ambos países centroeuropeos, ya estaban representados mediante Jean-Claude Juncker y Marin Schulz, a ello había que sumarle el nombramiento del polaco Donald Tusk, con quién los países del este de Europa también estaban representados. Si a eso le sumamos que hasta ahora en el reparto de poderes todos eran hombres, el hecho de considerar una mujer en uno de los más altos cargos del poder ejecutivo de la Unión, era de sentido común pensar en que la AR sea mujer.

Habían dos candidatas, Mogherini y la ex Comisaria Europea para Cooperación Internacional, Ayuda Humanitaria y Gestión de Crisis, Georgieva Kristalina, de nacionalidad búlgara, es decir, podría cubrir la representación de los países del sureste de Europa, además sus conocimientos sobre los asuntos europeos y experiencia de la maquinaria institucional europea, a todo ello, se sumaba su experiencia en asuntos internacionales, al haber trabajado antes de ser comisaria europea, como vice presidenta, secretaría corporativa y directora del Banco Mundial, sin embargo, ya estaban representados los países del este de Europa.

Moguerini demostró liderazgo político desde el minuto uno en su primera puesta de escena. En el cuestionario del Parlamento Europeo, el 10 de septiembre de 2014, en su calidad de Comisaria Propuesta, respondía a las preguntas de qué experiencia personales tenía y cómo iba a contribuir a elaborar la agenda estratégica de la Comisión. Mogherini iniciaba su contestación resaltando su experiencia política como parlamentaria y ministra, y remarcando la característica de su partido político como europeo. Otro aspecto relevante es que se define como parte de una generación que considera que Europa es:

El lugar en el que me he criado, mi meta política natural [...] Ahora más que nunca creo que necesitamos mirar con profundidad el panorama mundial. Necesitamos un enfoque estratégico no sólo para las crisis actuales sino también 
paras las potenciales [...] Europa tiene valor y amplitud de miras, puede verdaderamente desempeñar un papel crucial en la política mundial ${ }^{590}$.

\subsection{MOGHERINI Y AMÉRICA LATINA: UNA ASOCIACIÓN PARA LA PRÓXIMA GENERACIÓN}

En lo que respecta a ALC, ya en el cuestionario que presentó ante el Parlamento Europeo, por vía escrita, Mogherini había anunciado su interés por relanzar las relaciones con la región, así lo mencionó durante su intervención en el Comité sobre Relaciones Exteriores del PE, el 6 de octubre de 2014. El Comité sobre Relaciones Exteriores, estaba formado por setenta y uno miembros, incluido su presidente, que en este caso era el alemán Elmar Brok, miembro de la Unión Demócrata Cristiana Alemana (UDC) y perteneciente al PPE. De los 70 miembros del Comité, 45 participaron con preguntas hacia Federica Mogherini.

La gran mayoría de preguntas se centraron sobre el conflicto entre Rusia y Ucrania, las relaciones con Estados Unidos, el Mediterráneo, la OTAN y Asia. De las 45 preguntas, 4 tocaron asuntos sobre ALC. De las 4 preguntas, dos fueron sobre relacionamiento bilateral, caso Cuba y caso Brasil, y dos preguntas fueron realizadas desde una perspectiva de relacionamiento inter-regional.

Moguerini menciona la necesidad de contar con "socios claves", y que estos deben de ser escogidos partiendo de una visión estratégica de futuro para la Unión, así comienza definiendo como punto importante, el lograr el Acuerdo Transatlántico con los Estados Unidos, acto seguido dice: "Déjenme también mencionar a América Latina entre los socios clave [...] América Latina y el Caribe como un todo, es un potencial socio estratégico para la Unión Europea-Yo veo a la Cumbre de la UE-CELAC en junio como una oportunidad de relanzar nuestra asociación",591.

Estas declaraciones permiten ver el lugar que tendrá América Latina y el Caribe dentro de la agenda de la UE, y la vuelta de un interés sobre el interregionalismo. Esta afirmación podría ser tomada como subjetiva, por parte del lector, sobre el pensamiento

\footnotetext{
590 PARLAMENTO EUROPEO: Cuestionario del Parlamento Europeo respuestas de la Comisaria Propuesta Federica Mogherini Alta Representante de la Unión para Asuntos Exteriores y Política de Seguridad Vicepresidenta de la Comisión, 10 de septiembre de 2014, p. 1.

591 EUROPEAN PARLIAMENT: The Committee on Foreign Affairs. Hearing of Federica Mogherini Vice-President-Designate of the Commission, High Representative of the Union for Foreign Affairs and Security Policy, Monday, Brussels, 6.10.2014, p. 7. (Traducción propia).
} 
o deseo del autor de este trabajo; sin embargo, si escuchamos o leemos la presentación de Mogherini ante el Comité sobre Relaciones Exteriores, ella misma aclara "hablando sobre regionalismo, que es claramente el valor de América Latina, yo vengo de Asia donde nosotros definitivamente necesitamos trabajar con nuestros socios-China, India, Japón, la República de Corea- pero nosotros necesitamos trabajar sobre los grupos regionales ${ }^{592}$,.

Esta afirmación podría ser tomada como subjetiva, por parte del lector, sobre el pensamiento o deseo del autor de este trabajo; sin embargo, si escuchamos o leemos la presentación de Mogherini ante el Comité sobre Relaciones Exteriores, ella misma aclara "hablando sobre regionalismo, que es claramente el valor de América Latina, yo vengo de Asia donde nosotros definitivamente necesitamos trabajar con nuestros sociosChina, India, Japón, la República de Corea- pero nosotros necesitamos trabajar sobre los grupos regionales" ${ }^{\prime 593}$.

El europarlamentario Francisco Assis, de nacionalidad portuguesa, es el primero de los miembros del Comité que hace una pregunta sobre las perspectivas de las relaciones entre UE-ALC, las negociaciones entre la UE-MERCOSUR y el TTIP con los Estados Unidos y la prioridad que tendrá la región en la agenda de la Unión ${ }^{594}$. Mogherini responde que durante su visita a Santiago de Chile (la cual efectuó como Ministra de Asuntos Exteriores de Italia el 5 de agosto de 2014) abordó el asunto de MERCOSUR, como ministra de asuntos exteriores y bajo la presidencia Italia de la UE, ella apoyaba la revitalización de las negociaciones para un acuerdo entre la UE y el MERCOSUR ${ }^{595}$. Concuerda que la base común de las relaciones con ALC son bajo los lazos culturales e históricos, lo que brinda una comprensión política recíproca ${ }^{596}$.

\footnotetext{
${ }^{592}$ Ibíd.

${ }^{593}$ Ibíd.

594 EUROPEAN PARLIAMENT: The Committee on Foreign Affairs. Hearing of Federica Mogherini Vice-President-Designate of the Commission, High Representative of the Union for Foreign Affairs and Security Policy. Brussels, 6.10.2014. pp. 22-23.

${ }^{595}$ Federica Mogherini visitó Santiago de Chile en calidad de Ministra de Relaciones Exteriores de Italia, durante su visita dio una conferencia magistral en la sede de la CEPAL, el título de su conferencia fue "El regionalismo es la ruta más efectiva para conseguir la paz y prosperidad". Santiago de Chile, 5 de agosto de 2014. Más información puede verse en CEPAL:

http://www.cepal.org/cgi-

bin/getProd.asp?xml=/prensa/noticias/comunicados/0/53440/P53440.xml\&xsl=/prensa/tpl/p6f.xsl\&base=/ prensa/tpl/top-bottom.xsl [Última revisión: 20-03-15]

596 EUROPEAN PARLIAMENT: The Committe on Foreign Affairs. Hearing of Federica Mogherini Vice-President-Designate of the Commission, High Representative of the Union for Foreign Affairs and Secutirty Policy. Brussels, 6.10.2014. p. 23.
} 
El español Fernando Maura Barandiarán, del partido Unión, Progreso y Democracia, del Grupo de la Alianza de los Demócratas y Liberales de Europa, le pregunta ¿Cómo piensa afrontar el tema sobre "el tratado bilateral" entre la Unión Europea y Cuba? ${ }^{597}$. Mogherini respondió que el papel de la Unión sobre este asunto, se haría a través de un trabajo articulado entre el SEAE y el PE, con el fin de fomentar e impulsar el proceso de reformas en $\mathrm{Cuba}^{598}$.

El SEAE participa en los equipos de trabajo que asisten en las rondas de negociaciones entre la Unión Europea y Cuba:

- Por parte de Cuba: Representantes del ministerio de relaciones exteriores, representantes del ministerio de comercio exterior, e inversiones y responsables de la cooperación internacional.

- Por parte de la UE: Representantes del SEAE, representantes de la DG DEVCO y los miembros de la Delegación de la Unión Europea ante Cuba.

Las respectivas delegaciones estuvieron encabezadas por parte de Cuba, por el Vice Ministro de Relaciones Exteriores, Abelardo Moreno, y por la parte de la UE, estuvo el Director de las Américas del SEAE, Christian Leffler ${ }^{599}$.

El español Francisco José Millán Mon, del Partido Popular Europeo y miembro del Grupo Partido Popular Europeo, le preguntó sobre el acuerdo del TTIP con los Estados Unidos, sobre la II Cumbre UE-CELAC. Sobre el TTIP, Moguerini responde que queda mucho tiempo por delante para negociar el acuerdo y que se firmara si este es conveniente para la UE y hace algunas reflexiones, sobre cómo en Europa, apenas hace un año y medio atrás, existía un cierto sentimiento de pánico sobre el efecto "pivot Asia" y la idea del giro de interés entre el Pacífico y el Atlántico, pero deja entrever que con el TTIP, seguirá siendo el Atlántico el centro gravitacional. Resaltando además que

597 EUROPEAN PARLIAMENT: The Committe on Foreign Affairs. Hearing of Federica Mogherini Vice-President-Designate of the Commission, High Representative of the Union for Foreign Affairs and Secutirty Policy. Brussels, 6.10.2014. p. 26.

598 Ibíd.

${ }^{599}$ EUROPEAN EXTERNAL ACTION SERVICE: Delegation of the EU to Cuba. Third round of the EU-Cuba negotiations towards a bilateral Political Dialogue and Cooperation Agreement in Havana. http://eeas.europa.eu/delegations/cuba/documents/press_corner/20150305_press_lines_3rdround_negotiat ions_en.pdf [Última revisión: 20-3-2015] 
la importancia de las relaciones con Estados Unidos radica en que juntos pueden afrontar los grandes desafíos globales ${ }^{600}$.

EL SEAE en su página web ha publicado, los 100 primeros días de Federica Mogherini. El resultado de esos primeros 100 días dan un total de 10 visitas oficiales a terceros países, 5 visitas oficiales a Estados Miembros de la UE, 93 reuniones bilaterales de Alto Nivel (incluyendo encuentros con Jefes de Estado y/o Gobierno, Ministros de Asuntos Exteriores y Representantes de organismos internacionales) entre ellos, el encuentro con el Presidente de Colombia Manuel Santos, el 4 de noviembre de $2014^{601}$.

Participó en 14 foros internacionales, incluyendo reuniones internaciones y conferencias (entre las que estuvo su participación en la III Cumbre de la CELAC en Santo Domingo, el 28 de enero de 2015, durante esta reunión tuvo varias reuniones bilaterales, entre las que destaca su encuentro con el Ministro de Asuntos Exteriores de Cuba, Bruno Rodríguez). A la vez, Mogherini tuvo 31 reuniones con los instituciones de la Unión: 8 en la Comisión Europea, más 5 reuniones con el Grupo de Comisarios sobre Acción Exterior; 11 reuniones en el Consejo de la Unión Europea y 7 en el Parlamento Europeo ( 3 ante el plenario del PE y 4 ante el Comité de Asuntos Exteriores ${ }^{602}$.

Si comparamos con el número de visitas que efectúo Ashton a la región, cuatro durante todo su mandato (2009-2014), podemos decir que en menos de tres meses, Mogherini ya ha viajado a la región, la mitad de veces de lo que lo hizo Ashton, dos veces (república Dominicana y Cuba), y si tomamos en consideración sus visitas como Ministra de Asuntos Exteriores de Italia (Colombia y Chile), entonces iguala en cuatro el número de visitas a la región. Ashton no participó, en la anterior Cumbre de la CELAC, en cambio, Mogherini sí fue a la Cumbre de la CELAC, lo que demuestra otra vez, el interés por la región, el interregionalismo y su apuesta por la asociación

\footnotetext{
${ }^{600}$ EUROPEAN PARLIAMENT: The Committee on Foreign Affairs. Hearing of Federica Mogherini Vice-President-Designate of the Commission, High Representative of the Union for Foreign Affairs and Secutirty Policy. Brussels, 6.10.2014. pp. 38-39.

${ }^{601}$ EMBAJDA DE COLOMBIA EN BÉLICA: Presidente Santos y Canciller Holguín se reunieron con la Alta Representante de la Unión Europea para Asuntos Exteriores y Política de Seguridad, Federica Mogherini, 4 de noviembre de 2014. http://belgica.embajada.gov.co/newsroom/news/2014-11-04/4711 [Última revisión: 21-3-2015]

${ }_{602}$ EUROPEAN EXTERNAL ACTION SERVICE: HR/VP Federica Mogherini. First 100 days. http://www.eeas.europa.eu/top_stories/2015/090215_federica_mogherini_100_days_en.htm_[Última revisión: 22-03-2015]
} 
estratégica birregional. Durante su intervención en la Cumbre de la CELAC Mogherini manifestó que el "fortalecimiento de nuestra relación es una prioridad estratégica ${ }^{603}$ ".

Durante una intervención en la apertura de la sesión del Foro de la Sociedad Civil UECELAC en Bruselas, 1 el 19 de marzo de 2015, Mogherini brinda detalles de lo que será el compromiso de la UE en la II Cumbre UE-CELAC

mi prioridad para la Cumbre en junio es muy clara. La Cumbre deberá demostrar que nuestras relaciones son relanzadas y que nosotros ponemos más dinamismo en ello. Esto no es solo una expresión de buenas intenciones. Todo lo contrario, esto es algo que yo creo firmemente. Para mí, la Cumbre UE-CELAC en junio es una de las oportunidades más importantes para conseguir los futuros compromisos. [...] No es un accidente que mi visita a Cuba se haya adelantado [...] en mis primeros meses como AR/VP he recibido muchas delegaciones y personalidades desde América Latina y el Caribe (con mi primer encuentro de mi mandato comenzó con el Presidente Santos) y Yo personalmente cuando estuve en la Cumbre de la CELAC en Costa Rica. Estos no son "gestos diplomáticos": Ellos son políticos e institucionales compromisos ${ }^{604}$.

En el marco de la II Cumbre UE-CELAC, 10-11 de junio de 2015, celebrada en Bruselas, y cuyo título fue "Formando nuestro futuro común: trabajando para la prosperidad, cohesión y sociedades sostenibles para nuestros ciudadanos", se abordaron nuevos temas, como la conectividad transatlántica, inversión en programas de educación conjuntos, un fondo para apoyar la fase de postconflicto en Colombia y el cambio de estatus de la Fundación UE-LAC para a ser un organismo internacional.

En términos de gobernanza global, reafirmaron su compromiso por trabajar juntos de cara a configurar una Agenda de Desarrollo Post-2015, lograr en Paris un acuerdo sobre cambio climático, y la lucha contra las drogas.

${ }^{603}$ EURPEAN EXTERNAL ACTION SERVICVE: Speech of the HR/VP Federica Mogherini at the CELAC Summit, San José, 28.01.15. http://www.eeas.europa.eu/statements-eeas/2015/150128_04_en.htm [Última revisión: 22-03-2015] ${ }^{604}$ EUROPEAN EXTERNAL ACTIONS SERVICE: Speech of HR/VP Federica Mogherini at the opening session of the EU-CELAC Civil Society Forum. Brussels, 19.03.2015.

http://www.eeas.europa.eu/statements-eeas/2015/150319_01_en.htm [Última revisión: 22-03-15] 


\subsection{SÍNTESIS DEL ROL DE LA ALTA REPRESENTANTE PARA ASUNTOS EXTERIORES Y POLÍTICA DE SEGURIDAD}

Al estudiar los mandatos entre Ashton y Mogherini, podemos concluir tres puntos, el primero, que se da un aumento de funciones, pasando de acciones generales a acciones específicas; el segundo punto es que Ashton ejerció el rol de AR bajo una perspectiva de una diplomacia tradicional, propia de estados soberanos, más que de estados miembros de una unión regional, como es el caso de la Unión Europea. Razón por la cual, durante su mandato prevalece un preferencia a desarrollar relaciones bilaterales, de ahí que escogiese como prioridad fortalecer las relaciones con países, los llamados socios estratégicos, en vez de inclinarse por regiones. La renovación de los acuerdos con México, Chile, y el acuerdo multipartes firmado con Colombia y Perú, son una prueba de esto.

Por otro, lado ante el estancamiento de las relaciones con MERCOSUR, se barajó la posibilidad de firmar acuerdos bilaterales, como una alternativa. En cambio Moguerini, busca desarrollar relaciones entre regiones, y bajo una perspectiva de diplomacia común, donde el SEAE juega un rol importante. Y en tercer lugar, la preferencia que da Mogherini a las relaciones con América Latina y el Caribe, situándolas en segundo lugar, sólo después del principal socio para la Unión, los Estados Unidos, hecho que a nuestro entender, muestra la importancia que puede tener dicha región dentro de la agenda comunitaria. Y aunque es muy temprano para evaluar la gestión de Moguerini y su impacto en la región, todo parece indicar, que la predisposición y la visión, estratégica, que tiene hacia la región es distinta a la ejercida por Ashton.

Importante indicar que ambas, Ashton y Mogherini, poseen un estilo de liderazgo muy distintos, quizás influenciado por sus respectivas culturas, pero también es cierto, que ambas se encontraron en contextos diferentes. Ashton tuvo que poner en marcha una nueva institución, y jugar entre el equilibrio de poder entre los Estados Miembros y las instituciones comunitarias, lo que no fue una tarea fácil. Y que el propio establecimiento del SEAE, era en sí ya una ardua tarea. Por otro lado, los efectos económicos en la Unión como resultado de la crisis internacional, los conflictos en Medio Oriente, como el conflicto entre Rusia y Ucrania, fueron factores que afectaron a la agenda de la Unión con respecto al interés por América Latina y el Caribe, como región. 
Cuadro N. Responsabilidades de la Alta Representante de la Unión para Asuntos Exteriores y Política de Seguridad/Vicepresidente de la Comisión Europea

\begin{tabular}{|c|c|}
\hline Catherine Ashton (2009-2014) & Federica Mogherini (2014-2019) \\
\hline $\begin{array}{l}\text { - } \begin{array}{l}\text { Diplomacia tradicional } \\
\text { - }\end{array} \text { Coordinar los } \\
\text { instrumentos de política exterior: } \\
\text { - } \text { Asistencia al desarrollo } \\
\text { - } \text { Comercio } \\
\text { - } \text { Ayuda humanitaria y gestión de } \\
\text { crisis } \\
\text { Construir consenso entre los } 27 \\
\text { Estados Miembros y } \\
\text { respectivas prioridades-mediante } \\
\text { reuniones mensuales con los } \\
\text { ministros de asuntos exteriores, } \\
\text { reuniones que ella preside } \\
\text { Atender a las reuniones regulares } \\
\text { de los líderes de los Estados } \\
\text { Miembros en el Consejo Europeo } \\
\text { Representar a la UE en los foros } \\
\text { internacionales, tales como los de } \\
\text { Naciones Unidas } \\
\text { Dirigir la Agencia Europea de } \\
\text { Defensa y el Instituto para } \\
\text { Estudios de Seguridad de la UE }\end{array}$ & 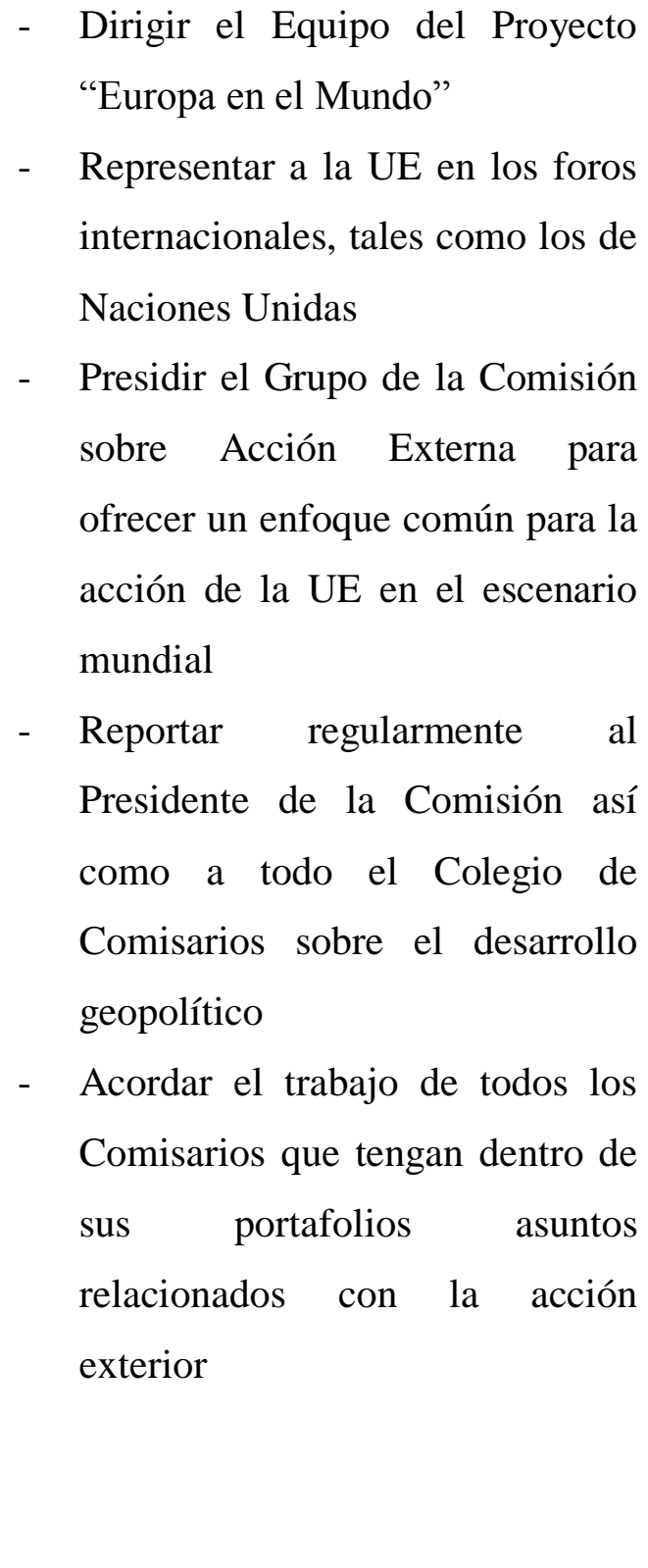 \\
\hline
\end{tabular}

Elaboración propia.

Datos obtenidos de la Comisión Europea y del Servicio Europeo de Acción Exterior de la

Unión Europea.

Las misiones entre una y otra son distintas, si analizamos los roles asignados podemos ver que en el caso de Ashton, la única función directiva que se le da es el de dirigir la 
Agencia Europea de Defensa y el Instituto para Estudios de Seguridad de la UE, además está como último punto, el resto de las funciones se limitan a acciones como: coordinar, construir y atender. Además si bien, su principal función que es representar a la UE, nótese que en el primer rol asignado se específica que desarrollará una diplomacia tradicional. Aunque no se brinda más detalles, es una clara alusión a que deberá de ejercitar una diplomacia basada en salvaguardar la soberanía de los Estados Miembros. Ashton en unas de su intervención en el Parlamento Europeo dice: "creo en la diplomacia tranquila $[. .$.$] no quiero que se corte el tráfico, prefiero que circule { }^{605,}$

Ashton demostró tener un mayor interés en fortalecer las relaciones comerciales, por lo que se inclinó por relaciones bilaterales con los países "socios estratégicos", un pragmatismo comercial, quizás en ese momento necesario, pensando en las necesidades y dificultades económicas por la que atravesaba la Unión, donde su principal problema interno era una tasa de desempleo alta, una pérdida de competitividad de sus empresas a nivel internacional y problemas en su comercio exterior.

Mogherini, ya con un SEAE en marcha, y con una perspectiva más política que comercial, hace que vea, a ALC como una región importante de cara a los intereses de la Unión, desde una óptica política, por cuanto que juntos pueden ser un peso importante en la toma de decisiones de los asuntos de la agenda internacional, y por ende pueden realizar cambios en la gobernanza global. Desde una perspectiva económica comercial, cree que una relación con una región similar a la europea, de cara al futuro, es una opción más sostenible en el tiempo.

${ }^{605}$ EL PAIS: MISSÉ, A.: “Ashton pasa su primera prueba ante el Parlamento Europeo”. 9 de diciembre de 2009.

http://internacional.elpais.com/internacional/2009/12/02/actualidad/1259708418_850215.html [Última revisión: 21-03-2015] 
CONCLUSIONES 
El acervo integracionista desarrollado en Europa a lo largo de los últimos siglos, ha contribuido a la construcción de un sistema internacional que se ha ido configurando y transformando sobre la base de unidades regionales; las cuales se organizaron desde ciudades-estados, federaciones, confederaciones, imperios, reinos, estados-nacionales hasta llegar uniones y comunidades regionales, integradas por estados nacionales, los que ejercen una doble membresía en el actual sistema internacional, el de ser estados nacionales soberanos y estados miembros de un proceso de integración regional, y que en el caso de los países que participan en el proceso de integración regional de la Unión Europea comparten su soberanía nacional con una soberanía común.

El capítulo II Fundamentos históricos del acervo integracionista en la Europa de la Edad Media, nos indica que la idea de la integración política regional en la Europa de la Edad Media se desarrolla, principalmente, con las ideas de tres personajes: Carlomagno, el Papa Pío II y Carlos V de Alemania y I de España, que mediante la comparación con otras regiones del mundo va dando forma a las ideas y concepciones de lo que es a su entender es Europa.

Carlomagno busca unificar gran parte de los pueblos que se encontraban en la Europa Occidental bajo la jurisdicción de su imperio, la cual toma como referencia la herencia del imperio romano y la cultura greco-romana. A pesar de la diversidad cultural existente entre los distintos pueblos, la lucha entre cristianos y musulmanes constituyó el referente de unidad política de Europa. Sentando la concepción de una identidad supranacional y común, sobre la base de una Cristiandad Latina. Tomando como referencia el rito latino, y buscando diferenciarse del ortodoxo, motivo por el concibe la idea de una Europa Latina.

Desde el punto de vista organizacional, Carlomagno organiza su imperio como una especie de confederación de regiones, llamadas "pagos" a los cuales los dota de autonomía administrativa y competencias jurisdiccionales. Siguiendo el modelo organizacional del imperio romano. Tomando como referencia a los griegos, Carlomagno concibe la idea del destino manifiesto de una civilización, cuyo caso era la civilización cristiana-europea, y que igual que el enemigo externo de los griegos en la Antigüedad, los bárbaros, sirven para establecer una diferencia cultural y límites geográficos a la hora de establecer las fronteras de la civilización griega, igual Carlomagno tiene un enemigo externo en la Edad Media, que les sirve para establecer 
las diferencias culturales y límites geográficos de su civilización cristiana-europea, los musulmanes.

El Papa Pío II afirma esta teoría al escribir sus obras Asia y Europa en las cuales resalta la diferenciación política, económica y cultural entre ambas regiones, a la par que expone la idea de una República Cristiana. República que ha perdido territorios en manos del Imperio Otomano, motivo por lo cual exhorta a todos los príncipes cristianos recuperar dichos territorios y defender la Cristiandad.

La defensa de la Cristiandad seguirá dentro de la idea integracionista de Carlos V de Alemania y I de España, quien convocará a todos los monarcas a la unidad política de Europa, a través de su idea de crear una Universitas Christiana, cuya propuesta es la necesidad de que exista una autoridad de carácter supranacional (imperial) para que diseñe y aplique políticas imperiales en temas de defensa y seguridad común.

Por otro lado, con Carlos V será el nexo entre Europa y América. Es durante su período que se produce la colonización en territorios americanos, y con ello la extrapolación de varios sistemas y modelo institucionales europeos, entre ellos el de la Universidad. El apoyo de Carlos V en la fundación de las primeras universidades americanas siguiendo el modelo de las universidades europeas, concretamente de la Universidad de Salamanca y posteriormente la de Alcalá de Henares, servirán para extender la Cristiandad y con ello los límites de la Europa Occidental y de la Europa Latina.

El desarrollo y crecimiento de las universidades americanas van creando en el continente un mapa, sobre cual, coincidirá con el nacimiento de las principales ciudades americanas, las cuales se convertirán en focos intelectual y de saber, en donde se estudiarán las ideas políticas europeas y se debatirán su aplicación en la vida política, económica y cultural en el continente americano.

Este mapa de universidades y ciudades americanas, se convertirá en el mapa de las capitales de las futuras repúblicas americanas, una vez finalizada las guerras de independencia contra España. Es mediante las universidades en que llegan el derecho de gentes, el derecho internacional, la escolástica, las ideas liberales de la ilustración, la soberanía nacional, el contrato social, los derechos individuales y las ideas que se oponían al absolutismo real. La división territorial de los Virreinatos y Capitanías 
Generales coinciden con los mismos grupos de países que iniciarán procesos de integración subregional, tanto en el siglo XIX como en el siglo XX.

El tercer capítulo El acervo integracionista en Europa y América en la Modernidad: Una historia común nos confirma parte de nuestra pregunta principal, ya que nos permite comprobar que existe un contante intercambio de ideas entre ambos continentes respecto a las ideas de la integración regional. Europa inicia la Edad Moderna tanto con las ideas de un sistema internacional basado en estados nacionales, el cual se establece mediante los congresos de Westfalia (1644-1648) y el congreso de Viena (1814-1815), creando un "Sistema de Estados Europeos". En América se comenzó durante el período de las guerras de independencia, entre las colonias americanas y la Corona de España, las cuales se dan en la primera mitad del siglo XIX.

Paralelamente a la construcción de este sistema internacional formado por las nacientes estados nacionales, también se sigue con las ideas de federaciones y confederaciones a escala europea, asambleas y/o dietas, serán el germen de las futuras ideas de los parlamentos regionales. En Europa encontramos el proyecto de paz general, que promueva el libre comercio y que establecía una corte internacional permanente compuesta por embajadores, y un tribunal internacional de Émeric Crucé, cuya inspiración para su propuesta la tomará de la historia entre Roma y Grecia, en cuanto a la organización política de sus pueblos.

En 1638, la propuesta de Maximilien de Bérthume, el Duque de Sully, propone una unión de estados mediante la formación de un Consejo de Europa, tomando como base la idea de ser una República Christiana, idea que también será defendida en 1676 por Gottfried Wilhelm Leibniz, buscando la reconciliación entre los católicos y protestantes. William Penn contribuye al acervo integracionista de Europa con sus ideas de una Dieta Europea, la creación de un Estado de Europa y los esbozos de un modelo federativo.

En el siglo XVIII Charles Irénée Castel de Saint Pierre, Adad de Saint Pierre, presenta en 1713 su proyecto de paz perpetua para Europa, mediante la creación de una liga o confederación, inspirándose en el proyecto del Duque de Sully. Este proyecto será actualizado más tarde en manos de Rousseau y que la llamara República Europea, mantienen los temas en los cuales debería de ocuparse la confederación: promover el comercio, agricultura, artes, inversiones y fondos comunes. Pero le quita la 
connotación o énfasis religioso o de vinculación directa con la cristiandad, ya no habla de República Cristiana sino de República Europea. Como queriéndole dar un carácter laico o de separación de poderes entre la Iglesia y el Estado dentro de la nueva República Europea. Kant que es conocido por su proyecto de paz perpetua (1795) en el cual propone una federación de pueblos basada en la paz, el derecho de gentes, el Estado de Derecho y el republicanismo como forma de gobierno. Kant concibe su proyecto de paz siguiendo las ideas de Sanit Pierre, leídas a través de los libros de Rousseau.

En el siglo XIX, en 1806 Napoleón propone su idea de un "sistema continental" sobre el cual establecía una unión aduanera continental. Estas ideas son importantes ya que serán la base del desarrollo de los conceptos de unión aduanera y unificación económica que realizará Alemania posteriormente, y que muchas veces el conjunto de la academia que estudia los procesos de integración regional citan el modelo alemán como el primer paso de un proceso de integración política, pero no destaca y reconoce que estas ideas son concebidas dentro de un sistema político de ámbito continental, como tampoco se menciona que dicha idea fue de Napoleón.

A lo largo del siglo XIX el debate de la integración política de Europa se generaliza a todos los ámbitos de la sociedad europea, ya no sólo se debate en los ambientes de gobierno y políticos acerca de la conveniencia o no de crear una gran federación o confederación; pensadores, filósofos, poetas y escritores comenzarán a enarbolar la idea de unos Estados Unidos de Europa, como Charles Lemonnier y Victor Hugo o la idea de que Europa sea una confederación de confederaciones, bajo el principio confederativo según Pierre-Joseph Proudhon.

El nexo entre el Abad de Saint Pierre y Immanuel Kant se produce gracias a los escritos de Rousseau, como se ha indicado anteriormente, estos tres personajes influirán mucho en el pensamiento político de las repúblicas americanas que se independizarán de España. Así lo vemos reflejado en los diez primeros proyectos de integración en los territorios americanos que se independizan de España. Los cuales, al igual que en Europa, convocarán la realización de varios congresos con el fin de definir y establecer el sistema organizacional político de las nacientes repúblicas, así como su interrelación con terceros y su rol en el sistema internacional. 
Lo que aporta este capítulo es la existencia de nueve proyectos de integración desarrollados antes del Congreso de Panamá, que junto a este forman los diez primeros proyectos que hemos mencionado, este punto es importante en cuanto muchas veces este congreso es tomado como punto de referencia y partida de la integración latinoamericana. Y no lo es. Así en nuestra investigación encontramos el Pacto de París de Miranda (1797) que propone una Unión del Continente Americano del Sur o también llamada América Meridional, fíjese que Miranda en su proyecto incluye varios conceptos antes descritos, unión continental. Miranda se inspirara en la obra del Abad Viscardo y Guzmán, quien escribió la "Carta dirigida a los Españoles Americanos”, y es sobre esta obra en que Miranda redactará su "proclamación a los pueblos del continente colombiano, alias Hispanoamérica". Pasando de América Española a Hispanoamérica, y con ella la concepción de una América Hispana que luego será llamada América Latina.

La segunda y tercera propuestas provienen de Chile, que propone una Confederación de los Pueblos del Pacífico (1810) y una Confederación Suramericana (1818). El Reino de Brasil propone una Alianza de Naciones de América (1818) y en ese mismo año, uno de los Libertadores, José de San Martín, plantea una quinta iniciativa, de convocar una Congreso Central para crear una alianza y federación perpetúa de los pueblos de América. El sexto y séptimo proyecto integracionista lo propone nuevamente Brasil mediante la creación de una Liga Americana (1819) y un Tratado de Confederación y Mutua Garantía de Independencia.

El octavo proyecto lo efectuará el hondureño Cecilio del Valle, a través de su obra "El proyecto de Confederación Americana. Soñaba el Abad de San Pedro: y yo también sé soñar”, publicada en 1822. La referencia del Abad de San Pedro, es en alusión al Abad de Saint Pierre. La novena propuesta la realiza Bernardo Monteagudo desde Argentina quien propone la necesidad de crear una Confederación General entre los Estados Hispanoamericanos en 1824. Después de todos estos proyectos integracionistas, llega la convocatoria del otro Libertador, Simón Bolívar, quien convocara en 1824 a un Congreso Anfictiónico en el Istmo de Panamá.

En las ideas y términos usados se evidencia la influencia y referencia de los proyectos integracionistas desarrollados en Europa, incluso tomando como fuentes de inspiración la propia Grecia y sus conceptos de Anfictionía, Ligas o federaciones, pasando por los 
proyectos de integración desarrollados en la Europa de la Edad Media y Moderna, los cuales hablan de congresos, asambleas, uniones y confederaciones de estados.

También es destacable, la sinergia que se produce al extrapolarse las ideas desde los países de Europa hacia América, y que casi nunca se habla de ello, o se escribe al respecto. Nos referimos al aporte que da el Panamericanismo como modelo político, y que fue diseñado y desarrollado para todo el continente americano.

El panamericanismo surge como una iniciativa de los Estados Unidos hacia los países hispanoamericanos, para formar un unión continental, para ello convoca la Primera Conferencia Internacional Americana en Washington, entre el 2 de octubre de 1889 al 19 de abril de 1890) esta conferencia, junto con la del Congreso de Panamá, serán para América, lo que fue en su momento los congreso de Westfalia y Viena para Europa, ya que marca una etapa nueva donde se ira configurando una forma nueva de relacionarse entre los estados americanos, tanto en temas de política, economía, seguridad y defensa.

De esta conferencia celebrada en Washington surgirá la Unión Internacional de Repúblicas Americanas, que luego cambiara de nombre, a Unión Panamericana y finalmente a la Organización de Estados Americanos (1948). Esta unión continental creara un sistema institucional que será llamado el sistema interamericano. El panamericanismo será admirado por uno de los Padres de la Unión Europea, Richard N. Coudenhove-Kalergi, quien escribirá la obra Pan-Europa, la cual se la dedica a la juventud europea, en Pan-Europa, deja fiel constancia de su admiración por este modelo, al escribir en la parte introductoria de su libro:

\section{Mientras estoy escribiendo estas líneas, se reúne en Chile la V Conferencia Panamericana [...] Entretanto, Europa va dando tumbos, sin guía y sin plan, de una crisis a otra [...] Es la juventud europea a quién corresponde modificar este estado de cosas. La juventud europea está llamada a levantar una nueva Europa sobre las ruinas de la antigua: a sustituir la Europa anárquica por una Europa organizada.}

Coudenhove-Kalergi habla de una nueva estructura del sistema internacional dividido en grandes regiones que él define como pannismos:

\section{Pan-América}




\section{El Imperio del Sur}

3. El Imperio del Norte

4. El Imperio del Este

5. Los Estados Occidentales

Coudenhove-Kalergi contribuirá al acervo integracionista europeo mediante la creación del movimiento paneuropeo, la "Unión Paneuropa", igual que la Unión Panamericana creada por los países del continente americano.

Por otro lado, la posta de las ideas de Coudenhove-Kalergi las tomará Aristide Briand, que en 1927 como ministro de asuntos exteriores de Francia y presidente de la Unión Paneuropa, crea un plan de acción política para la unificación de Europa. En 1929 como presidente de Francia propone una Liga a la que llamó "Unión Europea".

Jean Monnet será el que sintetice todas estas ideas, proyectos e iniciativas cuando concibe el Plan Schuman, en el que propone que los Estados de Europa se agrupen en una federación europea que los convierta en una unidad común.

El capítulo IV Construyendo regiones a través del diálogo bi-regional en los siglos xxxxi: institucionalización de las relaciones entre el proceso de integración europea y los procesos de integración en américa latina, nos describe como ya en el siglo XX a través de las relaciones entre los procesos de integración regional de la Unión Europea y los procesos de integración de América Latina se va originando un diálogo bi-regional que irá uniendo ambas regiones de cara al escenario internacional, decidiendo coordinar acciones y posiciones conjuntas en los diferentes foros y conferencias internacionales donde se tratan los asuntos de la gobernanza global.

El primer acercamiento se produce en la décadas de los sesenta, período en que acababan de crearse los primeros organismos de integración regional y subregional en ambos lados del atlántico. El primer acercamiento institucional se produce entre la entonces Comunidad Europea del Carbón y del Acero-el Instituto Latinoamericano de Hierro y del Acero y la Comisión Económica para América Latina. A la formalización institucional entre ambas regiones se suma las relaciones entre la Comunidad Económica Europea y la Comisión Especial de Coordinación Latinoamericana, con el fin de buscar una posición común ante las reuniones que se desarrollaban en el marco de la Conferencia de las Naciones Unidas sobre Comercio y Desarrollo. 
Estas relaciones se irán incrementando cada vez más y pasarán del ámbito económicocomercial al político y de cooperación internacional. Se puede decir que estas relaciones se dieron de manera paralela en diferentes esferas, así en la esfera económico comercial los europeos coordinaban con los latinoamericanos mediante las relaciones entre Comunidad Económica Europea y el Sistema Económico Latinoamericano, que fue la institución sucesora a la Comisión Especial de Coordinación Latinoamericana.

En la esfera política y de cooperación internacional se desarrollaron dos instancias de diálogo, una formal y otra informal. La de manera formal se gestaría y desarrollaría a través del proceso de paz en América Central, mediante el Proceso de Diálogo de San José, el cual generó la plataforma política sobre la cual se edificará una futura Asociación Estratégica Bi-regional, tal como la conocemos hoy.

Del proceso de San José surgirá la institucionalización de reuniones permanentes a nivel ministerial entre la Comunidad Económica Europea y el Grupo de Río (que como hemos visto surge del Grupo de contadora y del Grupo de Apoyo a Contadora, ambos grupos estaban formados por países latinoamericanos que apoyaron el proceso de pacificación en América Central). Estas relaciones crearán una agenda común sobre las cual se establecerán acciones conjuntas y se harán propuestas internacionales sobre los asuntos de la agenda global.

El segundo será a nivel diplomático y se desarrollara de manera informal, entre el Comité de Representantes Permanentes de la Comunidad Económica Europea (COREPER) y el Grupo de Embajadores Latinoamericanos (GRULAC) acreditados en Bruselas. La diferencia como se ha descrito antes, es que estas relaciones aunque continuas no se llegaron a institucionalizar dado que el GRULAC, jamás paso a ser una instancia incorporada en uno de los procesos de integración regional desarrollados en América Latina, a diferencia del COREPER que sí paso a ser incorporado e institucionalizado dentro del proceso de integración de la Unión Europea, y que de hecho fue la semilla de lo que hoy conocemos con el Servicio Europeo de Acción Exterior (SEAE), y que será la instancia comunitaria que se encarga de llevar las relaciones con América Latina a través de su Dirección para las Américas.

Estas relaciones a nuestro entender contribuyen en la creación de organismos de carácter subregional y regional, y cuyo modelo a seguir, desde el punto de vista 
institucional y/o organizacional será el modelo de integración europea. Existiendo una similitud en los objetivos (unión política, mercados comunes, desarrollo de una voz común frente a terceros en el escenario internacional, etc). La estructura organizacional e inclusive en el sistema de competencias. Con la gran salvedad, que en ninguno de los casos de los procesos de integración regional desarrollados en América Latina se llega dar una cesión de soberanía o el establecimiento de una soberanía compartida o común. Aspecto que a nuestro entender es la razón por la cual no se logra mayores niveles de profundización en el proceso de integración regional en la región de América Latina.

Si bien es cierto que los proceso de integración subregional centroamericano y andino se dan características de una cierta soberanía compartida, al dotarse de instituciones comunitarias y de carácter supranacional, el establecimiento de un derecho comunitario, y cuyas características tienen igual que en el caso de la integración europea, una supremacía del derecho comunitario sobre del derecho nacional y tribunales que buscan velar justamente estas normas, lo cierto es que también, en la práctica, ambos esquemas no logran con el cumplimiento de los objetivos trazados en sus respectivos tratados fundacionales, en donde se indican que aspiran a ser una unión política y establecer un sistema de trabajo comunitario. Ambos casos, el centro americano y el andino, son la excepción del conjunto de procesos que se desarrollan en toda la región al tratar de implementar un trabajo comunitario y la ideas de una supranacionalidad, pero nada parece indicar que exista una tendencia a seguir estos métodos de trabajo y extrapolarlos a nivel regional.

Las relaciones entre ambas regiones evolucionan hasta el punto de llegar a ser al más alto nivel, es decir a nivel de jefes de estado y de gobierno, creándose con ello un sistema de cumbres las cuales tendrán un carácter regular y permanente, con esto las relaciones se ven institucionalizadas a todos los niveles.

Por el lado europeo, su proceso evoluciona de comunidad de estados a unión de estados y nace la Unión Europea. En caso de América Latina, se crea la Comunidad de Estados Latinoamericanos y Caribeños, que es heredera del Grupo de Río más el Caribe. Desde el 2013 hasta la fecha las negociaciones entre ambas regiones se enmarcan dentro de la Asociación Estratégica entre la UE-CELAC, habiéndose desarrollado dos cumbres de jefes de estado y de gobierno, la primera en Santiago de Chile en 2013 y la última en Bruselas en 2015. 
Es importante indicar que durante todo este proceso, en América Latina se van creando una serie de procesos de integración subregional: SICA, CARICOM, MERCOSUR, CAN, entre otros. Con estos cuatro la UE institucionalizará relaciones, con el fin de apoyar y respaldar la integración regional en la respectiva región, es decir en su conjunto. A la vez, esta acción consolida también la imagen de la UE como modelo de unión de países a nivel internacional.

Otro aspecto es que este diálogo birregional a distintos niveles, subregional y a la vez regional, va también definiendo a la propia región de América Latina, cuyo reconocimiento se da en dos lados, desde lado interno, es decir entre los distintos proceso de integración regional de los propios países latinoamericanos y caribeños que se van sintiendo que son parte de una misma región y, por otro lado, el reconocimiento externo que le da las relaciones que desarrolla la UE con el conjuntos de los países de la región.

La definición de conceptos como subregión, región, actor, actores globales, diálogo birregional son algunos de los conceptos que se van dando dentro de las relaciones entre ambas regiones, y con ello también se contribuye al acervo integracionista común desarrollado por ambas regiones. A nuestro modo de ver el beneficio del diálogo birregional ha sido beneficioso para ambas partes, en cuanto ha servido para que ambas regiones hayan tenido que avanzar en sus respectivos procesos de integración de cara a poder actuar con mayor eficiencia y coherencia a nivel internacional.

El capítulo V El rol de los parlamentos subregionales y regionales: democracia e integración, nos explica cómo se materializa las primeras ideas de esas llamadas Dietas o Asambleas que eran propuestas tanto en la Edad Media como en la Edad Moderna. En el caso de los países europeos, en 1952 se crea la Asamblea Común de la Comunidad del Carbón y del Acero, la cual será renombrada como la Asamblea Parlamentaria Europea, mediante los Tratados de Roma (1957); y en 1962 se convertirá en un solo parlamento llamándose Parlamento Europeo.

En el caso de América Latina y el Caribe se crean 7 parlamentos subregionales, de acuerdo a cada uno de los procesos de integración en marcha. Así encontramos el Parlamento Latinoamericano, el Parlamento Andino, la Asamblea Parlamentaria de la Comunidad del Caribe, el Parlamento Centroamericano, el Parlamento del Mercado 
Común del Sur, el Parlamento de la Unión de Naciones Suramericanas y el Parlamento de la Comunidad de Estados Latinoamericanos y Caribeños.

De estos se espera que se produzca una convergencia entre el Parlamento Andino y del MERCOSUR, en el marco del Parlamento Suramericano, como también se espera que el Parlamento Latinoamericano, sea la asamblea parlamentaria que represente al conjunto de la población de América Latina y el Caribe siendo el parlamento de la CELAC. De hecho es el Parlamento Latinoamericano el que se relaciona con el Parlamento Europeo, relación que ha sido denominada como diálogo interparlamentario bi-regional EUROLAT.

La contribución de los parlamentos de carácter regional o subregional, es de emitir y dotar normas a los respectivos procesos de integración y ser los garantes de los derechos y obligaciones tanto de los Estados que firman los tratados y acuerdos fundacionales de las uniones o comunidades de estados. Así como defender los intereses de todos los ciudadanos de esas uniones y/o comunidades.

En el caso de la integración europea, el Parlamento Europeo sí ha tenido una papel relevantes tanto en la vida política interna de su proceso de integración, como en la política externa de la Unión, de hecho es gracias a sus informes sobre los cuales se toman las decisiones de cómo se deben desarrollar las relaciones exteriores frente a terceros países y grupo de regiones. Pero no es el caso de los parlamentos en América Latina y el Caribe. Ya que a diferencia del Parlamento Europeo, sus decisiones no son vinculantes y de carácter obligatorio, estos más que legislar, y crear leyes, lo que hacen son declaraciones o recomendaciones a los estados a través de informes que emiten y envían al consejo de ministros de asuntos exteriores o al consejo presidencial, según estén organizados los diferentes procesos de integración.

El capítulo VI Desarrollo y evolución de la acción exterior en los procesos de integración regional en la Unión Europea-América Latina y el Caribe describe como el desarrollo de una Acción Exterior en el caso del proceso de integración de la Unión Europea, se materializa con la creación de distintas instituciones encargadas de ejecutar las relaciones exteriores de la Unión, algunas de carácter intergubernamental y otros de carácter comunitario. 
La política exterior, la seguridad y defensa serán temas muy complicados de comunitarizar, por considerarse que son esencias y símbolos que representan la soberanía nacional. Pero igual lo es una moneda, y sin embargo, crearon una moneda común. La integración cada vez más profunda en términos comerciales y económicos, llevaron a los países europeos en pensar en crear una institución de carácter comunitaria que coordine con los diferentes servicios de acción exterior de los estados miembros y con las instituciones europeas, con el fin de poder hacer una acción exterior efectiva y evitar duplicidad de esfuerzos y recursos, tanto económicos como humanos.

La necesidad de concertar posiciones comunes, crear una red de información y armonizar puntos de vista entre todos los estados miembros de la Unión hace que se den pasos hacia lo que hoy será el Servicio Europeo de Acción Exterior.

Como hemos indicado el COREPER fue la semilla del SEAE, pero es el Tratado de Maastricht que en 1992 establece un sistema de pilares dentro de la Unión, el cual lo divide en tres, uno de carácter comunitario y dos de carácter intergubernamental:

\section{Comunidad Europea y la EURATOM}

2. Política Exterior y de Seguridad Común (PESC)

3. Cooperación judicial y de asuntos interiores

El Tratado de Ámsterdam definirá los objetivos y los ámbitos de la PESC, así como la creación de la figura del Alto Representantes para Asuntos Exteriores y de Seguridad Común. Con el Tratado de Lisboa se crea la figura del Alto Representante de la Unión para Asuntos Exteriores y Política de Seguridad (AR). Con este nuevo cargo se buscó unificar en un solo cargo, todos los cargos que tenían que ver con las relaciones externas de la Unión. Con este objeto con la figura del AR se refunden los siguientes puestos:

- Alto Representante para Asuntos Exteriores y de Seguridad Común

- Comisario Europeo de Relaciones Exteriores

- Presidente del Consejo de Asuntos Generales y Relaciones Internacionales

En el caso de América Latina se dan varias experiencias respecto a acción exterior a nivel de los diferentes procesos de integración regional y subregional, pero todos se dan a nivel de las secretarías o presidencias pro témpore en el marco de sus respectivos 
procesos, no se ha creado algún tipo de figura que busque representar a nivel externo a toda la región. A nivel subregional, muchas veces es el secretario general de las respectivas organizaciones son los encargados de ejercer la representación exterior, pero no tiene competencias similares a la del AR y mucho menos un sistema institucional.

En este apartado se resalta la experiencia de la integración andina, que sí ha desarrollado unos Lineamientos Política Exterior Común, y sobre la cual se puede pensar en que los países de América Latina y el Caribe pueden desarrollar un acción exterior a nivel regional, y con ello, instituciones comunitarias que se encarguen de desarrollar y ejecutar dicha acción exterior. Para esto se cree que es necesario que se haga por etapas, una primera sería que el proceso de convergencia entre CANMERCOSUR en el marco de UNASUR sea una realidad. De ser así se podría combinar las experiencias andinas, en materia de los lineamientos de su política exterior común, con la experiencia comercial común que ha desarrollado el MERCOSUR, y los temas de seguridad y defensa que son ejercidos mediante el Consejo de Defensa de UNASUR. Un siguiente paso sería extrapolar dicho modelo al marco de la CELAC.

Otro punto que trata este capítulo es que el diálogo birregional desarrollado entre la UECELAC ofrece la oportunidad perfecta para poder desarrollar e implementar esa acción exterior común. Sobre la base de un sistema de eslabones: andino, mercosuriano, suramericano, latinoamericano-caribeño.

El capítulo VII El Servicio Europeo de Acción Exterior y las relaciones Unión Europea-América Latina y el Caribe nos permite concluir que la creación de este servicio ha ayudado a la UE en la búsqueda de esa coherencia y eficiencia que espera tener dentro de sus relaciones exteriores. El SEAE está formado por una administración central y por las Delegaciones de la Unión ante terceros países y organismos internacionales. Siendo su máxima autoridad la AR, la cual es asistida por una Secretaría General, dos Vice Secretarios Generales, y Direcciones Generales.

Las direcciones generales cubren áreas geográficas, así como áreas temáticas y de multilaterales. El SEAE cuenta con siete direcciones generales, que a su vez se dividen en dos partes, cinco direcciones generales con carácter geográfico y dos direcciones de carácter temático:

\section{Dirección General Asia y el Pacífico}


2. Dirección General África

3. Dirección General Europa y Asia Central

4. Dirección General África del Norte, Medio Oriente, Península Arábica, Irán e Iraq

5. Dirección General de las Américas

6. Dirección General Asuntos Globales y Multilaterales

7. Dirección General Gestión de crisis y coordinación operacional

En el caso de las direcciones generales geográficas se subdividen en subregiones o grupos de países. Y en el caso de la dirección de Asuntos Globales y Multilaterales se divide en dos grandes temas:

- Derechos Humanos y Democracia

- Relaciones Multilaterales y Asuntos Globales

La Dirección de las Américas, Esta dirección se divide en cinco divisiones:

1. Estados Unidos y Canadá

2. México y América Central

3. América del Sur, que a su vez se subdivide en la subdivisión para los Países Andinos (que también se ocupa de las relaciones con Chile) y MERCOSUR

4. El Caribe

5. Asuntos Regionales

A estas divisiones se agregaron dos departamentos que antes pertenecían a la Secretaría del Consejo: COTRA, que se encarga de las relaciones transatlánticas y coordinaba con la división de Estados Unidos y Canadá); y AMLAT/COLAT (AMLAT se ocupaba de asuntos económicos, comerciales y de cooperación; COLAT en cambio se encargaba de temas políticos en América Latina). Para entender las relaciones entre UE y ALC, es necesario entender que aunque las relaciones tengan un contenido político y económico, el núcleo y nexo de las mismas es la cooperación al desarrollo, razón por la cual, la base legal sobre la cual se desarrolla todas las acciones hacia ALC, es mediante el Instrumento de Financiación de la Cooperación al Desarrollo (ICD). 
Las unidades que concretamente se centran en el trabajo con los países de América Latina y el Caribe, dentro de la Dirección de las Américas son las siguientes subdivisiones:

1. Subdivisión México y América Central

2. Subdivisión América del Sur

3. Subdivisión Caribe

Para el período 2007-2013 la Comisión elaboró los programas multianuales para el conjunto de los países de América Latina y el Caribe:

- Documento de Programación Regional 2007-2013

- Documento de Estrategia Regional-América Central 2007-2013

- Documento Estratégico Regional-MERCOSUR 2007-2013

- Documento Estratégico Regional-Comunidad Andina 2007-2013

- Documento Estratégico Regional-Región Caribe 2007-2013

Con la puesta en marcha del SEAE serán las Delegaciones de la Unión las encargadas de vigilar y controlar la ejecución de los mismos, antes los hacían las Delegaciones de la Comisión Europea, las cuales coordinaban exclusivamente con la misma, ahora las Delegaciones de la Unión dependen exclusivamente del SEAE y coordina con las otras instancias comunitarias.

El documento de la programación regional 2007-2013, define a América Latina como una región compuesta por grupos subregionales, entre los que se encuentran países y subregiones, tales como:

- México

- América Central

- El Caribe

- América del Sur (comprendida en Comunidad Andina y MERCOSUR)

- Chile

El documento incluye al Caribe dentro de América Latina, pero lo deja al margen del programa 2007-2013, dado que el Caribe, como se ha mencionado anteriormente, goza de sus propios instrumentos de cooperación y financiación. 
Volviendo al programa 2007-2013, este establece tres grandes áreas de trabajo a realizar durante el período 2007-2013:

1. Cohesión social

2. Integración regional y cooperación económica

3. Recursos humanos y entendimiento mutuo entre la Unión Europea y América Latina

Estas líneas de trabajo defiende nuestra teoría de cómo la UE ha contribuido en el fortalecimiento institucional de los procesos de integración regional en América Latina. El último programa diseñado para la región es el Programa Multianual Indicativo Regional para América Latina 2014-2020, el programa cuenta con una asignación indicativa de 925 millones de Euros. Si se compara con el presupuesto asignado en la programación regional anterior, 2007-2013, cuyo monto fue de 556 millones de Euros, existe que un incremento del presupuesto hacia la región de un $45 \%$. Esta vez, el programa contempla dos componentes:

1.Actividades a nivel continental

2.Programa Subregional para América Central

En el primer componente está diseñado para promover iniciativas regionales abiertas a todos los países de América Latina, estableciendo como países elegibles: Argentina, Bolivia, Brasil, Chile, Colombia, Costa Rica, Cuba, Ecuador, El Salvador, Guatemala, Honduras, México, Nicaragua, Panamá, Paraguay, Perú, Uruguay y Venezuela. De los 925 millones de Euros, como presupuesto indicativo, 805 irán destinados para el Componente 1 y 120 millones de Euros estarán destinados para el Componente 2. Pudiendo ser beneficiarios un total de 24 países latinoamericanos.

Lo novedoso de esta programación plurianual es que la UE deja de lado la cooperación que brindaba a los procesos de integración subregional como MERCOSUR, CAN; y sólo se queda con el proceso centroamericano. Opta por una cooperación de líneas temáticas. Interesante notar que el primer componente lo denomina "actividades a nivel continental", y no usa el término regional, quizás la UE trata de introducir un nuevo concepto, el de continental o quizás se deba a una nueva reconfiguración en sus relaciones transatlánticas en la cual contempla incluir a América Latina y el Caribe, no sería nada raro partiendo de la base que su dirección es llamada las Américas. 
En el caso del segundo componente podrán participar: Costa Rica, El Salvador, Guatemala, Honduras, Nicaragua y Panamá. El programa tiene un presupuesto indicativo de 120 millones de Euros. Dentro de las áreas de trabajo se encuentran:

- Integración económica regional

- Seguridad y Estado de Derecho

- Cambio climático y gestión de desastres

- Medidas de apoyo

Esta programación tiene una triple justificación y coherencia, la primera es que es el único proceso de integración subregional con el cual la UE pudo negociar y firmar un acuerdo de asociación. La segunda, la base del propio acuerdo con los centroamericanos. Y una tercera, es que la mayoría de los países centroamericanos siguen siendo "países de ingresos bajo" o "ingreso mediano bajo" por lo que ayuda al desarrollo en esta subregión es justificable.

Finalmente, en el capítulo VIII, El Alto Representante de la Unión para Asuntos Exteriores y Política de Seguridad, explica la diferencia en el trabajo entre Ashton (período 2009-2014) y Moguerini (período 2014-2020. La primera diferencia que se evidencia, es que Ashton, al encontrarse en el período de establecer el SEAE, se ha centrado y preocupado más en el plano interno, es decir en formar el propio servicio europeo y buscar conciliar las desconfianzas que existen entre los países miembros de la Unión que consideran que el SEAE es un paso hacia delante y en favor de consolidar a la UE como un Actor Global en el escenario internacional, grupo de países que están a favor de una Europa de modelo federal y método de trabajo comunitario, en contra de los países que consideran que el mejor método de trabajo es el intergubernamental, y que la UE debe de iniciar un proceso de renacionalización de competencias comunitarias hacia los Estados Miembros.

Pero después de estos años, la puesta en marcha del SEAE ha demostrado un grado de eficiencia y cumplido con sus objetivos de eficiencia y coherencia en el plano internacional. Lo que no significa que todo lo hace perfecto, y que existe de facto una posición común en todo lo relacionado con la acción exterior, un hecho último son la crisis financiera internacional, la crisis en Siria y los conflictos en Medio Oriente. Sin embargo podemos decir que el resultado es positivo. 
En lo que respecta a las relaciones con ALC, Ashton, aunque ha visitado la región y participado en los principales foros inter-regionales, parece haber prevalecido el interés por fortalecer las relaciones con los países que la Unión considera estratégicos, es decir, ha priorizado las relaciones bilaterales más que las de carácter bi-regional. Esta idea puede ser corroborada partiendo que dentro de su plan de trabajo como AR expuso como principal interés para la Unión fortalecer relaciones con los llamados socios estratégicos:

- Estados Unidos

- Rusia

- China

- India

- Brasil

- Sudáfrica

- Japón

- Corea del Sur

- Canadá

- México

En cambio Moguerini, en su exposición de intereses y prioridades para su período establece y la necesidad de relanzar las relaciones con América Latina y el Caribe sobre la base de una mayor profundización en las relaciones con la CELAC. Hecho que ha quedado demostrado, en su primer año, en el cual ha visitado y tenido más encuentros oficiales que la propia Ashton, tanto a nivel bilateral como subregional y regional con varios países de ALC.

Ahora bien, el último borrador de la estrategia global sobre acción exterior de la Unión Europea $^{606}$, presentado en junio de 2015, presentado por Federica Moguerini, anuncia la necesidad de redefinir el concepto de relaciones transatlánticas, y la UE propone expandir la cooperación atlántica profundizando los lazos con los países de América Latina y el Caribe, mediante acuerdos bilaterales y con los organismos regionales como CELAC, SICA, CARICOM, MERCOSUR y UNASUR.

606 EUROPEAN EXTERNAL ACTION SERVICE: Global Strategy to steer EU external action in increasingly connected, contested and complex world, EEAS, Brussels, June 2015. 
urante las últimas décadas las negociaciones para crear Mega Acuerdos Comerciales Regionales ${ }^{607}$ han ido reconfigurando el mapa mundial de los flujos comerciales y el tablero político mundial. En este marco internacional, las negociaciones entre los Estados Unidos y la Unión Europea para fortalecer la Zona Atlántica mediante el Transatlantic Trade and Investment Partnership ${ }^{608}$ (TTIP) y el proceso de negociaciones para consolidar a la Zona Asia- Pacífico, como futuro eje mundial, el Trans-Pacific Partnership $^{609}$ (TTP), son los dos grandes desafíos por los cuales se enfrentan los países de América Latina y el Caribe. El TTIP y TTP marcarán los pasos a seguir a nivel mundial en términos de relaciones internacionales, política económica internacional, comercio e inversiones, ya que con la entrada en vigor de los acuerdos se establecerán los estándares mundiales a seguir por el resto de países, en temas como barreras comerciales, propiedad intelectual, derecho laboral, derecho ambiental, así como la definición de cuáles serán las instancias internacionales a recurrir, en casos de diferencias entre inversores y estados.

Tomando en cuenta que las principales economías del mundo están dentro de estos dos grandes acuerdos, lo que acuerden y decidan será poder normativo para el resto de países e influirá en los otros procesos de negociaciones comerciales, sean estos bilaterales, regionales o multilaterales.

Ante este contexto internacional, América Latina tendrá que decidir qué rol pretende jugar dentro de la gobernanza global, en términos: políticos-económicos-comerciales. Tendrá que decidir entre ser un Observador Global o un Actor Global. No cabe duda que la región tiene un papel central dentro de esa gobernanza global, y que tiene todo el potencial para ser un Actor Global, y entre sus varias razones está que la región posee los recursos naturales que son indispensables tanto para los países de la Zona Atlántica como para la Zona Asia-Pacífico, sin ellos las respectivas económicas de ambas zonas no podrán la satisfacción de las demandas de su poblaciones, en términos de bienes y

\footnotetext{
${ }^{607}$ HOEKMAN, B.: The WTO and the global economy: contemporary challenges and possible response, in DADUSH, U. and OSAKWE, C.: Accessions and Trade Multilateralism. Cases Studies and Lessons from WTO at Twenty. Cambridge University Press, 2015.

${ }^{608}$ MORIN, J-F., NOVOTNÁ, T., PONJAERT, J. and TELÓ, M.: The Politics of Transatlantic Trade Negotiations. TTIP in a Globalized World, Frarnham-Burlington, Ashgate, 2015. HAMILTON, D.: The Geopolitics of TTIP: Repositioning the Transatlantic Relationship for a Changing World, Washington D.C., Center for Transatlantic Relations, Johnns Hopkins University, 2014.

${ }^{609}$ PALIT, A.: The Trans-Pacific Partnership, China and India. Economic and Political implications, London-New York, Routledge, 2014.
} 
servicios, como tampoco podrán mantener sus niveles de desarrollo, y por ende sus niveles de vida.

El rol de América Latina dentro de las Cadenas Globales de Valor $^{610}$ es vital para las empresas multinacionales, sean estas asiáticas, europeas, estadounidenses o latinoamericanas. Finalmente, pero no menos importante, está la variable que la región es una Bisagra entre las dos mares, Atlántico y Pacífico. América Latina tiene la oportunidad de convertirse en un Actor Global en la toma de decisiones de cada uno de los estándares mundiales que se vayan adoptar, y además beneficiarse de eso. La mejor manera de que la región pueda defender sus intereses es hacerlo de manera conjunta, es decir fortaleciendo su proceso de integración regional, para eso los organismos de integración regional jugarán un rol principal.

En términos regionales, la CELAC, es el organismo más idóneo para representar a la región y llevar las negociaciones frente a terceros. A la vez que puede ser el organismo en el cual converjan los intereses tanto de los países de la región que tiene costas atlánticas como costas pacíficas, de hacerlo puede ser el interlocutor idóneo en la negociación y ejecución de los tratados tanto en la Zona Atlántica como en la de AsiaPacífico. Las perspectivas de las relaciones entre la UE y CELAC, y la idea de que la UE redefina las relaciones transatlánticas, a través de su idea de buscar una ampliación del área atlántica, nos hace pensar que habrá cambios significativos en la relación con el conjunto de los países de América Latina y el Caribe.

Todo esto nos hace pensar que quizás es posible que las relaciones entre ambas organizaciones, UE-CELAC, quizás se vean ampliadas mediante la participación de la OEA, ya que al fin y al cabo es este el organismo continental por excelencia en la región americana, y quizás de ahí la idea de que la UE haya incluido en su organización interna del SEAE una Dirección de las Américas. Por otro lado, no hay que olvidar que la UE es observador de la OEA desde la década de los ochenta.

En el anexo Delegaciones de la Unión en los países de la CELAC, se comprueba que la UE tiene, geográficamente, cubierta toda la región de América Latina y el Caribe, a

${ }^{610}$ BID: BLYDE, J. (Coord.): Fábricas Sincronizadas: América Latina y el caribe en la Era de las Cadenas Globales de Valor, Washington, Banco Interamericano de Desarrollo, 2014. CEPAL: Informe de la reunión de expertos sobre cadenas globales de valor en América Latina: ¿Promoviendo el comercio con inclusión o exclusión?, Santiago de Chile, 2012. 
través de sus Delegaciones, sin embargo, no siempre tiene una representación diplomática en cada estado de la región.

Si tomamos en consideración que la CELAC, es ahora el interlocutor formal en las relaciones con la UE, entonces tomamos como marco de referencia, que esta Comunidad está compuesta por 33 Estados Miembros, de estos, la UE tiene delegaciones en 24 Estados, sin embargo, cubre la totalidad geográfica, a través de las concurrencias que tienen algunas Delegaciones de la UE.

Al estudiar las Delegaciones de la Unión, en la región de América Latina y el Caribe, se comprueba varios puntos, el primero que en el caso de América Latina, la Unión tiene delegaciones en todos los países, en el caso de El Caribe, el tema cambia, dado que la Unión no tiene delegaciones en todos los países caribeños, aunque si los llega a cubrir por medios de las concurrencias. La Unión no tiene delegaciones diplomáticas en diez países:

1. Antigua y Barbuda

2. Surinam

3. Las Bahamas

4. Belice

5. Dominica

6. Granada

7. Panamá

8. Santa Lucía

9. Federación San Cristóbal y Nieves

10. San Vicente y Las Granadinas

Los países de Antigua y Barbuda, Dominica, Granada, San Cristóbal y Nieves, Santa Lucía, San Vicente y Las Granadinas son cubiertos mediante las concurrencias a través de la Delegación de la Unión ante Barbados y Caribe Oriental. Y en el caso de Panamá, es cubierta por la Delegación de la Unión ante Nicaragua, la cual es concurrente a Costa Rica, Panamá y ante el SICA. Aunque se espera que en futuro inmediato Panamá cuenta con una propia misión diplomática por parte de la Unión.

Durante nuestra investigación de este apartado observamos también que sólo 5 países de los 33, que forman parte de la CELAC, tienen contempladas dentro de sus estructuras 
en sus servicios de acción exterior, direcciones dedicadas, exclusivamente, a las relaciones con a la Unión Europea.

A continuación, pasamos a describir los países que cuentan dentro de sus estructuras de acción exterior a la Unión Europea como un organismo regional:

1. Argentina.- La Secretaría de Relaciones Exteriores y de Culto de Argentina, establece sus relaciones con la UE, a través de su Subsecretaría de Política Exterior que contempla una dirección que la llama "Dirección de Europa Comunitaria".

2. Colombia.- El Ministerio de Relaciones Exteriores de Colombia cuenta con un Viceministerio de Relaciones Exteriores que tiene la Dirección Europa, dentro de ella tiene una unidad dedicada a las "Relaciones con la Unión Europea".

3. México.- La Secretaría de Relaciones Exteriores de México está dividida en direcciones generales, una de ella se llama, la Dirección General para Europa, dentro de ella está la Dirección General Adjunta para la Unión Europea y el Consejo de Europa.

4. Nicaragua.- El Ministerio de Relaciones Exteriores de Nicaragua, se divide en direcciones generales, dentro de ella, cuenta con una Dirección General Europa, y esta a su vez se subdivide en dos direcciones, una de ellas es la "Dirección Unión Europea".

5. Perú.- El Ministerio de Relaciones Exteriores de Perú, está dividido en direcciones generales, dentro de estas tiene una Dirección General Europa, la cual tiene una "Dirección Unión Europea".

De los cinco países, todos poseen acuerdos bilaterales con la Unión Europea. Por otro lado, de los 33 estados miembros de la CELAC sólo 4 países tienen, además de sus delegaciones ante la UE, delegaciones diplomáticas en los otros 28 Estados Miembros de la UE (EM-UE): Cuba, Ecuador, Uruguay y Chile. El resto de países no cuentan con delegaciones en todos los países. De los 33 podemos destacar 7 países, aparte de Brasil:

- Argentina, ante 2 EM-UE

- Brasil, ante 20 EM-UE

- Venezuela, ante 19 EM.UE

- México, ante 18 EM-UE 
- Perú, ante 15 EM-UE

- Panamá, ante 14 EM-UE

- Colombia, ante 12 EM-UE

En el caso de los países de América Latina, sus delegaciones diplomáticas suelen concentrarse en países como España, Francia, Italia, Alemania, Reino Unido, Países Bajos, Portugal, Grecia, Bélgica y Austria.

En cambio los países del Caribe, todos tienen un delegación ante el Reino Unido, pero no en el resto de EM-UE. De los países caribeños, existen 9 países que forman parte de la Mancomunidad de Naciones, también conocida como Commonwealth, los cuales tienen como Jefe de Estado a la Reina Isabel II del Reino Unido, quién es la que designa y es representada por un Gobernador General. Lo que nos hace pensar sobre: ¿Qué tanto influye la Corona británica en materia de política exterior de estos países? Y ¿Cómo afecta en las relaciones con la UE?. Lo que a su vez, no hace reflexionar hasta qué punto los países de la CELAC pueden argumentar la idea que con la creación de la CELAC, pretenden disminuir la influencia extra-regional, y que muchas veces es representada por Estados Unidos, mediante la OEA, y por ello muchos países latinoamericanos piensan que la CELAC puede ser un organismo sustituto a la OEA, pero parece que los países no se dan cuenta que en su propio seno, tiene a un conjunto de países cuya política exterior no parece ser tan autónoma, por el caso de los países caribeños.

Finalmente, podemos concluir que las ideas, iniciativas y proyectos integracionistas, es algo natural entre ambas regiones, pues a nuestro entender cuando se habla, en la actualidad, de que la Unión Europea y América Latina y el Caribe son "aliados naturales unidos por fuertes vínculos históricos, culturales y económicos, así como por una convergencia cada vez mayor de valores básicos y principios. Comparten un compromiso común respecto a los derechos humanos, la democracia, la buena

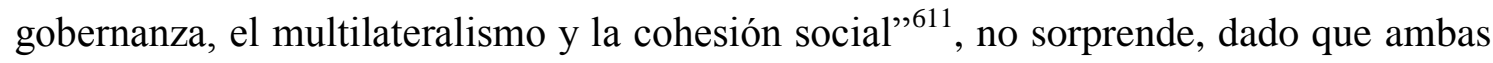
regiones comparten una historia común, y que no es sólo la historia de la integración regional, pues al fin y al cabo, ambas regiones forman parte de una historia común mayor, que es la historia de Occidente.

${ }^{611}$ COMISIÓN EUROPEA: La Asociación estratégica entre la Unión Europea, América Latina y el Caribe: un compromiso común. Comisión Europea. Dirección General de Relaciones Exteriores, Dirección América Latina, Bruselas, 2008, p. 5. 
- ANEXO

\section{LAS DELEGACIONES DE LA UNIÓN EUROPEA EN LOS PAÍSES} MIEMBROS DE LA CELAC 
Como se ha mencionado anteriormente, el SEAE se encuentra dividido, principalmente, por una Administración Central y las Delegaciones de la Unión. En este apartado veremos cómo se desarrollan las relaciones con América Latina y el Caribe, desde las Delegaciones de la Unión ubicadas en dicha región.

La UE tiene, geográficamente, cubierta toda la región de América Latina y el Caribe a través de sus Delegaciones, sin embargo, no siempre tiene una representación diplomática en cada estado de la región. Si tomamos en consideración que la CELAC es ahora el interlocutor formal en las relaciones con la UE, entonces tomamos como marco de referencia que esta Comunidad está compuesta por 33 Estados Miembros, de estos la UE tiene delegaciones en 24 Estados, pero cubre la totalidad geográfica a través de las concurrencias que tienen algunas Delegaciones de la UE.

Al estudiar las Delegaciones de la Unión en la región de América Latina y el Caribe, se comprueban varios puntos. El primero que en el caso de América Latina, la Unión tiene delegaciones en todos los países. En el caso de El Caribe, el tema cambia, dado que la Unión no tiene delegaciones en todos los países caribeños, aunque sí los llega a cubrir por medios de las concurrencias. La Unión no tiene delegaciones diplomáticas en diez países:

1. Antigua y Barbuda

2. Surinam

3. Las Bahamas

4. Belice

5. Dominica

6. Granada

7. Panamá

8. Santa Lucía

9. Federación San Cristóbal y Nieves

10. San Vicente y Las Granadinas

Los países de Antigua y Barbuda, Dominica, Granada, San Cristóbal y Nieves, Santa Lucía, San Vicente y Las Granadinas son cubiertos mediante las concurrencias a través de la Delegación de la Unión ante Barbados y Caribe Oriental. En el caso de Panamá, es cubierta por la Delegación de la Unión ante Nicaragua, la cual es concurrente a Costa 
Rica, Panamá y ante el SICA, aunque se espera que en futuro inmediato Panamá cuente con una propia misión diplomática por parte de la Unión.

Si tomamos en consideración el número de funcionarios que destina el SEAE hacia las 23 Delegaciones de la Unión existentes en la región de América Latina y el Caribe, estas se pueden dividir en cuatro grandes grupos:

I. Delegaciones de la Unión entre 15 y 50 funcionarios

II. Delegaciones de la Unión entre 9 y 10 funcionarios

III. Delegaciones de la Unión entre 6 y 7 funcionarios

IV. Delegaciones de la Unión entre 1 y 5 funcionarios

En el Grupo I de Delegaciones de la Unión, se observa que existen un promedio entre 15 y 50 funcionarios, y entre ellas encontramos a 5 delegaciones:

1. Haití

2. Barbados y Caribe Oriental

3. El Salvador

4. Cuba

5. Uruguay

La Delegación de la Unión con más funcionarios es la Delegación ante Haití, la cual cuenta con un total de 50 funcionarios y tiene como Jefe de Misión al Embajador Javier Niño Pérez, de nacionalidad española. La Delegación de la Unión ante Barbados y Caribe Oriental contabiliza un total de 46 funcionarios y está a cargo, como Jefe de Misión, el Embajador Mikael Barfod, de nacionalidad danesa. La Delegación ante El Salvador tiene 18 funcionarios, el Jefe de Misión es el Embajador Jaume Segura Sacias, de nacionalidad española. En el caso de la Delegación ante Cuba, ésta cuenta con 17 funcionarios, siendo el Jefe de Misión el Embajador Herman Portocarrero, de nacionalidad belga. Por último, en la Delegación de la Unión ante Uruguay, el Jefe de Misión es El Embajador Juan Fernández Trigo, de nacionalidad española.

Como se aprecia, de las cinco Delegaciones más grandes, tres tienen como Jefe de Misión a un español. También se puede deducir el peso que tiene el Caribe, pues de las cinco delegaciones con más funcionarios, tres son caribeños: Haití, Barbados y el Caribe Oriental y Cuba. Si sumamos, el número de funcionarios que tiene el SEAE a 
través de las 24 Delegaciones de la Unión, contabilizamos un total de 212 funcionarios, de ellos, casi una tercera parte (146 funcionarios) se encuentran destinados en estas cinco misiones diplomáticas, y si tomamos en consideración el peso geográfico, más de la mitad (114 funcionarios) se encuentran en tres países caribeños, Haití, Cuba, Barbados y Caribe Oriental.

En los casos de El Salvador y Uruguay responde a que en ambos países se encuentran las sedes de los organismos que dirigen los procesos de integración subregional en sus respectivas áreas geográficas, en el caso del El Salvador, que se encuentra la Secretaría del Sistema de Integración Centroamericana (SICA). Un dato muy importante a tener en cuenta es que la Unión Europea está acreditada como Miembro Observador del SICA, por lo que el Jefe de Misión de la Delegación de la Unión también se encuentra acreditado ante el SICA. En el caso de Uruguay, se encuentra la Secretaría del Mercado Común del Sur (MERCOSUR). Es decir, en ambos casos se justifica que la Unión destine tantos funcionarios ante estos países, dadas sus negociaciones inter-regionales: UE-SICA y UE-MERCOSUR.

En el Grupo II de las Delegaciones de la Unión entre 9 y 10 funcionarios, existen cuatro Delegaciones:

- La Delegación de Jamaica, que cuenta con 10 funcionarios y tiene como Jefe de Misión al Embajadora Paola Amadei, de nacionalidad italiana.

- La Delegación ante República Dominicana, tiene 9 funcionarios y tiene como Jefe de Misión al Embajador Alberto Navarro, de nacionalidad española

- La Delegación ante Brasil, que cuenta con 9 funcionarios y tiene como Jefe de Misión a la Embajadora Ana Paula Zacarías, de nacionalidad portuguesa.

- La Delegación ante Nicaragua, la cual es concurrente a Costa Rica, Panamá y ante el SICA, tiene 10 funcionarios y tiene como Jefe de Misión al Embajador Javier Sandomingo, de nacionalidad española.

En el Grupo III, encontramos a las Delegaciones de la Unión en: Bolivia, Colombia, Ecuador, México, Nicaragua, Perú y Venezuela.

En el Grupo IV, se encuentran las Delegaciones de la Unión ante: Argentina, Chile y Costa Rica. Y en el Grupo IV las Delegaciones ante: Guatemala, Honduras, Trinidad y Tobago y Paraguay. 
De los 23 embajadores como jefes de misión en las Delegaciones de la UE, 8 son españoles, 2 daneses, 2 británicos, 2 holandeses, 2 checos, 2 italianos, 1 francés, 1 austriaco, 1 griego, 1 belga, y 1 portugués. El peso de los españoles es evidente, pero también confirma que la UE hace uso del peso e importancia de España dentro de ALC para fortalecer sus relaciones con la región, dada su afinidad histórica, cultural y lingüística. Lo que, por otra parte, también evidencia el interés de España y el apoyo de España hacia ALC dentro de la agenda de la diplomacia comunitaria.

Entre los Jefes de Misión de la Unión Europea, de nacionalidad española encontramos:

1. Argentina, Embajador Alfonso Díez Torres (España)

2. Chile, Embajador Rafael Dochao Moreno (España)

3. Cuba, Embajador Herman Portocarero (Bélgica, pero tiene orígenes portuguesa y española)

4. República Dominicana, Embajador Alberto Navarro (España)

5. Nicaragua, Panamá y SICA, Embajador Javier Sandomingo Núñez (España)

6. El Salvador, Embajador Jaume Segura Sacias (España)

7. Haití, Embajador Javier Niño Pérez (España)

8. Uruguay, Embajador Juan Fernández Trigo (España)

\section{RELACIONES DIPLOMÁtiCAS ENTRE LA UE Y LOS PAÍSES DE LA CELAC}

A continuación, de manera sintetizada revisaremos cada país miembro de la CELAC con el fin de saber y determinar cómo se dan en la práctica, y al día de hoy, las relaciones diplomáticas entre la UE y cada país de la CELAC. Para ello hemos tomando en cuenta tres preguntas a responder, sobre las cuales hemos desarrollado, en cada caso, tres puntos:

1. El marco jurídico sobre el cual se desarrollan las relaciones entre las partes.

2. La UE dentro de las estructuras del servicio exterior de cada país.

3. Las delegaciones diplomáticas entre las partes. 
Este apartado pretende descubrir qué lugar ocupa la Unión Europea dentro de las estructuras de los servicios de acción exterior de los países de América Latina y el Caribe. Se parte de la hipótesis de que la existencia o no de una unidad, división, dirección, secretaría o subsecretaría dedicada a la UE, representará la percepción de la UE en cada uno de los países, a la par que nos permitirá conocer el grado de importancia que le brindan a la UE, además del tipo de relación política, económica o de cooperación existente, más si se considera que el conjunto de los países de ALC están embarcados en conseguir una Asociación Estratégica entre la CELAC y la UE. 


\section{- La UE-Antigua y Barbuda}

Marco jurídico de las relaciones:

Las relaciones con la Unión Europea se enmarcan dentro de su membresía en el llamado grupo de 79 Países ACP (África, Caribe y Pacífico), con los cuales mantiene relaciones en diferentes ámbitos: políticos, económicos y social, también en el área de ayuda de cooperación al desarrollo. La base jurídica de dichas relaciones se encuentran recogidas en el Acuerdo de Cotonú (2000) ${ }^{612}$, el cual sustituyó a los antiguos Convenios de Yaundé y de Lomé. El Acuerdo de Cotonú se diferencia de los otros convenios, porque agrega nuevos componentes, entre ellos el ámbito regional, e incluye, instrumentos de apoyo financiero al grupo de países ACP, mediante el Fondo Europeo de Desarrollo (FED). Por otro lado, Antigua y Barbuda, al igual que el resto de los países miembros de CARICOM, también participan en el CARIFORUM, el cual sirve como mecanismo de diálogo económico con la UE, lo que le permite obtener beneficios económicos y comerciales mediante el Acuerdo de Asociación Económica con la Unión Europea, suscrito en 2008.

Estructura del servicio de acción exterior de Antigua y Barbuda:

El servicio de acción exterior es ejercido por el Ministerio de Asuntos Exteriores y Comercio Internacional. No existe detalle sobre su organización interna, pero de acuerdo al resto de los países, que igual que Antigua y Barbuda, son parte de la "Mancomunidad de Naciones" o conocida por sus siglas en inglés Commonwealth of the Nations, suelen tener estructuras nucleares, es decir, pequeñas administraciones generales que suelen ser llamadas Secretarías de Estado, encargadas de llevar los asuntos exteriores. Suelen estar divididas en divisiones, direcciones o unidades, y al igual que en la mayoría de los ministerios de asuntos exteriores, suelen manejar sus estructuras de servicio exterior, en base a áreas geográficas y/o áreas temáticas. En este caso, no encontramos información de cómo está dividida.

\footnotetext{
${ }^{612}$ Acuerdo de Asociación entre los Estados de África, del Caribe y del Pacífico-Comunidad Europea y sus Estados Miembros, firmado en Cotonú, el 23 de junio de 2000. EUR-LEX. Europa. Síntesis de la legislación de la UE.

http://europa.eu/legislation_summaries/development/african_caribbean_pacific_states/r12101_es.htm [Última versión: 06-01-15]
} 
Delegaciones diplomáticas:

\section{Antigua y Barbuda ante la UE:}

Antigua y Barbuda sí cuenta con una delegación diplomática ante la Unión Europea. Sin embargo hay que mencionar que sólo cuenta con un representante, el jefe de misión, es decir un embajador ${ }^{613}$. Cuenta con una sola representación diplomática en toda la UE, ante el Reino Unido ${ }^{614}$.

\section{La UE ante Antigua y Barbuda:}

La Unión no cuenta con una representación en territorio de Antigua y Barbuda, sin embargo, es cubierta desde la Delegación de la Unión Europea en Barbados, la cual tiene como concurrencia a Antigua y Barbuda. Cuando tratemos sobre Barbados, se detallará la organización interna de la Delegación. Desde el 2010 la Delegación de la Unión Europea ante Antigua y Barbuda, destinó 130 Millones de Euros a los 10 países que forman parte del Caribe Oriental, 9. 174.910 Euros fueron destinados para Antigua y Barbuda $^{615}$.

${ }^{613}$ EUROPEAN COMMISION-SECRETARIAT GENERAL: Diplomatic Corps. Protocol Service. Missions accredited to European Union. Antigua y Barbuda. p. 8

http://ec.europa.eu/dgs/secretariat_general/corps/index.cfm?go=search.search\&missions=1 [Última versión: 08-01-15]

${ }_{614}$ MINISTRY OF FOREIGN AFFAIRS OF ANTIGUA Y BARBUDA: Overseas Missions. http://www.foreignaffairs.gov.ag/diplomacy/missions.php [Última versión: 08-01-15]

${ }^{615}$ DELEGATION OF THE EUROPEAN UNION TO BARBADOS AND THE EASTERN CARIBBEAN: Antigua and Barbuda \& European Union. Political and Economic Relations.

http://eeas.europa.eu/delegations/barbados/eu_oecs/antigua_barbuda/index_en.htm [Última versión: 0801-15] 


\section{- La UE-Argentina}

Marco jurídico de las relaciones:

En lo que concierne a las relaciones con la Unión Europea, mantienen una relación comercial y de cooperación, de larga data, en primer lugar a nivel bilateral y luego a nivel subregional, en el marco del proceso de negociaciones a nivel inter-regional entre el MERCOSUR-UE, sin embargo este proceso lleva varios años estancado.

En lo que respecta en las relaciones a nivel bilateral entre la UE-Argentina se regulan mediante el Acuerdo Marco de Cooperación Comercial y Económica ${ }^{616}$, firmado el 2 de abril de 1990. Las partes tienen un diálogo permanente e institucionalizado a través de una Comisión Mixta que aborda diferentes políticas sectoriales, con el fin de debatir temas de interés común. Para apoyar dicho diálogo político, se creó un fondo de 6.500.000 Euros (2007-2013) ${ }^{617}$. En Septiembre de 2010 la Comisión Mixta adoptó un Programa de Trabajo Conjunto para el período 2010-2013, el cual contendría los siguientes puntos:

1. Diálogo bilateral y cooperación multilateral

2. Promoción del Desarrollo Sostenible

3. Promoción de intercambios entre pueblos e intercambio culturales

4. Apoyo a la integración regional

De todos estos puntos podemos resaltar el número 1 y 4 . El primer punto busca obtener el compromiso de Argentina con el multilateralismo, de tal manera que la Unión pueda trabajar conjuntamente con Argentina en asuntos de interés común en temas globales, centrando sus trabajo en las Naciones Unidas, para ello acuerdan mantener un diálogo previo, de alto nivel, antes de las celebraciones de cada Sesión Anual de la Asamblea General de Naciones Unidas. Con respecto al punto cuatro, podemos comprobar el compromiso de la UE, siempre en favor de la integración regional, apoyo que ha sido manifestado en las relaciones establecidas como región entre el Grupo de RíoComunidad Europea, luego América Latina-Unión Europea, posteriormente Unión

${ }^{616}$ DIARIO OFICIAL DE LAS COMUNIDADES EUROPEAS Nº L 295/66. 26.10.90. Decisión del Consejo de 8 de octubre de 1990 relativa a la celebración del Acuerdo Marco de Cooperación Comercial y Económica entre la Comunidad Económica Europea y la República de Argentina.

http://eeas.europa.eu/delegations/argentina/documents/eu_argentina/coop_001_es.pdf [Última revisión: 28-11-14]

${ }^{617}$ EUROPEAN COMMISION: Argentina. Country Strategy Paper 2007-2013, Bruselas, 23 de abril de 2007. http://eeas.europa.eu/argentina/csp/07_13_en.pdf [Última revisión: 28-11-14] 
Europea-América Latina y el Caribe, también entre MERCOSUR-UE, y finalmente entre la Unión Europea-Comunidad de Estados Latinoamericanos y Caribeños.

Argentina y la Unión Europea destacan la importancia de trabajar conjuntamente para fortalecer la Asociación Estratégica con los objetivos de seguir profundizando el diálogo y la integración regional, promoviendo la inclusión y cohesión social [...]. Las Partes se comprometen a fortalecer sus procesos de integración como un instrumento eficaz para estimular el desarrollo sostenible y el crecimiento de la región [...] acuerdan contribuir activamente para la conclusión de un Acuerdo de Asociación Inter-regional UE-MERCOSUR ${ }^{618}$.

A nivel subregional, Argentina recibe cooperación a través de las relaciones entre la UE-MERCOSUR, dicha cooperación tiene como objetivo apoyar el proceso de integración del MERCOSUR, para lo cual se prevé una estrategia plurianual de cooperación $^{619}$.

Estructura del Servicio de Acción Exterior de Argentina:

El Servicio de Acción Exterior de Argentina se estructura a través de secretarías. Las relaciones con la Unión Europea se desarrollan dentro de la Dirección de Asuntos Regionales ${ }^{620}$, entre cuyas competencias está cubrir los “foros regionales". Resaltamos entre comillas el término foros regionales porque estos aparecerán como una definición constante y como denominador común dentro de las estructuras de los servicios de acción exterior de varios países, lo que nos hace pensar que es justamente la definición y aspiración política que le dan dentro de sus respectivas políticas de acción exterior. Por ello, no tienen problemas en juntar en una misma dirección diferentes procesos y tipos de diálogo con diferentes regionales y subregiones del mundo.

\footnotetext{
${ }^{618}$ Programa de Trabajo Argentina-Unión Europea 2010-2013. Bruselas, 28 de septiembre de 2010. Para más información puede ver el documento completo en el sitio web de la Delegación de la Unión Europea en Argentina.

http://eeas.europa.eu/delegations/argentina/eu_argentina/political_relations/index_es.htm_[Última revisión: $28-11-14]$

${ }^{619}$ DELEGACIÓN DE LA UNIÓN EUROPEA EN LA REPÚBLICA DE ARGENTINA: Argentina y la Unión Europea. Cooperación.

http://eeas.europa.eu/delegations/argentina/eu_argentina/cooperation/index_es.htm [Última revisión: 2811-14]

${ }^{620}$ MINISTERIO DE RELACIONES EXTERIORES Y CULTO DE LA REPÚBLICA DE ARGENTINA: Cancillería. Relaciones Exteriores. Dirección de Asuntos Regionales. https://www.mrecic.gov.ar/es/asuntos-regionales [Última revisión: 28-11-14]
} 
La Dirección de Asuntos regionales del Ministerio de Relaciones Exteriores y Culto de la República de Argentina tiene dentro de sus funciones ocuparse de los siguientes foros regionales:

- Cumbre de las Américas

- Conferencia Iberoamericana

- Comunidad de Estados Latinoamericanos y Caribeños

- Diálogo entre la Comunidad de Estados Latinoamericanos y Caribeños- Unión Europea

Como se puede constatar, Argentina le da el mismo orden de importancia dentro su política exterior a la CELAC, como al diálogo entre la CELAC y la UE, que el resto de cumbres y conferencias, tratándolas a todas como foros, es decir, un lugar donde se pueden discutir asuntos de interés general o específicos para los países, pero cuyos resultados o decisiones no son vinculantes ni representan responsabilidades. Lo que hace confirmar que los países de ALC no tienen claro lo que significa integración regional, y como ya se ha mencionado anteriormente y a lo largo del esta investigación, los países latinoamericanos y caribeños confunden integración con cooperación.

Argentina tiene una Subsecretaría de Política Exterior, la cual está subdividida en varias direcciones, en sus relaciones con Europa divide a ésta en dos:

- Dirección de Europa del Este

- Dirección de Europa Comunitaria

La Dirección de Europa Comunitaria es la encargada de las relaciones con la Unión, sin embargo, a pesar que el término Europa Comunitaria es correcta, también deja entrever un cierto desfase histórico del proceso de integración europea, o al menos una falta de actualización de los términos, que no es un asunto meramente terminólogo. Durante varias entrevistas realizadas a diplomáticos latinoamericanos para esta investigación, se ha podido comprobar que cada vez que los diplomáticos usan el término Europa Comunitaria es porque no conocen el estado actual de la Unión Europea, ni en tareas ni funciones. En otros casos usan también el término la Comunidad Europea, y bastará con seguir conversando con el diplomático para entender que sabe poco o nada de las reformas de los tratados de la Unión Europea, ni que decir ya de las novedades del Tratado de Lisboa. 
Delegaciones diplomáticas:

\section{Argentina ante la UE}

Argentina tiene una delegación diplomática ante la Unión Europea, concurrente a Bélgica. La misión diplomática cuenta con 8 funcionarios $^{621}$ :

- Embajador

- 1 Ministro

- 2 Consejeros

- 1 Primer Secretario

- 1 Segundo Secretario

- 1 Agregado Administrativo

- 1 Ministro Plenipotenciario

Argentina cuenta con Embajadas en 19 Estados Miembros de la UE.

\section{La UE ante Argentina}

La Unión Europea tiene una delegación diplomática ante Argentina, cuenta con 5 funcionarios y se organiza internamente de la siguiente manera ${ }^{622}$ :

- Jefe de Delegación. Embajador Alfonso Díez Torres (España)

- 1 Jefe de Sección Política, Prensa e Información, Ministro Consejero, César García Álvarez

- 1 Jefe de Sección Económica y Comercio, Primer Secretario, Nils Weller

- 1 Sección Cooperación, Agregado, Luis Pedro Pereira Mateus

- 1 Jefe de Sección Administración, Agregado, Gaetano Petralia

${ }^{621}$ EUROPEAN COMMISION-SECRETARIAT GENERAL: Diplomatic Corps. Protocol Service. Missions accredited to European Union. Argentina. pp. 9-10.

http://ec.europa.eu/dgs/secretariat_general/corps/index.cfm?go=search.search\&missions=1 [Última versión: 08-01-15]

${ }^{622}$ DELEGACIÓN DE LA UNIÓN EUROPEA EN LA REPÚBLICA DE ARGENTINA: Organización Interna.

http://eeas.europa.eu/delegations/argentina/about_us/internal_organisation/index_es.htm [Última versión: 08-01-15] 


\section{- La UE-Bahamas}

Marco jurídico de las relaciones:

Sus relaciones con la Unión Europea las desarrolla gracias a sus acuerdos vinculados con los Países ACP, del cual es miembro. Tal como se ha indicado antes, en el caso de Antigua y Barbuda, este grupo de países iniciaron sus relaciones con la Comunidad Económica Europea y luego con la Comunidad Europea, mediante los Acuerdos Lomé y continuaron con el Acuerdo de Asociación ACP-UE, firmado en Cotonú, el 23 de junio de 2000 y revisado en Luxemburgo, el 25 de junio de 2005. Por otro lado, al igual que Antigua y Barbuda también es miembro de la Commonwealth of Nations, como todos los países miembros de esta mancomunidad, siempre han gozado de los lazos económicos y políticos con Europa ${ }^{623}$. Como miembro de la Comunidad del Caribe, Las Bahamas es miembro de CARIFORUM, foro que une a la Unión Europea $^{624}$ y la Comunidad del Caribe. A través de CARIFORUM tiene un Acuerdo de Asociación Económica, entre ambas partes, el acuerdo fue suscrito el 15 de octubre de 2008. Las Bahamas también se beneficia de programas de cooperación de la UE de manera bilateral, el último programa fue para el período 2008-2013, con un presupuesto de 4.700.00 Millones de Euros ${ }^{625}$, el anterior programa fue también de carácter plurianual y cubrió el período 2002-2007, con un presupuesto de 4.500.000 Millones de Euros ${ }^{626}$. Parte de estos fondos provienen del Fondo Europeo de Desarrollo (FED).

\section{Estructura del Servicio de Acción Exterior de las Bahamas:}

El Ministerio de Asuntos Exteriores e Inmigración de Las Bahamas se fracciona en Divisiones, existiendo una División de Relaciones Bilaterales y otra División de

\footnotetext{
${ }^{623}$ DELEGATION OF THE EUROPEAN UNION TO JAMAICA, BELIZE, THE BAHAMAS, TURKS AND CAICOS ISLANDS AND CAYMAN ISLANDS: The Bahamas \& the European Union. Political \& economic relations.

http://eeas.europa.eu/delegations/jamaica/eu_bahamas/political_relations/index_en.htm [Última versión: 08-01-15]

${ }^{624}$ DELEGATION OF THE EUROPEAN UNION TO JAMAICA, BELIZE, THE BAHAMAS, TURKS AND CAICOS ISLANDS AND CAYMAN ISLANDS: The Bahamas \& the European Union. The Regional Dimension. http://eeas.europa.eu/delegations/jamaica/eu_bahamas/political_relations/regional_dimension/index_en.ht $\mathrm{m}$

${ }_{625}$ EUROPEAN COMMISSION: Country Strategy Paper For The Bahamas 2008-2013, Brussels, 18 November 2008. http://ec.europa.eu/development/icenter/repository/scanned_bs_csp10_en.pdf [Última versión: 08-01-15] ${ }^{626}$ EUROPEAN COMMISSION: Country Strategy Paper and National Indicative Programme for the period 2002-2007, Brussels, 6.2.2003.

http://ec.europa.eu/development/icenter/repository/scanned_bs_csp_en.pdf [Última versión: 08-01-15]
} 
Multilaterales $^{627}$. Dentro de la División de Relaciones Bilaterales, se promueven las relaciones con cada uno de los países europeos. Las relaciones con la Unión Europea se encuentran dentro de la División de Multilaterales, la cual se encarga de las relaciones con:

- Comunidad del Caribe

- Organización de Estados Americanos

- Comunidad Económica Africana

- Comisión Económica para América Latina y el Caribe

- Sistema Económico para América Latina y el Caribe

- Unión Europea

\section{Delegaciones diplomáticas:}

\section{Las Bahamas ante la UE:}

Las Bahamas cuenta con una delegación diplomática ante la UE y cuenta con 4 funcionarios $^{628}$ :

- Embajador

- 1 Primer Secretario

- 1 Segundo Secretario

- 1 Tercer Secretario

Las Bahamas sólo posee una Embajada en un Estado Miembro de la UE, ante el Reino Unido $^{629}$, y es por ser parte de la Mancomunidad de Naciones.

\section{La UE ante Las Bahamas:}

La UE no posee delegación diplomática en Las Bahamas. Pero es cubierta desde la Delegación de la Unión Europea ante Jamaica, la cual es concurrente a Belice, Las Bahamas, Las Islas Turcas y Caicos, y las Islas Caimán ${ }^{630}$.

627 THE GOVERNMENT OF THE BAHAMAS: MINISTRY OF FOREIGN AFFAIRS AND INMIGRATIONS. Areas of Responsibility. http://www.bahamas.gov.bs [Última versión: 08-01-15]

${ }_{628}$ EUROPEAN COMMISION-SECRETARIAT GENERAL: Diplomatic Corps. Protocol Service. Missions accredited to European Union. The Bahamas. p. 15.

http://ec.europa.eu/dgs/secretariat_general/corps/index.cfm?go=search.search\&missions=1

${ }^{629}$ MINISTRY OF FOREIGN AFFAIRS AND INMIGRATIONS: Overseas Missions.

http://www.bahamas.gov.bs [Última versión: 08-01-15] 


\section{- La UE-Barbados}

Marco jurídico de las relaciones:

Las relaciones con la UE también se producen a través del marco entre la UE y los acuerdos con los países ACP. El Banco Europeo de Inversiones también ayuda a implementar políticas de cooperación y desarrollo, así como en la facilitación e implementación de líneas de crédito para Barbados. Desde el 2010 hasta la fecha Barbados ha recibido un promedio de 23,1 millones de Euros, de los cuales 14,77 millones de Euros provienen de las ayudas comprendidas en el Protocolo del Azúcar ${ }^{631}$ y sus respectivas Medidas de Acompañamiento ${ }^{632}$, que recibe por parte de la UE, y 8,33 millones como parte del 10 programa del Fondo Europeo de Desarrollo ${ }^{633}$.

\section{Estructura del Servicio de Acción Exterior de Barbados:}

El Ministerio de Asuntos Exteriores y Comercio Exterior se encuentra dividido por áreas geográficas, las cuales se encuentra repartida en divisiones, contando con una División Europa ${ }^{634}$, que es la que lleva de manera general todos los temas tanto a nivel bilateral con los países europeos como las relaciones con la Unión.

\section{Delegaciones diplomáticas:}

\section{Barbados ante la UE:}

Barbados cuenta con una delegación diplomática ante la UE, que es concurrente a 4 Estados Miembros de la UE: Bélgica, Francia, Alemania e Italia.

${ }^{630}$ DELEGATION TO JAMAICA, BELIZE, THE BAHAMAS, TURKS AND CAICOS ISLANDS AND CAYMAN ISLANDS: The Bahamas \& the European Union.

http://eeas.europa.eu/delegations/jamaica/eu_bahamas/developement_cooperation/index_en.htm [Última versión: 08-01-15]

${ }^{631}$ Para más información sobre el Protocolo del Azúcar ver en:

http://eeas.europa.eu/delegations/barbados/eu_barbados/development_coop/sugar_protocol/index_en.htm [Última revisión: 08-01-15]

${ }_{632}$ EUROPEAN COMMISION: International Cooperation and Development. The Accompanying Measures for Sugar Protocol Countries (AMSP).

http://ec.europa.eu/europeaid/sectors/food-and-agriculture/sustainable-agriculture-and-ruraldevelopment/amsp_en [Última versión: 09-01-15]

633 DELEGATION OF THE EUROPEAN UNION TO BARBADOS AND THE EASTERN CARIBBEAN: Barbados and European Union. Political and Economic Relations.

http://eeas.europa.eu/delegations/barbados/eu_barbados/political_relations/index_en.htm [Última versión: 09-01-15]

${ }^{634}$ MINISTRY OF FOREIGN AFFAIRS AND FOREIGN TRADE: About the Ministry Organization. http://www.foreign.gov.bb/UserFiles/File/File/File/File/October.pdf [Última versión: 09-01-15] 
La Embajada cuenta con 4 funcionarios ${ }^{635}$ :

- Embajador

- Primer Secretario

- 2 Agregados

\section{La UE ante Barbados:}

La UE cuenta con una Delegación ante Barbados y el Caribe Oriental. La delegación tiene dentro de sus concurrencias a los siguientes países: Barbados, Antigua y Barbuda, Dominica, Granada, Santa Lucía, San Cristóbal y Nevis y San Vicente y Las Granadinas. También acreditados ante la Organización de Estados del Caribe Oriental (OECO).

La Delegación también cubre los siguientes Países y Territorios Ultramar (PTU): Anguila, Islas Vírgenes Británicas y Montserrat ${ }^{636}$. La misión cuenta con 8 funcionarios más 38 personas que trabajan en las distintas secciones ${ }^{637}$. Siendo esta Delegación de la Unión Europea una de las más grandes dentro de los países que forman parte de la CELAC. Desde esta misión la UE coordina y gestiona los proyectos regionales que tiene con los países que son parte del Foro de los Estados del Caribe, África, y del Pacífico (CARIFORUM).

Secciones de la Delegación de la UE:

- Jefe de Misión, Embajador, Mikael Barfod (Dinamarca)

- Jefe de Cooperación

- Jefe de Política, Comercio, Integración regional, Información y Prensa + 3 personas

- 1 Jefe de Desarrollo Social y Rural + 5 personas

635 EUROPEAN COMMISION-SECRETARIAT GENERAL: Diplomatic Corps. Protocol Service. Missions accredited to European Union. Barbados. p. 18

http://ec.europa.eu/dgs/secretariat_general/corps/index.cfm?go=search.search\&missions=1 [Última versión: 09-01-15]

${ }^{636}$ DELEGATION OF THE EUROPEAN UNION TO BARBADOS AND THE EASTERN CARIBBEAN.

http://eeas.europa.eu/delegations/barbados/index_en.htm [Última versión: 09-01-15]

637 DELEGATION OF THE EUROPEAN UNION TO BARBADOS AND THE EASTERN CARIBBEAN: Internal Organization:

http://eeas.europa.eu/delegations/barbados/about_us/internal_organisation/index_en.htm [Última versión: 09-01-15] 
- 1 Jefe de Economía + 5 personas

- 1 Jefe de Infraestructura, Cambio Climático, Turismo y Reducción de Riesgo de Desastres + personas

- 1 Jefe de finanzas y contractos +6 personas

- 1 Jefe de administración +9 personas 


\section{- La UE-Belice}

\section{Marco jurídico de las relaciones:}

Sus relaciones con la UE se producen a nivel multilateral y regional. A nivel bilateral, las relaciones con Belice se inician cuando este se incorpora al grupo de países ACP, mediante su adhesión al Segundo Acuerdo Lomé, en $1982^{638}$. En el ámbito regional sus relaciones con la UE se da mediante las relaciones UE-CARICOM ${ }^{639}$, y por consiguiente a través del UE-CARIFORUM ${ }^{640}$. En 2010, en la Cumbre UECARIFORUM, deciden impulsar una estrategia conjunta, la cual se comienza a implementar a partir del $2012^{641}$.

La Delegación de la UE en Jamaica es concurrente a Belice y es a través de ella que se gestiona las relaciones políticas, económicas y de cooperación que recibe Belice. Así mismo, parte de la cooperación al desarrollo que recibe Belice proviene vía el Banco Europeo de Desarrollo. También es beneficiaria de las Medidas de Acompañamiento para los Países del Protocolo del Azúcar, el Marco Especial de Asistencia para los Países ACP en Plátanos ${ }^{642}$, este último instrumento tenía como finalidad proporcionar asistencia técnica y financiera, de carácter temporal, a los países ACP, que tradicionalmente exportaban plátanos. La idea era que éstos pudieran adaptarse a las nuevas condiciones del mercado y lograsen ser más competitivos y buscar una mayor diversificación de su economía.

\footnotetext{
${ }^{638}$ DELEGATION OF THE EUROPEAN UNION TO JAMAICA, BELIZE, THE BAHAMAS, TURKS AND CAICOS ISLANDS AND CAYMAN ISLANDS: Belize \& the European Union. Political \& Legal Framework.

http://eeas.europa.eu/delegations/jamaica/eu_belize/political_relations/political_legal_framework/index_e n.htm [Última versión: 10-01-15]

${ }^{639}$ DELEGATION OF THE EUROPEAN UNION TO JAMAICA, BELIZE, THE BAHAMAS, TURKS AND CAICOS ISLANDS AND CAYMAN ISLANDS: Belize \& the European Union. Regional Dimension.

http://eeas.europa.eu/delegations/jamaica/eu_belize/political_relations/regional_dimension/index_en.htm [Última versión: 10-01-15]

${ }^{640}$ El CARIFORUM, incluye a 14 de los 15 miembros del CARICOM, más Cuba y República Dominicana.

${ }^{641}$ EUROPEAN COMMISION: Memo EU relations with the Caribbean, Brussels, 18.9.2013. http://europa.eu/rapid/press-release_MEMO-13-798_en.htm [Última versión: 10-01-15]

${ }^{642}$ DIARIO OFICIAL DE LAS COMUNIDADES EUROPEAS N ${ }^{\circ}$ L 286/1 Reglamento (CE) $\mathrm{N}^{\circ}$ 2686/94 del Consejo de 31 de octubre por el que se establece un sistema especial de asistencia a los proveedores ACP tradicionales de plátanos.

http://eur-lex.europa.eu/legal-content/ES/TXT/PDF/?uri=CELEX:31994R2686\&from=EN [Última versión: 10-01-15]
} 
Estructura del Servicio de Acción Exterior de Belice:

El Ministerio de Asuntos Exteriores de Belice está dividido en cuatro direcciones ${ }^{643}$ :

1. Dirección de Política Exterior

2. Dirección de Cooperación

3. Dirección de Protocolo

4. Dirección de Asuntos Consulares

Las relaciones con la Unión Europea se encuentran dentro de las funciones de la Dirección de Política Exterior, de manera general, no existe una unidad específica que se encargue sobre los asuntos de la UE.

Delegaciones diplomáticas:

\section{Belice ante la UE:}

Belice tiene una delegación diplomática ante la Unión Europea, la cual es concurrente a Bélgica. Además de dicha representación, sólo cuenta con otra delegación diplomática en toda la UE, y esta es ante el Reino Unido en donde cuenta con un Alto Comisionado como la mayoría de los países miembros de la Commonwealth ${ }^{644}$. La representación ante la UE cuenta con tres diplomáticos: un Embajador, un Consejero y un Agregado de Comercio $^{645}$.

\section{La UE ante Belice:}

La UE no tiene una delegación diplomática ante Belice. Sin embargo, cubre este país desde la Delegación de la Unión Europea ante Jamaica, la cual es concurrente a Belice, Las Bahamas, Las Islas Turcas y Caicos, y las Islas Caimán ${ }^{646}$.

${ }^{643}$ MINISTRY OF FOREIGN AFFAIRS OF BELIZE: Organization.
http://www.mfa.gov.bz/index.php/about-us/organogram [Última versión: 10-01-15]
MINISTRY OF FOREIGN AFFAIRS OF BELIZE: Embassies and Consulates of Belize.
http://www.mfa.gov.bz/index.php/what-we-do/consular-matters/embassies-consulates [Última versión:
10-01-15]
${ }^{645}$ EUROPEAN COMMISION-SECRETARIAT GENERAL: Diplomatic Corps. Protocol Service. Missions accredited to European Union. Belize. p. 21

http://ec.europa.eu/dgs/secretariat_general/corps/index.cfm?go=search.search\&missions=1 [Última versión: 10-01-15]

${ }^{646}$ DELEGATION OF THE EUROPEAN UNION TO JAMAICA, BELIZE, THE BAHAMAS, TURKS AND CAICOS ISLANDS AND CAYMAN ISLANDS: Belize \& the European Union. Political \& Economic Relations.

http://eeas.europa.eu/delegations/jamaica/eu_belize/political_relations/index_en.htm [Última versión: 1001-15] 


\section{- La UE-Bolivia}

\section{Marco jurídico de las relaciones:}

Sus relaciones con la Unión se desarrollan principalmente en el marco de la Comunidad Andina. Las relaciones entre la UE y la CAN se remontan casi a la creación de la CAN durante la década de los sesenta.

Entre los principales actos jurídicos que regulan las relaciones inter-regionales UECAN podemos mencionar: el Acuerdo de Cooperación económica y comercial de $1983^{647}$; el Acuerdo de Cooperación de $1993^{648}$; y la Declaración de Roma, declaración conjunta que establece el lanzamiento de las negociaciones hacia un diálogo político institucionalizado, en 1996. Todos estos pasos servirán para que en 2003 acuerden negociar un pacto que incluya el diálogo político y la cooperación ${ }^{649}$. Sobre esta base, los jefes de estado de ambas partes deciden en 2006, en el marco de la IV Cumbre ALC-UE, iniciar negociaciones conducentes al Acuerdo de Asociación que tendrá como estrategia, incluir un Acuerdo Global, que incluya tres pilares: diálogo político, económico-comercial y cooperación.

Durante el $2007^{650}$, y posteriormente en el 2008, se producen reuniones con el fin de concretar posiciones y firmar dicho acuerdo, pero lamentablemente, dicho acuerdo no logra materializarse; se abandona la negociación a nivel interregional, y se termina haciendo a nivel bilateral. Sin embargo se aprueba el Documento de Estrategia Regional Comisión Europea-Comunidad Andina 2007-2013, la cual identifica a la integración regional como el principal objetivo ${ }^{651}$. Se fundamenta en el apoyo de la integración regional a nivel subregional, es decir apoyar a la integración andina para reforzar, a

\footnotetext{
${ }^{647}$ Acuerdo de Cooperación entre la Comunidad Económica Europea, por un parte, y el Acuerdo de Cartagena y sus Países Miembros, por la otra, Bruselas, 28 de octubre de 1983. Ver: COMUNIDAD ANDINA. Normativa Andina: DECISIÓN 190. Trigesimonoveno Período de Sesiones Extraordinarias de la Comisión, Lima, 7-9 de noviembre de 1983.

${ }^{648}$ Acuerdo Marco de Cooperación entre la Comunidad Económica Europea y el Acuerdo de Cartagena, Copenhague, 23 de abril de 1993. Ver COMUNIDAD ANDINA. Normativa Andina: Decisión 329.

${ }^{649}$ Acuerdo de Diálogo Político y Cooperación entre la Comunidad Europea y sus Estados Miembros, por una parte, y la Comunidad Andina y sus Estados Miembros, por otra parte. Roma, 15 de diciembre de 2003. Ver COMUNIDAD ANDINA. Normativa Andina: Decisión 595.

${ }^{650}$ DECISIÓN 667 DEL CONSEJO DE MINISTROS DE RELACIONES EXTERIORES EN REUNIÓN AMPLIADA CON LA COMISIÓN DE LA COMUNIDAD ANDINA, aprueban el Marco general para las negociaciones del Acuerdo de Asociación entre la Comunidad Andina y la Unión Europea, Lima 8 de junio de 2007.

${ }^{651}$ EUROPEAN EXTERNAL ACTION SERVICE: COMISIÓN EUROPEA (E/2007/678): Comunidad Andina. Documento de Estrategia regional 2007-2013.

http://eeas.europa.eu/delegations/bolivia/documents/eu_bolivia/2007_2013_csp_es.pdf [Última versión: 11-01-15]
} 
nivel regional, la integración de América Latina y el Caribe, tal como se había establecido en la Declaración de Viena, en mayo de 2006. La estrategia comprendía 50 millones de Euros para la Comunidad Andina mediante el Instrumento de Cooperación para el Desarrollo (DCI). Adicionalmente a estos recursos, los países de la Comunidad Andina podían, obtener más cooperación mediante programas bilaterales para cada país, y mediante el programa regional latinoamericano ${ }^{652}$.

A nivel bilateral, la UE representa para Bolivia el primer donante de ayuda a la cooperación al desarrollo ${ }^{653}$. Las relaciones entre ambas partes, se vieron afectadas cuando Bolivia abandonó el proceso de negociaciones que pretendían un Acuerdo de Asociación UE-CAN, de similares características al Acuerdo firmado con América Central, sin embargo, ello no ocurrió. Sumado al abandono de Venezuela a la Comunidad Andina, el acuerdo de asociación apenas quedo reducido a dos Estados Miembros de la Comunidad Andina, Colombia y Perú, que firman un Acuerdo Comercial Multipartes entre Colombia, Perú y la Unión Europea, en Bruselas el 26 de junio de 2012.

El 23 de septiembre de 2014 Ecuador y la Unión llegan a un acuerdo respecto al texto ${ }^{654}$, quedando listo para su firma. Bolivia anunció que retomaría las negociaciones para sumarse al acuerdo, pero aún no ha iniciado las rondas de negociaciones correspondientes para llevarlo a efecto. Las relaciones entre Bolivia y la UE se realizan tanto en acciones bilaterales como regionales, las áreas de trabajo están principalmente centradas en tres grandes temas ${ }^{655}$ :

1. Solidaridad

2. Valores democráticos

3. Integración y diversidad

\footnotetext{
652 Ibíd.

653 MINISTERIO DE ASUNTOS EXTERIORES Y COOPERACIÓN DEL REINO DE ESPAÑA: Bolivia. Política Exterior. Oficina de Información Diplomática, Madrid, 2014. http://www.exteriores.gob.es/Documents/FichasPais/BOLIVIA_FICHA\%20PAIS.pdf [Última versión: 10-01-15]

654 Para mayor información ver: EUROPEAN COMMISION. Directorate-General for Trade. News. Andean Community, EU and Ecuador publish text of trade agreement, Brussels, 23.9.2014.

655 DELEGACIÓN DE LA UNIÓN EUROPEA EN BOLIVIA: Europa en Bolivia. http://eeas.europa.eu/delegations/bolivia/eu_bolivia/index_es.htm [Última versión: 10-01-15]
} 
Estructura del Servicio de Acción Exterior de Bolivia:

El Ministerio de Relaciones Exteriores se divide en viceministerios ${ }^{656}$, entre ellos se encuentra el Viceministerio de Relaciones Exteriores, el cual tiene una Dirección General de Relaciones Bilaterales, la que a su vez se divide en dos grandes unidades:

- Unidad Latinoamericana y el Caribe

- Unidad Estados Unidos, Canadá y Europa

Delegaciones diplomáticas:

\section{Bolivia ante la UE:}

Bolivia tiene una delegación diplomática ante la UE, la cual a su vez, es concurrente a Bélgica y Luxemburgo. Además de estos dos Estados Miembros de la UE, Bolivia tiene 9 embajadas más dentro del territorio comunitario ${ }^{657}$. La embajada tiene cuatro funcionarios diplomáticos: un Embajador, dos Segundo Secretario y un Agregado de Comercio $^{658}$.

2. La UE ante Bolivia:

La Delegación de la UE en Bolivia se estructura mediante 5 secciones ${ }^{659}$ :

1. Política, Comercio, Prensa e Información

2. Cooperación económica y cofinanciamiento. ONG/Acciones temáticas

3. Cooperación al Desarrollo

4. Financiación y Contratos

5. Administración

El Jefe de la Delegación es el Embajador Timothy Torlot (Reino Unido). No hay información exacta sobre el número de personal en cada una de las secciones, por lo que consideramos como mínimo, un total de seis funcionarios, uno por sección más el Jefe de Misión.

\footnotetext{
${ }^{656}$ MINISTERIO DE RELACIONES EXTERIORES DE BOLIVIA: Organigrama. http://www.cancilleria.bo/node/305 [Última versión: 10-01-15]

${ }^{657}$ MINISTERIO DE RELACIONES EXTERIORES DE BOLIVIA: Bolivia en el exterior. Embajadas. http://www.cancilleria.bo/node/505 [Última versión: 10-01-15]

658 EUROPEAN COMMISION-SECRETARIAT GENERAL: Diplomatic Corps. Protocol Service. Missions accredited to European Union. Belize. p. 24

http://ec.europa.eu/dgs/secretariat_general/corps/index.cfm?go=search.search\&missions=1 [Última versión: 10-01-15]

${ }^{659}$ DELEGACIÓN DE LA UNIÓN EUROPEA EN BOLIVIA: Organización interna.

http://eeas.europa.eu/delegations/bolivia/about_us/internal_organisation/index_es.htm [Última versión: 10-01-15]
} 


\section{- La UE-Brasil}

Marco jurídico de las relaciones:

Las relaciones con la Unión Europeas se rigen mediante el Acuerdo Marco de Cooperación Comunidad Europea-Brasil (1992) ${ }^{660}$, el Acuerdo Marco de Cooperación UE-MERCOSUR (1995) ${ }^{661}$ y el Acuerdo de Cooperación Científica y Tecnológica $(2004)^{662}$. Posteriormente, con la celebración de la I Cumbre UE-Brasil, en Lisboa el 4 de julio de 2007, se propone una Asociación Estratégica ${ }^{663}$. La UE busca con la asociación desarrollar trabajos en áreas como: multilateralismo, medio ambiente, problemas del cambio climático, turismo sostenible, lucha contra la pobreza, proceso de integración del MERCOSUR y estabilidad y prosperidad de América Latina ${ }^{664}$. Todos estas áreas serán implementadas mediante la ejecución de dos planes de acción plurianuales, el primero fue el Plan de Acción Conjunto 2008-2011 ${ }^{665}$, y el segundo, el Plan de Acción Conjunto 2012-2014 ${ }^{666}$. Todo esto convierte a Brasil en el primer socio comercial y estratégico para la UE en América Latina y el Caribe.

660 DIARIO OFICIAL DE LAS COMUNIDADES EUROPEAS NoL 262/54. Acuerdo Marco de Cooperación entre la Comunidad Económica Europea y la República Federativa de Brasil, firmado en Brasilia, 29 de junio de 1992. EUR-LEX:

http://eur-lex.europa.eu/legal-content/ES/TXT/PDF/?uri=CELEX:21995A1101\%2801\%29\&from=EN [Última versión:10-01-15]

${ }^{661}$ EUROPEAN UNION EXTERNAL ACTION: Treaties Office. Interregional Framework Cooperation Agreement between the European Community and its Member States, of the one part, and the Southern Common Market and its Party States, of the other part - Joint Declaration on political dialogue between the European Union and Mercosur, Madrid, 15.12.1995.

http://ec.europa.eu/world/agreements/prepareCreateTreatiesWorkspace/treatiesGeneralData.do?step=0\&r edirect=true\&treatyId=405 [Última versión: 10-01-15]

662 EUROPEAN UNION EXTERNAL ACTION: Treaties Office. Agreement for scientific and technological cooperation between the European Community and the Federative Republic of Brazil, Brasilia, 19.1.2004.

http://ec.europa.eu/world/agreements/prepareCreateTreatiesWorkspace/treatiesGeneralData.do?step=0\&r edirect=true\&treatyId=2041 [Última versión: 10-01-15]

${ }^{663}$ EUROPEAN COMMISION: EU-BRAZIL: Commission proposes Strategic Partnership, Brussels, 30.5.2007.

http://europa.eu/rapid/press-release_IP-07-725_en.htm?locale=en [Última versión: 10-01-15]

${ }^{664}$ EUROPEAN COMMISION: Joint Statement Second Brazil-EU Summit, Rio Janeiro, 22.12.2008. http://eeas.europa.eu/brazil/docs/2008_final_declaration_en.pdf Última versión: 10-01-15. Para mayor información, también puede ver el Comunicado de la Comisión Europea sobre Brasil: COM (2007) 281 de 30 de mayo de 2007.

${ }^{665}$ EUROPEAN EXTERNAL ACTION SERVICE: BRAZIL-EUROPEAN UNION Strategy Partnership Joint Plan, Rio Janeiro, 22.12.2008.

http://eeas.europa.eu/brazil/docs/2008_joint_action_plan_en.pdf [Última versión: 10-01-15]

${ }^{666}$ COUNCIL OF THE EUROPEAN UNION: European Union-Brazil Strategic Partnership Joint Action Plan. V European Union-Brazil Summit Joint Statement, Brussels, 4.10.2011.

http://www.consilium.europa.eu/uedocs/cms_Data/docs/pressdata/EN/foraff/124878.pdf [Última versión: 10-01-15.] 
Las relaciones diplomáticas entre Brasil y la Unión datan desde la década de los años sesenta, cuando Brasil se convierte en los primeros países en abrir una delegación diplomática ante la entonces Comunidad Económica Europea. En la actualidad las relaciones entre UE-Brasil abarcan cerca de 20 diferentes tipos de áreas de diálogo, las cuales todas se producen al más alto nivel. Las partes buscan trabajar juntas en asuntos globales como la paz y la seguridad internacional, el desarme y la no proliferación de armas, crisis financiera internacional o cambio climático ${ }^{667}$. Y en materia de integración interregional lo hacen entre MERCOSUR-UE y lograr consensos dentro de las rondas de negociaciones dentro del marco de la OMC.

\section{Estructura del Servicio de Acción Exterior de Brasil:}

El Ministerio de Relaciones Exteriores de Brasil se divide en subsecretarías ${ }^{668}$, entre ellas se encuentra la Subsecretaría Política General I, cuyos temas son: Estados Unidos, Canadá, Europa, Organización de Naciones Unidas, organismos internacionales y temas interamericanos.

La Subsecretaría General I, se subdivide en dos grandes departamentos, la que a su vez, se organizan en varias divisiones:

- Departamento de Europa

- División de Europa I

- División de Europa II

- División de Europa III

- Departamento de Estados Unidos, Canadá y Asuntos Interamericanos

- División Organización de Estados Americanos

- División de Estados Unidos y Canadá

Las relaciones con la Unión Europea se manejan dentro del Departamento de Europa. Un dato interesante de cara a poder identificar cuál es la visión y percepción de Brasil respecto a la integración regional y cuál es su compromiso con la integración regional de América Latina y el Caribe. Sorprende ver cómo Brasil equipara y ubica en el mismo nivel el diálogo que existe dentro de los BRICS con el de las que se desarrollan dentro

${ }^{667}$ DELEGATION OF EUROPEAN UNION TO BRAZIL: Brazil \& the European Union. http://eeas.europa.eu/delegations/brazil/eu_brazil/index_en.htm [Última versión: 10-01-15] ${ }^{668}$ MINISTERIO DE RELACIONES EXTERIORES DE BRASIL: Organigrama. http://www.itamaraty.gov.br/images/organograma/2011008Organograma.pdf [Última versión: 10-01-15] 
de las Cumbres UE-ALC y las Cumbres Iberoamericanas. Brasil los categoriza como "mecanismos inter-regionales". Pero esta definición es inexacta en principio y forma, dado que los BRICS son un foro informal de un grupo de países, los cuales, de acuerdo a la coyuntura económica en que viven durante los últimos años, son considerados economías emergentes, y por ende posibles o futuras potencias emergentes, políticamente y diplomáticamente hablando. Pero al día de hoy, aún no lo son. Y su grado de institucionalidad y objetivos son distintos en cada uno de los esquemas antes mencionados.

Se pueden decir que los tres esquemas representan un foro político, sí es verdad, que los tres buscan acordar posiciones y adoptar posturas en materias de política exterior, de manera consensuada, ante los principales foros y conferencias internacionales. También es cierto, pero la motivación del por qué lo hacen, ahí no es igual, pues en los dos otros esquemas distintos al de los BRICS, es decir, las cumbres de UE-ALC y las cumbres iberoamericanas, se parte de que existe una visión común en la defensa de los principios y valores universales, como la democracia, el estado de derecho, la defensa de los derechos humanos, entre otros, temas que son discutibles de argumentar y defender dentro de los BRICS. Lo que hace pensar que para Brasil tanto las cumbres UE-ALC como las cumbres iberoamericanas son simplemente un espacio más de diálogo, una opción más, en la cual pueden intentar satisfacer y defender sus intereses nacionales, más que pensar en la idea de desarrollar una integración regional, basada en principios y valores comunes, que son compartidas por un número de estados que deciden integrarse en una comunidad o unión de estados.

\section{Delegaciones diplomáticas:}

\section{Brasil ante la UE:}

Brasil tiene una delegación diplomática ante la UE, la cual no tiene concurrencias como otros países, es decir se ocupa y enfoca, exclusivamente, las relaciones con la UE. Cuenta con quince funcionarios ${ }^{669}$, lo que la hace una de las delegaciones diplomáticas con más funcionarios dentro de todos los países de América Latina y el Caribe.

${ }^{669}$ EUROPEAN COMMISION-SECRETARIAT GENERAL: Diplomatic Corps. Protocol Service. Missions accredited to European Union. Brazil. pp. 27-28

$\mathrm{http}: / /$ ec.europa.eu/dgs/secretariat_general/corps/index.cfm?go=search.search\&missions=1 [Última versión: 10-01-15] 
La embajada brasileña en Bruselas se componte de:

- 1 Embajador

- 2 Ministros Consejeros

- 2 Consejeros

- 2 Primer Secretario

- 3 Segundo Secretario

- 2 Tercer Secretario

- 3 Agregados

Brasil tiene embajadas en 20 Estados Miembros de la UE.

2. La UE ante Brasil:

La UE tiene una delegación diplomática ante Brasil, la cual está compuesta por nueve funcionarios que se encargan de las siguientes secciones ${ }^{670}$ :

- 1 Jefe de Delegación, Embajadora, Ana Paula Zacarías (Portugal)

- 1 Adjunto al Jefe de Delegación

- 1 Jefe de Política, Economía y Prensa

- 1 Jefe de Comercio e Inversiones

- 1 Jefe de Ciencia y Tecnología

- 1 Jefe de Sociedad de la Información

- 1 Jefe de Desarrollo y Cooperación

- 1 Jefe de Finanzas, Contratos y Auditoría

- 1 Jefe de Administración

${ }^{670}$ DELEGATION OF EUROPEAN UNION TO BRAZIL: Internal Organization. http://eeas.europa.eu/delegations/brazil/about_us/internal_organisation/index_en.htm [Última versión: 10-01-15] 


\section{- La UE-Chile}

Marco jurídico de las relaciones:

Las relaciones con la Unión Europea son estrechas y datan desde los albores del proceso de integración europea, desde la década de los sesenta. En 1964 las Comunidades Europeas abrieron una oficina de representación para América Latina en Santiago de Chile; posteriormente, con la fusión de los ejecutivos de las Comunidades Europeas, en 1967 la oficina de Santiago se convirtió en la Oficina de la Comisión Europea para América Latina ${ }^{671}$. El marco jurídico de las relaciones políticas y económicas entre la UE-Chile está enmarcado por el Acuerdo de Asociación (2002) ${ }^{672}$, mediante el cual se comprometen a trabajar juntos en temas de interés tanto bilateral (UE-Chile) como a nivel internacional, es decir acordar posiciones conjuntas en los foros y organismos multilaterales. En ese mismo año, las partes firmaron un Acuerdo de Cooperación en Ciencia y Tecnología.

Durante el período 2007-2013 se ejecutó un programa país que se enfocaban en implementar una estrategia para ayudar a Chile en temas como cohesión social e innovación y competitividad. Posteriormente, en $2010^{673}$, mediante una revisión a medio término del programa plurianual, se estableció que desde el 2010 al 2014 se centrará en materia de Derechos Humanos y en la coordinación en la organización y realización de la I Cumbre UE-CELAC. La estrategia comprendía un total de 15.580.000 millones de Euros.

\section{Estructura del Servicio de Acción Exterior de Chile:}

El Ministerio de Relaciones Exteriores de Chile se divide en direcciones ${ }^{674}$, entre ellas está la Dirección Europa, que es la encargada de las relaciones con los países europeos y la Unión Europea.

${ }^{671}$ MINISTERIO DE RELACIONES EXTERIORES DE CHILE: Misión de Chile ante la Unión Europea. Relación Bilateral Chile-Unión Europea. http://chileabroad.gov.cl/ue/relacion-bilateral/relacionbilateral-chile-union-europea/ Última versión: 10-01-15.

${ }^{672}$ EUROPEAN EXTERNAL ACTION SERVICE: Acuerdo mediante el cual se establece una Asociación entre la Comunidad Europea y la República de Chile.

http://eeas.europa.eu/delegations/chile/documents/eu_chile/eu-chile_assoc_agree_es.pdf [Última versión: 10-01-15]

${ }^{673}$ EUROPEAN EXTERNAL ACTION SERVICE: European Commission: Chile. Country Strategy Paper 2007-2013.

http://eeas.europa.eu/delegations/chile/documents/eu_chile/version_finale_es.pdf [Última versión: 1001-15]

${ }^{674}$ MINISTERIO DE RELACIONES EXTERIORES DE CHILE: Organigrama. 
Delegaciones diplomáticas:

\section{Chile ante la UE:}

Chile cuenta con una delegación diplomática ante la UE, la cual también es concurrente ante Bélgica y cuenta con 9 funcionarios ${ }^{675}$ :

- 1 Embajador

- 1 Ministro Consejero

- 1 Primer Secretario

- 2 Segundo Secretario

- 2 Tercer Secretario

- 2 Ministro Consejero

Chile cuenta con una representación diplomática en cada Estado Miembro de la Unión Europea, es decir en los 28 países ${ }^{676}$.

\section{La UE ante Chile:}

La UE tiene una delegación en Chile, cuenta con 5 funcionarios los cuales tienen las siguientes funciones ${ }^{677}$ :

- Jefe de Delegación, Embajador, Rafael Dochao Moreno (España)

- Jefe de Sección de Comercio

- 1 Jefe de Sección Política, Información y Prensa

- 1 Jefe de Administración

- 1 Agregado Adjunto

http://www.minrel.gov.cl/organigrama/minrel/2013-04-23/094110.html [Última versión: 10-01-15]

${ }^{675}$ EUROPEAN COMMISION-SECRETARIAT GENERAL: Diplomatic Corps. Protocol Service. Missions accredited to European Union. Chile. pp. 42-43.

$\mathrm{http}: / /$ ec.europa.eu/dgs/secretariat_general/corps/index.cfm?go=search.search\&missions=1 [Última versión: 11-01-15]

${ }^{676}$ MINISTERIO DE RELACIONES EXTERIORES DE CHILE: Chile en el exterior. Embajadas, Consulados y Misiones Multilaterales de Chile.

http://chileabroad.gov.c1/ [Última versión: 11-01-15]

${ }^{677}$ DELEGACIÓN DE LA UNIÓN EUROPEA EN CHILE. Organigrama de la Delegación en Chile.

http://eeas.europa.eu/delegations/chile/about_us/internal_organisation/index_es.htm [Última versión: 1001-15] 


\section{- La UE-Colombia}

Marco jurídico de las relaciones:

Las relaciones con la Unión Europea se enmarcan dentro del diálogo interregional realizado entre la UE-CAN. Su base jurídica es la misma que el conjunto de acuerdos firmados que los otros países andinos y como ha sido descrito en el apartado correspondiente a Bolivia.

En 2010 la UE era uno de los principales cooperantes en ayuda oficial para el desarrollo de Colombia, con cifras que ascendían a 37 millones de Euros, dicha cantidad respondían al deseo de la UE en trabajar con Colombia en tres ámbitos, el primero representaba un $70 \%$ del presupuesto y estaba dirigido a programas de paz y estabilidad; el segundo ámbito contenía el $20 \%$ del presupuesto y estaba destinado al fortalecimiento del Estado de Derecho, la Justicia y los Derechos Humanos; y un tercer ámbito incluía un $10 \%$ del presupuesto y comprendía temas como productividad, competitividad y comercio ${ }^{678}$.

Estructura del Servicio de Acción Exterior de Colombia:

El Ministerio de Relaciones Exteriores de Colombia se divide en viceministerios ${ }^{679}$, el cual cuenta con el Viceministerio de Relaciones Exteriores, el que a su vez se divide en direcciones y cuenta con la Dirección Europa, cuyas funciones son:

- Unión Europea

- Países no miembros de la Unión Europea

- Euroasia

Delegaciones diplomáticas:

1. Colombia ante la UE:

678 DELEGACIÓN DE LA UNIÓN EUROPEA EN COLOMBIA: Colombia y la Unión Europea. Relaciones Políticas.

http://eeas.europa.eu/delegations/colombia/eu_colombia/political_relations/index_es.htm_[Última versión: 11-01-15]

${ }^{679}$ MINISTERIO DE RELACIONES EXTERIORES DE COLOMBIA: Ministerio. Organigrama. https://www.cancilleria.gov.co/sites/default/files/fotos/FEB-1/organigrama_ministerio.pdf [Última versión: 11-01-15] 
Colombia tiene una delegación diplomática ante la UE, la cual está acreditada también para Bélgica y Luxemburgo. Cuenta con 13 funcionarios ${ }^{680}$ :

- Embajador

- Ministro Plenipotenciario

- 6 Ministro Consejero

- Consejero

- Primer Secretario

Colombia cuenta con embajadas en 12 Estados Miembros de la UE.

\section{La UE ante Colombia:}

La UE tiene una delegación en Colombia, la cual está compuesta por siete funcionarios $^{681}$ :

- Jefe de la Delegación, Embajadora, María Van Gool (Países Bajos)

- Jefe de Sección Comercial

- 1 Jefe de Sección Política y Prensa

- 1 Jefe de Sección de Cooperación

- 1 Jefe de Sección de Finanzas y Contratos

- 1 Jefe de Administración + 1 Asistente administrativo

680 EUROPEAN COMMISION-SECRETARIAT GENERAL: Diplomatic Corps. Protocol Service. Missions accredited to European Union. Colombia. pp. 51-52.

http://ec.europa.eu/dgs/secretariat_general/corps/index.cfm?go=search.search\&missions=1 [Última versión: 11-01-15]

681 DELEGACIÓN DE LA UNIÓN EUROPEA EN COLOMBIA: Organización interna. http://eeas.europa.eu/delegations/colombia/about_us/internal_organisation/index_es.htm [Última versión: 11-01-15] 


\section{- La UE-Costa Rica}

Marco jurídico de las relaciones:

Sus relaciones con la UE se inician en 1986, año en que la Comisión Europea abre una Delegación Diplomática, con el fin de apoyar el proceso de pacificación y democratización en Centroamérica (Nicaragua, El Salvador y Guatemala). Paralelamente a la apertura de la delegación la subregión centroamericana estaba iniciando el "Proceso de Esquipulas"682 con el fin de establecer la paz en la zona. Este contexto contribuyo a que se desarrollara el diálogo de San José, en 1984, y posteriormente, el Proceso de San José, este fue un período en el cual se entrelaza una fuerte relación no sólo con Costa Rica, sino también con la subregión centroamericana, pues servirá de base para las futuras relaciones diplomáticas entre toda las partes involucradas.

La UE, entonces Comunidad Europea, decide apoyar los esfuerzos del Grupo de Contadora y el Grupo de Apoyo a Contadora (también llamado “El Grupo de Lima”), el primero estaba formado por Colombia, México, Panamá y Venezuela, en 1983; y el segundo comprendía a Argentina, Brasil, Perú y Uruguay, iniciado en 1985.

El proceso de San José incluía tres grandes objetivos ${ }^{683}$ :

1. La solución pacífica de los conflictos en Centroamérica

2. El fortalecimiento de la democracia

3. La integración regional

Estos objetivos quedaron reflejados en el Acuerdo Marco para la Cooperación entre la Comunidad Económica Europea y los países centroamericanos ${ }^{684}$, en 1993; y

${ }^{682}$ DELEGACIÓN DE LA UNIÓN EUROPEA ANTE COSTA RICA Y PARA PANAMÁ: Costa Rica y la Unión Europea.

http://eeas.europa.eu/delegations/costa_rica/eu_costa_rica/index_es.htm

[Última versión: 11-01.15]

${ }^{683}$ DELEGACIÓN DE LA UNIÓN EUROPEA ANTE COSTA RICA Y PARA PANAMÁ: Relaciones políticas y económicas.

http://eeas.europa.eu/delegations/costa_rica/eu_costa_rica/political_relations/index_es.htm [Última versión: 11-01-15]

${ }^{684}$ DIARIO OFICIAL DE LAS COMUNIDADES EUROPEAS N ${ }^{\circ}$ L 63/39. 12.3.19.1999. Acuerdo Marco de Cooperación entre la Comunidad Económica Europea y Costa Rica, El Salvador, Guatemala, Honduras, Nicaragua y Panamá.

http://eur-lex.europa.eu/LexUriServ/LexUriServ.do?uri=OJ:L:1999:063:0039:0053:EN:PDF_ [Última versión: 11-01.15] 
posteriormente sus ámbitos fueron ampliados en el Acuerdo Diálogo Político y Cooperación CE-CA, en $2003^{685}$. En 2007 se inicia las conversaciones hacia un Acuerdo de Asociación, el cual se establece que se negociará "región a región" Tegucigalpa, 29 de junio de 2012, suscriben el Acuerdo de Asociación que incluye tres pilares $^{687}$ :

1. Comercio

2. Diálogo político

3. Cooperación

Estructura del Servicio de Acción Exterior de Costa Rica:

El Ministerio de Relaciones Exteriores de Costa Rica se divide en viceministerios, entre ellos hay una Dirección de Política Exterior ${ }^{688}$, que a su vez se divide en departamentos, dentro de los cuales existe el Departamento Áreas Geográficas, que es el encargado de las relaciones bilaterales con América Central y el Caribe, América del Norte, América del Sur, Asia, África y Oceanía, Europa y la Unión Europea; y con los organismos regionales correspondientes a cada área geográfica.

\section{Delegaciones diplomáticas:}

\section{Costa Rica ante la UE:}

Costa Rica tiene una delegación diplomática ante la UE, la cual a su vez tiene concurrencia a Bélgica. La embajada tiene 5 funcionarios ${ }^{689}$ :

${ }^{685}$ EUROPEAN EXTERNAL ACTION SERVICE: Political Dialogue and Cooperation Agreement between the European Community and Costa Rica, El Salvador, Guatemala, Honduras, Nicaragua and Panama, Roma 15.12.2003.

http://eeas.europa.eu/ca/pol/pdca_12_03_en.pdf [Última versión: 11-01.15]

${ }^{686}$ COMISIÓN EUROPEA: La Unión Europea y la Comunidad Centroamericana inician negociaciones para un nuevo Acuerdo de Asociación, Bruselas, 29 de junio 2007.

http://www.sice.oas.org/TPD/CACM_EU/Negotiations/Launch_s.pdf [Última versión: 11-01.15]

${ }_{687}^{6}$ SERVICIO EUROPEO DE ACCIÓN EXTERIOR: Acuerdo de Asociación entre la Unión Europea y Centroamérica, Tegucigalpa, 29 de junio de 2012.

http://eeas.europa.eu/delegations/nicaragua/documents/press_corner/news/20130204_acuerdo_asociacion -15-12-2012_es.pdf [Última versión: 11-01.15]

${ }^{688}$ MINISTERIO DE RELACIONES EXTERIORES DE COSTA RICA. Ministerio. Política Exterior. http://www.rree.go.cr/?sec=ministerio\&cat=politica\%20exterior [Última versión: 11-01.15]

${ }_{689}$ EUROPEAN COMMISION-SECRETARIAT GENERAL: Diplomatic Corps. Protocol Service. Missions accredited to European Union. Costa Rica. p. 57.

http://ec.europa.eu/dgs/secretariat_general/corps/index.cfm?go=search.search\&missions=1 [Última versión: 11-01.15] 
- 1 Embajador

- 1 Ministro Consejero y Cónsul General

- 1 Ministro Consejero

- 1 Primer Secretario

- 1 Consejero y Cónsul

Costa Rica tiene embajadas en 18 Estados Miembros de la Unión Europea ${ }^{690}$.

\section{La UE ante Costa Rica:}

La UE tiene una delegación diplomática en Costa Rica, con competencias para América Central, es decir, la misión es concurrente a: Nicaragua, Panamá y ante el Sistema de Integración Centroamericano. Cuenta con tres funcionarios ${ }^{691}$ :

- Jefe de la Delegación, Embajador Javier Sandomingo Núñez (España)

- 1 Encargado de Negocios

- 1 Encargado para Derechos Humanos

${ }^{690}$ MINISTERIO DE RELACIONES EXTERIORES DE COSTA RICA: Representaciones de Costa Rica en el exterior.

http://www.rree.go.cr/index.php?sec=relaciones $\% 20$ bilaterales \&cat=representaciones $\% 20 \mathrm{de} \% 20 \mathrm{cr} \% 20 \mathrm{en}$ $\% 20$ extranjero [Última versión: 11-01.15]

691 DELEGACIÓN DE LA UNIÓN EUROPPEA ANTE COSTA RICA Y PARA PANAMÁ: Organización interna.

http://eeas.europa.eu/delegations/costa_rica/about_us/internal_organisation/index_es.htm [Última versión: 11-01.15] 


\section{- La UE-Cuba}

Marco jurídico de las relaciones:

Las relaciones con la UE se efectúan en el marco de la "Posición Común" de 1996, posición que establece que el objetivo de la Unión Europea es sus relaciones con Cuba es incentivar "un proceso de transición hacia una democracia pluralista y el respeto de los derechos humanos y libertades fundamentales, así como una recuperación y mejora sostenibles del nivel de vida del pueblo cubano"692.

El 19 de noviembre de 2012 el Consejo de Ministros de Asuntos Exteriores de la Unión Europea aprobó la propuesta presentada por la Alta Representante de la Unión para Asuntos Exteriores y Política de Seguridad/Vice presidenta de la Comisión Europea, Catherine Ashton, de iniciar negociaciones con Cuba para firmar un acuerdo bilateral. El 10 de febrero de 2014 el Consejo de Ministros de Asuntos Exteriores de la Unión decidió aprobar el mandato de negociación, del cual se espera concluya entre uno o dos años. Mientras tanto sigue vigente la "Posición Común". Hasta la fecha se han efectuado dos ruedas de negociaciones:

1. La Habana, 29 y 30 de abril de 2014.

2. Bruselas, 7 y 8 de agosto de 2014 .

\section{Estructura del Servicio de Acción Exterior de Cuba:}

El Ministerio de Relaciones Exteriores de Cuba utiliza el concepto geográfico/temático regional, en tal sentido tiene seis grandes divisiones ${ }^{693}$ :

- América Latina y el Caribe

- África Subsahariana

- África Norte y Medio Oriente

- Asia y Oceanía

- América del Norte

- Europa

Dentro de la división Europa es donde se desarrollan las relaciones con la UE.

\footnotetext{
${ }^{692}$ Posición Común de 2 de diciembre de 1996 definida por el Consejo en virtud del artículo J.2. del Tratado de la Unión Europea, sobre Cuba. Diario Oficial n L 322 de 12/12/1996. En EUR-LEX: http://eur-lex.europa.eu/LexUriServ/LexUriServ.do?uri=CELEX:31996E0697:ES:HTML_ [Última revisión 26-12-14]

693 MINISTERIO DE RELACIONES EXTERIORES DE CUBA: Ministerio. Organigrama. http://www.cubaminrex.cu/es/ministerio [Última revisión 26-12-14]
} 
Delegaciones diplomáticas:

\section{Cuba ante la UE:}

Cuba tiene una delegación ante la UE y es concurrente a Bélgica y Luxemburgo. Además Cuba cuenta con una embajada en cada uno de los 28 Estados Miembros de la Unión Europea $^{694}$. La misión diplomática está formada por once funcionarios ${ }^{695}$ :

- Embajador

- 1 Primer Secretario

- 1 Consejero

- 1 Consejero Económico y Comercial

- 1 Consejero Político

- 1 Consejero

- 1 Tercer Secretario

- 1 Agregado de Comercio

- 2 Agregados para Asuntos Administrativos

- 1 Encargado

\section{La UE ante Cuba:}

La Unión Europea cuenta con una delegación en Cuba formada por 17 funcionarios que trabajan en cuatro secciones ${ }^{696}$ :

- Jefe de Delegación, Embajador, Herman Portocarero (Bélgica)

- 1 Jefe de Política y Económica

- 1 Jefe de Cooperación

- 1 jefe de Finanzas y Contratos

- 1 jefe de Administración

El resto de funcionarios se encuentran adscritos dentro de las correspondientes secciones como personal de apoyo.

${ }^{694}$ MINISTERIO DE RELACIONES EXTERIORES DE CUBA: Directorio Diplomático. http://www.cubaminrex.cu/es/directorio-diplomatico [Última revisión 26-12-14]

695 EUROPEAN COMMISION-SECRETARIAT GENERAL: Diplomatic Corps. Protocol Service. Missions accredited to European Union. Cuba. pp. 60-61.

http://ec.europa.eu/dgs/secretariat_general/corps/index.cfm?go=search.search\&missions=1 [Última versión: 11-01-15]

${ }^{696}$ DELEGACIÓN DE LA UNIÓN EUROPEA EN CUBA. Organización interna.

http://eeas.europa.eu/delegations/cuba/about_us/internal_organisation/index_en.htm [Última revisión 2612-14] 


\section{- La UE-República Dominicana}

\section{Marco jurídico de las relaciones:}

Sus relaciones con la Unión se enmarcan dentro de las relaciones con CARICOM. Sus relaciones se fortalecen cuando, en 1991, se crea una representación, como contraparte, la Oficina del Fondo del Convenio Lomé. En la actualidad es llamada Ordenador Nacional para los Fondos Europeos de Desarrollo. En tal sentido, será su membresía como país dentro del marco de los países ACP, primero con los convenios Lomé ${ }^{697}$, y posteriormente, con los acuerdos de Cotonú, los que regulan jurídicamente sus relaciones, tanto políticas como económicas, comerciales y en el ámbito de la cooperación para el desarrollo.

\section{Estructura del Servicio de Acción Exterior de República Dominicana:}

El Ministerio de Relaciones Exteriores de república Dominicana se divide en direcciones $^{698}$. Existe una Dirección Política Exterior, que a su vez se divide en divisiones de acuerdo a las relaciones con los diferentes continentes. Cuenta con una División Relaciones con Europa, la cual se divide en dos secciones:

- Sección Europa del Este

- Sección Europa Central y del Oeste

Delegaciones diplomáticas:

1. República Dominicana ante la UE:

La República Dominicana cuenta con una delegación diplomática ante la UE, concurrente a Bélgica, República Checa y Polonia; cuenta con 13 funcionarios ${ }^{699}$ :

- Embajador

\footnotetext{
${ }^{697}$ DELEGACIÓN DE LA UNIÓN EUROPEA ANTE LA REPÚBLICA DOMINICANA: República Dominicana y la Unión Europea. Relaciones políticas y económicas.

http://eeas.europa.eu/delegations/dominican/eu_dominican/political_relations/index_es.htm [Última versión: 11-01-15]

698 MINISTERIO DE RELACIONES EXTERIORTES DE LA REPÚBLICA DOMINICANA: MINISTERIO. ORGANIGRAMA. http://www.mirex.gob.do/index.php/conocenos/organigrama [Última versión: 11-01.15]

699 EUROPEAN COMMISION-SECRETARIAT GENERAL: Diplomatic Corps. Protocol Service. Missions accredited to European Union. Dominican Republic. p. 64.

http://ec.europa.eu/dgs/secretariat_general/corps/index.cfm?go=search.search\&missions=1 [Última versión: 11-01-15]
} 
- 5 Ministros Consejeros

- 7 Consejeros

República Dominicana cuenta con embajadas en 9 Estados Miembros de la UE ${ }^{700}$.

\section{La UE ante República Dominicana:}

La UE cuenta con una delegación ante República Dominicana, que cuenta con 8 secciones y 9 funcionarios ${ }^{701}$ :

- 1 Jefe de Delegación, Embajador, Alberto Navarro (España)

- 1 Jefe de Sección Política

- 1 Jefe de Sección Comercial

- 1 Jefe de Sección Operaciones I: Económica y Social

- 1 Jefe de Sección Operaciones II: Integración Regional, Comercio y Sector Privado

- 1 Jefe de Sección Finanzas y Contratos

- 1 Jefe de Sección Administración

- 1 Jefe de Derechos Humanos

- 1 Sección Comunicación

700 MINISTERIO DE RELACIONES EXTERIORES DE LA REPÚBLICA DOMINICANA: REPÚBLICA DOMINICA EN EL EXTERIOR.

http://www.mirex.gob.do/ [Última versión: 11-01-15]

${ }^{701}$ DELEGACIÓN DE LA UNIÓN EUROPEA EN LA REPÚBLICA DOMINICANA: Organización interna:

http://eeas.europa.eu/delegations/dominican/about_us/internal_organisation/index_es.htm [Última versión: 11-01-15] 


\section{- La UE-Dominica}

Marco jurídico de las relaciones:

Sus relaciones con la UE se desarrollan dentro del grupo de países ACP y al ser miembro del CARICOM ${ }^{702}$ participa en CARIFORUM. Por otro lado, Dominica es beneficiaria del apoyo especial de la Unión a los exportadores de plátanos, a través del "Special Framework Assistance Budget", también conocida por sus siglas SFA, de este mecanismo ha recibido durante el período (1999-2008) 52, 5 millones de Euros. Como se ha indicado anteriormente, la Unión posee una delegación diplomática en Barbados que es concurrente a Dominica. Desde el 2010 la respectiva misión ha destinado a Dominica 130 millones de Euros ${ }^{703}$.

\section{Estructura del Servicio de Acción Exterior de Dominica:}

El Ministerio de Relaciones Exteriores y Asuntos de CARICOM de Dominica, al igual que los otros países que forman parte de la Mancomunidad de Naciones, y al ser Estados tan pequeños, su administración general es reducida, en este caso concreto no existe una unidad, dirección o división concreta que se encargue de llevar las relaciones con la UE. El Ministerio se divide de la siguiente manera ${ }^{704}$ :

- 1 Jefe de Oficina de Protocolo

- 1 Oficial Ejecutivo

- 1 Oficial Ejecutivo de Protocolo

- 1 Oficial General

- 1 Secretaría del Ministro

- 1 Secretaría Permanente

- 1 Oficial Administrativo

- 1 Letrado Mayor

${ }^{702}$ MINISTERIO DE ASUNTOS EXTERIORES Y COOPERACIÓN DEL REINO DE ESPAÑA: Dominica Política Exterior. Oficina de Información Diplomática, Madrid, 2014.

http://www.exteriores.gob.es/Documents/FichasPais/DOMINICA_FICHA\%20PAIS.pdf [Última versión: 11-01-15]

703 DELEGATION OF THE EUROPEAN UNION TO BARBADO AND THE EASTERN CARIBBEAN: Dominica and European Union. Political and Economic relations. http://eeas.europa.eu/delegations/barbados/eu_oecs/dominica/index_en.htm [Última versión: 11-01-15]

${ }^{704}$ MINISTRY OF FOREIGN AFFAIRS AND CARICOM AFFAIRS OF DOMINICA.

http://www.dominica.gov.dm/foreign-affairs-and-caricom-affairs [Última versión: 11-01-15] 
Delegaciones diplomáticas:

\section{Dominica ante la UE:}

Dominica tiene una delegación ante la UE, y es concurrente a Bélgica, Luxemburgo y Países Bajos, además de estos países Dominica tiene embajadas en dos Estados Miembros de la UE, en Francia y Reino Unido ${ }^{705}$. La delegación ante la UE cuenta con tres funcionarios ${ }^{706}$ :

- Embajador

- Primer Secretario

- Tercer Secretario

2. La UE ante Dominica:

La UE no tiene una delegación diplomática en Dominica, esta es cubierta desde la Delegación de la UE en Barbados.

${ }^{705}$ GOVERNMENT OF THE COMMONWEALTH OF DOMINICA: Embassies. http://www.dominica.gov.dm/ [Última versión: 11-01-15]

706 EUROPEAN COMMISION-SECRETARIAT GENERAL: Diplomatic Corps. Protocol Service. Missions accredited to European Union. Dominica. p. 63.

http://ec.europa.eu/dgs/secretariat_general/corps/index.cfm?go=search.search\&missions=1 [Última versión: 11-01-15] 


\section{- La UE-Ecuador}

\section{Marco jurídico de las relaciones:}

En lo concerniente a las relaciones con la UE, estas se han desarrollado en el marco de las relaciones entre la UE-CAN mediante los acuerdos firmados en $1993^{707}$, al igual que en el caso de Colombia, como antes se ha descrito. Cabe señalar que en 2007 la UE y la CAN iniciaron las negociaciones para lograr un Acuerdo Comercial Multipartes, el cual no fue firmado por Ecuador, ni Bolivia, sólo Colombia y Perú lo firmaron. Sin embargo, a lo largo del 2014, el gobierno de Ecuador ha expresado su interés de retomar las negociaciones del acuerdo y se espera que el mismo se firme durante el 2015 o 2016.

A nivel bilateral, en junio de 2001 firmaron un Memorándum que sirve de base para regular la cooperación entre la Comunidad Europea y Ecuador, el mismo incluía la cooperación técnica y financiera para implementar proyecto en salud, políticas medioambientales e integración física ${ }^{708}$. Cuenta con presupuesto de 92 millones de Euros. La UE abre una delegación de la Comisión Europea en 2003 en Ecuador, también existe una oficina especial del Departamento de Ayuda Humanitaria de la Comisión Europea (ECHO), la cual actúa en los casos de emergencia en desastres para toda América Latina. En 2007 se suscribe un Memorándum de Entendimiento que define las prioridades de la cooperación para el período 2007-2013, el cual estipula tres áreas de trabajo: el aumento de inversiones sociales, crear oportunidades económicas sostenibles y promover la integración regional ${ }^{709}$, con un presupuesto de 137 millones de Euros.

${ }^{707}$ MINISTERIO DE ASUNTOS EXTERIORES Y COOPERACIÓN DEL REINO DE ESPAÑA: Ecuador. Política Exterior. Oficina de Información Diplomática, Madrid, 2014.

http://www.exteriores.gob.es/Documents/FichasPais/Ecuador_FICHA\%20PAIS.pdf [Última versión: 1101-15]

${ }^{708}$ EUROPEAN EXTERNAL ACTION SERVICE: Memorándum de Entendimiento entre la Comunidad Europea y Ecuador relativo a las orientaciones plurianuales para la puesta en práctica de la Cooperación Comunitaria. Bruselas, 1 de junio de 2001.

http://eeas.europa.eu/delegations/ecuador/documents/eu_ecuador/pol_eu-ecuador_002_es.pdf [Última versión: 11-01-15]

${ }^{709}$ EUROPEAN EXTERNAL ACTION SERVICE: Memorándum de Entendimiento entre la Comisión Europea y Ecuador relativo al Programa Indicativo para el período 2007-2013, Quito, 23 de mayo de 2007.

http://eeas.europa.eu/delegations/ecuador/documents/eu_ecuador/pol_eu-ecuador_003_es.pdf [Última versión: 11-01-15]

También puede verse COMISIÓN EUROPEA (E/2007/621) Ecuador. Documento Estrategia País 20072013.

http://eeas.europa.eu/delegations/ecuador/documents/eu_ecuador/eu-ecuador_001_es.pdf 
Estructura del Servicio de Acción Exterior de Ecuador:

El Ministerio de Relaciones Exteriores y Movilidad Humana de Ecuador se estructura a través de viceministerios y subsecretarías ${ }^{710}$. Así cuenta con un Viceministerio de Relaciones Exteriores e Integración Política, que a su vez cuenta con una Subsecretaría de América del Norte y Europa, la cual se divide en dos direcciones:

- Dirección de Relaciones Bilaterales con América del Norte

- Dirección de Relaciones Bilaterales y Multilaterales con Europa

Es dentro de ésta última dirección desde donde se manejan las relaciones con la Unión Europea.

Delegaciones diplomáticas:

\section{Ecuador ante la UE:}

Ecuador tiene una delegación diplomática ante la UE y posee embajadas en los 28 Estados Miembros de la Unión ${ }^{711}$. La misión ante la UE cuenta con 9 funcionarios ${ }^{712}$ :

- Embajador

- Cónsul

- Ministro

- Consejeros

- 1 Primer Secretario

- 1 Tercer Secretario

- Agregados

\section{La UE ante Ecuador:}

La UE cuenta con una delegación en Ecuador, la cual cuenta con 7 funcionarios que se ocupan de 5 secciones $^{713}$ :

\footnotetext{
${ }^{710}$ MINISTERIO DE RELACIONES EXTERIORES Y MOVILIDAD HUMANA DE LA REPÚBLICA DEL ECUADOR: Ministerio. Organigrama. https://www.cancilleria.gob.ec/el-ministerio/ [Última versión: 11-01-15]

${ }^{711}$ MINISTERIO DE RELACIONES EXTERIORES Y MOVILIDAD HUMANA DE LA REPÚBLICA DEL ECUADOR: Representaciones ecuatorianas en el exterior.

https://www.cancilleria.gob.ec/representaciones-ecuatorianas-en-el-exterior/ Última versión: 11-01-15

712 EUROPEAN COMMISION-SECRETARIAT GENERAL: Diplomatic Corps. Protocol Service. Missions accredited to European Union. Ecuador. p 65.

http://ec.europa.eu/dgs/secretariat_general/corps/index.cfm?go=search.search\&missions=1 [Última versión: 11-01-15]
} 
- 1 Jefe de Delegación, Embajadora Maria Wilhelmina Josepha Antonia Van Gool (Países Bajos)

- 1 Encargado de Negocios

- 1 Jefe de Política, Prensa e Información

- 1 Jefe de Cooperación

- 1 Encargado de Cooperación para los Derechos Humanos

- 1 Jefe de Administración + 1 Asistente administrativo

713 DELEGEACIÓN DE LA UNIÓN EUROPEA EN ECUADOR: Organización interna. http://eeas.europa.eu/delegations/ecuador/about_us/internal_organisation/index_es.htm [Última versión: 11-01-15] 


\section{- La UE-El Salvador}

Marco jurídico de las relaciones:

Sus relaciones con la Unión Europea se inician, al igual que el resto de los países centroamericanos, con el Diálogo de San José (1984), seguido por el Acuerdo Marco de Cooperación UE-CA de 1985 y el Acuerdo de Asociación UE-CA firmado en 2012. La UE representa uno de los mayores contribuyentes en materia de cooperación al desarrollo, también brinda asistencia en materia electoral a través de observadores electorales.

Dichas acciones se desarrollan dentro del Instrumento Europeo para la Democracia y los Derechos Humanos (IEDDH), como su propio nombre indica, el instrumento tiene como objetivos promover la democracia, los derechos humanos y el Estado de Derecho. Durante las elecciones efectuadas en 2009, la UE envió una Misión de Observación para las elecciones generales en el Salvador ${ }^{714}$. Posteriormente, en 2012 y 2014 también envío un grupo de expertos para apoyar en las respectivas elecciones.

\section{Estructura del Servicio de Acción Exterior de El Salvador:}

El Ministerio de Relaciones Exteriores, Integración y Promoción Económica de El Salvador se divide en direcciones generales, las cuales se subdividen en subdirecciones y direcciones de acuerdo a áreas temáticas y geográficas ${ }^{715}$. El Ministerio cuenta con una Dirección General de Política Exterior, que es la encargada de promover la política exterior del país en tres ámbitos: bilateral, multilateral e integración. Esta Dirección General se subdivide de la siguiente forma:

- Sub Dirección General de Política Exterior:

- Dirección Europa

Dentro de la Dirección Europa hay una Subdirección que se encarga de las relaciones con la Unión Europea.

\footnotetext{
${ }^{714}$ SERVICIO EUROPEO DE ACCIÓN EXTERIOR: Misión de Observación Electoral Unión Europea, El Salvador 2009. Informe final de las Elecciones Generales. http://eeas.europa.eu/delegations/el_salvador/documents/content/informe_final_moe_ue_el_salvador.pdf [Última versión: 11-01-15]

${ }_{715}$ MINISTERIO DE RELACIONES EXTERIORES EL SALVADOR: Organigrama.

http://www.rree.gob.sv/index.php/institucion/marco-institucional/organigrama [Última versión: 11-01-15]
} 
Delegaciones diplomáticas:

\section{El Salvador ante la UE:}

El Salvador tiene una delegación diplomática ante la UE, que es concurrente a Bélgica, Holanda y Luxemburgo. Además de cubrir estos países El Salvador cuenta con embajadas en 7 Estados Miembros de la $\mathrm{UE}^{716}$. La misión diplomática ante la UE tiene 5 funcionarios $^{717}$ :

- 1 Embajador

- 1 Ministro Plenipotenciario

- 1 Ministro Consejero

- 2 Tercer Secretario

\section{La UE ante El Salvador:}

La UE cuenta con una delegación diplomática ante El Salvador y tiene 18 funcionarios en la respectiva misión, se encuentra dirigida por un Jefe de Delegación, Embajador, Jaume Segura Sacias (España) y cuenta con tres secciones ${ }^{718}$ :

- Sección de Asuntos Políticos e Información

- Sección de Cooperación

- Sección de Administración

\footnotetext{
716 MINISTERIO DE RELACIONES EXTERIORES EL SALVADOR: Embajadas en el mundo. http://embajadasyconsulados.rree.gob.sv/ [Última versión: 11-01-15]

717 EUROPEAN COMMISION-SECRETARIAT GENERAL: Diplomatic Corps. Protocol Service. Missions accredited to European Union. El Salvador. p. 69.

http://ec.europa.eu/dgs/secretariat_general/corps/index.cfm?go=search.search\&missions=1 [Última versión: 11-01-15]

718 DELEGACIÓN DE LA UNIÓN EUROPEA EN EL SALVADOR: Organización interna. http://eeas.europa.eu/delegations/el_salvador/about_us/internal_organisation/index_es.htm_[Última versión: 11-01-15]
} 


\section{- La UE-Granada}

Marco jurídico de las relaciones:

Las relaciones con la UE se regulan a través de su pertenencia al grupo de países ACP, y como tal es beneficiario de los mecanismos e instrumentos de ayuda que ofrece la UE a este grupo de países. Por citar ejemplos, podemos mencionar las ayudas que recibe mediante el Fondo de Desarrollo Europeo (regulado en los acuerdos de Cotonú), el Banco Europeo de Inversiones (para el financiamiento de infraestructura). La UE trabaja con Granada en temas como: cambio climático, energías renovables, género, gobernanza en la cooperación al desarrollo ${ }^{719}$.

\section{Estructura del Servicio de Acción Exterior de Granada:}

EL Ministerio de Asuntos Exteriores y Negocios Internacionales de Granada está formado por divisiones ${ }^{720}$, una División Administrativa y una División Política e Investigación. Esta última tiene dos secciones, una Sección Bilateral y Sección Multilateral, dentro de la multilateral se encuentran varias unidades:

- Asuntos Caribeños

- Asuntos Interamericanos

- Asuntos Asia, África y Medio Oriente

- Asuntos Europeos

Es en esta última unidad en la que se desarrollan las relaciones con la Unión Europea.

\section{Delegaciones diplomáticas}

\section{Granada ante la UE:}

Granada no tiene embajada ante la UE, sólo tiene dos delegaciones diplomáticas en Reino Unido y Bélgica ${ }^{721}$.

719 DELEGATION OF THE EUROPEAN UNION TO BARBADO AND THE EASTERN CARIBBEAN: Grenada \& the European Union. Political and Economic relations. http://eeas.europa.eu/delegations/barbados/eu_oecs/grenada/index_en.htm [Última versión: 11-01-15]

${ }^{720}$ MINISTRY OF FOREIGN AFFAIRS GRENADA: Ministry. http://www.gov.gd/ministries/foreign_affairs.html [Última versión: 11-01-15]

${ }^{721}$ MINISTRY OF FOREIG AFFAIRS GRENADA: Grenada's Diplomatic \& Consular Representatives Abroad.

http://www.gov.gd/embassies_consulates.html [Última versión: 11-01-15] 
2. La UE ante Granada:

La UE no tiene una delegación propia en la misma Granada, esta es cubierta desde la Delegación de la Unión Europea ante Barbados y el Caribe Oriental. 


\section{- La UE-Guatemala}

Marco jurídico de las relaciones:

Las actuales relaciones entre Guatemala con la UE se regulan jurídicamente a través del Acuerdo de Asociación entre la UE-CA (2012), al igual que en el caso de sus vecinos centroamericanos sus relaciones se inician en el marco del diálogo y el proceso de San José. Previo al Acuerdo de Asociación, la UE implementó una Estrategia Regional para América Central 2007-2013, la cual tenía como objetivo, justamente, generar el marco necesario para el Acuerdo de Asociación, para lo cual estableció como líneas de trabajo: apoyar la integración política, económica, y social de América Central ${ }^{722}$.

La UE ha sido una fiel defensora del proceso de integración de Centroamérica y ha apoyado los esfuerzos de Guatemala por consolidar el Estado de Derecho, en tal sentido la Unión ha aumentado su presupuesto destinado a Guatemala un promedio desde 96 millones de Euros, para el período 2002-2006) a 135 millones de Euros, para el período 2007-2013 $3^{723}$; los respectivos presupuestos estaban destinados a cubrir las siguientes áreas de trabajo:

- Justicia y seguridad

- Mejora de gestión presupuestaria

- Seguridad alimentaria

- Ayuda a la juventud (particularmente creando programas de prevención de la delincuencia y en la promoción del empleo)

- Crecimiento económico

- $\quad$ Integración regional ${ }^{724}$

Por otro lado, la UE también contribuye con la financiación de la Comisión Internacional contra la Impunidad en Guatemala.

722 COMISIÓN EUROPEA: Documento de Estrategia Regional para América Central 2007-2013. Bruselas, marzo 2007.

http://eeas.europa.eu/delegations/guatemala/documents/eu_guatemala/es_reg_es.pdf [Última revisión: 2712-14]

${ }^{723}$ DELEGACIÓN DE LA UNIÓN EUROPEA EN GUATEMALA. Relaciones políticas y económicas. http://eeas.europa.eu/delegations/guatemala/eu_guatemala/political_relations/index_es.htm [Última revisión: 27-12-14]

${ }^{724}$ SERVICIO EUROPEO DE ACCIÓN EXTERIOR: COMISIÓN EUROPEA (E/2007/480) Guatemala. Documento Estrategia País. 2007-2013.

http://eeas.europa.eu/delegations/guatemala/documents/eu_guatemala/es_gt_es.pdf [Última revisión: 2712-14] 
Estructura del Servicio de Acción Exterior de Guatemala:

El Ministerio de Relaciones Exteriores de Guatemala, está dividido en direcciones generales $^{725}$ : Dirección General de Relaciones Internacionales Bilaterales y la Dirección General de Relaciones Multilaterales y Económicas. Dentro de la dirección encargada de las relaciones bilaterales existen varias subdirecciones, entre ellas, la Subdirección de Europa, la cual se encarga de las relaciones con la UE.

\section{Delegaciones diplomáticas}

\section{Guatemala ante la UE:}

Guatemala tiene una delegación diplomática ante la Unión, la que a su vez es concurrente con Bélgica y Luxemburgo. Además, Guatemala tiene embajadas en 6 en otros Estados Miembros de la $\mathrm{UE}^{726}$. Dentro de la misión ante la UE, la embajada cuenta con 6 funcionarios ${ }^{727}$ :

- 1 Embajador

- 2 Ministro Consejero

- 1 Consejero

- 2 Tercer Secretario

\section{La UE ante Guatemala:}

La Unión Europea tiene una delegación ante Guatemala, la cual está formada por 3 funcionarios que cumplen las siguientes funciones ${ }^{728}$ :

- 1 Jefe de Delegación, Embajadora, Stella Zervoudaki (Grecia)

- 1 Jefe de Sección de Cooperación

- 1 Encargado de Negocios

\footnotetext{
${ }^{725}$ MINISTERIO DE RELACIONES EXTERIORES DE GUATEMALA: Ministerio. Organigrama. http://www.minex.gob.gt/Visor_Pagina.aspx?PaginaID=12 [Última revisión: 27-12-14]

${ }^{726}$ MINISTERIO DE RELACIONES EXTERIORES DE GUATEMALA: Embajadas de Guatemala en la región de Europa.

http://www.minex.gob.gt/DirectorioRegion.aspx?ID_TIPO=5\&ID_REGION=10 [Última revisión: 27-12$14]$

${ }^{727}$ EUROPEAN COMMISION-SECRETARIAT GENERAL: Diplomatic Corps. Protocol Service. Missions accredited to European Union. Guatemala. p. 79.

http://ec.europa.eu/dgs/secretariat_general/corps/index.cfm?go=search.search\&missions=1 [Última versión: 11-01-15]

728 DELEGACIÓN DE LA UNIÓN EUROPEA EN GUATEMALA: Organización interna. http://eeas.europa.eu/delegations/guatemala/about_us/internal_organisation/index_es.htm [Última versión: 11-01-15]
} 


\section{- La UE-Guyana}

Marco jurídico de las relaciones:

Las relaciones con la UE se encuadran a través de los acuerdos firmados entre la UECARICOM, a través de CARIFORUM. El 20 de octubre de 2008 Guyana se suma al grupo de países que firmaron el Acuerdo CARIFORUM-UE, convirtiéndose en el país décimo cuarto en hacerlo. Dentro de las áreas de trabajo que desarrolla la UE en Guyana se encuentran los asuntos a nivel bilateral y los asuntos globales. En el caso de los temas bilaterales están la democracia, derechos humanos y la lucha contra la pobreza; en términos globales la paz y la seguridad ${ }^{729}$.

\section{Estructura del Servicio de Acción Exterior de Guayana:}

El Ministerio de Asuntos Exteriores de Guyana se encuentra formado por Unidades, cuenta con una Unidad de Multilaterales y Asuntos Globales ${ }^{730}$, la cual se encarga de los temas Bilaterales, dentro de sus áreas de responsabilidad están manejar las relaciones bilaterales, las cuales contemplan una Sección destinada a las relaciones con Europa y África.

\section{Delegaciones diplomáticas:}

\section{Guyana ante la UE:}

Guyana cuenta con una delegación ante la UE, la cual es concurrente a Bélgica, Alemania y Noruega. Aparte de esta delegación sólo posee una embajada en otro Estado Miembro de la UE, en el Reino Unido ${ }^{731}$. La misión ante la UE cuenta con 4 funcionarios $^{732}$ :

\footnotetext{
${ }^{729}$ DELEGATION TO GUYANA, SURINAME, TRINIDAD AND TOBAGO AND FOR THE DUTCH OVERSEAS COUNTRIES AND TERRITORIES: Guyana \& the European Union. Political and Economic relations.

http://eeas.europa.eu/delegations/guyana/eu_guyana/political_relations/index_en.htm [Última revisión: $11-01.15]$

${ }^{730}$ MINISTRY FOREIGN AFFAIRS OF REPUBLIC OF GUYANA: Multilateral \& Global Affairs Unit. http://www.minfor.gov.gy/index.php?option=com_content\&task=view\&id=21\&Itemid=34 [Última revisión: 11-01.15]

${ }^{731}$ MINISTRY FOREIGN AFFAIRS OF REPUBLIC OF GUYANA: Guyana Missions Overseas. http://www.minfor.gov.gy/index.php?option=com_wrapper\&Itemid=99 [Última versión: 11-01-15]

${ }^{732}$ EUROPEAN COMMISION-SECRETARIAT GENERAL: Diplomatic Corps. Protocol Service. Missions accredited to European Union. Guyana. p. 83.

http://ec.europa.eu/dgs/secretariat_general/corps/index.cfm?go=search.search\&missions=1 [Última
} versión: 11-01-15] 
- Embajador

- Primer Secretario

- Agregado de Comercio

- Agregado para Asuntos Administrativos

\section{La UE ante Guayana:}

La UE tiene una delegación ante Guayana, la cual es concurrente a: Surinam, Trinidad y Tobago, así como a los Países y Territorios de Ultramar (pertenecientes a Reino de los Países Bajos: Aruba, Bonaire, Curazao, Saba, San Eustaquio y San Martín). La misión cuenta con 8 funcionarios, que cubren 7 secciones $^{733}$ :

- Jefe de Delegación, Embajador, Robert Kopecky (República Checa)

- Jefe de Política, Información y Prensa

- Jefe de Cooperación

- Jefe de Bilaterales

- Jefe de Comercio

- Jefe de Finanzas y Contratos

- 1 Jefe de Administración

- 1 Asistente

${ }^{733}$ DELEGATION TO GUYANA, SURINAME, TRINIDAD AND TOBAGO AND FOR THE DUTCH OVERSEAS COUNTRIES AND TERRITORIES: Internal organization.

http://eeas.europa.eu/delegations/guyana/about_us/internal_organisation/index_en.htm [Última versión: 11-01-15] 


\section{- La UE-Haití}

Marco jurídico de las relaciones:

Sus relaciones con la UE se efectúan a través de su membresía del grupo de países $\mathrm{ACP}^{734}$. Al ser miembro del CARICOM, Haití participa en CARIFORUM, pero hasta la fecha, aún no ha ratificado el Acuerdo de Asociación UE-CARIFORUM. Por otro lado, tras el terremoto de 2010, la cooperación de la UE hacia este país fue de 200 millones de Euros, representando la principal ayuda recibida desde el exterior ${ }^{735}$.

\section{Estructura del Servicio de Acción Exterior de Haití:}

El Ministerio de Asuntos Exteriores de Haití se dividen en direcciones las cuales están formadas por áreas temáticas, así existe una Secretaría de Estado de Asuntos Exteriores, la cual tiene una Dirección General de Relaciones Exteriores ${ }^{736}$, siendo esta la que cubre los asuntos con la UE, pero sin tener una unidad específica.

\section{Delegaciones diplomáticas:}

\section{Haití ante la UE:}

Haití cuenta con una delegación ante la UE, esta también es concurrente a: Bélgica, Luxemburgo y Países Bajos. Además de esta representación diplomática, cuenta con cuatro embajadas más dentro de los Estados Miembros de la Unión, Alemania, España, Italia y Francia ${ }^{737}$. La misión ante la UE tiene 10 funcionarios $^{738}$ :

- Embajador

\footnotetext{
734 DELEGACIÓN DE LA UNIÓN EUROPEA EN HAITÍ: Haití \& la Unión Europea. Relaciones políticas y económicas.

http://eeas.europa.eu/delegations/haiti/eu_haiti/political_relations/index_fr.htm [Última versión: 11-0115]

${ }^{735}$ MINISTERIO DE ASUNTOS EXTERIORES Y COOPERACIÓN DEL REINO DE ESPAÑA: Haití. Política Exterior. Oficina de Información Diplomática, Madrid, 2014.

http://www.exteriores.gob.es/Documents/FichasPais/Haiti_FICHA\%20PAIS.pdf [Última versión: 11-0115]

${ }^{736}$ MINISTÈRE DES AFFAIRES ÉTRANGÈRES D'HAÏTI: Les Directions.

http://www.mae.gouv.ht/les_directions.html [Última versión: 11-01-15]

${ }^{737}$ MINISTÈRE DES AFFAIRES ÉTRANGËRES D'HAÏTI: Ambassade et Consulats d'Haiti à l'étranger. http://www.mae.gouv.ht/ambassade_et_consulat_haitien.html [Última versión: 11-01-15]

738 EUROPEAN COMMISION-SECRETARIAT GENERAL: Diplomatic Corps. Protocol Service. Missions accredited to European Union. Haití. p. 84.

http://ec.europa.eu/dgs/secretariat_general/corps/index.cfm?go=search.search\&missions=1 [Última
} versión: 11-01-15] 
- Consejero

- Ministro Consejero

- Primer Secretario

- Segundo Secretario

\section{La UE ante Haití:}

La UE tiene una delegación en Haití, la que cuenta con 50 funcionarios, siendo la segunda representación diplomática más grande del continente de América, sólo antecedida por la misión diplomática en Washington, y es la primera delegación en número de funcionarios dentro de todos los países de América Latina y el Caribe. La delegación está formada por un jefe de misión y 6 secciones $^{739}$ :

- Jefe de la Delegación, Embajador, Javier Niño Pérez (España)

- Política, Prensa e Información

- Gobernabilidad, cooperación económica y social

- Infraestructura

- Desarrollo Rural

- Contratos y Finanzas

- Administración

${ }^{739}$ DELEGACIÓN DE LA UNIÓN EUROPEA ANTE HAITÍ: Organización interna. http://eeas.europa.eu/delegations/haiti/about_us/delegation_role/index_fr.htm [Última versión: 11-01-15] 


\section{- La UE-Honduras}

Marco jurídico de las relaciones:

Al ser un país centroamericano, sus relaciones con la UE, se basan en el diálogo y proceso de San José ${ }^{740}$ y con los acuerdos: Acuerdo Marco de Cooperación UE-CA (1993); Acuerdo de Diálogo Político y Cooperación (2003), y posteriormente, el Acuerdo de Asociación (2010), el cual servirá de marco estratégico común para promover el progreso de integración regional en América Central y el establecimiento de las relaciones a nivel inter-regional.

\section{Estructura del Servicio de Acción Exterior de Honduras:}

La Secretaría de Relaciones Exteriores de Honduras, está formada por direcciones generales $^{741}$. La Secretaría cuenta con una Subsecretaría de Estado de Política Exterior, que a su vez tiene una Dirección General de Política Exterior, la que se encarga de las relaciones y política internacional, esta a su vez se divide en dos secciones:

- Asuntos Bilaterales

- Asuntos Multilaterales

Es dentro de esta dirección general en la que se trabajan los temas relacionados con la Unión Europea.

\section{Delegaciones diplomáticas:}

\section{Honduras ante la UE:}

Honduras cuenta con una delegación ante la UE, la cual tiene como concurrencias a: Bélgica y Luxemburgo. Además de esta delegación Honduras cuenta con embajadas en 8 Estados Miembros de la Unión ${ }^{742}$. La misión diplomática en Bruselas cuenta con 5 funcionarios $^{743}$ :

${ }^{740}$ MINISTERIO DE ASUNTOS EXTERIORES Y COOPERACIÓN DEL REINO DE ESPAÑA: Honduras. Política Exterior. Oficina de Información Diplomática, Madrid, 2014.

http://www.exteriores.gob.es/Documents/FichasPais/Honduras_FICHA\%20PAIS.pdf [Última versión: 11-01-15]

${ }^{741}$ MINISTERIO DE RELACIONES EXTERIORES DE HONDURAS: Organigrama.

http://www.sre.gob.hn/organigrama_srenew.html Última versión: 11-01-15

${ }^{742}$ MINISTERIO DE RELACIONES EXTERIORES DE HONDURAS: Directorio de representaciones de Honduras en el exterior. 
- 1 Embajador

- 1 Ministro

- 1 Ministro Consejero

- 1 Consejero Económico

- 1 Administrativo

\section{La UE ante Honduras:}

La UE tiene una delegación ante Honduras, la cual posee tres funcionarios ${ }^{744}$ :

- 1 Jefe de Delegación, Embajador, Ketel Karlsen (Dinamarca)

- 1 Jefe de Sección de Cooperación

- 1 Encargado de Negocios

http://www.sre.gob.hn/directorio\%20de\%20embajadas\%20y\%20consulados\%20new.html

[Última versión: 11-01-15]

743 EUROPEAN COMMISION-SECRETARIAT GENERAL: Diplomatic Corps. Protocol Service. Missions accredited to European Union. Honduras. p. 86.

http://ec.europa.eu/dgs/secretariat_general/corps/index.cfm?go=search.search\&missions=1 [Última versión: 11-01-15]

744 DELEGACIÓN DE LA UNIÓN EUROPEA EN HONDURAS: Organización interna. http://eeas.europa.eu/delegations/honduras/about_us/internal_organisation/index_es.htm [Última versión: 11-01-15] 


\section{- La UE-Jamaica}

Marco jurídico de las relaciones:

Sus relaciones con la UE se desarrollan a través de su pertenencia a CARICOM, a través de CARIFORUM, y por su pertenencia al grupo de países ACP. Jamaica es país receptor de fondos europeos en distintas áreas. Durante las últimas cuatro décadas, Jamaica ha recibido de la UE, 1.000 millones de Euros, por concepto de ayuda a la cooperación al desarrollo. El 9 de mayo de 2014, la UE y Jamaica firman un Acuerdo de Cooperación, el cual incluye una aportación de 75 millones de Euros, los cuales deberán de estar destinados a las siguientes áreas de trabajo ${ }^{745}$ :

1. Protocolo de Medidas de Acompañamiento para el Sector del Azúcar

2. Proyecto de Seguridad Judicial y Transparencia

3. Apoyo adicional al Programa de Reducción de la pobreza

4. Programa de Apoyo a la Gestión Financiera al Sector Público

5. Apoyo adicional para el Proyecto de Capacitación EPA (Acuerdo de Asociación Económica)

6. Facilidad financiera para cooperación técnica

Por otra parte, Jamaica se beneficia del Acuerdo de Asociación Económica, firmada entre la UE-CARIFORUM, contemplado en el Programa Regional, que tiene un presupuesto de 165 millones de Euros, para el período 2008-2013, del cual está destinado para Jamaica, 110 millones de Euros para programas específicos, y 12, 9 millones de Euros para necesidades imprevistas ${ }^{746}$.

Estructura del Servicio Exterior de Jamaica:

El Ministerio de Asuntos Exteriores y Comercio Exterior, cuenta con una Secretaría General que a su vez se divide en Subsecretarías ${ }^{747}$ :

${ }^{745}$ DELEGATION TO JAMAICA, BELIZE, THE BAHAMAS, TURKS AND CAICOS ISLANDS AND CAYMAN ISLANDS: Jamaica \& the European Union. Political and Economic relations. http://eeas.europa.eu/delegations/jamaica/eu_jamaica/political_relations/index_en.htm [Última versión: 11-01-15]

746 DELEGATION TO JAMAICA, BELIZE, THE BAHAMAS, TURKS AND CAICOS ISLANDS AND CAYMAN ISLANDS: Jamaica \& the European Union. Agreements.

http://eeas.europa.eu/delegations/jamaica/eu_jamaica/political_relations/agreements/index_en.htm [Última versión: 11-01-15]

${ }^{747}$ MINISTRY FOREIGN AFFAIRS AND FOREIGN TRADE OF JAMAICA: Organizational structure 
- Subsecretaría División de Asuntos Bilaterales \& Regionales

- Subsecretaría División de Asuntos Multilaterales

Dentro de esta última se encuentra el Departamento de Organismos Internacionales y Asuntos Económicos, dado que las bases de colaboración entre Jamaica y la UE se dan a través de los Acuerdos de los Países Asia Pacífico y para Jamaica este es un asunto multilateral. Las relaciones con la UE están comprendidas dentro de esta dirección.

\section{Delegaciones diplomáticas:}

\section{Jamaica ante la UE:}

Jamaica cuenta con una delegación ante la UE, esta misión a su vez es concurrente a Bélgica, Irlanda, Luxemburgo y Países Bajos. Además de esta representación, Jamaica cuenta con embajadas en 3 Estados Miembros de la Unión ${ }^{748}$. La misión ante la UE cuenta con 4 funcionarios $^{749}$ :

- 1 Embajador

- 1 Ministros Consejero

- 1 Primer Secretario

- 1 Agregado

\section{La UE ante Jamaica:}

La Unión Europea cuenta con una delegación ante Jamaica, la cual es concurrente a Belice, Las Bahamas, Las Islas Turcas y Caicos, y las Islas Caimán. Esta misión se divide en 6 secciones y cuenta con 10 funcionarios, 3 dedicados a las tareas de Belice y 7 dedicados a cubrir Jamaica y las otras concurrencias ${ }^{750}$ :

http://www.mfaft.gov.jm/jm/images/MFA_Organisational_Chart_for_website.pdf [Última versión: 1101-15]

${ }^{748}$ MINISTRY FOREIGN AFFAIRS AND FOREIGN TRADE OF JAMAICA: Jamaican representatives overseas. http://www.mfaft.gov.jm/jm/missions/embassies-and-high-commissions/embassies [Última versión: 11-01-15]

749 EUROPEAN COMMISION-SECRETARIAT GENERAL: Diplomatic Corps. Protocol Service. Missions accredited to European Union. Jamaica. p. 100.

http://ec.europa.eu/dgs/secretariat_general/corps/index.cfm?go=search.search\&missions=1 [Última versión: 11-01-15]

${ }^{750}$ DELEGATION TO JAMAICA, BELIZE, THE BAHAMAS, TURKS AND CAICOS ISLANDS AND CAYMAN ISLANDS: Internal organization.

http://eeas.europa.eu/delegations/jamaica/about_us/internal_organisation/index_en.htm

[Última versión: 11-01-15] 
- 1 Jefe de Delegación, Embajadora, Paola Amadei (Italia)

- Cooperación

- Política, Información y Prensa

- Operaciones I: Desarrollo Social y Económico y Comercio

- Operaciones II: Infraestructura y Desarrollo Rural

- Finanzas y Contratos

- Administración 


\section{- La UE-México}

\section{Marco jurídico de las relaciones:}

Sus relaciones con la UE se regulan, principalmente, mediante dos instrumentos jurídicos:

1. Acuerdo de Asociación Económica, también llamado "Acuerdo Global", firmado en Bruselas el 8 de diciembre de 1997, y el cual, entró en vigor el 1 de octubre de 2000.

2. Asociación Estratégica UE-México, firmada en 2008.

Este último acuerdo de asociación convierte a México en uno de los diez socios estratégicos que cuenta la Unión Europea ${ }^{751}$, para implementar su política exterior y de seguridad común; y para ejecutar su acción exterior a nivel global. A su vez, es conjuntamente, con Brasil, uno de los países de la región de América Latina y el Caribe que cuenta con este status de "socio estratégico" para la UE, aunque se diferencia de Brasil, pues México es el único que cuenta con un "Acuerdo Global”, acuerdo que ha contribuido en el fortalecer y profundizar en sus relaciones de manera bilateral; las mismas que se encuentran institucionalizadas mediante reuniones periódicas del más alto nivel y que cubre una agenda de temas en común. Cada dos años se realiza una cumbre de jefes de estado y de gobierno UE-México, reunión del Consejo Conjunto (a nivel ministerial) y el Comité Conjunto. Entre los temas que tratan las partes se encuentran: derechos humanos, medio ambiente, cambio climático, cultura, macroeconomía y seguridad $^{752}$.

\section{Estructura del Servicio de Acción Exterior de México:}

La Secretaría de Relaciones Exteriores de México, está dividida en subsecretarías y direcciones generales $^{753}$. Existe una Subsecretaría de Relaciones Exteriores que está dividida en 3 direcciones generales, entre ellas está la Dirección General para Europa, que es la encarga de llevar los temas relacionados con la UE.

\footnotetext{
${ }^{751}$ Entre los diez socios de la Unión Europea se encuentran: Brasil, Canadá, China, India, Japón, México, Rusia, Sudáfrica, Corea del Sur y Estados Unidos.

${ }^{752}$ DELEGACIÓN DE LA UNIÓN EUROPEA EN MÉXICO: Relaciones políticas y económicas. http://eeas.europa.eu/delegations/mexico/eu_mexico/political_relations/index_es.htm [Última revisión: 27-12-14]

${ }^{753}$ SECRETARÍA DE RELACIONES EXTERIORES: Organigrama.

http://www.sre.gob.mx/index.php/cancilleria/organigrama [Última versión: 11-01-15]
} 
Delegaciones diplomáticas:

\section{México ante la UE:}

México cuenta con una delegación ante la UE, tiene concurrencia con Bélgica. La misión es una de las más grandes misiones de los países de América Latina y el Caribe, teniendo 22 funcionarios acreditados ante la $\mathrm{UE}^{754}$ :

- 1 Embajador

- 4 Ministros

- 6 Consejeros

- 5 Primeros Secretarios

- 5 Segundos Secretarios

- 1 Tercer Secretario

Además de esta representación ante la UE, México cuenta con embajadas en 18 Estados Miembros de la Unión ${ }^{755}$.

\section{La UE ante México:}

La UE cuenta con una delegación en México, la cual está dividida en 4 secciones con un total de 7 funcionarios ${ }^{756}$ :

- Jefe de Delegación, Embajador, Andrew Standley (Reino Unido)

- Adjunto al Jefe de Delegación

El resto de funcionarios se encuentran dentro de cuatro secciones:

1. Política, Información y Prensa

2. Comercio y Economía

3. Cooperación

4. Administración

754 EUROPEAN COMMISION-SECRETARIAT GENERAL: Diplomatic Corps. Protocol Service. Missions accredited to European Union. México. p. 131-133.

http://ec.europa.eu/dgs/secretariat_general/corps/index.cfm?go=search.search\&missions=1 [Última versión: 11-01-15]

${ }^{755}$ SECRETARÍA DE RELACIONES EXTERIORES: Embajadas de México en el exterior.

http://www.sre.gob.mx/index.php/representaciones/embajadas-de-mexico-en-el-exterior [Última versión: 11-01-15]

${ }^{756}$ DELEGACIÓN DE LA UNIÓN EUROPEA EN MÉXICO: Organización interna.

http://eeas.europa.eu/delegations/mexico/about_us/internal_organisation/index_en.htm [Última versión: 11-01-15] 


\section{- La UE-Nicaragua}

\section{Marco jurídico de las relaciones:}

Las relaciones con la UE se inician, al igual que con los otros países centroamericanos, dentro del Diálogo y Proceso de San José en la década de los ochenta. Al ser parte de SICA se beneficia del Acuerdo de Asociación entre la UE-CA (2010). En el ámbito bilateral, la UE mantiene una línea de trabajo desarrollada en torno a la ayuda a la cooperación al desarrollo, en el nuevo período presupuestario de 2014-2020, el presupuesto para Centroamérica es de 900 millones de Euros, de los cuales 204 millones de Euros van destinados a Nicaragua. Dicha cooperación se centrará en las siguientes áreas: apoyo a sectores productivos, educación para la generación de empleo y cambio climático ${ }^{757}$.

El trabajo desarrollado por la UE en Nicaragua ha respondido a los mismos objetivos planteados para el conjunto de los países centroamericanos, a través de la búsqueda de la consolidación de la paz y el Estado de Derecho, la promoción de la democracia, el fomento de un modelo desarrollo sostenible, y su apoyo a la profundización de la integración regional, tanto a nivel económico como político ${ }^{758}$. De ahí que la propia Delegación de la UE ante Nicaragua y los países centroamericanos esté acreditada también ante el Sistema de la Integración Centroamericana (SICA), hecho que demuestra el apoyo de la UE con la integración centroamericana.

\section{Estructura del Servicio de Acción Exterior de Nicaragua:}

El Ministerio de Relaciones Exteriores de Nicaragua se divide en direcciones generales $^{759}$, entre ellas se encuentra la Dirección General Europa, la cual está fraccionada en dos:

- Dirección de Países Nórdicos, Occidental, Central y Este

- Dirección Unión Europea

\footnotetext{
757 DELEGACIÓN DE LA UNIÓN EUROPEA EN NICARAGUA, COSTA RICA Y PANAMÁ, Y ANTE EL SISTEMA DE LA INTEGRACIÓN CENTROAMERICANA: Nicaragua y la Unión Europea. Relaciones económicas y políticas.

http://eeas.europa.eu/delegations/nicaragua/eu_nicaragua/political_relations/index_es.htm [Última versión: 06-01-15]

${ }^{758}$ Ibíd.

759 MINISTERIO DE RELACIONES EXTERIORES DE NICARAGUA: Organigrama. http://oaip.cancilleria.gob.ni/index.php/es/acerca-oaip/organigrama [Última versión: 06-01-15]
} 
Nicaragua cuenta con una Dirección dedicada a la Unión Europea.

Delegaciones diplomáticas:

\section{Nicaragua ante la UE:}

Nicaragua tiene una delegación ante la UE, la cual es concurrente a Bélgica, Luxemburgo y Países Bajos. Además de esta representación Nicaragua tiene embajadas en 10 Estados Miembros de la Unión ${ }^{760}$. La misión diplomática ante la UE cuenta con dos funcionarios ${ }^{761}$ :

- 1 Embajador

- 1 Primer Secretario

\section{La UE ante Nicaragua:}

La UE tiene una delegación diplomática ante Nicaragua, la cual es concurrente a Costa Rica, Panamá y ante el Sistema de Integración Centroamericana (SICA). Esta misión cuenta con 7 funcionarios, que se encargan de 4 secciones $^{762}$ :

- 1 Jefe de Delegación, Embajador Javier Sandomingo (España)

- 1 Jefe Adjunto de Delegación

Los cinco otros funcionarios se encuentran dentro de las cuatro siguientes secciones:

1. Política, Información y Prensa

2. Cooperación

3. Cooperación Regional

4. Administración

\footnotetext{
${ }^{760}$ MINISTERIO DE RELACIONES EXTERIORES DE NICARAGUA: Cuerpo diplomático y consular de Nicaragua.

http://www.cancilleria.gob.ni/embajadas/index.shtml [Última versión: 06-01-15]

761 EUROPEAN COMMISION-SECRETARIAT GENERAL: Diplomatic Corps. Protocol Service. Missions accredited to European Union. Nicaragua. p. 146.

http://ec.europa.eu/dgs/secretariat_general/corps/index.cfm?go=search.search\&missions=1 [Última versión: 11-01-15]

762 DELEGACIÓN EN NICARAGUA, COSTA RICA Y PANAMÁ, Y ANTE EL SISTEMA DE LA INTEGRACIÓN CENTROAMERICANA: Organización interna.

http://eeas.europa.eu/delegations/nicaragua/about_us/internal_organisation/index_es.htm [Última versión: 11-01-15]
} 


\section{- La UE-Panamá}

Marco jurídico de las relaciones:

Las relaciones con la Unión Europea se desarrollan dentro del mismo marco jurídico que el de los países centroamericanos, es decir, se inician con el Diálogo y Proceso de San José durante la década de los años ochenta. Posteriormente se firmarán los acuerdos de cooperación de 1985 y 1993. Durante la primera década del siglo XXI se logra firmar el Acuerdo de Diálogo Político y Cooperación (2003) y, finalmente, el Acuerdo de Asociación firmado en 2010.

\section{Estructura del Servicio de Acción Exterior de Panamá:}

El Ministerio de Relaciones Exteriores está dividido en direcciones generales ${ }^{763}$, dentro de ellas existen departamentos. Así encontramos que hay una Dirección General de Política Exterior y dentro de ella un Departamento Europa, dedicado a las relaciones con la Unión Europea.

\section{Delegaciones diplomáticas:}

\section{Panamá ante la UE:}

Panamá cuenta con una delegación ante la UE y ésta tiene concurrencias a Bélgica, Luxemburgo y Países Bajos. Además de esta representación Panamá tiene embajadas en 14 Estados Miembros de la Unión Europea ${ }^{764}$. La misión ante la UE cuenta con 4 funcionarios $^{765}$ :

- 1 Embajador

- 1 Consejero

- 1 Ministro Consejero

- 1 Agregado Cultural

763 MINISTERIO DE RELACIONES EXTERIORES DE PANAMÁ: Direcciones. http://www.mire.gob.pa/departamentos [Última revisión: 06-01-15]

${ }_{764}$ MINISTERIO DE RELACIONES EXTERIORES DE PANAMÁ: Panamá en el exterior. http://www.panamaenelexterior.gob.pa/ [Última revisión: 11-01.15]

${ }_{765}$ EUROPEAN COMMISION-SECRETARIAT GENERAL: Diplomatic Corps. Protocol Service. Missions accredited to European Union. Panamá. p. 158.

http://ec.europa.eu/dgs/secretariat_general/corps/index.cfm?go=search.search\&missions=1 [Última versión: 11-01-15] 
2. La UE ante Panamá:

La UE no cuenta con una delegación diplomática en Panamá, este país es cubierto desde la Delegación de la UE ante Nicaragua, la cual es concurrente a Costa Rica, Panamá y ante el Sistema de Integración Centroamericana (SICA), como se ha indicado anteriormente. 


\section{- La UE-Paraguay}

\section{Marco jurídico de las relaciones:}

Las relaciones con la Unión Europea se desarrollan en dos ámbitos, al igual que el de sus vecinos del MERCOSUR, a nivel bilateral (UE-Paraguay) e inter-regional (MERCOSUR-UE), el acuerdo que regula dichas relaciones es el Acuerdo Marco de Cooperación (1991) ${ }^{766}$, el mismo incluye la celebración periódica de comisiones mixtas, las cuales acuerdas las áreas de trabajo de manera común. En el ámbito bilateral, Paraguay es receptora de la ayuda de cooperación al desarrollo de la UE, durante el período 2007-2013, el país recibió 130 millones de Euros ${ }^{767}$.

\section{Estructura del Servicio de Acción Exterior de Paraguay:}

El Ministerio de Relaciones Exteriores se divide en viceministeriosy estos a su vez en direcciones generales, entre los que se encuentran ${ }^{768}$ :

- Dirección de Política Bilateral

- Dirección de Política Multilateral

A pesar que dentro de la Dirección de Política Bilateral se existe una Dirección Europa, las relaciones con la UE se llevan dentro de la Dirección de Política Multilateral por ser considerado un organismo internacional.

Delegaciones diplomáticas:

\section{Paraguay ante la UE:}

Paraguay cuenta con una delegación ante la UE, concurrente a Bélgica, Luxemburgo y Países Bajos. Además de esta representación, Paraguay cuenta con embajadas en 9 Estados Miembros de la $\mathrm{UE}^{769}$.

\footnotetext{
766 MINISTERIO DE ASUNTOS EXTERIORES Y COOPERACIÓN DEL REINO DE ESPAÑA: Paraguay. Política Exterior. Oficina de Información Diplomática, Madrid, 2014.

http://www.exteriores.gob.es/Documents/FichasPais/Paraguay_FICHA\%20PAIS.pdf [Última revisión: 11-01.15]

${ }^{767}$ DELEGACIÓN DE LA UNIÓN EUROPEA EN PARAGUAY: Paraguay y la Unión Europea. http://eeas.europa.eu/delegations/paraguay/eu_paraguay/political_relations/index_es.htm_[Última revisión: 11-01.15]

${ }^{768}$ MINISTERIO DE RELACIONES EXTERIORES DE PARAGUAY: Organigrama. http://www.mre.gov.py/v1/Adjuntos/Organigrama.pdf [Última revisión: 11-01.15]
} 
La misión cuenta con 5 funcionarios ${ }^{770}$ :

- 1 Embajador

- 2 Ministro

- 1 Primer Secretario

- 1 Agregado

\section{La UE ante Paraguay:}

La UE tiene una delegación ante Paraguay, y en la actualidad están formando el equipo que se será parte de la representación diplomática de la Unión, sin embargo, ya cuenta con la designación de un Jefe de Delegación, el Embajador Alessandro Palmero $(\text { Italia })^{771}$.

\footnotetext{
${ }^{769}$ MINISTERIO DE RELACIONES EXTERIORES DE PARAGUAY: Representaciones diplomáticas de Paraguay en el mundo. Europa. http://www.mre.gov.py/v1/Representaciones/0-Todos.aspx\#cont_4 [Última revisión: 11-01.15]

770 EUROPEAN COMMISION-SECRETARIAT GENERAL: Diplomatic Corps. Protocol Service. Missions accredited to European Union. Paraguay. p. 160.

http://ec.europa.eu/dgs/secretariat_general/corps/index.cfm?go=search.search\&missions=1 [Última versión: 11-01-15]

771 DELEGACIÓN DE LA UNIÓN EUROPEA EN PARAGUAY: Organización interna. http://eeas.europa.eu/delegations/paraguay/about_us/internal_organisation/index_es.htm [Última versión: $11-01-15$
} 


\section{- La UE-Perú}

\section{Marco jurídico de las relaciones:}

Las relaciones entre la UE y Perú se enmarcan dentro dos ámbitos: bilateral e interregional, es decir entre la UE-CAN, y las bases jurídicas de las respectivas relaciones son las mismas que la de los países andinos. En su conjunto la UE sigue siendo el principal socio comercial de Perú ${ }^{772}$. A nivel bilateral en 2009, mediante el Memorándum de Entendimiento entre la Comisión Europea y Perú, se establece la creación de un mecanismo de consulta bilateral, cuyo objetivo es institucionalizar un diálogo al más alto nivel de funcionarios ${ }^{773}$, cuyo fin es identificar y crear una agenda de trabajo común. Entre los principales temas de trabajo común, entre Perú y UE, se encuentran varios asuntos y desafíos globales tales como: macroeconomía, finanzas, derechos humanos, cambio climático, tecnología, migración, lucha contra las drogas ilícitas y delitos conexos.

A nivel inter-regional entre la UE-CAN, las relaciones entre las partes se inician en la década de los noventa, en 1993, en 1996 se emite la Declaración de Roma, la cual define las relaciones entre las partes, a través del establecimiento de un Diálogo Político $^{774}$. En 2003 el diálogo se amplió, firmándose el Acuerdo de Diálogo Político y Cooperación entre la Unión Europea y la Comunidad Andina ${ }^{775}$. Este sirvió de instrumento jurídico para profundizar las relaciones entre ambas regiones, abarcando temas como prevención de conflictos, buen gobierno, inmigración, medio ambiente, cambio climático, desarrollo sostenible, lavado de dinero, lucha contra la delincuencia organizada y el terrorismo. El mismo excluía el ámbito comercial. Posteriormente, durante los últimos años, Perú, al igual que Colombia, deseaban concretar el Acuerdo

\footnotetext{
772 MINISTERIO DE ASUNTOS EXTERIORES Y COOPERACIÓN DEL REINO DE ESPAÑA: Perú. Política Exterior. Oficina de Información Diplomática, Madrid, 2014. http://www.exteriores.gob.es/Documents/FichasPais/PERU_FICHA\%20PAIS.pdf [Última versión: 1101-15]

773 Memorándum de Entendimiento entre la Comisión Europea y la República del Perú para el establecimiento de un Mecanismo de Consulta Bilateral, Bruselas 29 de octubre de 2009. http://eeas.europa.eu/peru/docs/mou_peru_es.pdf [Última revisión: 06-01-15]

${ }^{774}$ Declaración Conjunta Diálogo Político entre la Unión Europea y la Comunidad Andina, Roma 30 de junio de 1996.

http://www.eeas.europa.eu/andean/docs/decl_rome_en.pdf [Última revisión: 06-01-15]

${ }^{775}$ COM (2003) 695 FINAL. COMISIÓN DE LAS COMUNIDADES EUROPEAS, relativa a la firma de un Acuerdo de Diálogo Político y Cooperación entre la Comunidad Europea y sus Estados miembros, por un parte, y la Comunidad Andina y sus países miembros, las Repúblicas de Bolivia, Colombia, Ecuador, Perú y la República Bolivariana, por otra parte. Bruselas, 14 de noviembre de 2003.
} 
de Asociación que se estaba negociando entre la UE-CAN a nivel inter-regional, pero el retiro de las negociaciones, primero por parte de Venezuela, luego Ecuador y Bolivia, originó que sólo se lograra un acuerdo mínimo, dando como resultado, el Acuerdo Comercial Multipartes entre UE-Colombia y Perú, el cual fue firmado en 2012, y entró en vigor en 2013.

Cabe destacar que Perú es el país creador e impulsor de la Alianza del Pacífico y participa en el Acuerdo de Asociación Transpacífico ${ }^{776}$. La Alianza del Pacífico se ha convertido en un tema central dentro de la actual política exterior de cada uno de sus miembros: Colombia, Chile, Perú y México. Un dato interesante es que todos estos países tienen un acuerdo comercial con la UE. Chile tiene Acuerdo de Asociación con la UE y, con México, la UE tiene un Acuerdo Global y el estatus de Socio Estratégico.

\section{Estructura del Servicio de Acción Exterior de Perú:}

El Ministerio de Relaciones Exteriores de Perú está formado por direcciones generales $^{777}$, dentro de ellas se encuentra la Dirección General de Europa, la cual se divide en:

- Dirección Europa I (Europa Comunitaria)

- Dirección Europa II (Europa no Comunitaria)

La Dirección Europa I a su vez, tiene una subdirección llamada concretamente, Subdirección Relaciones con la Unión Europea. Siento esta la que encarga de coordinar y gestionar los temas políticos tratados con la UE y sus instituciones como son el Consejo, Comisión Europea y el Parlamento Europeo.

\section{Delegaciones diplomáticas:}

\section{Perú ante la UE:}

Perú tiene una delegación ante la UE, la cual es concurrente a Bélgica y Luxemburgo. Además de esta representación Perú tiene embajadas en 15 Estados Miembros de la Unión $^{778}$.

\footnotetext{
${ }^{776}$ Ministerio de Asuntos Exteriores y Cooperación del Reino de España: Perú. Perfil País. Oficina de Información Diplomática, Madrid, 2014. http://www.exteriores.gob.es/Documents/FichasPais/PERU_FICHA\%20PAIS.pdf [Última revisión: 0601-15]

${ }^{777}$ MINISTERIO DE RELACIONES EXTERIORES DE PERÚ: Organigrama. http://www.rree.gob.pe/elministerio/Paginas/Organigrama.aspx [Última versión: 11-01-15]
} 
La misión ante la UE cuenta con 7 funcionarios ${ }^{779}$ :

- 1 Embajador

- 2 Ministros Consejeros

- 2 Consejero

- 1 Segundo Secretario

- 1 Tercer Secretario

2. La UE ante Perú:

La UE cuenta con una delegación ante Perú, esta misión se encarga de 5 secciones y cuenta con 6 funcionarios ${ }^{780}$ :

- 1 Jefe de Delegación, Embajadora, Irene Horejs (Austria)

El resto de funcionarios se encuentran dentro de las cinco secciones:

1. Política y Prensa

2. Comercio y Asuntos Económicos

3. Cooperación

4. Finanzas y Contratos

5. Administración

${ }^{778}$ MINISTERIO DE RELACIONES EXTERIORES DE PERÚ: Directorio de embajadas peruanas en el exterior.

http://www.rree.gob.pe/servicioalciudadano/Paginas/Embajadas.aspx [Última versión: 11-01-15]

779 EUROPEAN COMMISION-SECRETARIAT GENERAL: Diplomatic Corps. Protocol Service. Missions accredited to European Union. Perú. p. 161.

http://ec.europa.eu/dgs/secretariat_general/corps/index.cfm?go=search.search\&missions=1 [Última versión: 11-01-15]

${ }^{780}$ DELEGACIÓN DE LA UNIÓN EUROPEA EN PERÚ: Organización interna.

http://eeas.europa.eu/delegations/peru/about_us/internal_organisation/index_en.htm [Última versión: 1101-15] 
- La UE-Santa Lucía

Marco jurídico de las relaciones:

Su relación con la UE se realiza a través de su participación en CARIFORUM, por lo que participa dentro del Acuerdo de Asociación Económica con la Unión Europea. Santa Lucía ha sido uno de los países más activos en la defensa de la integración caribeña $^{781}$.

Estructura del Servicio de Acción Exterior de Santa Lucía:

El Ministerio de Asuntos Exteriores, Comercio Internacional y Aviación Civil, al igual que el resto de países que forman parte de la Mancomunidad de Naciones, no tienen mucha estructura y sus funciones están centralizadas dentro de secretarías, que en el caso de Santa Lucía se dividen en dos $^{782}$ :

- Secretaría Permanente

- Secretaría Adjunta

Delegaciones diplomáticas:

\section{Santa Lucía ante la UE:}

Santa Lucía tiene una delegación ante la UE, la cual es concurrente a Luxemburgo y Países Bajos, además de esta representación cuenta con embajadas en 5 Estados Miembros de la Unión ${ }^{783}$.

La misión ante la Unión tiene 3 funcionarios ${ }^{784}$ :

\footnotetext{
${ }^{781}$ MINISTERIO DE ASUNTOS EXTERIORES Y COOPERACIÓN DEL REINO DE ESPAÑA: Santa Lucía. Perfil País. Oficina de Información Diplomática, Madrid, 2014.

http://www.exteriores.gob.es/Documents/FichasPais/SANTALUCIA_FICHA\%20PAIS.pdf [Última revisión: 06-01-15]

${ }^{782}$ MINISTRY OF EXTERNAL AFFAIRS, INTERNATIONAL TRADE AND CIVIL AVIATION: Administration http://externalaffairs.govt.lc/

${ }^{783}$ MINISTRY OF EXTERNAL AFFAIRS, INTERNATIONAL TRADE AND CIVIL AVIATION: Accreditation of Saint Lucian Representatives Overseas.

http://externalaffairs.govt.lc/services/accreditation-of-saint-lucian-representatives-overseas [Última revisión: 11-01-14.]

784 EUROPEAN COMMISION-SECRETARIAT GENERAL: Diplomatic Corps. Protocol Service. Missions accredited to European Union. Saint Lucia. p. 174.

http://ec.europa.eu/dgs/secretariat_general/corps/index.cfm?go=search.search\&missions=1 [Última
} versión: 11-01-15] 
- 1 Embajador

- 1 Primer Secretario

- 1 tercer Secretario

2. La UE ante Santa Lucía:

La UE no tiene una delegación en Santa Lucía, pero esta es cubierta desde la Delegación de la UE ante Barbados y el Caribe Oriental. 


\section{- La UE-Federación San Cristóbal y Nieves}

Marco jurídico de las relaciones:

Sus relaciones con la UE se articulan a través de su vinculación con los países ACP y su membresía con CARICOM, por lo que igual que sus pares, forma parte de CARIFORUM y por consiguiente se beneficia del Acuerdo de Asociación Económica con la Unión Europea ${ }^{785}$. También se beneficia del Protocolo del Azúcar firmado con la UE y de las medidas de acompañamiento para el período 2006-2013, de la Comisión Europea, la cual destinaba 45.130.000 Euros. Las respectivas medidas pretendían apoyar reformas económicas, el sector público y privado en el país. El BEI es otra fuente de financiamiento con la que cuenta el país, para conseguir préstamos para infraestructura, PYMES, industria, etc.

Entre los temas de trabajo de la UE con San Cristóbal y Nieves están: el cambio climático, energías renovables, seguridad alimentaria, igualdad, género, protección de medio amiente, gobernanza en la cooperación al desarrollo, promoción de la defensa de los derechos humanos, el Estado de Derecho y la democracia ${ }^{786}$.

Estructura del Servicio de Acción Exterior de la Federación San Cristóbal y Nieves:

El Misterio de Asuntos Exteriores de la Federación San Cristóbal y Nieves, cuenta con una estructura muy pequeña, tal como ocurre en los otros países miembros de la Mancomunidad de Naciones, por lo que no dispone con una unidad, dirección o secretaría dedicada a las relaciones con la UE.

\section{Delegaciones diplomáticas:}

\section{Federación San Cristóbal y Nieves ante la UE}

La Federación San Cristóbal y Nieves cuenta con una delegación ante la UE, al cual es concurrente a Bélgica, Luxemburgo y Países Bajos. Además de esta representación,

\footnotetext{
${ }^{785}$ MINISTERIO DE ASUNTOS EXTERIORES Y COOPERACIÓN DEL REINO DE ESPAÑA: San Cristóbal y Nieves. Perfil País. Oficina de Información Diplomática, Madrid, 2014. http://www.exteriores.gob.es/Documents/FichasPais/SANCRISTOBALYNIEVES_FICHA\%20PAIS.pdf [Última revisión: 06-01-14]

786 DELEGACIÓN DE LA UNIÓN EUROPEA ANTE BARBADOS Y EL CARIBE ORIENTAL: Relaciones Económicas y políticas Unión Europea-San Cristóbal y Nieves. http://eeas.europa.eu/delegations/barbados/eu_oecs/st_kitts_nevis/index_en.htm\# [Última revisión: 06-01-14]
} 
sólo cuenta con una embajada más dentro de toda la UE, en Reino Unido ${ }^{787}$. La misión diplomática ante la UE consta de 3 funcionarios:

- 1 Embajador

- 1 Primer Secretario

- 1 Tercer Secretario

2. La UE ante Federación San Cristóbal y Nieves:

La UE no tiene representación diplomática directamente en territorio de la Federación de San Cristóbal y Nieves, pero es cubierta desde la Delegación de la UE en Barbados, la cual tiene a la Federación dentro de sus concurrencias.

787 MINISTRY OF FOREIGN AFFAIRS: Embassies. http://www.foreign.gov.kn/node/17 [Última revisión: 06-01-14] 


\section{- La UE-San Vicente y Las Granadinas}

Marco jurídico de las relaciones:

Sus relaciones con la UE se desarrollan mediante su pertenencia al grupo de países ACP y al ser miembro de CARICOM, por tanto se beneficia del Acuerdo de Asociación Económica con la Unión Europea. El BEI también juega un papel importante en el desarrollo del país a través de préstamos. Después del huracán "Tomás" en 2010, la UE canalizó su ayuda a través del Departamento de Ayuda Humanitaria, ECHO. Los trabajos de la UE se centran, al igual que en San Cristóbal y Nieves, en asuntos como: seguridad alimentaria, igualdad, género, protección de medio amiente, gobernanza en la cooperación al desarrollo, promoción de la defensa de los derechos humanos, el Estado de Derecho y la democracia ${ }^{788}$.

Estructura del Servicio de Acción Exterior de San Vicente y Las Granadinas:

El Ministerio de Asuntos Exteriores, Comercio Exterior, Comercio y Tecnología de la Información, cuenta con una Unidad de Política Exterior e Investigación ${ }^{789}$, que es la que se encarga de manera general sobre todos los asuntos exteriores del país, sean estos a nivel bilateral o multilateral.

Delegaciones diplomáticas:

\section{San Vicente y Las Granadinas ante la UE:}

San Vicente y Las Granadinas cuenta con una representación diplomática ante la UE, la cual también es concurrente a Bélgica, Luxemburgo y Países Bajos. No cuenta con otra embajada en otro Estado Miembro de la Unión. La misión ante la UE cuenta con tres funcionarios $^{790}$ :

\footnotetext{
788 DELEGACIÓN DE LA UNIÓN EUROPEA ANTE BARBADOS Y EL CARIBE ORIENTAL: Relaciones Económicas y políticas Unión Europea-San Vicente y las Granadinas. http://eeas.europa.eu/delegations/barbados/eu_oecs/st_vincent_grenadines/index_en.htm [Última revisión: 06-01-14]

789 MINISTRY OF FOREIGN AFFAIRS, FOREING TRADE, COMMERCE \& INFORMATION TECHNOLOGY: Departments. http://www.foreign.gov.vc/ [Última revisión: 11-01-14]

790 EUROPEAN COMMISION-SECRETARIAT GENERAL: Diplomatic Corps. Protocol Service. Missions accredited to European Union. Saint Vicent and The Granadines p. 175.

http://ec.europa.eu/dgs/secretariat_general/corps/index.cfm?go=search.search\&missions=1 [Última
} versión: 11-01-15] 
- 1 Embajador

- 1 Tercer Secretario

- 1 Primer Secretario

2. La UE ante San Vicente y Las Granadinas:

La UE no cuenta con una delegación diplomática en territorio de San Vicente y Las Granadinas, dado que este país es cubierto por la Delegación de la UE ante Barbados, concurrente al Caribe Oriental. 


\section{- La UE-Surinam}

Marco jurídico de las relaciones:

Sus relaciones con la UE se basan en las relaciones con CARICOM y CARIFORUM, de los cuales Surinam es miembro.

Estructura del Servicio de Acción Exterior de Surinam:

El Ministerio de Relaciones Exteriores de Surinam está dividido en direcciones y subdirecciones, entre ellas, se encuentra la Subdirección Asuntos Geopolíticos, el cual se encarga de cubrir las siguientes áreas ${ }^{791}$ :

- Integración regional

- Relaciones bilaterales

- Relaciones multilaterales

Dentro de las relaciones multilaterales están las relaciones con la Unión Europea.

Delegaciones diplomáticas:

1. Surinam ante la UE:

Surinam tiene una delegación ante la UE, la cual tiene concurrencia ante Bélgica, Francia e Italia. La misión cuenta con 5 funcionarios ${ }^{792}$ :

- 1 Embajador

- 1 Consejero

- 1 Primer Secretario

- 1 Segundo Secretario

- 1 Agregado

2. La UE ante Surinam:

La Unión Europea no tiene una delegación ante Surinam, pero la cubre desde la Delegación de la UE en Guyana.

\footnotetext{
${ }^{791}$ MINISTERIO DE RELACIONES EXTERIORES DE SURINAM:

http://www.gov.sr/sr/kabinetten-ministeries.aspx [Última revisión: 06-01-14]

${ }^{792}$ EUROPEAN COMMISION-SECRETARIAT GENERAL: Diplomatic Corps. Protocol Service. Missions accredited to European Union. Suriname. p. 197.

http://ec.europa.eu/dgs/secretariat_general/corps/index.cfm?go=search.search\&missions=1 [Última
} versión: 11-01-15] 


\section{- La UE-Trinidad y Tobago}

Marco jurídico de las relaciones:

Sus relaciones con la UE se desarrollan dada su pertenencia al grupo de países ACP y su membresía al CARICOM. Entre los temas de trabajo que desarrolla la UE con Trinidad y Tobago están: educación, desastres naturales, reconversión del sector azucarero, gobernanza y diversificación económica ${ }^{793}$.

Estructura del Servicio de Acción Exterior de Trinidad y Tobago:

El Ministerio de Asuntos Exteriores de Trinidad y Tobago cuenta con una Secretaría Permanente y una Secretaría Adjunta ${ }^{794}$, las cuales se encargan de las relaciones bilaterales y multilaterales, dentro de estas últimas se encuentran las relaciones con la UE.

Delegaciones diplomáticas:

\section{Trinidad y Tobago ante la UE:}

Trinidad y Tobago cuenta con una misión diplomática acreditada ante la UE, la cual es concurrente a Bélgica, Francia, Santa Sede, Luxemburgo, Holanda y Suiza. No posee otra embajada en un Estado Miembro de la UE, excepto y como ocurre con la mayoría de los países miembros de la Mancomunidad de Naciones, sólo tiene una delegación diplomática ante el Reino Unido ${ }^{795}$.

La misión ante la capital comunitaria cuenta con seis funcionarios acreditados ${ }^{796}$ :

- 1 Embajador

- 1 Consejero

${ }^{793}$ MINISTERIO DE ASUNTOS EXTERIORES Y COOPERACIÓN DEL REINO DE ESPAÑA: Trinidad y Tobago. Perfil País. Oficina de Información Diplomática, Madrid, 2014.

http://www.exteriores.gob.es/Documents/FichasPais/TRINIDADYTOBAGO_FICHA\%20PAIS.pdf [Última revisión: 06-01-14]

${ }_{794}$ MINISTRY OF FOREIGN AFFAIRS OF TRINITY AND TOBAGO: The ministry. http://www.foreign.gov.tt/ [Última revisión: 11-01.15]

$795^{\circ}$ MINISTRY OF FOREIGN AFFAIRS OF TRINITY AND TOBAGO: Diplomatic missions. http://www.foreign.gov.tt/representatives/tt/diplomatic_missions/ [Última revisión: 11-01.15]

${ }_{796}$ EUROPEAN COMMISION-SECRETARIAT GENERAL: Diplomatic Corps. Protocol Service. Missions accredited to European Union. Trinity and Tobago. p. 211.

http://ec.europa.eu/dgs/secretariat_general/corps/index.cfm?go=search.search\&missions=1 [Última versión: 11-01-15] 
- 1 Segundo Secretario

- 1 Encargado de Negocios

- 1 Encargado Administrativo

- 1 Encargado de Finanzas

\section{La UE ante Trinidad y Tobago:}

La Unión Europea tiene una delegación diplomática ante Trinidad y Tobago, aunque cuenta con una Encargada de Negocios, Daniela Tramacere, de nacionalidad italiana y que tiene como Jefe de Misión, al Embajador de la República Checa, Robert Kopecky, quien es el Jefe de la Delegación de la UE ante Guyana. Por el momento no hay mayor estructura organizativa y más funcionarios acreditados que la Encargada de Negocios. 


\section{- La UE-Uruguay}

\section{Marco jurídico de las relaciones:}

Las relaciones con la UE se realizan a dos niveles, a nivel bilateral (UE-Uruguay) e inter-regional UE-MERCOSUR. En el plano bilateral las áreas de trabajo se centran en cooperación, principalmente en los siguientes ámbitos: cohesión social y territorial, apoyo a la investigación, innovación, desarrollo económico ${ }^{797}$, apoyo a Actores no Estatales, derechos humanos, cultura, medio ambiente, migraciones, entre otros.

En lo que respecta al plano regional, Uruguay se beneficia de la cooperación subregional, vía UE-MERCOSUR y de la cooperación regional vía UE-ALC. Esta cooperación se da a través de los programas plurianuales que tiene la UE para ALC y mediante sus programas temáticos como: URB-AL, AL-INVEST, EUROSOCIAL, ALFA, ALIS, COPOLAD, etc. Uruguay también accede a otras fuentes de financiamiento comunitario como el Séptimo Programa Marco de Investigación y Desarrollo Tecnológico (2007-2013) o las ayudas recibidas al apoyo de la reforma de la justicia y el sistema penal y penitenciario, éstas últimas a solicitud del gobierno uruguayo $^{798}$.

Estructura del Servicio de Acción Exterior de Uruguay:

El Ministerio de Relaciones Exteriores de Uruguay se divide en Direcciones Generales $^{799}$, dentro de ellas está la Dirección General para Asuntos Políticos, y dentro de esta están:

- Dirección General América

- Dirección General Europa

Es dentro de esta dirección en la cual se desarrolla las relaciones con la UE.

\footnotetext{
797 DELEGACIÓN DE LA UNIÓN EUROPEA ANTE URUGUAY: Uruguay y la Unión Europea. Cooperación financiera y técnica. http://eeas.europa.eu/delegations/uruguay/eu_uruguay/tech_financial_cooperation/index_es.htm [Última revisión: 06-01-14]

798 MINISTERIO DE ASUNTOS EXTERIORES Y COOPERACIÓN DEL REINO DE ESPAÑA: Uruguay. Perfil País. Oficina de Información Diplomática, Madrid, 2014. http://www.exteriores.gob.es/Documents/FichasPais/Uruguay_FICHA\%20PAIS.pdf [Última revisión: 06-01-14]

799 MINISTERIO DE RELACIONES EXTERIORES DE URUGUAY: Estructura. http://www.mrree.gub.uy/frontend/page?1,inicio,estructura,O,es,0, [Última versión: 11-01-15]
} 
Delegaciones diplomáticas:

\section{Uruguay ante la UE:}

Uruguay cuenta con una delegación diplomática ante la UE, la cual a su vez, es concurrente a Bélgica y Luxemburgo. La misión cuenta con cuatro funcionarios ${ }^{800}$ :

- 1 Embajador

- 1 Ministro

- 1 Primer Secretario

- 1 Segundo Secretario

Uruguay tiene presencia diplomática en los 28 Estados Miembro de la UE ${ }^{801}$.

\section{La UE ante Uruguay:}

La Unión Europea cuenta con una delegación diplomática ante Uruguay, la cual cuenta con 15 funcionarios, encabezado por un Jefe de Misión, el Embajador, Juan Fernández Trigo, de nacionalidad española y el cual es asistido por tres jefes de sección que se encargan de cubrir las siguientes áreas ${ }^{802}$ :

- Política y Comunicación

- Comercio y Economía

- Administración

${ }^{800}$ EUROPEAN COMMISION-SECRETARIAT GENERAL: Diplomatic Corps. Protocol Service. Missions accredited to European Union. Uruguay. p. 229.

http://ec.europa.eu/dgs/secretariat_general/corps/index.cfm?go=search.search\&missions=1 [Última versión: 11-01-15]

801 MINISTERIO DE RELACIONES EXTERIORES DE URUGUAY: Misiones en el exterior. http://www.mrree.gub.uy/frontend/page?1,inicio,misiones-en-el-exterior,O,es,0, [Última versión: 11-01${ }_{802}^{15}$

802 DELEGACIÓN DE LA UNIÓN EUROPEA EN URUGUAY: Organización interna. http://eeas.europa.eu/delegations/uruguay/about_us/internal_organisation/index_en.htm [Última versión: $11-01-15]$ 


\section{- La UE-Venezuela}

Sus relaciones con la UE se efectúan mediante la base jurídica desarrollada con la Comunidad Andina. Al retirarse Venezuela de la CAN (2006) se quedó en un limbo jurídico respecto a dichas relaciones. Se espera que mediante su adhesión al MERCOSUR (2012) Venezuela pueda acogerse al marco con el que cuenta el MERCOSUR con la UE y así restablecer sus relaciones con la UE. Sin embargo, esto está aún por determinar. Por estas razones las relaciones políticas entre UE-Venezuela se desenvuelven dentro del marco de las relaciones entre la UE-CELAC, del cual Venezuela es uno de sus principales impulsores y defensores. A nivel bilateral la Delegación de la UE cumple con sus funciones de fortalecimiento de un diálogo político y busca establecer una agenda de trabajo conjunto entre las partes ${ }^{803}$.

Estructura del Servicio de Acción Exterior de Venezuela:

El Ministerio del Poder Popular para las Relaciones Exteriores de la República Bolivariana de Venezuela se divide en viceministerios ${ }^{804}$, entre ellos se encuentra el Vice Ministerio para Europa, la cual cuenta con una Dirección General Europa. También cuenta con una Oficina de Asuntos Multilaterales y de integración, la cual se subdivide en dos direcciones:

- Dirección de organismos internacionales

- Dirección de mecanismo de concertación política y de integración

Según sea el tema, es dentro de estas direcciones en las cuales se desarrollan las relaciones con la UE, el ministerio no cuenta con una dirección específica o unidad que regule y coordine las relaciones con la UE.

\section{Delegaciones diplomáticas:}

\section{Venezuela ante la UE:}

\footnotetext{
${ }^{803}$ DELEGACIÓN DE LA UNIÓN EUROPEA ANTE VENEZUELA. Venezuela y la Unión Europea. Relaciones políticas.

http://eeas.europa.eu/delegations/venezuela/eu_venezuela/political_relations/index_es.htm_[Última revisión: 06-01-14]

${ }^{804}$ MINISTERIO DEL PODER POPULAR PARA LAS RELACIONES EXTERIORES DE LA REPÚBLICA BOLIVARIANA DE VENEZUELA: Organigrama.

http://www.mre.gov.ve/ [Última versión: 11-01-15]
} 
Venezuela cuenta con una delegación diplomática ante la UE, la cual es concurrente a

Bélgica y Luxemburgo, y la cual tiene 11 funcionarios acreditados ${ }^{805}$ :

- 1 Embajador

- 1 Ministro Consejero

- 2 Consejero

- 1 Primer Secretario

- 3 Segundo Secretario

- 2 Tercer Secretario

- 1 Agregado

Venezuela cuenta con representaciones diplomáticas en 19 Estados Miembro de la Unión Europea $^{806}$.

\section{La UE ante Venezuela:}

La UE cuenta con una delegación ante Venezuela, esta cuenta con siete funcionarios acreditados, cuyo Jefe de Misión es Aude Maio-Coliche, de nacionalidad francesa. La delegación cuenta con tres secciones ${ }^{807}$ :

- Política, comercial, prensa y visibilidad

- Administración

- Cooperación

805 EUROPEAN COMMISION-SECRETARIAT GENERAL: Diplomatic Corps. Protocol Service. Missions accredited to European Union. Venezuela. p. 232.

http://ec.europa.eu/dgs/secretariat_general/corps/index.cfm?go=search.search\&missions=1 [Última versión: 11-01-15]

806 MINISTERIO DEL PODER POPULAR PARA LAS RELACIONES EXTERIORES DE LA REPÚBLICA BOLIVARIANA DE VENEZUELA: Misiones diplomáticas. Europa.

http://www.mre.gov.ve/index.php?option=com_content\&view=category\&layout=blog\&id=13\&Itemid=2 59 [Última versión: 11-01-15]

807 DELEGACIÓN DE LA UNIÓN EUROPEA EN VENEZUELA: Organización interna. http://eeas.europa.eu/delegations/venezuela/about_us/internal_organisation/index_es.htm [Última revisión: 11-01.15] 


\section{RESULTADO DE LAS RELACIONES ENTRE LAS DELEGACIONES DE LA UE Y LOS PAÍSES DE LA CELAC}

Después de todo lo expuesto, se puede decir que en términos cuantitativos, los países de la CELAC destinan un promedio de 208 funcionarios ante la UE y que la UE destina un promedio de 212 funcionarios a sus relaciones con los países de la región de ALC. También se puede concluir que las relaciones que lleva la UE con la gran mayoría de los países miembros de la CELAC, son relaciones estrictamente de cooperación y que el sentido estratégico de los temas es dado por la UE a través de los programas de cooperación que da hacia los países de ALC.

Aunque en todos los casos existe un "diálogo político" para desarrollar una agenda común que aborde los asuntos y desafíos globales, el interés por el desarrollo de dicha agenda sólo se da por el lado de la UE. Y esto se debe a que la UE es vista como un organismo internacional de cooperación al desarrollo y no tanto como un proceso de integración política. Esta afirmación la hacemos partiendo de la base que en las propias estructuras de los servicios de acción exterior de la gran mayoría de los países miembros de la CELAC, ubican a la UE dentro de la dirección o división de multilaterales y no en bilaterales, lo que nos permite seguir afirmando un punto que repetidamente se defiende a lo largo de esta investigación, América Latina y el Caribe confunde los términos y conceptos de integración regional con el de cooperación regional.

Se comprueba que sólo 5 países de los 33 que forman parte de la CELAC tienen contempladas dentro de sus estructuras, en sus servicios de acción exterior, direcciones dedicadas, exclusivamente, a las relaciones con a la Unión Europea. A continuación, pasamos a describir los países que cuentan dentro de sus estructuras de acción exterior a la Unión Europea como un organismo regional:

1. Argentina.- La Secretaria de Relaciones Exteriores y de Culto de Argentina establece sus relaciones con la UE a través de su Subsecretaría de Política Exterior que contempla una dirección que llama "Dirección de Europa Comunitaria".

2. Colombia.- El Ministerio de Relaciones Exteriores de Colombia cuenta con un Viceministerio de Relaciones Exteriores que tiene la Dirección Europa, dentro de ella tiene una unidad dedicada a las "Relaciones con la Unión Europea". 
3. México.- La Secretaría de Relaciones Exteriores de México está dividida en direcciones generales, una se llama Dirección General para Europa, dentro de ella está la Dirección General Adjunta para la Unión Europea y el Consejo de Europa.

4. Nicaragua.- El Ministerio de Relaciones Exteriores de Nicaragua se divide en direcciones generales, dentro de ellas cuenta con una Dirección General Europa, y ésta a su vez se subdivide en dos direcciones, como la "Dirección Unión Europea".

5. Perú.- El Ministerio de Relaciones Exteriores de Perú está dividido en direcciones generales, dentro de estas tiene una Dirección General Europa, la cual tiene una "Dirección Unión Europea".

De los cinco países, todos poseen acuerdos bilaterales con la Unión Europea. Paralelamente también ha desarrollado relaciones dentro de sus procesos de integración subregionales de los cuales son parte, caso Argentina, con el MERCOSUR, Colombia y Perú, con la Comunidad Andina, Nicaragua dentro las relaciones con Centroamérica, y con México tiene un Acuerdo de Asociación y es considerado "Socio Estratégico" para la Unión. A pesar de que las relaciones con México se han llevado a cabo a nivel bilateral, no hay que olvidar que la Unión también apoyó a México con sus proyectos integracionistas, como fue el Proyecto Mesoamérica.

Hay que recordar que en el caso de Argentina, y desde el punto de vista institucional, fue el primer país de América Latina que consiguió firmar un acuerdo comercial en la década de los setenta, con la entonces Comunidad Económica Europea (CEE), el Acuerdo Comercial entre CEE-Argentina, fue firmado el 8 de noviembre de 1971. Argentina posee varios acuerdos de distinta índole, entre los cuales podemos mencionar:

- El Acuerdo marco de cooperación comercial y económica, (1990) ${ }^{808}$.

- El Acuerdo sobre las relaciones en materia de pesca marítima entre la CEE y Argentina, y el Protocolo de Posibilidades de pesca y aporte financiero

\footnotetext{
${ }^{808}$ Diario Oficial n ${ }^{\circ}$ L 295 de 26/10/1990 p. 0067 - 0073. http://eur-lex.europa.eu/LexUriServ/LexUriServ.do?uri=CELEX:21990A1026\%2801\%29:ES:HTML [Última revisión: 28-11-14]
} 
establecido en el acuerdo entre Argentina y Comunidad sobre las relaciones en materia marítima, $(1993)^{809}$.

- Acuerdo de cooperación relativo a los usos pacíficos de la energía nuclear entre la Comunidad Europea de la Energía Atómica (EURATOM) y el Gobierno de la República de Argentina, (1997) ${ }^{810}$.

- Acuerdo de cooperación científica y tecnológica entre la Comunidad Europea y la República Argentina, (1999) ${ }^{811}$.

Por tanto no es extraño que Argentina dedique de manera particular una unidad que se encargue específicamente de las relaciones con la UE. Por otro lado se puede pensar que las relaciones establecidas con Argentina durante la década de los noventa, sirvieron para acercar a la UE al MERCOSUR, iniciativa que fue siempre respaldada e impulsada por Argentina. La creación del MERCOSUR, el cual seguía el mismo objetivo de la $\mathrm{CEE}$, de establecer un mercado común, representaba un gran aliciente para acercar a la UE hacia esta subregión (MERCOSUR).

Todo estos antecedentes, sin duda contribuyeron a iniciar negociaciones dentro del marco subregional, entre CEE-MERCOSUR. Dichas relaciones se institucionalizan mediante la firma del Acuerdo Marco Interregional de Cooperación entre la CEEMERCOSUR y también a través de la Declaración Conjunta sobre el Diálogo Político entre, esta vez ya con, la Unión Europea y MERCOSUR, (1996) ${ }^{812}$.

Del mismo modo ocurre con México, el cual también en la misma década de los setenta, firma un Acuerdo Comercial entre CEE-México, el 15 de julio de $1975^{813}$. Posteriormente, de manera bilateral, las partes, negociarían y firmarían 3 acuerdos de cooperación, los cuales se concretaron durante de la década de los noventa:

\footnotetext{
${ }^{809}$ Diario Oficial n ${ }^{\circ}$ L 318 de 20/12/1993 p. 0002 - 0017. http://eur-lex.europa.eu/LexUriServ/LexUriServ.do?uri=CELEX:21993A1220\%2801\%29:ES:HTML [Última revisión: 28-11-14]

${ }^{810}$ Diario Oficial n ${ }^{\circ}$ L 296 de 30/10/1997 p. 0032 - 0040. http://eur-lex.europa.eu/LexUriServ/LexUriServ.do?uri=CELEX:21997A1030\%2801\%29:ES:HTML [Última revisión: 28-11-14]

${ }^{811}$ Diario Oficial n ${ }^{\circ}$ L 006 de 11/01/2000 p. $0032-0038$. http://eur-lex.europa.eu/LexUriServ/LexUriServ.do?uri=CELEX:22000A0111\%2801\%29:ES:HTML [Última revisión: 28-11-14]

${ }^{812}$ Diario Oficial n L 069 de 19/03/1996 p. 0004 -0022 L 112 29/04/1999 P. 0066. http://eur-lex.europa.eu/LexUriServ/LexUriServ.do?uri=CELEX:21996A0319\%2802\%29:ES:HTML [Última revisión: 28-11-14]

${ }^{813}$ Diario Oficial ${ }^{\circ}$ L247 de 23 de septiembre de 1975. http://eeas.europa.eu/delegations/mexico/documents/eu_mexico/acuerdo75_es.pdf [Última revisión: 28-11-14]
} 
- Acuerdo Marco de Cooperación entre la Comunidad Económica Europea y los Estados Unidos Mexicanos (1991).

- Acuerdo entre la Comunidad Europea y México para la cooperación en materia de control de los precursores y sustancias químicas utilizados con frecuencia en la fabricación ilícita de estupefacientes o de sustancias sicotrópicas (1997)

- Acuerdo de Asociación Económica, Concertación Política y Cooperación entre la Comunidad Europea y México (1997).

- Acuerdo entre la Comunidad Europea y México para el reconocimiento mutuo y la protección de las denominaciones en el sector de las bebidas espirituosas (1997).

Todos estos acuerdos sirvieron para que en 2000 entre en vigor el Acuerdo Global que sería la base jurídica sobre la cual se desarrollarían las negociaciones que llevaron a México ser considerado Socio Estratégico de la Unión. Por lo que mantienen un Diálogo político de alto nivel, en el cual se han institucionalizado reuniones de jefes de estado y de gobierno, las cuales se realizan cada dos años. Hasta el 2012 se celebraron VI Cumbres UE-México, del mismo modo, para profundizar cada vez más en la Asociación Estratégica UE-México.

Además de las cumbres se realizan reuniones a nivel ministerial, las reuniones del Consejo Conjunto de Ministros, Comité Conjunto que es quién hace el seguimiento de lo acordado tanto en las cumbres como en las reuniones del Consejo Conjunto de Ministros. Finalmente también existe una Comisión Interparlamentaria Parlamento Europeo-Parlamento Mexicano.

En el caso de Colombia y Perú, ambos son parte de la Comunidad Andina, comunidad de naciones que tuvo como modelo el proceso de integración europea, y de ahí que se priorizó la construcción de un sistema institucional de carácter comunitario, que privilegiaba la toma de decisiones y la acción común y es el único esquema de integración en América Latina y el Caribe que diseña una Política Exterior Común y piensa en el desarrollo de instrumentos de acción exterior, como aplicar posiciones comunes y ejercer una representación exterior de manera común, con el fin de tener una voz única como organismo regional. 
La diferencias de modelos económicos e ideologías políticas entre los gobiernos de turno, en los Estados Miembros de la Comunidad Andina, hizo que el acuerdo de asociación que se estaba negociando con la Unión Europea, se rompiera, quedándose fuera Bolivia y Ecuador, lo que sumando a la renuncia de Venezuela a ser parte de la Comunidad Andina, sólo dejo a Colombia y Perú con el deseo expreso de firmar el acuerdo de asociación, el cual estaba casi ya acordado por las partes. El marco institucional y formal de las relaciones entre Colombia, Perú y la Unión Europea se hacen dentro del marco de la CAN, así en 1993 se firma entre la UE-CAN un Acuerdo de Cooperación que se comienza a implementar en 1998.

Posteriormente, en 2003 se firma un Acuerdo de Diálogo Político y de Cooperación entre la UE-CAN. Durante 2006 se anuncia que las partes iniciarán un proceso de negociaciones cuyo objetivo es firmar un Acuerdo de Asociación, y el cual contemplaba tres vertientes:

1. Diálogo político

2. Cooperación

3. Acuerdo Comercial

$\mathrm{Al}$ quedar divida la CAN por sus problemas internos, las dos vertientes no se pudieron concretar, ya que estaban diseñadas para ser ejecutadas a nivel de Comunidad, por ello, Colombia y Perú, firman con la UE el Acuerdo Comercial en 2010, que entró en vigor en 2013.

En el caso de Nicaragua ocurre lo mismo que con los casos de Colombia y Perú, es decir, sus relaciones se realizan desde una perspectiva de integración regional, en este caso, no andina, sino centroamericana. En el caso de la integración centroamericana, sus Estados Miembros se consiguieron firmar un Acuerdo de Asociación entre Unión Europea-América Central. Sus antecedentes de relaciones se encuentran recogidas en el Acuerdo Marco de Cooperación para América Central (1985), un segundo Acuerdo Marco de Cooperación en 1993 y el Acuerdo de Diálogo Político y Cooperación en 2003.

Todos estos acuerdos constituyen varias etapas en las relaciones entre ambas partes, las cuales sirven de cimientos hasta llegar al Acuerdo de Asociación. La Cumbre de Madrid en mayo de 2010, fue la última etapa previa a la Asociación y en ella anuncian que las 
negociaciones han finalizado. El acuerdo se firma el 29 de junio de 2012, en Tegucigalpa, siendo el marco la Cumbre entre el Sistema de Integración Centroamericana y la Unión Europea, y con ello, las partes dan un ejemplo al resto de los países de América Latina y el Caribe de la dirección a seguir en materia de interregionalismo, un éxito, desde la perspectiva del modelo europeo en materia de integración. Dado que la integración centroamericana, al igual que la andina, son esquemas inspirados en la institucionalidad, método de trabajo y toma de decisiones de la Unión Europea, de ahí un sistema institucional, un derecho comunitario y la idea de una acción exterior a nivel regional. El Acuerdo entró en vigor en 2013, y al igual que en el caso andino también se contempla tres vertientes: diálogo político, cooperación y acuerdo comercial.

El Acuerdo de Asociación es el lazo institucional más profundo e importante que establece la Unión Europea con terceros y lo hace sólo con los que considera "socios". Es un acuerdo reservado para aquellos socios con los que la Unión desear fortalecer y profundizar lazos fuertes, a largo plazo, y cuyas relaciones están basadas en la confianza mutua y en la defensa de valores y principios compartidos.

En los otros casos la mayoría de los países de ALC tienen una secretaría, subsecretaría, viceministerio o dirección superior encargada de la política exterior, la cual suele dividirse en dos partes, bilateral y multilateral. El tema de integración regional suele estar en la sección encargada de las relaciones multilaterales, tanto a nivel de sus propios procesos en los que participan los países en la región de ALC, como a nivel de sus relaciones con la UE.

También se observa, que en la gran mayoría de las cancillerías los propios procesos de integración regional en ALC los contemplan dentro de la categoría de foros internacionales, congresos o conferencias internacional, como lo veremos a continuación el Capítulo VI ALC dentro de las estructuras de los servicios de acción exterior de América Latina y el Caribe, lo que evidencia que tampoco para las propias cancillería, realmente representaron o representan una idea de integrarse como Estados, lo que hace que tampoco quede reflejada, la integración regional, como una prioridad en su acción exterior, a pesar que algunos países digan que es una prioridad de política exterior, pues en la práctica, de que sirve anunciar una meta política, si no se establecen 
los mecanismos e instrumentos necesarios para implementar dichas medidas políticas. A nuestro modo de ver, es el caso de ALC.

Este tipo de acciones en materia de política exterior explica, por qué, a pesar que la UE han querido ver a ALC como una región y siempre apoyado la búsqueda de su unidad, no sólo con apoyo político, sino también con recursos financieros para su integración, los países de ALC nunca ha actuado como región y por esa razón sus acciones exteriores, y por consiguientes acuerdos, terminan por realizarse de manera bilateral, en lugar de ejecutarse a escala interregional (marco sobre el cual la UE siempre ha priorizado en lugar de la bilateral).

Hay una diferencia en la base del concepto de integración regional, que es lo que hace que los países de ALC no avancen en su proceso de unidad política, y es lo que dificulta el poder aplicar una acción exterior conjunta, concertada o coordina, con terceros, en nuestro caso con la UE. La prueba de ello es que la UE desde el inicio siempre ha buscado interrelacionarse con los países de América Latina y luego con América Latina y el Caribe. A nivel regional sus esfuerzos han sido traducidos institucionalizando el diálogo político desde la década de los sesenta, desde los ciernes de la Unión Europea, recordemos el Capítulo en el cual estudiamos el desarrollo de un diálogo bi-regional: Europa y América, en el cual estudiamos el Informe Martino (1963); o los intentos por establecer relaciones formales y de paridad como socios.

Basta con recordar la decisiones de la entonces Comunidad Europea del Carbón y del Acero por establecer relaciones con su par, el Instituto Latinoamericano de Hierro y del Acero (ILAFA) e incluso vincularlas con el trabajo que estaba comenzando a desarrollar la Comisión Económica para América Latina. Y como hemos podido ver que el trabajo de la UE desde entonces siempre ha sido de apoyar la integración tanto subregional como regional de ALC, y así ha quedado reflejado en cada acuerdo firmado.

De los 208 funcionarios destinados ante la Unión, los países que más funcionarios tienen en sus respectivas relaciones diplomáticas con la UE son:

1. México (22 funcionarios)

2. Brasil (15 funcionarios)

3. Colombia y República Dominicana (13 funcionarios) 
4. Cuba y Venezuela (11 funcionarios)

5. Haití (10 funcionarios)

6. Argentina (8 funcionarios)

7. Ecuador (7 funcionarios)

8. Perú (6 funcionarios)

9. Guatemala (6 funcionarios)

10. Trinidad y Tobago (6 funcionarios)

De todos estos países hay que remarcar el caso de Brasil, que es el único país que tiene una Delegación diplomática exclusivamente ante la Unión, el resto de países tienen concurrencias ante otros países europeos, en la mayoría de los casos son ante Bélgica, Luxemburgo y Países Bajos.

De los 33 estados miembros de la CELAC sólo 4 países tienen, además de sus delegaciones ante la UE, delegaciones diplomáticas en los otros 28 Estados Miembros de la UE (EM-UE): Cuba, Ecuador, Uruguay y Chile. El resto de países no cuentan con delegaciones en todos los países. De los 33 podemos destacar 7 países, aparte de Brasil:

- Argentina, ante 2 EM-UE

- Brasil, ante 20 EM-UE

- Venezuela, ante 19 EM.UE

- México, ante 18 EM-UE

- Perú, ante 15 EM-UE

- Panamá, ante 14 EM-UE

- Colombia, ante 12 EM-UE

En el caso de los países de América Latina sus delegaciones diplomáticas suelen concentrarse en países como España, Francia, Italia, Alemania, Reino Unido, Países Bajos, Portugal, Grecia, Bélgica y Austria.

En cambio, los países del Caribe, todos tienen una delegación ante el Reino Unido, pero no en el resto de EM-UE. De los países caribeños existen 9 países que forman parte de la Mancomunidad de Naciones, también conocida como Commonwealth, los cuales tienen como Jefe de Estado a la Reina Isabel II del Reino Unido, quién es la que designa y es representada por un Gobernador General. Lo que hace preguntar qué tanto influye 
la Corona británica en materia de política exterior de estos países y cómo afecta en las relaciones con la UE. Lo que a su vez, nos hace preguntar hasta qué punto los países de la CELAC pueden argumentar la idea que con la creación de la CELAC, pretenden disminuir la influencia extra-regional, y que muchas veces es representada por Estados Unidos en la OEA, por ello, piensan que la CELAC puede ser un organismo sustituto a la OEA, pero parece no darse cuenta que en su propio seno, tiene a un conjunto de países cuya política exterior no parece ser tan autónoma. 
- FUENTES Y BIBLIOGRAFÍA 


\section{FUENTES:}

- Acta de la sesión inaugural de los Consejos de la CEE y la CEEA, celebrada en Bruselas el 25 de enero de 1958.

- Actas de la conferencia de las Naciones Unidas sobre comercio y desarrollo, tercer período de sesiones, Santiago de Chile, 13 de abril-21 de mayo de 1972. Vol. I. Informes y Anexos. Naciones Unidas, New York, 1973

- Acuerdo Asociación entre los Estados de África, del Caribe y del Pacífico-Comunidad Europea y sus Estados Miembros, firmado en Cotonú, el 23 de junio de 2000.

- Acuerdo Centro Europeo de Libre Comercio, Cracovia diciembre de 1992. World Intellectual Property Organization.

- Acuerdo de Cooperación entre la Comunidad Económica Europea, por un parte, y el Acuerdo de Cartagena y sus Países Miembros, por la otra, Bruselas, 28 de octubre de 1983.

- Acuerdo de Cooperación entre el Acuerdo de Cartagena y sus Países Miembros, la Comunidad Económica Europea y la Comunidad Europea del Carbón y del Acero. Documento de la Secretaría General de la Comunidad Andina. Trigesimo noveno Período de Sesiones Extraordinarias de la Comisión del 7 al 9 de noviembre de 1983. Decisión 190. Lima, 9 de noviembre de 1983.

- Acuerdo de Establecimiento de la Comunidad de Estados Independientes. Minsk, 8 de diciembre de 1991.

- Acuerdo de Integración Subregional Andino (Acuerdo de Cartagena). Cartagena de Indias, 26 de mayo de 1969.

- Acuerdo de Libre Comercio del Báltico, Tallin 13 de septiembre de 1993. B

- Acuerdo Marco de la Alianza del Pacífico. Secretaría de Relaciones Exteriores de los Estados Unidos de México. Paranal, 6 de junio de 2012.

- Acuerdo Marco de Cooperación entre la Comunidad Económica Europea y el Acuerdo de Cartagena. Copenhague, 23 de abril de 1993.

- Acuerdo para la Aplicación de la Alternativa Bolivariana para los Pueblos de Nuestra América y el Tratado de Comercio de los Pueblos. Banco Interamericano de Desarrollo. Sistema de Información sobre Comercio e Integración. La Habana, 29 de abril de 2006.

- Acuerdo sobre el Espacio Económico Europeo. Síntesis de la Legislación de la Unión Europea. Oporto, 2 de mayo 1992.

- Acuerdo sobre la Fundación de la Comunidad Económica de Eurasia. Banco Mundial. Astana, 10 de octubre de 2000.

- Agreement Establish the Caribbean Free Trade Association. Caribbean Community (CARICOM) Secretariat, Legal Instruments. Georgetown 10.12.1966. 
- Agreement Establishing the East Caribbean Common Market. Treaties United Nations States. Grenada 11.6.1968.

- Asamblea General Americana iniciada por México. Guatemala, 2 de noviembre de 1831.

- Asociación de Estados del Caribe. Convenio Constitutivo. Banco Interamericano de Desarrollo. Sistema de Información sobre Comercio e Integración. Cartagena de Indias, 24 de julio de 1994.

- Breve de Pío V para la Universidad de San Marcos, Lima.

- CAN: Oportunidad histórica para la integración continental. Boletín sobre integración de América Latina y el Caribe, Secretaría General Permanente del SELA, Convenio UNESCO-SELA “Comunicación para la integración de América Latina y el Caribe, N 182, 29 de enero 2013.

- Carta de Naciones Unidas, San Francisco 26 de junio de 1945.

- Carta de la Organización de Estados Centroamericanos (Carta de San Salvador). 14 de octubre de 1951.

- Carta Dirigida a los Españoles Americanos, de Juan Pablo Viscardo y Guzmán. Archivo General de Indias, Sevilla, 1799.

- Carta Magna de los Pueblos de América Latina, aprobada en la III Asamblea Ordinaria del Parlamento Latinoamericano. Brasilia, 22 de junio de 1968.

- CEPAL: Informe de la reunión de expertos sobre cadenas globales de valor en América Latina: ¿Promoviendo el comercio con inclusión o exclusión?, Santiago de Chile, 2012.

- Circular de su Excelencia, El Libertador de Colombia y Encargado del Supremo Mando de la República del Perú, Simón Bolívar, invitando a los Gobiernos de las demás Repúblicas de Colombia, México, Río de la Plata, Chile y Guatemala a enviar a sus Representantes al Istmo de Panamá con el fin de celebrar una Asamblea General. Lima, 7 de diciembre de 1824 .

- COMISIÓN EUROPEA: La Unión Europea y el mundo. Serie: Europa en movimiento, Bruselas, 2001.

- COMISIÓN EUROPEA: La asociación estratégica entre la Unión Europea, América Latina y Caribe: Un compromiso común. Dirección General de Relaciones Exteriores, Comisión Europea, Oficina de publicaciones oficiales de las Comunidades Europeas, Luxemburgo, 2008.

- Comunicado Conjunto de la Reunión Ministerial de San José, San José, Costa Rica, 1984. Comunicado Político Conjunto de la Conferencia Ministerial de Luxemburgo sobre diálogo político y la cooperación económica entre los países de la Comunidad 
Europea, España, Portugal y los Países de América Central y de Contadora, 11 y 12 de noviembre de 1985.

- Comunicados de prensa de la Comisión Económica para América Latina y Caribe. Cartagena de Indias, 14 de abril de 2012.

- Comunicación de la Comisión al Consejo sobre las relaciones con América Latina, 27 de enero de 1987.

- Comunicación de la Comisión al Consejo y al Parlamento Europeo: Una asociación reforzada entre la Unión Europea y América Latina, COM (2005) Oficina de publicaciones oficiales de las Comunidades Europeas, Luxemburgo, 2006.

- Comunicación de la Comisión al Parlamento Europeo y al Consejo. La Unión Europea y América Latina: Una asociación de actores globales, COM (2009) 495/3. Comisión Europea. Bruselas, 30 de septiembre de 2009.

- Comunicado de Brasilia. I Reunión de Presidentes de América del Sur. Brasilia, 1 de septiembre de 2000 .

- Convenio Aduanero, firmado en Londres, el 5 de septiembre de 1944. United Nations University. Institute on Comparative regional Integration Studies.

- Convención de la Organización Europea para la Cooperación Económica, firmado en Paris el 16 de abril de 1948. The Organization for Economic Cooperation and Development.

- Convenio de Panamá Constitutivo del Sistema Económico Latinoamericano. Panamá 17 de octubre de 1975. Secretaría Permanente del Sistema Económico Latinoamericano y del Caribe, Documento Institucional, Caracas, enero 2006.

- Convención del Establecimiento de la Asociación Europea de Libre Comercio, Estocolmo 4 de enero 1960. World Intellectual Property Organization.

- Cooperación en el proceso de integración regional y subregional Acta de la Primera Reunión Ministerial Institucionalizada entre la Comunidad Económica Europea y el Grupo de Río, Luxemburgo, 26 de abril de 1991.

- COMISIÓN EUROPEA: Firma de un Acuerdo de Diálogo Político y Cooperación entre la Comunidad Europea y sus Estados miembros, por un parte, y la Comunidad Andina y sus países miembros, las Repúblicas de Bolivia, Colombia, Ecuador, Perú y la República Bolivariana, por otra parte. Bruselas, 14 de noviembre de 2003.

- COMISIÓN EUROPEA: Comunicación de la Comisión al Parlamento Europeo y al Consejo. La Unión Europea y América Latina: Una asociación de actores globales. Bruselas, 30 septiembre de 2009. COM (2009) 495/3. 
- COMISIÓN EUROPEA: Press realease. Palabras de Catherine Ashton, Alta Representante de la Unión para Asuntos Exteriores y Política/Vice Presidenta de la Comisión, en la sesión inaugural de la Sexta Asamblea Parlamentaria EUROLAT.

- COMISIÓN EUROPEA: La Unión Europea y la Comunidad Centroamericana inician negociaciones para un nuevo Acuerdo de Asociación, Bruselas, 29 de junio 2007.

- CONSEJO EUROPEO: Decisión del Consejo Europeo de 30 de agosto de 2014 por la que se nombra Alto Representante de la Unión para Asuntos Exteriores y Política de Seguridad (2014/639/UE). DO L 328 de 15.12.2009.

- CONSEJO EUROPEO: "Declaración sobre el futuro de la Unión Europea", Conclusiones de la Presidencia, Laeken, 11 y 12 de diciembre de 2001.

- COUNCIL OF THE EUROPEAN UNION: Presidency report to the European Council on the European External Action Service. Note from Presidency to Council/European Council, Brussels, 23 October 2009.

- COUNCIL OF THE EUROPEAN UNION 8029/10: Proposal from the High Representative for Foreign Affairs and Security Policy Council. Draft Council decision establishing the organization and functioning of the European External Action Service. Brussels, 25.3.2010.

- COUNCIL OF THE EUROPEAN UNION: Council Decision of 26 July 2010 establishing the organization and functioning of the European External Actions Service (2010/427/EU). Official Journal of the European Union L 201/30. 3.8.2010.

- Decisiones del Diálogo Político entre los Jefes de Estado y de Gobierno. I Cumbre Energética Suramericana. Isla de Margarita, 16 de abril de 2007.

- Decisión del Consejo Europeo adoptada con el acuerdo del Presidente de la Comisión de 1 de diciembre de 2009 por la que se nombra a la Alta Representante de la Unión para Asuntos Exteriores y Política de Seguridad (2009/880/UE).

- Declaración Conjunta Diálogo Político entre la Unión Europea y la Comunidad Andina. Roma, 30 de junio de 1996.

- Declaración Conjunta Iniciativa de Europa Central. Budapest, 11 de noviembre de 1989.

- Declaración común de intenciones relativa a desarrollo y la intensificación de las relaciones con los países de Latinoamérica, Acta final relativa a la Adhesión de España y Portugal a la CE. DO n ${ }^{\circ}$ C 302 de 15.11.1985

- Declaración de Ayacucho, 9 de diciembre de 2004.

- Declaración de Buenos Aires. Documentos. CECLA: América Latina ante la Comunidad Económica Europea. Comercio Exterior, Vol. XIX, N 6, junio de 1969.

- Declaración de Cancún, Comunidad de Estados Latinoamericanos y Caribeños. Gobierno de Venezuela, 23 de febrero de 2010. 
- Declaración de Guadalajara. III Cumbre América Latina y el Caribe-Unión Europea. Guadalajara, 28 y 29 de Mayo de 2004.

- Declaración de Intenciones sobre América Latina, Tratado de Adhesión de España y Portugal a la Comunidad Europea, 12 de junio de 1985.

- Declaración de Roma sobre las relaciones entre el Grupo de Río y la Comunidad Europea. Roma, 20 de diciembre de 1990.

- Declaración de Sao Paulo, IV Reunión Ministerial Institucionalizada Unión EuropeaGrupo de Río. Sao Paulo, 22-23 de abril de 1994.

- Declaración de la Cumbre sobre la Cooperación Económica del Mar Negro. Estambul, 25 de junio de 1992.

- Declaración del Cusco sobre la Comunidad Sudamericana de Naciones. III Cumbre Presidencial Sudamericana. Cusco, 8 de diciembre de 2004.

- Declaración Presidencial y Agenda Prioritaria. I Reunión de Jefes de Estado de la Comunidad Sudamericana de Naciones. Brasilia, 30 de septiembre de 2005.

- Declaración sobre la Convergencia de los Procesos de Integración en América del Sur. Reunión de Jefes de Estado de la Comunidad Sudamericana de Naciones. Brasilia, 30 de septiembre de 2005.

- DELEGATION OF THE EUROPEAN UNION TO BARBADO AND THE EASTERN CARIBBEAN: Dominica and European Union. Political and Economic relations.

- DELEGACIÓN DE LA UNIÓN EUROPEA ANTE BARBADOS Y EL CARIBE ORIENTAL: Relaciones Económicas y políticas Unión Europea-San Vicente y las Granadinas.

- $\quad$ DIARIO OFICIAL DE LAS COMUNIDADES EUROPEAS No L 63/39. 12.3.1999. Acuerdo Marco de Cooperación entre la Comunidad Económica Europea y Costa Rica. El Salvador, Guatemala, Honduras, Nicaragua y Panamá.

- DIARIO OFICIAL DE LAS COMUNIDADES EUROPEAS N L 286/1 Reglamento (CE) $\mathrm{N}^{\circ}$ 2686/94 del Consejo de 31 de octubre por el que se establece un sistema especial de asistencia a los proveedores ACP tradicionales de plátanos.

- DIARIO OFICIAL DE LAS COMUNIDADES EUROPEAS N L 295/66. 26.10.90. Decisión del Consejo de 8 de octubre de 1990 relativa a la celebración del Acuerdo Marco de Cooperación Comercial y Económica entre la Comunidad Económica Europea y la República de Argentina.

- Discurso de Marco Vinicio en la toma de posesión como Presidente de la República de Guatemala, enero de 1986.

- Discurso de Su Majestad el rey de España en Aquisgrán, al recibir el Premio Carlomagno, 20 de mayo de 1982. 
- Discurso de Viviane Reding, Vicepresidenta de la Comisión Europea y Comisaria Europea de Justicia, Derechos Fundamentales y Ciudadanía, 8 de noviembre de 2012.

- Discurso del Secretario General de la Comunidad Andina, Adalid Contreras con ocasión de la presentación de su informe de gestión, mayo 2010-febrero 2013.

- Disposiciones generales relativas a la acción exterior de la Unión y disposiciones específicas relativas a la política exterior y de seguridad común. Tratado de la Unión Europea.

- EUROPEAN COMMISION: Argentina. Country Strategy Paper 2007-2013. Bruselas, 23.4.2007.

- EUROPEAN COMMISSION: Country Strategy Paper and National Indicative Programme for the period 2002-2007. Brussels, 6.2.2003.

- EUROPEAN COMMISSION: Country Strategy Paper For The Bahamas 2008-2013, Brussels, 18.11.2008.

- EUROPEAN COMMISION: International Cooperation and Development. The Accompanying Measures for Sugar Protocol Countries (AMSP).

- EUROPEAN COMMISSION: Jean-Claude Juncker, President of the European Commission "Mission Letter" to Federica Mogherini High Representative of the Union for Foreign Policy and Security/Vice-President of the European Commission. Brussels, 1.11.2014.

- EUROPEAN COMMISION: Memo EU relations with the Caribbean. Brussels, 18.9.2013.

- EUROPEAN COMMISIÓN: President of European Commission, Jose Manuel Barroso "Letter Mission" to Baroness Catherine Ashton. Brussels, 27.11.2009.

- EUROPEAN COMMISION: Taking Europe to the world. 50 years of the European Commission's External Service. Office for Official Publications of the European Communities. Luxembourg, 2004

- EUROPEAN COMMISSION: Latin America Regional Programming Document 20072013. 12.07.2007 (e/2007/1417).

- EUROPEAN COMMISION-SECRETARIAT GENERAL: Diplomatic Corps. Protocol Service. Missions accredited to European Union. Perú.

- EUROPEAN COMMISION-SECRETARIAT GENERAL: Diplomatic Corps. Protocol Service. Missions accredited to European Union. Cuba.

- EUROPEAN COMMISION-SECRETARIAT GENERAL: Diplomatic Corps. Protocol Service. Missions accredited to European Union. Dominican Republic.

- EUROPEAN EXTERNAL ACTION SERVICE AND EUROPEAN COMMISSIONDIRECTORATE GENERAL FOR DEVELOPMENT AND COOPERATION- 
EUROPEAID. Development Cooperation Instrument (DCI) 2014-2020 Multiannual Indicative Regional.

- EUROPEAN EXTERNAL ACTION SERVICE: Acuerdo mediante el cual se establece una Asociación entre la Comunidad Europea y la República de Chile.

- EUROPEAN EXTERNAL ACTION SERVICE: European Commission: Chile. Country Strategy Paper 2007-2013.

- EUROPEAN EXTERNAL ACTIONS SERVICE: High Representative of the Union for Foreign Affairs \& Security Policy/Vice-President of the European Commission. "As EU Foreign Affairs chief her portfolio includes a wide variety of roles: coordination other foreign policy tools-development assistance, trade, humanitarian aid and crisis response".

- EUROPEAN EXTERNAL ACTION SERVICE. The High Representative of the Union for Foreign Affairs and Security Policy. Political Career in the United Kingdom.

- EUROPEAN PARLIAMENT: Resolution of 22 October 2009 on the institutional aspects of setting up the European External Action Service (2009/2133(INI)).

- EUROPEAN PARLIAMENT: The Committee on Foreign Affairs. Hearing of Federica Mogherini Vice-President-Designate of the Commission, High Representative of the Union for Foreign Affairs and Security Policy. Brussels, 6.10.2014.

- Global Economic Prospects 2005: Trade, Regionalism and Development. Chapter 2. Regional Trade and Preferential Trading Agreements: A Global Perspective and Chapter 3. Regional Trade Agreements: Effects on Trade. Washington DC, 2005

- Informe 2015 del Instituto Cervantes. El Español: una lengua viva.

- Informe sobre el Comercio Mundial 2011. La OMC y los acuerdos comerciales preferenciales: de la coexistencia a la coherencia. Organización Mundial del Comercio. Ginebra, 2011

- Informe sobre las relaciones entre la Comunidad Europea y América Latina. En EuropaAmérica Latina: 20 años de documentos oficiales (1976-1996). Instituto de Relaciones Europeo-Latinoamericanas. Madrid, 1996.

- Junta de Ministros Hispano-Americanos en Paris. Conveniencia de la Reunión de un Congreso en Panamá. Legación de los Estados Unidos Mexicanos en Francia. Reservada, Número 18. Reunión citada por el Ministro de Bolivia. Paris, 11 de octubre de 1886.

- La Asociación estratégica entre la Unión Europea, América Latina y el Caribe: un compromiso común. Comisión Europea. Dirección General de Relaciones Exteriores, Dirección América Latina. Bruselas, 2008 
- Le nouveau Cynée, Émeric Crucé: Ou discours des occasions et moyens d'establir une paix generale \& la liberté du commerce par tout le monde. Aux monarques \& souverains de ce temps, Paris, Villery, 1623.

- Memoria reservada sobre la necesidad de un Congreso de Plenipotenciarios de los diversos Estados Hispano-Americanos, 1857.

- Memorándum de Entendimiento entre la Comunidad Europea y Ecuador relativo a las orientaciones plurianuales para la puesta en práctica de la Cooperación Comunitaria. Bruselas, 1 de junio de 2001.

- Memorándum de Entendimiento entre la Comisión Europea y Ecuador relativo al Programa Indicativo para el período 2007-2013. Quito, 23 de mayo de 2007.

- Memorándum de Entendimiento entre la Comisión Europea y la República del Perú para el establecimiento de un Mecanismo de Consulta Bilateral. Bruselas 29 de octubre de 2009.

- MINISTERIO DE RELACIONES EXTERIORES DE BRASIL: Relaciones Exteriores: "Visita ao Brasil de Alta Representante para Relacoes Exteriores e Política de Seguranca da União Europeia Catherine Ashton”, Brasilia y Sao Paulo, 6 y 7 de febrero de 2012.

- PARLAMENTO EUROPEO: Declaración de la Cumbre de Jefes de Estado y de Gobierno Unión Europea-Comunidad de Estados Latinoamericanos y Caribeños (UECELA) “Declaración de Santiago". Santiago de Chile, 26 y 27 de enero de 2013.

- PARLAMENTO EUROPEO: XII Comité de Asociación Chile-Unión Europea: Hacia la modernización del Acuerdo de Asociación.

- PARLAMENTO EUROPEO: Cuestionario del Parlamento Europeo, respuestas de la Comisaria Propuesta Federica Mogherini Alta Representante de la Unión para Asuntos Exteriores y Política de Seguridad, Vicepresidenta de la Comisión, 10 de septiembre de 2014,

- Pacto de Paris. Francisco de Miranda, Colombeia, Primera Sección, Miranda (17501780) T. I, Presidencia de la República. Caracas, 1978

- Programa de Acción. I reunión de Jefes de Estado de la Comunidad Sudamericana de Naciones. Brasilia, 30 de septiembre de 2005.

- Programa de Trabajo Argentina-Unión Europea 2010-2013. Bruselas, 28 de septiembre de 2010.

- Protocolo de la conferencia verbal tenida entre los Plenipotenciarios de Colombia, Centro América y Estados Unidos Mejicanos. Villa de Tacubaya, 9 de octubre de 1828.

- Real Cédula de Fundación de la Universidad de San Marcos. 
- Reales Cédulas de la real y Pontificia Universidad de México de 1551 a 1816 . Versión Paleográfica y nota de Jhon Tate Lanning, estudio preliminar de Rafael Heliodoro Valle. México, Imprenta Universitaria, 1946.

- Reglamento (CEE) N 442/81 del Consejo, de 17 de febrero de 1981, relativo a la ayuda financiera y técnica en favor de los países en vías de desarrollo no asociados. DO L 48 de 21.2.1981,

- Reglamento (CEE) N N $^{\circ}$ 2955/85 del Consejo por el que se establecen excepciones, para los países de la Asociación de Naciones del Asia Sudoriental, para los países del Mercado Común de América Central y para los países signatarios del Acuerdo de Cartagena (Grupo Andino), al Reglamento (CEE) No 3749/83 Relativo a la definición de la noción de productos originarios para la aplicación de preferencias arancelarias concedidas por la Comunidad Económica Europea a determinados productos de países en vías de desarrollo. 22 de octubre de 1985 .

- Resolución del Consejo de Ministros de Relaciones Exteriores de UNASUR sobre la entrada en vigencia del Tratado Constitutivo. Quito 11 de marzo de 2011.

- Resolución sobre la cooperación entre la Comunidad Europea y Latinoamérica. DO n C175 de 15 de septiembre de1985.

- Resoluciones sobre la conclusión del Acuerdo de cooperación entre la Comunidad Económica Europea y los países del Tratado General de Integración Económica Centroamericana así como Panamá. DO n C 148 de 16 de junio de 1986.

- Resolución sobre la deuda de los países latinoamericanos y la reunión de los Siete en Bonn. DO n ${ }^{\circ} 122$ de 20 de mayo de 1985.

- Resolución sobre la situación de Sudamérica. DO n C36 de 17 de febrero de 1986

- Resolución sobre las relaciones económicas entre la Comunidad Europea y Latinoamérica, 23 de enero de 1987.

- Resolución relativa a la conclusión del Acuerdo Marco de cooperación entre la Comunidad Económica Europea y el Acuerdo de Cartagena. DO n C 127 de 14 de mayo de 1984.

- Reunión de las Secretarías Técnicas de las Instituciones regionales y Subregionales de la Comunidad Sudamericana de Naciones. Bases para un plan de trabajo conjunto. Secretaría General de la Comunidad Andina. Lima 30 y 31 de mayo de 2005.

- SECRETARÍA GENERAL COMUNIDAD ANDINA: Hacia una Política Exterior Común Andina. Santa Fe de Bogotá, 1999.

- SERVICIO EUROPEO DE ACCIÓN EXTERIOR: Acuerdo de Asociación entre la Unión Europea y Centroamérica. Tegucigalpa, 29 de junio de 2012.

- SERVICIO EUROPEO DE ACCIÓN EXTERIOR: Misión de Observación Electoral Unión Europea, Informe final de las Elecciones Generales. El Salvador 2009. 
- Trade Blocs. A World Bank Policy Research Report N 20809. World Bank and Oxford University Press, New York, 2000.

- Trade, Investment and Sustainable Prosperity. Summit of the European Union and the Community of Latin American and Caribbean States. Santiago de Chile, 26.1.2013.

- Traité Intituant un Conseil Unique et Une Commission Unique des Communautés Européennes. Chapitre I. Le Conseil des Communautés Européennes. Journal Officiel des Communautés Européennes, 13.7.1967.

- Tratado Constitutivo de la Comunidad Económica Europea (Tratados de Roma), 25 de marzo de 1957.

- Tratado Constitutivo de la Comunidad Europea del Carbón y del Acero (Tratado de París), 18 de abril 1951.

- Tratado Constitutivo de la Unión de Naciones Suramericanas. Brasilia, 23 de mayo de 2008.

- Tratado Constitutivo del Parlamento Andino y Protocolo Adicional sobre elecciones directas y universales de sus representantes. Sucre, 23 de abril de 1997.

- Tratado de Ámsterdam por el que se modifican el Tratado de la Unión europea, los Tratados Constitutivos de las Comunidades Europeas y determinados Actos conexos. Diario Oficial N C 340 de 10 de noviembre de 1997.

- Tratado de Confederación firmado en Lima por los delegados de Perú, Bolivia, Chile, Colombia y Ecuador. Lima, 8 de febrero de 1848.

- Tratado de Confederación y Alianza entre las Repúblicas de Venezuela, Nueva Granada, Guatemala, El Salvador, Costa Rica, México y Perú, firmado en Washington, 8 de noviembre de 1856 .

- Tratado de Establecimiento de la Comunidad Europea de la Energía Atómica (Tratados de Roma), 25 de marzo de 1957. Unión Europea. Síntesis de la Legislación de la Unión Europea.

- Tratado de Fusión (Tratado de Bruselas), firmado el 8 de abril de 1965 y entró en vigor el 1 de julio de 1967.

- Tratado de Montevideo, 18 de febrero 1960. Poder Legislativo. República Oriental del Uruguay.

- Tratado de Unión Continental, firmado en Santiago de Chile el 15 de septiembre de 1856.

- Tratado General de Integración Económica Centroamericana entre los Gobiernos de las Repúblicas de Guatemala, El Salvador, Honduras y Nicaragua. Managua, 13 de diciembre de 1960. 
- Tratado de Libre Comercio de América del Norte. Ottawa, 11 de diciembre de 1992, en vigor desde el 1 de enero de 1994.

- Tratado para la Constitución del Mercado Común del Sur entre las Repúblicas de Argentina, Federativa de Brasil, Paraguay y Oriental del Uruguay (Tratado de Asunción). Asunción, 26 de marzo de 1991.

- Tratado sobre conservación de la paz entre los Estados de América contratantes, suscrito entre Venezuela, Colombia, Ecuador, Perú, Bolivia, Chile y El Salvador, firmado el 23 de enero de 1865 en Lima, en el marco del Congreso Americano.

- Tratado sobre la Colaboración Económica, Social y Cultural y de Defensa Colectiva (Tratado de Bruselas), firmado el 17 de marzo de 1948.

- Treaty of Alliance and Mutual Assistance Between his Majesty in Respect of the United Kingdom of Great Britain and Northern Ireland and the President of the French Republic, signed at Dunkirk. 4.3.1947. League of Nations, Treaty Series, Vol. CCIV.

\section{BIBLIOGRAFÍA:}

- AHCAR, S., GALOFRE, O. y GONZÁLES, R.: "Procesos de integración regional en América Latina: Un enfoque político". Revista de Economía del caribe, $\mathrm{N} 11$, enerojunio 2013. Universidad del Norte, Colombia, 2013.

- AJENJO, N. y STAVRIDIS, S.: La Asamblea Parlamentaria EUROLAT: ¿Un modelo de relación entre bloques de integración regional? Working Paper N31, Programa de América Latina, Centro Argentino de Estudios Internacionales, Buenos Aires, 2011.

- ALDECOA, F.: La diplomacia común europea: el servicio europeo de acción exterior, Marcial Pons, Madrid, 2011.

- AlDECOA, F. and KEATING, M. (Eds.): Paradiplomacy in Action: The Foreign Relations of Subnational Governments. Psychology Press/Taylor \& Francis Group, Hove, 1999.

- ÁlvareZ, C.: "La CELAC requiere de un brazo político como el Parlatino", en CELAC, Centro de Noticias del Parlamento Latinoamericano, Panamá, 2012.

- ARMAS, C. y PFIRTER, F.: "El acuerdo comercial de la Comunidad Económica Europea con la Argentina y su correlación con los celebrados en otros países latinoamericanos". Revista de Instituciones Europeas, Vol. 3, N 3, 1976.

- AYALA, E. y POSADA, E.: Los proyectos nacionales latinoamericanos: Sus instrumentos y articulación 1870-1930. Historia General de América Latina VII, Ediciones UNESCO, Paris, 2008.

- AYLlÓN, B.: "España ante la segunda cumbre entre la Unión Europea y América Latina y el Caribe. Encuentros y desencuentros en las relaciones de Brasil con la 
Comunidad Económica Europea (1957-2000). Revista CIDOB D’AFERS INTERNATIONALS 54-55, Fundación CIDOB, Barcelona, 2001.

- AZOULAI, L.: The Question of Competence in the European Union, Oxford University Press, New York, 2011.

- BAILES, A.: "Sub-regional organizations: The Cinderellas of European Security". NATO Review, N² 2, March 1997. Vol. 45

- BALASSA, B. (Ed): European Economic Integration, North-Holland, Amsterdam, 1975.

- BALDERMANN, A.: ¿La unidad en la diversidad? Visiones de Europa en ensayos alemanes del Romanticismo, en Programa de Estudios Europeos: Europa frente a Europa, Universidad de Concepción, Santiago de Chile, 2011.

- BALDI, B.: "Enea Silvio Piccolomini e il De Europa: umanesimo, religione e política" en Archivo Storico Italiano 161, 2003.

- $\quad$ BATLLORI, M.: El Abate Viscardo, Editorial Mapfre, Madrid, 2005.

- BALCH, T.: “The Proposed International Tribunal of Arbitration of 1623”, Proceedings of the America Philosophical Society, Vol. 46 N 186, April-September, 1907.

- BARBÉ, E.: Política exterior y de seguridad común: de Luxemburgo a Ámsterdam, Política y Sociedad, 28, Madrid, 1998.

- BARBÉ, E y GRASA, R.: La Comunitat Europea i la Nova Europa, Fundación Bofill, Barcelona, 1992.

- BetANCOURT, F.: Derecho Romano Clásico, Universidad de Sevilla, Sevilla, 2007.

- BLYDE, J. (Coord.): Fábricas Sincronizadas: América Latina y el caribe en la Era de las Cadenas Globales de Valor, Banco Interamericano de Desarrollo, Washington, 2014.

- BRAGUE, R.: Europa. Eine excentrische Identität, Campus, Frankfurt a.M-New York, 1993.

- BRANDI, J. C: O Brasil e o Congreso Anfictiónico do Panamá, Revista Brasileña de Política Internacional año/vol. 43, $\mathrm{N}^{\circ}$ 002, Instituto Brasileño de Relaciones Internacionales, Brasilia, 2000.

- $\quad$ BRESLIN, S., HUGHES, C., PHILLIPS, N and ROSAMOND, B.: New regionalisms in the global political economy. Routledge, New York, 2002.

- BRETHERTON C. and VOGLER, J.: The European Union as a Global Actor, Routledge, London and New York, 2006.

- BRICEÑO, J., QUINTERO, M., y RUIZ, D.: "El pensamiento estructuralista de la CEPAL sobre el desarrollo y la integración latinoamericana. Reflexiones sobre su 
vigencia actual". Revista Aportes para la integración Latinoamericana, Año XIX N 28/junio 2013.

- CAMPBELl, K and O’HANLON, M.: Hard Power: The New politics of National Security, Basic Books, New York, 2006.

- CANCELA, C.: El proceso de constitucionalización de la Unión Europea. De Roma a Niza, Universidad Santiago de Compostela, Santiago de Compostela, 2001.

- CANTORI, L and SPIEGEL, S.: International Politics of regions: A Comparative Approach, Engelwoods Cliffs, Pretice Hall, New York, 1970.

- CANTORI, L and SPIEGEL, S.: "The Analysis of regional international Politics: The Integration Versus the Empirical Systems Approach", International Organization 27, N 4, 1973.

- CANTÚ, C.: Historia Universal. Tomo II, Gaspar y Roig Editores, Madrid, 1866.

- CASSEN, B.: Una Europa cada vez menos europea. Le Monde Diplomatique, Edición española, $\mathrm{N}^{\circ} 87$, enero 2003.

- $\quad$ CHABOD, F.: Historia de la idea de Europa, Norte y Sur, Madrid, 1967.

- CHARleSWORTH, A.-GUILLEN, H.: European Community Law, Pitman, London, 1994.

- CIENFUEGOS, M. y SANAHUJA, J.A. (Editores): Una región en construcción. UNASUR y la integración en América del Sur, Fundación CIDOB, Barcelona, 2010.

- CORRAL, L.: Génesis de la Unión Europea. Cuadernos de Estudios Empresariales. $\mathrm{N}^{\circ}$ 8, Universidad Complutense, Madrid, 1998.

- COSTA, M.: "Las relaciones comerciales de la UE con Brasil". Boletín Económico de ICE N 3054, Agosto, Madrid, 2014.

- COSTA, O., DRI, C. and STAVRIDIS, S. (Eds): Parliamentary Dimensions of regionalization and Globalization, Palgrave Mac Millan, Bakingstoke, 2013.

- COTTEY, A.: "Sub-regional Cooperation in Europe: An Assessment", Bruges Regional Integration \& Global Governance Papers 3/2009.

- CRAIG, P. and BÚRCA, C.: EU Law. Text, cases and materials, Oxford University Press, New York, 2011.

- D’ ESCRAGNOLLE, J.: O sentido da integração sul-americana. Secretaría General de la Comunidad Andina. Valor Econômico, 2007.

- DE LA REZA, G.: Las Memorias del duque de Sully (o los avatares del primer proyector de unión europea). Revista Brasileira de Política Internacional, Vol. $52 \mathrm{~N}^{\circ} 2$, 2009. 
- DE LA REZA, G.: Documentos sobre el Congreso Anfictiónico de Panamá, Fundación Biblioteca Ayacucho y Banco Central de Venezuela, Caracas, 2010.

- DE LAS HERAS, J.: La idea de Europa en Carlos V. Cuadernos del Lazarillo № 18 Revista literaria y cultural. Enero-Junio 2000.

- DE LOMBARDE, P. and SÖDERBAUM, F.: Regionalism: Volumen 1-4, Sage Publications, London, 2013.

- DE SCHOUTHEETE, P.: La Coopération Politique Européenne, Labor, Bruselas, 1986.

- DEBLOCK, C.: Régionalisme Économique et Mondialisation: Ques nous apprennent les théories? Cahier de recherche 05-07. Continentalisation. Groupe de recherché sur I'intégration continentale. Centre Études Internationales et Mondialisation, Institutut d études internationales de Montréal. Université du Québec à Montréal, Octobre 2005.

- DAVIS CROSS, M and MELISSEN, J.: European Public Diplomacy: Soft Power at work, Basingstoke, Palgrave Macmillan, 2013.

- DEL POZO, J.: Historia de América Latina y del Caribe. Desde la independencia hasta hoy, LOM Ediciones, Santiago de Chile, 2009.

- DÍAZ, C., FERNÁNDEZ, C. y ZAPATERO, M.: Perspectivas sobre las relaciones entre la Unión Europea y América Latina. Universidad Carlos III de Madrid. Boletín Oficial del Estado, Madrid, 2008.

- ERKEN, F-R.: Europa und die osmanische Expansion im ausgehenden Mittelalter, Duncker \& Humblot, Berlín, 2007.

- ESTEBAN, M.: Los inicios del Servicio Europeo de Acción Exterior, Documento de Trabajo, Serie Unión Europea, N 52/2011, Instituto Universitario de Estudios Europeos, Universidad San Pablo CEU, Madrid, 2011.

- FARREL M, HETTNE B, and VAN LANGENHOVE, L.: Global Politics of Regionalism, Pluto Press, London, 2005,

- FEBVRE, L.: L'Europé, genese d'une civilisation, París, 1999

- FRERES, C. y SANAHUJA, J.: América Latina y la Unión Europea. Estrategias para una asociación necesaria, Icaria Editorial, Barcelona, 2006.

- GALASSO, N: Manuel Ugarte. La Nación Latinoamericana. Biblioteca de Ayacucho, $\mathrm{N}^{\circ}$ 45. Caracas, 1978.

- GARCÍA, F.: Platón. Mitos, Ediciones Siruela, Madrid, 1998.

- GARCIA, F.: La creación de un continente (Primera edición de 1912), Fondo Editorial del Congreso del Perú, Lima, 2001. 
- GARCÍA, J.: Compendio de la Historia de Santo Domingo, Santo Domingo, 1890.

- GARCÍA, M.: José Cecilio del Valle, Biblioteca de Ayacucho, N 96, Caracas, 14 de junio de 1982.

- GARCÍA, J.: La universidad de Santo Domingo. Reseña Histórica. La Ciudad Universitaria, Cuadro cronológico. Anuario de la Universidad de Santo Domingo, Vol. XXXI. Ciudad Trujillo, 1944-45.

- GIL, J: Historia de la Integración Europea. Universidad Nacional de Educación a Distancia, Madrid, 2012.

- GILSON, J.: Asia meets Europe: Inter-Regionalism and the Asia-Europé Meeting, Edward Elgar Publishing Limited, Glos, 2002.

- GINZO, A.: Eneas Silvio Piccolomini (Pío II) y su concepción de Europa, Anales del Seminario de Historia de la Filosofía, Vol. 28, Universidad Complutense de Madrid, Madrid, 2011.

- GÓMEZ. M.: La integración andina en tela de juicio. La Prensa, La Paz, 27 de noviembre de 2005.

- GONZÁLEZ, L. (Ed.): Between autonomy and cooperation: shaping the institutional profile of the European External Action Service. Cleer Working Paper 2014/6. The Hague: Centre for the Law of EU External Relations. ASSER Institute Centre for International \& European Law, 2014.

- GRAY, C.: Hard power and soft power: The utility of military force as an instrument of policy in the 21ST Century, Strategic Studies Institute-US Army War College, Pennsylvania, 2011.

- GUALDONI, F.: Entrevista: María Emma Mejía, Secretaría General de la UNASUR. "Veo a los Ejércitos sudamericanos protegiendo los recursos naturales". Diario El País, Madrid, 23 de junio de 2011.

- GUTIÉRreZ, A.: Juan Pablo Viscardo y su "Carta Dirigida a los Españoles Americanos". Araucaria, Vol. 9, № 17, Revista Iberoamericana de Filosofía, Política y Humanidades, Universidad de Sevilla, Sevilla, 2007.

- HAAS, E.: The Uniting of Europea, Stevens and Sons, London, 1958.

- HAAS, E.: Beyond the Nation State, functionalism and the international organization, Stanford University press, 1964.

- HADFIELD, A. and FIOTT, D.: Europe and the rest of the World. Journal of Common Market Studies, 51, 168-182. 2013

- HALPHEN, L.: Carlomagno y el Imperio carolingio, Akal Universitaria, Madrid, 1992. 
- HAMILTON, D.: The Geopolitics of TTIP: Repositioning the Transatlantic Relationship for a Changing World, Center for Transatlantic Relations, Johnns Hopkins University, Washington D.C., 2014.

- HÄNGGI, H., ROLOFF, R. and RÜLAND, J.: Interregionalism and International Relations, Routledge, Oxon, 2006.

- HARDACRE, A.: The rise and fall of interregionalismo in EU external relations. International Relations Studies Series. Series Editor Patrick James, University of Southern California, Vol 9. Republic of Letters Publishing BV, Dordrecht, Danvers, 2010.

- HASSON, A.: La formación de cuadros en el marco de la integración regional, en Documento de Trabajo 12/1995. Centro de Formación para la Integración Regional, Montevideo, 1995.

- HESÍODO: Obras y fragmentos. Gredos, Madrid, 1978.

- HETTNE, B., and BERTIL O.: Global Governance in the 21st Century: Alternative Perspectives on World Order. Norstedts Tryckeri AB, Stockholm, 2002.

- HETTNE, B., INOTAI, A. AND SUNKEL, O.: Globalism and the new regionalism. Palgrave Macmillan, New York, 2002.

- HETTNE, B., SÖDERBAUM F. and STÅLGREN P.: The EU as Global Actor in the South. Swedish Institute for European Policy Studies, Report $N^{\circ} 8$, Stockholm, June/2008.

- ILGEN, T.: Hard power, soft power and the future of transatlantic relations, Burlington-Hampshire, Ashgate, 2006.

- ISÓCRATES: Elogio de Helena, Gredos, Madrid, 1979.

- JARA, E.: La Unión Europea, los países de América Latina y el Caribe. Una relación con pasado, presente y futuro. Fundación Manuel Giménez Abad, Zaragoza, 2011.

- JOLLEY, N.: The Cambridge Companion to Leibniz, The Press Syndicate of the University of Cambridge, Cambridge, 1995.

- JÖNSSON, C. and HALL, M.: Essence of Diplomacy, Basingstoke, Palgrave Mcmillan, Hampshire, 2005.

- JUDGE, D. and EARNSHAW: The European Parliament. Palgrave Macmillan, Basingstoke-New York, 2008.

- KANT, I.: Hacia la paz perpetua. Un esbozo filosófico. Ed. de Jacobo Muñoz, Biblioteca Nueva, Madrid, 1999.

- KATZENSTEIN, P. J.: A World of Regions: Asia and Europe in the American Imperium. Cornell University Press, Ithaca, 2005. 
- KEOHANE, R. and NYE, J.: Power and Interdependence, Little Brow, Boston, 1977.

- KLEINSORGE, T.: Council of Europe, Klumer Law International, The Netherlands, 2010.

- LAÏDI, Z.: (Ed): EU Foreign Policy in a Globalized World: Normative Power and Social reference, Routledge, London, 2008.

- $\quad$ LANDAU, E.: Napoleon Bonaparte. Twenty-First Century Books, Mineapolis, 2006.

- LE GOFF, J.: ¿Nació Europa en la Edad Media? Crítica, Barcelona, 2003.

- LEFEBVRE, M., and HILLION, C.: The European External Action Service: towards a common diplomacy? Swedish Institute for European Policy Studies, June, 2010.

- LEGUEY-FEILlEUX, J.-R.: The dynamics of diplomacy. Lynne Rienner Publishers, Boulder, 2009.

- LEIVA. P. (Ed): Hacia un espacio eurolatinoamericano para la educación superior, ciencia, tecnología e innovación. Foro Académico Permanente ALC-UE. Universidad Central, Santiago de Chile, 2013.

- LERMAN, A.: Evolución histórica de las relaciones comerciales entre América Latina y la CEE. Comercio Exterior, Vol. 41, N 2, México, febrero de 1991.

- LINDEBERG, L. and SCHEINGOLD, S. (Ed): Regional integration: Theory and research, Cambridge University Press, New York, 1971.

- LINDEBERG, B. RASMUSSEN, A. and WARNTJEN, A.: The role of political parties in the European Union. Routledge, New York, 2010.

- LONDOÑO. B. y GÓMEZ. D. M.: Diez años de investigación jurídica y socio-jurídica en Colombia: balances desde la Red Socio-jurídica, tomo II. Universidad Colegio Mayor de Nuestra Señora del Rosario y la Universidad de La Sabana, Bogotá, 2010.

- LOPÉZ. A.: CAN, MEROCSUR y UNASUR ¿Tiene sentido la convergencia? Secretaría General de la Comunidad Andina. Revista de integración No 2. La Construcción de la integración Suramericana, Lima, julio de 2008.

- LOVEDAY J.: Hacia una Unión Monetaria Sudamericana, Universidad del Pacífico, Perú, 2004.

- MAÍZ. C.: Unir lo diverso. Problemas y desafíos de la integración latinoamericana. Universidad Nacional de Cuyo, Mendoza, 2010.

- MALLO, T y SANAHUJA, J.A. (Coords.): Las relaciones de la Unión Europea con América Latina y el Caribe, Siglo XXI y Fundación Carolina, Madrid, 2011.

- MANDEL, E.: Europe vs America: Contradictions of Imperialism, Monthly Review Press, New York, 2009. 
- MANGAS, A.: “¿Es creíble una Unión Suramericana de Naciones?” Entrevista en Diario El Mundo, 2 de junio de 2008.

- MANGAS, A. y LIÑÁN, D.: Instituciones y Derecho de la Unión Europea, Editorial Tecnos, Madrid, 2006.

- MANNERS, I., LYNGGAARD, K., LÖFGREN K.: The European Union in Global Politics: Normative power and longitudinal interpretation, Palgrave Macmillan, Basingstoke, 2014.

- MANSI, J.D.: Sacrorum Conciliorum: nova et amplissima collectio, vol. 32, Akademische druck u. Verlaganstalt, Graz, 1960.

- MARTÍN Y PÉREZ DE NANCLARES, J.: El sistema de competencias de la Comunidad Europea, McGraw-Hill, Madrid, 1997.

- MARTÍN Y PÉREZ DE NANCLARES, J., y URREA CORRES, M.: Estudio Preliminar al Tratado de Lisboa. Real Instituto Elcano, Madrid, 2008.

- McCORMICK, J.: Understanding the European Union: A concise introduction. Palgrave MacMillan, New York, 2011.

- MELISSEN, J. (Ed): The New Public Diplomacy: Soft Power in International Relations, Palgrave Macmillan, London, 2005.

- MENDOZA, V.: Vida y costumbres de la Universidad de México. Imprenta Universitaria, México, 1950.

- MENDOZA, V.: La primera universidad de América. Orígenes de la Antigua real y Pontifica Universidad de México. Imprenta Universitaria, México, 1940.

- $\quad$ MENIT, R and RUSSET, B (Eds): From national Development to Global CommunityEssays in honour of Karls W Deutsch, Allen and Unwin, London, 1981.

- MITRANY, D.: The Progress of International Government, National Peace Council, Allen and Unwin, London, 1944.

- MITRANY, D.: The Functional Theory of Politics, Martin Robertson and Co., London, 1975.

- MITRE, E.: Una primera Europa. Romanos, cristianos y germanos (400-1000), Ediciones Encuentro, Madrid, 2009.

- MONNET, J.: Memorias, Instituto Universitario de Estudios Europeos, Ediciones Encuentro, Madrid, 2010.

- MONTEAGUDO, B.: "Sobre la necesidad de una Federación General entre los Estados Hispano-Americanos y Plan de su organización" Obra póstuma, Imprenta del Estado, Lima, 1825. 
- MORIN, J-F., NOVOtnÁ, T., PONJAeRT, J. and TElÓ, M.: The Politics of Transatlantic Trade Negotiations. TTIP in a Globalized World, Frarnham-Burlington, Ashgate, 2015.

- MUNDELL, R.: “International trade and factor mobility”, American Economic Review, 47 (2), June 1957.

- MUNDELL, R.: "A Theory of Optimun Currency Area", American Economic Review, 51 (4): 657-665, September, 1961.

- NAEF, W.: La idea de estado en la Edad Moderna, Madrid, Época, 1946.

- $\quad$ NÉRE, J: The Foreign Policy of France from 1914 to 1945, Routledge, London, 2002.

- NYE, J.: Integración regional comparada: concepto y medición. Revista de Integración, (1969) Vol. 5, Instituto para la Integración de América Latina, Banco Interamericano de Desarrollo. Base Bibliográfica del Centro de Documentación INTAL.

- O'NEAL J. and RUSSETT, B.: The Kantian Peace: The Pacific Benefits of democracy, Interdependence, and International Organizations, 1885-1992, World Politics, Vol. N 52, Issue 01, October 1999.

- ORTEGA Y GASSET, J: "De Europa mediatio quaedam", en Obras completas IX, Madrid, Alianza, 1983.

- OYARZÚN, L.: Sobre la naturaleza de la integración regional: teorías y debates. Revista de Ciencia política, vol. 28, núm. 2, Pontificia Universidad Católica de Chile, 2008.

- PALIT, A.: The Trans-Pacific Partnership, China and India. Economic and Political implications, Routledge, London-New York, 2014.

- PASCUAL RUIZ MACIÁ, J.: Los cimientos de los Estados Unidos de Europa, Netbiblio S.L., La Coruña, 2007.

- PENN, W.: An Essay towards the Present and Future Peace of Europe, by the Establishment of an European Dyet, Parliament or States, Georg Olms AG, 1983.

- PEÑA, F. y TORRENT, R.: Hacia una etapa en las relaciones Unión Europea-América Latina: Un diagnóstico inicial. Universidad de Barcelona, Observatorio Relaciones Unión Europea-América Latina, Barcelona, 2005.

- PETERSON J. and SJURSEN H.: A Common Foreign Policy for Europé. Competing visions of the CFSP. Routledge, London and New York, 1998.

- PICCOLOMINI, E.S. (Pío II): La Europa de mi tiempo, Secretariado de Publicaciones de la Universidad de Sevilla, Sevilla, 1998. 
- PICCOLOMINI E.S. (Pío II): Asia, Edición de N. Casella, Bellinzona, Casagrande, 2004.

- PINEDA, J. C.: UNASUR: Más allá de la CAN y MERCOSUR. Secretaría General de la Comunidad Andina. Observatorio UNASUR. El Universal (Venezuela), 3 de setiembre de 2009 .

- PINTO, J. (Comp.): Entre la integración y la fragmentación regional: El desafío político de nuestro tiempo, Eudeba, Buenos Aires, 2009.

- $\quad$ PlANTEY, A.: Principes de Diplomatie. Editions A. Pedone. 2000.

- REBOSSIO. A.: América del Sur hace frente común contra la crisis. La amenaza al crecimiento económico impulsa la ansiada integración regional. El País, Entrevista Digital, Buenos Aires, 14 de Agosto de 2011.

- RIPOLL, A.: Institutional and Policy Change in the European Parliament. Deciding on freedom, security and justice, Palgrave Macmillan, New York, 2010.

- RODÓ, J.: Ariel, Editorial Kapelusz, Buenos Aires, 1962.

- RODRÍGUEZ, A.: La proyección de la Universidad de Salamanca en Hispanoamérica: modelo institucional y pedagógico de las Universidades Hispanoamericanas, revista de Educación de Extremadura N 4, 2012.

- ROJAS, F. (Ed) América Latina y el Caribe: Relaciones Internacionales en el siglo XXI. Diplomacia de Cumbres y espacios de concertación regional y global. FLACSO, AECID, TESEO, Buenos Aires, 2012.

- ROMEU, G.: Valores socioculturales en México y América Latina, Palilibro, Bloomington, 2011.

- ROUGEMENT DE, D.: Vingt-huit siécles d'Europé, Payot, París,1961.

- ROUQUAYROL, L y HERRERO, S.: Guía sobre la Cooperación Unión EuropeaAmérica Latina, Asociación CEFICALE, Francia, 2007.

- ROUQUIÉ, A.: América Latina. Introducción al Extremo Occidente, Siglo XXI, Madrid, 1989.

- $\quad$ ROUSSEAU, J.J.: Escritos Políticos. Editorial Trotta, Madrid, 2006.

- RUSSETT, B.: International regions and the international system: a study in political ecology. Rand-McNally, Chicago, 1967.

- SAINZ, N.: Tres modelos de cooperación en América: La Organización de Estados Americanos, el Grupo de Río y el Mercado Común del Sur. Documento de Trabajo. Universidad Autónoma de Barcelona, Barcelona, 2000.

- SALMON, T. and NICILL, W.: Building European Union. Manchester University Press, Manchester, 1997. 
- SANTANDER, S.: Le régionalisme sudaméricain, L’Union européenne et les ÉtatsUnis, Institut d’Etudes Européennes, Bruxelles, 2008.

- SANZ, D.: Un texto inédito de Eneas Silvio Piccolomini acerca de Hispania. Exclass 11, Universidad de Huelva, Huelva, 2007.

- SANTARCANGELI, P.: El libro de los laberintos. Ediciones Siruela, Madrid, 2002.

- SCHMIDT, J.: Between Irrelevance and Integration? New Challenges to Diplomacy in the 21st Century and the Role of the EEAS, Department of EU International Relations and Diplomacy Studies, College of Europe, EU Diplomacy Paper 08/2014.

- SCHULZ, M., SÖDERBAUM, F. and ÖJENDAL, J.: Regionalization in a Globalizing World. A Comparative Perspective on Forms, Actors and Processes. Zed Book, London, 2001

- SEBASTIAN, J.: "La idea de Europa en el pensamiento político de Ortega y Gasset". Revista de Estudios Políticos (Nueva Época) N 83, Enero-Marzo, 1994.

- SEIJAS, R.: El derecho internacional Hispano-americano, El Monitor, Caracas, 1884.

- SERROU, R; Balduino, el rey. Ediciones Palabra, Madrid, 2000

- SIDJANSKI, D: The Federal future of Europe. From the European Community to the European Union, University of Michigan, Michigan, 2000.

- SÖDERBAUM, F.: The Political Economy of Regionalism. The case of Southern Africa. Hampshire, Palgrave Macmilan, 2004.

- SÖDERBAUM F. y TIMOTHY S.: Theories of New Regionalism: A Palgrave Reader, Basingstoke, Palgrave-McMilan. New York, 2003.

- STAVRIDIS, S. and IRRERA, D. (Eds.): The European Parliament and its International Relations. Routledge, London-Ney York, 2015.

- STIGLITZ, J.: El Malestar de la Globalización, Taurus, Madrid, 2002.

- STRANGE, S.: The Retreat of the State. The Diffusion of Power in the World Economy. Cambridge University Press, New York, 1996.

- TELÓ, M.: European Union and New Regionalism. Regional Actors and Global Governance in a Post-Hegemonic Era, Ashgate Publishing Company, Burlington, 2007.

- TELÓ, M.: The European Union and Global Governance, Routledge, London, 2009.

- TOBÓN. G.: Persiste el sueño de una integración latinoamericana, Secretaría General de la Comunidad Andina. Observatorio UNASUR. Portafolio de Colombia, Bogotá 29 de mayo de 2008.

- TOMASSINI, L. (Ed.): Nuevas formas de concertación regional en América Latina, grupo Editor Latinoamericano, Buenos Aires, 1990. 
- TOWNSEND A.: Patria Grande, pueblo, parlamento e integración, Fondo Editorial del Congreso, Lima, 1991.

- TRUJILLO, C.: "La construcción de la idea europea: la perspectiva histórico-cultural, más allá de la identidad. Desafíos, Bogotá (10):64-93, semestre I, 2004.

- TRUYOL Y SERRA, A.: La integración Europea. Idea y Realidad. Discurso de recepción del Académico de Número. Academia de Ciencias Morales y Políticas, Madrid, 1972.

- UllmANN, W.: Historia del pensamiento político en la Edad Media, Barcelona, Ariel, 1983.

- ULlOA, F.: Los partidos políticos actores de la institucionalización democrática en Centroamérica. Theorethiko, Revista de la Universidad Francisco Gavidia, Año V, N 001, Enero-Junio, 2001.

- VACA, A.: Europa: Proyecciones y perspectivas históricas. Octavas Jornadas de Estudios Históricos organizadas por el Departamento de Historia Medieval, Moderna y Contemporánea, Facultad de Geografía e Historia de la Universidad de Salamanca, Salamanca, 1997.

- VALENCIA, J.: Integración en la UNASUR. Secretaría General de la Comunidad Andina. Observatorio UNASUR. Hoy (Ecuador) 13 de agosto de 2009.

- VAN CREVELED, M.: The Rise and Decline of the State. Cambridge University Press, New York, 1999.

- VELIT. E.: Los desafíos de la Unión Sudamericana. Secretaría General de la Comunidad Andina. Observatorio UNASUR. El Comercio, Lima, 2008.

- VINER, J.: The Customs Union Issue, Carneige Endowment for International Peace, New York, 1950.

- VITTINI, I.: La Asamblea Euro-Latinoamericana EUROLAT. Antecedentes y su importancia para la promoción de la comunidad de valores. Programa de Estudios Europeos: Europa América Latina. Dos caminos, ¿Un destino común? Universidad de Concepción, Chile, 2012.

- WEILER, J.: Europa, fin, en Il Sistema comunitario europeo. Structura giuridica e processo político. II Mulino, Bolonia, 1985.

- WHITMAN, R.G.: Normative Power Europe: Empirical and Theoretical Perspective, Palgrave Macmillan, Basingstoke, 2011.

- WOUTERS, J. and DUQUET, S.: The EU, EEAS and Union Delegations and International Diplomatic Law: New Horizons. Working Paper N 62 Leuven Centre for Global Governance Studies, Katholieke Universiteit Leuven, May 2011. 
EL ACERVO INTEGRACIONISTA N EUROPA Y AMÉRICA:

UNA HISTORIA COMÚN 


\section{CONTENIDO}

CAPÍTULO I: INTRODUCCIÓN 13

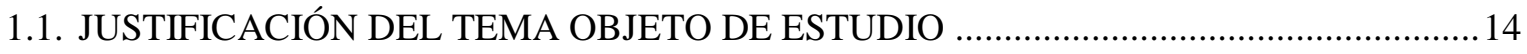

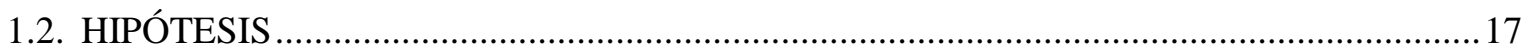

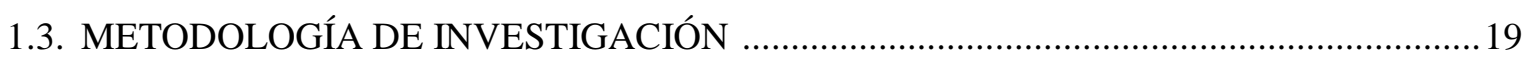

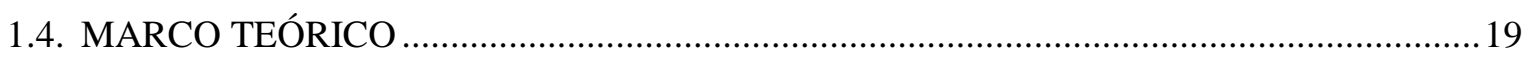

CAPÍtUlO II: FUNDAMENTOS HISTÓRICOS DEL ACERVO INTEGRACIONISTA EN LA EUROPA DE LA EDAD MEDIA ....................................39

2.1.EUROPA: LA HISTORIA DE LA CONSTRUCCIÓN DE UNA REGIÓN ….........................40

2.2. LAS IDEAS INTEGRACIONISTAS DE CARLOMAGNO: LA ACCIÓN

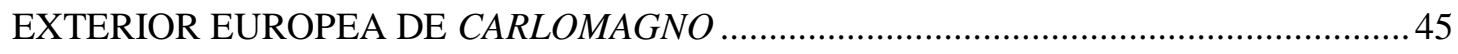

2.3. LAS IDEAS INTEGRACIONISTAS DE CARLOS V: UNIVERSITAS CHRISTIANA ..........55

2.4. DE LA UNIVERSITAS CHRISTIANA A LA UNIVERSITAS UNIVERSALIS: EL LEGADO DE CARLOS V HACIA AMÉRICA.

CAPÍTULO III: EL ACERVO INTEGRACIONISTA EN EUROPA Y AMÉRICA EN LA MODERNIDAD: UNA HISTORIA EN COMÚN ....................................................

3.1.LA CONSTRUCCIÓN DE UNA IDEA: LA UNIDAD POLÍTICA DE LOS ESTADOS ..........72

3.2. EL SUEÑO DE LA ANFICTIONÍA: DE EUROPA A AMÉRICA LATINA ............................. 74

3.3. LA BÚSQUEDA DE UNA IDENTIDAD CONTINENTAL: EL PANAMERICANISMO Y EL PANEUROPEÍSMO

CAPÍTULO IV: CONSTRUYENDO REGIONES A TRAVÉS DEL DIÁLOGO BIREGIONAL EN LOS SIGLOS XX-XXI: INSTITUCIONALIZACIÓN DE LAS RELACIONES ENTRE EL PROCESO DE INTEGRACIÓN EUROPEA Y LOS PROCESOS DE INTEGRACIÓN EN AMÉRICA LATINA 101

4.1. PRIMEROS PASOS HACIA UN DIÁLOGO BI-REGIONAL 102

4.2. EN LA BÚSQUEDA DE UNA SOLA VOZ: LAS COMISIONES Y LOS CONSEJOS DE INTEGRACIÓN REGIONAL

4.3. LA INSTITUCIONALIZACIÓN DE UN DIÁLOGO BI-REGIONAL: LAS BASES DE UNA ACCIÓN EXTERIOR CONJUNTA BI-REGIONAL

4.4. INICIO DE UNA NUEVA ETAPA: HACIA EL DESARROLLO DE UNA ACCIÓN EXTERIOR BIRREGIONAL

4.5. NEGOCIACIONES PARA UNA ASOCIACIÓN ESTRATÉGICA BI-REGIONAL 150

4.6. UN NUEVO DIÁlOGO BIRREGIONAL PARA EL SIGLO XXI: LAS NEGOCIACIONES UE-CELAC 
CAPÍtulo V: EL ROL DE LOS PARLAMENTOS SUBREGIONALES Y REGIONALES: DEMOCRACIA E INTEGRACIÓN. 169

5.1. LOS PARLAMENTOS SUBREGIONALES Y REGIONALES EN EUROPAAMÉRICA LATINA Y EL CARIBE 170

5.2. EL ROL DEL PARLAMENTO REGIONAL EN LA INTEGRACIÓN DE EUROPA:

EL PARLAMENTO DE LA UNIÓN EUROPEA

5.3. EL ROL DE LOS PARLAMENTOS SUBREGIONALES Y REGIONALES EN LA INTEGRACIÓN DE AMÉRICA LATINA Y CARIBE 175

5.4. EL DIÁLOGO INTERPARLAMENTARIO BIRREGIONAL: EUROLAT .202

CAPÍTULO VI: DESARROLLO Y EVOLUCIÓN DE LA ACCIÓN EXTERIOR EN LOS PROCESOS DE INTEGRACIÓN REGIONAL EN LA UNIÓN EUROPEAAMÉRICA LATINA Y EL CARIBE .209

6.1.LA ACCIÓN EXTERIOR: CASO UNIÓN EUROPEA 210

6.2. LA ACCIÓN EXTERIOR: CASO AMÉRICA LATINA Y EL CARIBE. 221

CAPÍTULO VII: EL SERVICIO EUROPEO DE ACCIÓN EXTERIOR Y LAS RELACIONES UNIÓN EUROPEA-AMÉRICA LATINA Y EL CARIBE .271

7.1.EL SERVICIO EUROPEO DE ACCIÓN EXTERIOR .272

7.2. LA DIRECCIÓN DE LAS AMÉRICAS .278

7.3. LA PROGRAMACIÓN REGIONAL PARA AMÉRICA LATINA 2007-2013 .280

7.4. EL PROGRAMA MULTIANUAL INDICATIVO REGIONAL PARA AMÉRICA LATINA 2014-2020 .284

7.5. EL SEAE EN LOS CONSEJOS Y COMITÉS DE LOS ACUERDOS DE ASOCIACIÓN 290

7.6. SÍNTESIS DE LAS RELACIONES ENTRE EL SEAE Y AMÉRICA LATINA .294

CAPÍTULO VIII: EL ROL DE LA ALTA REPRESENTANTE DE LA UNION PARA ASUNTOS EXTERIORES Y POLITICA DE SEGURIDAD EN LAS RELACIONES CON AMÈRICA LATINA Y EL CARIBE: 2010-2015. .295

8.1. EL ALTO REPRESENTANTE DE LA UNIÓN PARA ASUNTOS EXTERIORES Y POLÍTICA DE SEGURIDAD. .296

8.2. LA ERA DE CATHERINE ASTHON .298

8.3. LA ALTA REPRESENTANTE, EL SERVICIO EUROPEO DE ACCIÓN EXTERIOR Y AMÉRICA LATINA. 300

8.4. ASHTON Y AMÉRICA LATINA: UNA ASOCIACIÓN ESTRATÉGICA BIREGIONAL 302

8.5. LA ERA DE FEDERICA MOGUERINI .306 
8.6. MOGHERINI Y AMÉRICA LATINA: UNA ASOCIACIÓN PARA LA PRÓXIMA GENERACIÓN

8.7. SÍNTESIS DEL ROL DE LA ALTA REPRESENTANTE PARA ASUNTOS EXTERIORES Y POLÍTICA DE SEGURIDAD

CONCLUSIONES: 319

ANEXO: LAS DELEGACIONES DE LA UNIÓN EN LOS PAÍSES DE LA CELAC 343

1. RELACIONES DIPLOMÁTICAS ENTRE LA UE Y LOS PAÍSES DE LA CELAC 347

2. RESULTADO DE LAS RELACIONES ENTRE LAS DELEGACIONES DE LA UE Y LOS PAÍSES DE LA CELAC 424

FUENTES Y BIBLIOGRAFÍA: 433 

Salamanca, 2015 